\title{
LOAD DISTRIBUTION FACTORS FOR CURVED CONCRETE SLAB-ON-STEEL I-GIRDER BRIDGES
}

BY

Mohammed A. Al-Hashimy, P. Eng. B.Sc., M.A.Sc., Baghdad University, IRAQ

\author{
A Thesis \\ Presented to Ryerson University \\ In partial fulfillment of the \\ Requirement for the degree of \\ Master of Applied Science \\ In the program of \\ Civil Engineering \\ Toronto, Ontario, Canada, 2005
}




\title{
UMI Number: EC53002
}

\author{
All rights reserved \\ INFORMATION TO USERS
}

The quality of this reproduction is dependent upon the quality of the copy submitted. Broken or indistinct print, colored or poor quality illustrations and photographs, print bleed-through, substandard margins, and improper alignment can adversely affect reproduction.

In the unlikely event that the author did not send a complete manuscript and there are missing pages, these will be noted. Also, if unauthorized copyright material had to be removed, a note will indicate the deletion.

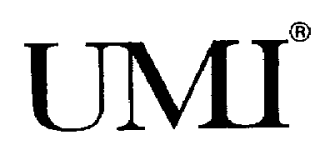

\section{UMI Microform EC53002 \\ Copyright 2008 by ProQuest LLC}

All rights reserved. This microform edition is protected against unauthorized copying under Title 17, United States Code.

\author{
ProQuest LLC \\ 789 East Eisenhower Parkway \\ P.O. Box 1346 \\ Ann Arbor, MI 48106-1346
}


I hereby declare that I am the sole author of this thesis.

I authorize Ryerson to lend this document to other institutions or individuals for the purpose of scholarly research.

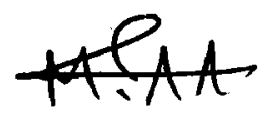

Mohammed Al-Hashimy

I further authorize Ryerson University to reproduce the document by photocopying or by other means, in total or part, at the request of other institutions or individuals for the purpose of scholarly research.

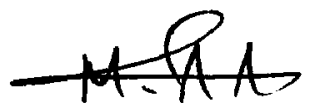

Mohammed Al-Hashimy 


\section{BORROWERS' PAGE}

Ryerson University requires the signatures of all persons using or photocopying this thesis.

Please sign below, and give address and date.

\begin{tabular}{|c|c|c|}
\hline Student Name & Signature & Date \\
\hline & & \\
\hline & & \\
\hline & & \\
\hline & & \\
\hline & & \\
\hline & & \\
\hline & & \\
\hline & & \\
\hline & & \\
\hline & & \\
\hline & & \\
\hline & & \\
\hline & & \\
\hline & & \\
\hline & & \\
\hline
\end{tabular}


"Load Distribution Factors for Curved Concrete Slab-on-Steel I-Girder Bridges"

By Mohammed A. Al-Hashimy, P. Eng., M.A.Sc.

Ryerson University - Civil Engineering

Toronto, Ontario, Canada, 2005

\begin{abstract}
The use of complex interchanges in modern highway urban systems have increased recently in addition to the desire to conform to existing terrain; both have led to increase the demand for horizontally curved bridges. One type of curved bridges consists of composite concrete deck over steel I-girders which has been the preferred choice due to its simplicity in fabrication, transportation and erection. Although horizontally curved steel bridges constitute roughly one-third of all steel bridges being erected today, their structural behavior still not well understood. Due to its geometry, simple presence of curvature in curved bridges produces non uniform torsion and consequently, lateral bending moment (warping or bi-moment) in the girder flanges. The presence of the lateral bending moments would significantly complicate the analysis and the design of the structure. Hence, a parametric study is required to scrutinize a simplified method in designing horizontally curved steel Igirder bridges.
\end{abstract}

A parametric study is conducted, using the finite-element analysis software "SAP2000", to examine the key parameters that may influence the load distribution on the curved composite steel girders. 'Based on the data generated from the parametric study, sets of empirical equations are developed for the moment and shear distribution factors for straight and curved steel I-girder bridges when subjected to the Canadian Highway Bridge Design Code (CHBDC) truck loading. 


\section{ACKNOWLEDGEMENTS}

The author wishes to express his deep appreciation to his advisor Dr. K. Sennah, for his constant support and valuable supervision during the development of this research. Dr. Sennah devoted his time and effort to make this study a success. His most helpful guidance is greatly appreciated. Also, the author is very grateful to his father, mother, wife, son, and daughters for their great support and encouragement during the course of this study.

The financial support from the Natural Scientific Research Council of Canada, NSERC, as well as Ryerson University, is greatly appreciated. 


\section{TO MY FAMILY}




\section{TABLE OF CONTENT}

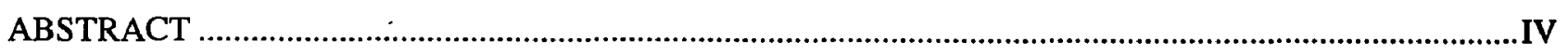

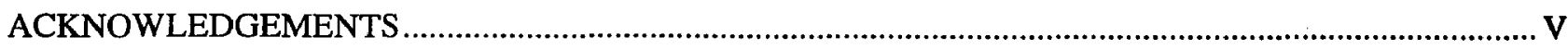

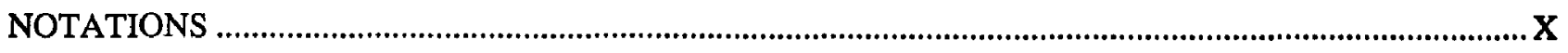

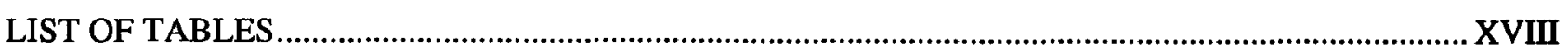

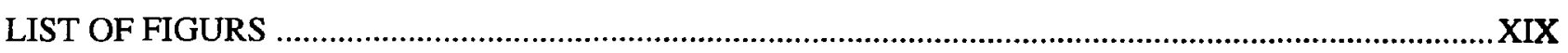

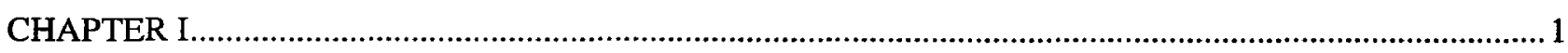

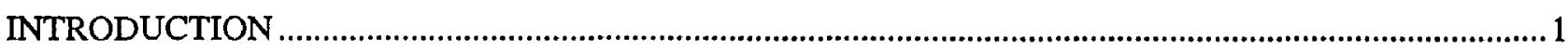

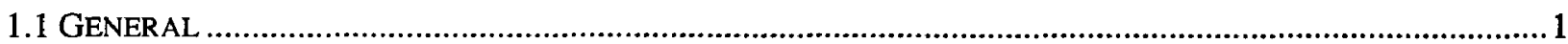

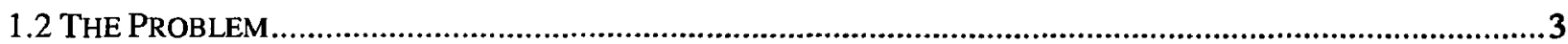

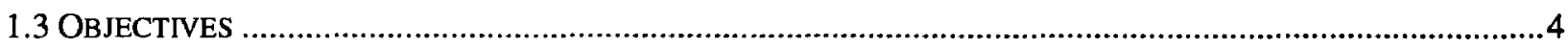

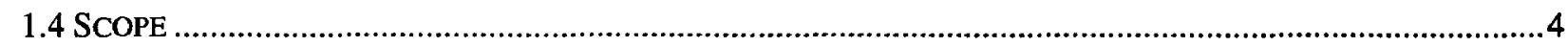

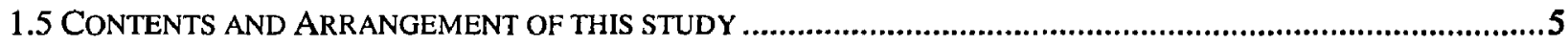

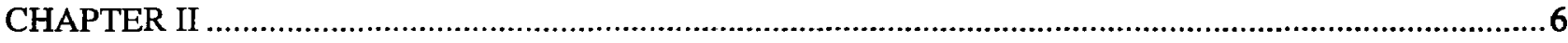

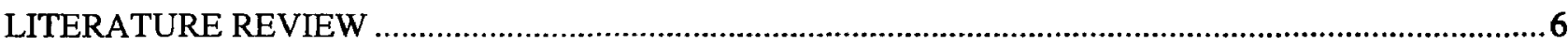

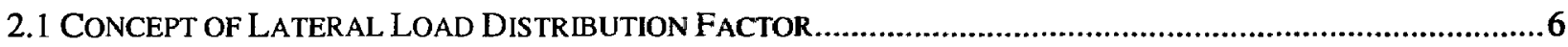

2.2 REVIEW OF PREVIOUS RESEARCH ON LOAD DISTRIBUTION ........................................................... 11

2.2.1 Review of Study on Distribution Factors for Straight Bridges................................................11

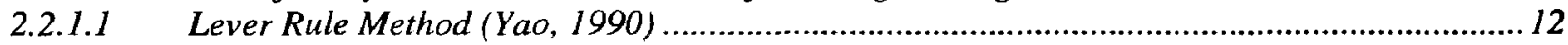

2.2.1.2 Eccentric Compression Method (Yao, 1990) ....................................................................12

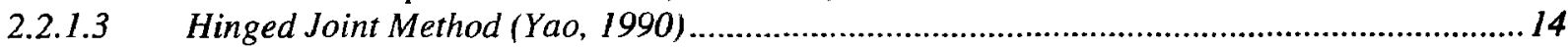

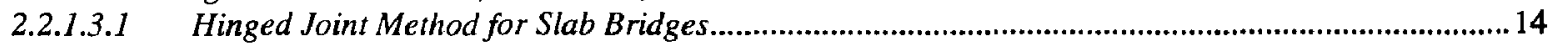

2.2.1.3.2 Hinged Joint Method for T-Shaped Girder Bridge ............................................................................. 16

2.2.1.4 Fixed Joint Girder method (Yao, 1990) ............................................................................ 16

2.2.1.5 Orthotropic Plate Analogy (Guyon-Massonnet or G-M Method) ........................................16

2.2.1.6 AASHTO Methods .......................................................................................................... 18

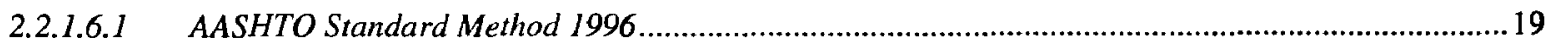

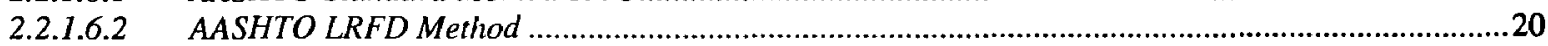

2.2.1.7 Canadian Highway Bridge Design Code, 2000 (CHBDC) .....................................................2]

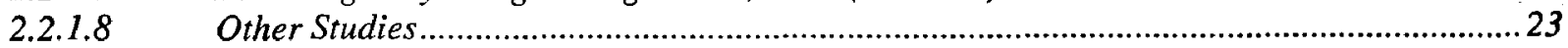

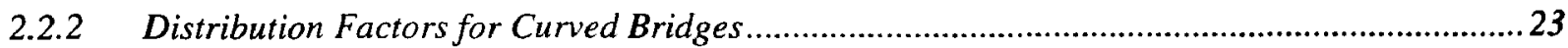

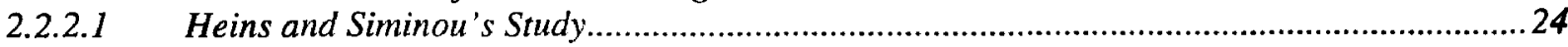

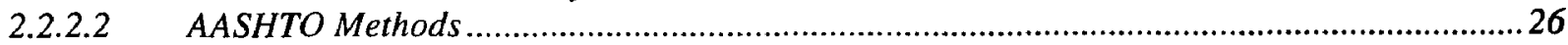

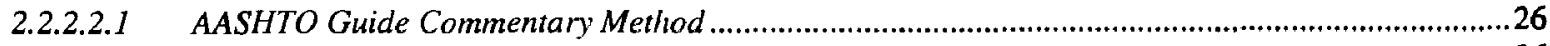

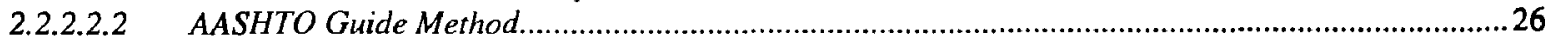

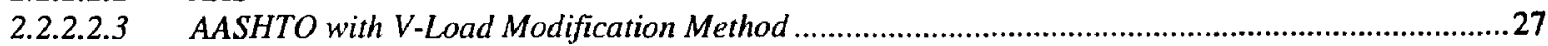

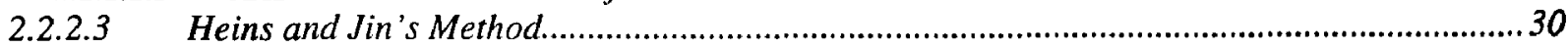

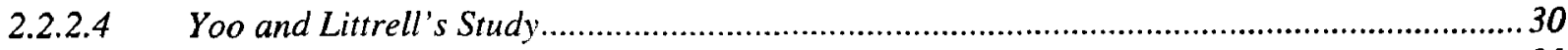

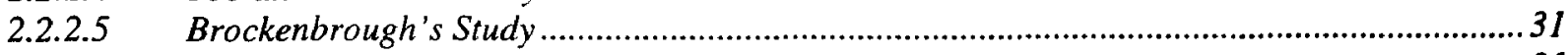

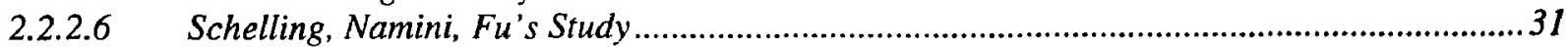

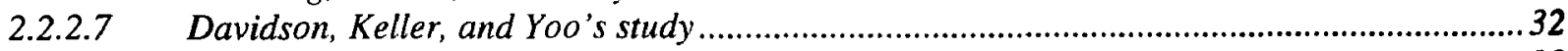

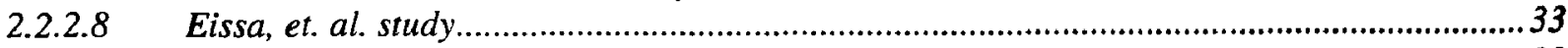

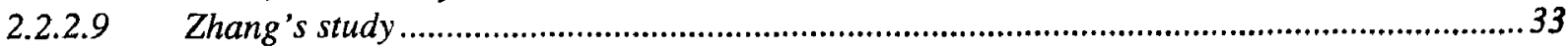

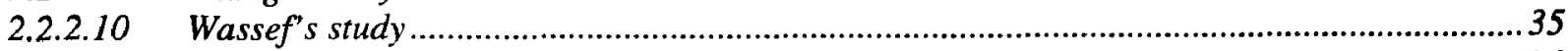

2.3 REVIEW OF LINEAR ELASTIC BEHAVIOUR OF CURVED I- GIRDER SYSTEM ...................................36

$2.4 \quad$ REVIEW OF ANALYSIS METHODS FOR CURVED SYSTEM ..............................................................40

2.4.1 Approximate methods............................................................................................................4I

2.4.1.1 The Plane-grid or Grillage method ........................................................................................4I 
2.4.1.2 The Space-frame method........................................................................................................42

2.4.1.3 The V-Load method (Grubb 1984) .........................................................................42

2.4.2 Refined methods ...................................................................................................................4

2.4.2.1 The Finite-strip method ....................................................................................................44

2.4.2.2 The Finite-difference method ...................................................................................................44

2.4.2.3 Analytical solution to differential equations ...................................................................44

2.4.2.4 The Slope deflection method.................................................................................................45

2.4.2.5 The Finite-Element Method (FEM), By Logan (2002) .........................................................45

2.4.2.5.1 Three-Dimensional Method .................................................................................................46

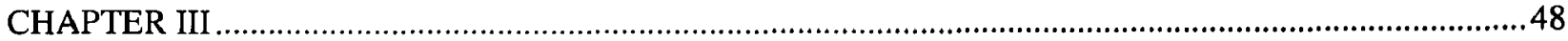

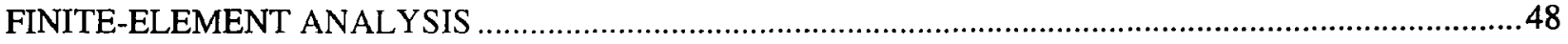

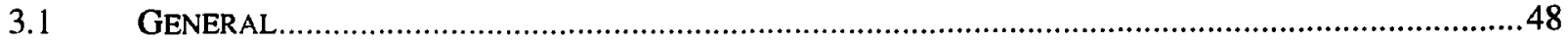

3.2 FINITE-ELEMENT APPROACH....................................................................................5

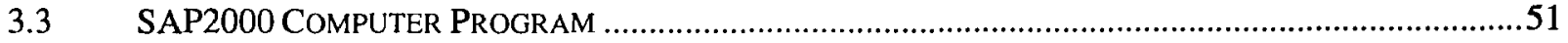

$3.4 \quad$ CHBDC DESIGN LOADING ..................................................................................................5

3.5 TRUCK LOADING CASES ………………………………………………………………....5

3.6 COMPOSITE BRIDGE CONFIGURATIONS ...............................................................................5

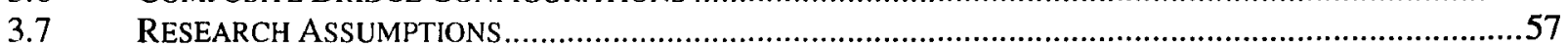

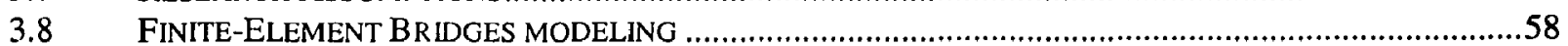

3.8.1 Geometric Modeling......................................................................................................5

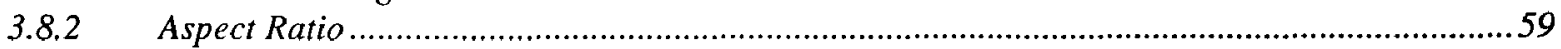

3.8 .3 Boundary conditions.......................................................................................................59

3.9 CALCULATION OF THE SHEAR DISTRIBUTION FACTORS .............................................................6

3.10 CALCULATION OF THE MOMENT DISTRIBUTION FACTORS ………………………………..........62

3.11 CALCULATION OF THE DEFLECTION DISTR IBUTION FACTORS .......................................................64

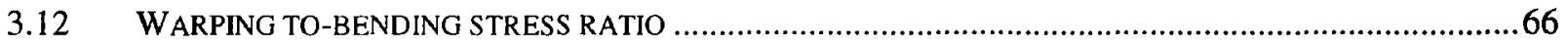

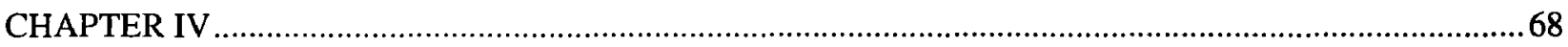

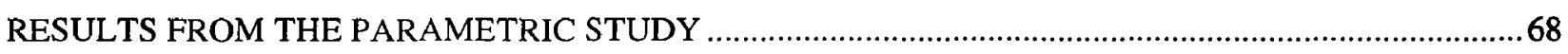

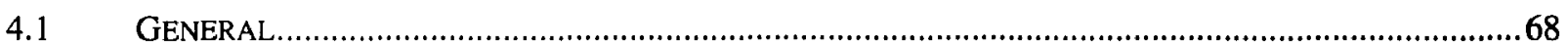

4.2 SHEAR DISTRIBUTION IN SIMPLY SUPPORTED COMPOSITE CUR VED BRIDGES....................................69

4.2.1 Effect of Curvature

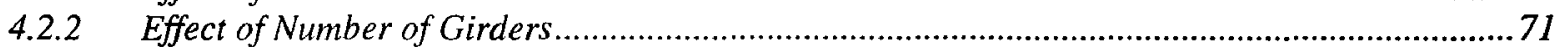

4.2.3 Effect of Girders Spacing............................................................................................. 72

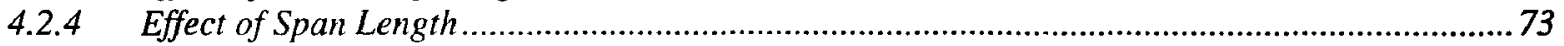

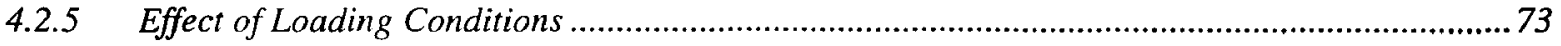

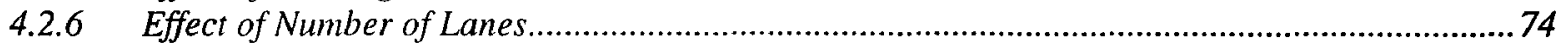

4.2.7 Effect of Number of Bracing Intervals ................................................................................75

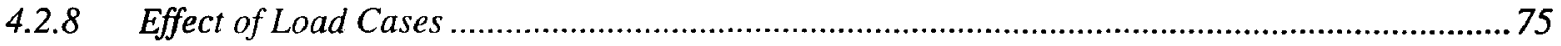

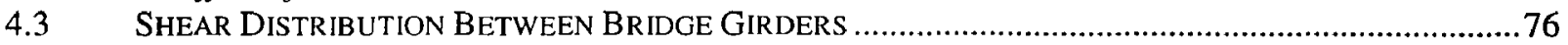

$4.4 \quad$ SDF EFFECT WITH TYPE OF THE SUPPORT ...........................................................................77

4.5 ShEAR DisTRIBUTION EQUATIONS COMPARISON BETWEEN CHBDC...........................................77

4.6 MOMENT AND DEFLECTION DISTRIBUTIONS IN SIMPLY SUPPORTED .................................................78

COMPOSITE CURVED BRIDGES..................................................................................................

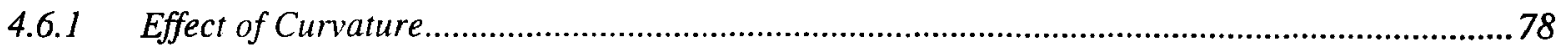

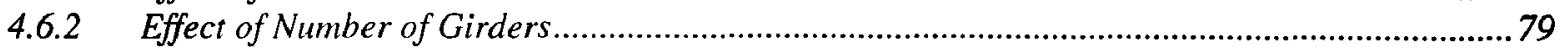

4.6.3 Effect of Girders Spacing ....................................................................................... 80

4.6.4 Effect of Loading Conditions .........................................................................................8

4.7 WARPING STRESS DISTRIBUTION IN SIMPLY SUPPORTED CURVED BRIDGES...................................81

4.8 COMPARISON BETWEEN CHBDC MOMENT DISTRIBUTION EQUATIONS ...........................................8 83

4.9 DEVELOPMENT OF NEW LOAD DISTRIBUTION FACTOR EQUATIONS.................................................8

4.9.1 Shear Distribution Factor Equations...............................................................................8

4.9.1.1 Shear Distribution Factors for Straight I-Girder Bridges..........................................................8 84

4.9.1.2 Shear Distribution Factors for Curved I-Girder Bridges......................................................... 85 


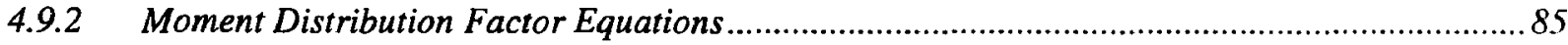

4.9.2.1 Moment Distribution Factors for Straight I-Girder Bridges.................................................85

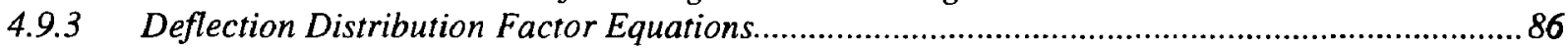

4.9.3.1 Deflection Distribution Factors for Straight I-Girder Bridges ............................................. 86

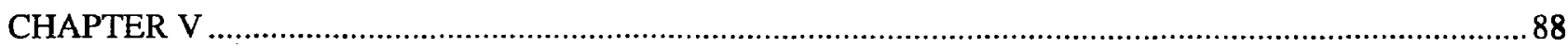

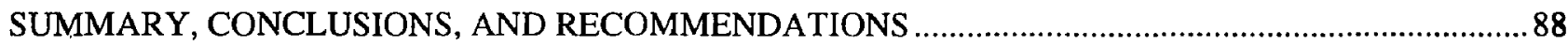

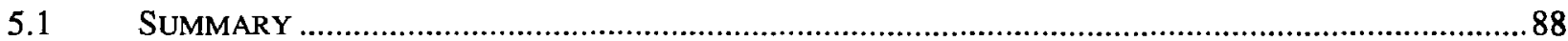

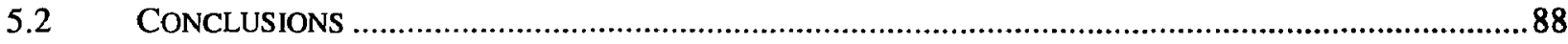

$5.3 \quad$ RECOMMENDATIONS FOR FUTURE RESEARCH .........................................................................90

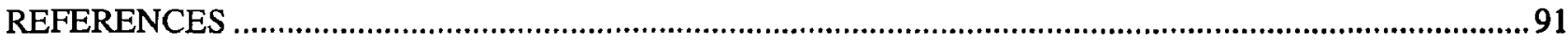

APPENDEX (A): SAP 2000 INPUT FILE FOR A STRAIGHT BRIDGE (SDF)....................................2214

APPENDEX (B): SAP 2000 INPUT FILE FOR A CURVED BRIDGE (SDF) ..........................................219

APPENDEX (C): EXCEL DATA SHEET FOR SECTION AND GIRDER PROPERTIES..........................2227

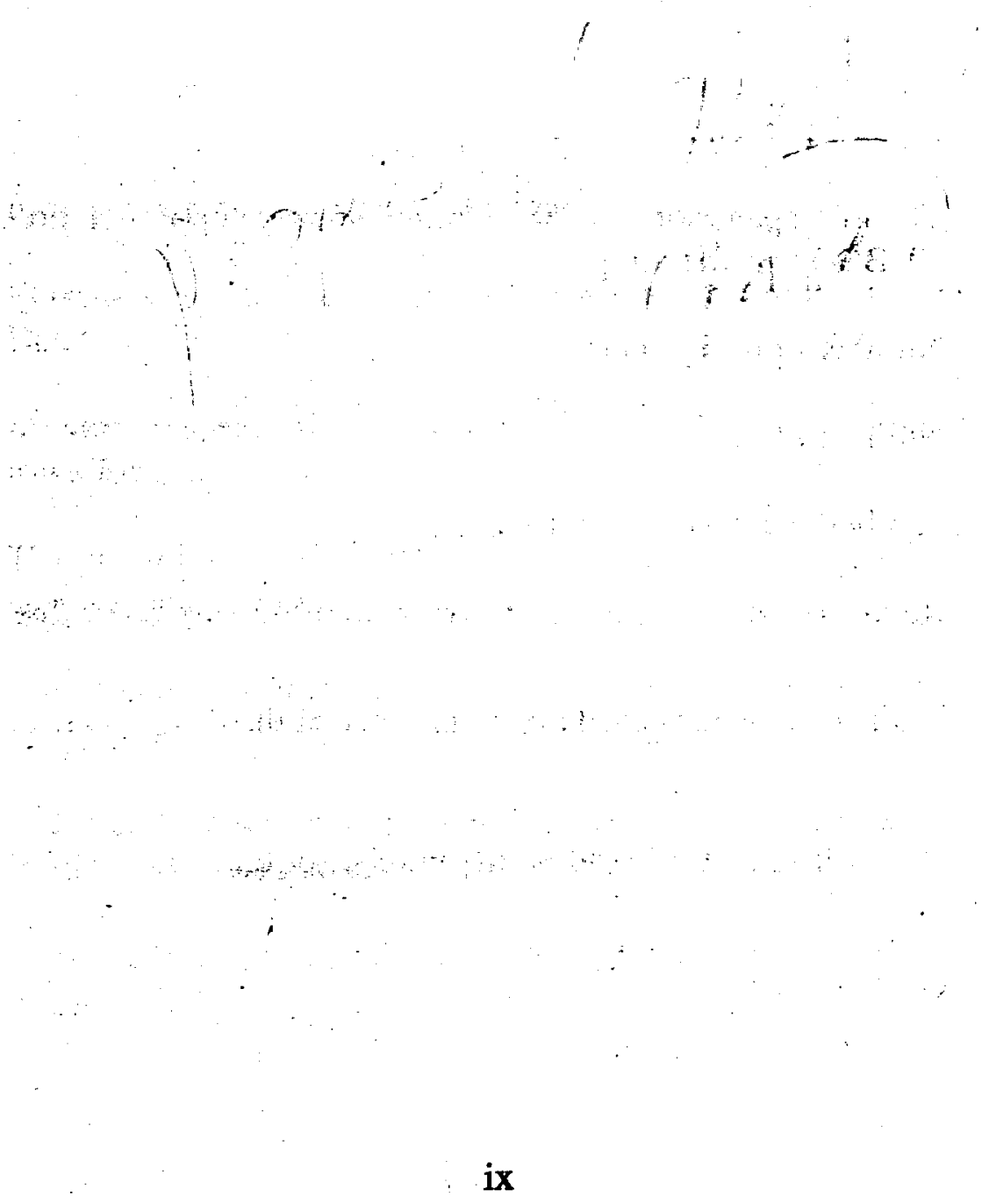




\section{NOTATIONS}
A
Bridge width
B
The clear spacing between girders
$\mathrm{Be}$
Effective concrete slab width
E
Modulus of Elasticity
F
Width dimension factor
Fv
Shear distribution factor
$I_{t}$
The moment of inertia of the composite girder
The global stiffness matrix
L
Centre line span of a simply supported bridge
$\mathrm{M}_{\mathrm{DL}}$
The mid-span moment for a straight simply supported girder due to a single girder dead load
$\mathrm{M}_{\mathrm{T}}$
The mid-span moment for a straight simply supported girder due to a single CHBDC truck loading
n Number of design lanes
$\mathrm{N} \quad$ Number of girders
[P] Applied loads vector at the nodes
R Radius of curvature of the centre span of the curved bridge
$\mathrm{R}_{\mathrm{L}} \quad$ Multi-lane factor based on the number of the design lanes
$\mathrm{R}_{\mathrm{L}}{ }^{\prime} \quad$ Multi-lane factor based on the number of the loaded lanes 
$\mathrm{W}_{\mathrm{c}}$

$\mathrm{W}_{\mathrm{e}}$

$Y_{b}$

$\left(\mathrm{R}_{\mathrm{R}}\right)_{\mathrm{DL}}$

$\left(\mathbf{R}_{\mathrm{L}}\right)_{\mathrm{DL}}$

$\left(\mathrm{R}_{\mathrm{R}}\right)_{\mathrm{FL}}$

$\left(\mathrm{R}_{\mathrm{L}}\right)_{\mathrm{FL}}$

$\left(\mathbf{R}_{\mathrm{R}}\right)_{\mathrm{PL} 1}$

$\left(\mathrm{R}_{\mathrm{L}}\right)_{\mathrm{PL} 1}$

$\left(\mathrm{R}_{\mathrm{R}}\right)_{\mathrm{PL} 2}$

$\left(\mathrm{R}_{\mathrm{L}}\right)_{\mathrm{PL} 2}$

$\left(\mathbf{R}_{\mathbf{R}}\right)_{\text {Fat }}$

$\left(\mathbf{R}_{\mathrm{L}}\right)_{\text {Fat }}$

$\left(\mathrm{R}_{\text {straight }}\right)_{\mathrm{DL}}$

$\left(\boldsymbol{R}_{\text {straight }}\right)_{\text {truck, }}$,

$\left(\mathrm{R}_{\mathrm{FE} . \text { ext }}\right)_{\mathrm{DL}}$

$\left(\mathrm{R}_{\mathrm{FE} . \text { ext }}\right)_{\mathrm{FL}}$

$\left(\mathrm{R}_{\mathrm{FE} . ~ e x t}\right)_{\mathrm{PL}}$

$\left(\mathrm{R}_{\text {FE.ext }}\right)_{\text {Fat }}$
Deck width

Width of design lane

The distance from the neutral axis to the bottom flange

Right Support reaction due to Dead Load

Left Support reaction due to Dead Load

Right Support reaction due to Fully Loaded lanes

Left Support reaction due to Fully Loaded lanes

Right Support reaction due to Partially Loaded lanes type 1

Left Support reaction due to Partially Loaded lanes type 1

Right Support reaction due to Partially Loaded lanes type 2

Left Support reaction due to Partially Loaded lanes type 2

Right Support reaction due to Fatigue Loading

Left Support reaction due to Fatigue Loading

Maximum shear forces calculated for straight simply supported beam due to Dead Load

Maximum shear forces calculated for straight simply supported beam due to truck loading

The greater reaction at the exterior girder supports found from the finiteelement analysis due to dead load

The greater reaction at the exterior girder supports found from the finiteelement analysis due to Fully loaded lanes

The greater reaction at the exterior girder supports found from the finiteelement analysis due to Partially loaded lanes

The greater reaction at the exterior girder supports found from the finiteelement analysis due to Fatigue loading 
$\left(R_{\mathrm{FE}} \text { mid }\right)_{\mathrm{DL}} \quad$ The greater reaction at the middle girder supports found from the finiteelement analysis due to dead load

$\left(R_{\mathrm{FE} . ~ m i d}\right)_{\mathrm{FL}} \quad$ The greater reaction at the middle girder supports found from the finiteelement analysis due to Fully loaded lanes

$\left(R_{\mathrm{FE} . ~ m i d}\right)_{\mathrm{PL}} \quad$ The greater reaction at the middle girder supports found from the finiteelement analysis due to Partially loaded lanes

$\left(R_{\mathrm{FE} \text {.mid }}\right)_{\mathrm{Fat}} \quad$ The greater reaction at the middle girder supports found from the finiteelement analysis due to Fatigue loading

$\left(R_{\mathrm{FE} \text { int }}\right)_{\mathrm{DL}} \quad$ The greater reaction at the interior girder supports found from the finiteelement analysis due to dead load

$\left(\mathrm{R}_{\mathrm{FE} . \mathrm{int}}\right)_{\mathrm{FL}} \quad$ The greater reaction at the interior girder supports found from the finiteelement analysis due to Fully loaded lanes

$\left(\mathrm{R}_{\mathrm{FE} \text {. int }}\right)_{\mathrm{PL}} \quad$ The greater reaction at the interior girder supports found from the finiteelement analysis due to Partially loaded lanes

$\left(\mathrm{R}_{\mathrm{FE} \text {.int }}\right)_{\mathrm{Fat}} \quad$ The greater reaction at the interior girder supports found from the finiteelement analysis due to Fatigue loading

$(\mathrm{SDF})_{\mathrm{DL} \text { ext }} \quad$ Shear distribution factor for the exterior girder due to Deal Load

$(\mathrm{SDF})_{\mathrm{FL} \text { ext }}$ Shear distribution factor for the exterior girder due to Fully Loaded lanes

$(\mathrm{SDF})_{\mathrm{PL} \text { ext }}$ Shear distribution factor for the exterior girder due to Partially Loaded lanes

$(\mathrm{SDF})_{\text {Fat ext }}$ Shear distribution factor for the exterior girder due to Fatigue Loading

$(\mathrm{SDF})_{\mathrm{DL} \text { mid }} \quad$ Shear distribution factor for the middle girder due to Deal Load

$(\mathrm{SDF})_{\mathrm{FL} \text { mid }} \quad$ Shear distribution factor for the middle girder due to Fully Loaded lanes

$(\mathrm{SDF})_{\mathrm{PL} \text { mid }} \quad$ Shear distribution factor for the middle girder due to Partially Loaded lanes

$(\mathrm{SDF})_{\text {Fat mid }}$ Shear distribution factor for the middle girder due to Fatigue Loading

$(\mathrm{SDF})_{\mathrm{DL} \text { int }} \quad$ Shear distribution factor for the interior girder due to Deal Load

$(\mathrm{SDF})_{\mathrm{FL}}$ int $\quad$ Shear distribution factor for the interior girder due to Fully Loaded lanes

$(\mathrm{SDF})_{\mathrm{PL} \text { int }} \quad$ Shear distribution factor for the interior girder due to Partially Loaded lanes

$(\mathrm{SDF})_{\text {Fat int }} \quad$ Shear distribution factor for the interior girder due to Fatigue Loading 
$\left(\sigma_{\mathrm{E} 1}\right)_{\mathrm{DL}} \quad$ Maximum flexural stresses in bottom flange fibers at point 1 of exterior girder, for the dead load case, obtained from finite-element analysis

$\left(\sigma_{\mathrm{E} 3}\right)_{\mathrm{DL}} \quad$ Maximum flexural stresses in bottom flange fibers at point 3 of exterior girder, for the dead load case, obtained from finite-element analysis

$\left(\sigma_{\mathrm{EI}}\right)_{\mathrm{FL}} \quad$ Maximum flexural stresses in bottom flange fibers at point 1 of exterior girder, for the full lane loading case, obtained from finite-element analysis

$\left(\sigma_{\mathrm{E} 1}\right)_{\mathrm{PL}} \quad$ Maximum flexural stresses in bottom flange fibers at point 1 of exterior girder, for the partial lane loading case, obtained from finite-element analysis

$\left(\sigma_{\mathrm{E} 3}\right)_{\mathrm{FL}} \quad$ Maximum flexural stresses in bottom flange fibers at point 3 of exterior girder, for the full lane loading case, obtained from finite-element analysis

$\left(\sigma_{\mathrm{E} 3}\right)_{\mathrm{PL}} \quad$ Maximum flexural stresses in bottom flange fibers at point 3 of exterior girder, for the partial lane loading case, obtained from finite-element analysis

$\left(\sigma_{\mathrm{E} 1}\right)_{\mathrm{Fat}} \quad$ Maximum flexural stresses in bottom flange fibers at point 1 of exterior girder, for the fatigue case, obtained from finite-element analysis

$\left(\sigma_{\mathrm{E} 3}\right)_{\mathrm{Fat}} \quad$ Maximum flexural stresses in bottom flange fibers at point 3 of exterior girder, for the fatigue case, obtained from finite-element analysis

$\left(\sigma_{\mathrm{M} 1}\right)_{\mathrm{DL}} \quad$ Maximum flexural stresses in bottom flange fibers at point 1 of middle girder, for the dead load case, obtained from finite-element analysis

$\left(\sigma_{\mathrm{M} 3}\right)_{\mathrm{DL}} \quad$ Maximum flexural stresses in bottom flange fibers at point 3 of middle girder, for the dead load case, obtained from finite-element analysis

$\left(\sigma_{\mathrm{M} 1}\right)_{\mathrm{FL}} \quad$ Maximum flexural stresses in bottom flange fibers at point 1 of middle girder, for the full lane loading case, obtained from finite-element analysis

$\left(\sigma_{\mathrm{M} 3}\right)_{\mathrm{FL}} \quad$ Maximum flexural stresses in bottom flange fibers at point 3 of middle girder, for the full lane loading case, obtained from finite-element analysis

$\left(\sigma_{\mathrm{M} 1}\right)_{\mathrm{Fat}} \quad$ Maximum flexural stresses in bottom flange fibers at point 1 of middle girder, for the fatigue case, obtained from finite-element analysis

$\left(\sigma_{\mathrm{M} 3}\right)_{\mathrm{Fat}} \quad$ Maximum flexural stresses in bottom flange fibers at point 3 of middle girder, for the fatigue case, obtained from finite-element analysis

$\left(\sigma_{11}\right)_{\mathrm{DL}} \quad$ Maximum flexural stresses in bottom flange fibers at point 1 of interior girder, for the dead load case, obtained from finite-element analysis 
$\left(\sigma_{\mathrm{B}}\right)_{\mathrm{DL}} \quad$ Maximum flexural stresses in bottom flange fibers at point 3 of interior girder, for the dead load case, obtained from finite-element analysis

$\left(\sigma_{\mathrm{II}}\right)_{\mathrm{FL}} \quad$ Maximum flexural stresses in bottom flange fibers at point 1 of interior girder, for the full lane loading case, obtained from finite-element analysis

$\left(\sigma_{\mathrm{II}}\right)_{\mathrm{PL}} \quad$ Maximum flexural stresses in bottom flange fibers at point 1 of interior girder, for the partial lane loading case, obtained from finite-element analysis

$\left(\sigma_{\mathrm{I} 3}\right)_{\mathrm{FL}} \quad$ Maximum flexural stresses in bottom flange fibers at point 3 of interior girder, for the full lane loading case, obtained from finite-element analysis

$\left(\sigma_{\mathrm{I}}\right)_{\mathrm{PL}} \quad$ Maximum flexural stresses in bottom flange fibers at point 3 of interior girder, for the partial lane loading case, obtained from finite-element analysis

$\left(\sigma_{\mathrm{I}}\right)_{\text {Fat }} \quad$ Maximum flexural stresses in bottom flange fibers at point 1 of interior girder, for the fatigue case, obtained from finite-element analysis

$\left(\sigma_{\mathrm{L}}\right)_{\text {Fat }} \quad$ Maximum flexural stresses in bottom flange fibers at point 3 of interior girder, for the fatigue case, obtained from finite-element analysis

$\left(\sigma_{\text {straight }}\right)_{\text {DL }}$ Maximum flexural stresses in bottom flange fibers, for the straight simply supported beam due to Deal Load

$\left(\sigma_{\text {straight }}\right)_{\text {truck }}$ Maximum flexural stresses in bottom flange fibers, for the straight simply supported beam due to CHBDC truck loading

$\left(\sigma_{\mathrm{FE} . ~ e x t}\right)_{\mathrm{DL}} \quad$ the bigger flexural stresses of points 1 and 3 of exterior girder due to dead load case

$\left(\sigma_{\mathrm{FE} . ~ e x t}\right)_{\mathrm{FL}} \quad$ the bigger flexural stresses of points 1 and 3 of exterior girder due to Fully loaded lanes case

$\left(\sigma_{\mathrm{FE} . \text { ext }}\right)_{\mathrm{PL}} \quad$ the bigger flexural stresses of points 1 and 3 of exterior girder due to Partially loaded lanes case

$\left(\sigma_{\mathrm{FE} . \text { ext }}\right)_{\text {Fat }}$ the bigger flexural stresses of points 1 and 3 of exterior girder due to Fatigue loading case

$\left(\sigma_{\mathrm{FE} . \mathrm{mid}}\right)_{\mathrm{DL}} \quad$ the bigger flexural stresses of points 1 and 3 of middle girder due to dead load case

$\left(\sigma_{\mathrm{FE} . \mathrm{mid}}\right)_{\mathrm{FL}} \quad$ the bigger flexural stresses of points 1 and 3 of middle girder due to Fully loaded lanes case 
$\left(\sigma_{\mathrm{FE} . ~ m i d}\right)_{\mathrm{PL}} \quad$ the bigger flexural stresses of points 1 and 3 of middle girder due to Partially loaded lanes case

$\left(\sigma_{\text {FE. mid }}\right)_{\text {Fat }} \quad$ the bigger flexural stresses of points 1 and 3 of middle girder due to Fatigue loading case

$\left(\sigma_{\mathrm{FE}, \text { int }}\right)_{\mathrm{DL}} \quad$ the bigger flexural stresses of points 1 and 3 of interior girder due to dead load case

$\left(\sigma_{\mathrm{FE} \text { int }}\right)_{\mathrm{FL}} \quad$ the bigger flexural stresses of points 1 and 3 of interior girder due to Fully loaded lanes case

$\left(\sigma_{\mathrm{FE} . ~ i n t}\right)_{\mathrm{PL}} \quad$ the bigger flexural stresses of points 1 and 3 of interior girder due to Partially loaded lanes case

$\left(\sigma_{\text {FE. int }}\right)_{\text {Fat }}$ the bigger flexural stresses of points 1 and 3 of interior girder due to Fatigue loading case

$(\mathrm{MDF})_{\mathrm{DL} \text { ext }}$ the moment distribution factor of exterior girder for dead load case

$(\mathrm{MDF})_{\mathrm{FL} \text { ext }}$ the moment distribution factor of exterior girder for full load case

$(\mathrm{MDF})_{\mathrm{PL} \text { ext }}$ the moment distribution factor of exterior girder for partial load case

$(\mathrm{MDF})_{\text {Fat.ext }}$ the moment distribution factor of exterior girder for fatigue case

$(\mathrm{MDF})_{\mathrm{DL} \text { mid }}$ the moment distribution factor of middle girder for dead load case

$(\mathrm{MDF})_{\text {FL mid }}$ the moment distribution factor of middle girder for full load case

(MDF) $)_{\text {PL mid }}$ the moment distribution factor of middle girder for Partial load case

$(\mathrm{MDF})_{\text {Fat.mid }}$ the moment distribution factor of middle girder for fatigue case

$(\mathrm{MDF})_{\mathrm{DL} \text { int }}$ the moment distribution factor of interior girder for dead load case

$(\mathrm{MDF})_{\mathrm{FL} \text { int }}$ the moment distribution factor of interior girder for full load case

$(M D F)_{\mathrm{PL}}$ int the moment distribution factor of interior girder for partial load case

$(\mathrm{MDF})_{\text {Fat.int }}$ the moment distribution factor of interior girder for fatigue case

$\left(\Delta_{\text {simple }}\right)_{\mathrm{DL}} \quad$ mid-span deflection in bottom flange fibers, for a straight simply supported girder subject to dead load 
$\left(\Delta_{\text {simple }}\right)_{\text {truck }}$ mid-span deflection in bottom flange fibers, for a straight simply supported girder subject to CHBDC truck loading

$\left(\Delta_{\mathrm{FE}} \text { ext }\right)_{\mathrm{DL}} \quad$ mid-span deflection in bottom flange fibers at point 2 of exterior girder, for the dead load case, obtained from finite-element analysis

$\left(\Delta_{\mathrm{FE} \text { ext }}\right)_{\mathrm{FL}} \quad$ mid-span deflection in bottom flange fibers at point 2 of exterior girder, for the full lane loading case, obtained from finite-element analysis

$\left(\Delta_{\mathrm{FE} \text { ext }}\right)_{\mathrm{PL}} \quad$ mid-span deflection in bottom flange fibers at point 2 of exterior girder, for the partial lane loading case, obtained from finite-element analysis

$\left(\Delta_{\text {FE ext }}\right)_{\text {Fat }} \quad$ mid-span deflection in bottom flange fibers at point 2 of exterior girder, for the fatigue case, obtained from finite-element analysis

$\left(\Delta_{\mathrm{FE} \text { mid }}\right)_{\mathrm{DL}} \quad$ mid-span deflection in bottom flange fibers at point 2 of middle girder, for the dead load case, obtained from finite-element analysis

$\left(\Delta_{\mathrm{FE}} \mathrm{mid}\right)_{\mathrm{FL}} \quad$ mid-span deflection in bottom flange fibers at point 2 of middle girder, for the full lane loading case, obtained from finite-element analysis

$\left(\Delta_{\mathrm{FE} \text { mid }}\right)_{\mathrm{PL}} \quad$ mid-span deflection in bottom flange fibers at point 2 of middle girder, for the partial lane loading case, obtained from finite-element analysis

$\left(\Delta_{\mathrm{FE} \text { mid }}\right)_{\mathrm{Fat}} \quad$ mid-span deflection in bottom flange fibers at point 2 of middle girder, for the fatigue case, obtained from finite-element analysis

$\left(\Delta_{\mathrm{FE} \text { int }}\right)_{\mathrm{DL}} \quad$ mid-span deflection in bottom flange fibers at point 2 of interior girder, for the dead load case, obtained from finite-element analysis

$\left(\Delta_{\mathrm{FE} \text { int }}\right)_{\mathrm{FL}} \quad$ mid-span deflection in bottom flange fibers at point 2 of interior girder, for the full lane loading case, obtained from finite-element analysis

$\left(\Delta_{\mathrm{FE} \text { int }}\right)_{\mathrm{PL}} \quad$ mid-span deflection in bottom flange fibers at point 2 of interior girder, for the partial lane loading case, obtained from finite-element analysis

$\left(\Delta_{\mathrm{FE} \text { int }}\right)_{\mathrm{Fat}} \quad$ mid-span deflection in bottom flange fibers at point 2 of interior girder, for the fatigue case, obtained from finite-element analysis

(DDF)DL ext the deflection distribution factor of exterior girder for dead load case

$(\mathrm{DDF})_{\mathrm{FL} \text { ext }}$ the deflection distribution factor of exterior girder for full load case

$(\mathrm{DDF})_{\mathrm{PL} \text { ext }}$ the deflection distribution factor of exterior girder for partial load case

$(\mathrm{DDF})_{\text {Fat.ext }}$ the deflection distribution factor of exterior girder for fatigue case 
$(\mathrm{DDF})_{\mathrm{DL} \text { mid }}$

$(\mathrm{DDF})_{\mathrm{FL} \mathrm{mid}}$

$(\mathrm{DDF})_{\text {Fat.mid }}$

$(\mathrm{DDF})_{\mathrm{DL} \text { int }}$

$(\mathrm{DDF})_{\mathrm{FL} \text { int }}$

$(\mathrm{DDF})_{\mathrm{PL} \text { int }}$

$(\mathrm{DDF})_{\text {Fat.int }}$

$(\mathrm{WBR})_{\mathrm{DL} \text { ext }}$

$(\mathrm{WBR})_{\mathrm{FL} \mathrm{ext}}$

$(\mathrm{WBR})_{\mathrm{PL} \text { ext }}$

$(\mathrm{WBR})_{\text {Fat.ext }}$

$(\mathrm{WBR})_{\mathrm{DL}_{\text {mid }}}$

$(\mathrm{WBR})_{\mathrm{FL} \mathrm{mid}}$

$(\mathrm{WBR})_{\mathrm{PL} \mathrm{mid}}$

$(\mathrm{WBR})_{\text {Fat.mid }}$

$(\mathrm{WBR})_{\mathrm{DL} \text { int }}$

$(\mathrm{WBR})_{\mathrm{FL} \mathrm{int}}$

$(\mathrm{WBR})_{\mathrm{PL} \text { int }}$

$(\text { WBR })_{\text {Fat.int }}$ the deflection distribution factor of middle girder for dead load case

the deflection distribution factor of middle girder for full load case

the deflection distribution factor of middle girder for fatigue case

the deflection distribution factor of interior girder for dead load case

the deflection distribution factor of interior girder for full load case

the deflection distribution factor of interior girder for partial load case

the deflection distribution factor of interior girder for fatigue case

the warping bending stress ratio of exterior girder for dead load case

the warping-to-bending stress ratio of exterior girder for full load case

the warping-to-bending stress ratio of exterior girder for partial load case

the warping-to-bending stress ratio of exterior girder for fatigue case

the warping-to-bending stress ratio of middle girder for dead load case

the warping-to-bending stress ratio of middle girder for full load case

the warping-to-bending stress ratio of middle girder for Partial load case

the warping-to-bending stress ratio of middle girder for fatigue case

the warping-to-bending stress ratio of interior girder for dead load case

the warping-to-bending stress ratio of interior girder for full load case

the warping-to-bending stress ratio of interior girder for partial load case

the warping-to-bending stress ratio of interior girder for fatigue case 


\section{LIST OF TABLES}

$\underline{\text { Table }}$

$\underline{\text { Page }}$

Table 2. 1 Coefficient, C, for Various Multi-Girder Systems Assuming Equal Girder Spacing (Grubb, 1984) .............................................96

Table 3. 1 Bridge Configurations Considered in the Parametric Study.................96

Table 3. 2 Number of Design Lanes............................................97

Table 3. 3 Modification Factors for Multilane Loading...............................97

Table 4. 1 Table 4.1 Effect of loading conditions, extreme cases...................................98

Table 4.2 Value of $F$ for longitudinal shear for Straight Bridges (ULS and SLS).........99

Table 4.3 Value of $F$ for longitudinal shear for Straight Bridges (FLS) $\ldots \ldots \ldots \ldots \ldots \ldots . .100$

Table 4.4 Value of $F$ for longitudinal shear for Curved Bridges (ULS and SLS).........101

Table 4.5 Value of $F$ for longitudinal shear for Curved Bridges (FLS) .................102

Table 4.6 Value of $F$ for longitudinal moment for Straight Bridges (ULS and SLS),.....103

Table 4.7 Value of $F$ for longitudinal moment for Straight Bridges (FLS).............104

Table 4.8 Value of $F$ for Deflection for Curved Bridges (ULS and SLS) .................105

Table 4.9 Value of $F$ for Deflection for Curved Bridges (FLS) .........................106 


\section{LIST OF FIGURS}

FIGURE 1. 1 TYPICAL I-GIRDER BRIDGE CROSS-SECTION

FiguRE 2. 1 Single AND MULTi-GIRDER SySTEM UNDER CONCENTRATED Live LOAD P ................................108

FIGURE 2. 2 LATERAL LOAD DISTRIBUTION OF TRUCK AXLE LOAD ........................................................... 108

FIGURE 2. 3 GIRDER DEFLECTION WITH DIFFERENT TRANSVERSE STIFFNESS ................................................ 109

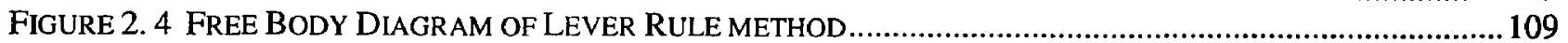

FIGURE 2. 5 LOAD DISTR IBUTION UNDER ECCENTRIC LOAD ................................................................. 110

FIGURE 2. 6 FREE BODY DIAGRAM OF A HINGED SLAB BRIDGE UNDER CONCENTRATED LOAD .......................111

FigURE 2. 7 FREE BODY Diagram OF A HINGED SLAB BRIDGE UNDER SinUSOIDAL LOAD .............................111

FIGURE 2. 8 FREE BODY DIAGRAM FOR HINGED T-SHAPED GIRDER BRIDGE ............................................. 112

FIGURE 2.9 FREE BODY DIAGRAM OF FIXED JOINT GIRDER BRIDGE .................................................. 113

FigURE 2. 10 REAL STRUCTURE AND ORTHOTROPIC PLATE ANALOGY ..................................................... 113

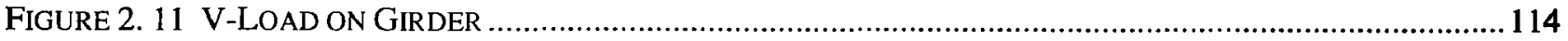

FIGURE 2. 12 EFFECT OF W ARPING MOMENT APPLIED TO I-GIRDER .................................................. 114

Figure 3. 1 Canadian Highway Bridge Design Codes’' Truck and Lane loadings .............................115

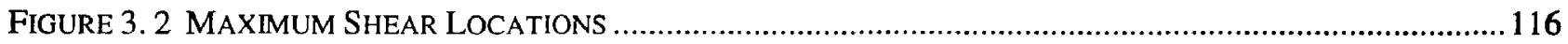

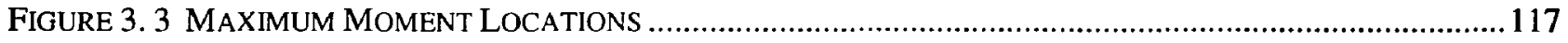

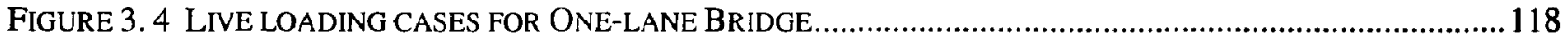

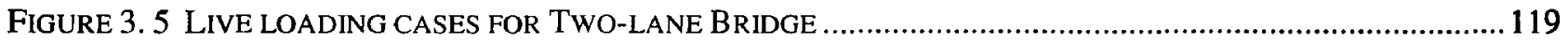

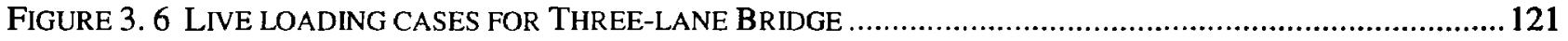

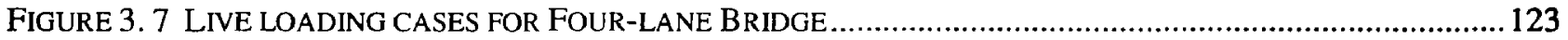

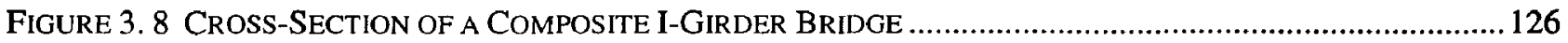

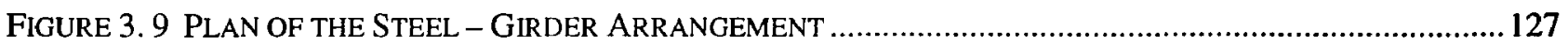

FIGURE 3. 10 FINITE - ELEMENT REPRESENTATION OF BRIDGE CROSS - SECTION .........................................128

FIGURE 3. 11 VIEWS OF SAP2000 FINITE-ELEMENT MODEL - WITHOUT SLAB PANELS...................................129

FigURE 3. 12 VIEWS OF SAP2000 FINITE-ELEMENT MODEL - WITH SLAB PANELS ........................................129

FIGURE 3. 13 VIEWS OF SAP2000 FINITE-ELEMENT MODEL - BOUNDARY CONDITIONS ............................. 130

FIGURE 3. 14 CROSS-SECTION DIMENSIONS OF THE STEEL GIRDER .................................................. 131

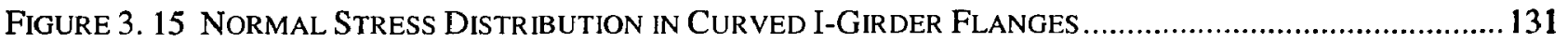

FiguRE 4. 1 EFFECT OF CURVATURE ON THE SHEAR Distribution FACTOR FOR THE EXTERIOR GiRDER DUE TO DEAD LOAD...

FIGURE 4. 2 EFFECT OF CURVATURE ON THE SHEAR DISTR IBUTION FACTOR FOR THE EXTERIOR GIRDER DUE TO

FULLY LOADED LANES ……................................................................................................... 132

FIGURE 4. 3 EFFECT OF CURVATURE ON THE SHEAR DISTR IBUTION FACTOR FOR THE EXTERIOR GIRDER DUE TO

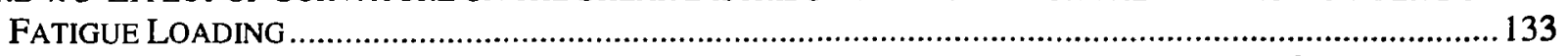

FIGURE 4. 4 EFFECT OF CURVATURE ON THE SHEAR DISTRIBUTION FACTOR FOR THE MIDDLE GIRDER DUE TO DEAD LOAD... 
FIGURE 4. 5 EFFECT OF CURVATURE ON THE SHEAR DISTRIBUTION FACTOR FOR THE MIDDLE GRDER DUE TO

FULLY LOADED LANES

FIGURE 4. 6 EFFECT OF CURVATURE ON THE SHEAR DISTRIBUTION FACTOR FOR THE MIDDLE GIRDER DUE TO FATIGUE LOADING

FIGURE 4. 7 EFFECT OF CURVATURE ON THE SHEAR DISTRIBUTION FACTOR FOR THE INTERIOR GIRDER DUE TO DEAD LOAD.

FIGURE 4. 8 EFFECT OF CURVATURE ON THE SHEAR DISTRIBUTION FACTOR FOR THE INTERIOR GIRDER DUE TO FULLY LOADED LANES

FIGURE 4. 9 EFFECT OF CURVATURE ON THE SHEAR DISTRIBUTION FACTOR FOR THE INTERIOR GIRDER DUE TO FATIGUE LOADING.

Figure 4. 10 EFFECT OF CURVATURE ON THE SHEAR Distribution FACTOR FOR THE EXTERIOR GIRDER DUE TO DEAD LOAD .

Figure 4. 11 EFFECT OF CUR VATURE ON THE SHEAR Distribution FACTOR FOR THE EXTERIOR GIRDER DUE TO FULLY LOADED LANES

FIGURE 4. 12 EFFECT OF CURVATURE ON THE SHEAR DisTRIBUTION FACTOR FOR THE EXTERIOR GIRDER DUE

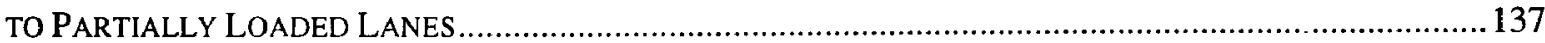

FIGURE 4. 13 EFFECT OF CUR VATURE ON THE SHEAR DISTRIBUTION FACTOR FOR THE EXTERIOR GIRDER DUE TO

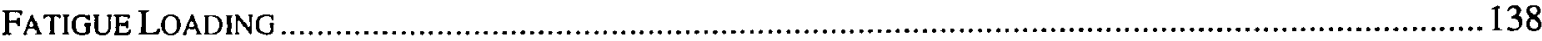

FIGURE 4. 14 EFFECT OF CURVATURE ON THE SHEAR DISTRIBUTION FACTOR FOR THE INTERIOR GIRDER DUE TO DEAD LOAD...

FigURE 4. 15 EFFECT OF CURVATURE ON THE SHEAR DisTRIBUTION FACTOR FOR THE INTERIOR GRDER DUE TO

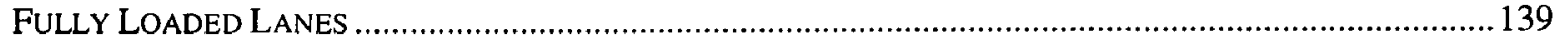

FIGURE 4. 16 EFFECT OF CURVATURE ON THE SHEAR DISTRIBUTION FACTOR FOR THE INTERIOR GIRDER DUE TO

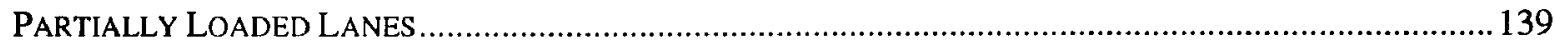

FIGURE 4. 17 EFFECT OF NUMBER OF GIRDERS ON THE SHEAR DISTR IBUTION FACTOR FOR THE EXTERIOR

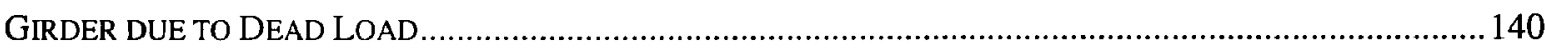

FIGURE 4. 18 EFFECT OF NUMBER OF GIRDERS ON THE SHEAR DISTRIBUTION FACTOR FOR THE EXTERIOR

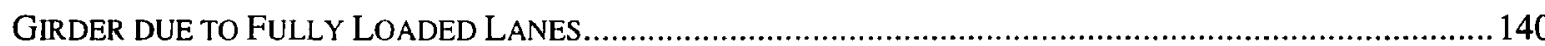

FIGURE 4. 19 EFFECT OF NUMBER OF GIRDERS ON THE SHEAR DISTR IBUTION FACTOR FOR THE EXTERIOR GIRDER DUE TO PARTIALLY LOADED LANES

FIGURE 4. 20 EFFECT OF NUMBER OF GIRDERS ON THE SHEAR DISTRIBUTION FACTOR FOR THE EXTERIOR GIRDER DUE TO FATIGUE LOADING

FIGURE 4. 21 EFFECT OF NUMBER OF GIRDERS ON THE SHEAR DISTR IBUTION FACTOR FOR THE MIDDLE GIRDER DUE TO DEAD LOAD.....

FIGURE 4. 22 EFFECT OF NUMBER OF GIRDERS ON THE SHEAR DISTR IBUTION FACTOR FOR THE MIDDLE GIRDER

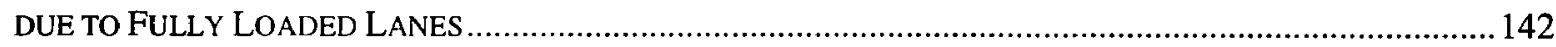

FIGURE 4. 23 EFFECT OF NUMBER OF GIRDERS ON THE SHEAR DISTR IBUTION FACTOR FOR THE MIDDLE GIRDER

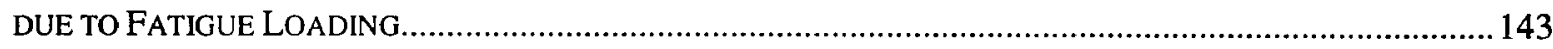

FiguRE 4. 24 EFFECT OF NUMBER OF GIRDERS ON THE SHEAR DISTRIBUTION FACTOR FOR THE INTERIOR GIRDER DUE TO DEAD LOAD.

FIGURE 4. 25 EFFECT OF NUMBER OF GIRDERS ON THE SHEAR DISTRIBUTION FACTOR FOR THE INTER IOR GIRDER DUE TO FULLY LOADED LANES.

FIGURE 4. 26 EFFECT OF NUMBER OF GIRDERS ON THE SHEAR DISTRIBUTION FACTOR FOR THE INTER IOR GIRDER DUE TO PARTIALLY LOADED LANES .

FIGURE 4. 27 EFFECT OF NUMBER OF GIRDERS ON THE SHEAR DISTRIBUTION FACTOR FOR THE INTERIOR GIRDER DUE TO FATIGUE LOADING

FIGURE 4. 28 EFFECT OF GIRDER SPACING ON THE SHEAR DISTRIBUTION FACTOR FOR THE EXTERIOR GIRDER DUE TO DEAD LOAD

Figure 4. 29 EFFECT OF GIRDER SPACING ON THE SHEAR DISTRIBUTION FACTOR FOR THE EXTERIOR GIRDER DUE TO FULLY LOADED LANES.

Figure 4. 30 EFFECT OF GIRDER SPACING ON THE SHEAR Distribution FACTOR FOR THE EXTERIOR GIRDER DUE TO PARTIALLY LOADED LANES

FIGURE 4. 31 EFFECT OF GIRDER SPACING ON THE SHEAR DISTRIBUTION FACTOR FOR THE EXTERIOR GIRDER DUE TO FATIGUE LOADING.

FigURE 4. 32 EFFECT OF GIRDER SPACING ON THE SHEAR DISTRIBUTION FACTOR FOR THE MIDDLE GIRDER DUE TO FULLY LOADED LANES 
Figure 4. 33 EFFECT Of Girder Spacing on the Shear Distribution Factor for the Middle GiRder DUE TO FATIGUE LOADING

FIGURE 4. 34 EFFECT OF GIRDER SPACING ON THE SHEAR DisTRIBUTION FACTOR FOR THE INTERIOR GIRDER DUE TO FULLY LOADED LANES

FIGURE 4. 35 EFFECT OF GIRDER SPACING ON THE SHEAR DISTRIBUTION FACTOR FOR THE INTERIOR GIRDER DUE TO PARTIALLY LOADED LANES

FigURE 4. 36 EFFECT OF SPAN LENGTH ON THE SHEAR DistRIBUTION FACTOR FOR THE EXTERIOR GIRDER DUE TO DEAD LOAD

FIGURE 4. 37 EFFECT OF SPAN LENGTH ON THE SHEAR DISTRIBUTION FACTOR FOR THE EXTERIOR GIRDER DUE TO FULLY LOADED LANES ...

FIGURE 4. 38 EFFECT OF SPAN LENGTH ON THE SHEAR DisTRIBUTION FaCtOR FOR THE MidDle GiRder DUE TO FULLY LOADED LANES

FiguRE 4. 39 EFFECT OF SPAN LENGTH ON THE SHEAR DistRIBUTION FACTOR FOR THE INTERIOR GIRDER DUE TO DEAD LOAD

FIGURE 4. 40 EFFECT OF SPAN LENGTH ON THE SHEAR DISTRIBUTION FACTOR FOR THE INTERIOR GIRDER DUE

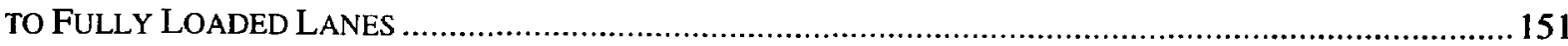

FiguRE 4. 41 EFFECT OF LOADING CONDITIONS ON THE SHEAR DISTRIBUTION FACTOR FOR THE EXTERIOR

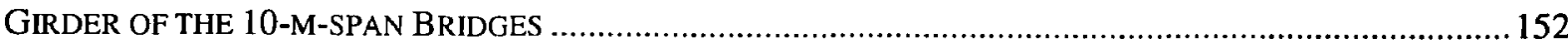

FigURE 4. 42 EFFECT OF LOADING CONDITIONS ON THE SHEAR DISTRIBUTION FACTOR FOR THE EXTERIOR GIRDER OF THE 15-M-SPAN BRIDGES ..................................................................................... 152

FIGURE 4. 43 EFFECT OF LOADING CONDITIONS ON THE SHEAR DISTRIBUTION FACTOR FOR THE EXTERIOR

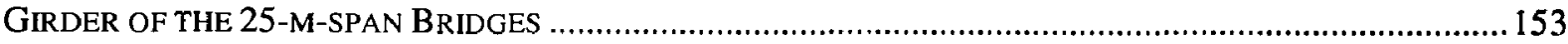

FiguRE 4. 44 EFFECT OF LOADING CONDITIONS ON THE SHEAR Distribution FACTOR FOR THE EXTERIOR

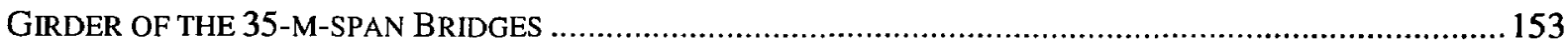

FIGURE 4. 45 EFFECT OF LOADING CONDITIONS ON THE SHEAR DISTRIBUTION FACTOR FOR THE INTERIOR

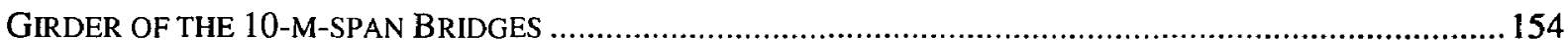

FigURE 4. 46 EFFECT OF LOADING CONDITIONS ON THE SHEAR DISTRIBUTION FACTOR FOR THE INTERIOR

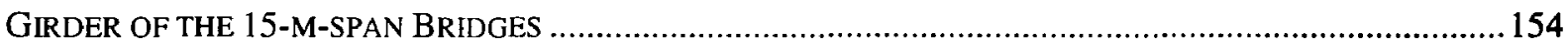

FiguRE 4. 47 EFFECT OF LOADING CONDITIONS ON THE SHEAR DiSTRIBUTION FACTOR FOR THE INTERIOR

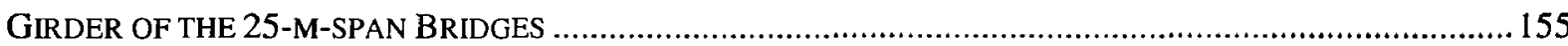

FIGURE 4. 48 EFFECT OF LOADING CONDITIONS ON THE SHEAR DISTRIBUTION FACTOR FOR THE INTERIOR

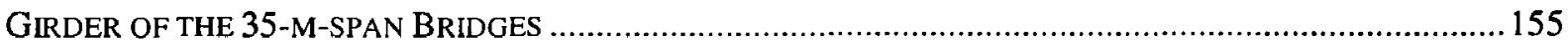

FigURE 4. 49 EFFECT OF NUMBER OF LANES ON THE SHEAR DISTRIBUTION FACTOR FOR THE EXTERIOR GIRDER DUE TO FULLY LOADED LANES ............................................................................................ 156

FIGURE 4. 50 EFFECT OF NUMBER OF LANES ON THE SHEAR DISTR IBUTION FACTOR FOR THE EXTERIOR GIRDER DUE TO PARTIALLY LOADED LANES ........................................................................................... 156

FIGURE 4. 51 EFFECT OF NUMBER OF LANES ON THE SHEAR DISTR IBUTION FACTOR FOR THE MIDDLE GIRDER

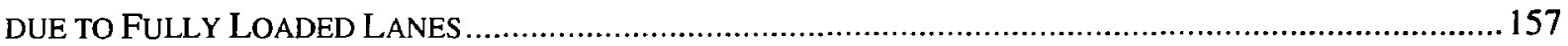

FIGURE 4. 52 EFFECT OF NUMBER OF LANES ON THE SHEAR DISTRIBUTION FACTOR FOR THE MIDDLE GIRDER

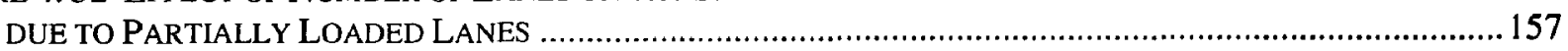

FIGURE 4. 53 EFFECT OF NUMBER OF LANES ON THE SHEAR DISTRIBUTION FACTOR FOR THE INTERIOR GIRDER DUE TO FULLY LOADED LANES .................................................................................................... 158

FIGURE 4. 54 EFFECT OF NUMBER OF LANES ON THE SHEAR DISTR IBUTION FACTOR FOR THE INTERIOR GIRDER

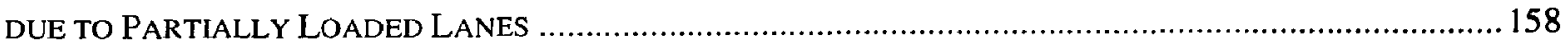

Figure 4. 55 EFFECT OF THE NUMBER OF CROSS-BRACING INTERVALS ON THE SHEAR DISTRIBUTION FACTOR

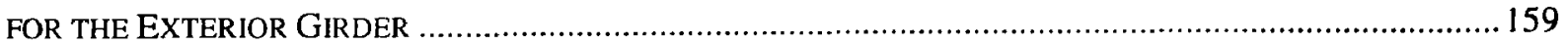

FIGURE 4. 56 EFFECT OF THE LOAD CASES NUMBER ON THE SHEAR DISTRIBUTION FACTOR FOR THE EXTERIOR

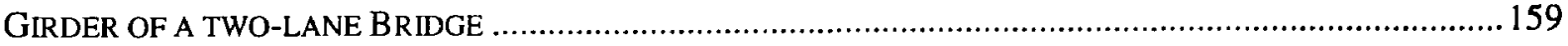

FIGURE 4. 57 EFFECT OF THE LOAD CASES NUMBER ON THE SHEAR DISTRIBUTION FACTOR FOR THE MIDDLE

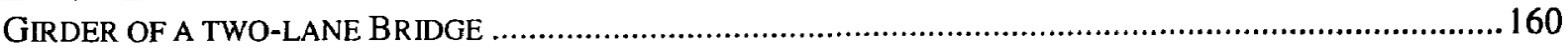

FIGURE 4. 58 EFFECT OF THE LOAD CASES NUMBER ON THE SHEAR DISTRIBUTION FACTOR FOR THE INTERIOR

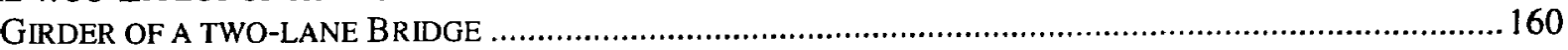

FIGURE 4. 59 EFFECT OF THE LOAD CASES NUMBER ON THE SHEAR DISTRIBUTION FACTOR FOR THE EXTERIOR GIRDER OF A 3-LANE BRIDGE.

FIGURE 4. 60 EFFECT OF THE LOAD CASES NUMBER ON THE SHEAR DISTRIBUTION FACTOR FOR THE MIDDLE GIRDER OF A 3-LANE BRIDGE. 
FIGURE 4.61 EFFECT OF THE LOAD CASES NUMBER ON THE SHEAR DISTRIBUTION FACTOR FOR THE INTERIOR GIRDER OF A 3-LANE BRIDGE

FIGURE 4.62 EFFECT OF THE LOAD CASES NUMBER ON THE SHEAR DiSTRIBUTION FACTOR FOR THE EXTERIOR

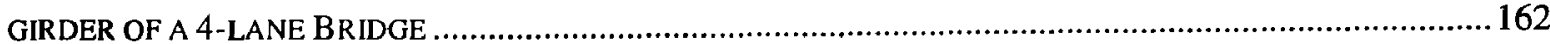

FIGURE 4. 63 EFFECT OF THE LOAD CASES NUMBER ON THE SHEAR DisTRIBUTION FACTOR FOR THE MIDDLE

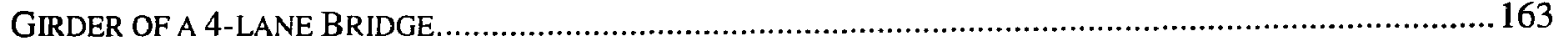

FIGURE 4. 64 EFFECT OF THE LOAD CASES NUMBER ON THE SHEAR DISTRIBUTION FACTOR FOR THE INTERIOR

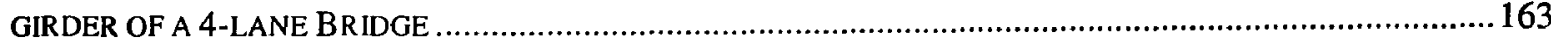

FiguRE 4.65 EFFECT OF GIRDER LOCATION ON THE SHEAR DisTR IBUTION FACTOR DUE TO DEAD LOADING 164

FiguRE 4. 66 EFFECT OF GiRDER LOCATION ON THE SHEAR DisTR IBUTION FaCtOR DUE TO FULLY LOADED

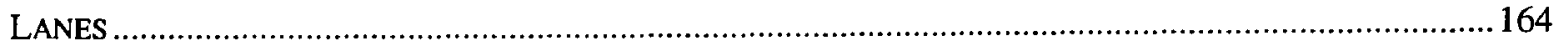

FigURE 4.67 EFFECT OF GIRDER LOCATION ON THE SHEAR DiSTR IBUTION FACTOR DUE TO DEAD LOADING 165 FiguRE 4. 68 EFFECT OF GIRDER LOCATION ON THE SHEAR DiSTRIBUTION FACTOR DUE TO FULLY LOADED LANES

FiguRE 4. 69 EFFECT OF THE TYPE OF SUPPORT ON THE SHEAR DiSTRIBUTION FACTOR DUE TO DEAD LOADING

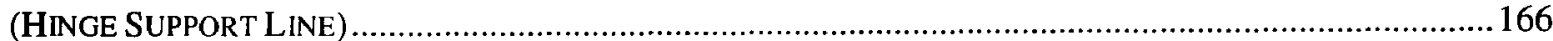

FiguRE 4. 70 EFFECT OF THE TYPE OF SUPPORT ON THE SHEAR DISTRIBUTION FACTOR DUE TO FULLY LOADED

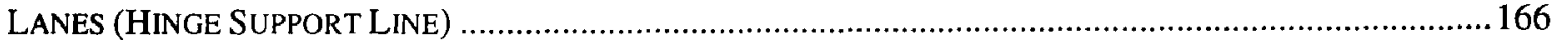

FIGURE 4.71 EFFECT OF THE TYPE OF SUPPORT ON THE SHEAR DISTRIBUTION FACTOR DUE TO DEAD LOADING

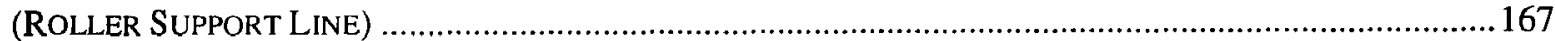

FiguRE 4. 72 EFFECT OF THE TYPE OF SUPPORT ON THE SHEAR DISTR IBUTION FACTOR DUE TO FULLY LOADED

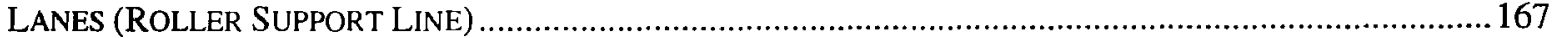

FIGURE 4. 73 COMPARISON BETWEEN THE SHEAR DISTRIBUTION FACTORS OF THE EXTERIOR GIRDER DUE TO TRUCK LOADING AS SPECIFIED IN THE CHBDC AND FROM THE CURRENT STUDY ................................168

Figure 4. 74 COMParison BETWEEN THE SHEAR Distribution FaCtors OF THE EXTER IOR GIRDER DUE TO FATIGUE LOADING AS SPECIFIED IN THE CHBDC AND FROM THE CURRENT STUDY .............................168

FIGURE 4. 75 COMPARISON BETWEEN THE SHEAR DiSTRIBUTION FACTORS OF THE MIDDLE GIRDER DUE TO TRUCK LOADING AS SPECIFIED IN THE CHBDC AND FROM THE CURRENT STUDY .................................169

FIGURE 4. 76 COMPARISON BETWEEN THE SHEAR DISTR IBUTION FACTORS OF THE MIDDLE GIRDER DUE TO Fatigue dUE TO TRUCK LOAding as SPECIFIEd IN THE CHBDC AND FROM THE CURRENT STUDY ....... 169

Figure 4.77 EFFECT OF CURVATURE ON THE MOMENT DISTRIBUTION FACTOR FOR THE EXTERIOR GIRDER DUE

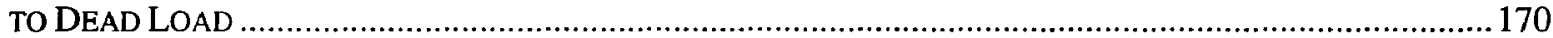

FIGURE 4. 78 EFFECT OF CURVATURE ON THE MOMENT DISTRIBUTION FACTOR FOR THE EXTERIOR GIRDER DUE

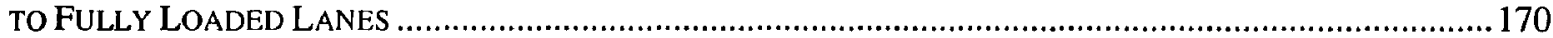

Figure 4. 79 EFFECT OF CUR VATURE ON THE MOMENT Distribution FACTOR FOR THE EXTERIOR GIRDER DUE

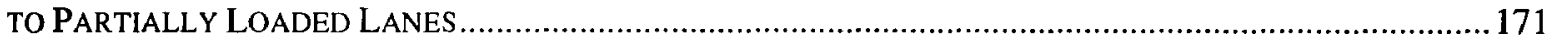

FIGURE 4. 80 EFFECT OF CURVATURE ON THE MOMENT DISTRIBUTION FACTOR FOR THE EXTERIOR GIRDER DUE

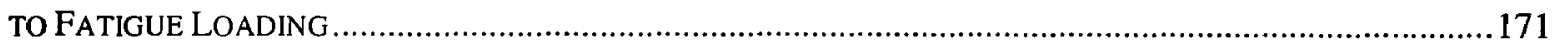

FIGURE 4. 81 EFFECT OF CURVATURE ON THE MOMENT DISTRIBUTION FACTOR FOR THE MiDDLE GIRDER DUE

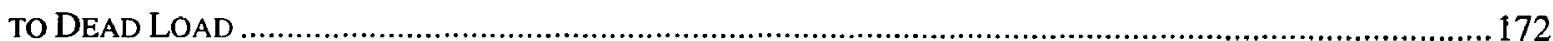

FIGURE 4. 82 EFFECT OF CUR VATURE ON THE MOMENT DISTRIBUTION FACTOR FOR THE MIDDLE GIRDER DUE

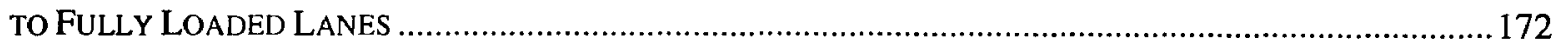

FIGURE 4. 83 EFFECT OF CURVATURE ON THE MOMENT DISTRIBUTION FACTOR FOR THE MIDDLE GIRDER DUE

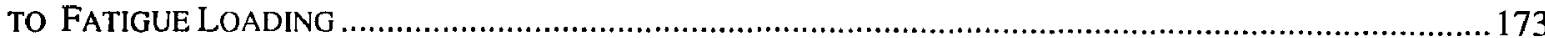

Figure 4. 84 EFFECT OF CURVATURE ON THE MOMENT Distribution FACTOR FOR THE INTERIOR GiRdER DUE TO DEAD LOAD

FIGURE 4. 85 EFFECT OF CURVATURE ON THE MOMENT DISTRIBUTION FACTOR FOR THE INTERIOR GIRDER DUE

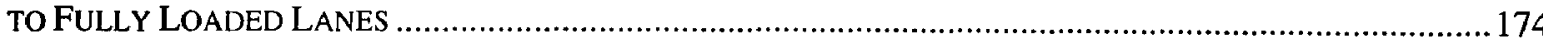

FIGURE 4. 86 EFFECT OF CURVATURE ON THE MOMENT DISTRIBUTION FACTOR FOR THE INTERIOR GIRDER DUE

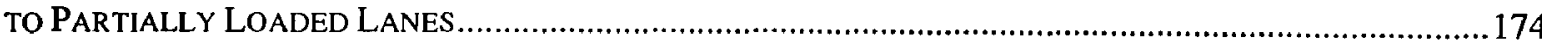

FIGURE 4. 87 EFFECT OF CURVATURE ON THE MOMENT DISTRIBUTION FACTOR FOR THE INTERIOR GIRDER DUE TO FATIGUE LOADING 175

FIGURE 4. 88 EFFECT OF NUMBER OF GIRDERS ON THE MOMENT DISTRIBUTION FACTOR FOR THE EXTERIOR GIRDER DUE TO DEAD LOAD.

FIGURE 4.89 EFFECT OF NUMBER OF GIRDERS ON THE MOMENT DISTRIBUTION FACTOR FOR THE EXTERIOR GIRDER DUE TO FULLY LOADED LANES. 
FIGURE 4. 90 EFFECT OF NUMBER OF GIRDERS ON THE MOMENT DISTRIBUTION FACTOR FOR THE EXTERIOR GIRDER DUE TO PARTIALLY LOADED LANES

FIGURE 4.91 EFFECT OF NUMBER OF GIRDERS ON THE MOMENT DISTRIBUTION FACTOR FOR THE EXTERIOR GIRDER DUE TO FATIGUE LOADING

FIGURE 4. 92 EFFECT OF NUMBER OF GIRDERS ON THE MOMENT DISTR IBUTION FACTOR FOR THE MIDDLE GIRDER DUE TO DEAD LOAD.

FIGURE 4. 93 EFFECT OF NUMBER OF GIRDERS ON THE MOMENT DISTRIBUTION FACTOR FOR THE MIDDLE GIRDER DUE TO FULLY LOADED LANES.

FIGURE 4. 94 EFFECT OF NUMBER OF GIRDERS ON THE MOMENT DISTRIBUTION FACTOR FOR THE MIDDLE GIRDER DUE TO PARTIALLY LOADED LANES

FIGURE 4. 95 EFFECT OF NUMBER OF GIRDERS ON THE MOMENT DISTRIBUTION FACTOR FOR THE MIDDLE GIRDER DUE TO FATIGUE LOADING ....

FIGURE 4.96 EFFECT OF NUMBER OF GIRDERS ON THE MOMENT DISTRIBUTION FACTOR FOR THE INTERIOR GIRDER DUE TO DEAD LOAD.

FIGURE 4. 97 EFFECT OF NUMBER OF GIRDERS ON THE MOMENT DISTRIBUTION FACTOR FOR THE INTERIOR GIRDER DUE TO FULLY LOADED LANES.

FIGURE 4.98 EFFECT OF NUMBER OF GIRDERS ON THE MOMENT DISTR IBUTION FACTOR FOR THE INTERIOR GIRDER DUE TO PARTIALLY LOADED LANES

FIGURE 4. 99 EFFECT OF NUMBER OF GIRDERS ON THE MOMENT DISTRIBUTION FACTOR FOR THE INTERIOR GIRDER DUE TO FATIGUE LOADING

FigURE 4. 100 EFFECT OF GIRDER SPACING ON THE MOMENT DisTRIBUTION FACTOR FOR THE EXTERIOR GIRDER DUE TO DEAD LOAD.

FIGURE 4. 101 EFFECT OF GIRDER SPACING ON THE MOMENT DISTRIBUTION FACTOR FOR THE EXTERIOR GIRDER DUE TO FULLY LOADED LANES

FiguRE 4. 102 EFFECT OF GIRDER SPACING ON THE MOMENT DisTRIBUTION FACTOR FOR THE EXTERIOR

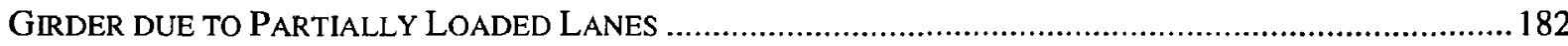

FIGURE 4. 103 EFFECT OF GIRDER SPACING ON THE MOMENT DISTRIBUTION FACTOR FOR THE EXTERIOR GIRDER DUE TO FATIGUE LOADING

Figure 4. 104 EFFECT OF GIRDER SPACING ON THE MOMENT DistribUTION FACTOR FOR THE MIDDLE GiRDER DUE TO FULLY LOADED LANES.

Figure 4. 105 EFFECT OF GiRdER SPACING ON THE MOMENT Distr IBUTION FACTOR FOR THE MIDDLE GiRDER DUE TO FATIGUE LOADING.

FIGURE 4. 106 EFFECT OF GIRDER SPACING ON THE MOMENT DISTR IBUTION FACTOR FOR THE INTERIOR GIRDER DUE TO FULLY LOADED LANES.

FigURE 4. 107 EFFECT OF GIRDER SPACING ON THE MOMENT DISTRIBUTION FACTOR FOR THE INTERIOR GIRDER DUE TO FATIGUE LOADING.

FIGURE 4. 108 EFFECT OF LOADING CONDITIONS ON THE MOMENT DISTRIBUTION FACTOR FOR THE EXTER IOR

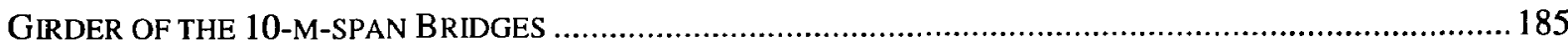

FIGURE 4. 109 EFFECT OF LOADING CONDITIONS ON THE MOMENT DISTRIBUTION FACTOR FOR THE MIDDLE

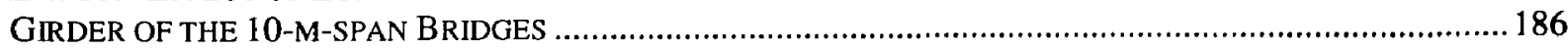

FIGURE 4. 110 EFFECT OF LOADING CONDITIONS ON THE MOMENT DISTR IBUTION FACTOR FOR THE INTER IOR GIRDER OF THE 10-M-SPAN BRIDGES

FIGURE 4. 111 EFFECT OF CURVATURE ON THE DEFLECTION DISTRIBUTION FACTOR FOR THE EXTERIOR GIRDER DUE TO DEAD LOAD

FIGURE 4. 112 EFFECT OF CURVATURE ON THE DEFLECTION DISTRIBUTION FACTOR FOR THE EXTERIOR GiRDER DUE TO FULLY LOADED LANES.

FIGURE 4. 113 EFFECT OF CURVATURE ON THE DEFLECTION DISTRIBUTION FACTOR FOR THE EXTERIOR GIRDER DUE TO PARTIALLY LOADED LANES

Figure 4. 114 EFFECT OF CURVATURE ON THE DEFLECTION DISTRIBUTION FACTOR FOR THE EXTERIOR GIRDER DUE TO FATIGUE LOADING.

FIGURE 4. 115 EFFECT OF CURVATURE ON THE DEFLECTION DISTRIBUTION FACTOR FOR THE MIDDLE GIRDER DUE TO DEAD LOAD.

FigURE 4. 116EFFECT OF CURVATURE ON THE DEFLECTION DISTRIBUTION FACTOR FOR THE MIDDLE GIRDER DUE TO FULLY LOADED LANES.

FIGURE 4. 117 EFFECT OF CURVATURE ON THE DEFLECTION DISTRIBUTION FACTOR FOR THE MIDDLE GIRDER DUE TO PARTIALLY LOADED LANES 
FIGURE 4. 118 EFFECT OF CURVATURE ON THE DEFLECTION DISTRIBUTION FACTOR FOR THE MIDDLE GIRDER

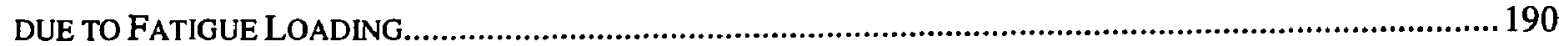

FIGURE 4. 119 EFFECT OF CURVATURE ON THE DEFLECTION DISTRIBUTION FACTOR FOR THE INTERIOR GIRDER DUE TO DEAD LOAD.

FIGURE 4. 120 EFFECT OF CURVATURE ON THE DEFLECTION DISTR IBUTION FACTOR FOR THE INTERIOR GIRDER

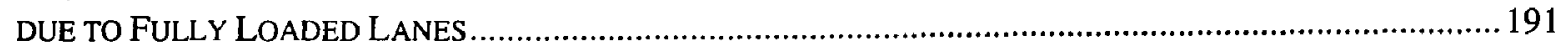

FIGURE 4. 121 EFFECT OF CURVATURE ON THE DEFLECTION DISTR IBUTION FACTOR FOR THE INTERIOR GIRDER

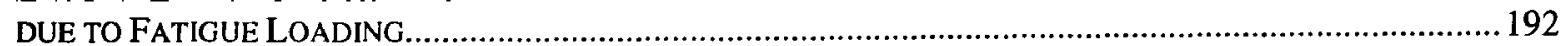

FIGURE 4. 122 EFFECT OF NUMBER OF GIRDERS ON THE DEFLECTION DISTRIBUTION FACTOR FOR THE EXTERIOR GIRDER DUE TO DEAD LOAD................................................................................................. 192

FIGURE 4. 123 EFFECT OF NUMBER OF GIRDERS ON THE DEFLECTION DISTRIBUTION FACTOR FOR THE EXTERIOR

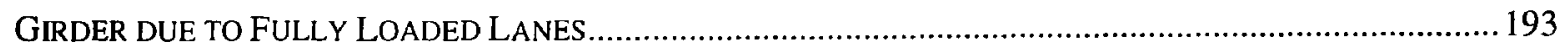

FIGURE 4. 124 EFFECT OF NUMBER OF GIRDERS ON THE DEFLECTION DISTRIBUTION FACTOR FOR THE EXTERIOR GIRDER DUE TO PARTIALLY LOADED LANES ................................................................................ 193

FIGURE 4. 125 EFFECT OF NUMBER OF GIRDERS ON THE DEFLECTION DISTRIBUTION FACTOR FOR THE EXTERIOR

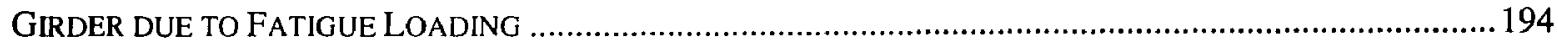

FIGURE 4. 126 EFFECT OF NUMBER OF GiRDERS ON THE DEFLECTION DistR IBUTION FACTOR FOR THE MIDDLE

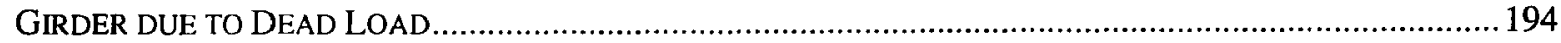

FIGURE 4. 127 EFFECT OF NUMBER OF GIRDERS ON THE DEFLECTION DISTRIBUTION FACTOR FOR THE MidDLE

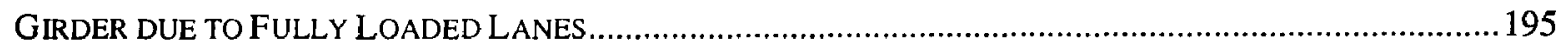

FIGURE 4. 128 EFFECT OF NUMBER OF GIRDERS ON THE DEFLECTION DISTRIBUTION FACTOR FOR THE MIDDLE

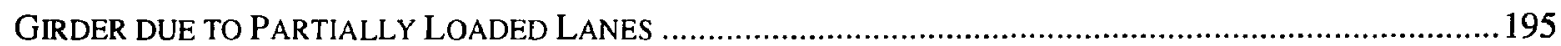

FIGURE 4. 129 EFFECT OF NUMBER OF GIRDERS ON THE DEFLECTION DISTRIBUTION FACTOR FOR THE MIDDLE

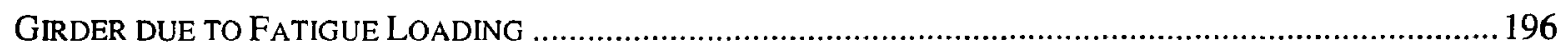

FIGURE 4. 130 EFFECT OF NUMBER OF GIRDERS ON THE DEFLECTION DISTRIBUTION FACTOR FOR THE INTERIOR

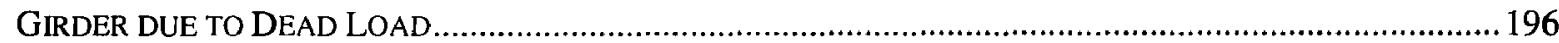

FIGURE 4. 131 EFFECT OF NUMBER OF GIRDERS ON THE DEFLECTION DISTR IBUTION FACTOR FOR THE INTERIOR

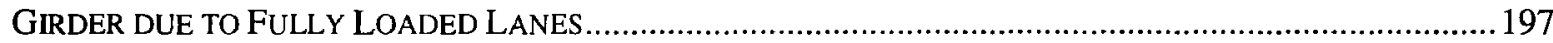

FIGURE 4. 132 EFFECT OF GIRDER SPACING ON THE DEFLECTION DISTRIBUTION FACTOR FOR THE EXTERIOR

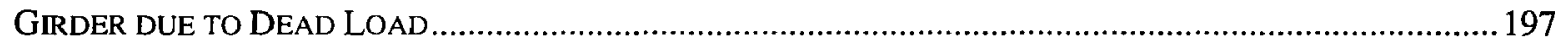

FIGURE 4. 133 EFFECT OF GIRDER SPACING ON THE DEFLECTION DISTRIBUTION FACTOR FOR THE EXTERIOR

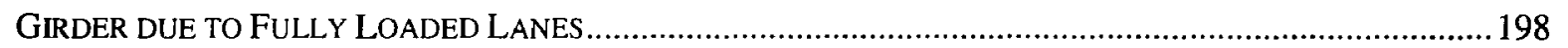

FIGURE 4. 134 EFFECT OF GIRDER SPACING ON THE DEFLECTION DISTRIBUTION FACTOR FOR THE EXTERIOR GIRDER DUE TO PARTIALLY LOADED LANES ..................................................................................... 198

FIGURE 4. 135 EFFECT OF GIRDER SPACING ON THE DEFLECTION DISTRIBUTION FACTOR FOR THE EXTERIOR

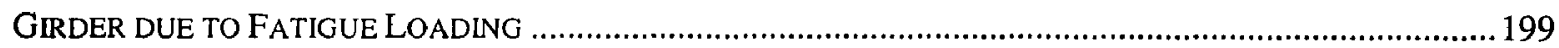

FIGURE 4. 136 EFFECT OF GIRDER SPACING ON THE DEFLECTION DISTRIBUTION FACTOR FOR THE MDDLE

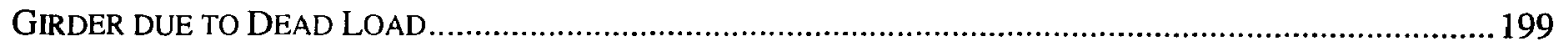

FiguRE 4. 137 EFFECT OF GiRDER SPACING ON THE DEFLECTION DisTRIBUTION FACTOR FOR THE MIDDLE GIRDER DUE TO FULLY LOADED LANES..

FIGURE 4. 138 EFFECT OF GIRDER SPACING ON THE DEFLECTION DISTRIBUTION FACTOR FOR THE MIDDLE GIRDER DUE TO FATIGUE LOADING .

FIGURE 4. 139 EFFECT OF GIRDER SPACING ON THE DEFLECTION DISTRIBUTION FACTOR FOR THE INTERIOR

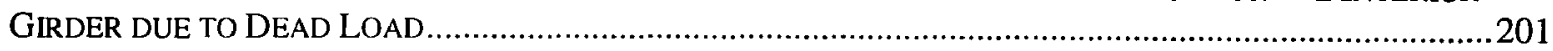

FIGURE 4. 140 EFFECT OF GIRDER SPACING ON THE DEFLECTION DISTRIBUTION FACTOR FOR THE INTERIOR

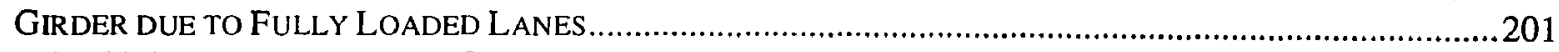

FIGURE 4. 141 EFFECT OF LOADING CONDITIONS ON THE DEFLECTION DISTR IBUTION FACTOR FOR THE

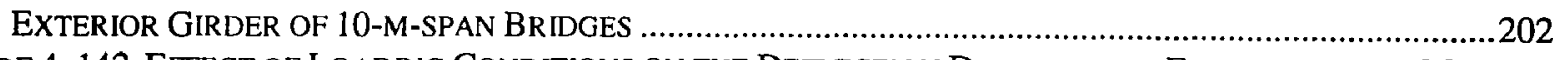

FIGURE 4. 142 EFFECT OF LOADING CONDITIONS ON THE DEFLECTION DISTR IBUTION FACTOR FOR THE MIDDLE GIRDER OF 10-M-SPAN BRIDGES

FIGURE 4. 143 EFFECT OF LOADING CONDITIONS ON THE DEFLECTION DISTR IBUTION FACTOR FOR THE

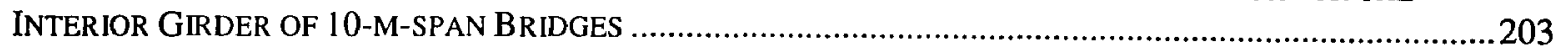

FIGURE 4. 144 EFFECT OF CURVATURE ON THE WARPING-TO-BENDING RATIO FOR THE EXTERIOR GIRDER DUE TO DEAD LOAD ...

FIGURE 4. 145 EFFECT OF CURVATURE ON THE WARPING-TO-BENDING RATIO FOR THE EXTERIOR GIRDER DUE TO FULLY LOADED LANES . 
FIGURE 4. 146 EFFECT OF CURVATURE ON THE WARPING-TO-BENDING RATIO FOR THE EXTERIOR GIRDER DUE TO PARTIALLY LOADED LANES.

FIGURE 4. 147 EFFECT OF CURVATURE ON THE WARPING-TO-BENDING RATIO FOR THE EXTERIOR GIRDER DUE TO FATIGUE LOADING.

FIGURE 4. 148 EFFECT OF CURVATURE ON THE WARPING-TO-BENDING RATIO FOR THE MIDDLE GIRDER DUE TO DEAD LOAD

FiguRE 4. 149 EFFECT OF CURVATURE ON THE WARPING-TO-BENDING RATIO FOR THE MIDDLE GIRDER DUE TO FULLY LOADED LANES.

FiguRE 4. 150 EFFECT OF CURVATURE ON THE WARPING-TO-BENDING RATIO FOR THE MIDDLE GIRDER DUE TO PARTIALLY LOADED LANES.

FIGURE 4. 151 EFFECT OF CURVATURE ON THE W ARPING-TO-BENDING RATIO FOR THE MIDDLE GIRDER DUE TO FATIGUE LOADING.

FIGURE 4. 152 EFFECT OF CURVATURE ON THE WARPING-TO-BENDING RATIO FOR THE INTERIOR GIRDER DUE TO DEAD LOAD

FIGURE 4. 153 EFFECT OF CURVATURE ON THE W ARPING-TO-BENDING RATIO FOR THE INTERIOR GIRDER DUE TO FULLY LOADED LANES

FIGURE 4. 154 EFFECT OF CURVATURE ON THE WARPING-TO-BENDING RATIO FOR THE INTERIOR GIRDER DUE TO PARTIALLY LOADED LANES.

FIGURE 4. 155 EFFECT OF CURVATURE ON THE WARPING-TO-BENDING RATIO FOR THE INTERIOR GIRDER DUE TO FATIGUE LOADING.

FIGURE 4. 156 COMPARISON BETWEEN THE MOMENT DISTRIBUTION FACTORS OF THE EXTERIOR GIRDER DUE TO TRUCK LOADING AS SPECIFIED IN THE CHBDC AND FROM THE CURRENT STUDY ...........................210

FIGURE 4. 157 COMPARISON BETWEEN THE MOMENT DISTR IBUTION FACTORS OF THE EXTERIOR GIRDER DUE TO FATIGUE LOADING AS SPECIFIED IN THE CHBDC AND FROM THE CURRENT STUDY .

FIGURE 4. 158 COMPARISON BETWEEN THE MOMENT DISTRIBUTION FACTORS OF THE MIDDLE GIRDER DUE TO TRUCK LOADING AS SPECIFIED IN THE CHBDC AND FROM THE CURRENT STUDY .....

FIGURE 4. 159 COMPARISON BETWEEN THE MOMENT DISTRIBUTION FACTORS OF THE MIDDLE GIRDER DUE TO FATIGUE LOADING AS SPECIFIED IN THE CHBDC AND FROM THE CURRENT STUDY 211

FIGURE 4. 160 CORRELATION BETWEEN MOMENT AND DEFLECTION DISTR IBUTION FACTORS FOR THE EXTERIOR GIRDER OF THE STUDIED BRIDGES DUE TO TRUCK LOADING

FIGURE 4. 161 CORRELATION BETWEEN MOMENT AND DEFLECTION DISTRIBUTION FACTORS FOR THE EXTERIOR GIRDER OF THE STUDIED BRIDGES DUE TO FATIGUE LOADING ....................................................212

FIGURE 4. 162 CORRELATION BETWEEN MOMENT AND DEFLECTION DISTRIBUTION FACTORS FOR THE MIDDLE

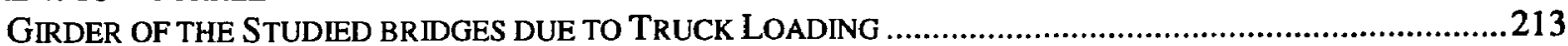

FIGURE 4. 163 CORRELATION BETWEEN MOMENT AND DEFLECTION DISTRIBUTION FACTORS FOR THE MIDDLE GIRDER OF THE STUDIED BRIDGES DUE TO FATIGUE LOADING 


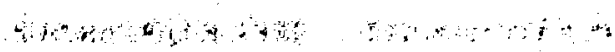

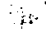

\section{CHAPTER I \\ INTRODUCTION}

W.

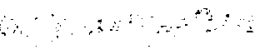

\subsection{General}

The widely use of elevated highways to alleviate traffic congestions at existing at-grade signalized junctions in urban areas became the common answer to ensure uninterrupted smooth traffic flow in modern heavy traffic networks. One of the major components of the elevated highways is the horizontally curved bridges, which in many cases are located in onand off-ramps with very tight radii of curvature and are characterized by complex vertical and horizontal geometries. For this application, curved steel I-girder system is the preferred choice for most designers for the following reasons:

1. Simplicity of fabrication and construction,

2. Less land is needed during erection,

3. Shallower sections can be designed,

4. Impose lighter weights on bridge foundation when compared to precast/prestressed beams or segmental prestressed concrete box girder deck,

5. Excellent serviceability performance.

Generally, the horizontally curved girder bridges are more attractive to conform to existing terrain. However, from the design point of view, the simple presence of curvature in curved steel girders complicates, to a great extent, their behavior and design considerations over those of straight girders. 
There are two fabrication methods of the horizontally curved girders: (a) the flanges are cut from plates to the stipulated curve (cut curve) and are then welded to the web plate, or (b) fabrication of straight girder is carried out in the conventional manner and then the entire girder is curved to the specific curve by applying heat in a controlled continuous or intermittent manner to the edges of the flanges (heat curve). Figure 1.1 shows typical cross section of a four-girder bridge. It consists of concrete deck slab supported over steel Igirders. To enhance the bridge structural integrity during construction, cross-bracings as well as top and bottom chords are used at equal intervals between bridge support lines.

In designing highway bridges, bridge codes require dead, live and other types of loads to be considered. For live load design, the codes define a standard truck loading with concentrated wheel loads. Both the longitudinal position and the transverse distribution of the wheel loads are of great importance. In other words, the truck load must be positioned longitudinally to produce the maximum positive and negative bending moments, shear and deflection in the girders. North American Bridge codes define lateral-distribution factors for different materials of construction that specify the fraction of each wheel load that must be applied to each girder. For straight girder bridges, this allows each girder to be designed as an isolated single girder. Thus, the distribution factor is of fundamental importance in bridge design. 


\subsection{The Problem}

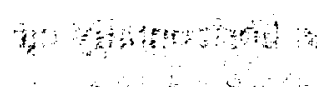

Although horizontally curved bridges constitute roughly one third of all steel bridges, the structural behavior still not well understood (Zureick and Naqib 1999). Curvature greatly complicates the behavior of curved steel used in bridges. It introduces outof-plane "bulging" displacement of the curved web resulting in an increase in stresses. Based on literature review, the investigation of load distribution characteristics of such bridges is needed. Currently, the Canadian Highway Bridge Design Code (CHBDC, 2000), as well as the American bridge codes (AASHTO-LRFD, 2004; AASHTO, Guide, 2003; AASHTO, 1996) specify load distribution factor equations for the design of straight composite I-girder bridges and provide geometrically defined criterion when horizontally curved bridges may be treated the same as straight bridges. In both cases, there is no practical design method in the form of expressions for moment, shear and deflection distribution factors for composite concrete-steel I-girder bridges with significant curved alignment.

The CHBDC (2000) and the AASHTO Guide Specifications for Horizontally Curved Bridges, (Guide, 2003) have recommended the use of grillage analogy, folded plate, finitestrip, and finite-element methods for analysis of the curved steel bridges. Among the above methods is the finite element method (FEM) which is a matter of concern in this study and is frequently employed for accurate final analysis and results. Unfortunately, most engineers are not familiar with the FEM and are reluctant to use this technique, especially in the preliminary designs because of its time consuming in terms of modeling, results interpretation, when the girders dimensions are not known. Consequently, the need of simplified equations and methods are required to facilitate the design procedure. Hence, a 
practical design method in the form of empirical expressions for moment, shear, and deflection distribution factors need to be developed for curved composite steel I-girder bridges to fill the gabs found in the bridge codes.

This study is an endeavor to achieve the abovementioned need. The results and the formulas developed in this study will assist bridge engineers in predicting the live load distribution in the horizontally curved composite steel I-girder bridges more reliably and economically.

\subsection{Objectives}

The objectives of this study are:

1. Identifying the key parameters that influence the lateral distribution of loads in straight and curved composite concrete-steel I-girder bridges and calculating the load distribution factors,

2. Providing accurate database that can be used for developing simplified design method for curved composite concrete-steel I-girder bridges,

3. Developing simplified formulas for shear, moment, and deflection distribution factors for straight and curved composite concrete-steel I-girder bridges.

\subsection{Scope}

The scope of this study includes the following:

1. A literature review of previous researches, text books, and codes of practice related to the study,

2. Conducting a parametric-design-oriented study on the effect of key parameters on load distribution among girders. The range of studied parameters include: The radius 
of curvature, span length, number of girders, girders spacing, number of designs lanes, cross-bracing intervals, and truck loading conditions, The parametric study was performed using commercially available Finite Element Software "SAP2000" on 240 curved and 80 straight composite I-girder bridge prototypes subjected to CHBDC truck loading and bridges' own weight,

3. Preparation of database that can be used to develop simplified design method,

4. Developing shear, moment, and deflection distribution factor formulas for curved Igirder bridges.

\subsection{Contents and Arrangement of this study}

Following this introductory chapter, chapter II contains the literature review which is thorough explanation of lateral load distribution factor concept and review of previous works of distribution factors for straight and curved bridges. Chapter III describes the finiteelement method and "SAP2000" software used in the analysis, modeling, bridge configurations, loading cases, and the methodological and theory-based approach for predicting the lateral load distribution factors pertained to the topic of this study. Chapter IV presents the outcomes of the parametric study performed on the bridge prototypes, and proposed empirical equations for load distribution factors. Lastly, Chapter $\mathbf{V}$ is the summary and conclusions drawn from this study. 


\section{CHAPTER II \\ LITERATURE REVIEW}

\subsection{Concept of Lateral Load Distribution Factor}

Dead loading and live truck loading are imposed on Bridges. The calculation of dead load, in case of straight bridges, is simple. The distribution of deck slab, wearing surface, and curbs or traffic barriers can be considered evenly among girders. Due to the fact that curbs or traffic barriers are constructed after the concrete deck is cured, for better accuracy, these dead loads can also be considered as the live load applied to the girders. However, this approach is not valid in case of horizontally curved bridges due to the torsion effects resulting from curvature. The curvature tends to increase the longitudinal moment in the outside girder, decrease the longitudinal moment in the inside girder, and have an intermediate effect on the remaining girders. Furthermore, curvature causes torsion and consequently, lateral bending (warping) in the flanges of the girders that must be considered (Brockenbrough, 1986).

In order to calculate the live load carried by each girder in case of a straight bridge, lateral load distribution factor is a key element and important in analyzing existing bridges and designing new ones. For simplicity, the concept of lateral load distribution factor can be introduced herein by using a straight single girder and multi-girder bridge. Figure (2.1a) shows the free body diagram of a straight single girder under live load P. Let $\eta(x)$ be the influence line of a certain section of the girder, then the internal force at this section can be 
calculated as $\mathrm{F}=\mathrm{P} \times \eta(\mathrm{x})$. It can be inferred from the above figure that this is a simple twodimensional problem since both the load and the girder deformation are in the (x-z) plane. However, the mechanism is totally different for multi-girder straight bridge subjected to live load $\mathrm{P}$, as shown in Figure (2.1b). Lateral rigidity makes the live load $\mathrm{P}$ to distribute in the lateral direction (y direction) as well as in the longitudinal direction ( $\mathrm{x}$ direction). As a result, the live load on the bridge is shared among the girders, and each girder is subjected to different magnitude of the live load. In such case, the live load position and structural deformation are three-dimensional (planes $x-y-z$ ) and consequently three-dimension theory is needed to solve the internal forces of the structure. The common characteristic of threedimension theory is that the internal forces and deformation at any point of the structure can be solved directly. Alternatively, the internal forces can be calculated using the influence surface, in the same manner of using influence line to determine the internal forces in the single girder. Let $\eta(x, y)$ be the influence surface of a certain section of the structure under live load, the response of the structure is then $F=P \times \eta(x, y)$. Since the live loads on the bridge are multiple concentrated wheel loads, which can move both longitudinally and transversely, the determination of maximum internal forces using influence surface is still tedious and complicated. Accordingly, the influence surface method is not widely used in practice.

To simplify the analysis, a frequently used method is to convert the complex threedimensional problem Figure (2.1b) into a simple two-dimensional problem Figure (2.1a). The principle of this method is to break down and simplify the two-variable that influence 
surface function $\eta(x, y)$ into the product of two single-variable functions, that is, $\eta(x, y)=\eta$ (x) $\times \eta(y)$. Then the internal force at the section can be expressed as,

$\mathrm{F}=\mathrm{P} \times \eta(\mathrm{x}, \mathrm{y})=\mathrm{P} \times \eta(\mathrm{x}) \times \eta(\mathrm{y})$

Where $\eta(x)$ is the longitudinal influence line of that section for a single girder (Figure 2.1a), $\eta(y)$ is the live load distributed to one certain girder when a unit load moves transversely across the bridge. $\eta(y)$ is referred to as the transverse influence line for that girder and $P \times \eta$ $(y)$ is the load distributed to that girder when live load $P$ is at point $a(x, y)$ (Figure 2.1b). As a result, the internal forces at a certain section for a specific girder can be determined using the longitudinal and transverse influence lines, which simplifies the three-dimensional problem. In reality, actual truck loads are multiple wheel loads moving on the bridge. Figure (2.2a) shows a multi-girder bridge subjected to truck loads. The rear, middle and front axle loads of the truck are $P 1, P 2$ and $P 3$, respectively. To determine the maximum response at point $(k)$ of girder No. 3, for example, the transverse influence line of girder No. 3, and the worst loading position to determine the maximum magnitude of each axle load distributed to girder No. 3 are first obtained. Secondly, the maximum response at section $(k)$ of girder No. 3 using the longitudinal single girder influence line at section $(\mathrm{k})$ is determined. Obviously, if the positions of the truck wheels on the bridge are fixed, the load distributed value to girder No. 3 is then fixed. In practice, the product of a factor $(\mathrm{g})$ and the axle load expresses this fixed value. Hence, the loads distributed to girder No. 3 of the rear, middle, and front truck axle loads can be expressed as gP1, gP2, and gP3, respectively, as shown in Figure (2.2b). The factor $(\mathrm{g})$ is referred to'as lateral load distribution factor. It is important to know 
that the maximum load distributed to one certain girder (here is girder No. 3) is a fraction of each axle load (usually less than one).

It is noted that it is an approximate approach to convert the three-dimensional problem into a two-dimensional problem, since the paths of the load being distributed to the adjacent girders are complex. The concentrated load at one girder would no longer be concentrated load at the same longitudinal position after being distributed to the adjacent girders. However, (Yao, 1990) investigated theoretical and experimental research and showed that the error was relatively small for lateral load distribution by lateral deformation relationship. Moreover, the actual truck load on the bridge is not one single concentrated load, but several wheel loads distributed at different longitudinal positions. Therefore, the error would be even smaller for truck loading. Field testing has shown that distribution factors to be conservative (Mounir, 1997).

The distribution factor $(g)$ is different for each girder within the same bridge. It varies with the variation of truck configuration, truck longitudinal location on the bridge, and the bridge lateral rigidity. The effect of truck longitudinal location is insignificant and usually the distribution factor at girder maximum response location is used for design. The bridge lateral rigidity is related to the relative stiffness of the girders and the deck. The load distribution between girders is poor for transversely flexible bridges and is even for transversely stiff bridges (Zhang, 2002). Figure (2.3) shows various deflections of the bridge girders in a cross section when subjected to applied load $P$. In this Figure, $E I_{T}$ is the bridge transverse or lateral rigidity. Figure (2.3a) shows the deformation of the bridge structure 
when the bridge transverse rigidity $E I_{T}$ is zero (very poor rigidity) and the middle girder is subjected to load $P$. Since the load can only transfer to the middle girder, the distribution factor $(g)$ for the middle girder is one and for other girders is zero. But, when the bridge transverse rigidity is infinity (full rigid section) and the same load $P$ is applied at the middle girder position, every girder has the same deflection and the same magnitude of the load as shown in figure (2.3c). As a result, the distribution factor $(g)$ is identical for every girder is equal to $-1 / N$, where $N$ is the numbers of girders. For a five- girder bridge shown in Figure 2.3c, the distribution factor $(g)$ is 0.2 . While for concrete, reinforced concrete, and steel girder bridges, the transverse rigidity is between zero and infinity. When the middle girder is subjected to load $P$, as shown in Figure (2.3b), the distribution factor for each girder is between $1 / N$ and one. The determination of the exact magnitude of the live load distributed to each girder is a matter of interest and it is a key issue in bridge analysis and has been studied by many researchers.

The analysis of structures under different types of loadings witnessed great advancement due to the development of fast speed and high capacity computers, many computer programs were evolved and can be used to accurately analyze the structures under dead and live loads and would promote more realistic calculation of the actual bridge capacity. The availability of powerful personal computers and finite element analysis software will assist bridge engineers in performing detailed and realistic modeling of the deck geometry and boundary conditions and then in performing the analysis. However the engineer needs to be familiar with the finite element method, mesh generation and its density, accurate modeling of the geometry and support conditions, selection of proper 
element types and their material properties, and loading positions that produce the maximum response in the bridge. One way to estimate the maximum moment and shear response in individual bridge girder would be to model the entire bridge in a three dimensional problem which can be solved by using the finite element method (FEM) or other analytical methods and determine all the internal forces and deflections in any individual member. The loading in this case has to be varied, in both longitudinal and transverse positions, to find the worst loading positions. For bridges with very complex configurations, this method might be the only way to determine the accurate maximum moment and shear under live load for each girder. However, for many types of bridges, this process could be very cumbersome and unnecessary.

Distribution factors and empirical methods are still the major methods used in design of modern bridges in North America. Empirical formulas were obtained by analyzing many bridge systems and models. The development of the curved girder load distribution factors procedure followed the same technique employed in determining the straight girder load distribution equations. The difference is that to analyze a curved system is more complicated than a straight one. For this reason, the following sections will review available literatures for both straight bridges and curved bridges.

\subsection{Review of Previous Research on Load Distribution}

\subsubsection{Review of Study on Distribution Factors for Straight Bridges}

According to the level of bridge lateral rigidity, different methodologies are implemented in practice, including lever rule, eccentric compression method, hinged joint 
method, fixed joint method, orthotropic plate analogy, AASHTO Standard, AASHTOLRFD and CHBDC simplified method.

\subsubsection{Lever Rule Method (Yao, 1990)}

The levèr rule is one of the most frequently used methods for calculation of distribution factors. In this method the deck between the girders is assumed to acts as a simply supported beam or cantilever beam, as shown in Figure (2.4). In this case, the load on each girder shall be taken as the reaction of the wheel loads. Lever rule is very accurate for two girder bridges. Lever rule can also be used for shear distribution near support, since the load would pass to the pier or abutment mostly through the adjacent two girders. Lever rule can also give very good results when the bridge transverse stiffness is relatively flexible. However, the results usually would be slightly conservative for the interior girders and unconservative for the exterior girders.

\subsubsection{Eccentric Compression Method (Yao, 1990)}

This method can be applied to "narrow bridge" with adequate diaphragms along bridge span. "Narrow Bridge" is defined as that the ratio of bridge width, $B$, to span length, $L$, is less than 0.5 , or for $B / L$ is equal to 0.5 satisfying the ratios of bridge longitudinal rigidity per unit length, $D_{y}$, to transverse rigidity per unit width, $D_{x}$, is greater than 0.48 . The deflection of a narrow bridge with adequate diaphragms under truck load is similar to that of an eccentric compression member, as shown in Figure 2.5.

From the theory of mechanics, when girder $k$ is subjected to load $P$, the load distributed to girder $i$ is: 


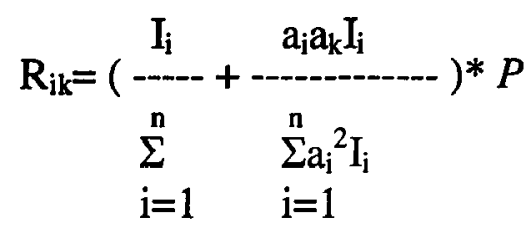

Where $\mathrm{n}$ is number of girders, $I_{i}$ is the moment of inertia of girder No. $i ; \mathrm{a}_{i}$ and $\mathrm{a}_{k}$ are the distances from bridge centerline to girder No. $i$ and $k$ respectively. Therefore, the transverse influence line can be obtained from Equation 2.2 when load $P$ is equal to one. If all the girders have the same cross section or the same moment of inertia, the control values of the transverse influence line for girder No. 1 are simplified as (note that $a_{1}=a_{5}$ ):

$$
\eta_{11}=\left(\frac{1}{N}+\frac{\mathrm{a}_{1}^{2}}{\sum_{i=1}^{\mathrm{n}} \mathrm{a}_{\mathrm{i}}^{2}}\right)
$$

$$
\eta_{15}=\left(\frac{1}{N}-\frac{\mathrm{a}_{1}{ }^{2}}{\sum_{i=1}^{\mathrm{n}} \mathrm{a}_{\mathrm{i}}{ }^{2}}\right)
$$

Where $N$ is the number of girders. Once the two control values $\eta_{11}$ and $\eta_{15}$ are determined, the transverse influence line for girder No 1 is determined. The distribution factor can then be obtained by arranging the trucks transversely on the bridge to get the worst situation. Note that in the above procedure, the girder torque is ignored. When considering the girder torque, Equations (2.3a) and (2.3b) become:

$$
\eta_{11}=\left(\frac{1}{N}+\beta \frac{a_{1}^{2}}{\sum_{i=1}^{n} a_{j}^{2}}\right)
$$




$$
\eta_{15}=\left(\frac{1}{N}-\beta \frac{a_{1}{ }^{2}}{\sum_{i=1}^{n} a_{i}^{2}}\right)
$$

where

$$
\beta=\frac{1}{1+\frac{G L^{2} \sum_{i=1}^{n} J_{i}}{12 E \sum_{i=1}^{n} a_{i}^{2} I_{i}}}<1
$$

and $G$ is modulus of elasticity in shear or modulus of rigidity; $E$ is modulus of elasticity in tension or compression; $L$ is the bridge span length; $J_{i}$ is the torsional inertia of girder No. $i$.

\subsubsection{Hinged Joint Method (Yao, 1990)}

\subsection{Hinged Joint Method for Slab Bridges}

This method can be utilized for slab bridges with pre-cast members connected by tongue-and-groove joint. The deflection of a slab bridge under concentrated wheel load is shown in Figure (2.6a). Figure (2.6b) illustrates the general internal forces occurred at the tongue and groove joint, which are vertical shear $\mathrm{g}(\mathrm{x})$, transverse moment $\mathrm{m}(\mathrm{x})$, longitudinal shear $t(x)$, and normal force $n(x)$. It was noted that the longitudinal shear $t(x)$ and the normal force $n(x)$ are relatively small compared with vertical shear $g(x)$ when the bridge is subjected to truck load. Because of the joint is relatively short in configuration and very flexible in resisting moment, the transverse moment $m(x)$ as well as the longitudinal shear $t(x)$ and normal force $n(x)$ can be neglected in analysis. Consequently, the joint can be simplified and 
considered as a hinge; assuming only vertical shear force $g(x)$ exists, as shown in Figure (2.6c).

To convert the three-dimensional problem into a two-dimensional problem, the ratio of the deflection, moment, shear, and applied load, in any two strips or girders must be equal and equal to a constant $\mathbf{C}$,

$$
\frac{w_{1}(x)}{w_{2}(x)}=\frac{M_{1}(x)}{M_{2}(x)}=\frac{Q_{1}(x)}{Q_{2}(x)}=\frac{P_{1}(x)}{P_{2}(x)}=C
$$

Sinusoidal load is assumed to meet this requirement and the sinusoidal load is in the form of

$$
P(x)=P_{0} \sin \frac{\pi x}{L}
$$

The free body diagram of a slab strip under sinusoidal load is shown in Figure (2.7). The error of the sinusoidal load assumption is very small in view of the fact that along the bridge span there will be many wheel loads. In order to obtain the distribution factor, the girder transverse influence line must be obtained first. For a bridge with $n$ strips, an indeterminate problem of $(n-1)$ order is to be solved to obtain the influence line. For convenience, transverse influence line control values for bridges with 3 to 10 slab strips are tabulated and the tables can be found in Bridge Engineering (Yao, 1990). After the transverse influence line is obtained, trucks can then be arranged transversely across the bridge to find the worst situation and the maximum distribution factors. 


\subsection{Hinged Joint Method for T-Shaped Girder Bridge}

The hinged joint method can also be used for small span concrete T-shaped girder bridges without intermediate diaphragms. Figures $(2.8 \mathrm{a})$ and $(2.8 \mathrm{~b})$ demonstrate the free body diagrams of unit length section at bridge middle span of the hinged T-shaped girder bridge under unit sinusoidal load. Unlike the case of slab bridges, the deflection of the Tshaped girder flanges must be considered, as shown in Figures (2.8c) and (2.8d). When the cantilever length is within $0.80 \mathrm{~m}$ and the span length is greater than $10 \mathrm{~m}$, the tables for calculating transverse influence line values for hinged slab bridges can also be used for hinged girder bridges. For better accuracy, detailed calculation is required for bridges beyond this range.

\subsubsection{Fixed Joint Girder method (Yao, 1990)}

In case when the lateral connection between girders is stiffer, the joint can be considered as a fixed joint. In addition to shear force at the joint, moment must also be considered, as shown in Figure (2.9). For $n$-girder Bridge, a 2(n-1) order of indeterminate problem is to be solved to obtain the shear and moment at each joint. However, only shearing force $g_{i}$ is considered for calculating distribution factor. Once $g_{i}$ is known, the same procedure as in hinged joint method can be followed to obtain the transverse influence line as well as the distribution factors.

\subsubsection{Orthotropic Plate Analogy (Guyon-Massonnet or G-M Method)}

In the case of concrete bridges with continuous slab, intermediate diaphragms and when the bridge width to span length ratio $\mathrm{B} / \mathrm{L}$ greater than 0.5 , grillage system may be used 
to simulate the bridge system. Alternatively, the bridge may be analogized to a rectangular thin plate, which is called orthotropic plate analogy or known as Guyon-Massonnet (G-M) method (Yao, 1990). Orthotropic plate is referred to when a plate possesses elastic properties which are different in $x$ and $y$ directions. Figure (2.10a) shows the longitudinal and transverse configuration of a bridge structure. In this case, the girder spacing is considered as $S$, girder moment of inertia and torsional inertia are $I_{x}$ and $I_{T x}$, respectively, diaphragm spacing is $S_{c}$, and diaphragm moment of inertia and torsional inertia are $I_{y}$ and $I_{T y}$ respectively. For very small values of $S$ and $S_{c}$ compared to the bridge width and span length, and for fully composite action, we can distribute girder moment of inertia and torsional inertia $I_{x}$ and $I_{T x}$ to the distance $S$ and distribute diaphragm moment of inertia and torsional inertia $I_{y}$ and $I_{T y}$ to the distance $S_{\mathrm{c}}$. Thus, the real grid system in Figure (2.10a) is analogized to an imaginary plate as shown in Figure (2.10b). In Figure (2.10b), the thickness in the $x$ direction is shown in dashed line, which indicates that, the equivalent thickness in the $x$ and $y$ directions are different for the analogized plate. The moment of inertia and torsional inertia per unit width in the $x$ and $y$ directions for the analogized plate are considered as follows:

$J_{x}=\frac{I_{x}}{S}, J_{T x}=\frac{I_{T x}}{S}, J_{y}=\frac{I_{y}}{S_{c}}, J_{T y}=\frac{I_{T y}}{S_{c}}$

For beam and slab concrete bridges and pre-stressed concrete bridges, Poisson's ratio $v$ can be neglected for simplicity. In that case, the bridge can be analogized to an orthotropic plate with rigidity per unit width $E_{x} J_{x}, G_{x} J_{T x}, E_{x} J_{y,}$ and $G_{x} J_{T y}$. The analogized orthotropic (in configuration) plate differential equilibrium with $E_{x}=E_{y}=E$ and $v_{x}=v_{y}=v$ is: 


$$
E J_{x} \frac{\partial^{4} w}{\partial x^{4}}+G\left(J_{T x}+J_{T y}\right) \frac{\partial^{4} w}{\partial x^{2} \partial y^{2}}+E J_{y} \frac{\partial^{4} w}{\partial y^{4}}=p(x, y)
$$

Let $D_{x}=E J_{x}, D_{y}=E J_{y}$ and $H=G\left(J_{T x}+J_{T y}\right) / 2 E$, Equation 2.9 becomes:

$$
D_{x} \frac{\partial^{4} w}{\partial x^{4}}+2 H \frac{\partial^{4} w}{\partial x^{2} \partial y^{2}}+D_{y} \frac{\partial^{4} w}{\partial y^{4}}=p(x, y)
$$

This is identical to the differential equation for orthotropic plate (in material elastic properties). This means that analogized orthotropic (in configuration) plate can be solved the same way as orthotropic (in material properties) plate, except that the stiffness constants contained in the equations are different.

The internal forces can be obtained by solving the above equation for displacement $w$ under applied load. Directly solving the partial differential equation is difficult. For convenience, solution charts had been developed by Guyon and Massonnet, which can be found in Bridge Engineering (Yao, 1990) and can be used to easily obtain the transverse influence line. Once the transverse influence line is obtained, the distribution factors can be obtained by arranging the trucks transversely on the bridge.

\subsubsection{AASHTO Methods}

AASHTO introduced empirical methods which are more convenient to use as Compared with the theoretical methods mentioned above. AASHTO defines the distribution factor as the ratio of the moment (or shear) obtained from the bridge system to the moment 
(or shear) obtained from a single girder loaded by one truck wheel line (AASHTO Standard 1996) or the axle loads (AASHTO-LRFD 2004). It should be noted that AASHTO Standard Specifications and AASHTO LRFD Specifications define the live load differently. The live load in the Standard specifications consists of an HS 20 truck or a lane load. While, the live load in the LRFD specifications consists of an HS 20 truck in conjunction with a lane load. Since both trucks have a $1.8 \mathrm{~m}$ axle (gauge) width, it is assumed that the difference in the live load configuration does not affect the lateral load distribution (Wassef, 2004).

\subsection{AASHTO Standard Method 1996}

AASHTO Standard specifications (1996) contain simple procedures used in the analysis and design of highway bridges. AASHTO adopted the simplified formulas for distribution factors based on the work done in the 1940s by Newmark (1948). AASHTO typical procedure is used to calculate the maximum bending moment based on a single line of wheel loads from the HS20 design truck or lane loading. This calculated bending moment is then multiplied by the load distribution factor $(\mathrm{S} / 5.5)$ or in the format of $(S / D)$, where $S$ is the girder spacing in feet and $D$ is a constant based on the bridge type to obtain the moment in an individual girder. This method is applicable to straight and right (non-skewed) bridges only. It was proved to be accurate when girder spacing was near $1.8 \mathrm{~m}$ and span length was about $18 \mathrm{~m}$ (Zokaie, 2000). For relatively medium or long bridges, these formulas would lose accuracy. 


\subsection{AASHTO LRFD Method}

The specifications outlined in Load and Resistance Factor Design, LRFD Design specifications (AASHTO, 1994b) were adopted. This code introduced another load distribution factors based on a comprehensive research project, National Cooperation Highway Research Program (NCHRP) 12-26 which was entitled "Distribution of Live Loads on Highway Bridges" and initiated in 1985, consequently the guide specification for Distribution of Loads for Highway Bridges (AASHTO, 1994a) was found. This guide recommends the use of simplified formulas, simplified computer analysis, and/or detailed finite-element analysis (FEA) in calculating the actual distribution of loads in highway bridges. It was noted that those new formulas were generally more complicated than those recommended by the Standard Specifications for Highway Bridges (the above AASHTO 1996), but their use is associated with a greater degree of accuracy (Munir, 1997). For example the lateral load distribution factor for bending moment in interior girders of concrete slab on steel girder bridge superstructure is:

$\mathrm{g}=0.15+(\mathrm{S} / 3)^{0.6}(\mathrm{~S} / \mathrm{L})^{0.2}\left(\mathrm{Kg} / 12 \mathrm{Lt}_{\mathrm{s}}^{3}\right)^{0.1}$

Where $\mathrm{g}=$ wheel load distribution factor; $\mathrm{S}=$ girder spacing $(\mathrm{ft}, 3.5<\mathrm{S}<16$ ); $\mathrm{L}=$ span length of the beam (ft, $20<\mathrm{L}<200$ ); $\mathrm{t}_{\mathrm{s}}=$ concrete slab thickness (in., $4.5<\mathrm{t}<12$ ); $\mathrm{Kg}=$ longitudinal stiffness parameter $=n\left(I+. A^{2}{ }_{g}\right) ; n=$ modular ratio between beam and deck material; $\mathrm{I}=$ moment of inertia of beam (in. $\left.{ }^{4}\right) ; \mathrm{A}=$ cross-sectional area of beam (sq in.) and $e_{g}=$ distance between the center of gravity of the basic beam and deck (in.). 
AASHTO LRFD Specifications have become highly attractive for bridge engineers because of its incentive permitting the better and more economical use of material. The rationality of LRFD and its many advantages over the Allowable Stress Design method, ASD, are indicative that the design philosophy will downgrade ASD to the background in the next few years (Salmon and Johnson, 1996). The research results were first adopted by AASHTO Standards in 1994 and were then officially adopted by AASHTO-LRFD in 1998. More parameters, such as girder spacing, bridge length, slab thickness, girder longitudinal stiffness, and skew effect are considered in the developed formulas which earned them sound accuracy. The AASHTO-LRFD formulas were evaluated by Shahawy and Huang (2001), their evaluation showed a good agreement with test results for bridges with two or more loaded design lanes, provided that girder spacing and overhang deck did not exceed $2.4 \mathrm{~m}$ and $0.9 \mathrm{~m}$, respectively. Outside of these ranges, the error could be as much as up to $30 \%$. For one loaded design lane, the relative error was less than $10 \%$ for interior girders and could be as high as $100 \%$ and as low as $-30 \%$ for exterior girders. Shahawy and Huang (2001) presented modification factors for the AASHTO LRFD formulas and the results of the modified formulas showed good agreement with their test results.

\subsubsection{Canadian Highway Bridge Design Code, 2000 (CHBDC)}

The Canadian Highway Bridge Design Code, CAN/CSA-S6-00 is the $9^{\text {th }}$ edition of the CSA Standard CAN/CSA-S6. It amalgamates and supersedes both the CAN/CSA-S6-88, Design of Highway Bridges, and the OHBDC-91-01, Ontario Highway Bridge Design Code, $3^{\text {rd }}$ Edition. Earlier Editions of the Ontario Highway Bridge Design Code (OHBDC) were 
published in 1983, and 1979 by the Ministry of Transportation of Ontario. Earlier editions of the CSA Standards were published in 1978, 1974, 1966, 1952, 1938, 1929, and 1922.

The above CHBDC used the limit state design philosophy and introduced simplified methods for the analysis of different types of bridges after satisfying certain conditions. In its simplified methods of analysis, CHBDC defines the lateral load distribution factors as amplification factors that used to account for the transverse variation in maximum longitudinal moments and shear intensities. The moment distribution factor is $F_{m}$ and defined as:

$$
F_{m}=\frac{S N}{F\left(1+\frac{\mu C_{f}}{100}\right)} \geq 1.05
$$

And the shear distribution factor is $F_{v}$ and defied as:

$$
F_{v}=\frac{S N}{F}
$$

Where $\mathbf{S}$ is center to center girders spacing in meters, $\mathbf{N}$ is number of girders, $\mathbf{F}$ is a width dimension that characterize load distribution for a bridge, $\mathbf{C}_{\mathbf{f}}$ is a correction factor, in $\%$ obtained from tables in $\mathrm{CHDBC}$, and $\mu$ is:

$$
\mu=\frac{W_{e}-3.3}{0.6} \text { but } \leq 1.0
$$

Where $W_{\mathrm{e}}$ is the width of the design lane in meters. 


\subsubsection{Other Studies}

Besides the AASHTO formulas, numerous papers have been published for load distribution factors since 1950. Their findings are invaluable for further studies. Kostem and DeCastro (1977) showed that the contribution of diaphragms to lateral load distribution was marginal regardless of the loading pattern. Many graphical and simplified computer based methods are also available for calculating wheel load distribution. Ontario Highway Bridge Design Code (OMTC, 1983) used a one popular technique of design charts, However, Hayes et al. (1986) developed a grillage analysis and simple computer program, SALOD [developed at the University of Florida], to evaluate the lateral load distribution of simplespan bridges in flexure, which have become more acceptable than monographs and design charts. Bakht and Moses (1988) presented a procedure to calculate the constant $D$ in the AASHTO load distribution formula $(S / D)$. Tarshini and Frederick (1992), using FEM, they studied the effect of various parameters on wheel load distribution for I-girder highway bridges and found that composite and non composite construction showed a negligible effect; the effect of the most common types of channel diaphragm and cross bracing between beams had negligible effect.

\subsubsection{Distribution Factors for Curved Bridges}

The first treatment of the analysis of curved beams was presented in 1843 by Barré de Saint Venant as referred by Zureik $(1998,1999)$. McManus et al. (1969) presented the first survey of the most published works related to horizontally curved bridges. His bibliography list contained 202 references. After that his paper was discussed by Ketcheck 
(1969); Pandit et al, (1970) who added additional references to the original list. Even though thousands of articles on the subject have appeared in the literatures, however, serious stúdies pertaining to the analysis and design of horizontally curved bridges begun only in 1969 when the Federal Highway Administration (FHWA) in the United States formed the Consortium of University Research Teams (CURT). This team consisted of Carnegie Mellon University, University of Pennsylvania, University of Rhode Island, and Syracuse University, whose research efforts, along with those at University of Maryland, resulted in the initial development of working Stress Design (WSD) or Allowable Stress Design (ASD) criteria and tentative design specifications. The American Society of Civil Engineers (ASCE) and the AASHTO Task Committee on flexural members (1977) compiled the results of most of the research efforts prior to 1976 and presented a set of recommendations pertaining to the design of curved I-girder bridges. The CURT research activity was followed by the development of Load Factor Design (LFD) criteria (Stegmann and Galambos 1976, Galambos 1978) adopted by AASHTO to go along with the ASD criteria. These provisions appeared in the first Guide (1980) as well as the Guide (1993). It is worthwhile to mention that the AASHTO guide specification for horizontally curved highway bridges (1993) is primarily based upon research work conducted prior to 1978.

\subsubsection{Heins and Siminou's Study}

In their study, Heins and Siminou (1970) presented and explained a simplified method for evaluating the internal forces and deformations in radial curved girder system. They introduced equations and factors that permit the determination of required crosssectional properties in a single, two, and three-span curved girder system, which are 
necessary in utilizing various computer programs. A series of factors were developed by comparing single straight; single curved; and curved system. They used AASHTO HS20-44 truck loading, and utilized two, three, and four trucks for four, six and eight girder system respectively. The introduced factors were:

Amplification Factor, $K_{1}=\frac{f_{s c}}{f_{s s}}$,

Distribution Factor, $K_{2}=\frac{f_{c s y}}{f_{s c}}$,

Reduction Factor, $K_{3}=\frac{f_{c s y}}{f_{s c}}$

Where $f_{s c}$ is the reaction on a single curved girder, $f_{s s}$ is the reaction on a single straight girder, and $f_{c s y}$ is the reaction on a system of curved girders. The studies, which were conducted, resulting in design equations, have the following limitations:

1. Girder spacing may be $2.1,2.4,2.7$ or $3 \mathrm{~m}$.

2. Individual girder span lengths varied from 15 to $30 \mathrm{~m}$.

3. The girders of the system must have a constant curvature limited to radii of 30 to $180 \mathrm{~m}$.

4. The number of girders in the system may be 4,6 or 8 .

5. Only two-and three-span continuous bridges were examined, with all interior end spans of equal length.

Heins and Siminou's concluded their study by introducing design charts for modification factors of moment, shear, deflection, rotation, and warping torsion. 


\subsubsection{AASHTO Methods}

\subsection{AASHTO Guide Commentary Method}

The Guide Commentary of the AASHTO Specifications 1993, (Guide, 1993), which as mentioned earlier adopted the research results of Heins and Siminou (1970), gives the distribution factors for bending moment as:

$g=\frac{S}{5.5}\left[(\bar{N}+3) \frac{L}{4 R}+0.7\right]$

where

$\mathrm{S}=$ girder spacing in $\mathrm{ft} .(7 \leq \mathrm{S} \leq 12)$,

$\bar{N}=\frac{R}{100}(R>100 \mathrm{ft})$,

$\mathrm{L}=$ span length in $\mathrm{ft}$., and

$\mathrm{R}=$ radius of curvature in $\mathrm{ft} .(\mathrm{R}>100 \mathrm{ft})$.

It is interesting to note that Equation 2.15 is analogous to AASHTO Standard equation S/D. This equation is intended to present moment distribution of the exterior girder and would be increasingly conservative for other girders across the bridge. Heins-Siminou's result is too conservative, mainly because of that the entire deck in the three-dimensional model was not included. This method was omitted from the current version of the AASHTO Guide (Guide, 2004)

\subsection{AASHTO Guide Method}

The effect of lateral bracing was considered in AASHTO Guide Specifications for Horizontally Curved Bridges (1993). The AASHTO Guide equations take into account the 
effect of lateral bracing, connecting the bottom flanges of the girders. The distribution factors for both ASD and LRFD, in terms of the resulting maximum live load (normal stress component + warping stress component) bottom flange stress in the girder, can be calculated as:

For outside exterior girder:

$\mathrm{g}_{\text {ebf }}=\frac{3.0-0.06(\mathrm{~L})}{\mathrm{S}^{3 / 2}}\left[\frac{\mathrm{L}}{\mathrm{R}}\right]+0.9$ for all bays with bottom lateral bracing

$\mathrm{g}_{\text {ebf }}=\frac{3.0-0.06(\mathrm{~L})}{\mathrm{S}^{3 / 2}}\left[\frac{\mathrm{L}}{\mathrm{R}}\right]+0.95$ or bottom lateral bracing in every other bay

For inside exterior girder:

$g_{\text {ibf }}=g_{\text {ebf }}\left[-0.366 \times\left[\frac{L}{R}\right]+0.944\right]$ for all bays with bottom lateral bracing

$g_{\text {ibf }}=g_{\text {ebf }}\left[-0.473 \times\left[\frac{L}{R}\right]+0.934\right]$ for bottom lateral bracing in every other bay (2.19)

All the dimensions in the equations (2.16) through (2.19) are in feet. Where, $\mathrm{L}$ is the outside exterior girder span length, $\mathrm{S}$ is the girder spacing, and $\mathrm{R}$ is the radius of curvature of the outside exterior girder. The maximum live load flange stress is obtained by multiplying the distribution factor with the maximum stress based on grid analysis.

\subsection{AASHTO with V-Load Modification Method}

The history of the V-load method started in 1963 when it was presented by USX in their report entitled USS Structural report, Analysis and Design of Horizontally Curved Steel Bridge Girders. It was a simplified analysis of two-girder curved bridge. And it was presented in 1965 as a chapter in U.S. Steel's Highway Structures Design Handbook. The V- 
Load method was a computer programmed about 1966 which was used for the analysis and design of many curved bridges in the 1970 (Poellot, 1987). However, a limitation was that the method and the program were applicable only to structures with radial support lines. In the early of $80 \mathrm{~s}$, the V-Load method continued to serve as a state of the art design tool when it was applied to skewed bridges by USS Research. And it was first recognized by AASHTO through some provisions included in ASSHTO Guide Specifications for Horizontally Curved Bridges (1980). Figure (2.11), shows the interaction forces in two girder system between girder and floor-beam consist of lateral reactive $\mathbf{H}$ forces along with vertical shears $\mathbf{V}$. If the cross fames are spaced at a distance $\mathbf{d}$, then the radial flange reaction at girder (1) is $\mathbf{H}_{\mathbf{1}}=\mathbf{M}_{1} \mathbf{d}_{1} / \mathbf{h} \mathbf{R}_{\mathbf{1}}$ and at girder (2) is $\mathbf{H}_{\mathbf{2}}=\mathbf{M}_{\mathbf{2}} \mathbf{d}_{2} / \mathbf{h} \mathbf{R}_{\mathbf{2}}$. And with concentric girders and radial cross frames $d 1 / R 1=d 2 / R 2$, hence the vertical shear force $V$ between the cross frame and the girder is obtained from the static's:

$$
\mathrm{V}=(\mathrm{H} 1+\mathrm{H} 2) \mathrm{h} / \mathrm{D}=(\mathrm{M} 1+\mathrm{M} 2) /(\mathrm{RD} / \mathrm{d})=(\mathrm{M} 1+\mathrm{M} 2) / \mathrm{K}
$$

Where $\mathrm{K}=\mathrm{RD} / \mathrm{d}$ is a constant. Those shear forces then react on the girders resulting in a set of self-equilibrating girder shears. The net effect of the shears is to shift the total load on the curved bridge toward the outside girder because they produced moments in the girders outside of the bridge centerline which add to those that would exist in a straight girder of the same developed length, and moments in the girders inside of the bridge centerline which subtract from those that would exist in a straight girder of the same developed length. These girder shears, which are applied as the external loads to the equivalent straight structure to account for the curvature, are known as the V-loads. 
Application of the external V-loads ensures that the internal forces in the straight structure be nearly the same as those that exist in the curved structure under applied vertical loads. In the V-Load analysis of a Multi-girder system, the bending moments caused by the applied vertical loads at the cross bracings in each isolated developed straight girder are first determined by applying the loads to straight girders. These vertical-bending moments will hereafter be referred to as primary moments. The corresponding V-load moments, which are caused by the V-load and are referred to as secondary moments, are then determined by applying the $\mathrm{V}$ - loads in the proper directions to the straight girders at the cross bracings. The final moments in the curved girder are then obtained by simply summing the respective straight-girder primary and secondary moments. The V-load is calculated by (Grubb, 1984):

$\mathrm{V}=\sum \mathrm{M}_{\mathrm{p}} /(\mathrm{C} \times \mathrm{K})$

Where

$\sum \mathbf{M}_{\mathrm{p}}=$ summation of the primary moments in each girder at a particular cross bracing, $\mathrm{C}=$ coefficient depending on the number of girder in the system (see Table 2.1), $K=(R \times D) / S_{d}, R$ and $S_{d}$ are for the outside girder

Where $\mathrm{R}=$ radius of curvature in feet,

$$
\begin{aligned}
& S_{d}=\text { diaphragm spacing, and } \\
& D=\text { girder spacing. }
\end{aligned}
$$

The distribution factor can then be calculated as:

$$
\mathrm{g}_{\mathrm{B}}=\frac{\mathrm{S}}{5.5} \times \frac{\text { primary }+ \text { secondary moment }}{\text { primary moment }}
$$


This method is referred to as the AASHTO with modified V-load Method. The results were proved to agree with those from the FEM analysis (Brockenbrough, 1986) for exterior girder and to be conservative for the interior girders.

\subsubsection{Heins and Jin's Method}

The effect of cross bracing spacing on curved bridge distribution factors was studied by Heins and Jin (1984). They investigated single-girder system and multi-girder system. They developed a space model frame idealization and used grid analysis for obtaining their results. They produced number of graphs and equations that correlate the effect of the cross bracing and distribution factor, one major finding was as follows:

$$
\mathrm{g}=\frac{\mathrm{S}}{5.5}\left[0.0083 \frac{S c}{S} \frac{L^{2}}{R}+1.0\right](0.4)
$$

Where $\mathrm{g}$ is the distribution factor, $\mathrm{S}_{\mathrm{c}}$ is the cross bracing spacing in feet, $\mathrm{S}$ is girder spacing in feet. The above distribution factor included the warping effect, and hence the equation 2.23 showed a good agreement with Brockenbrough's, 1986 Study.

\subsubsection{Yoo and Littrell's Study}

Yoo and Littrell (1985) studied the response of a system of 5 girders horizontally curved, connected by a slab and cross bracing under dead load and live load using threedimensional finite-element method (Sap6). There study considered the following different value parameters: radius; length; and number of braced intervals. They developed empirical 
design equations to predict the ratio of: (a) Maximum bending stress; (b) maximum warping stress; and (c) maximum deck deflection. Their findings were (1) maximum bending stresses and maximum deck deflections stabilized with minimal bracing; (2) warping stresses were sensitive to the number of braced intervals. They also observed that partially loaded lanes; 2 trucks out of 3 trucks (deck width capacity) located near the outside edge of the bridge produced higher stresses and deflection in the curved bridges due to the tilting of the bridge deck created by the nonsymmetrical load distribution.

\subsubsection{Brockenbrough's Study}

Brockenbrough (1986) utilized a 3-dimensinal model to study the effect of various parameters on the load distribution for 4-girder curved bridge using FEM. His model was 2span continuous structure comprised of composite concrete deck with steel I-shape girder and intermediate transverse cross frames between girders. His findings were as follows: (1) the central angle per span, which includes the combined effect of curvature and span length had larger effects, (2) the girder spacing, had larger effects identified; (3) variation in girder stiffness and cross-frame spacing had relatively small effects on live-load distribution factors. Brockenbrough also provided charts depicting the variation of the distribution factors with the variation of these parameters.

\subsubsection{Schelling, Namini, Fu's Study}

Schelling and Namini, (1989) studied the response of simple and continuous span horizontally curved steel I-girder bridges with and without cross bracing, during construction phase due to self own weight. They utilized 3-dimensional space frame model 
and developed empirical equations of moment distribution factors for two, four, and six girders bridges to determine the effect of the lateral bracing on curved bridges during construction. Their analysis revealed that the results from the simple-span can be applied conservatively to the continuous span bridges provided that the supports and radial and the span length ratios do not differ greatly from unity. The empirical equation they developed had a drawback because it can be used in conjunction with the results given by the 2 dimentional grid analysis method. Another thing, is the range of the bridges spans considered in their models were $(36 \mathrm{~m}$ to $90 \mathrm{~m})$ which are not practical for slab on steel Igirder bridges.

\subsubsection{Davidson, Keller, and Yoo's study}

Davidson et al. (1996) studied the effect of a number of parameters on the behavior of the horizontally curved steel I-girder bridges connected by cross bracings. Their model comprised of 3-girder Bridge and used shell elements to model the concrete deck; and girders webs, whereas they used beam elements to model flanges, shear connectors and cross frames. Finite-element, ABAQUS software was utilized for their investigation. The above study resulted with the conclusions of that the (1) span length, (2) radius of curvature, (3) flange width, and (4) cross frame spacing; have the greatest effect on the warping-tobending stress ratio. Based on this information, a regression analysis was performed to predict the effect of these parameters on the warping-to-bending stress ratio. Consequently, an equation was developed from this regression and proposed for the preliminary crossframe spacing design: 
$\mathrm{S}_{\max }=\mathrm{L} \quad-\ln \left[\left(\frac{\mathrm{Rb}_{\mathrm{f}}}{2000 \mathrm{~L}^{2}}\right)\right]^{-1.52}$

Where $S_{\max }$ is the maximum bracing spacing in meters, $L$ is the span length in meters, $R$ is the radius of curvature in meters, and $b_{f}$ is the flange width in millimeters.

\subsubsection{Eissa, et. al. study}

The shear distribution in curved steel I-girder bridges at construction phase (due to self weight loading) was studied by Eissa et. al, (2000). They utilized finite-element software SAP2000 to carry out bridge modeling. A three-dimensional, four-node shell element was used to model the steel web, and two-node element was used to model the top and bottom steel flanges. They studied the effect of number of parameters on the behavior of shear distribution in curved steel I-girder bridge system, these parameters were: span-to radius ratio (L/R), span length, number of girders, girder spacing and type of supports. For 3,4 , and 5 girders bridge models and for $15 \mathrm{~m}, 25 \mathrm{~m}$, and $35 \mathrm{~m}$ span lengths. Part of their findings was proposing empirical expressions to determine the reaction forces at the supports (hinges or rollers). Other parts of their findings were deduced that the degree of curvature $(\mathrm{L} / \mathrm{R})$ ratio, number of girders, span length, and girder spacing were considered as key parameters affecting the structural response of such bridges.

\subsubsection{Zhang's study}

Zhang H., (2002) studied the load distribution factors for curved I-girder bridges using finite-element method. A total of 111 bridge models with radius of curvature less than 
$450 \mathrm{~m}$ were selected in his study, subjected to AASHTO truck loading. Mr. Zhang considered the following range of parameters in his study:

$>$ Radius of Curvature: 45 to $450 \mathrm{~m}$;

Girder spacing: 1.8 to $5.0 \mathrm{~m}$;

$>$ Span length: 15 to $70 \mathrm{~m}$;

$>$ Slab thickness: 170 to $300 \mathrm{~mm}$;

Longitudinal stiffness: 32122 to $72226 \mathrm{~cm}^{4}$;

$>$ Number of girders: 3 to 7 ;

Cross frame spacing: 2 to $7 \mathrm{~m}$;

He concluded that radius of curvature, girder spacing, and number of girders had significant effect on the load distribution. Whereas, span length, slab thickness, and longitudinal stiffness had slight effect. Moreover the effect of cross frame spacing and girder torsional inertia could be neglected. He also concluded that the shear distribution factors have similar trend as that of moment distribution factors. The difference is that the shear distribution factor of the outside exterior girder and the inside exterior girder are close. Mr. Zhang developed simplified equations for positive moment, negative moment, and shear distribution factors for exterior and interior girders due to one-lane loading and multiple-lane loading. It was found that the distribution factors of the outside exterior girder positive moment obtained from AASHTO Guide Commentary method (1993) for multiple-lane loading were less conservative compared with the results of FEM analysis. However, the results obtained from AASHTO Guide Commentary were too conservative for other cases. AASHTO-LRFD 
formulas for straight bridges led to either larger or smaller results when used for curved bridges. The Heins and Jin's formula was too conservative for all cases.

\subsubsection{Wassef's study}

Wassef, (2004) conducted a theoretical study on 192 simply supported straight and curved concrete slab-on-steel I-girder bridge prototypes to evaluate their structural response. He examined the influence of several parameters on the moment, deflection, and warping stress distribution in such bridges using commercially available finite-element computer software SAP2000. In the study the bridge models were subjected to the Canadian Highway Bridge Design Code (CHBDC) CL-625 truck and lane loading and dead loading. The study considered the following parameters:

Span length: 15,25 , and $35 \mathrm{~m}$;

$>$ Girder spacing: $2,2.5$, and $3 \mathrm{~m}$

$>$ Number of girders: $3,4,5,6, \& 7$ for $2 \mathrm{~m}$ girder spacing; $3,4,5, \& 6$ for $2.5 \mathrm{~m}$ girder spacing; $3,4 \& 5$ for $3 \mathrm{~m}$ girder spacing;

$>$ Span-to-radius ratio, $\mathrm{L} / \mathrm{R}: 0.0,0.1,0.2, \& 0.3$ for $\operatorname{span} \mathrm{L}=15 \mathrm{~m} ; 0.0,0.1,0.3, \& 0.5$ for span $\mathrm{L}=25 \mathrm{~m} ; 0.0,0.1,0.4, \& 0.7$ for span $\mathrm{L}=35 \mathrm{~m}$

The study findings were: (1) curvature is the most critical parameter that influence the design of curved bridges; (2) other parameters like span length, number of girders, and girder spacing affect the values of the moment and deflection distribution factors in general; (3) Full bridge live loading does not necessary produce the extreme design values of the moment or deflection distribution factors; (4) warping-to-bending stress ratio values were 
acceptable and within the limits, except for bridge with $L / R$ ratio 0.7 and span length $35 \mathrm{~m}$; (5) CHBDC moment and deflection distribution factors overestimate the structural response of straight bridges.

\subsection{Review of Linear Elastic Behaviour of Curved I- Girder System}

The behavior of thin-walled members of open cross-section under flexure and torsion has been established for a long time and has been reviewed in many books on elementary mechanics. A recent comprehensive presentation of the basic theory of thin-walled beams, including flexure, torsion, distortion, and stress distribution, can be found in "Analysis and Design of Curved Steel Bridges" (Nakai and Yoo, 1988). In curved bridge, the curvature makes the cross bracings (or diaphragms) to resist torsional loads, which are of importance for curved bridge stability. Correspondingly, cross bracings introduce restoring torques to the girders and therefore cause non-uniform torsions in the girders. The torsions are resisted partly by St.-Venant torsion and to some extent by warping torsion. The warping causes lateral bending moment of the top and bottom flanges. The product of the lateral flange moment and lever arm of the couple (less than girder depth) is often referred to as bimoment (in the unit of force $\mathrm{x}$ length ${ }^{2}$ ). This bimoment causes twisting of the curved girders about their longitudinal axes. For compression flange, the axial flange force tends to accentuate curvature while the lateral flange bending moment tends to reduce it. However, the net effect is always to increase curvature of the compression flange. For tension flange, the axial force tends to reduce the curvature and the lateral flange bending moment tends to increase it. The net effect can be either to increase or decrease the curvature of the tension flange, depending on flange stress and stiffness. 
Two approximate methods: AASHTO Guide (1993) and V-load method presented below, can be used to estimate the flange lateral bending moment, $\boldsymbol{M}_{\boldsymbol{L A T}}$

\section{1) AASHTO Guide (1993) method}

$$
M_{L A T}=M_{S} \times D F_{B} \times D F_{B i} \times\left[\frac{(0.35 \mathrm{~L}-15)}{0.108 \mathrm{~L}-1.68} \times \frac{\mathrm{L}}{\mathrm{DR}}\right] / \mathrm{D}^{\prime}
$$

Where Ms is the equivalent straight girder moment due to truck load, which straight girder will have a length equal to the arc length of the curved girder; $D F_{B}$ is the distribution factor for bending moment; $D F_{B i}$ is the distribution factor for bimoment; $D$ is the girder depth in feet; $R$ is the radius of curvature in feet; $L$ is the span length in feet; and $D^{\prime}$ is the arm from the centroid of girder top flange to the centroid of girder bottom flange in feet. This equation should satisfy that the radius of curvature is greater than 100 feet.

\section{2) V-Load Method}

$\mathrm{M}_{\mathrm{LAT}}=\mathrm{M}_{\mathrm{V}} \times\left[\frac{L^{2}{ }_{U N}}{10 \mathrm{DR}}\right]$

Where $M_{V}$ is the vertical moment of curved girder, and $L_{U N}$ is the unbraced length. The exact solution of lateral flange moment is discussed in the following sections. 
From the classic strength of material theory, St.-Venant torque, $T_{P}$, is commonly expressed in terms of the torsional rotation, $\varnothing$ at any cross section as

$$
T_{P}=G J \frac{\mathrm{d} \emptyset}{\mathrm{dx}}
$$

Where $\mathbf{J}$ is the St. Venant torsion rigidity; $\mathbf{G}$ is the elastic modulus in shear; $\mathbf{x}$ is measured along the member.

From warping theory, the warping torque, $T_{w}$, can be expressed as:

$$
T_{w}=V h
$$

Where $V$ is the lateral shearing force in the flanges as shown in Figure 2.11; and $h$ is the distance from the top flange-shearing center to the bottom flange-shearing center. The equation of equilibrium for torsion of a thin-walled member is then

$$
G J \frac{d \varnothing}{d x}+V h=T
$$

Where $\mathrm{T}$ is the total torsion at the cross section.

From the elastic curve equation, lateral bending moment in the lateral direction of the upper flange in Figure 2.12 is

$$
\frac{E I_{y} d^{2} y}{2 d x^{2}}=-M
$$


in which the $\mathrm{X}$ and $\mathrm{Y}$ axes are chosen with positive directions as shown in Figure 2.12; $M$ is the lateral bending moment in the flange at any section producing lateral bending in the flange; $E$ is the modulus of elasticity in tension or compression; and $I_{y}$ is the moment of inertia of the entire cross section of the beam with respect to the axis of symmetry in the web so that $1 / 2 I_{y}$ closely approximate the value of the moment of inertia of a flange cross section. In Figure 2.12, the deflection of the flange at section $A B$ is $y=(h / 2) \emptyset$

Differentiation of Equation 2.31 twice with respect to $x$ gives

$$
\frac{d^{2} y}{d x^{2}}=\frac{h d^{2} \varnothing}{2 d x^{2}}
$$

Substituting this value of $d^{2} y / d x^{2}$ into Equation 2.30 gives

$$
\frac{E I_{y} h^{2} \emptyset}{4 d x^{2}}=-M
$$

Since $\mathrm{dM} / \mathrm{dx}=\mathrm{V}$ by differentiating both sides of Equation 2.33 with respect to $\mathrm{x}$ we obtain

$$
\frac{\mathrm{EI}_{\mathrm{y}} \mathrm{hd}^{3} \emptyset}{4 \mathrm{dx}^{3}}=-\mathrm{V}
$$

Substituting the value of $\mathrm{V}$ in Equation 2.34 into Equation 2.29, which then becomes 
$\mathrm{JG} \frac{\mathrm{d} \emptyset}{\mathrm{dx}}-\frac{E I_{y} h^{2} d^{3} \emptyset}{4 \mathrm{dx}^{3}}=\mathrm{T}$

Let $I_{w}=E I_{y} h^{2} / 4$, the warping torque can be written as

$T_{w}=-E I_{w} \frac{d^{3} \emptyset}{d x^{3}}$

And Equation 2.35 can be rewritten as

$$
E I_{w} \frac{d^{4} \emptyset}{d x^{4}}-G J \frac{d^{2} \emptyset}{d x^{2}}=t
$$

Where $t$ is the distributed torque applied to the member; and $\mathrm{EI}_{\mathrm{w}}$ is warping rigidity. Equation 2.37 along with two boundary conditions at each end can be used to describe the behavior of a thin-walled member subject to torsion. The boundary conditions at each end may be the rotation $\varnothing$ and warping $d \varnothing / d x$.

\subsection{Review of Analysis Methods for Curved System}

In reality the exact solution of the above Equation 2.37 is difficult and complex. Therefore for practical purposes, it is required to adopt other types of solutions which should be easier and sufficiently accurate. The analysis methods found in the literature can be classified into two major categories: approximate and refined methods as follows, Zureick and Naqib, (1999): 


\subsubsection{Approximate methods}

From its name, approximate methods require a least modeling effort from the designer, and therefore, are adequate for preliminary analysis and design purposes. The following are some most frequently used in the analysis of curved bridges:

- The Plane-grid method

- The Space-frame method

- The V-load method

\subsubsection{The Plane-grid or Grillage method}

This method was first introduced in year 1965 by Lavelle and Boick and further developed in 1971 by Lavelle et al. and in 1975 by Lavelle and Laska. This method model the structure as an assemblage of two-dimensional grid members with one translational and two rotational degrees of freedom. It is advisable to mention that this method does not account for warping (Zureick and Naqib, 1999). The advantages of this method are: (1) integration of stresses is not required, shear and moment values on girders are directly obtained; (2) simple beam theory can be used to distribute the wheel load to adjacent nodes when loads are applied between the nodal points; (3) it utilizes a less computer running time with a plain grid idealization and only moderate effort is required for modeling. Whereas the disadvantages of this method are: (1) the method is non rigorous and does not exactly converge to the exact solution of the mathematical model; (2) Experience is required with the grillage method (the mesh design and refinement can be artistic) in order to obtain good solutions; (3) some discretion is required for assigning the cross section properties. 


\subsubsection{The Space-frame method}

This method was first introduced in year 1973 by Brennan and Mandel for the analysis of open and closed curved members. This method idealized the curved members as three-dimensional straight members. In this method diaphragms and lateral bracing are assumed as truss-like members that can carry only axial loads. The warping effect is not usually included in this analysis (Zureick and Naqib, 1999).

\subsubsection{The V-Load method (Grubb 1984)}

Developed in the early of 1960's, the V-Load method is a simplified approximate analysis method for curved I-girder bridges. The United State Steel Corp had initially extended the V-Load method to multi-girder bridges. The V-Load method evaluates curved girders as a system of straight girders with additional loads externally applied (VLoad) to account the effect of curvature and can be considered as a two-step process. First, equivalent straight girders with span lengths equal to the arc lengths instead of the individual curved girders are used so that the applied vertical loads are assumed to induce only longitudinal girder stresses. Second, self-equilibrating external vertical shear forces (acting on diaphragm location) are applied to the straight structure so that the resulting internal forces are the same as those existing in the curved structure subjected to only vertical load (refer to Figure 2.11). Thus, in the V-Load development, the curvature forces on the equivalent straight structure are treated as externally applied load. These loads are dependent on the radius of curvature, the bridge width, and diaphragm spacing (refer to Equation 2.24). The V-load method was found suitable for approximate analysis of composite sections, variable radius of curvature, and skewed supports. The effects of bracing in the plane of the 
bottom flange are not considered. The dead load results obtained from the V-load metho were proved to be very close to those obtained from the FEM analysis. For live load, th lateral load distribution factor used in the V-load analysis has a significant influence on th results. However; the V-load method has some drawbacks as follows: the V-Load method i not valid when lateral bracing was present, furthermore, it is not accurate in predicting diaphragm shear forces (McElwain and Laman, 2000); also it underestimate the innermos girder stresses, does not consider bracing effect in the plane of the bottom flange, and it: reliability depends on the selection of the proper live-load distribution factors. Thus the Vload method can only be recommended for preliminary analysis (Zureick et. al. 1998).

\subsubsection{Refined methods}

The refined methods are more reliable, elaborate, computationally intensive, and time consuming in terms of modeling. And hence these methods are used for final or detailed analysis. Some major refined methods are stipulated as follows:

* The Finite-strip method

The Finite-difference method

Analytical solution to differential equations

The Slope deflection method

The Finite-element method 


\subsubsection{The Finite-strip method}

The curved bridge is divided in this numerical method into many narrow strips in the circumferential direction that are supported in their radial direction. The analysis of this method considers bending, membrane action, warping, and distortional effect. This method has been successfully utilized to analyze composite curved box and plate girders with complete and incomplete interaction, using curved strip elements for the concrete slab and steel girder and spring elements for shear connectors (Arizumi et al., 1982). This method provides some simplicity (since only one single variable in the circumferential direction is considered in the function, i.e. smaller unknown required) over the finite-element method, however it does not offer the flexibility and the versatility of the latter method (Zureick and Naqib, 1999).

\subsubsection{The Finite-difference method}

This method was utilized in the dynamic analysis of curved bridges with large deflections and small rotations (Tene al et. 1975; Sheinman 1982). The basic of this method is superimposing a grid on the structure and the governing differential equations are replaced by algebraic difference equations that are solved for each grid point.

\subsubsection{Analytical solution to differential equations}

An analytical solution to the Governing Differential Equations (GDE) is obtained in the method. The solution is usually a closed form or a convergent series solution, such as a 
Fourier series. This method was used in studying curved bridge dynamic response (Culver 1967; Montalvao e Silva and Urgueira 1988).

\subsubsection{The Slope deflection method}

The partial differential equations are established in terms of slope-deflectior equations, and the solution is assumed to be a Fourier series. The effects of curvature, nonuniform torsion, and diaphragms are included the above analysis. The COBRA (Curved Orthotropic Bridge Analysis) program (Bell and Heins 1969), developed by University of Maryland, is based on analytical techniques of the slop-deflection-Fourier series and it is recommended by AASHTO Guide Specifications of 1993 to study composite and non composite girder-slab action. This method was proved by experiment to be an accurate analytical method of curved orthotropic deck bridge systems (Heins and Bell 1972).

\subsubsection{The Finite-Element Method (FEM), By Logan (2002)}

This is the most famous and widely used method in many engineering applications. The principal of this numerical method is discretizing the structure into small divisions, or elements, where each element is defined by specific number of nodes (hence this process of modeling a body by dividing it into an equivalent system of smaller bodies or units called finite elements). The finite-element method is a numerical acceptable solution, it formulation of the problem results in a system of simultaneous algebraic equations for solution, rather than requiring analytical solutions (solutions of ordinary or differential equations), which because of the complicated geometries, loadings, and material properties, 
are not usually obtainable. The behavior of each element, and ultimately the structure, is assumed to be a function of its nodal quantities (displacements and/or stresses), which considered as the primary unknown of its nodal quantities. The modern development of the finite-element method began by Hrennikoff in the 1941 and McHenry in 1943 using (onedimensional) elements (bars and beams) in the field of structural engineering. In 1947 Levy developed the flexibility or force method, and in 1953 he suggested that another method (the stiffness or displacement method) could be a promising alternative for use in analyzing statically redundant aircraft structures. However his equations were cumbersome to solve by hand, and hence it only became popular after the advent of the high speed computers. Turner et al. was the first who introduced the treatment of two-dimensional elements in 1956, they derived stiffness matrices for truss elements, beam elements, and two-dimensional triangular and rectangular elements in plane stress. The finite-element method extended to cover threedimensional problems only after the development of tetrahedral stiffness matrix which was done by Martin in 1961 .

\subsection{Three-Dimensional Method}

University of Pennsylvania developed the STACRB (Shore and Wilson, 1973) computer program which is characterized by a fully compatible three-dimensional flat plate circular element. Many different elements and shape functions have been studied since then, including using segmental and quadrilateral element for plate bending, annular conforming and fully compatible four-node segment element for thin plates, horizontally curved threenode isoparametric beam element, three-dimensional beam element with axial and transverse displacements or arbitrary polynomial order, and so on. General finite element 
packages, such as ABAQUS, ADINA, ALGOR, SAP, ANASYS and MSC/NASTRAN ar also frequently used for curved bridges. The rapid advancement of computer technolog: representing in producing high-speed and high capacity computer allows the three dimensional modeling be possible. The bridge deck is usually modeled as shell element including membrane and bending effects. Girder flanges are usually modeled as bean elements to include axial and bending strains in two directions and torsional effects. Girde web can be modeled as shell element to account for the bending stiffness. Rigid beams are usually used to connect the deck slab to girder flange and simulate the composite action with slab. Cross bracings and wind bracings can be modeled as hinged bar element.

Three-dimensional plate/shell models can consider unusual geometry and complex configuration and can get the most accurate results. The disadvantages are: (a) since most of the programs do not allow loads to be placed at any point on the elements, equivalent nodal loads must be calculated with care and the mesh must be fine enough to minimize errors that may arise because of load approximations; (b) since the programs report stresses and strains other than shear and moment values, calculation of shear and moment values from the stresses must be carefully performed through integration over the beam section, and (c) integration of stresses at node points is normally less accurate and may lead to inaccurate results. 


\section{CHAPTER III}

\section{FINITE-ELEMENT ANALYSIS}

\subsection{General}

The advancement of computers in terms of speed and storage capacity has led the engineering researches to enter a new era. More extensive and approximate numerical solutions to complicated engineering problems were initiated due to the wide use of the finite element method. Finite element analysis has proven to give reliable results when compared to experimental findings; this built up trust encouraged the designers and code writers to allow the implementation of the finite element method in the analysis and design of different engineering structures. The Canadian Highway Bridge Design Code (CHBDC 2000), section 5.9, permits the use of six different refined methods of analysis for short and medium span bridges. The finite element method is one of the methods recognized by CHBDC. Of all the above-mentioned six permitted methods, the finite element method is considered to be the most powerful, and versatile. Stipulated below the most important advantages of the finite element method:

1- Solutions can be without the use of governing differential equations,

2- It permits the combination of various structural elements such as plates, beams, and shells,

3- It is able to analyze structures having arbitrary geometries with any material variations thereof,

4- It is possible to automate every step involved in the method. 
As a result, the finite-element method is very suitable for the analysis of curver composite I-girder bridges. The recent development in finite-element methods has facilitater to model a bridge in a very realistic manner and to provide a full description of its structura response within the elastic and post-plastic stages of loading.

In this chapter a brief description of finite-element approach will be reviewed as wel as descriptions of modeling the different components of the composite I-girder bridges. The models that intended to be analyzed by the finite-element method comprised of the reinforced concrete deck, steel top flanges, steel webs, steel bottom flanges, and crossbracing as described in subsequent sections in this chapter. The available commercial finiteelement program, SAP2000 (Wilson and Habibullah, 2002), was utilized through this study to determine the structural response of the modeled bridge prototypes. A general description of this software is presented later in this chapter. The procedure to perform an extensive parametric study on selected straight and curved bridge prototypes, loading cases, and different bridge configurations, to evaluate loads distribution characteristics is explained also in this chapter.

As mentioned earlier, the presence of curvature induces non-uniform torsion in the curved girders which as a result produces lateral bending moment (warping or bi-moment) in the top and bottom flanges that must be considered. Hence, the design of such girders becomes complicated. The methodology of how to obtain the warping-to-bending stress ratio is presented at the end of this chapter. 


\subsection{Finite-Element Approach}

The finite-element method is a numerical method for solving problems of engineering and mathematical physics. It is the best solution for problems involving complicated geometries, loading, and material properties, when it is generally not possible to obtain analytical mathematical solution. This numerical method of analysis which begins by dividing a body into an equivalent system of smaller bodies or units (finite-elements) interconnected at points (nodes) common to two or more elements and/or boundary lines and/or surfaces is called discretization. Hence, instead of solving the problem for the entire body in one operation, it facilitates the formation of equations for each finite-element and at the end; it will combine them to obtain the solution of the whole body. For the purpose of simplifying the formulation of the above elements equations, matrix methods are implemented. Matrix methods are considered as an important tools used to structure the program of the finite-element methods to facilitate their computation process in high-speed computers.

In general there are two approaches associated with the finite-element; (1) force or flexibility method, and (2) displacement or stiffness method. It has been shown that for computational purposes, the latter method is more desirable because its formulation is simpler for most structural analysis problems; moreover a vast majority of general-purpose finite-element programs have incorporated the displacement formulation for solving structure problems. The finite-element method uses different types of elements; (1) one dimensional element or so called linear element; (2) two-dimensional element which can be in the forms of plane element or triangular and quadrilateral shape elements; and (3) threedimensional solid shape elements. 
Selecting the most appropriate element type should be to model the most closely to thi actual physical behavior. An equation is then formulated combining all the elements to obtain : solution for one whole body. Using a displacement formulation, the stiffness matrix of eact element is derived and the global stiffness matrix of the entire structure can be formulated by the direct stiffness method. This global stiffness matrix, along with the given displacemen boundary conditions and applied loads is then solved, thus that the displacements and stresses for the entire system are determined. The global stiffness matrix represents the nodal forcedisplacement relationships and is expressed in a matrix equation form as follows:

$$
[P]=[K][U]
$$

Where:

$$
\begin{array}{lll}
{[\mathrm{P}]} & = & \text { nodal load vector; } \\
{[\mathrm{K}]} & = & \text { the global stiffness matrix; } \\
{[\mathrm{U}]} & = &
\end{array}
$$

\subsection{SAP2000 Computer Program}

The available commercial software "SAP2000" is a structural analysis program that employs the finite-element method in the analysis and designs of complicated structures. This program has a range of capabilities depending on the version used. SAP2000 is also capable of analyzing structures in static and/or dynamic modes. Its finite-element library consists of six elements.

1- Two-dimensional PLANE element

2- Three-dimensional FRAME element.

3- Three-dimensional SHELL element 
4- Two-dimensional SOLID element

5- Three-dimensional SOLID element

6- Three- dimensional NLLINK element

In addition, subsets of these elements with varying degrees of freedom are available in the form of truss, frame, membrane, beam, strain, gap, and hook elements.

\subsection{CHBDC Design Loading}

The design of Highways and Bridges in Canada has its own criteria in terms of the critical live loads selected in the design. Two types of live loads were specified in the Canadian Highway Bridge Design Code (CHBDC, 2000); namely: truck loading and lane loading. Both above mentioned loads were investigated in this study. Figure 3.1 shows a view the abovementioned CHBDC live truck and lane loads namely; CL-W truck loading and the CL-W lane loading. The CL-W truck is an idealized five-axle truck, the number "W" indicates the gross load (625) of the CL-W truck in KN. Wheel and axle loads are shown in terms of $\mathrm{W}$, and are also shown specifically for CL-625 truck. Whereas the CL-W lane loading consists of CL-W truck loading, with each axle load reduced to $80 \%$ of its original value, and superimposed within a uniformly distributed load of $9 \mathrm{KN} / \mathrm{m}$ over $3.0 \mathrm{~m}$ width. For the purpose of this study, the following different CHBDC truck loading configurations were considered:

(1) For studying the shear distribution between the girders, four levels of loading were employed in this study, namely: Level 1, Level 2, Level 3 and Level 4 truck. Figure 3.2 shows the configurations of each of these load levels. 
(2) For studying the moment and deflection distributions between the girders. one level is employed in this study, namely: Level 1 as shown in Figure 3.3. since bridges with $10 \mathrm{~m}$ spans were considered in this study as a continuation of Wassef's research work on moment distribution. Level 2, Level 3, and Level 4 shown in Figure 3.3 were studied by (Wassef, 2004).

Levels $1,2,3$ and 4 refer to the different bridge span lengths, 10, 15, 25 and $35 \mathrm{~m}$, respectively. In studying the shear, moment and deflection distributions, the loading on the bridge prototypes was applied in such a way to produce maximum forces and longitudinal stresses.

\subsection{Truck Loading Cases}

The selection between the two different CHBDC types of live loads (CL-625 truck and CL-625 lane) depends on whichever gives the greatest design values. A sensitivity study was carried out in this regard showed that the CL-625 truck loading is governing the extreme design values for the single girder of $10,15,25$, and $35 \mathrm{~m}$ span lengths. Accordingly, the CL-625 lane loading was not utilized in this study. The CHBDC requires considering three limit states in bridge designs; namely:

i. The Ultimate Limit State (ULS), that involve failure, including rupture, overturning, sliding, and other instability,

ii. The Serviceability Limit State (SLS), at which the effect of vibration, permanent deformation, and cracking on the usability or condition of the structure are considered, 
iii. The Fatigue Limit State (FLS), at which the effect of fatigue on the strength or condition of the structure are considered.

Dead load and truck load cases were considered for each of the above three CHBDC requirements. Different loading configurations were also considered in this study represented by: one-lane, two-lane, three-lane and four-lane bridges. As a result, a total of 48 different load cases assembled in 4 groups were employed on each level of the above mentioned design requirements. Figures $3.4,3.5,3.6$ and 3.7 show schematic diagrams of the loading cases considered in determining the structural response of the exterior girder, middle girder, and interior girder. It is essential to mention that the exterior girder here refers to the girder which is far away from the centre of curvature in the bridge, whereas the interior girder is the one which is closest to the centre of the curvature. The middle girder considered herein is any girder between the exterior and interior girders. A brief description might be required here to give an idea on how these load cases were assembled in the above diagrams. Diagrams in Figure 3.5 are taken as an example, the first loading case, Load case (1) in each figure is always for the dead load of the structure. For the exterior girder, two truck loading cases were considered. Load case (2) included a single truck load located in the outer lane far away from the centre of curvature, on which the outer wheel load was located at $0.6 \mathrm{~m}$ from the barrier. Load case (3) included two trucks one in each lane with the outer wheel load located at $0.6 \mathrm{~m}$ from the barrier for the first truck and at $0.6 \mathrm{~m}$ from the outer edge of the inner lane for the second truck. Load case (4) was intended to provide the maximum load on the middle girder, which is at or very close to the centroid of the bridge cross-section. In this case one truck was considered in each lane and located as shown in Figure 3.5. Load cases (5) and (6) were intended to provide the maximum load in 
the interior girder. Whereas Load cases (7) and (8) were intended to provide the maximun load in the girders for fatigue design. In this case, CHBDC specifies only one truck loadin located at the centre of the actual lane, the width of this actual lane is determined aftes deducting the width of both side shoulders from the total bridge width and dividing the outcome by the number of design lanes. In this study the shoulder width taken to be in the range of 1.0 to $1.5 \mathrm{~m}$.

\subsection{Composite Bridge Configurations}

320 simply supported straight and curved concrete slab-on-steel I-girder bridge prototypes were considered for finite-element analysis in this parametric study. Several major parameters were considered as follows:

Span length (L): $10,15,25$, and $35 \mathrm{~m}$;

Girder spacing (S): 2, 2.5, and $3 \mathrm{~m}$

Number of girders (N): 3, 4, 5, 6, \& 7 for $2 \mathrm{~m}$ girder spacing; 3, 4, 5, \& 6 for $2.5 \mathrm{~m}$ girder spacing; $3,4 \& 5$ for $3 \mathrm{~m}$ girder spacing;

Span-to-radius of curvature ratio (L/R): $0.0,0.1,0.2, \& 0.3$ for spans $\mathrm{L}=10 \mathrm{~m}$ and $\mathrm{L}=15 \mathrm{~m} ; 0.0,0.1, \quad 0.3, \& 0.5$ for $\operatorname{span} \mathrm{L}=25 \mathrm{~m}$; and $0.0,0.1,0.4, \& 0.7$ for span $\mathrm{L}=35 \mathrm{~m}$.

Based on CHBDC code which specifies number of design lanes as a basis for bridge width (see Tables $3.1 \& 3.2$ ), some of the above diversity of parameters were determined. Other bridge configurations are listed as below:

The deck slab thickness of was taken as $225 \mathrm{~mm}$, 
$>$ The deck slab width $\left(\mathrm{W}_{\mathrm{c}}\right)$ was taken equal to the total bridge width minus $1.0 \mathrm{~m}$ to consider the parapet thickness of $0.5 \mathrm{~m}$ on each side of the bridge,

The depth of the girder webs was taken $(1 / 20)$ of the centre line span except for spans length $=10 \mathrm{~m}$, the depth was taken $0.75 \mathrm{~m}$,

$>$ The girder web thickness was considered equal to $16 \mathrm{~mm}$,

$>$ The over-hanged slab length was considered equal to half the girder spacing,

$>$ The bottom and top steel flanges width and thickness were maintained $300 \mathrm{~mm}$, and $20 \mathrm{~mm}$, respectively.

Table 3.1 summarizes the straight bridge configurations considered in this study. Figure 3.8 visualizes the details of the typical composite deck steel I-girder bridge cross-section used in this study.

X-type cross-bracings with top and bottom chords were utilized in this study as shown in Figure 3.8. These bracings were spaced at equal intervals between the support lines and

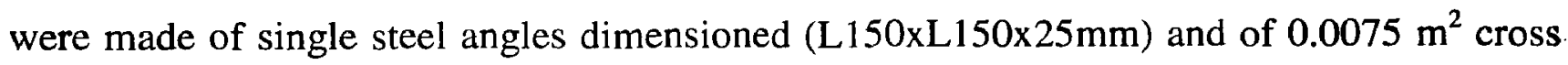
sectional area. The equal intervals spacing between these cross-bracings were based on equation 2.24, which was developed by Davidson et al. (1996) to reduce and limit the warping-to-bending stress ratio. Typical plan of straight and curved girders with the distribution of the transverse bracings are shown in Figure 3.9. 


\subsection{Research Assumptions}

This study was based on the following assumptions:

(1) The reinforced deck slab had complete composite action with the top steel flange of the girders (fully restrained, $100 \%$ shear interaction),

(2) All the bridges were simply supported,

(3) All materials were elastic and homogenous,

(4) The effect of road superelevation, and curbs were ignored;

(5) Bridges had constant radii of curvature between support lines.

Regarding the first assumption, Wassef, (2004) performed a sensitivity study to verify the full composite action between the concrete deck and top girder flange. He used 35-m span bridge with 7 girders spaced at $2.0 \mathrm{~m}$, the concrete deck connected with the steel top flange by M22 studs. The bridge was first analyzed using the finite-element method for a case representing the M22 studs of $0.5 \mathrm{~m}$ spacing as frame elements and for a case representing the M22 studs as shell element with equivalent area. Wassef then verified the results manually using flexural beam theory, he concluded that the shell element revealed better agreement with the manual calculation than the frame element, hence the latter was ignored. Other design values were taken as follows; the modulus of elasticity of concrete material was taken $28 \mathrm{GPa}$ with Poisson's ratio of $\mathbf{0 . 2 0}$, while these design values for steel material were taken; $200 \mathrm{GPa}$ and 0.30 , respectively. 


\subsection{Finite-Element Bridges modeling}

\subsubsection{Geometric Modeling}

Finite element modeling is partly an art guided by visualizing physical interactions taking place within the body (Logan, 2002). One can appear to acquire good modeling techniques through experience and by working with experienced people. To analyze all the above mentioned composite bridges and to determine their structural response, a threedimensional finite-element model was adopted. To facilitate the analysis, the structure was divided into major components as follows: a concrete deck slab, top steel flange, steel web, bottom steel flange, and cross-bracings. In modeling, choosing the proper type of element or elements to match as closely as possible the physical behavior of the problem is sometimes difficult task if not guided by an educated judgment. In general an element yield best results if its shape is compact and regular. Hence, in this study, four-node shell elements with six degree of freedom at each node were used to model the concrete deck slab, the top and bottom girder flanges, and finally the girder web. Whereas frame elements, pinned at both ends, were used to model the cross-bracings with the top and bottom chords. Based on previous work on finite-element modeling, four vertical shell elements were used in each web, and another four were used horizontally for the deck slabs between the webs, whereas two shell elements were used for the overhanged deck slab, and for the upper and lower steel flanges. Figure 3.10 shows a finite-element discretization of four-girder cross section. Figures 3.11 and 3.12 visualized views from the SAP2000 finite-element models for 6girder curved bridge. 


\subsubsection{Aspect Ratio}

In finite-element modeling, the aspect ratio is defined as the ratio of the longes dimension to the shortest dimension of a quadrilateral element. In many cases, as the aspec। ratio increases, the inaccuracy of the solution increases (Logan, 2002). Logan presented a graph showing that as the aspect ratio raises above 4, the percentage of error from the exact solution increases greater than $15 \%$. Consequently, in this study, 72 elements in the longitudinal direction were considered for 15,25 , and $35-\mathrm{m}$ bridge span lengths, whereas only 36 elements were considered for the 10-m bridge span length to keep down the aspect ratio in acceptable ranges.

\subsubsection{Boundary conditions}

Setting proper boundary conditions to suit the nature of the problem and type of structure is sometimes a complicated mission. Experience and previous work are also called herein to choose carefully proper boundary conditions. In modeling the bridge supports in this study, the lower nodes of the web ends were restrained against translation in such way to simulate temperature-free bridge superstructure. In Figure 3.13, the interior support at the right end of the bridge was restrained against movements in all direction. The middle supports and the exterior support at the same right end of the bridge were restrained against the vertical movement and against the movement in y-direction (towards the bridge longitudinal direction). On the other end of the bridge (left end), all the supports were restrained only against vertical movement, except for the interior support which in addition to the vertical restraining, it was restrained in $\mathrm{x}$-direction (towards the bridge transverse 
direction) and as shown in Figure 3.13. Appendices A and B demonstrate samples of SAP2000 input files used in this study.

\subsection{Calculation of the Shear Distribution Factors}

In determining the shear distribution factor (SDF) for curved girder, the maximum shear forces, $\left(R_{\text {straight }}\right)_{\text {truck, }}$ and $\left(R_{\text {straight }}\right)_{D L}$, were calculated for straight simply supported beam due to a single CHBDC truck loading and own dead load, respectively, as shown in Appendix C. It is important to mention that the span length for the above straight simply supported beam is taken equal to the centerline length of the curved bridges. And from the finite-element modeling, the maximum shear forces for dead load, fully loaded lanes, partially loaded lanes, and fatigue loading were determined. Consequently, the shear distribution factors (SDF) were calculated as follows:

\section{For Exterior girders:}

$(\mathrm{SDF})_{\mathrm{DL} \mathrm{ext}}=\left(\mathrm{R}_{\mathrm{FE} . \text { ext }}\right)_{\mathrm{DL}} /\left(\mathrm{R}_{\text {straight }}\right)_{\mathrm{DL}}$

$(\mathrm{SDF})_{\mathrm{FL} \mathrm{ext}}=\left(\mathrm{R}_{\mathrm{FE} . \text { ext }}\right)_{\mathrm{FL}} \times \mathrm{N} /\left(\left(\mathrm{R}_{\text {straight }}\right)_{\mathrm{truck}} \times \mathrm{n}\right)$

$(\mathrm{SDF})_{\mathrm{PL} \mathrm{ext}}=\left(\mathrm{R}_{\mathrm{FE} . \text { ext }}\right)_{\mathrm{PL}} \times \mathrm{N} \times \mathrm{R}_{\mathrm{L}}^{\prime} /\left(\left(\mathrm{R}_{\text {straight }}\right)_{\text {truck }} \times \mathbf{n} \times \mathrm{R}_{\mathrm{L}}\right)$

$(\mathrm{SDF})_{\text {Fat ext }}=\left(\mathrm{R}_{\text {FE.ext }}\right)_{\text {Fat }} \times \mathrm{N} /\left(\mathrm{R}_{\text {straight }}\right)_{\text {truck }}$

For Middle girders:

$(\mathrm{SDF})_{\mathrm{DL} \text { mid }}=\left(\mathrm{R}_{\mathrm{FE} \cdot \text { mid }}\right)_{\mathrm{DL}} /\left(\mathrm{R}_{\mathrm{straight}}\right)_{\mathrm{DL}}$

$(\mathrm{SDF})_{\mathrm{FL} \mathrm{mid}}=\left(\mathrm{R}_{\mathrm{FE} \cdot \mathrm{mid}}\right)_{\mathrm{FL}} \times \mathrm{N} /\left(\left(\mathrm{R}_{\text {straight }}\right)_{\text {truck }} \times \mathrm{n}\right)$ 
$(\mathrm{SDF})_{\mathrm{PL} \mathrm{mid}}=\left(\mathrm{R}_{\mathrm{FE} . \mathrm{mid}}\right)_{\mathrm{PL}} \times \mathrm{N} \times \mathrm{R}_{\mathrm{L}}^{\prime} /\left(\left(\mathrm{R}_{\text {straight }}\right)_{\text {truck }} \times n \times \mathrm{R}_{\mathrm{L}}\right)$

$(\mathrm{SDF})_{\text {Fat mid }}=\left(\mathrm{R}_{\mathrm{FE} . \mathrm{mid}}\right)_{\mathrm{Fat}} \times \mathrm{N} /\left(\mathrm{R}_{\text {straight }}\right)_{\text {truck }}$

\section{For Interior girders:}

$(\mathrm{SDF})_{\mathrm{DL} \text { int }}=\left(\mathrm{R}_{\mathrm{FE} . \text { int }}\right)_{\mathrm{DL}} /\left(\mathrm{R}_{\text {straight }}\right)_{\mathrm{DL}}$

$(\mathrm{SDF})_{\mathrm{FL} \mathrm{int}}=\left(\mathrm{R}_{\mathrm{FE} . \text { int }}\right)_{\mathrm{FL}} \times \mathrm{N} /\left(\left(\mathrm{R}_{\text {straight }}\right)_{\text {truck }} \times \mathrm{n}\right)$

$(\mathrm{SDF})_{\mathrm{PL} \text { int }}=\left(\mathrm{R}_{\mathrm{FE} . \mathrm{int}}\right)_{\mathrm{PL}} \times \mathrm{N} \times \mathrm{R}_{\mathrm{L}}^{\prime} /\left(\left(\mathrm{R}_{\text {straight }}\right)_{\text {truck }} \times \mathrm{n} \times \mathrm{R}_{\mathrm{L}}\right)$

$(\mathrm{SDF})_{\text {Fat int }}=\left(\mathrm{R}_{\mathrm{FE} \text {.int }}\right)_{\text {Fat }} \times \mathrm{N} /\left(\mathrm{R}_{\text {straight }}\right)_{\text {truck }}$

Where $(\mathrm{SDF})_{\mathrm{DL}},(\mathrm{SDF})_{\mathrm{FL}},(\mathrm{SDF})_{\mathrm{PL}}$, and $(\mathrm{SDF})_{\mathrm{Fat}}$ are the shear distribution factors for dead load, fully loaded lanes, partially loaded lanes, and fatigue loading respectively. And the symbols ext, mid, and int. refer to the exterior, middle, and interior girders respectively. $\left(\mathrm{R}_{\mathrm{FE} . \mathrm{ext}}\right)_{\mathrm{DL}},\left(\mathrm{R}_{\mathrm{FE} \text {.ext }}\right)_{\mathrm{FL}},\left(\mathrm{R}_{\mathrm{FE} \text {.ext }}\right)_{\mathrm{PL}}$, and $\left(\mathrm{R}_{\mathrm{FE} . \text { ext }}\right)_{\mathrm{Fat}}$ are the greatest reaction at the exterior girder supports found from the finite-element analysis due to dead load, fully loaded lanes, partially loaded lanes, and fatigue loading respectively. The same can be said for $\left(\mathrm{R}_{\mathrm{FE} . \mathrm{mid}}\right)_{\mathrm{DL}}$, $\left(\mathrm{R}_{\mathrm{FE} . \mathrm{mid}}\right)_{\mathrm{FL}},\left(\mathrm{R}_{\mathrm{FE} . \mathrm{mid}}\right)_{\mathrm{PL}}$, $\left(\mathrm{R}_{\mathrm{FE} . \mathrm{mid}}\right)_{\mathrm{Fat}},\left(\mathrm{R}_{\mathrm{FE} \text {.int }}\right)_{\mathrm{DL}}$, $\left(\mathrm{R}_{\mathrm{FE} \text {.int }}\right)_{\mathrm{FL}},\left(\mathrm{R}_{\mathrm{FE} \text {.int }}\right)_{\mathrm{PL}}$, and $\left(\mathrm{R}_{\mathrm{FE} . \text { int }}\right)_{\mathrm{Fat}}$, but for the middle and interior girders supports.

$\mathrm{n}$ : number of design lanes, as listed in Table 3.2,

$\mathrm{R}_{\mathrm{L}}$ : multi-lane factor based on the number of the design lanes; as shown in Table 3.3, $\mathrm{R}_{\mathrm{L}}{ }^{\prime}$ : multi-lane factor based on the number of the loaded lanes; as shown in Table 3.3,

$\mathrm{N}$ : number of girders. 


\subsection{Calculation of the Moment Distribution Factors}

In the same manner mentioned above, the moment distribution factors (MDF) for curved girders were determined. The maximum flexural stresses $\left(\sigma_{\text {straight }}\right)_{\text {truck, }}\left(\sigma_{\text {straight }}\right)_{\text {DL }}$ were calculated for the straight simply supported beam due to CHBDC truck loading and own dead load, respectively. It is important here to determine the effective concrete slab width, $\mathrm{Be}$, in order to calculate the moment of inertia of the idealized girder. CHBDC specifies the following two equations for calculating $\mathrm{Be}$ :

$$
\begin{array}{ll}
\frac{\mathrm{Be}}{\mathrm{B}}=1-\left[1-\frac{\mathrm{L}}{15 \mathrm{~B}}\right]^{3}, & \text { for } \frac{\mathrm{L}}{\mathrm{B}} \leq 15 \\
\frac{\mathrm{Be}}{\mathrm{B}}=1, & \text { for } \frac{\mathrm{L}}{\mathrm{B}}>15
\end{array}
$$

Where $B$ is the clear spacing between girders $=\left(S-2 b_{f}\right) ; b_{f}$ is the steel flange width; $\mathrm{L}$ is the girder span length; and $\mathrm{S}$ is the girder spacing (all the units are in meters). The following flexural formula was used to calculate the flexural stress of the idealized girder:

$$
\left(\sigma_{\text {straight }}\right)_{\text {truck }}=\mathrm{M}_{\mathrm{T}}\left(\mathrm{y}_{\mathrm{b})} / \mathrm{I}_{\mathrm{t}}\right.
$$

where $\mathrm{M}_{\mathrm{T}}=$ the mid-span moment for a straight simply supported girder due to a single CHBDC truck loading.

$y_{b}=$ the distance from the neutral axis to the bottom flange.

$I_{t}=$ the moment of inertia of the composite girder. 
In likewise manner, the flexure stress of the idealized girder due to dead load was calculated as in the following flexural stress equation:

$$
\left(\sigma_{\text {straight }}\right)_{\mathrm{DL}}=\mathrm{M}_{\mathrm{DL}}\left(\mathrm{y}_{\mathrm{b})} / \mathrm{I}_{\mathrm{t}}\right.
$$

where $\mathrm{M}_{\mathrm{DL}}=$ the mid-span moment for a straight simply supported girder due to a single girder dead load.

Also the results of the above equations were tabulated in Appendix $C$ and were verified by SAP2000 program. And from the finite-element modeling, the maximum longitudinal moment stresses along the bottom flange for dead load, fully loaded lanes, partially loaded lanes, and fatigue loading were calculated. Consequently, the moment distribution factors (MDF) were calculated as follows:

\section{For Exterior girders:}

$(\mathrm{MDF})_{\mathrm{DL} \text { ext }}=\left(\sigma_{\mathrm{FE} . \text { ext }}\right)_{\mathrm{DL}} /\left(\sigma_{\text {straight }}\right)_{\mathrm{DL}}$

$(\mathrm{MDF})_{\mathrm{FL} \mathrm{ext}}=\left(\sigma_{\mathrm{FE} . \text { ext }}\right)_{\mathrm{FL}} \times \mathrm{N} /\left(\left(\sigma_{\text {straight }}\right)_{\text {truck }} \times \mathrm{n}\right)$

$(\mathrm{MDF})_{\mathrm{PL} \mathrm{ext}}=\left(\sigma_{\mathrm{FE} . \text { ext }}\right)_{\mathrm{PL}} \times \mathrm{N} \times \mathrm{R}_{\mathrm{L}}{ }^{\prime} /\left(\left(\sigma_{\text {straight }}\right)_{\text {truck }} \times \mathrm{n} \times \mathrm{R}_{\mathrm{L}}\right)$

$(\mathrm{MDF})_{\mathrm{Fat} \mathrm{ext}}=\left(\sigma_{\text {FE. ext }}\right)_{\mathrm{Fat}} \times \mathrm{N} /\left(\sigma_{\text {straight }}\right)_{\text {truck }}$

\section{For Middle girders:}

$(\mathrm{MDF})_{\mathrm{DL} \text { mid }}=\left(\sigma_{\mathrm{FE} . \mathrm{mid}}\right)_{\mathrm{DL}} /\left(\sigma_{\text {straight }}\right)_{\mathrm{DL}}$

$(\mathrm{MDF})_{\mathrm{FL} \mathrm{mid}}=\left(\sigma_{\mathrm{FE} . \text { mid }}\right)_{\mathrm{FL}} \times \mathrm{N} /\left(\left(\sigma_{\text {straight }}\right)_{\mathrm{truck}} \times \mathrm{n}\right)$

$(\mathrm{MDF})_{\mathrm{PL} \text { mid }}=\left(\sigma_{\mathrm{FE} . \text { mid }}\right)_{\mathrm{PL}} \times \mathrm{N} \times \mathrm{R}_{\mathrm{L}}^{\prime} /\left(\left(\sigma_{\text {straight }}\right)_{\text {truck }} \times \mathrm{n} \times \mathrm{R}_{\mathrm{L}}\right)$

$(\mathrm{MDF})_{\mathrm{Fat} \mathrm{mid}}=\left(\sigma_{\text {FE. mid }}\right)_{\text {Fat }} \times \mathrm{N} /\left(\sigma_{\text {straight }}\right)_{\text {truck }}$ 


\section{For Interior girders:}

$(\mathrm{MDF})_{\mathrm{DL} \text { int }}=\left(\sigma_{\mathrm{FE} . \text { int }}\right)_{\mathrm{DL}} /\left(\sigma_{\text {straight }}\right)_{\mathrm{DL}}$

$(\mathrm{MDF})_{\mathrm{FL} \mathrm{int}}=\left(\sigma_{\mathrm{FE} . \text { int }}\right)_{\mathrm{FL}} \times \mathrm{N} /\left(\left(\sigma_{\text {straight }}\right)_{\mathrm{truck}} \times \mathrm{n}\right)$

$(\mathrm{MDF})_{\mathrm{PL} \mathrm{int}}=\left(\sigma_{\mathrm{FE} . \text { int }}\right)_{\mathrm{PL}} \times \mathrm{N} \times \mathrm{R}_{\mathrm{L}}^{\prime} /\left(\left(\sigma_{\text {straight }}\right)_{\text {truck }} \times \mathrm{n} \times \mathrm{R}_{\mathrm{L}}\right)$

$(\mathrm{MDF})_{\text {Fat int }}=\left(\sigma_{\text {FE. int }}\right)_{\text {Fat }} \times N /\left(\sigma_{\text {straight }}\right)_{\text {truck }}$

Where $(\mathrm{MDF})_{\mathrm{DL}},(\mathrm{MDF})_{\mathrm{FL}},(\mathrm{MDF})_{\mathrm{PL}}$, and $(\mathrm{MDF})_{\mathrm{Fat}}$ are the moment distribution factors for dead load, fully loaded lanes, partially loaded lanes, and fatigue loading respectively. And the symbols ext, mid, and int. refer to the exterior, middle, and interior girders respectively. $\left(\sigma_{\mathrm{FE} . ~ e x t}\right)_{\mathrm{DL}},\left(\sigma_{\mathrm{FE} . \text { ext }}\right)_{\mathrm{FL}},\left(\sigma_{\mathrm{FE} . \text { ext }}\right)_{\mathrm{PL}}$, and $\left(\sigma_{\mathrm{FE} . ~ e x t}\right)_{\mathrm{Fat}}$ are the maximum longitudinal stresses which are the greater at bottom flange points 1 and 3 , as shown in Figure 3.14, found from the finite-element analysis for the exterior girder due to dead load, fully loaded lanes, partially loaded lanes, and fatigue loading, respectively. In the same criteria, $\left(\sigma_{\text {FE. mid }}\right)_{\mathrm{DL}},\left(\sigma_{\text {FE. mid }}\right)_{\mathrm{FL}},\left(\sigma_{\text {FE. mid }}\right)_{\mathrm{PL}},\left(\sigma_{\text {FE. mid }}\right)_{\mathrm{Fat}},\left(\sigma_{\mathrm{FE} . \text { int }}\right)_{\mathrm{DL}},\left(\sigma_{\mathrm{FE} .}\right.$ int $)_{\mathrm{FL}},\left(\sigma_{\mathrm{FE} . \text { int }}\right)_{\mathrm{PL}}$, and $\left(\sigma_{\mathrm{FE} . \text { int }}\right)_{\mathrm{Fat}}$ are the maximum stresses which are the greater of points 1 and 3 but for the middle and interior girders under the same above types of loading. While $R_{L}, R_{L}^{\prime}, N$, and $n$ are defined as before.

\subsection{Calculation of the Deflection Distribution Factors}

To determine the deflection distribution factor (DDF) for curved girder, the mid-span deflection, $\left(\Delta_{\text {straight }}\right)_{\text {truck, }}\left(\Delta_{\text {straight }}\right)_{\mathrm{DL}}$, were calculated for a straight simply supported 
girder subjected to CHBDC truck loading, and dead loads, respectively. Similar to the above SDF and MDF cases, the span of the straight simply supported girder is taken as the curved length of the bridge centre-line. The deflections values of the idealized girder due to truck loading and dead load, were calculated using SAP2000 software, and then verified by manual calculations. Results of these calculations are presented in Appendix C. And from the finite-element modeling, the mid-span deflection values at the middle of the bottom flange due to dead load, fully loaded lanes, partially loaded lanes, and fatigue loading were determined. Consequently, the deflection distribution factors (DDF), were calculated from the following relationships:-

\section{For exterior girders:}

$(\mathrm{DDF})_{\mathrm{DL} \mathrm{ext}}=\left(\Delta_{\mathrm{FE} \mathrm{ext}}\right)_{\mathrm{DL}} /\left(\Delta_{\text {straight }}\right)_{\mathrm{DL}}$

$(\mathrm{DDF})_{\mathrm{FL} \text { ext }}=\left(\Delta_{\mathrm{FE} \mathrm{ext}}\right)_{\mathrm{FL}} \times \mathrm{N} /\left(\left(\Delta_{\text {straight }}\right)_{\mathrm{truck}} \times \mathrm{n}\right)$

$(\mathrm{DDF})_{\mathrm{PL} \mathrm{ext}}=\left(\Delta_{\mathrm{FE} \mathrm{ext}}\right)_{\mathrm{PL}} \times N \times \mathrm{R}_{\mathrm{L}}^{\prime} /\left(\left(\Delta_{\text {straight }}\right)_{\mathrm{truck}} \times \mathrm{n} \times \mathrm{R}_{\mathrm{L}}\right)$

$(\mathrm{DDF})_{\text {Fat.ext }}=\left(\Delta_{\text {FE ext }}\right)_{\text {Fat }} \times \mathrm{N} /\left(\Delta_{\text {straight }}\right)_{\text {truck }}$

\section{For middle girders:}

$(\mathrm{DDF})_{\mathrm{DL} \text { mid }}=\left(\Delta_{\mathrm{FE} \mathrm{mid}}\right)_{\mathrm{DL}} /\left(\Delta_{\text {straight }}\right)_{\mathrm{DL}}$

$(\mathrm{DDF})_{\mathrm{FL} \mathrm{mid}}=\left(\Delta_{\mathrm{FE} \mathrm{mid}}\right)_{\mathrm{FL}} \times N /\left(\left(\Delta_{\text {straight }}\right)_{\text {truck }} \times \mathrm{n}\right)$

$(\mathrm{DDF})_{\mathrm{PL} \text { mid }}=\left(\Delta_{\mathrm{FE} \mathrm{mid}}\right)_{\mathrm{PL}} \times \mathrm{N} \times \mathrm{R}^{\prime}{ }_{\mathrm{L}} /\left(\left(\Delta_{\text {straight }}\right)_{\text {truck }} \times \mathrm{n} \times \mathrm{R}_{\mathrm{L}}\right)$

$(\mathrm{DDF})_{\text {Fat.mid }}=\left(\Delta_{\mathrm{FE} \mathrm{mid}}\right)_{\mathrm{Fat}} \times \mathrm{N} /\left(\Delta_{\text {straight }}\right)_{\text {truck }}$ 


\section{For interior girders:}

$(\mathrm{DDF})_{\mathrm{DL} \text { int }}=\left(\Delta_{\mathrm{FE} \mathrm{int}}\right)_{\mathrm{DL}} /\left(\Delta_{\text {straight }}\right)_{\mathrm{DL}}$

$(\mathrm{DDF})_{\mathrm{FL} \mathrm{int}}=\left(\Delta_{\mathrm{FE} \mathrm{int}}\right)_{\mathrm{FL}} \times \mathrm{N} /\left(\left(\Delta_{\text {straight }}\right)_{\text {truck }} \times \mathrm{n}\right)$

$(\mathrm{DDF})_{\mathrm{PL} \text { int }}=\left(\Delta_{\mathrm{FE} \text { int }}\right)_{\mathrm{PL}} \times \mathrm{N} \times \mathrm{R}_{\mathrm{L}}^{\prime} /\left(\left(\Delta_{\text {straight }}\right)_{\text {truck }} \times \mathrm{n} \times \mathrm{R}_{\mathrm{L}}\right)$

$(\mathrm{DDF})_{\text {Fat.int }}=\left(\Delta_{\mathrm{FE} \mathrm{int}}\right)_{\mathrm{Fat}} \times \mathrm{N} /\left(\Delta_{\text {straight }}\right)_{\text {truck }}$

Where $(\mathrm{DDF})_{\mathrm{DL}},(\mathrm{DDF})_{\mathrm{FL}},(\mathrm{DDF})_{\mathrm{PL}}$, and $(\mathrm{DDF})_{\mathrm{Fat}}$ are the deflection distribution factors for dead load, fully loaded lanes, partially loaded lanes, and fatigue loading respectively. And the symbols ext, mid, and int. refer to the exterior, middle, and interior girders respectively. $\left(\Delta_{\mathrm{FE} \mathrm{ext}}\right)_{\mathrm{DL}},\left(\Delta_{\mathrm{FE} \mathrm{ext}}\right)_{\mathrm{FL}},\left(\Delta_{\mathrm{FE} \mathrm{ext}}\right)_{\mathrm{PL}}$, and $\left(\Delta_{\mathrm{FE} \text { ext }}\right)_{\mathrm{Fat}}$ are the deflections at point 2, refer to Figure 3.14, found from finite-element analysis for the exterior girder due to dead load, fully loaded lanes, partially loaded lanes, and fatigue loading respectively. In the same manner, $\left(\Delta_{\mathrm{FE} \text { mid }}\right)_{\mathrm{DL}},\left(\Delta_{\mathrm{FE} \text { mid }}\right)_{\mathrm{FL}},\left(\Delta_{\mathrm{FE} \text { mid }}\right)_{\mathrm{PL}},\left(\Delta_{\mathrm{FE}}\right.$ mid $)_{\mathrm{Fat}},\left(\Delta_{\mathrm{FE} \text { int }}\right)_{\mathrm{DL}},\left(\Delta_{\mathrm{FE} \text { int }}\right)_{\mathrm{FL}},\left(\Delta_{\mathrm{FE} \text { int }}\right)_{\mathrm{PL}}$, and $\left(\Delta_{\mathrm{FE} \text { int }}\right)_{\mathrm{Fat}}$ are the finite-element deflections for the middle and interior girders under the same above types of loading. While $R_{L}, R_{L}^{\prime}, N$, and $n$ are defined as before.

\subsection{Warping to-bending stress ratio}

As previewed in chapter 2 , curved bridges are subjected to lateral bending moments acted at the top and bottom flanges due to curvature as shown in Figure 3.15. This lateral bending moment also called "bi-moment" or "torsional warping moment"; which induces warping of the girder cross-section. This bi-moment will increase the longitudinal flexural 
stress in flanges, and hence is called "warping stress". To study the effect of this warpin stress and its changes with different bridges parameters and load cases, the ratio betwee warping stress to the average bending stress in the bottom flange is examined in this study with the following relationship:

$\mathbf{W B R}=\sigma_{\mathrm{w}} / \sigma_{\mathrm{b}}=\left(\sigma_{1}-\sigma_{3}\right) /\left(\sigma_{3}+\sigma_{1}\right)$

where $\sigma_{1}$ and $\sigma_{3}$ : the corresponding mid-span stresses at points 1 and 3 shown in Figur $3.14 ; \sigma_{w}$ is the warping stress; and $\sigma_{b}$ is the average bending stress in the bottom stee flange. 


\section{CHAPTER IV \\ RESULTS FROM THE PARAMETRIC STUDY}

\subsection{General}

As mentioned in the previous chapter the finite element "SAP2000" program was chosen to conduct the current research. A parametric study on 256 simply supported straight and curved concrete slab-on-steel I-girder bridge prototypes was conducted to investigate the shear distribution factors. In addition to that; another parametric study conducted on 64 composite bridge prototypes to investigate the moment and deflection distribution factors as a continuation of Wassef's research work (2004). All the above-mentioned bridge prototypes were analyzed to evaluate their structural response against a total of 48 different combinations of load cases (dead loading as well as the Canadian Highway Bridge Design truck loading, CHBDC truck). This chapter presents the results of the above parametric studies in terms of (1) shear distribution among composite girders, (2) moment distribution among composite girders, (3) deflection distribution, and (4) warping-to-bending stress ratios in steel flanges. In this study the following major key parameters were considered:

(i). Span-to-radius of curvature ratio (L/R),

(ii). Number of girders (N),

(iii). Girder spacing (S),

(iv). Bridge span length (L),

(v). Number of cross-bracing intervals between support lines. 
As mentioned in Chapter (I) and based on the results from this research, the objectives this parametric study were to:

1- Scrutinize the influence of the major parameters on the structural response composite I-girder bridges.

2- Generate a database for the maximum longitudinal bending stresses in bottc flanges and shear forces at support locations.

3- Developing new simplified formulas for Shear and Moments Distribution Factors $f_{t}$ curved composite concrete steel I-girder bridges that help the design engineers and code authors.

\subsection{Shear Distribution in Simply Supported Composite Curved Bridges}

\subsubsection{Effect of Curvature}

Curvature is considered one of the major factors that influencing the curved bridge behavic and controlling the stress distribution among their girders. The results of current parametri study conformed this fact. Figures $4.1,4.2$ and 4.3 show the variation in the she distribution factors with increase in span-to-radius of curvature ratio (L/R), for the exterio girder of one-lane bridge comprised of 3 girders spaced at $2 \mathrm{~m}$ under dead load, fully loader lanes with truck loading, and fatigue loading, respectively. It can be observed that as $\mathrm{L} / \mathrm{F}$ ratio increases, the shear distribution factor for the exterior girder increases, for example ir

Figure 4.2 , as the L/R ratio increased from 0.1 to 0.4 for the $35 \mathrm{~m}$ bridge span length, the 
shear distribution factor increased from 1.87 to 2.43 . Also, the rate of increase of the shear distribution factor is observed to generally increases with the increase in span length.

The above trend however, is considerably changed in the behavior of the shear distribution factors of the middle girder as shown in Figures 4.4, 4.5, and 4.6 due to dead load, fully loaded lanes, and fatigue loading, respectively. Except for the dead load case, it can be observed that the shear distribution factor slightly decreases as the $L / R$ ratio increases for bridge span lengths 10 and $15 \mathrm{~m}$, whereas it follows the same pattern of the exterior girder for the span lengths 25 and $35 \mathrm{~m}$. On the other hand, an inverse relation between the shear distribution factors and the curvature become more dominant in the behavior of the interior girder (the closest to the central of curvature) as shown in Figures 4.7, 4.8 and 4.9 for dead load, fully loaded lanes, and fatigue loading, respectively. This is due to the fact that the torsion stresses induced from the curvature tend to increase longitudinal bending stresses in the exterior girders and to reduce them in the interior girders. A two-lane bridge, with 4 girders spaced at $2.5 \mathrm{~m}$ was also investigated to broaden the findings with respect to the effect of curvature. The effects of the span-to-radius ratio $(L / R)$ on the shear distribution factor found to be similar to those of the above-mentioned one-lane, 3 girder system. This can be observed in Figures 4.10, to 4.16, for different load cases of the exterior and interior girders.

CHBDC considers curved bridge to be treated as a straight one if $\mathbf{L}^{2} /(\mathbf{b . R})$ is not greater than 1, where $\mathbf{L}$ is the curved span length, $\mathbf{b}$ is half of the bridge width, and $\mathbf{R}$ is the radius of curvature. Considering the above CHBDC limitations in this study, the resulting $\mathrm{L} / \mathrm{R}$ ratio for the bridges considered in this study are: 
(1) For $10-\mathrm{m}$ bridge span; $\mathrm{L} / \mathrm{R}$ ratio equal 0.3 and 0.7 for $6-\mathrm{m}$ and $14-\mathrm{m}$ bridge wic respectively;

(2) For $15-\mathrm{m}$ bridge span; L/R ratio equal 0.2 and 0.47 for $6-\mathrm{m}$ and $14-\mathrm{m}$ bridge wid respectively;

(3) For $25-\mathrm{m}$ bridge span; $\mathrm{L} / \mathrm{R}$ ratio equal 0.12 and 0.28 for $6-\mathrm{m}$ and $14-\mathrm{m}$ bridge wid respectively;

(4) For 35-m bridge span; L/R ratio equal 0.09 and 0.2 for $6-\mathrm{m}$ and $14-\mathrm{m}$ bridge widı respectively;

When the above limiting values are applied to Figures 4.1 to 4.6 for the exterior and midd girders of a one-lane bridge and Figures 4.10 to 4.13 for the exterior girders of a two-lar bridge, it can be clearly seen that CHBDC significantly underestimates the shear distributic factors for the exterior and middle girders of the curved system bridges.

\subsubsection{Effect of Number of Girders}

A bridge of $35-\mathrm{m}$ span with $2.0 \mathrm{~m}$ girder spacing was selected to investigate the effect of th number of girders on the shear distribution factors. Results on the shear distribution factor 0 the exterior girder due to dead load revealed a reduction in the shear distribution factor wit] the increase in number of girders for span-to-radius of curvature ratio greater than 0.1 , a shown in Figure 4.17. However, different trend is noticed in Figures 4.18 and 4.19 for full! loaded lanes and partially loaded lanes, respectively. It can be observed that the shea: distribution factor decreases (from 2.43 to 1.60 as shown in Figure 4.18 for $\mathrm{L} / \mathrm{R}=0.4$ ) as number of girders increase to 4 , then the above relation is reversed (from 1.6 to 1.92 ) for number of girders more than 4. Figure 4.20 showed another trend in the relation between the 
shear distribution factors and the number of girders for fatigue loading case, the shear distribution factors fluctuate with increase in number of girders. Figures $4.21,4.22$, and 4.23 represent the above-mentioned relationship for the middle girder under dead load, fully loaded lanes, and fatigue loading respectively. While Figures 4.24, 4.25, 4.26, and 4.27 show the change of the shear distribution factor for the interior girder under dead load, fully loaded lanes, partially loaded lanes and fatigue loading, respectively, with increase in number of girders. In general, the shear distribution factors for the middle and the interior girders increase with the increase in number of girders except for the middle girder dead loading case where insignificant effect is witnessed.

\subsubsection{Effect of Girders Spacing}

Figures $4.28,4.29,4.30$, and 4.31 show the relationship between the shear distribution factors and girder spacing for the exterior girder of two-lane, 25-m span bridge having 4 girders under dead load, fully loaded lanes, partially loaded lanes, and fatigue loading, respectively. Generally, it can be noticed that the shear distribution factor increases as the girder spacing increase ( from Figure 4.29, as the girder spacing increased from 2 to $3 \mathrm{~m}$, the shear distribution factor increased by $23.5 \%$ for $L / R=0.3$ ) except for the deal load case, where the above relation is slightly reversed. Similar behavior is observed in case of the middle girder (Figures 4.32, and 4.33) for fully loaded lanes and fatigue loading, respectively, and for the interior girder (Figures 4.34 , and 4.35 ) for fully loaded lanes, and partially loaded lanes, respectively. 


\subsubsection{Effect of Span Length}

Figures 4.36 and 4.37 show the effect of span length on the shear distribution factors for $t$ exterior girder of one-lane, 3-girder bridge due to dead load and fully loaded lant respectively. In case of dead load, insignificant effect of the span length on the she distribution factors is observed except for the span-to-radius ratio (L/R) of 0.3 , at tho values the shear distribution factor increases as the span length increases. However, tt shear distribution factor of the exterior girder under fully loaded lanes increases as the spe length increases (from Figure 4.37, as the span length increased from 10 to $25 \mathrm{~m}$, the she: distribution factor increased from 1.73 to 2.10 for $L / R=0.3$ ). It is also observed that th rate of increase in the shear distribution factor increases with increase in the $L / R$ ratio. Th effect of the span length on the shear distribution factor for the middle girder is observed $t$ be insignificant for spans greater than $25 \mathrm{~m}$, as shown in Figure 4.38. However, the shea distribution factor for the interior girder decreases with the increase of the span length it curved bridges as shown in Figures 4.39 and 4.40 for dead load and fully loaded lanes respectively. Once again the rate of the slop decrease of the shear distribution factor line is increases as the $\mathrm{L} / \mathrm{R}$ ratio increase.

\subsubsection{Effect of Loading Conditions}

When analyzing bridge prototypes to determine the shear distribution factors, many loading cases for CHBDC truck loading were considered. These loading cases can be divided into two main groups; namely: bridges with fully loaded lanes and bridges with partially loaded lanes. To investigate the effect of these two loading cases on the shear distribution factors,

Figures $4.41,4.42,4.43$, and 4.44 represent the relationship between the shear distribution 
factors of the exterior girder of $10,15,25$, and 35-m span bridges, respectively, due to fully loaded lanes and partially loaded lanes. The horizontal axis represents the shear distribution' factor due to fully loaded lanes while the vertical axis represents the corresponding shear distribution factor for the case of partially loaded lanes. These plotted relationships are for all bridges regardless on number of girders, girders spacing, and number of lanes. It can be observed that shear distribution factors obtained for partially loaded lanes are usually higher than those for fully laded lanes, especially for shorter spans. Figures $4.45,4.46,4.47$, and 4.48 show similar relationship but for the interior girder. Results revealed that in some exterior and middle girders cases of 10-m span bridges with 4 design lanes; partially loaded lanes with two trucks only produced higher shear distribution factors than the case of partially loaded lanes with 3 trucks and fully loaded lanes as shown in Table 4.1.

\subsubsection{Effect of Number of Lanes}

Figures 4.49 , and 4.50 illustrate the relationship between the shear distribution factors and the number of lanes for the exterior girder of a bridge with $2 \mathrm{~m}$ girder spacing and $35-\mathrm{m}$ span length due to fully loaded lanes and partially loaded lanes respectively. It can be noticed that as the number of lanes increases, the shear distribution factors decreases. Example of that can be observed in Figure 4.49, as the number of lanes increased from 1 to 3 lánes, the shear distribution factor decreased from 3.07 to 1.6 for $L / R=0.7$. Middle and interior girders demonstrate different relationship between the shear distribution factors and the number of lanes for the same bridge configuration as shown in Figures 4.51 to 4.54. 


\subsubsection{Effect of Number of Bracing Intervals}

It was mentioned in chapter (II) that the number of bracing intervals used in this study $w$ based on equation 2.24 . To verify the reliability of this equation and to study the effect number of bracing interval on the shear distribution factor, a sensitivity study was conducts on a two-lane Bridge of 35-m span length, with 4 girders, and span-to-radius of curvatu ratio (L/R) of 0.7 , against various numbers of bracing intervals; $(2,3,4,6,8,9$, and 12 Figure 4.55 shows the effect of the number of bracing intervals on the shear distributic factor of the exterior girder when the bridge is subjected to dead load, fully loaded lane: and partially loaded lanes. It can be observed that the shear distribution factor decreases wit increase in number of cross-bracing intervals up to 4 . No further reduction is observe beyond 4 bracing intervals. This means that the outcome of equation 2.24 is too conservativ in case of shear distribution, while it is required for limiting the warping-to-bending stresse ratios.

\subsubsection{Effect of Load Cases}

As mentioned earlier in chapter III, this research investigated different patterns of load cases shown in Figures 3.4 to 3.7 to produce the maximum shear distribution factors. Figures 4.56, 4.57, and 4.58 show the shear distribution factor obtained from each loading case for the exterior, middle, and interior girders, respectively, of two-lanes, 25-m span, bridge with 4 girders spaced at $2 \mathrm{~m}$. As expected, in the exterior girder case number 2 governs the shear distribution factor value for $L / R$ ratio of 0.1 and below, and case number 3 governs it for the $L / R$ ratio greater than 0.1 , whereas cases number 4 and 5 govern the shear distribution factor 
for the middle and interior girders, respectively. It's important to mentions that in the exterior girders (when $L / R<=0.1$ ) and interior girders, the governing cases are those for the partially loaded lanes (one truck loaded in a two-lane bridge). Figures $4.59,4.60$, and 4.61 show SDF obtained from each load case for 3-lane, 25-m span bridge, with 7 girders spaced at $2 \mathrm{~m}$ for the exterior, middle, and interior girders, respectively. It can be observed that for exterior and interior girders, loading cases 3 and 10, respectively, (two trucks loaded in 3lane bridge) provide the design values, whereas for middle girder, cases 3 and 5 (two trucks loaded in 3-lane bridge) govern the design shear distribution factor. To show the diversity in the outcome from loading cases, results from a 4-lane bridge with $35 \mathrm{~m}$ span are shown in Figures $4.62,4.63$, and 4.64. Two cases ( $4 \& 9)$, (4\& 9), and (10\& 15$)$ show the peak SDF values for the exterior, middle, and interior girders, respectively. All these loading cases represent partially loaded lanes of ( 3 trucks loaded in 4-lane bridge) except case 15 of 2 trucks loaded in 4-lane bridge.

\subsection{Shear Distribution Between Bridge Girders}

Figures 4.65 , and 4.66 investigate the distribution of the shear between the girders of the composite bridges to understand how the loads are distributed between the girders with increase in $L / R$ ratios. A two-lane bridge of $35-\mathrm{m}$ span with 5 girders spaced at $2.0 \mathrm{~m}$, was analyzed under dead loading and fully loaded lanes, respectively, It was observed that the shear distribution factor increases as the span-to-radius ratio increases for the girders located between bridge centre-line and the exterior girder. However it decreases as the span-toradius ratio increase for the rest of the girders between the inner (interior) girder and the centre-line of the bridge. This is attributed to the high torsional moments associated with 
curvature. Similar trend was observed in case of a 4-lane bridge with girders, spaced at 2 $\mathrm{m}$ as shown in Figures 4.67 and 4.68.

\subsection{SDF Effect with Type of the Support}

A two-lane bridge of $35-\mathrm{m}$ span and 5 girders spaced at $2 \mathrm{~m}$ was chosen to investigat whether there is a change in shear distribution at the roller and hinge support line mentioned in the finite-element modeling of support conditions in chapter III. Figures 4.6! and 4.70 show the values of shear distribution factor along the hinged support line unde dead load and fully loaded lanes, respectively, while Figures 4.71 and 4.72 show simila results along the roller support line under the same above load configuration. No significan effect was witnessed; this means that calculation of shear forces or reactions along the rolles or the hinge support lines does not effect the design value.

\subsection{Shear Distribution Equations Comparison between CHBDC and those obtained from Current Finite Element Analysis}

The Canadian Highway Bridge Design Code specifies equations for calculating the shear distribution factors for straight slab-on-girder bridges, including reinforced concrete girders, pre-stressed concrete girders and composite concrete-steel girders. CHBDC applied some conditions to use these equations, one of them related to the type of girders' lateral supports, identified as diaphragms which are required to be provided at support lines and at equal intervals between the supports to enhance girders stability. There are different types of diaphragms that can be used to satisfy CHBDC requirements. As mentioned in chapter (III), this study utilized, cross-bracing type diaphragm with top and bottom chords, which is 
considered as lateral supports to the steel girders. This study conducted a comparison between the shear distribution factors obtained from the empirical expressions in the CHBDC for straight slab-on-girder bridges and the results acquired from the current study using the finite-element analysis for the same types of bridges. Figures 4.73 and 4.74 show the correlation between the shear distribution factors of the exterior girder due to truck loading and fatigue loading, respectively as obtained from CHBDC equations and from the current study. In a similar manner, Figures 4.75 and 4.76 show similar correlation for the middle girder under the same loading configurations. It can be concluded that the CHBDC equations always overestimate the structural response except of very few cases for truck loading as shown in Figure 4.75. This may be attributed to the presence of cross-bracings between support lines that was ignored when developing CHBDC equations.

\subsection{Moment and Deflection Distributions in Simply Supported Composite Curved Bridges}

\subsubsection{Effect of Curvature}

Once again the results of current parametric study revealed that the curvature of bridges is considered as a major parameter which significantly effects the distribution of bending moments among girders. Figures $4.77,4.78,4.79$, and 4.80 present the moment distribution factor for the exterior girder of a two-lane bridge with 7 girders equally spaced at $2 \mathrm{~m}$, under dead load, fully loaded lanes, partially loaded lanes, and fatigue loading, respectively. It can be observed that the moment distribution factor increases as the span-to-radius of curvature ratio $(\mathrm{L} / \mathrm{R})$ increases. Similar trend was observed in case of the middle girder, as shown in Figures $4.81,4.82$, and 4.83 for dead load, fully loaded lanes, and fatigue loading, 
respectively. Figures $4.84,4.85,4.86$, and 4.87 show the effect of curvature ratio on tl moment distribution factor for the interior girder due to dead load, fully loaded lane partially loaded lanes, and fatigue loading, respectively. It can be observed for the case fully loaded lanes that the moment distribution factor follows the above-mentione dominant behavior for the exterior girder, (i.e. increase in moment distribution factor as th. curvature ratio increase). However, in case of dead loading, the moment distribution factc increases as the curvature ratio increases till reaching a certain value of $L / R(0.2)$, beyon which the moment distribution factor starts to decrease as shown in Figure 4.84. Simile behavior but with less effect is witnessed in case of fatigue load as shown in Figure 4.87 The case of partially loaded lanes shown in Figure 4.86, shows insignificant effect of L/I ratio on the MDF. This behavior can be attributed to the fact that the increase in $L / R$ rati and the decrease in the span length of the interior girder. So, at low $\mathrm{L} / \mathrm{R}$ values the increast of curvature dominates the decrease in span length, but when the $L / R$ increases the decrease in span length become dominant. Going back to clause 4.2 .1 to in the CHBDC for a curvec bridge to be treated as a straight one, results in Figures 4.77 to 4.87 revealed that CHBDC is significantly underestimate the moment distribution factors in curved bridges that meet the requirement of $\mathrm{L}^{2} /(\mathrm{b} . \mathrm{R})$ being less than 1 . The effect of curvature ratio on deflection factors was also studied parallel to the MDF study and similar trend was observed as shown in Figures 4.111 to 4.121 .

\subsubsection{Effect of Number of Girders}

Figures $4.88,4.89,4.90$, and 4.91 show the effect of number of longitudinal girders on the moment distribution factor for the exterior girder of a two-lane, $10-\mathrm{m}$ span bridge with $2.0 \mathrm{~m}$ 
girder spacing under dead load, fully loaded lanes, partially loaded lanes, and fatigue loading respectively. Although insignificant effect is observed between the number of girders and moment distribution factor for the dead load case as shown in Figure 4.88, significant increase in the moment distribution factor was found with increase in number of girders for fully loaded and partially loaded lane cases as shown in Figures 4.89, and 4.90 respectively. Fatigue load case revealed another pattern as shown in Figure 4.91; following a pattern other than a straight line. For the middle girder, the effect of number of girders on the moment distribution factor revealed that the moment distribution factor increases as the number of girder increases except for the dead load case, where insignificant behavior is found as shown in Figures 4.92 to 4.95 . Figures 4.96 to 4.99 show the moment distribution factor of the interior girder under dead load, fully loaded lanes, partially loaded lanes, and fatigue loading, respectively, with the increase in number of girders. A trend similar to that in case of the exterior girder is observed. The effect of number of girders on the deflection distribution factor was also investigated in parallel to the study on moment distribution factor. A similar trend was observed as shown in Figures 4.122 to 4.131.

\subsubsection{Effect of Girders Spacing}

Figures 4.100 to 4.103 for two-lane, 10-m span, bridge with 4 girders show the effect of the girders spacing on moment distribution factor it can be observed that, the moment distribution factor increases as the girder spacing increases except for the dead load case when insignificant relationship was found. Similar trend is observed in case of the middle and interior girders as shown in Figures 4.104 to 4.107. Similar behavior was observed in case of the deflection distribution factors as shown in Figures 4.132 to 4.140. 


\subsubsection{Effect of Loading Conditions}

As examined in the case of the shear distribution factor study, it is important to examine th effect of number of loaded lanes on the moment distribution factor to establish the critic. cases that produce extreme values of moment distribution factors. Accordingly, two loadin cases were considered; fully loaded lanes with truck loading and partially loaded lanes wit truck loading. Figures $4.108,4.109$, and 4.110 show the relationship between resul obtained from the case of fully loaded lanes and the case that provides the maximu moment distribution factor of all the partially loaded cases for the exterior, middle, an interior girders, respectively. It is worthwhile to reiterate that these plotted values are for a bridges of $10-\mathrm{m}$ spans regardless of number of lanes, or number of girders or girder spacing. It can be infer from the above Figures that sometimes even though the partiall. loaded lanes are almost half of the live load of the fully loaded lanes, still they can provid extreme design values. However, the results from the fully loaded lanes generally dominat the design value when compared to the partially loading. Similar trend was observed for thi deflection distribution factors as shown in Figures 4.141 to 4.143.

\subsection{Warping Stress Distribution in Simply Supported Curved Bridges}

To study the effect of the warping stress distribution in simply supported curved bridge, 10 . m span bridge was selected. As mentioned earlier in chapter III, in order to investigate the change in warping stresses with the changes in bridge geometry and loading conditions, the ratio of the warping stress-to-the-average bending stress in the bottom flanges (WBR as calculated in equation 3.42) was calculated in this study. The AASHTO Guide specification 
for Horizontally Curved Bridges (Guide, 2003) acknowledged a limitation value for the warping-to-bending stress ratio (WBR) of 0.5 to ensure the stability of the structure. In this parametric study, the values for WBR were calculated for the exterior, middle, and interior girders due to different load cases.

Figures $4.144,4.145,4.146$, and 4.147 illustrate the WBR values for the exterior girder of all the curved bridges of 10-m span considered in this study in ascending order, due to dead load, fully loaded lanes, partially loaded lanes, and fatigue loading, respectively. The negative values observed in these figures refer to the orientation of the lateral stresses at the bottom flange which is not affecting the absolute value of the warping-to-bending stress ratio. It can be inferred from the above figures that the WBR increases with the increase of the span-to-radius of curvature $(\mathrm{L} / \mathrm{R})$ ratio. Another important remark is that the extreme values of WBR shown in the above all figures did not exceed 0.2 which is considered complying with the requirements of AASHTO Guide 2003. Figures 4.148, 4.149, 4.150, and 4.151 illustrate the warping-to-bending stress ratio for the middle girder of all the curved bridges considered in this study in ascending order, due to dead load, fully loaded lanes, partially loaded lanes, and fatigue loading respectively. Similar pattern of WBR to that of the exterior girder was observed; however there was slight increase in the upper limit of the WBR values for the middle girder as compared to those of the exterior girder. Nevertheless in all cases the WBR values did not exceed 0.25 which is still below the AASHTO requirements. The warping-to-bending stress ratio in the interior girder followed the same trend to that of the exterior and the middle girders. Figures $4.152,4.153,4.154$, and 4.155 illustrate the warping-to-bending stress ratio for the interior girder of all the curved bridges considered in this study in ascending order, due to dead load, fully loaded lanes, partially 
loaded lanes, and fatigue loading, respectively. There was slight increase in the upper lim of the WBR values in the interior girder as compared to those of the middle girder ( 0.4 : shown in Figure 4.152), which still below the AASHTO limits.

\subsection{Comparison Between CHBDC Moment Distribution Equations and those obtained from Current Finite Element Analysis}

As mentioned earlier in this chapter, the Canadian Highway Bridge Design Code (CHBDC specifies empirical equations for the moment distribution factors in case of straight bridges including different types of bridges supported laterally by diaphragms at the support lines. I order to study the correlation between the CHBDC empirical equations and the results fron this study, the outcome from this research and the corresponding values obtained fron CHBDC equations were drawn against each other in graphical format. The produced graph: were for the exterior and middle girders due to truck loading and fatigue loading respectively, as shown in Figures 4.156, 4.157, 4.158, and 4.159. It was observed that the CHBDC moment distribution equations always overestimate the structural response of the studied bridges except for few cases for the exterior girders due to fatigue loading. In orde1 to investigate the correlation between the moment distribution factors and the deflection distribution factors, the results from the finite-element analysis for moment distribution factors and deflection distribution factors were plotted against each other in Figures 4.160, $4.161,4.162$, and 4.163 for the exterior girder under truck loading and fatigue loading and for the middle girders under the same type of loading, respectively. For straight bridges, it can be observed that the moment distribution factor correlates very well with the deflection distribution factor, however in curved bridges the deflection distribution factors are always 
bigger than the corresponding moment distribution factors. As a result, the deflection distribution factors for curved bridges should not be taken as the moment distribution factors and new deflection distribution factors should be developed for curved bridges in addition to the moment distribution factors.

\subsection{Development of New Load Distribution Factor Equations}

\subsubsection{Shear Distribution Factor Equations}

Two types of equations were developed from the results of this study; namely: (1) shear distribution factors for straight composite concrete-steel I-girder bridges, and (2) shear distribution factors for curved composite-steel I-girder bridges.

\subsubsection{Shear Distribution Factors for Straight I-Girder Bridges}

The general equation for the shear distribution factor for straight I-girder bridges takes the following form:

$F_{v}=S \times N \times F$

$F=\left(a+b \times L^{c}\right)^{d}$

Where

$F_{v}:$ is the shear distribution factor,

$\mathrm{S}:$ is the girder spacing in meters,

$\mathrm{N}$ : is the number of girders,

$\mathrm{F}:$ is a width dimension factor that characterizes load distribution for a bridge on which $a$,

$b, c$, and $d$ are equation variables and shall be obtained from Tables 4.2, and 4.3.

$\mathbf{L}$ : is bridge span length in meters. 


\subsubsection{Shear Distribution Factors for Curved I-Girder Bridges}

The general equation for the shear distribution factor for curved I-girder bridges takes the following form:

$$
\begin{aligned}
& F_{v}=S \times N \times F \\
& F=\left(a+b \times L^{c}\right)^{d} \times\left[1+e(L / R)^{f}+g(L / R)^{h}\right]
\end{aligned}
$$

Where;

$e, f, g$, and $h$ are equation variables and shall be obtained from Tables 4.4, and 4.5,

$L / R$ : is span-to-radius of curvature ratio.

\subsubsection{Moment Distribution Factor Equations}

Following the criteria in building the moment distribution factor equation as stated in the CHBDC with the difference of developing new MDF values generated from this study.

\subsubsection{Moment Distribution Factors for Straight I-Girder Bridges}

The general equation of the moment distribution factor for straight I-girder bridges takes the following form:

$$
F_{m}=\frac{S N}{F\left(1+\frac{\mu C_{f}}{100}\right)}
$$




\section{$\mathbf{F}=\mathbf{a}+\mathbf{b} / \mathbf{L}$}

Where

$F_{m}:$ is the moment distribution factor,

$\mathrm{S}:$ is the girder spacing in meters,

$\mathrm{N}:$ is the number of girders,

$\mathrm{F}:$ is a width dimension factor that characterizes load distribution for a bridge, $a$, and $b$ are equation variables and shall be obtained from Tables 4.6, and 4.7.

$$
\mu=\frac{W_{e}-3.3}{0.6} \text { but } \leq 1.0
$$

$\mathrm{W}_{\mathrm{e}}$ : is the width of a design lane in meters, calculated with CHBDC clause 3.8.2;

$\mathrm{C}_{\mathrm{f}}$ : is a correction factor, in \%, obtained from Table A5.7.1.2.1 (CHBDC);

\subsubsection{Deflection Distribution Factor Equations}

\subsubsection{Deflection Distribution Factors for Straight I-Girder Bridges}

The general equation of the moment distribution factor for straight I-girder bridges takes the following form:

$$
F_{\Delta}=\frac{S N}{F\left(1+\frac{\mu C_{f}}{100}\right)}
$$

$\mathbf{F}=\mathbf{a}+\mathbf{b} / \mathbf{L}$ 
Where

$F_{\Delta}:$ is the Deflection distribution factor;

$S:$ is the girder spacing in meters,

$\mathrm{N}$ : is the number of girders,

$\mathrm{F}:$ is a width dimension factor that characterizes load distribution for a bridge, $a$, and $b$ are equation variables and shall be obtained from Tables 4.8, and 4.9.

$\mu=\frac{W_{e}-3.3}{0.6} \quad$ but $\leq 1.0$

$\mathrm{W}_{\mathbf{e}}$ : is the width of a design lane in meters, calculated with CHBDC clause 3.8.2;

$\mathrm{C}_{\mathrm{f}}$ : is a correction factor, in \%, obtained from Table A5.7.1.2.1 (CHBDC); 


\section{CHAPTER V}

\section{SUMMARY, CONCLUSIONS, AND RECOMMENDATIONS FOR FUTURE RESEARCH}

\subsection{Summary}

This study investigated the effect of the following parameters on the lateral load distribution factors for straight and horizontally curved composite concrete-steel I-girder bridges using the finite-element analysis:

Span length (L): 10, 15, 25, and $35 \mathrm{~m}$;

Girder spacing (S): 2, 2.5, and $3 \mathrm{~m}$;

Number of girders $(\mathbf{N}): 3,4,5,6, \& 7$ for $2 \mathrm{~m}$ girder spacing; $3,4,5, \& 6$ for $2.5 \mathrm{~m}$ girder spacing; 3, 4 \& 5 for 3 m girder spacing;

Span-to-radius of curvature ratio, $(\mathbf{L} / \mathbf{R}): 0.0,0.1,0.2, \& 0.3$ for spans $\mathrm{L}=10 \mathrm{~m}$ and $\mathrm{L}=15 \mathrm{~m} ; 0.0,0.1, \quad 0.3, \& 0.5$ for span $\mathrm{L}=25 \mathrm{~m}$; and $0.0,0.1,0.4, \& 0.7$ for span $\mathrm{L}=35 \mathrm{~m}$;

Loading conditions: fully loaded lanes and partially loaded lanes;

Cross-bracing intervals, 2, 3, 4, 6, 8, 9, and 12;

Number of lanes: $1,2,3$, and 4

\subsection{Conclusions}

Based on the results from the parametric study, the following conclusions are drawn: 
(1) Curvature is the most significant factor which is playing an important role determining the lateral load distribution factors. The increase in the span-to-radius curvature ratio $(\mathbf{L} / \mathbf{R})$ leads to significant increase in the shear distribution factors $f$ the exterior and middle girders and a decrease in the SDF for the interior girde whereas the increase in the curvature ratio results in significant increase in tl moment distribution factors and deflection distribution factors for all the girders. Th same conclusion can be drawn for the effect of curvature on warping-to-bendin stress ratio.

(2) The number of girders and girders spacing are other important parameters that affer the lateral load distribution factors. In general, the increase in the number of girder: as well as in girders spacing results in an increase in the shear distribution factol moment distribution factor, and deflection distribution factor.

(3) In general, the span length slightly affects the shear distribution factors; howeve I span length shows significant effect when the L/R ratio exceeds 0.10 .

(4) This study revealed that the partially loaded lane cases almost govern the extrem values of the shear distribution factors. However, the moment distribution factor: and deflection distribution factors showed rebellious results compared to those of the shear distribution factors, when the fully loaded lane cases govern the design.

(5) The number of cross-bracing intervals over 3, proved to have less significant effec on the shear distribution factors.

(6) In general, this study revealed that CHBDC overestimates the structural response of the straight composite I-girder bridges. 
(7) This study showed that CHBDC significantly underestimates the structural response of curved bridges by treating them as straight bridges when $L^{2} /$ (b.R) is not greater than 1 . This provision should be investigated.

(8) Sets of empirical expressions for shear, moment and deflection distribution factors were developed for both straight and curved bridges, yielding more economical bridge construction.

\subsection{Recommendations for Future Research}

The author recommends future research in the following areas:

1- More experimental verification studies to gather field response data for on site bridges having the same configuration and geometry of the bridges considered in this study to evaluate the compatibility of the results.

2- The study of load distribution in continuous curved composite I-girder bridges.

3- Study of the effect of dynamic loads on curved composite I-girder bridges.

4- The study of the non-linear behavior on the structural response of curved composite I-girder bridges and evaluates the critical stresses at failure.

5- Investigation on the safe limiting curvature ratio to treat a curved bridge as a straight one.

6- Investigate the effect of curvature on bracing axial forces. 


\section{REFERENCES}

American Association for State Highway and Transportation Officials, AASHTO. $1980 G u$ Specification for Horizontally Curved Highway Bridges. Washington, D.C.

American Association for State Highway and Transportation Officials, AASHTO. 1993. Gui Specification for Horizontally Curved Highway Bridges. Washington, D.C.

American Association of State Highway and Transportation Officials, AASHTO. 1996. Standa Specifications for Highway Bridges. Washington, D.C.

American Association for State Highway and Transportation Officials, AASHTO. 2003. Gui Specification for Horizontally Curved Highway Bridges. Washington, D.C.

American Association of State Highway and Transportation Officials, AASHTO. 2004. AASHT LRFD Bridge Design Specifications. Washington, D.C.

Arizumi Y., Oshiro T., and Hamado S., "Finite-Strip Analysis of Curved Composite Girders wi incomplete interaction", Computers \& Structures, 15(6): 603-612, 1982.

Bakht B., and Moses F., "Lateral Distribution Factors for Highway Bridges", Journal of Structur. Engineering ASCE, 114(8): 1785-1803, 1982.

Bell L. C., and Heins C.P., "Curved Girder Computer Manual", Report No. 30, Program Report o the Design of Curved Viaducts, University of Maryland, 1969.

Brennan P. J., and Mandel J. A., "Users Manual-Program for Three-Dimensional Analysis c Horizontally Curved Bridges", Syracuse University Report, Research Project HPR-2(111, 1973.

Brockenbrough R. L., "Distribution Factors for Curved I-Girder Bridges", ASCE Journal o Structural Engineering, 112(10): 2200-2215, 1986. 
Canadian Standard Association, "Canadian Highway Bridge Design Code", CHBDC. Etobicoke, Ontario, 2000.

Culver C. G., "Natural Frequencies of Horizontally Curved Beams", Journal of Structural Division, ASCE, 93(2): 189-203, 1967.

Davidson J. S., Keller M. A., and Yoo C. H., "Cross-frame Spacing and Parametric Effects in Horizontally Curved I-Girder Bridges", ASCE Journal of Structural Engineering, 122(9): 1089-1096, 1996.

Galambos T.V., "Tentative load factor design criteria for curved steel bridges", Research Report No. 50, School of Engineering and Applied Science, Civil Engineering Department, Washington University, St. Louis, 1978.

Grubb M. A., "Horizontally curved I-girder bridge analysis: V-load method", Transportation Research Board Record 982, National Research Council, 26-35, 1984.

Hayes C. O., Jr., Sessions L. M., and Berry A. J., "Further studies on lateral load distribution using finite element methods", Transportation Research Record, (1072), Transportation Research Board, Washington, D.C., 6-14, 1986.

Heins C. P., and Siminou J., "Preliminary Design of Curved Bridges", AISC Engineering Journal, $7(2), 50-61,1970$.

Heins C. P., and Bell L. C., "Curved Girder Bridge Analysis", Journal of Computers and Structures, 2: 785-797, 1972.

Heins C. P., and Jin J. O., "Live Load Distribution on Braced Curved I-Girders", ASCE Journal of Structural Engineering, 110(3): 523-530, 1984.

Ketchek K.F., "Discussion of Horizontally curved girders - state of the art by McManus PF et al.", Journal of Structural Division, ASCE, 95 (ST12): 2999-3001, 1969. 
Kostem C.N., and DeCastro E.S., "Effect of diaphragms on lateral load distribution in bea slab bridges", Transportation Research Record, Bridge Test, No. 645, 6-9, 1977.

Lavelle F. H., and Lasks R. J., “CUGAR2 and CUGAR3 user's Manuals”, CURT Final Repc Research Project HPR-2(111), University of Rhode Island, 1975.

Logan D., "A first course in the finite element method", $3^{\text {rd }}$ Edition, Text Book, 2002.

Mclwain A. Brett, and Laman A. Jeffrey, "Experimental Verification of Horizontally curved girder Bridge Behavior", Journal of Bridge Engineering, Vol.5, No.4, Nov. 2000.

McManus P.F., Nasir G.A., and Culver C. G., "Horizontally curved girders - state of the art Journal of Structural Division. ASCE, 95(ST5): 853-870, 1969.

Montalvao E Silva J. M., and Urgueira A., "Out-of-Plane Dynamic Response of Curve Beams", an Analytical Model. International Journal of Solids and Structures, 24(3): 27 284, 1988.

Mounir E., and Kassim M., "Finite-Element Analysis of steel I-girder Highway Bridges", Journal of Bridge Engineering, Vol. 2, No. 3, 1997.

Nakai H. and Yoo C.H., "Analysis and Design of Curved Steel Bridges", McGraw Hill Book Co., Inc., New York, N.Y, 1988.

Pandit G.S., Ceradini G., Garvarini P., and Eremin A.A., "Discussion of Horizontally curve, girders - state of the art", Journal of Structural Division, ASCE, 96(ST2): 433-436, 1970.

Poellot W. J., "Computer aided Design of Horizontally Curved girders by the V-load Method" Engineering Journal, American institute of steel construction, first quarter, 1987.

Salmon C. G., and Johnson J. E., "Steel Structures: Design and Behavior, Emphasizing Loac and Resistance Factor Design", $4^{\text {th }}$ Edition, HarperCollins College Publishers Inc., New York, N.Y., 1996. 
Schelling D., Namini A. H., and Fu C. C., "Construction Effects on Bracing on Curved I-Girders", ASCE Journal of Structural Engineering, 115(9): 2145-2165, 1989.

Sennah K., Eissa O., and Lee G., "Moment Distribution in Curved composite Syeel I-Girder Bridges at Construction Phase”, CSCE Canadian Society for Civil Engineering, 2000.

Shahawy M., and Hunag D. Z., "Analytical and field investigation of lateral load distribution in concrete slab-on-girder bridges", Structural Journal, ACI, 98 (4): 590-599, 2001.

Sheinman I., "Large Deflection of Curved Beam with Shear Deformation. Journal of Engineering Mechanics Division”, ASCE: 108(4): 636-647, 1982.

Shore S., and Wilson J. L., "Users' Manual for Static analysis of Curved Bridges (STACRB)", CURT Report No. T0173, Research Project HPR-2(111), Graduate Division of Civil \& Environmental Engineering, University of Pennsylvania, 1973.

Stegmann T.H., and Galambos T.V., "Load factor design criteria for curved steel girders of open section", Research Report 23, Civil Engineering Department, Washington University, St. Louis, 1976.

Tarshini K.M., and Frederick G.R., "Wheel load distribution in 1-girder highway bridges", Journal of Structural Engineering, ASCE, 118(5): 1285-1294, 1992.

Tene Y., Epstein M., and Sheinman T., "Dynamics of Curved Beams involving Shear Deformation. International Journal of Solids and Structures", 11(7): 827-840, 1975.

Wassef J., "Simplified Design Method of Curved Concrete slab-on-steel I-girder Bridges", M.A.Sc. thesis, Civil Engineering Dept., Ryerson University, Toronto, Ont., Canada, 2004.

Wilson E. L., and Habibullah A., "Structüral Analysis Program SAP2000", Computers \& Structures, 2002.

Yao L., “Bridge Engineering”, $1^{\text {st }}$ Edition, People's Transportation Publisher, P.R. China, 1990. 
Yoo C. H., and Littrell P. C., "Cross-Bracing Effects in Curved Stringer Bridges", ASCE Journ of Structural Engineering, 112(9): 2127-2140, 1985.

Zhang H., "Lateral Load Distribution for Curved Steel I-Girder Bridges", Ph.D. Dissertatic Florida International University, Miami, Florida, 2002.

Zokaie T., "AASHTO-LRFD Live Load Distribution Specifications", Journal of Brid Engineering, 5(2): 131-138, 2000.

Zuerick A., and Naqib R., "Horizontally Curved Steel I-Girders State-of-the-Art Analys Methods", Journal of Bridge Engineering, 4 (1): 38-47, 1999.

Zureick A., Linzell D., Leon R.T. and Burrell J., "Curved steel I-girder bridges: Experimentc and analytical studies". Engineering Structures, 22(2), Elsevier Science Ltd., 180-19( 1998. 
Table 2.1 Coefficient, C, for Various Multi-Girder Systems Assuming Equal Girder Spacing (Grubb, 1984)

\begin{tabular}{|l|c|c|c|c|c|c|c|c|c|}
\hline $\begin{array}{l}\text { Number of } \\
\text { Girders }\end{array}$ & 2 & 3 & 4 & 5 & 6 & 7 & 8 & 9 & 10 \\
\hline $\begin{array}{l}\text { Coefficient } \\
\text { C }\end{array}$ & 1 & 1 & $10 / 9$ & $5 / 4$ & $7 / 5$ & $14 / 9$ & $12 / 7$ & $15 / 8$ & $165 / 81$ \\
\hline
\end{tabular}

Table 3.1 Bridge Configurations Considered in the Parametric Study

\begin{tabular}{|c|c|c|c|c|}
\hline $\begin{array}{l}\text { Bridge } \\
\text { Width }\end{array}$ & $\begin{array}{l}\text { Deck Width } \\
\text { Wc }\end{array}$ & $\begin{array}{l}\text { Number of } \\
\text { Girders }\end{array}$ & $\begin{array}{l}\text { Number } \\
\text { Spacing }\end{array}$ & $\begin{array}{l}\text { Number of Design } \\
\text { Lanes }\end{array}$ \\
\hline 6 & 5 & 3 & 2 & 1-lane \\
\hline 7.5 & 6.5 & 3 & 2.5 & 2-lane \\
\hline 9 & 8 & 3 & 3 & 2-lane \\
\hline \multicolumn{5}{|l|}{} \\
\hline 8 & 7 & 4 & 2 & 2-lane \\
\hline 10 & 9 & 4 & 2.5 & 2-lane \\
\hline 12 & 11 & 4 & 3 & 2-lane \& 3-lane \\
\hline \multicolumn{5}{|l|}{} \\
\hline 10 & 9 & 5 & 2 & 2-lane \\
\hline 12.5 & 11.5 & 5 & 2.5 & 2-lane \& 3-lane \\
\hline 15 & 14 & 5 & 3 & 4-lane \\
\hline \multicolumn{5}{|l|}{} \\
\hline 12 & 11 & 6 & 2 & 2-lane \& 3-lane \\
\hline 15 & 14 & 6 & 2.5 & 4-lane \\
\hline \multicolumn{5}{|l|}{} \\
\hline 14 & 13 & 7 & 2 & 2-lane \& 3-lane \\
\hline
\end{tabular}


Table 3.2 Number of Design Lanes

\begin{tabular}{|l|c|}
\hline Wc & $\mathrm{n}$ \\
\hline $6.0 \mathrm{~m}$ or less & 1 \\
\hline Over $6.0 \mathrm{~m}$ to $10.0 \mathrm{~m}$ incl. & 2 \\
\hline Over $10.0 \mathrm{~m}$ to $13.5 \mathrm{~m}$ incl. & 2 or 3 \\
\hline Over $13.5 \mathrm{~m}$ to $17.0 \mathrm{~m}$ incl. & 4 \\
\hline Over $17.0 \mathrm{~m}$ to $20.5 \mathrm{~m}$ incl. & 5 \\
\hline Over $20.5 \mathrm{~m}$ to $24.0 \mathrm{~m}$ incl. & 6 \\
\hline Over $24.0 \mathrm{~m}$ to $27.5 \mathrm{~m}$ incl. & 7 \\
\hline Over $27.5 \mathrm{~m}$ & 8 \\
\hline
\end{tabular}

Table 3.3 Modification Factors for Multilane Loading

\begin{tabular}{|l|c|}
\hline Number of Loaded Design Lanes & Modification Factor \\
\hline 1 & 1.00 \\
\hline 2 & 0.90 \\
\hline 3 & 0.80 \\
\hline 4 & 0.70 \\
\hline 5 & 0.60 \\
\hline 6 or more & 0.55 \\
\hline
\end{tabular}


Table 4.1 Effect of loading conditions, extreme cases

\begin{tabular}{|c|c|c|c|c|c|c|c|c|c|c|c|}
\hline \multirow[b]{3}{*}{ No. } & \multicolumn{5}{|c|}{ Bridge Geometry } & \multicolumn{6}{|c|}{ Shear Distribution Factors } \\
\hline & \multirow{2}{*}{$\begin{array}{c}\text { span } \\
\text { L }\end{array}$} & \multirow{2}{*}{$\begin{array}{c}\begin{array}{l}\text { No. of } \\
\text { girders }\end{array} \\
\mathrm{N} \\
\end{array}$} & \multirow{2}{*}{$\begin{array}{c}\begin{array}{c}\text { girder } \\
\text { spacing }\end{array} \\
\mathrm{S} \\
\end{array}$} & \multirow{2}{*}{$L / R$} & \multirow{2}{*}{\begin{tabular}{|c|}
$\begin{array}{c}\text { No. } \\
\text { of } \\
\text { Lanes }\end{array}$ \\
$\mathrm{n}$ \\
\end{tabular}} & \multicolumn{3}{|c|}{ Exterior girder } & \multicolumn{3}{|c|}{ Middle girder } \\
\hline & & & & & & $(\mathrm{LDF})_{\mathrm{FL} . \mathrm{ext}}$ & $(\mathrm{LDF})_{\mathrm{PL1} . \mathrm{ext}}$ & $(\mathrm{LDF})_{\mathrm{PL2.ext}}$ & $(\mathrm{LDF})_{\mathrm{FL} . \mathrm{ext}}$ & $(\mathrm{LDF})_{\mathrm{PL} 1 . e \times 1}$ & $(\mathrm{LDF})_{\mathrm{PL} 2 . \mathrm{ext}}$ \\
\hline 1 & 10 & 5 & 3 & 0 & 4 & 1.005 & 1.285 & 1.324 & 1.302 & 1.625 & 1.727 \\
\hline 2 & 10 & 5 & 3 & 0.1 & 4 & 1.029 & 1.326 & 1.358 & 1.286 & 1.584 & 1.641 \\
\hline 3 & 10 & 5 & 3 & 0.2 & 4 & 1,049 & 1.356 & 1.377 & 1.275 & 1.562 & 1.583 \\
\hline 4 & 10 & 5 & 3 & 0.3 & 4 & 1.071 & 1.381 & 1.395 & 1.278 & 1.558 & 1.583 \\
\hline 5 & 10 & 6 & 2.5 & 0 & 4 & 0.891 & 1.176 & 1.216 & 1.448 & 1.869 & 1.883 \\
\hline 6 & 10 & 6 & 2.5 & 0.1 & 4 & 0.940 & 1.206 & 1.247 & 1.401 & 1.818 & 1.794 \\
\hline 7 & 10 & 6 & 2.5 & 0.2 & 4 & 0.974 & 1.255 & 1.287 & 1.372 & 1.783 & 1.740 \\
\hline 8 & 10 & 6 & 2.5 & 0.3 & 4 & 0.995 & 1.279 & 1.303 & 1.376 & 1.792 & 1.746 \\
\hline 9 & 15 & 5 & 3 & 0 & 4 & 1.081 & 1.274 & 1.272 & 1.229 & 1.360 & 1.310 \\
\hline 10 & 15 & 5 & 3 & 0.1 & 4 & 1.115 & 1.312 & 1.292 & 1.216 & 1.334 & 1.270 \\
\hline 11 & 15 & 5 & 3 & 0.2 & 4 & 1.134 & 1.327 & 1.292 & 1.205 & 1.314 & 1.242 \\
\hline 12 & 15 & 5 & 3 & 0.3 & 4 & 1.158 & 1.351 & 1.307 & 1.216 & 1.300 & 1.218 \\
\hline 13 & 15 & 6 & 2.5 & 0 & 4 & 0.894 & 1.064 & 1.070 & 1.354 & 1.551 & 1.508 \\
\hline 14 & 15 & 6 & 2.5 & 0.1 & 4 & 0.931 & 1.107 & 1.097 & 1.343 & 1.534 & 1.475 \\
\hline 15 & 15 & 6 & 2.5 & 0.2 & 4 & 0.940 & 1.105 & 1.087 & 1.360 & 1.561 & 1.491 \\
\hline 16 & 15 & 6 & 2.5 & 0.3 & 4 & 0.976 & 1.146 & 1.112 & 1.341 & 1.531 & 1.458 \\
\hline
\end{tabular}

FL: Full load (4 trucks loaded in 4 lanes) PL1: Partial load 1 (3 trucks loaded in 4 lanes) PL2: Partial load 2 (2 trucks loaded in 4 lanes) 
Table 4.2 Value of $\boldsymbol{F}$ for Longitudinal Shear for Straight Bridges (ULS and SLS)

\begin{tabular}{|c|c|c|}
\hline Number of Lanes, $n$ & Exterior girder & Eq. No. \\
\hline 1 & $\left(1.69+4.74 \mathrm{~L}^{-1.93}\right)^{-2.39}$ & 4.1 \\
\hline 2 & $(3.0+0.0024 \mathrm{~L} \mathrm{0.92})^{-1.69}$ & 4.2 \\
\hline 3 & $(4.9+2.4 \mathrm{~L} \mathrm{-0.6})^{-1.32}$ & 4.3 \\
\hline 4 & $(5.7-0.54 \mathrm{~L}-3)^{-1.4}$ & 4.4 \\
\hline
\end{tabular}

\begin{tabular}{|c|c|c|}
\hline Number of Lanes, $n$ & Middle girder & Eq. No. \\
\hline 1 & $\left(2.17+4.1 \mathrm{~L}^{-5.9}\right)^{-1.73}$ & 4.5 \\
\hline 2 & $\left(2.38+1.21 \mathrm{~L}^{-2.25}\right)^{-1.82}$ & 4.6 \\
\hline 3 & $\left(2.545+1.99 \mathrm{~L}^{-6.05}\right)^{-2.189}$ & 4.7 \\
\hline 4 & $\left(2.89+1.95 \mathrm{~L}^{-6}\right)^{-2}$ & 4.8 \\
\hline
\end{tabular}


Table 4.3 Value of $F$ for Longitudinal Shear for Straight Bridges (FLS)

\begin{tabular}{|c|c|c|}
\hline Number of Lanes, $n$ & Exterior girder & Eq. No. \\
\hline 1 & $\left(1.935+5 \mathrm{~L}^{-1.53}\right)^{-2.81}$ & 4.9 \\
\hline 2 & $\left(1.68+4.04 \mathrm{~L}^{-1.09}\right)^{-2.38}$ & 4.10 \\
\hline 3 & $\left(1.918+0.62 \mathrm{~L}^{-0.045}\right)^{-8.85}$ & 4.11 \\
\hline 4 & $\left(1.88-0.63 \mathrm{~L}^{-0.016}\right)^{-8.9}$ & 4.12 \\
\hline
\end{tabular}

\begin{tabular}{|c|c|c|}
\hline Number of Lanes, $n$ & Middle girder & Eq. No. \\
\hline 1 & $\left(2.17+4.1 \mathrm{~L}^{-5.9}\right)^{-1.73}$ & 4.13 \\
\hline 2 & $\left(1.8+3.4 \mathrm{~L}^{-6.15}\right)^{-2.13}$ & 4.14 \\
\hline 3 & $\left(1.95+9 \mathrm{~L}^{-8}\right)^{-1.89}$ & 4.15 \\
\hline 4 & $\left(2.14+8.9 \mathbf{L}^{-8}\right)^{-1.87}$ & 4.16 \\
\hline
\end{tabular}


Table 4.4 Value of $\boldsymbol{F}$ for Longitudinal Shear for Curved Bridges (ULS and SLS)

\begin{tabular}{|c|c|c}
\hline $\begin{array}{c}\text { No. of } \\
\text { Lanes, } \\
n\end{array}$ & Exterior girder & Eq \\
\hline 1 & $\left(1.69+4.74 \mathrm{~L}^{-1.93}\right)^{-2.39} \times\left[1+2.15(\mathrm{~L} / \mathrm{R})^{1.5}-1.1(\mathrm{~L} / \mathrm{R})^{9.5}\right]$ & 4. \\
\hline 2 & $\left(3.0+0.0024 \mathrm{~L}^{0.92}\right)^{-1.69} \times\left[1+4(\mathrm{~L} / \mathrm{R})^{2.15}-3.1(\mathrm{~L} / \mathrm{R})^{2.7}\right]$ & 4 \\
\hline 3 & $\left(4.9+2.4 \mathrm{~L}^{-0.6}\right)^{-1.32} \times\left[1+3(\mathrm{~L} / \mathrm{R})^{0.86}-2.4(\mathrm{~L} / \mathrm{R})^{0.79}\right]$ & 4. \\
\hline 4 & $\left(5.7-0.54 \mathrm{~L}^{-3}\right)^{-1.4} \times\left[1+2.9(\mathrm{~L} / \mathrm{R})^{0.94}-2.51(\mathrm{~L} / \mathrm{R})^{0.9}\right]$ & 4 \\
\hline
\end{tabular}

\begin{tabular}{|c|c|c}
\hline $\begin{array}{c}\text { No. of } \\
\text { Lanes, } \\
n\end{array}$ & Middle girder & Eq. \\
\hline 1 & $\left(2.17+4.1 \mathrm{~L}^{-5.9}\right)^{-1.73} \times\left[1+1.3(\mathrm{~L} / \mathrm{R})^{4.5}-0.178(\mathrm{~L} / \mathrm{R})^{0.42}\right]$ & $4 .$. \\
\hline 2 & $\left(2.38+1.21 \mathrm{~L}^{-2.25}\right)^{-1.82} \times\left[1+1.2(\mathrm{~L} / \mathrm{R})^{4.7}-0.19(\mathrm{~L} / \mathrm{R})^{0.41}\right]$ & $4 .$. \\
\hline 3 & $\left(2.545+1.99 \mathrm{~L}^{-6.05}\right)^{-2.189} \times\left[1+1.6(\mathrm{~L} / \mathrm{R})^{3.1}-0.16(\mathrm{~L} / \mathrm{R})^{0.59}\right]$ & $4 .$. \\
\hline 4 & $\left(2.89+1.95 \mathrm{~L}^{-6}\right)^{-2} \times\left[1+0.67(\mathrm{~L} / \mathrm{R})^{0.09}-0.75(\mathrm{~L} / \mathrm{R})^{0.12}\right]$ & $4 .$. \\
\hline
\end{tabular}

\begin{tabular}{|c|c|c}
\hline $\begin{array}{c}\text { No. of } \\
\text { Lanes, } \\
\mathrm{n}\end{array}$ & Interior girder & Eq. \\
\hline 1 & $\left(0.255+14 \mathrm{~L}^{-0.085}\right)^{-0.53} \times\left[1-7.7(\mathrm{~L} / \mathrm{R})^{3.15}+5.1(\mathrm{~L} / \mathrm{R})^{3}\right]$ & 4.2 \\
\hline 2 & $\left(-3.403+5.78 \mathrm{~L}^{-0.0125}\right)^{-2.32} \times\left[1-3.9(\mathrm{~L} / \mathrm{R})^{0.57}+3.79(\mathrm{~L} / \mathrm{R})^{0.57}\right]$ & 4.2 \\
\hline 3 & $\left(-2.82+6.33 \mathrm{~L}^{-0.019}\right)^{-1.89} \times\left[1-4.05(\mathrm{~L} / \mathrm{R})^{0.84}+3.71(\mathrm{~L} / \mathrm{R})^{0.775}\right]$ & 4.2 \\
\hline 4 & $\left(-2.33+6.6 \mathrm{~L}^{-0.001}\right)^{-1.64} \times\left[1-3.62(\mathrm{~L} / \mathrm{R})^{0.46}+3.62(\mathrm{~L} / \mathrm{R})^{0.46}\right]$ & 4.2 \\
\hline
\end{tabular}


Table 4.5 Value of $\boldsymbol{F}$ for Longitudinal Shear for Curved Bridges (FLS)

\begin{tabular}{|c|c|c|}
\hline $\begin{array}{c}\text { No. of } \\
\text { Lanes, } \\
n\end{array}$ & Exterior girder & Eq. No. \\
\hline 1 & $\left(1.935+5 \mathrm{~L}^{-1.53}\right)^{-2.81} \times\left[1+18.66(\mathrm{~L} / \mathrm{R})^{6.5}+1.7(\mathrm{~L} / \mathrm{R})^{0.95}\right]$ & 4.29 \\
\hline 2 & $\left(1.68+4.04 \mathrm{~L}^{-1.09}\right)^{-2.38} \times\left[1-0.449(\mathrm{~L} / \mathrm{R})^{4.31}-10.16(\mathrm{~L} / \mathrm{R})^{7.99}\right]$ & 4.30 \\
\hline 3 & $\left(1.918+0.62 \mathrm{~L}^{-0.045}\right)^{-8.85} \times\left[1-2.6(\mathrm{~L} / \mathrm{R})^{4.2}+(\mathrm{L} / \mathrm{R})^{1.6}\right]$ & 4.31 \\
\hline 4 & $\left(1.88-0.63 \mathrm{~L}^{-0.016}\right)^{-8.9} \times\left[1-0.95(\mathrm{~L} / \mathrm{R})^{1.29}+1.045(\mathrm{~L} / \mathrm{R})^{1.16}\right]$ & 4.32 \\
\hline
\end{tabular}

\begin{tabular}{|c|c|c|}
\hline $\begin{array}{c}\text { Lo. of } \\
\mathrm{n}\end{array}$ & Middle girder & Eq. No. \\
\hline 1 & $\left(2.17+4.1 \mathrm{~L}^{-5.9}\right)^{-1.73} \times\left[1-0.13(\mathrm{~L} / \mathrm{R})^{0.25}+0.2(\mathrm{~L} / \mathrm{R})^{5.13}\right]$ & 4.33 \\
\hline 2 & $\left(1.8+3.4 \mathrm{~L}^{-6.15}\right)^{-2.13} \times\left[1-0.22(\mathrm{~L} / \mathrm{R})^{0.32}+400(\mathrm{~L} / \mathrm{R})^{23.2}\right]$ & 4.34 \\
\hline 3 & $\left(1.95+9 \mathrm{~L}^{-8}\right)^{-1.89} \times\left[1+0.99(\mathrm{~L} / \mathrm{R})^{0.07}-1.06(\mathrm{~L} / \mathrm{R})^{0.06}\right]$ & 4.35 \\
\hline 4 & $\left(2.14+8.9 \mathrm{~L}^{-8}\right)^{-1.87} \times\left[1-0.2(\mathrm{~L} / \mathrm{R})^{0.41}+0.02(\mathrm{~L} / \mathrm{R})^{0.5}\right]$ & 4.36 \\
\hline
\end{tabular}

\begin{tabular}{|c|c|c|}
\hline $\begin{array}{c}\text { Lo. of } \\
n\end{array}$ & Interior girder & Eq. No. \\
\hline 1 & $\left(0.33+13.95 \mathrm{~L}^{-0.2}\right)^{-0.95} \times\left[1-188.6(\mathrm{~L} / \mathrm{R})^{5.73}+223.65(\mathrm{~L} / \mathrm{R})^{6.38}\right]$ & 4.37 \\
\hline 2 & $\left(2.69+3.5 \mathrm{~L}^{-0.76}\right)^{-1.33} \times\left[1-8.73(\mathrm{~L} / \mathrm{R})^{2.509}+7.38(\mathrm{~L} / \mathrm{R})^{2.42}\right]$ & 4.38 \\
\hline 3 & $\left(2.1+6.1 \mathrm{~L}^{-0.94}\right)^{-1.8} \times\left[1+3.49(\mathrm{~L} / \mathrm{R})^{0.33}-3.6(\mathrm{~L} / \mathrm{R})^{0.363}\right]$ & 4.39 \\
\hline 4 & $\left(3.06+3.3 \mathrm{~L}^{-1.1}\right)^{-1.51} \times\left[1+3.45(\mathrm{~L} / \mathrm{R})^{1.64}-3.9(\mathrm{~L} / \mathrm{R})^{1.74}\right]$ & 4.40 \\
\hline
\end{tabular}


Table 4.6 Value of $\boldsymbol{F}$ for Longitudinal Moment for Straight Bridges (ULS and SLS)

\begin{tabular}{|c|c|c|}
\hline Number of Lanes, $n$ & Exterior girder & Eq. No. \\
\hline 1 & $(3.89-2.38 / \mathrm{L})$ & 4.41 \\
\hline 2 & $(7.4-6.4 / \mathrm{L})$ & 4.42 \\
\hline 3 & $(8.01+10.4 / \mathrm{L})$ & 4.43 \\
\hline 4 & $(10.2+4.5 / \mathrm{L})$ & 4.44 \\
\hline
\end{tabular}

\begin{tabular}{|c|c|c|}
\hline Number of Lanes, $n$ & Middle girder & Eq. No. \\
\hline 1 & $(6.06-6.83 / \mathrm{L})$ & 4.45 \\
\hline 2 & $(8.7-32.5 / \mathrm{L})$ & 4.46 \\
\hline 3 & $(11.95-21.1 / \mathrm{L})$ & 4.47 \\
\hline 4 & $(15.0-19.5 / \mathrm{L})$ & 4.48 \\
\hline
\end{tabular}


Table 4.7 Value of $\boldsymbol{F}$ for Longitudinal Moment for Straight Bridges (FLS)

\begin{tabular}{|c|c|c|}
\hline Number of Lanes, $n$ & Exterior girder & Eq. No. \\
\hline 1 & $(5.58+3.46 / \mathrm{L})$ & 4.49 \\
\hline 2 & $(3.9-20.5 / \mathrm{L})$ & 4.50 \\
\hline 3 & $(2.8-2.7 / \mathrm{L})$ & 4.51 \\
\hline 4 & $(4.35-19 / \mathrm{L})$ & 4.52 \\
\hline
\end{tabular}

\begin{tabular}{|c|c|c|}
\hline Number of Lanes, $n$ & Middle girder & Eq. No. \\
\hline 1 & $(6.02-5.98 / \mathrm{L})$ & 4.53 \\
\hline 2 & $(9.0-43.21 / \mathrm{L})$ & 4.54 \\
\hline 3 & $(8.6-25.3 / \mathrm{L})$ & 4.55 \\
\hline 4 & $(16.3-95.8 / \mathrm{L})$ & 4.56 \\
\hline
\end{tabular}


Table 4.8 Value of $F$ for Deflection for Straight Bridges (ULS and SLS)

\begin{tabular}{|c|c|c|}
\hline Number of Lanes, $\mathbf{n}$ & Exterior girder & Eq. No. \\
\hline 1 & $(4.15-4.07 / \mathrm{L})$ & 4.57 \\
\hline 2 & $(7.6-7.7 / \mathrm{L})$ & 4.58 \\
\hline 3 & $(8.5+5.5 / \mathrm{L})$ & 4.59 \\
\hline 4 & $(10.1-2.1 / \mathrm{L})$ & 4.60 \\
\hline
\end{tabular}

\begin{tabular}{|c|c|c|}
\hline Number of Lanes, $n$ & Middle girder & Eq. No. \\
\hline 1 & $(6.05-5.94 / L)$ & 4.61 \\
\hline 2 & $(8.8-28.1 / \mathrm{L})$ & 4.62 \\
\hline 3 & $(12.2-21.5 / \mathrm{L})$ & 4.63 \\
\hline 4 & $(15.25-23.2 / \mathrm{L})$ & 4.64 \\
\hline
\end{tabular}


Table 4.9 Value of $\boldsymbol{F}$ for Deflection for Straight Bridges (FLS)

\begin{tabular}{|c|c|c|}
\hline Number of Lanes, $n$ & Exterior girder & Eq. No. \\
\hline 1 & $(5.78+2.23 / \mathrm{L})$ & 4.65 \\
\hline 2 & $(3.15-12.5 / \mathrm{L})$ & 4.66 \\
\hline 3 & $(3.0-4.0 / \mathrm{L})$ & 4.67 \\
\hline 4 & $(4.0-22 / \mathrm{L})$ & 4.68 \\
\hline
\end{tabular}

\begin{tabular}{|c|c|c|}
\hline Number of Lanes, $n$ & Middle girder & Eq. No. \\
\hline 1 & $(6.05-5.94 / \mathrm{L})$ & 4.69 \\
\hline 2 & $(9.0-38.2 / \mathrm{L})$ & 4.70 \\
\hline 3 & $(10.6-60.0 / \mathrm{L})$ & 4.71 \\
\hline 4 & $(16.4-93.5 / \mathrm{L})$ & 4.72 \\
\hline
\end{tabular}




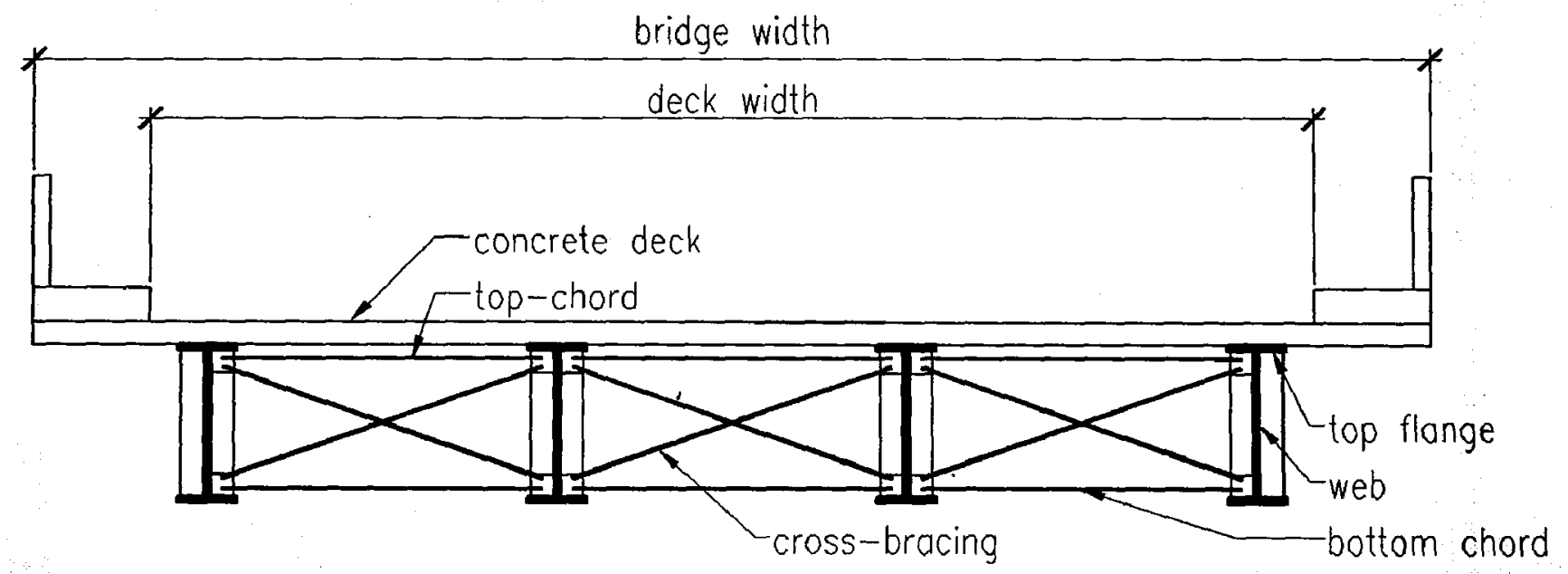

Figure 1. 1 Typical I-Girder Bridge Cross-Section 


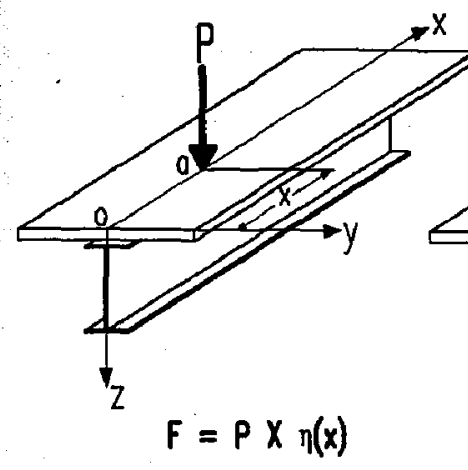

a) Single Girder

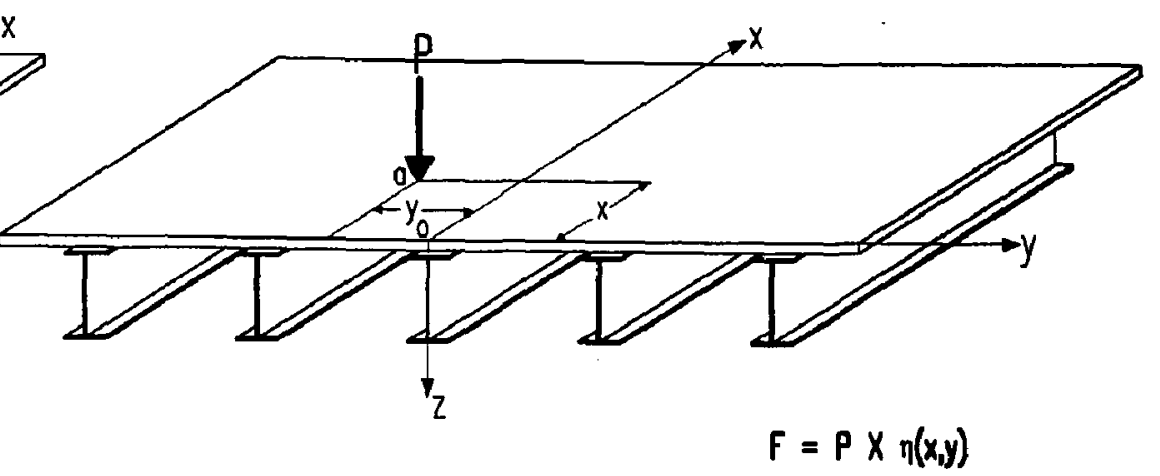

b) Multi-girder bridge

Figure 2. 1 Single and Multi-girder System under Concentrated Live Load P

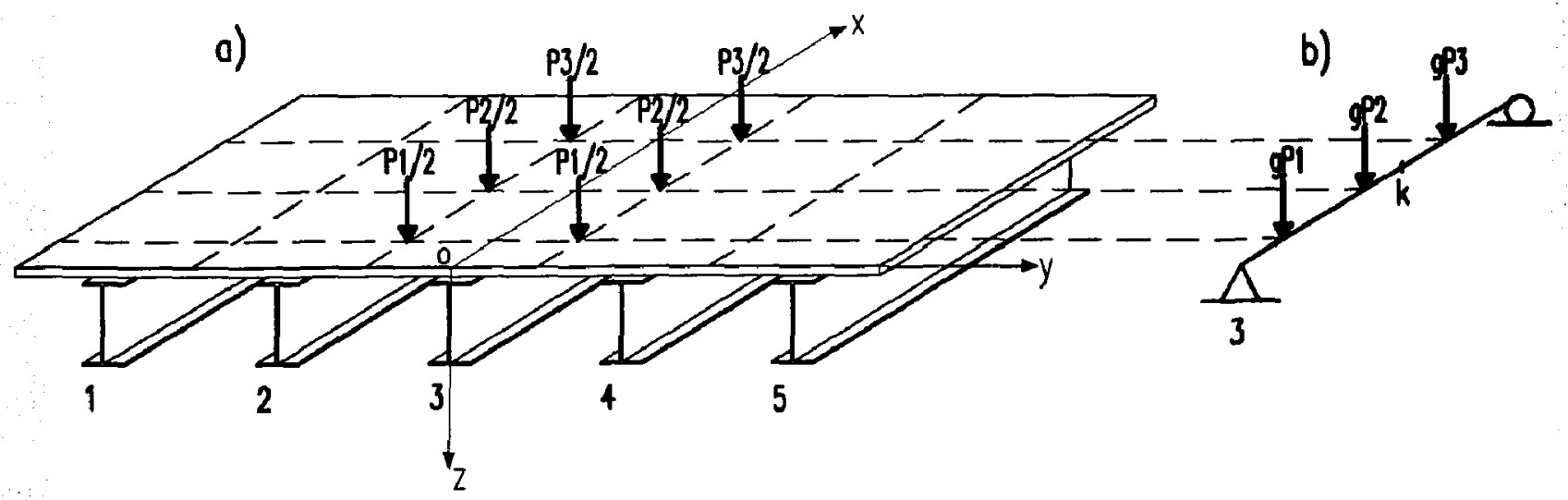

Figure 2. 2 Lateral Load Distribution of Truck Axle Load 

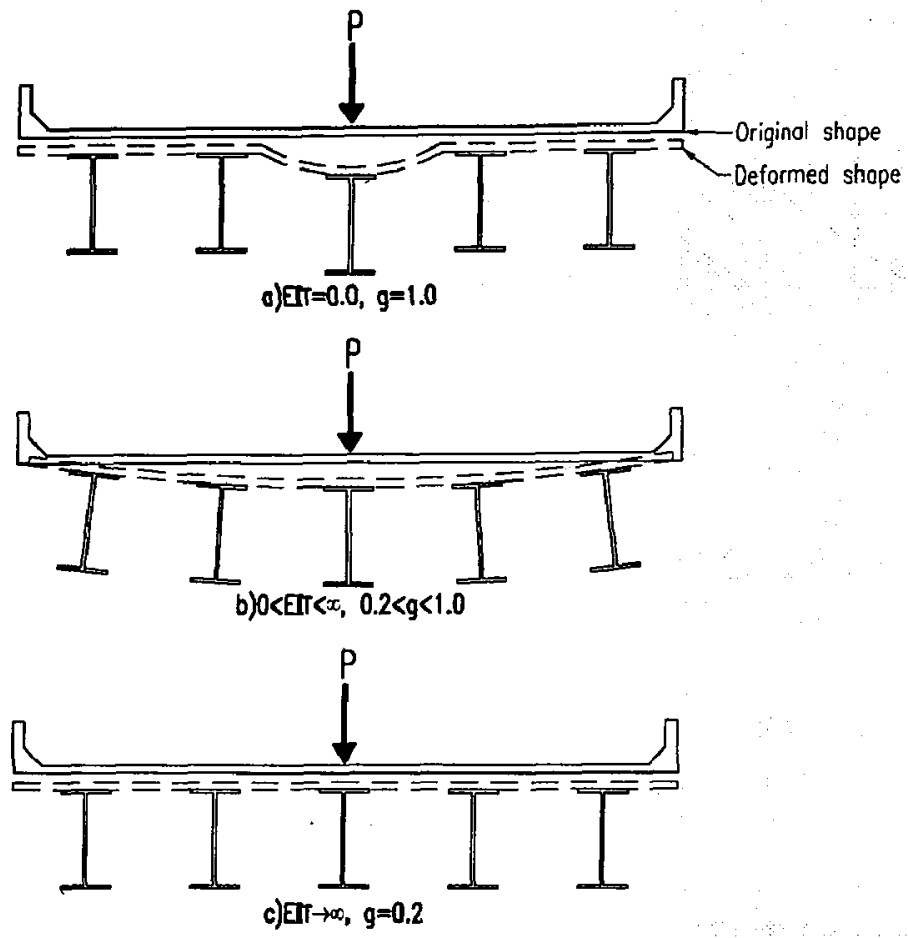

Figure 2.3 Girder Deflection with Different Transverse Stiffness

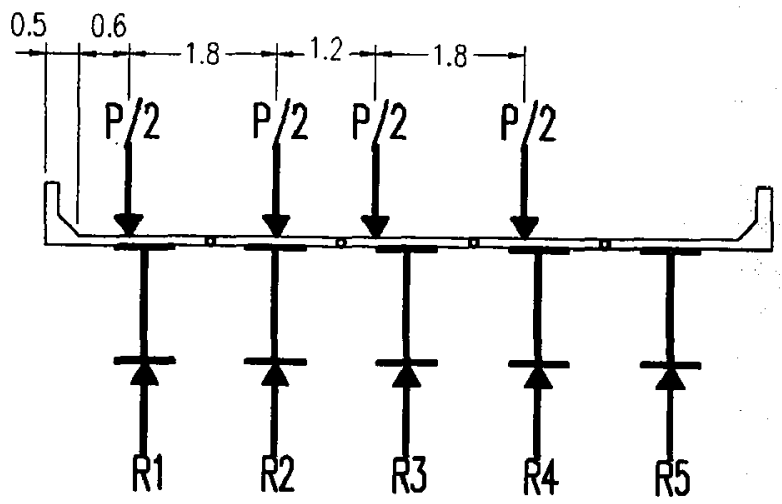

Figure 2. 4 Free Body Diagram of Lever Rule method 
a)

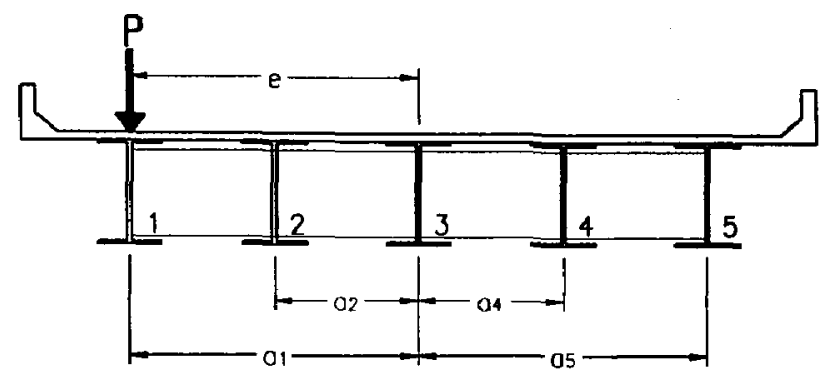

b)

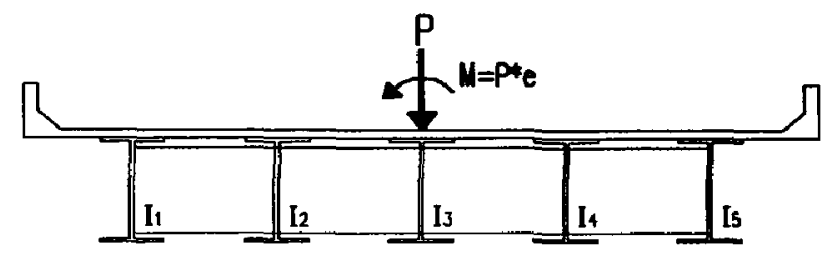

c)

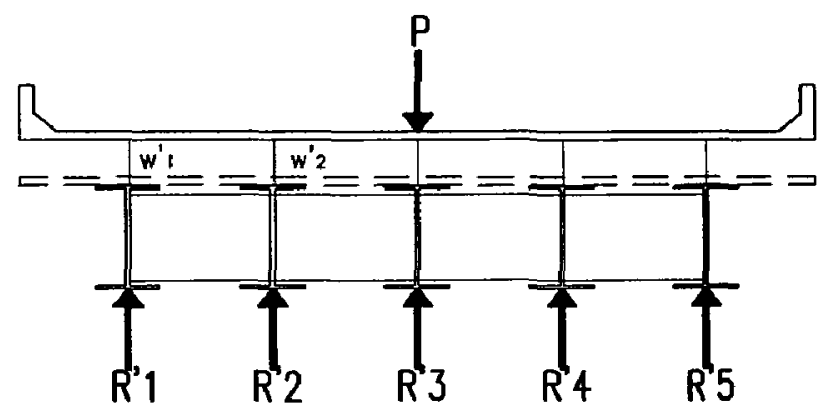

d)

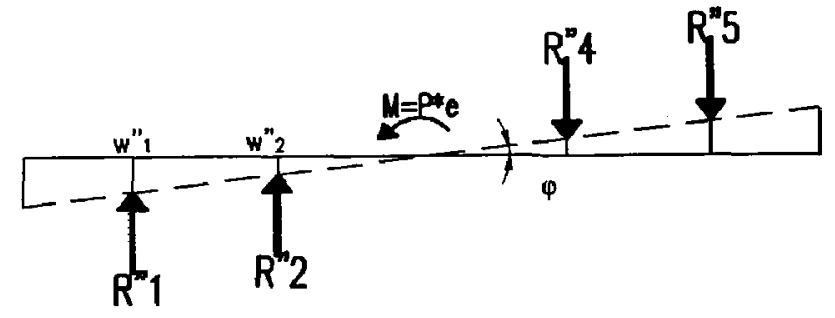

e)

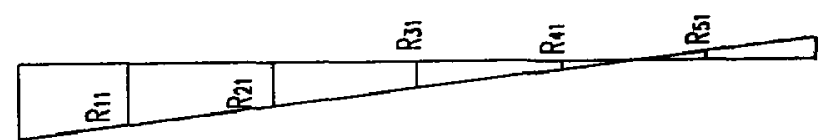

Figure 2. 5 Load Distribution under Eccentric Load 


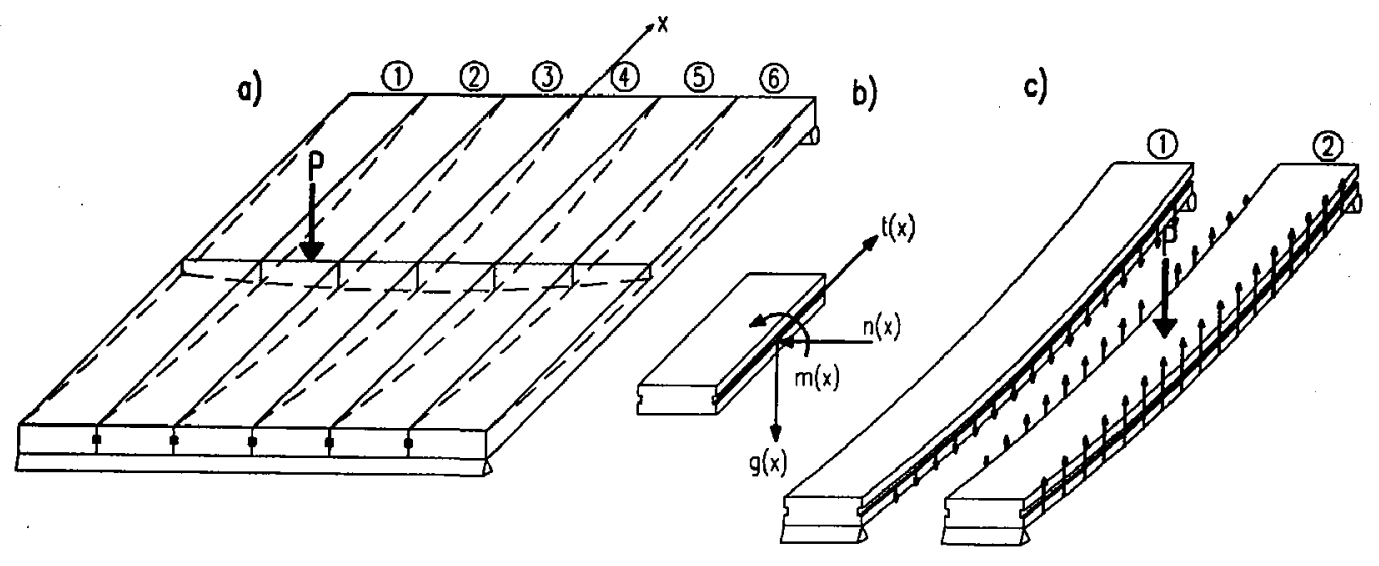

Figure 2. 6 Free Body Diagram of a Hinged slab Bridge under Concentrated Load

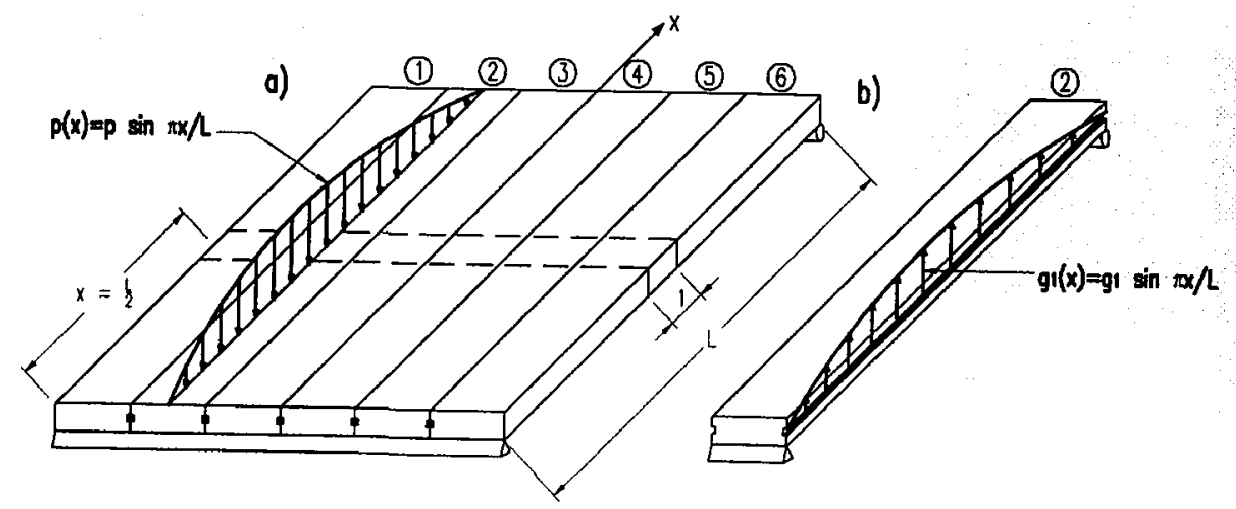

Figure 2. 7 Free Body Diagram of a Hinged slab Bridge under Sinusoidal Load 
a)

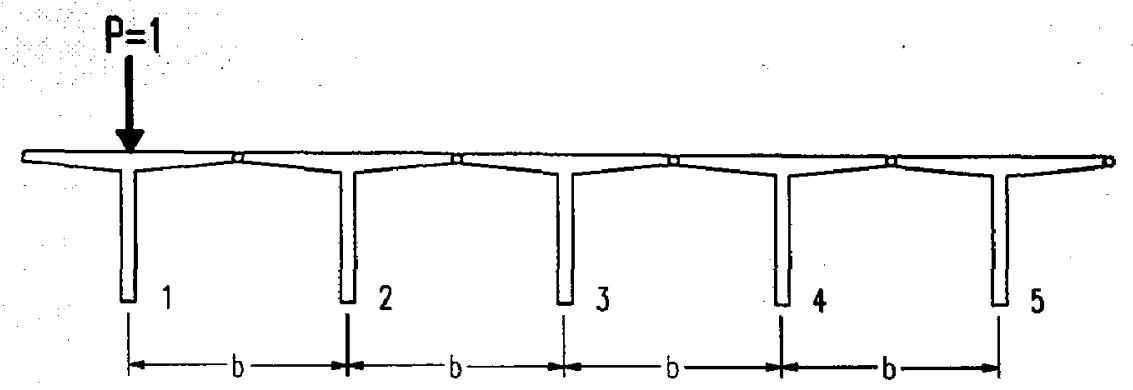

b)

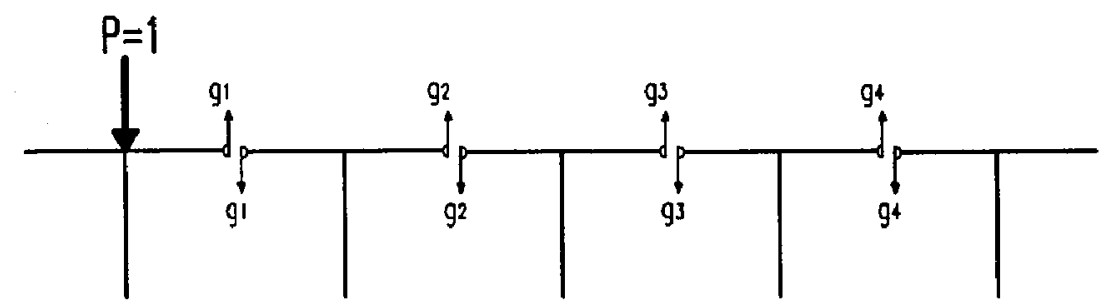

c)
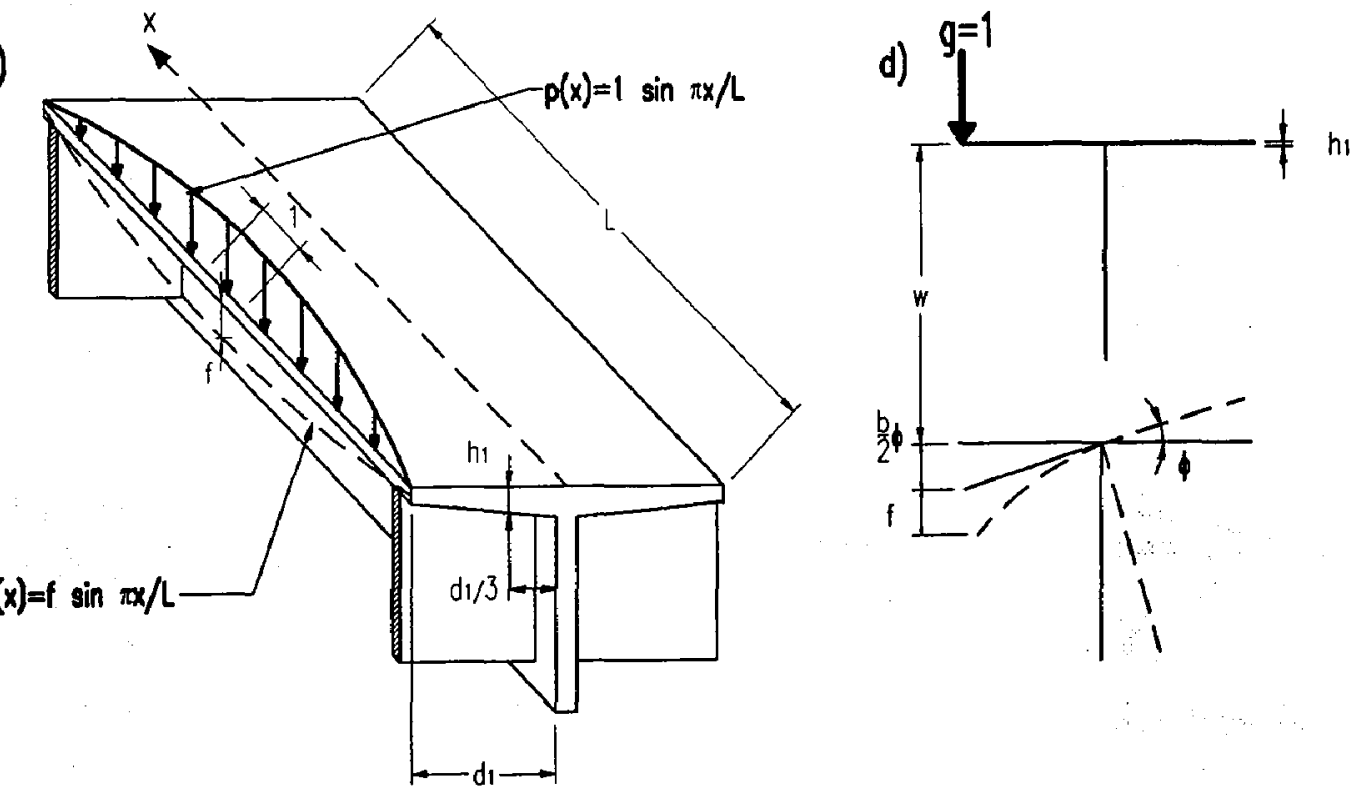

Figure 2. 8 Free Body Diagram for Hinged T-shaped Girder Bridge 
o)

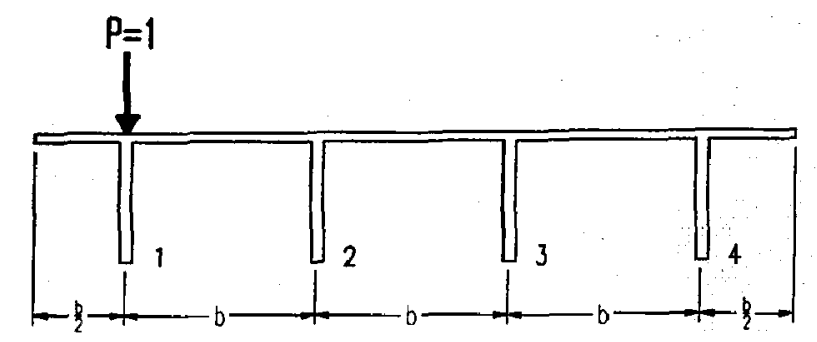

b)

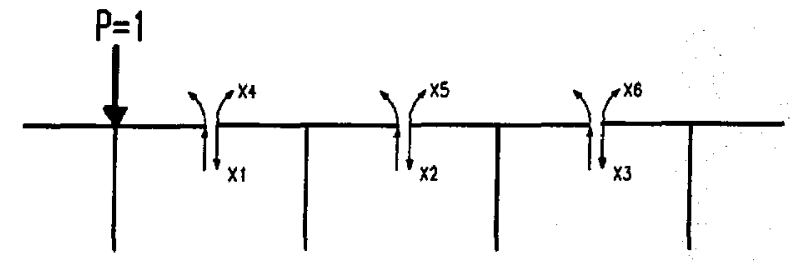

c)

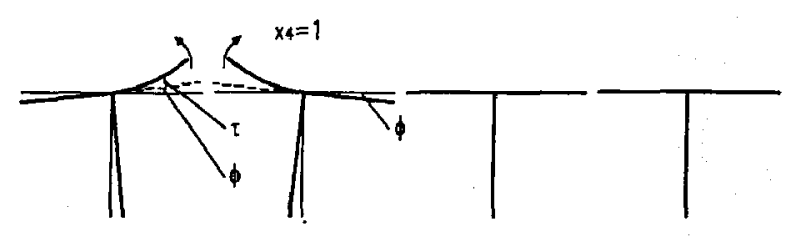

Figure 2.9 Free Body Diagram of Fixed Joint Girder Bridge
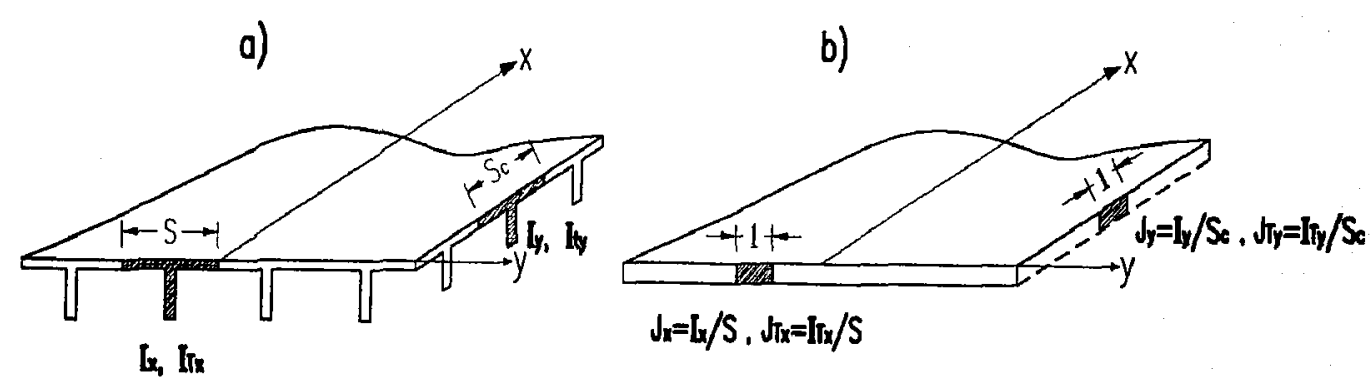

a) Real Structure

b) Analogized Equivalent

Orthotropic Plate

Figure 2. 10 Real Structure and Orthotropic Plate Analogy 


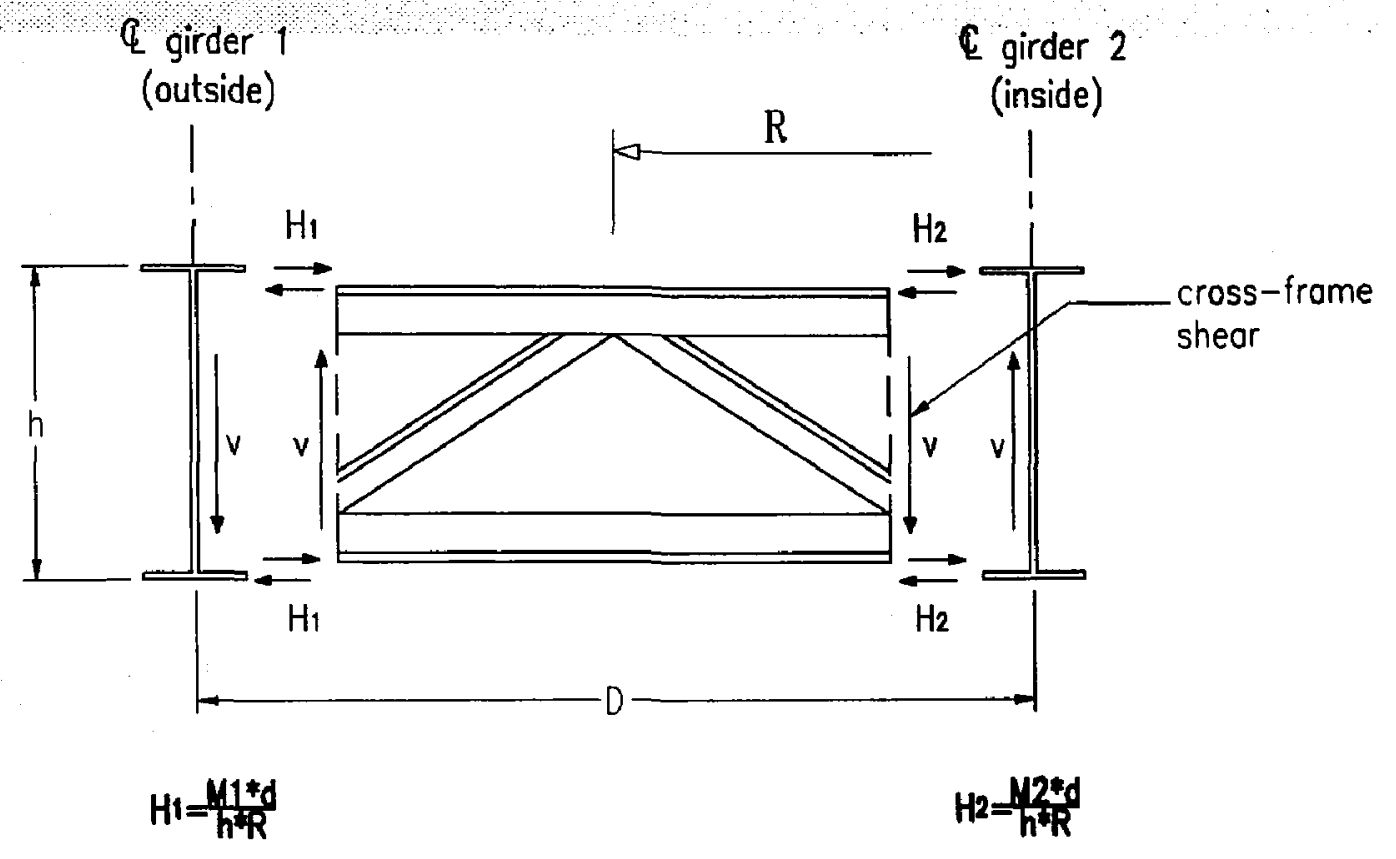

Figure 2. 11 V-Load on Girder

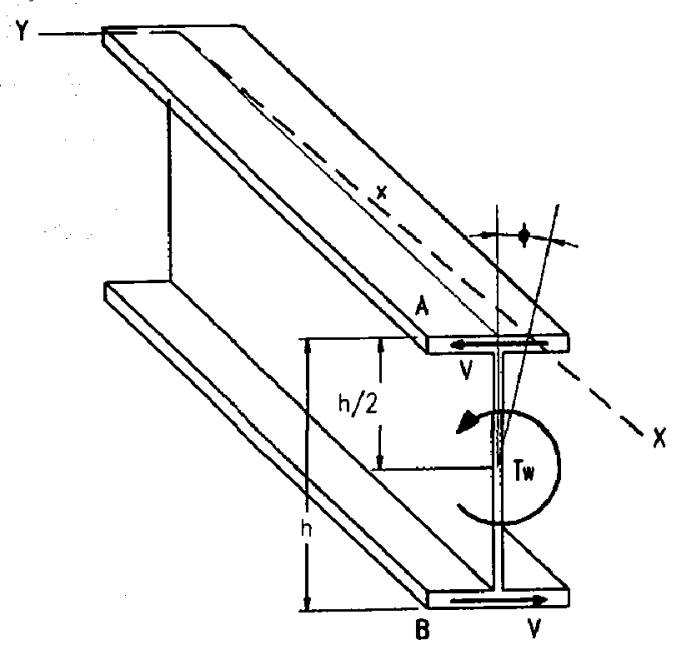

Figure 2. 12 Effect of Warping Moment Applied to I-Girder 


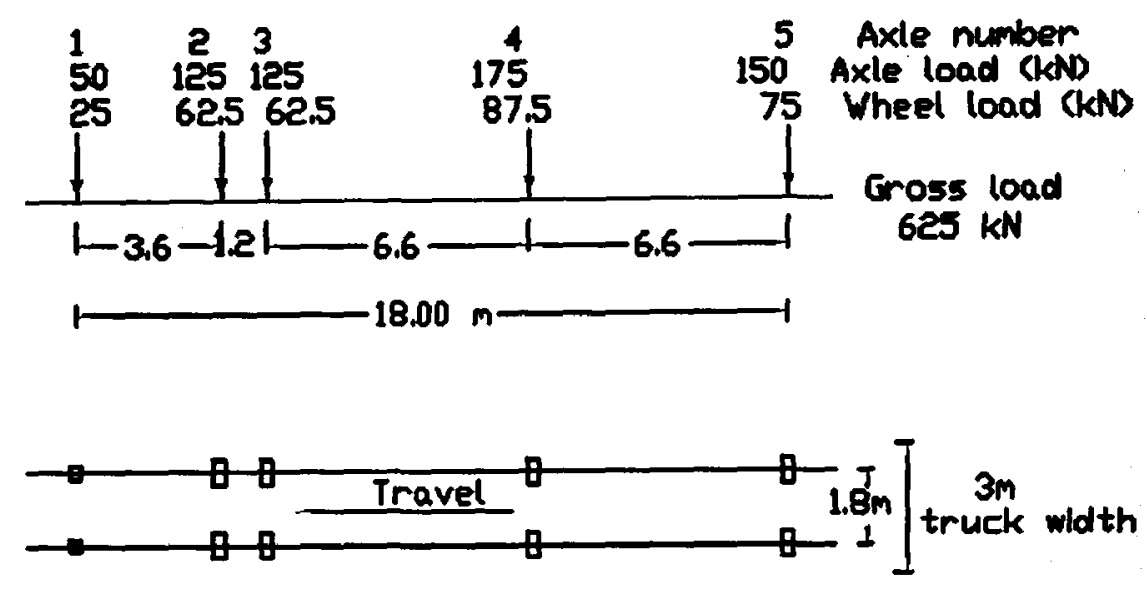

(a) CHBDC truck looding

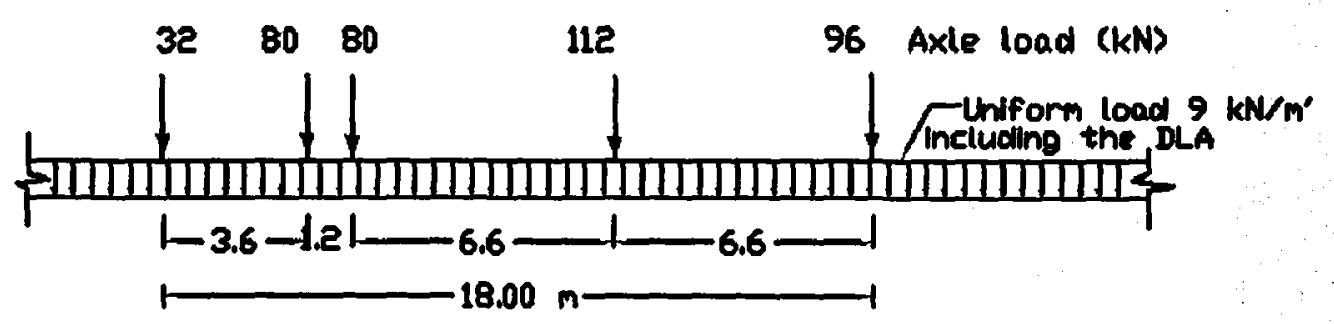

(b) CHBDC lane loading

Figure 3. 1 Canadian Highway Bridge Design Codes' Truck and Lane loadings 
Level 1

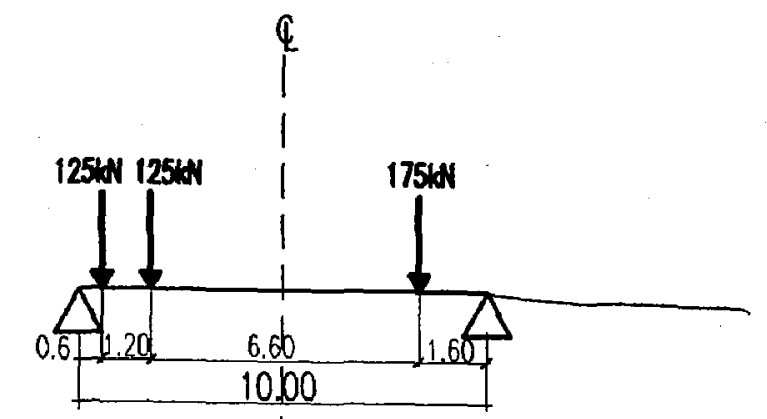

Level 2
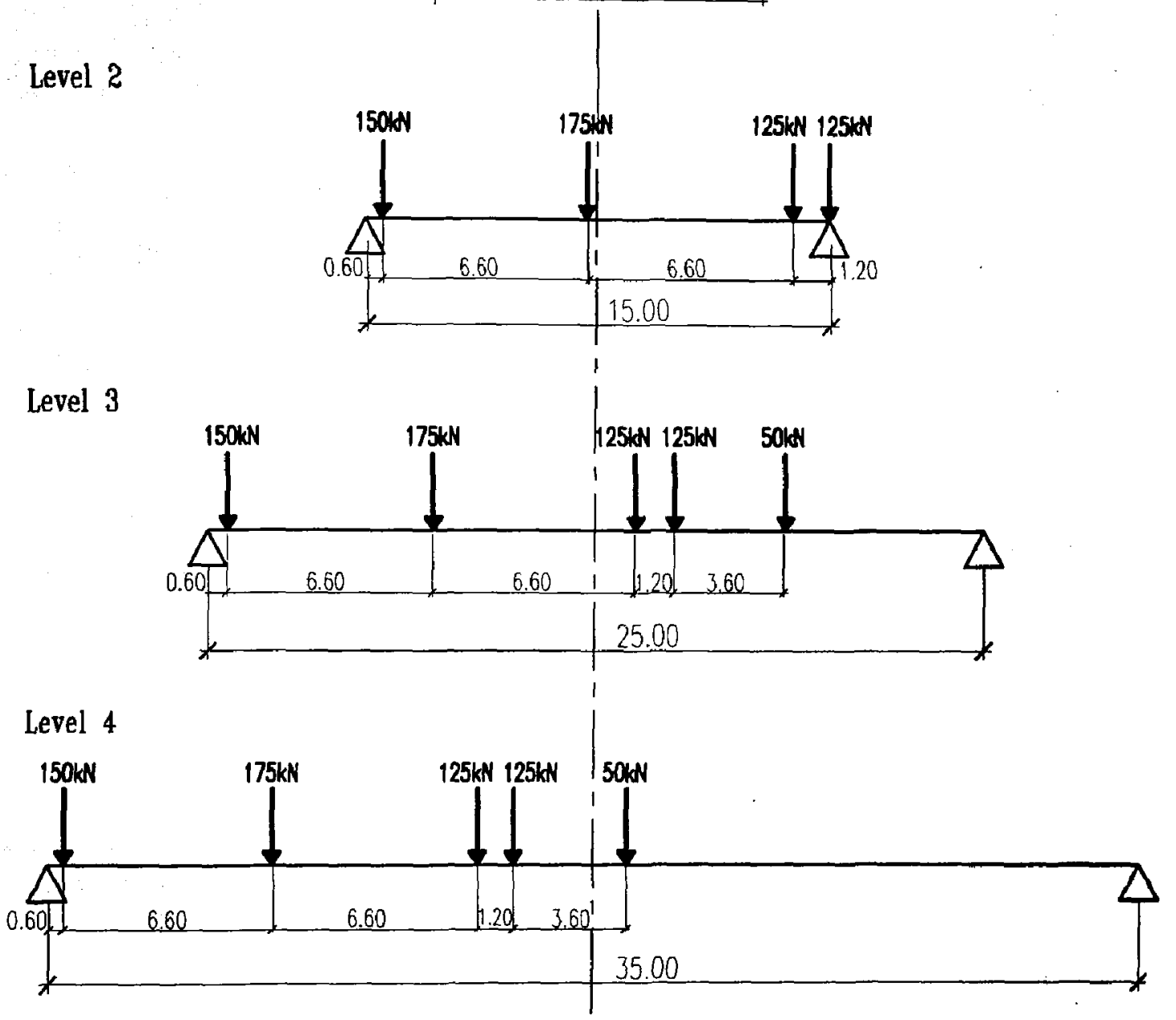

Dimensions are in meters

Figure 3. 2 Maximum Shear Locations 
Level 1

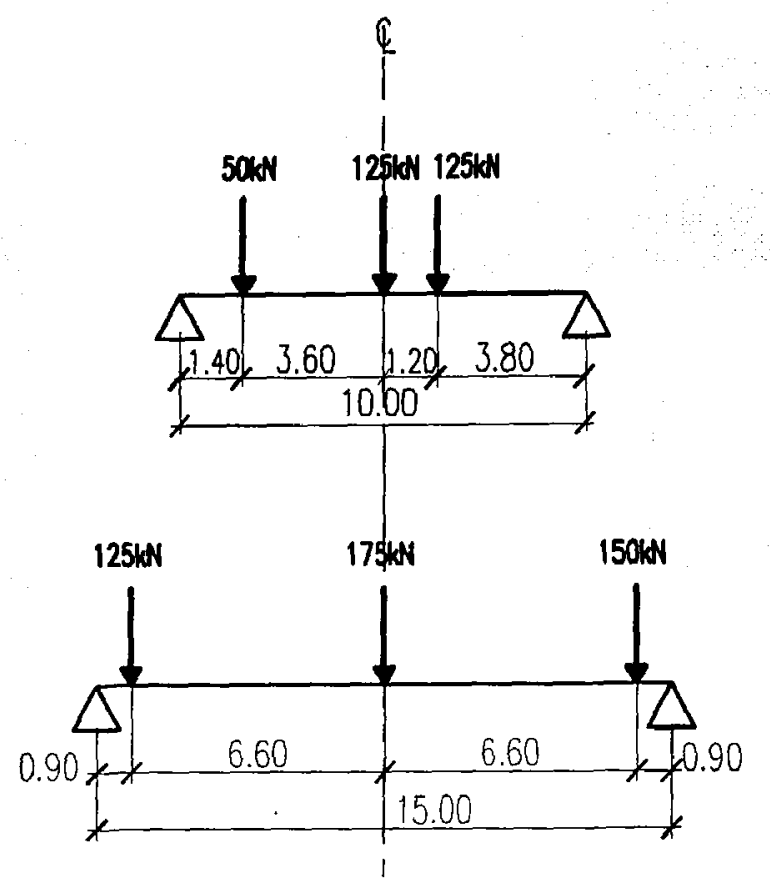

level 2

Level 3
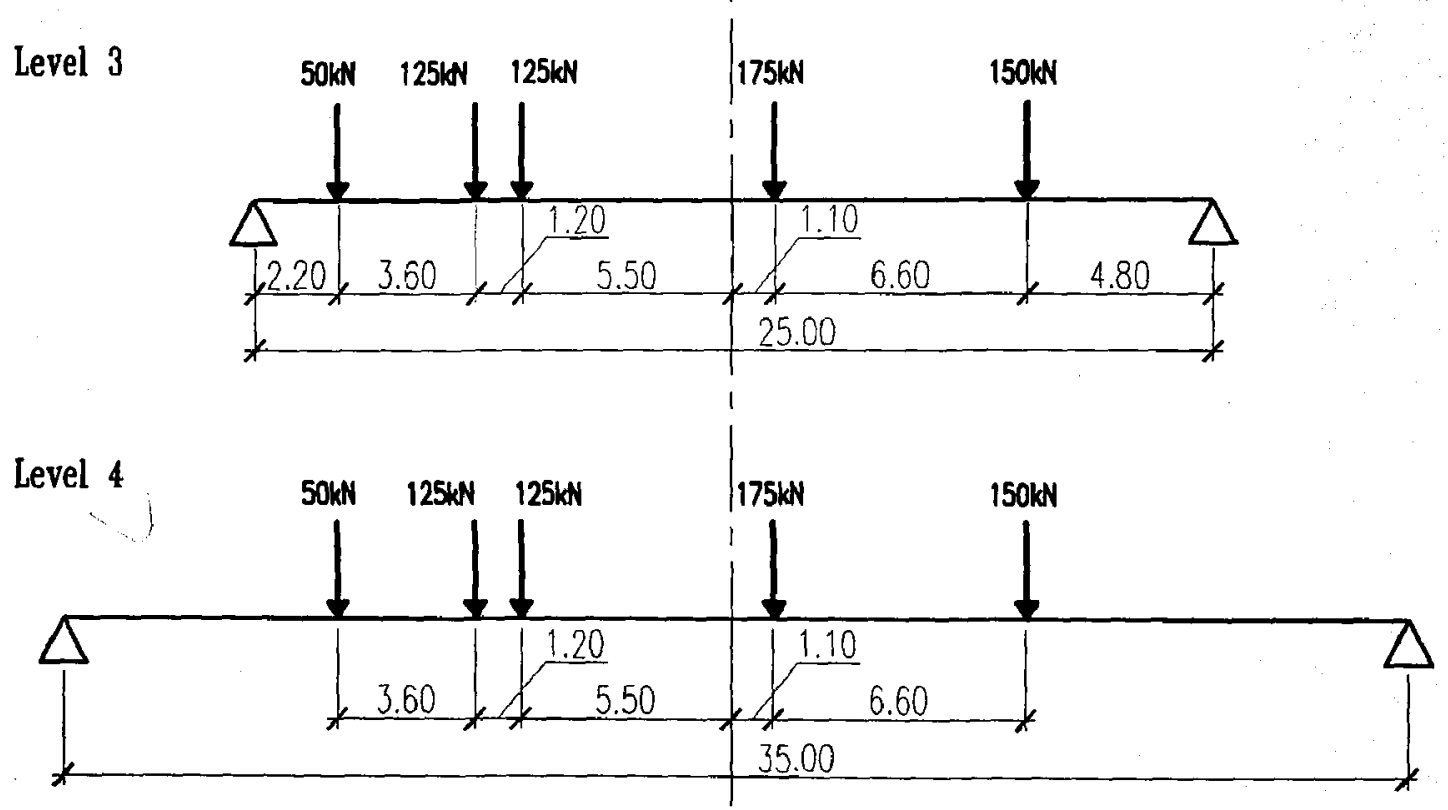

Dimensions are in meters

Figure 3. 3 Maximum Moment Locations 
Case (1): Dead load

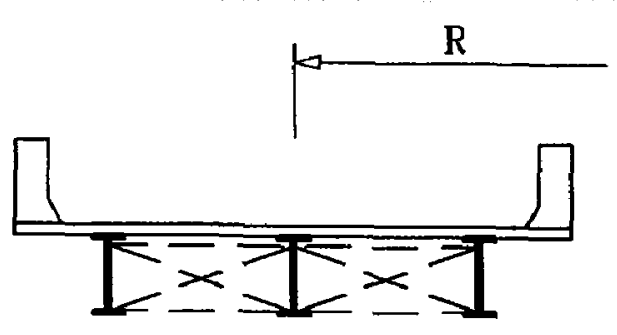

Case (2): Loading case for exterior girder

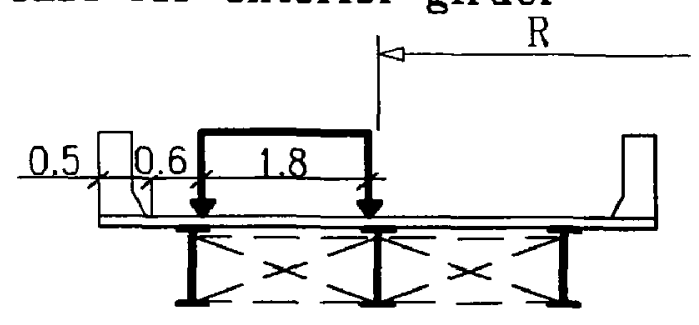

Case (3): Loading case for middle girder

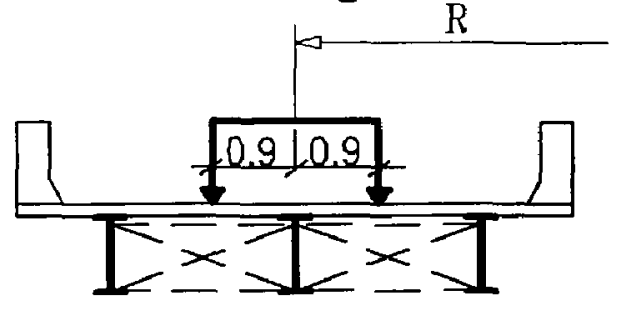

Case (4): Loading case for interior girder

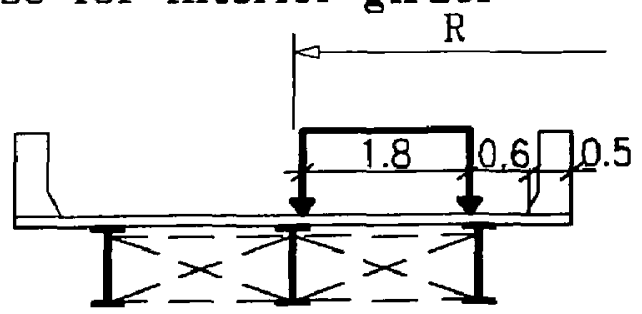

Case (5): Loading case for fatigue

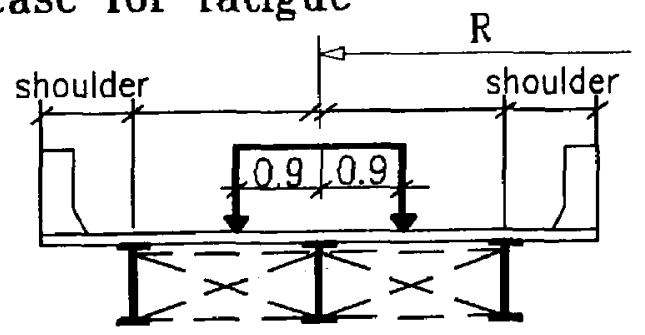

Dimensions are in meters

Figure 3. 4 Live Loading Cases for One-lane Bridge 
R

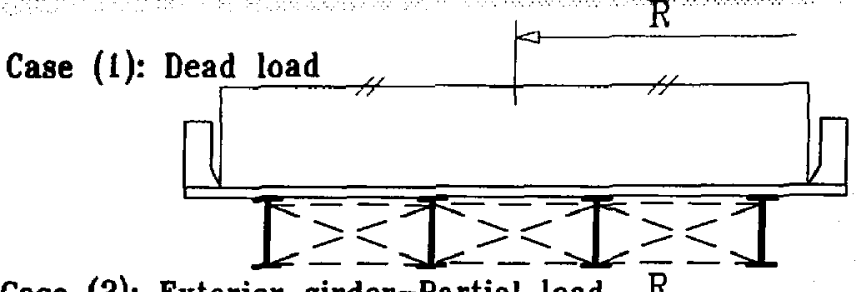

Case (2): Exterior girder-Partial load $R$

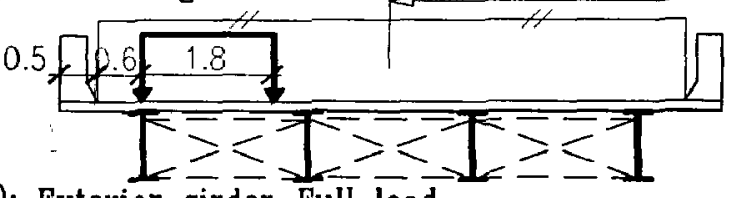

Case (3): Exterior girder-Full load

$\mathrm{R}$ "

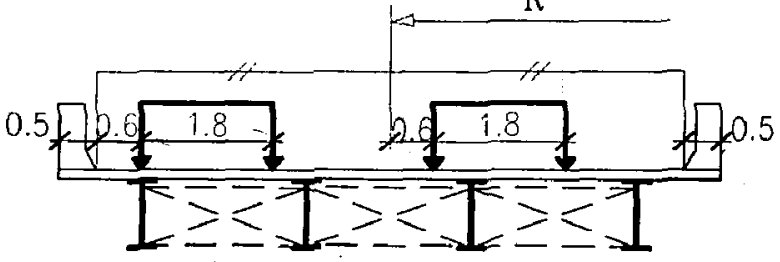

Case (4): Middle girder

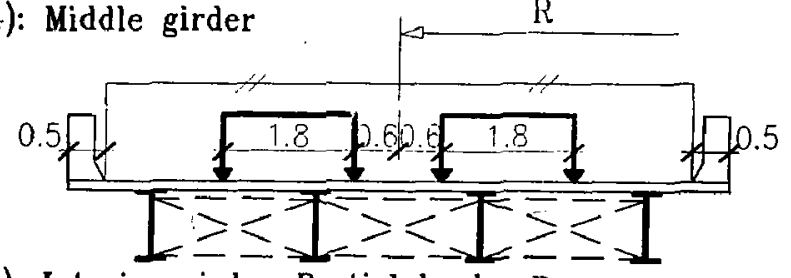

Case

(5): Interior girder-Partial load $R$

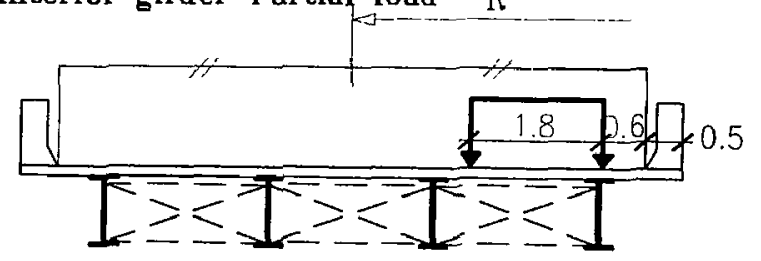

Case (6):Interior girder-Full load

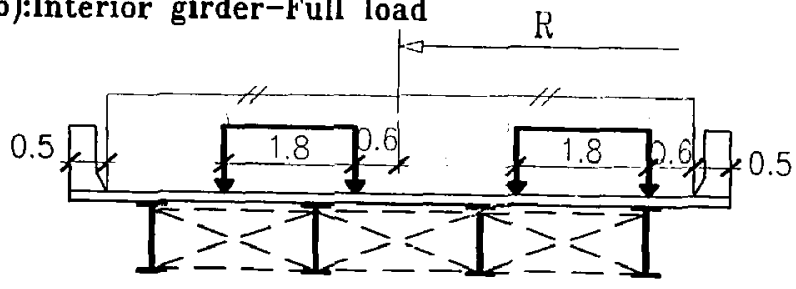

Dimensions are in meters

Figure 3.5 Live Loading Cases for Two-lane Bridge 

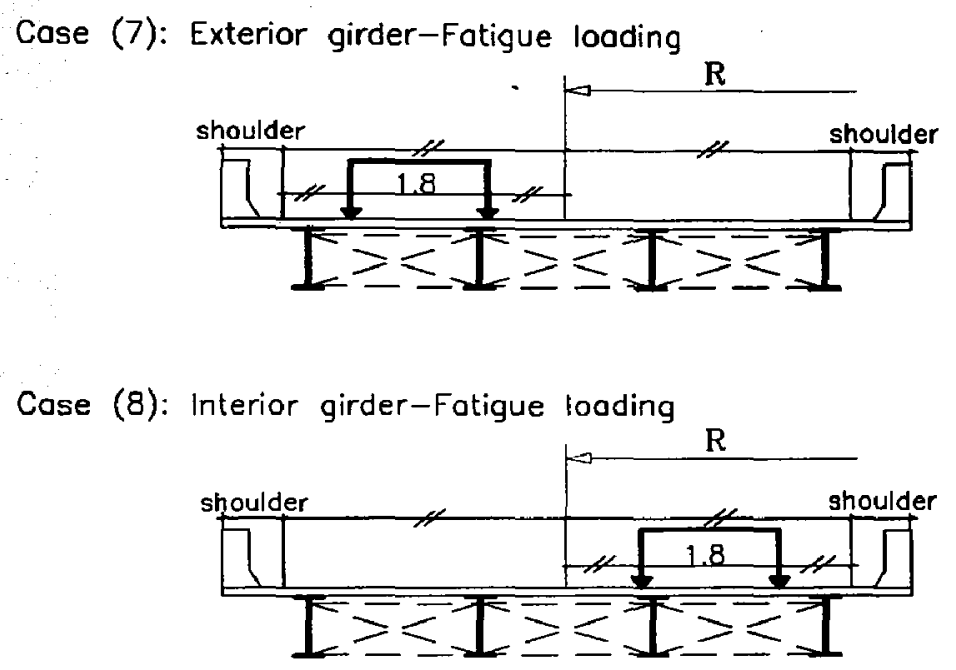

Figure 3.5 Live Loading Cases for Two-lane Bridge - Continue 
Case (1): Dead load

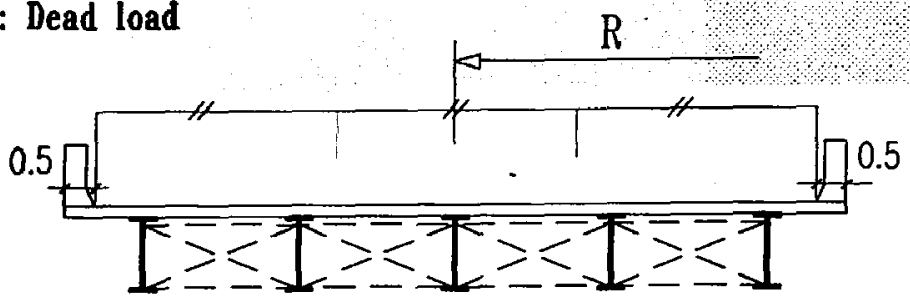

Case (2): Exterior girder-Partial loadl

$\mathrm{R}$

Case (3): Exterior girder-Partial load2
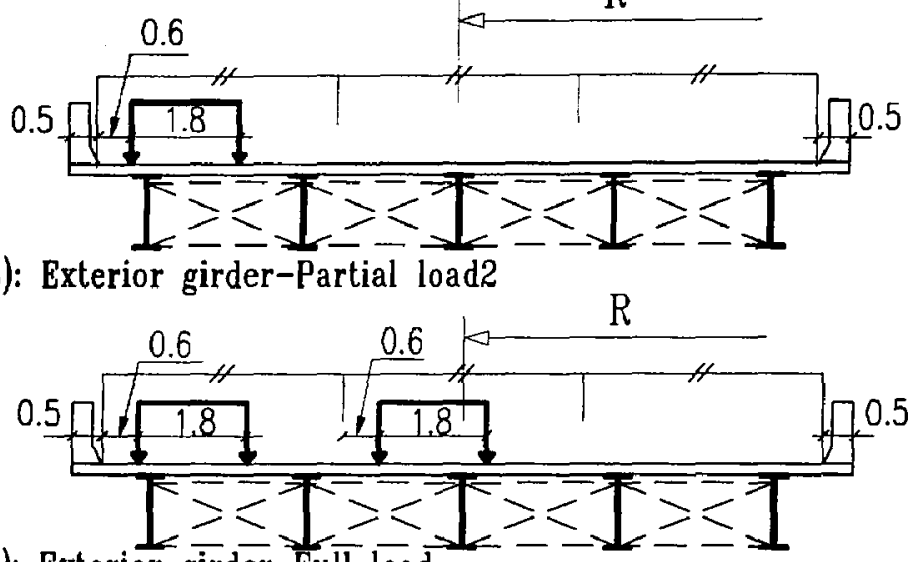

Case (4): Exterior girder-Full load

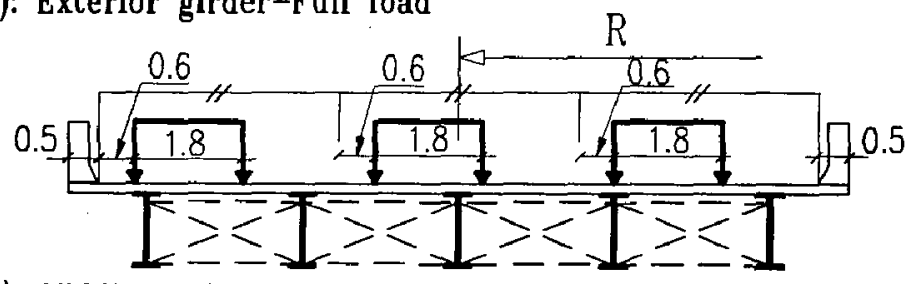

Case (5): Middle girders

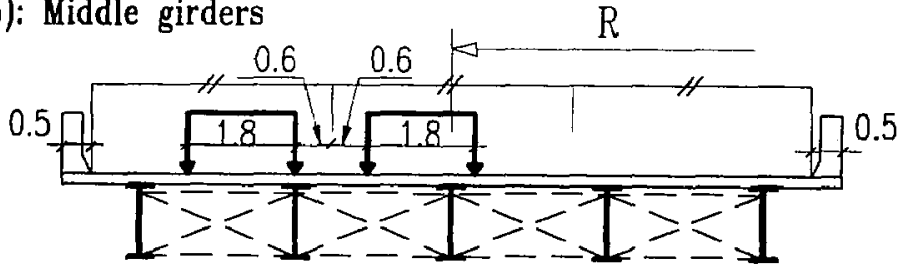

Case (6): Middle girders

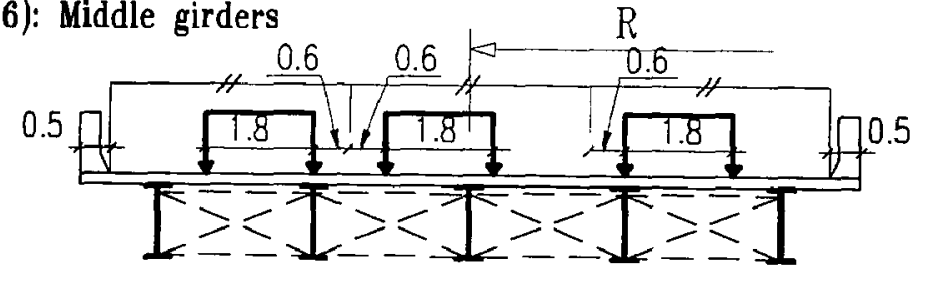

Case (7): Middle girders

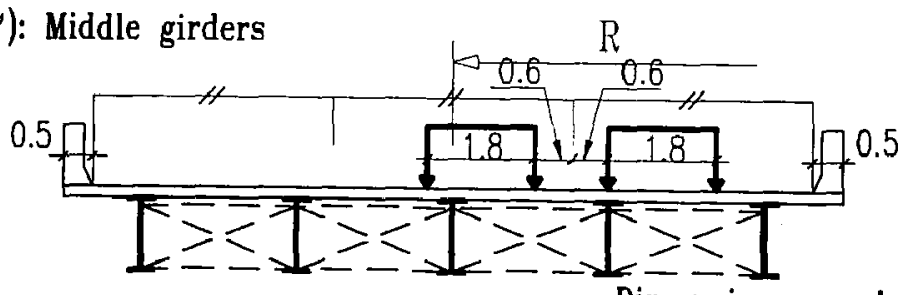

Dimensions are in meters

Figure 3. 6 Live Loading Cases for Three-lane Bridge 
Case (8): Middle girders

Case (9): Interior girder-Partial load1

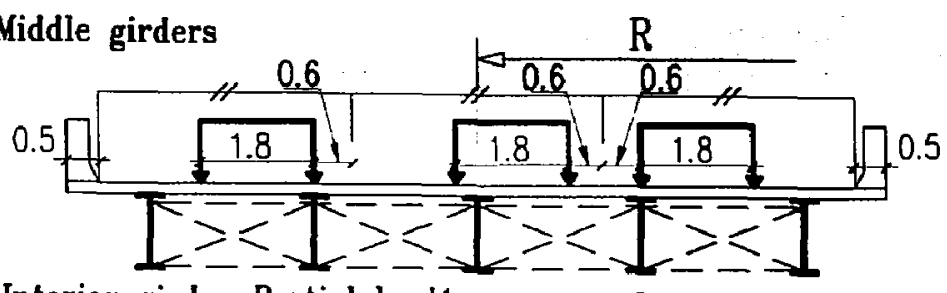

Case (10): Interior girder-Partial load2

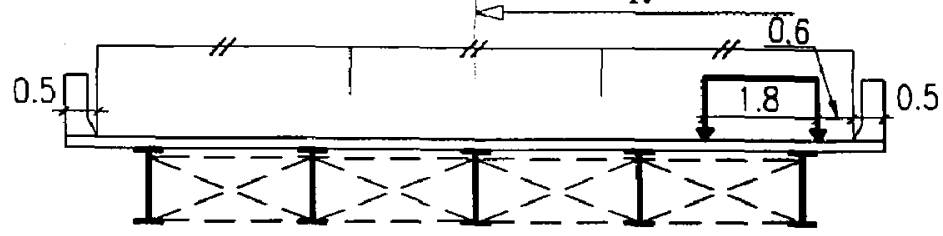

(11): Interior girder-Full load

Case (12): Fatigue, Exterior girder

0.5

$R$

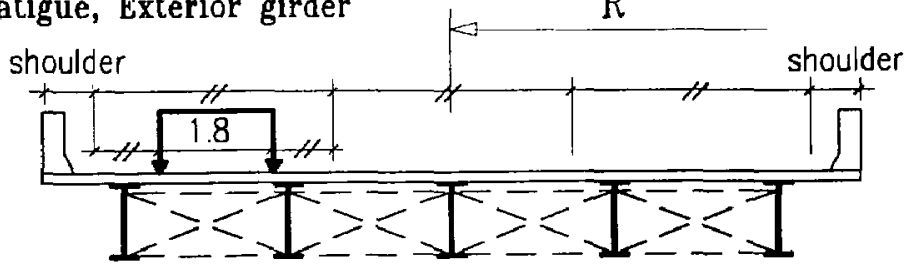

Case (13): Fatigue, middle girder

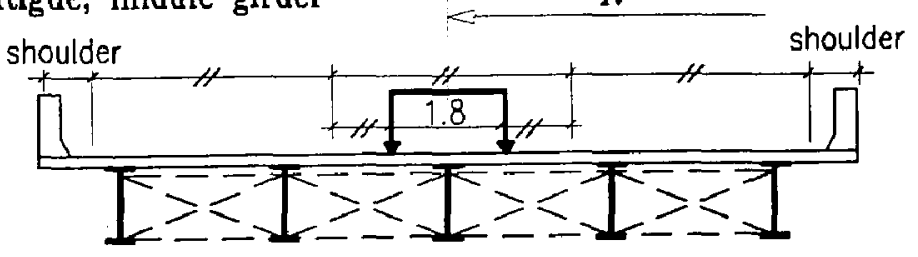

Case (14): Fatigue, interior girder

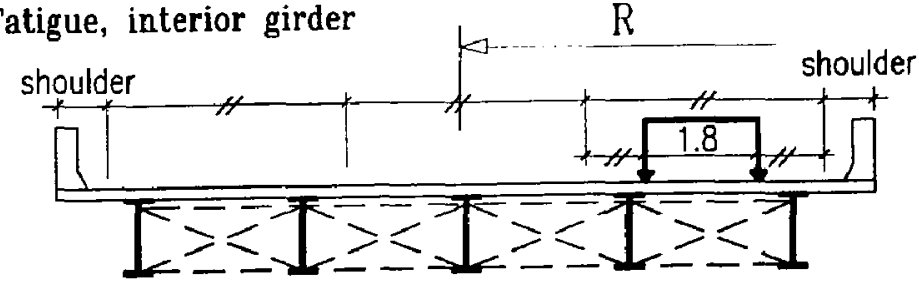

Figure 3.6 Live Loading Cases for Three-lane Bridge - Continue 
Case (1): Dead load<smiles>[AsH2]=[SnH2]</smiles>

0.5

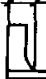

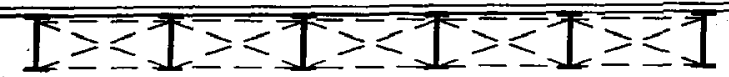

Case (2): Exterior girder-Partial load

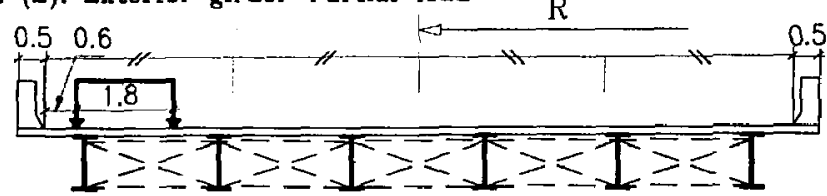

Case (3): Exterior girder-Parial load

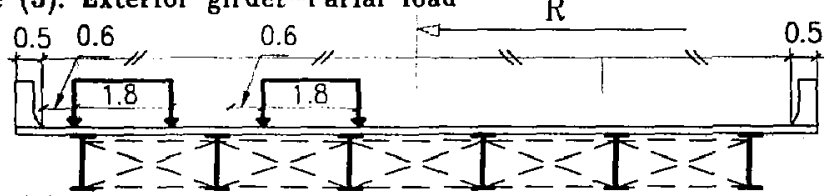

Case (4): Exterior girder-Parial load

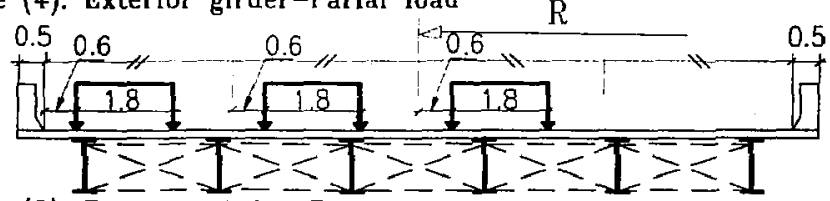

Case (5): Exterior girder-Full load

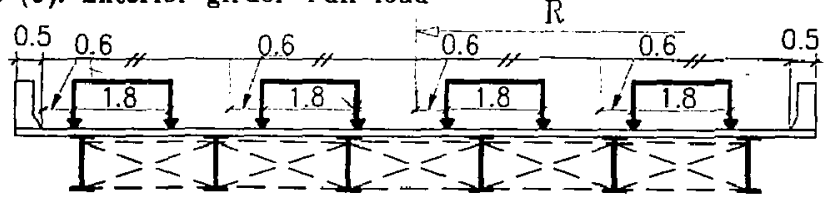

Case (6): Middle girder-Parial load

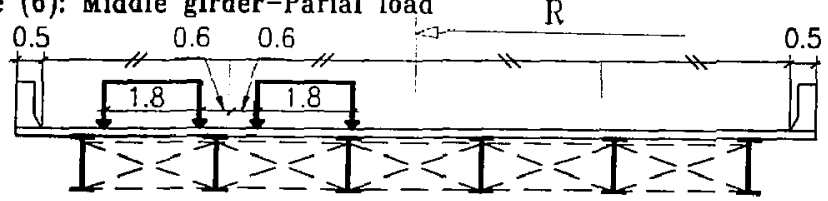

Case (7): Middle girder-Parial load

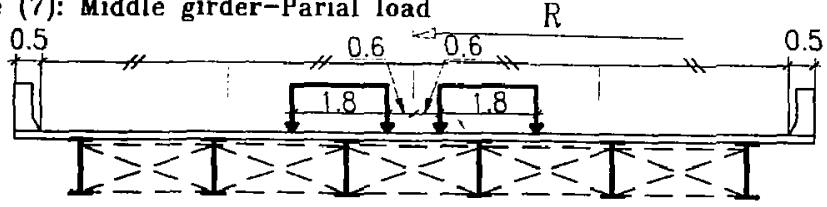

Dimensions are in meters

Figure 3. 7 Live Loading Cases for Four-lane Bridge 
Case (8): Middle girder-Parial load

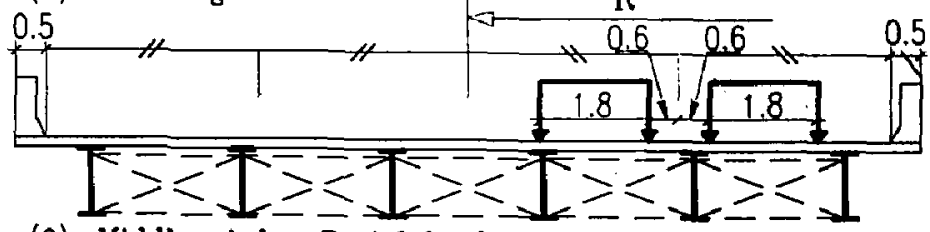

Case (9): Middle girder-Parial load

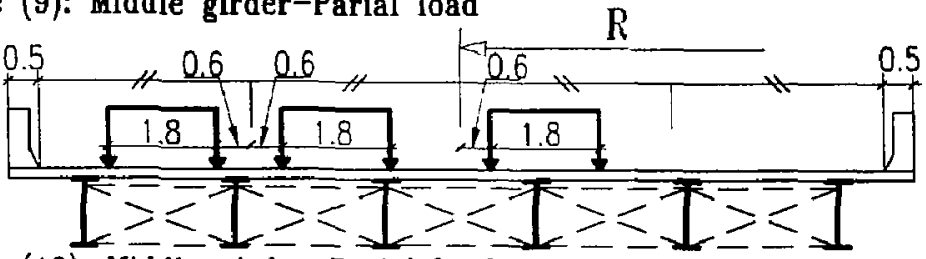

Case (10): Middle girder-Parial load

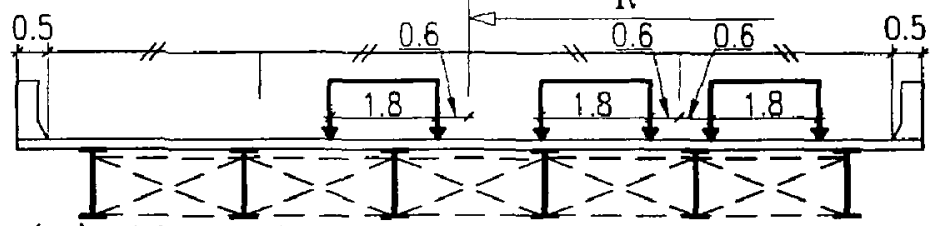

Case (11): Middle girder-Full load

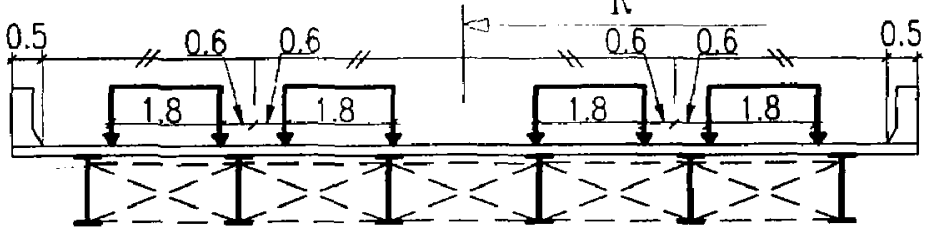

Case (12): Middle girder-Full load

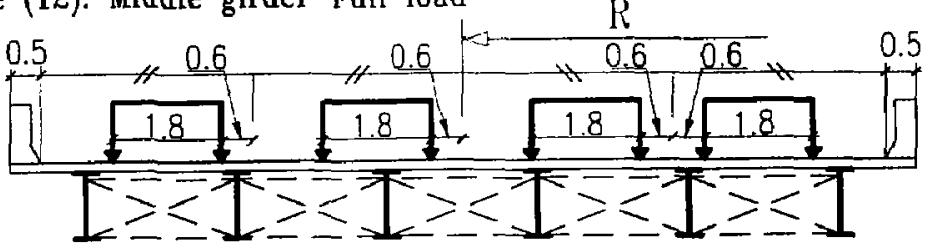

Case (13): Middle girder-Full load

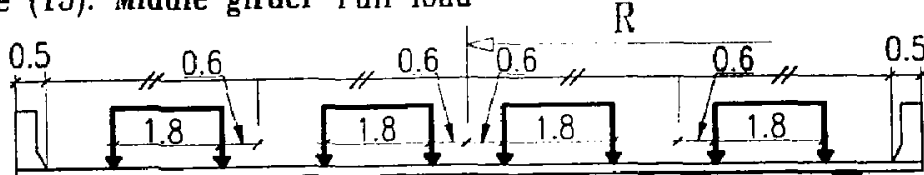

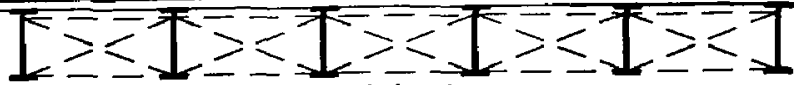

Case (14): Interior girder-Parial load

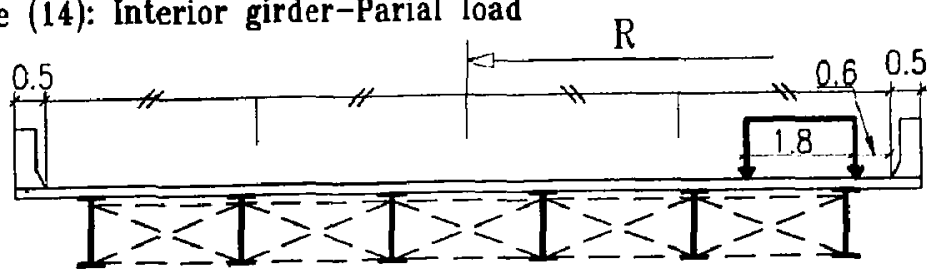

Dimensions are in meters

\section{Figure 3.7 Live Loading Cases for Four-lane Bridge - Continue}




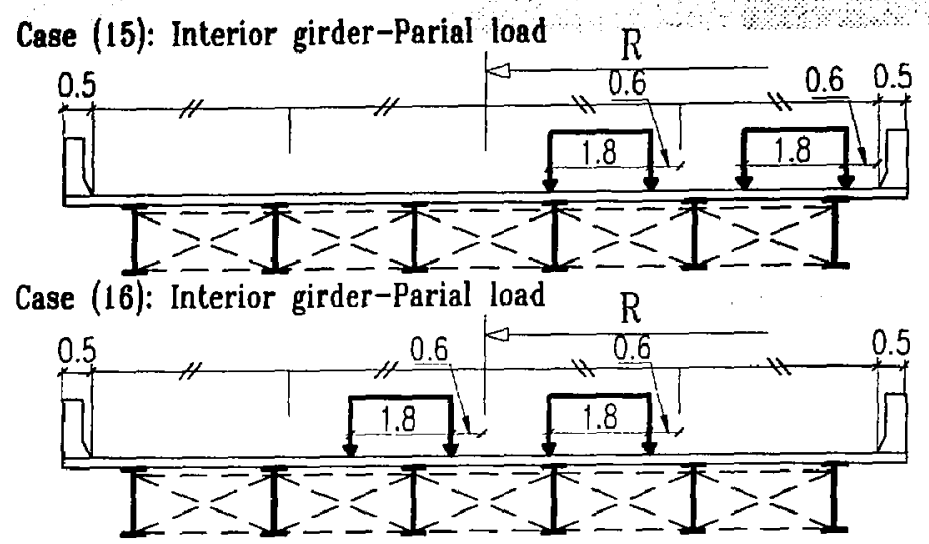

Case (17): Interior girder-Full load

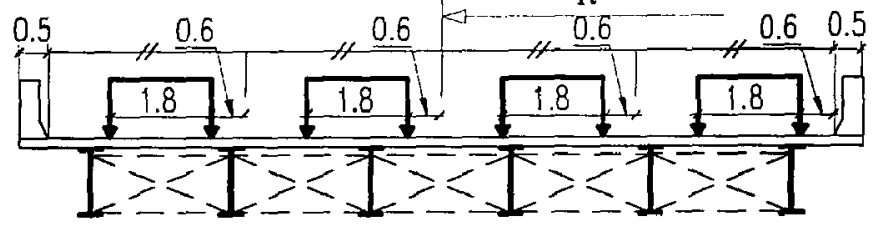

Case (18): Fatigue, Exterior girder

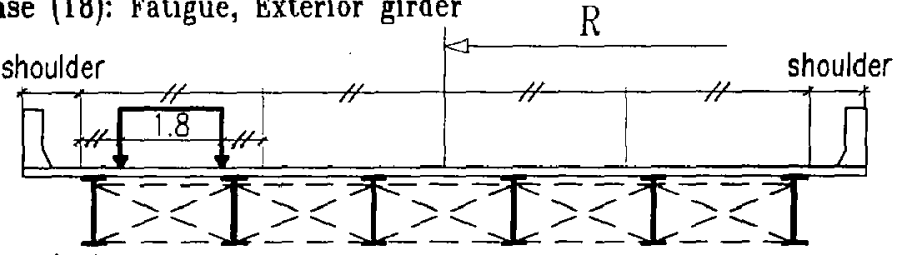

Case (19): Fatigue, Middle girder

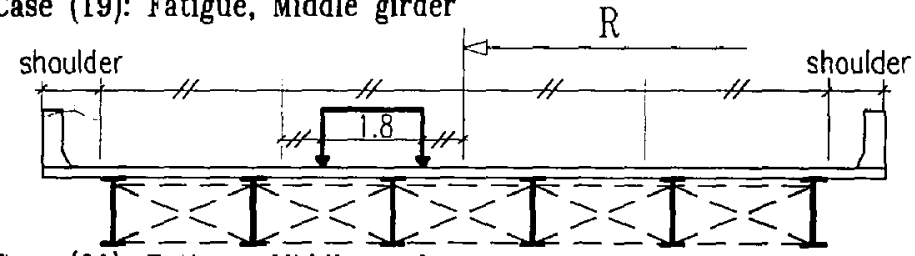

Case (20): Fatigue, Middle girder

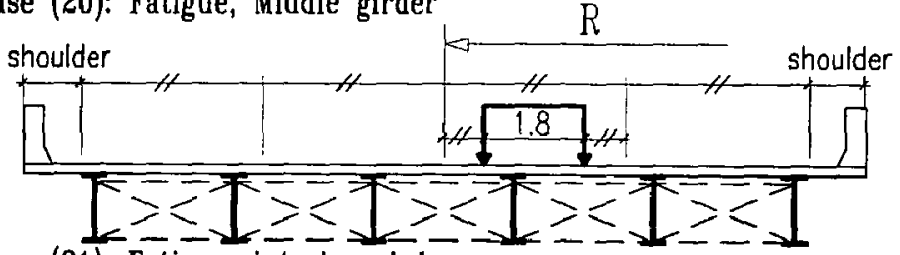

Case (21): Fatigue, interior girder

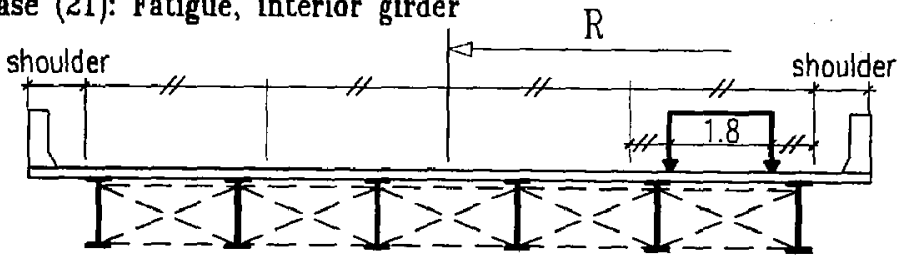

Dimensions are in meters

Figure 3.7 Live Loading Cases for Four-lane Bridge - Continue 


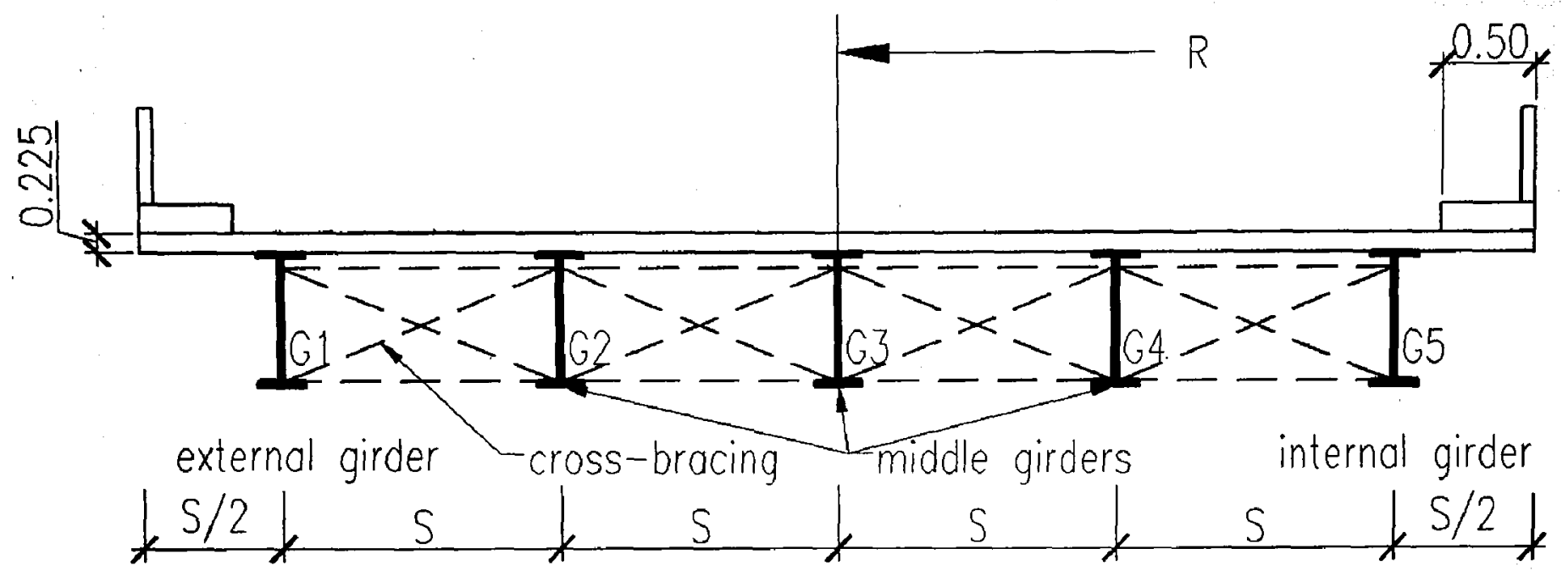

Figure 3. 8 Cross-Section of a Composite I-Girder Bridge 


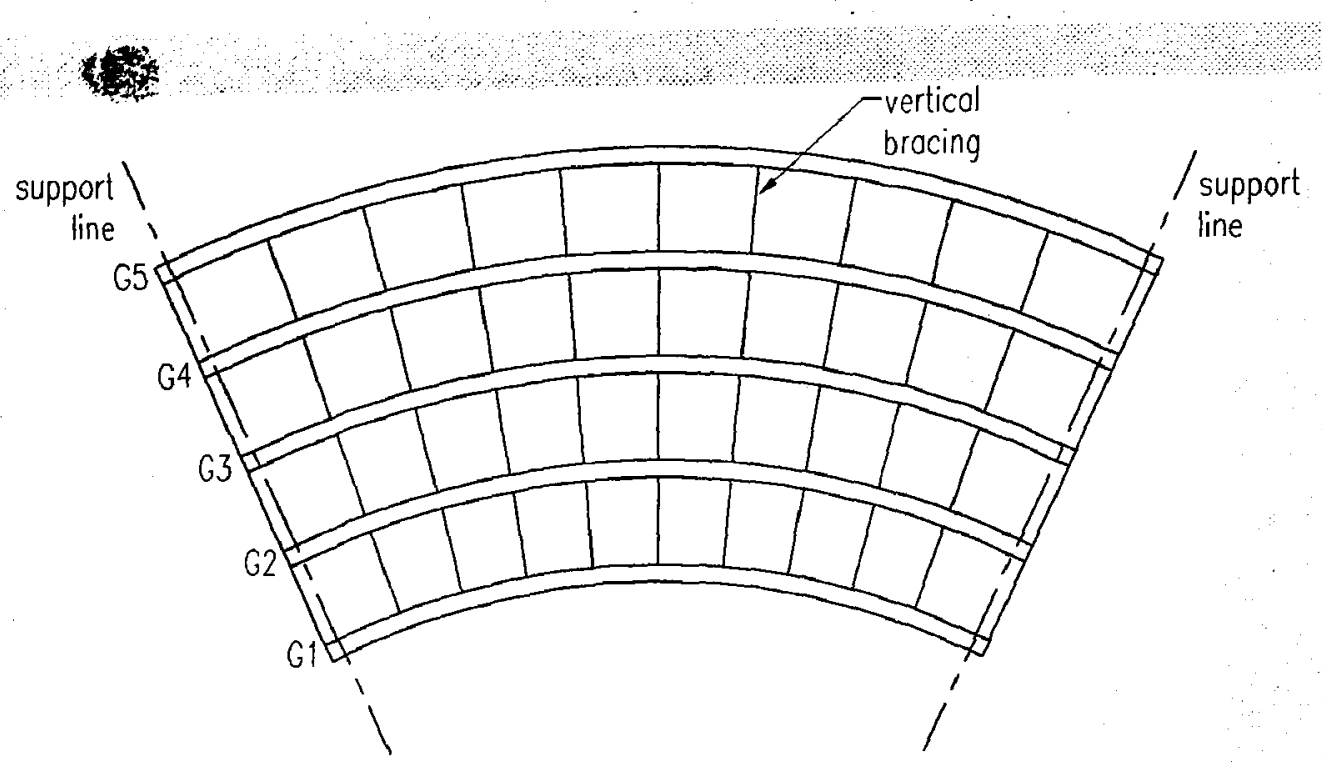

a) I-Girder with Radial Cross-Bracings

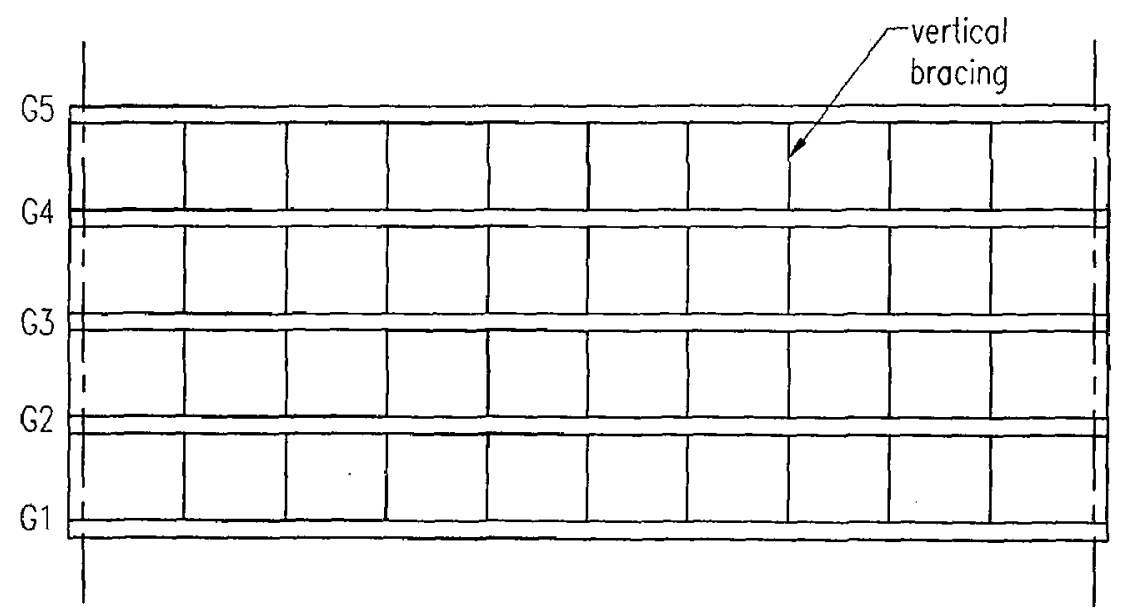

b) I-Girder with Transverse Cross-Bracings

Figure 3.9 Plan of the Steel Girder Arrangement 


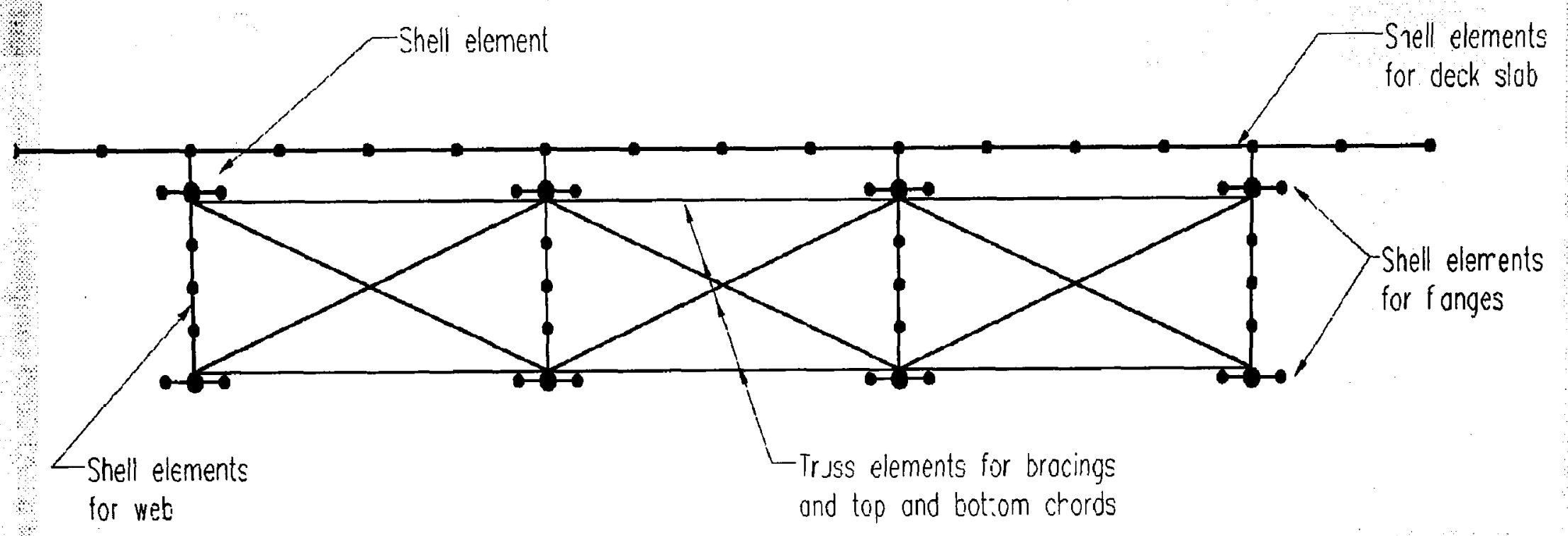

Figure 3.10 Finite Element Representation of Bridge Cross section 


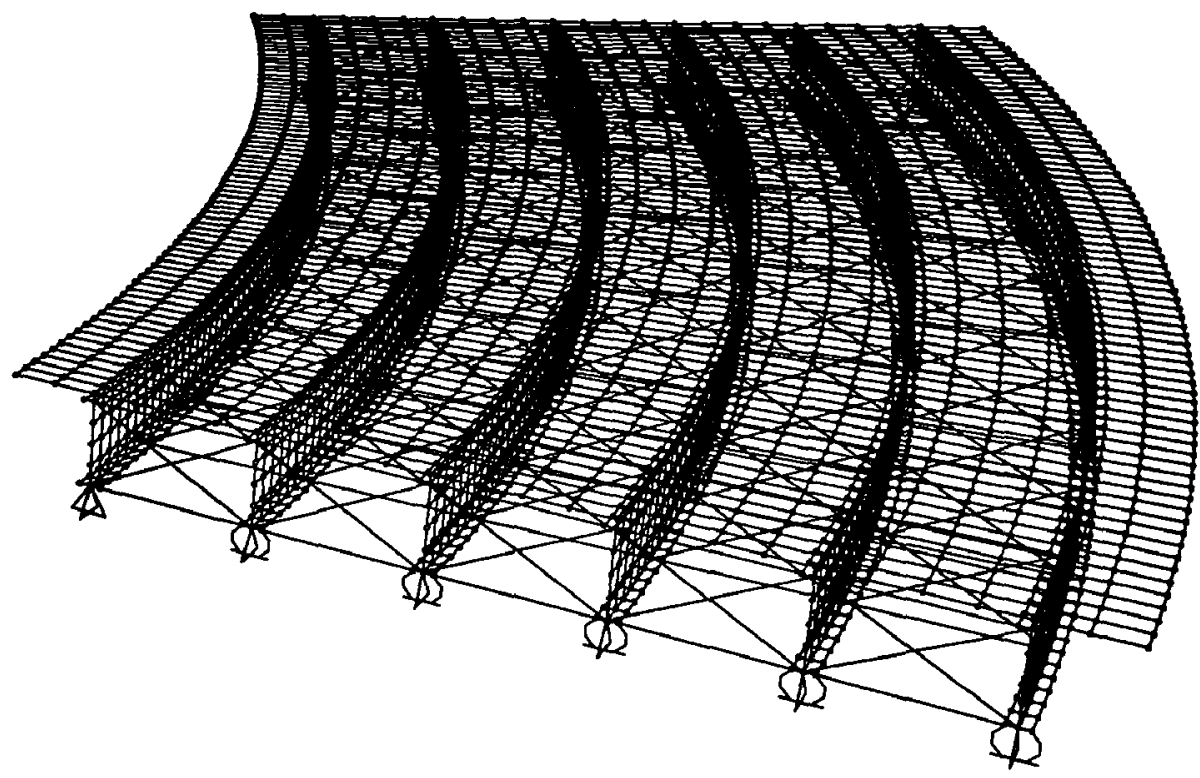

Figure 3.11 View of a SAP2000 non-composite Finite-Element Model

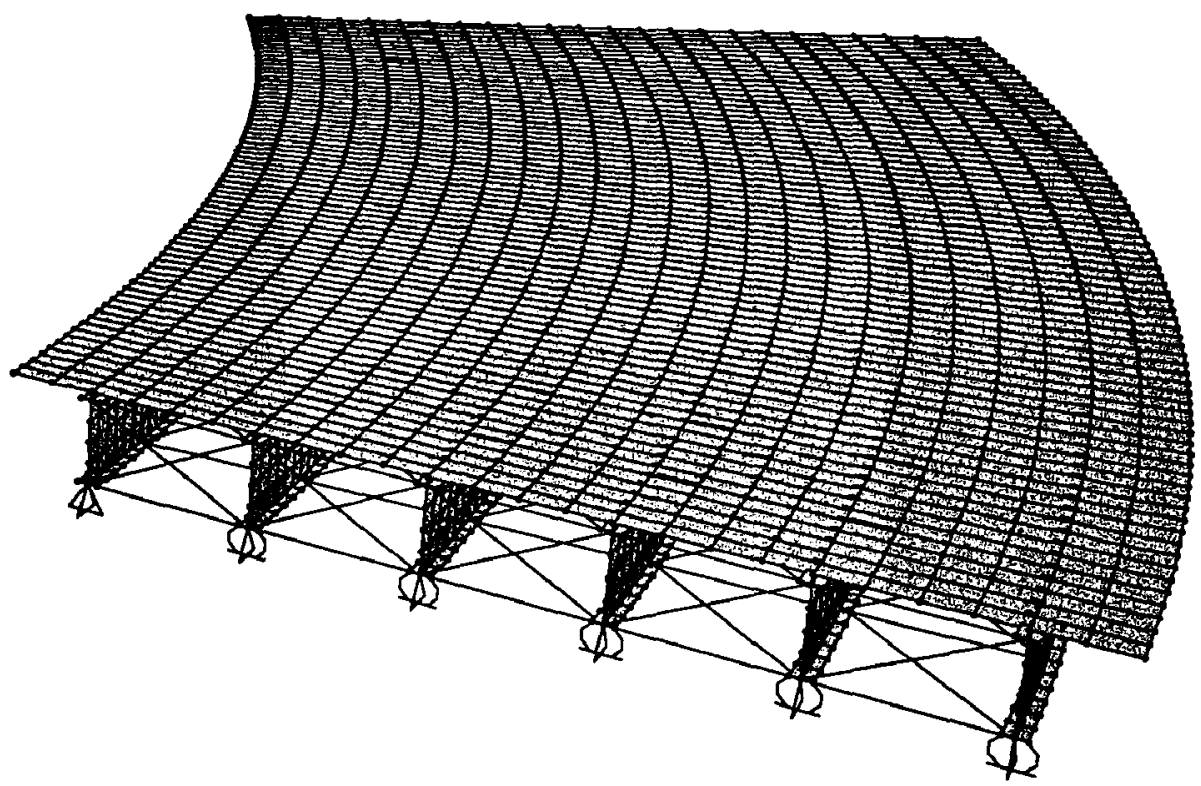

Figure 3.12 View of a SAP2000 composite Finite-Element Model 


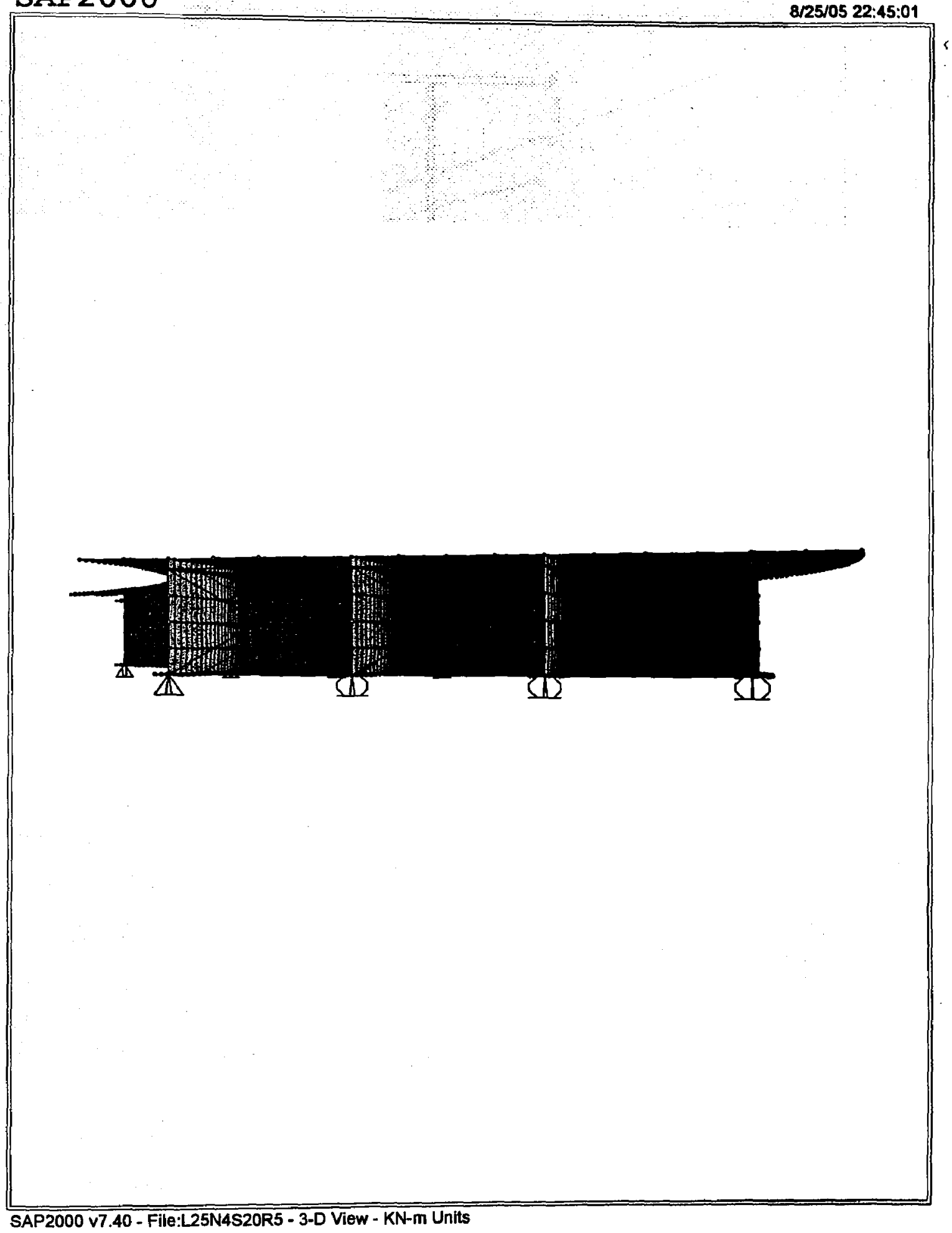

Figure 3. 13 View of a SAP2000 Finite-Element Model with support Conditions 


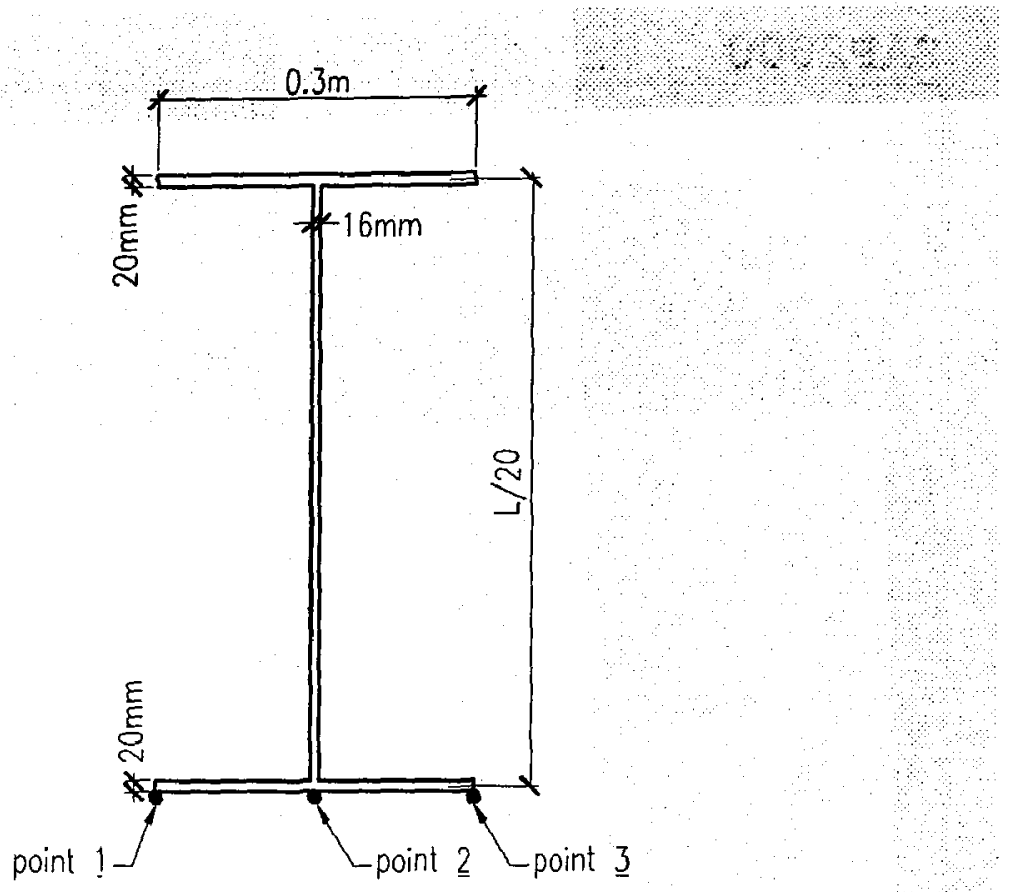

Figure 3.14 Cross-Section Dimensions of the Steel Girder

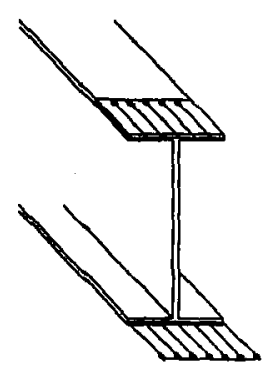

a) Major Axis Bending Stress

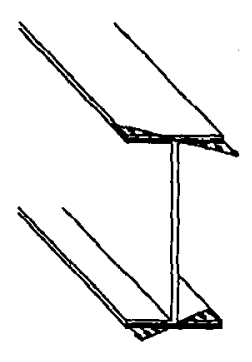

b) Narping Stress

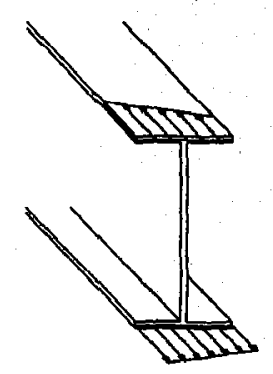

c) Combined Bending and Yarping Stress

Figure 3.15 Normal Stress Distribution in Curved I-Girder Flanges 


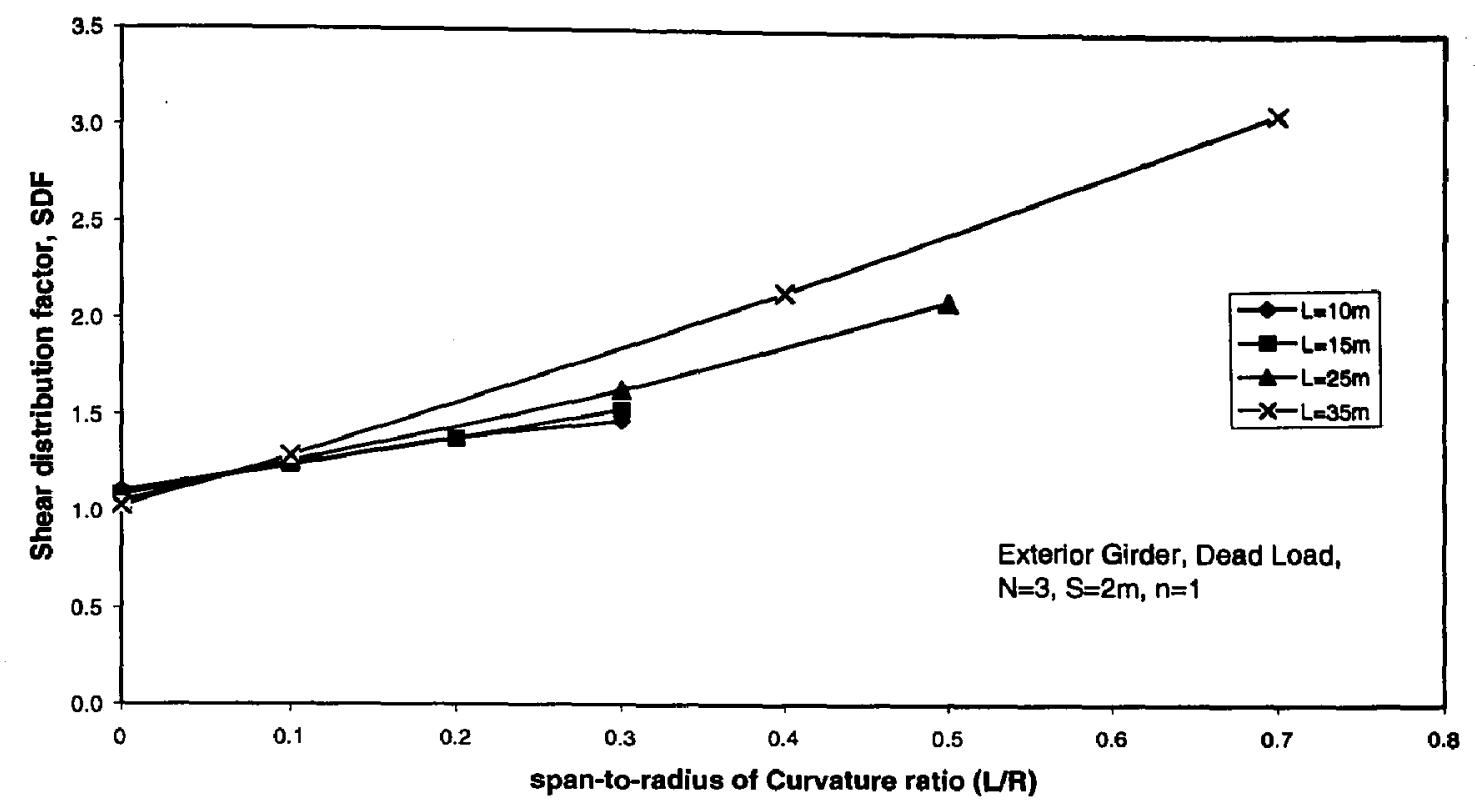

Figure 4. 1 Effect of Curvature on the Shear Distribution Factor for the Exterior Girder due to Dead Load

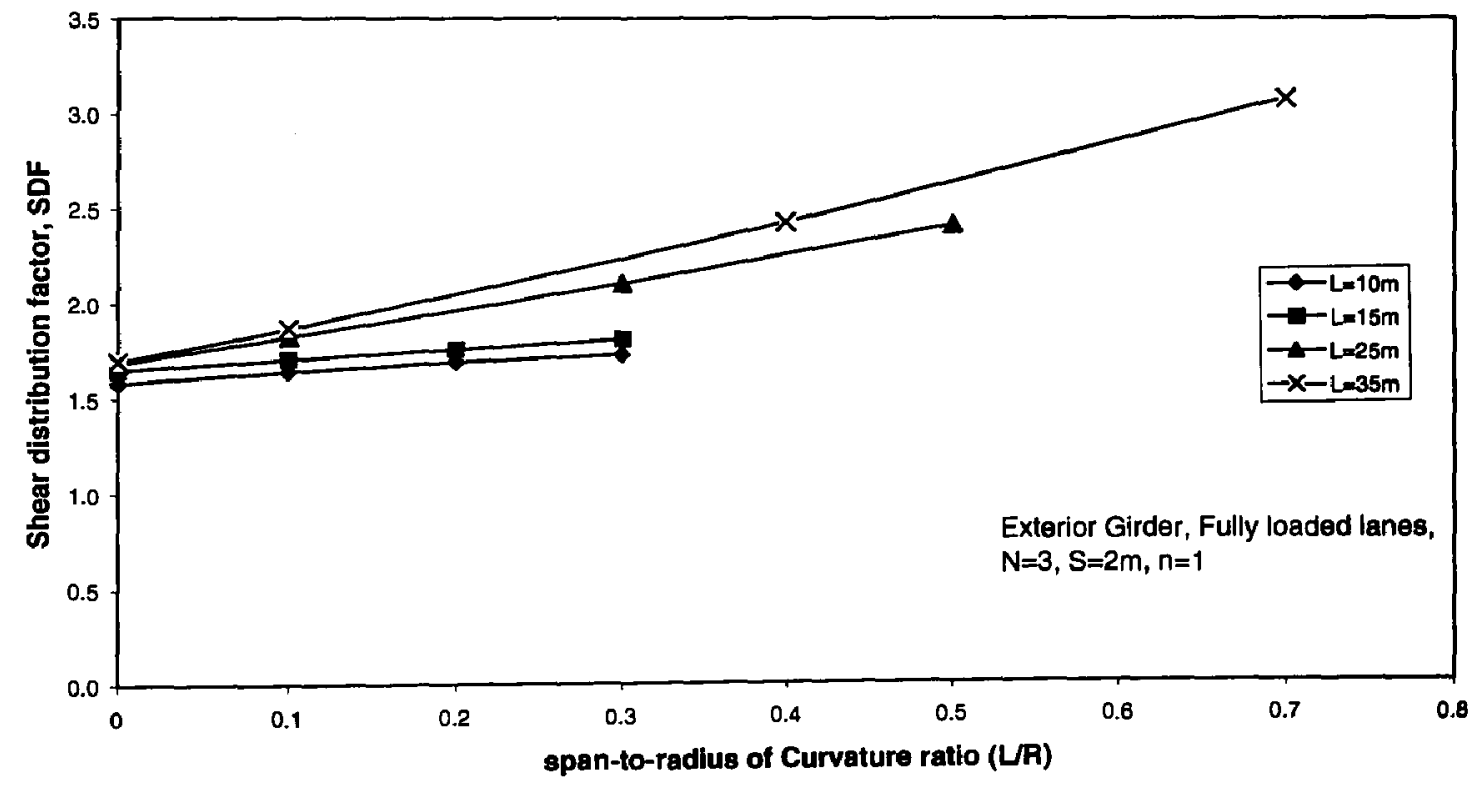

Figure 4. 2 Effect of Curvature on the Shear Distribution Factor for the Exterior Girder due to Fully Loaded Lanes 


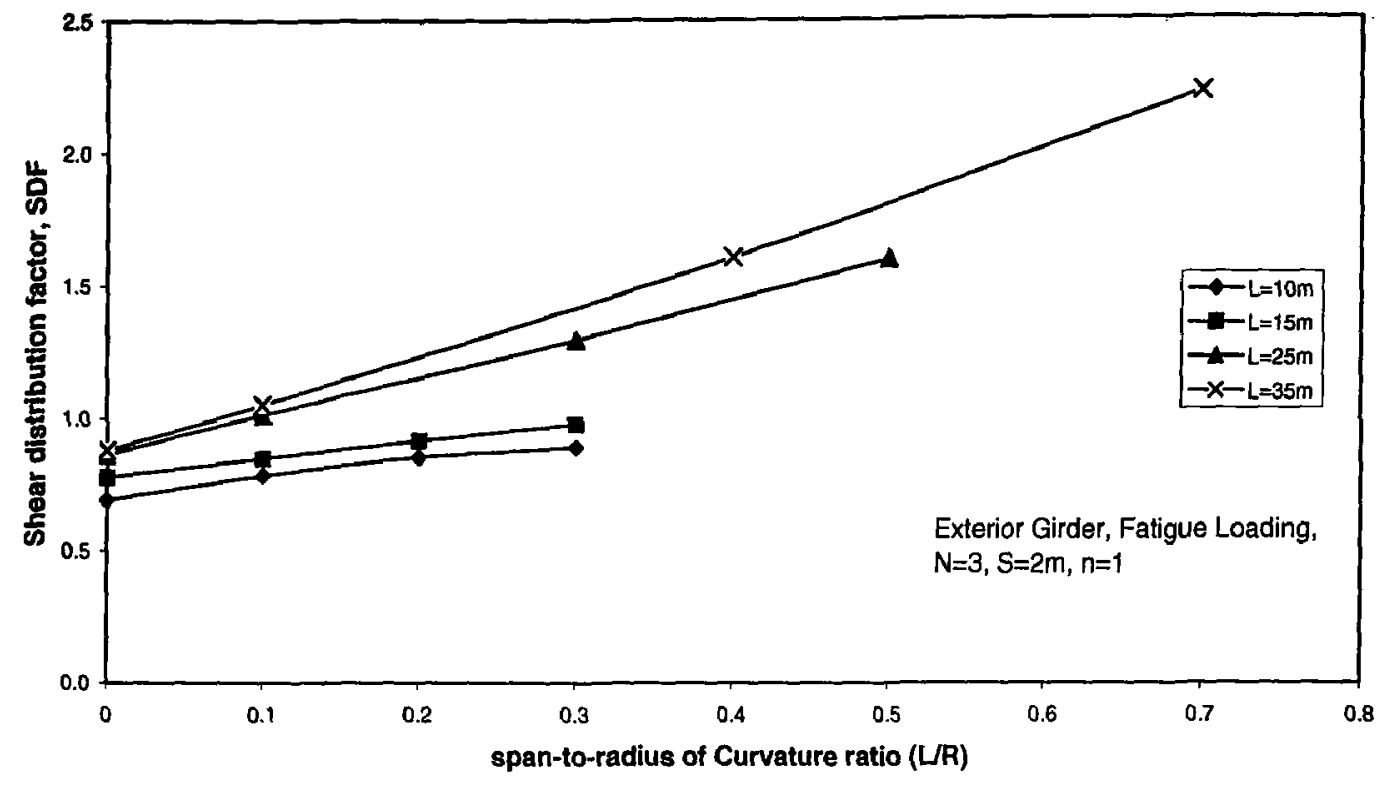

Figure 4. 3 Effect of Curvature on the Shear Distribution Factor for the Exterior Girder due to Fatigue Loading

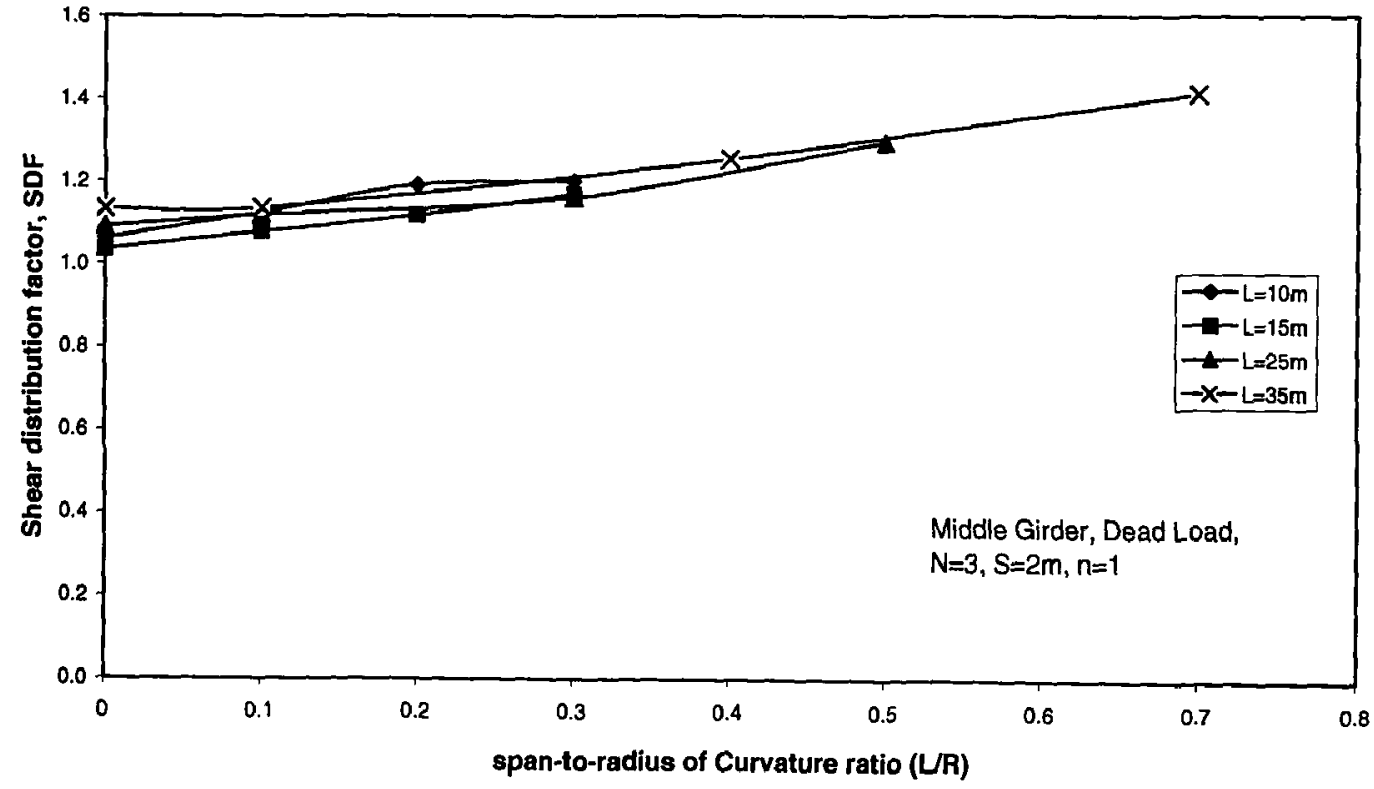

Figure 4. 4 Effect of Curvature on the Shear Distribution Factor for the Middle Girder due to Dead Load 


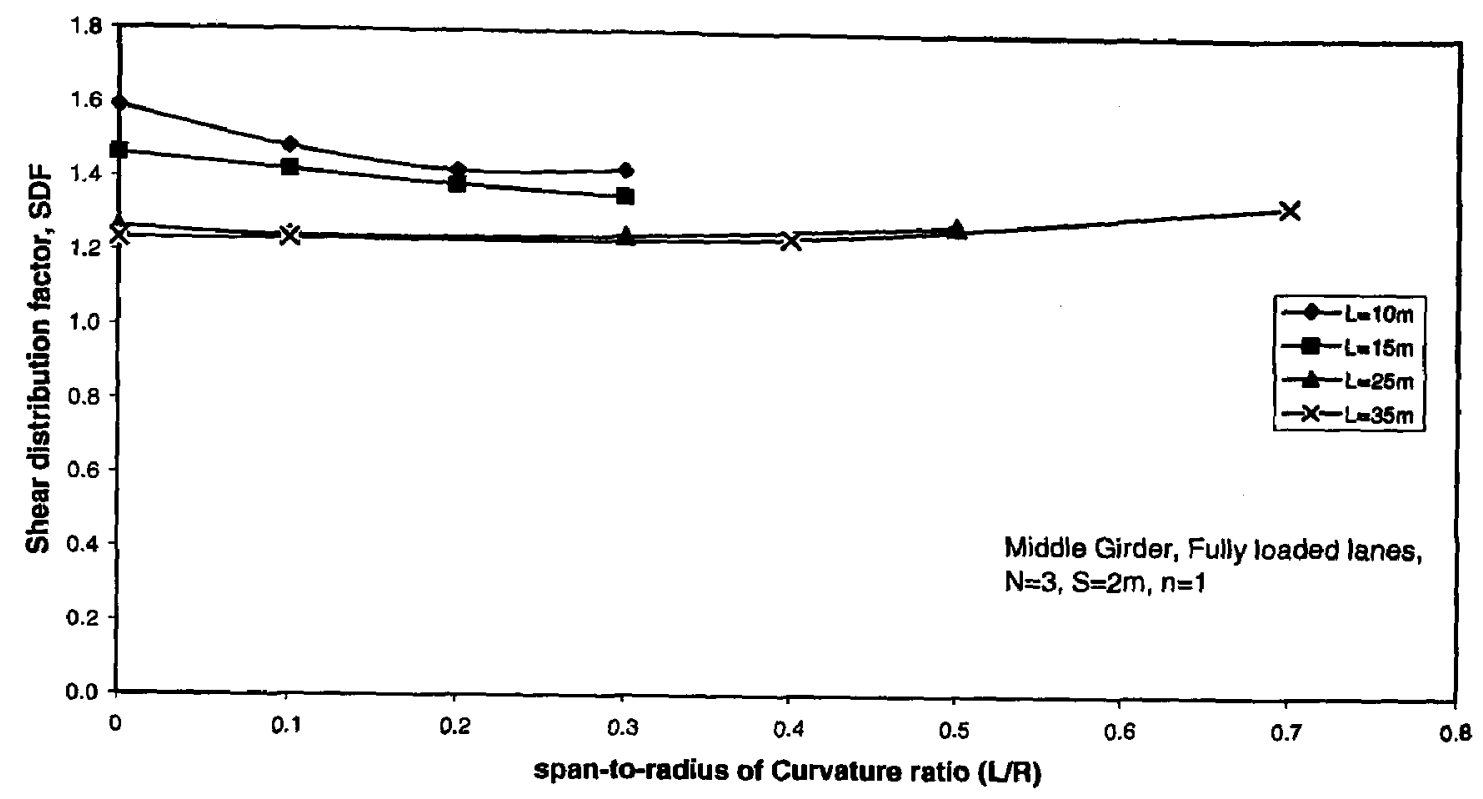

Figure 4. 5 Effect of Curvature on the Shear Distribution Factor for the Middle Girder due to Fully Loaded Lanes

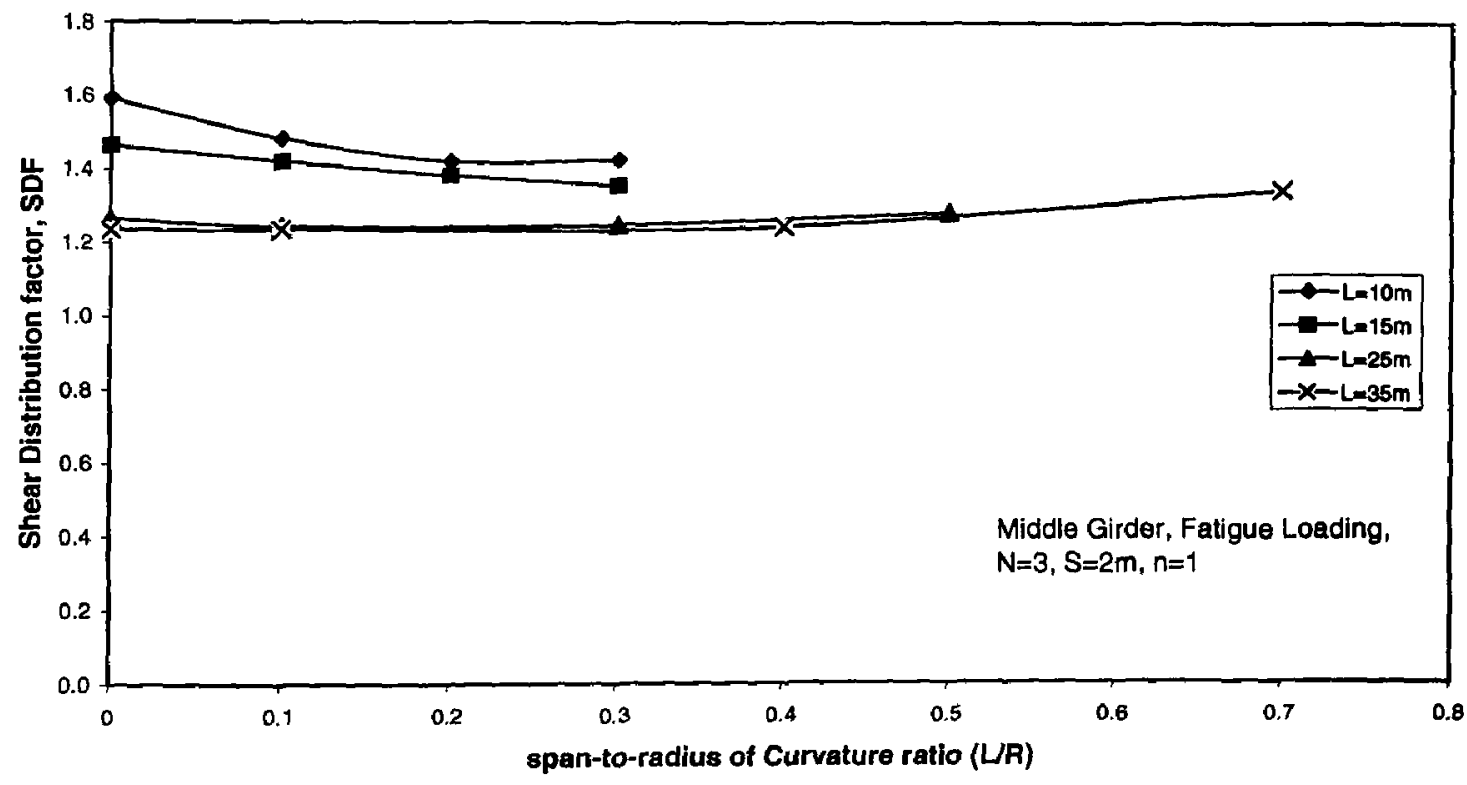

Figure 4. 6 Effect of Curvature on the Shear Distribution Factor for the Middle Girder due to Fatigue Loading 


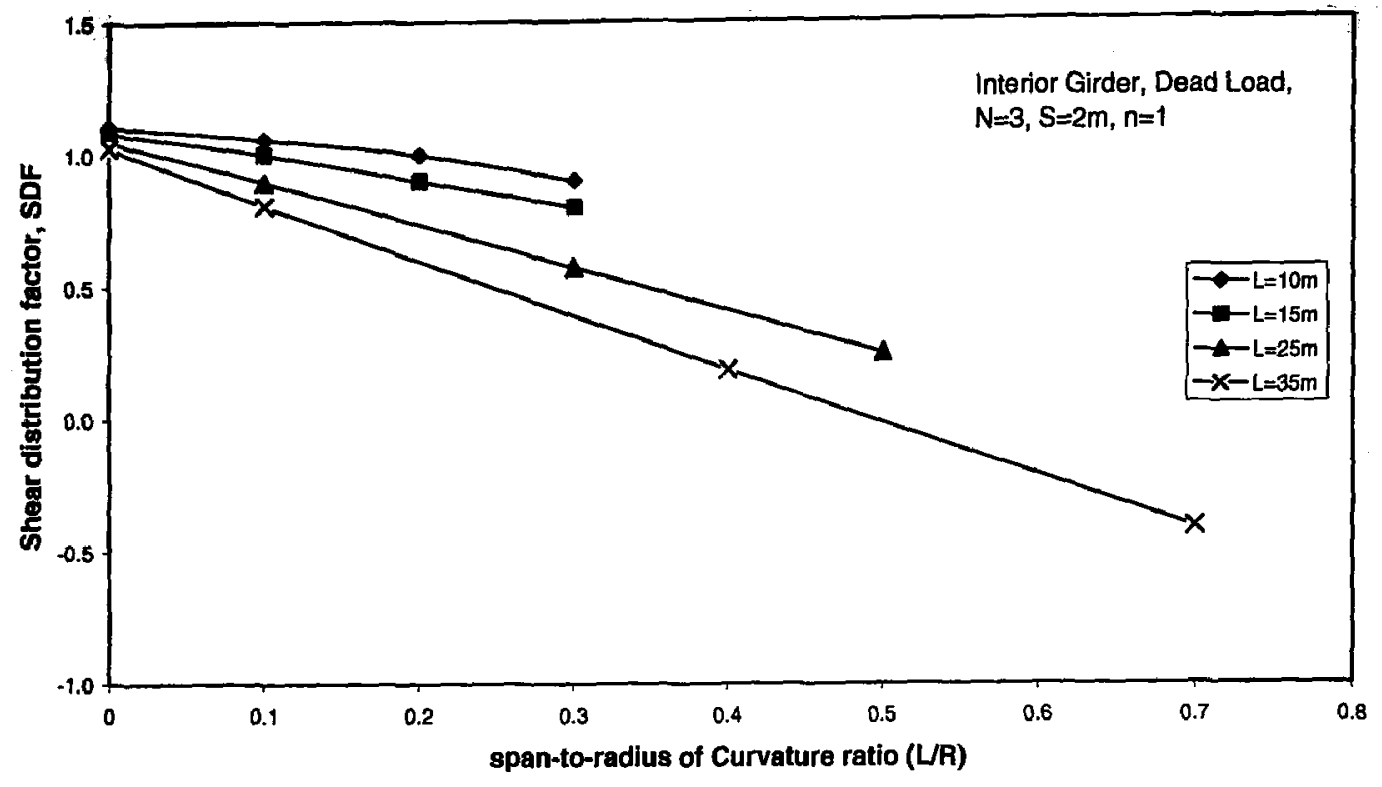

Figure 4. 7 Effect of Curvature on the Shear Distribution Factor for the Interior Girder due t Dead Load

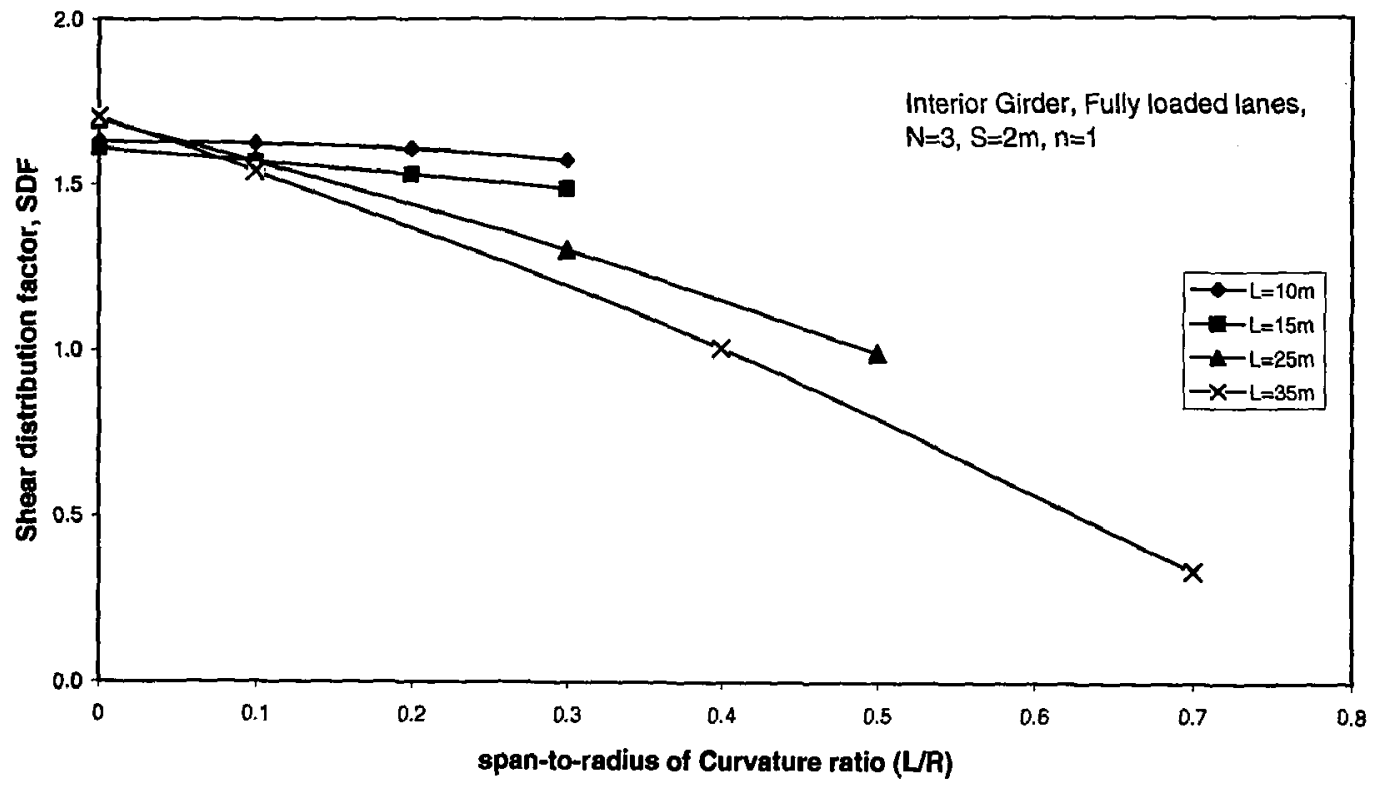

Figure 4.8 Effect of Curvature on the Shear Distribution Factor for the Interior Girder due to Fully Loaded Lanes 


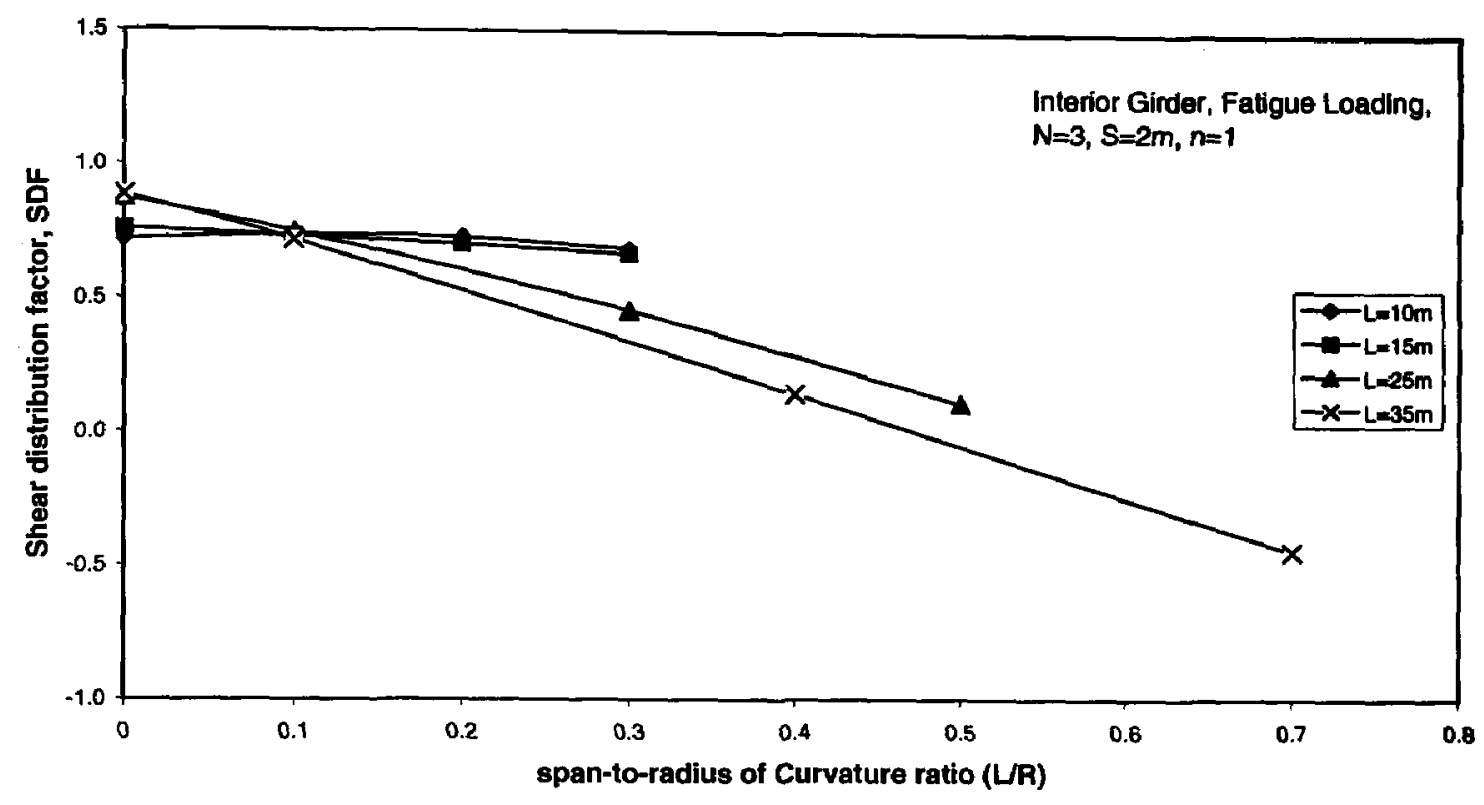

Figure 4.9 Effect of Curvature on the Shear Distribution Factor for the Interior Girder due to Fatigue Loading

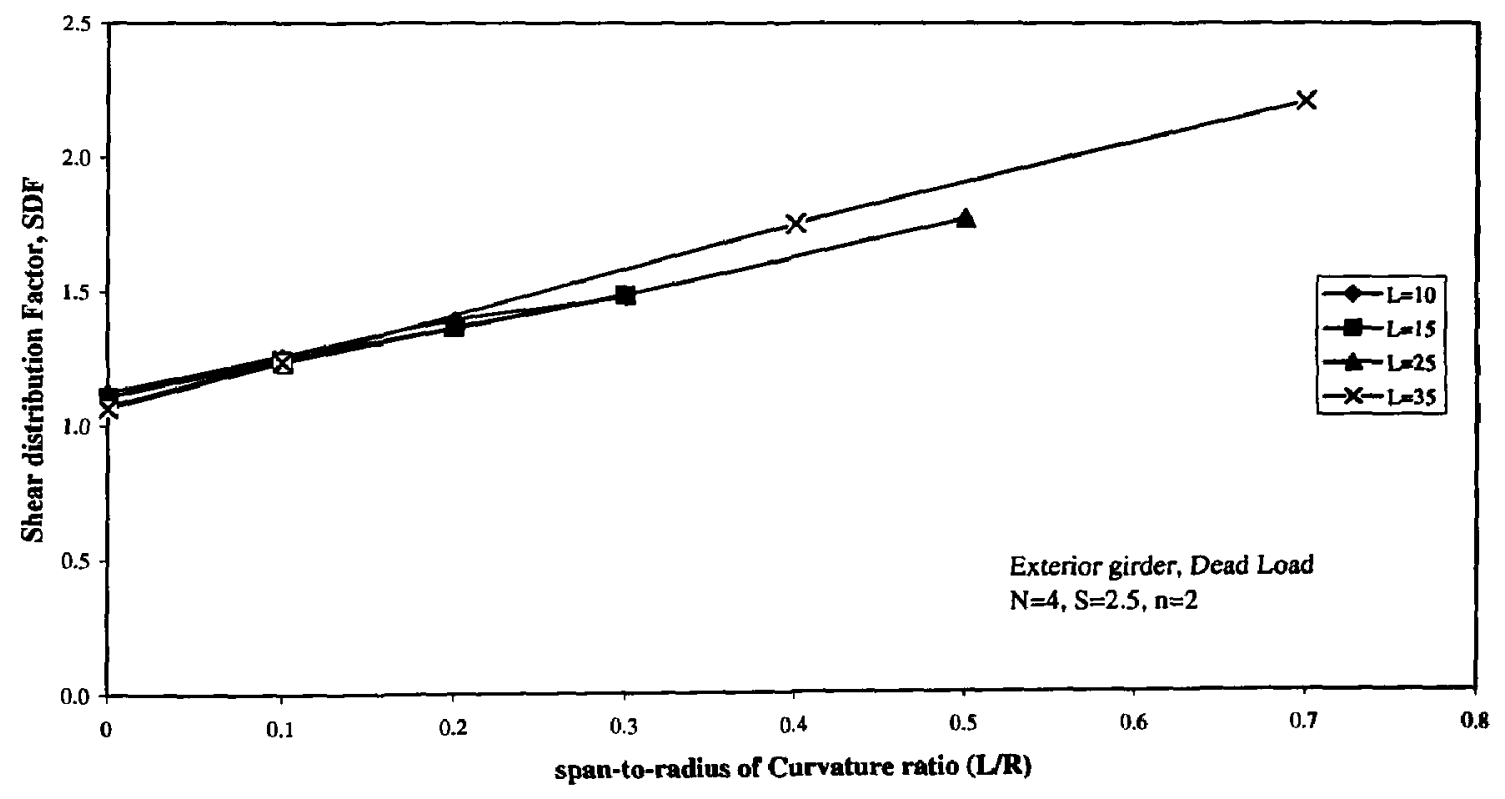

Figure 4. 10 Effect of Curvature on the Shear Distribution Factor for the Exterior Girder due to Dead Load 


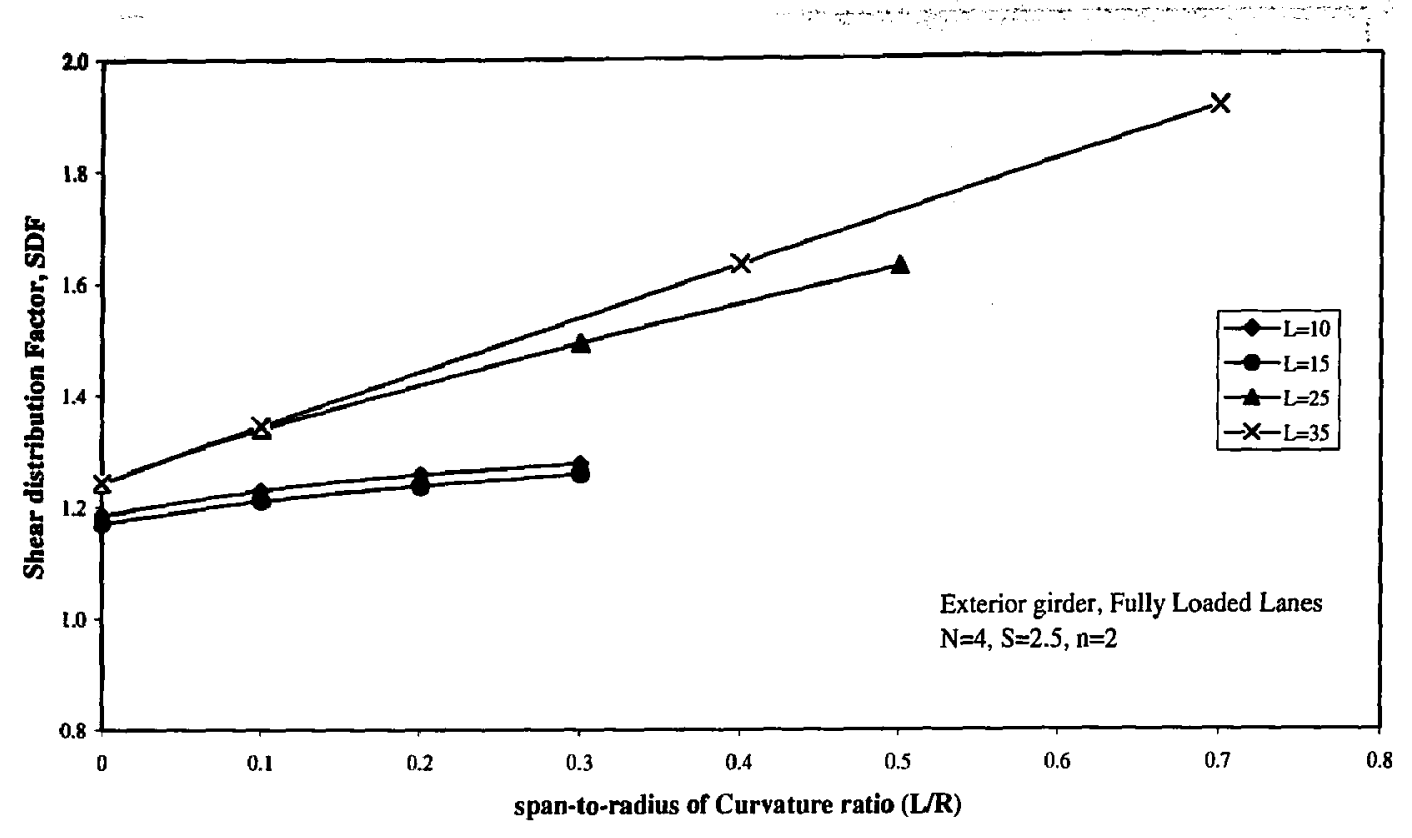

Figure 4. 11 Effect of Curvature on the Shear Distribution Factor for the Exterior Girder due to Fully Loaded Lanes

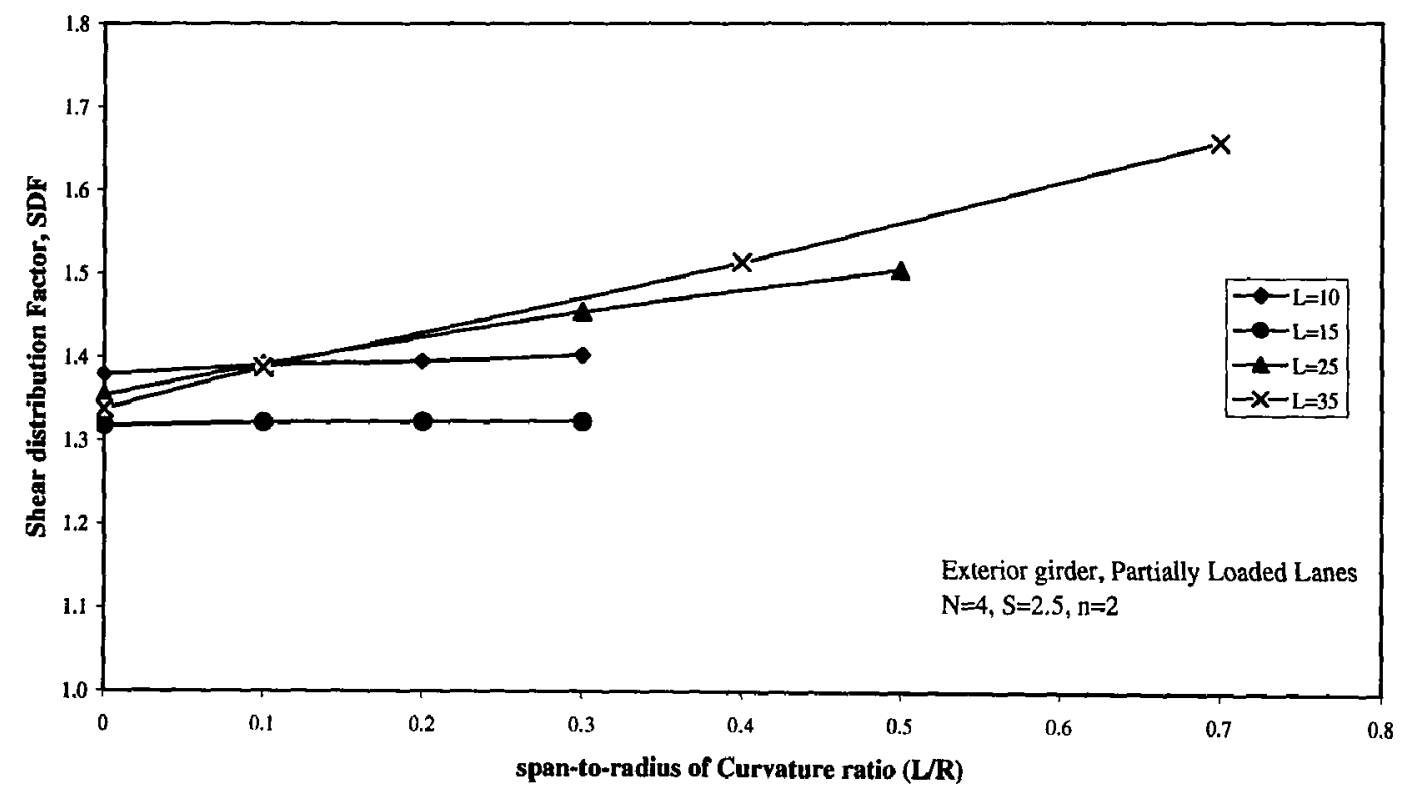

Figure 4. 12 Effect of Curvature on the Shear Distribution Factor for the Exterior Girder due to Partially Loaded Lanes 


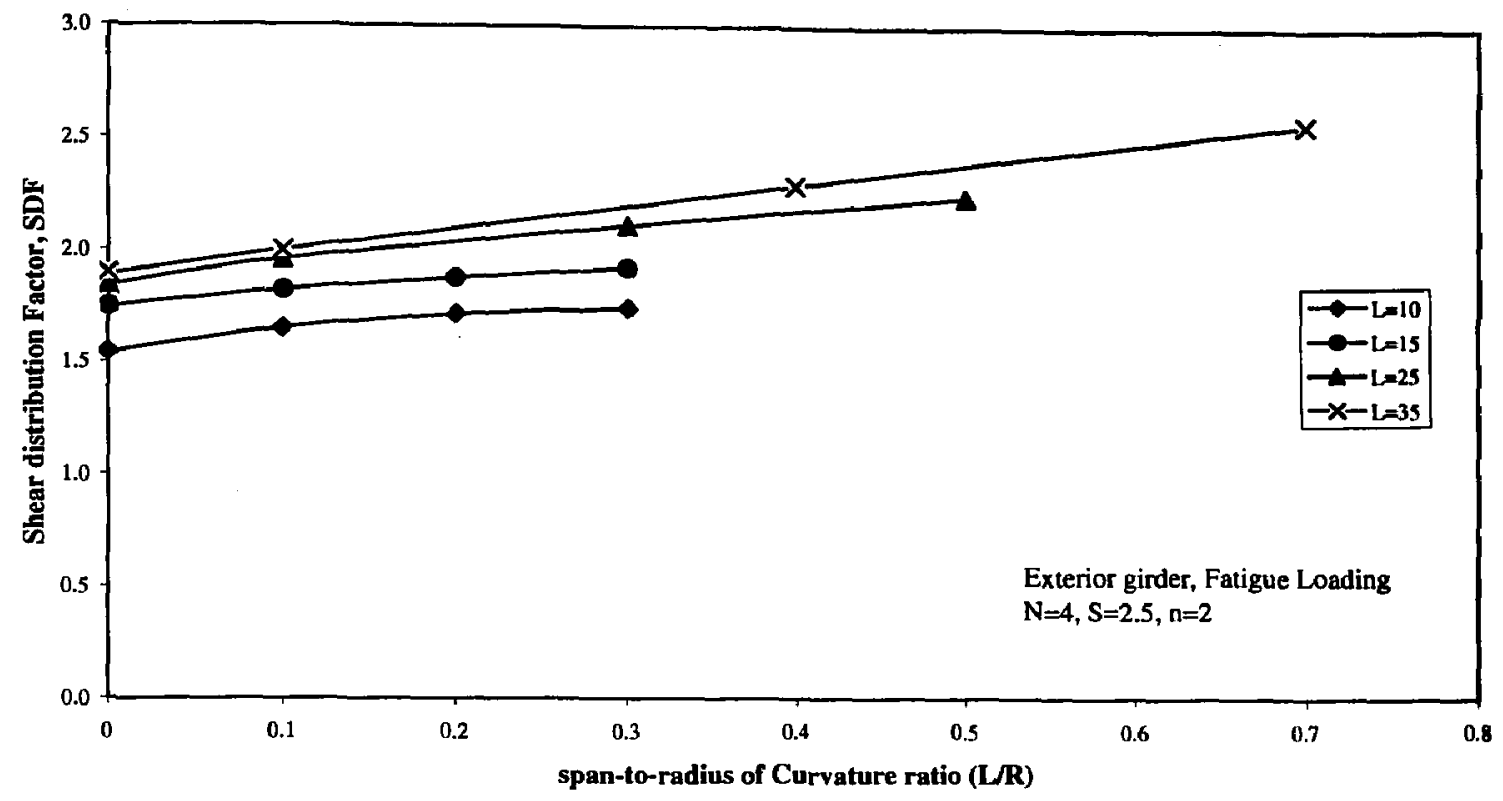

Figure 4. 13 Effect of Curvature on the Shear Distribution Factor for the Exterior Girder due to Fatigue Loading

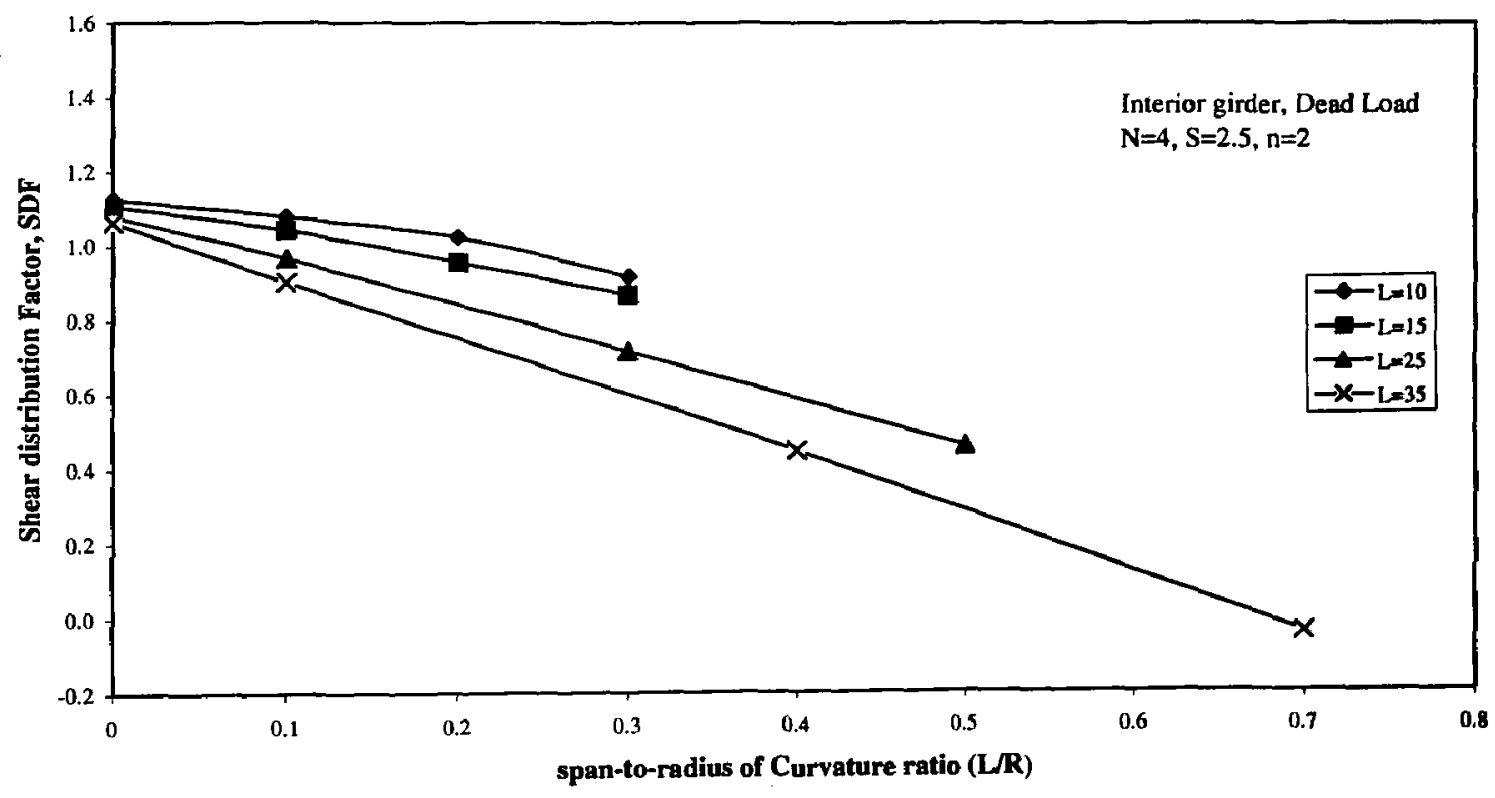

Figure 4. 14 Effect of Curvature on the Shear Distribution Factor for the Interior Girder due to Dead Load 


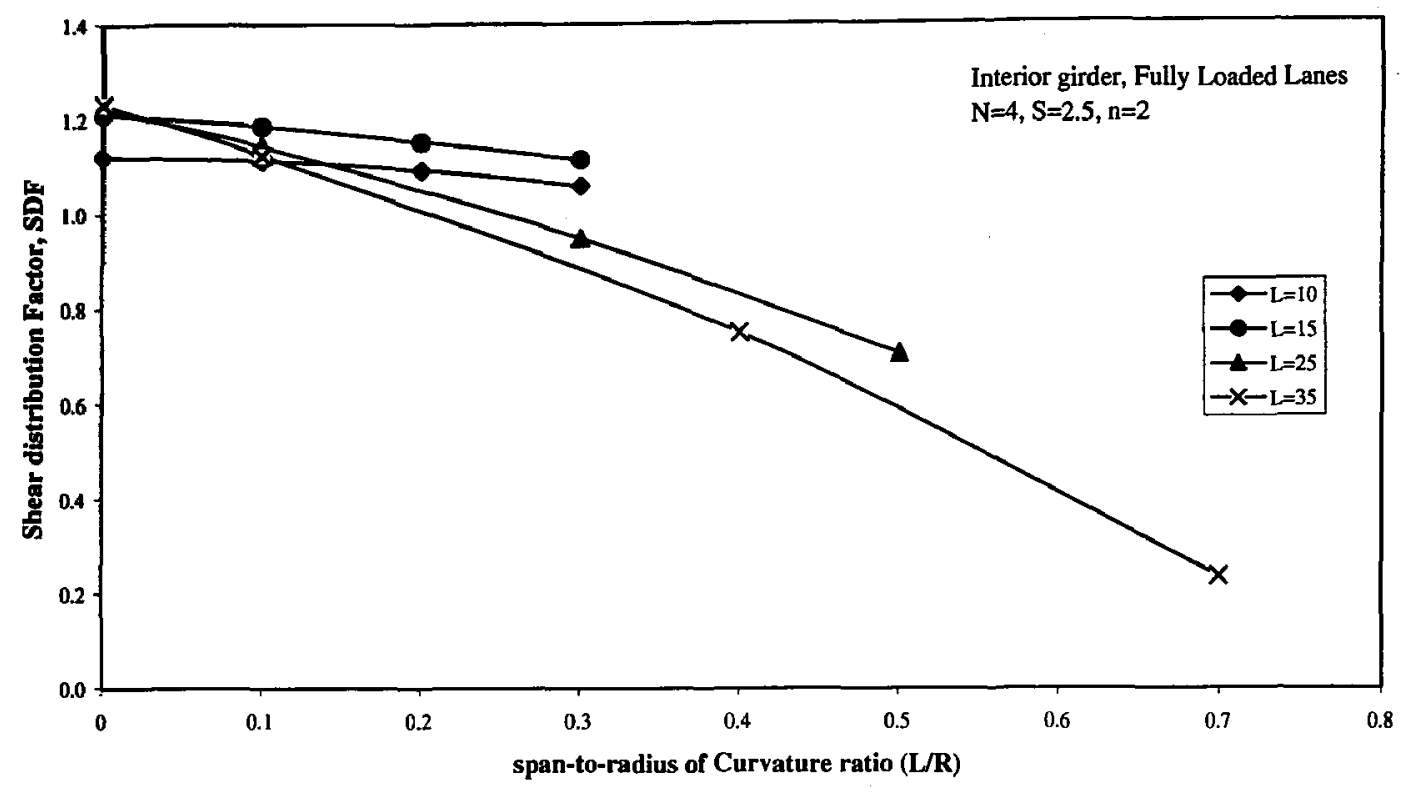

Figure 4. 15 Effect of Curvature on the Shear Distribution Factor for the Interior Girder d to Fully Loaded Lanes

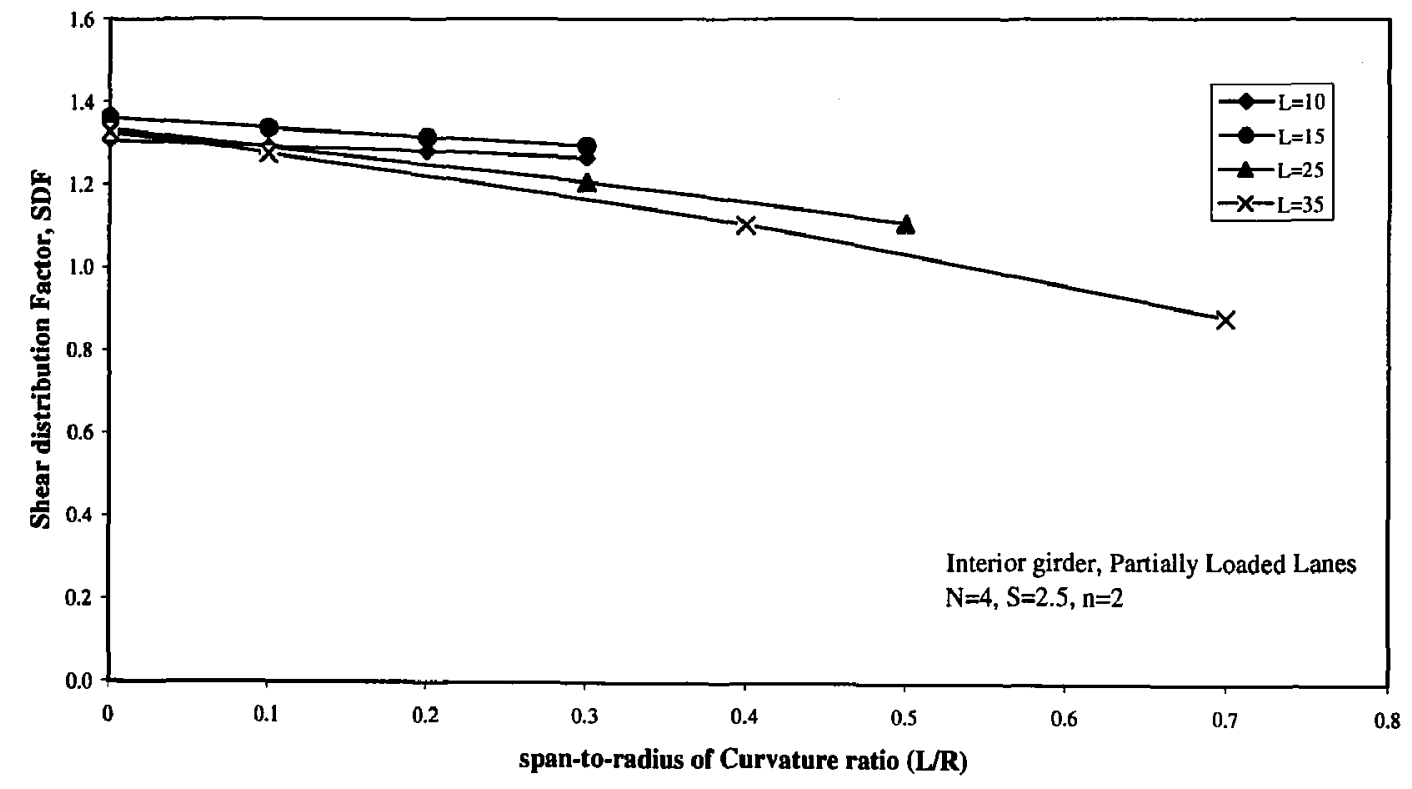

Figure 4. 16 Effect of Curvature on the Shear Distribution Factor for the Interior Girder d to Partially Loaded Lanes 


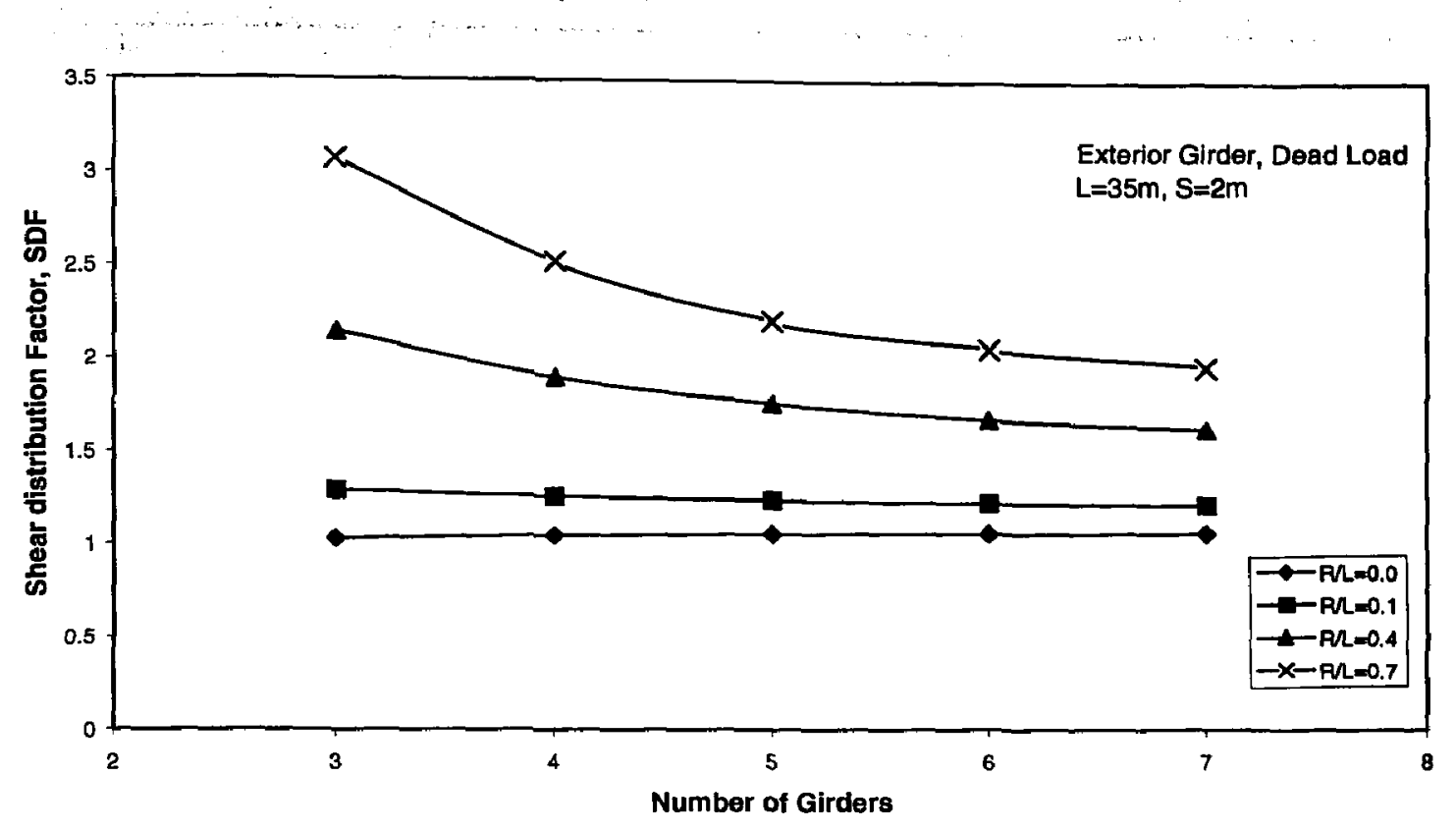

Figure 4. 17 Effect of Number of Girders on the Shear Distribution Factor for the Exterior Girder due to Dead Load

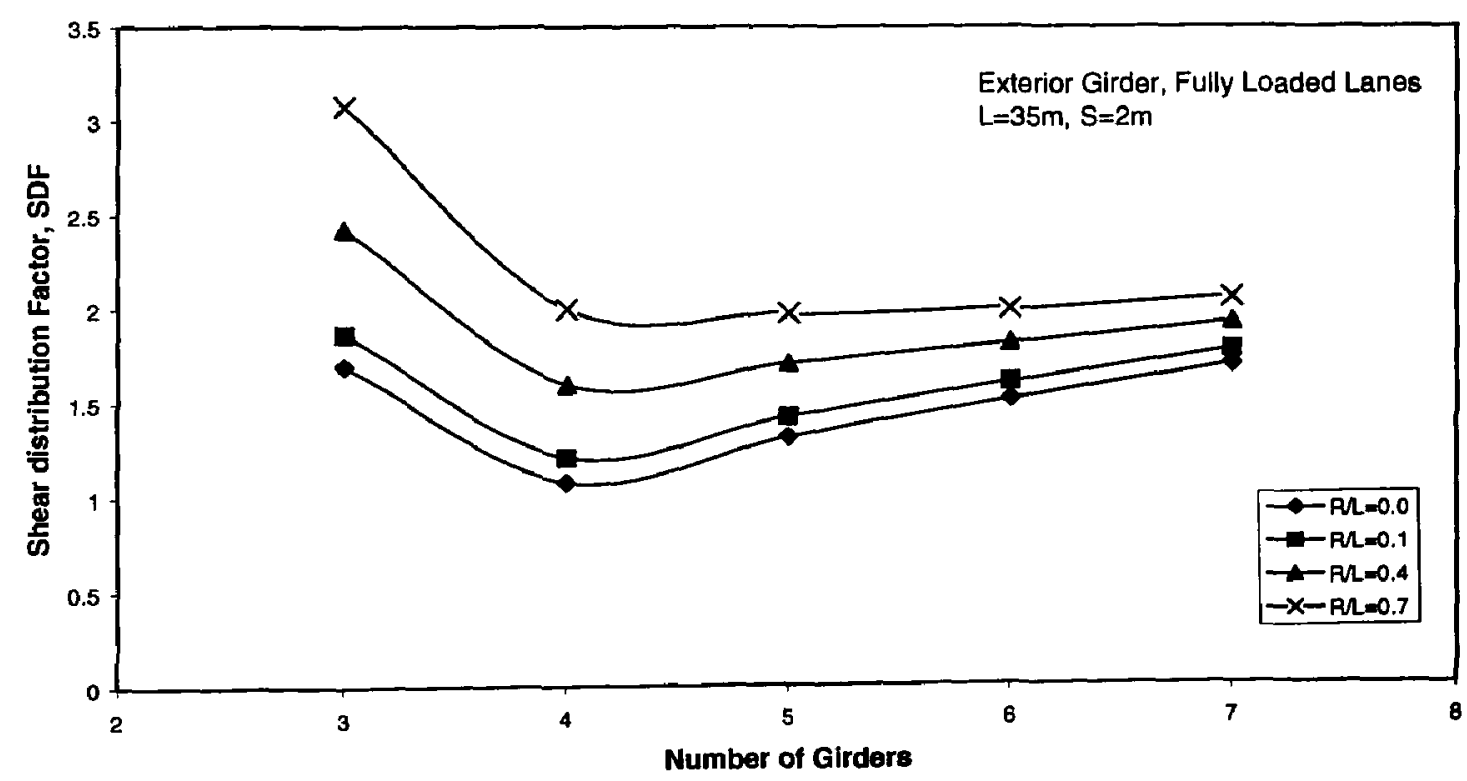

Figure 4. 18 Effect of Number of Girders on the Shear Distribution Factor for the Exterior Girder due to Fully Loaded Lanes 


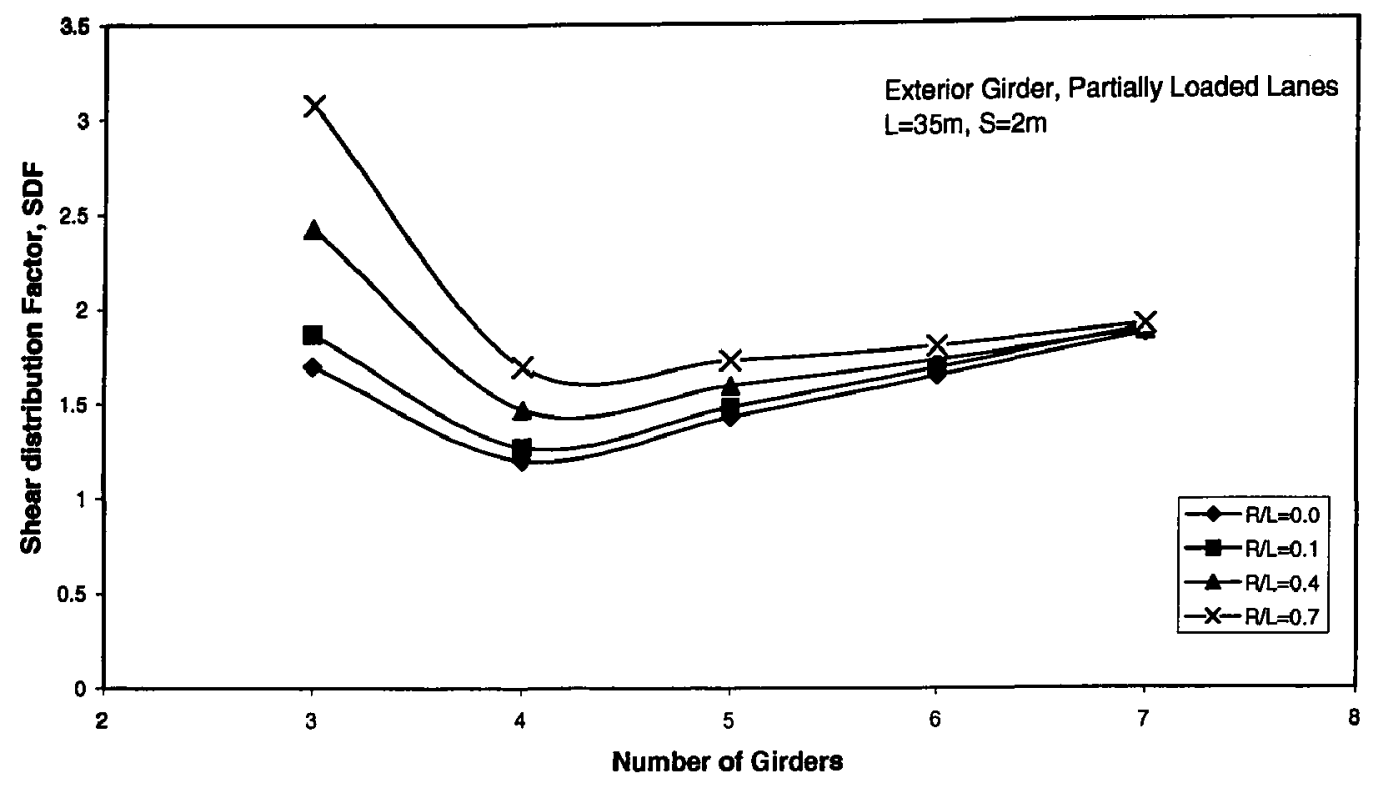

Figure 4.19 Effect of Number of Girders on the Shear Distribution Factor for the Exterior Girder due to Partially Loaded Lanes

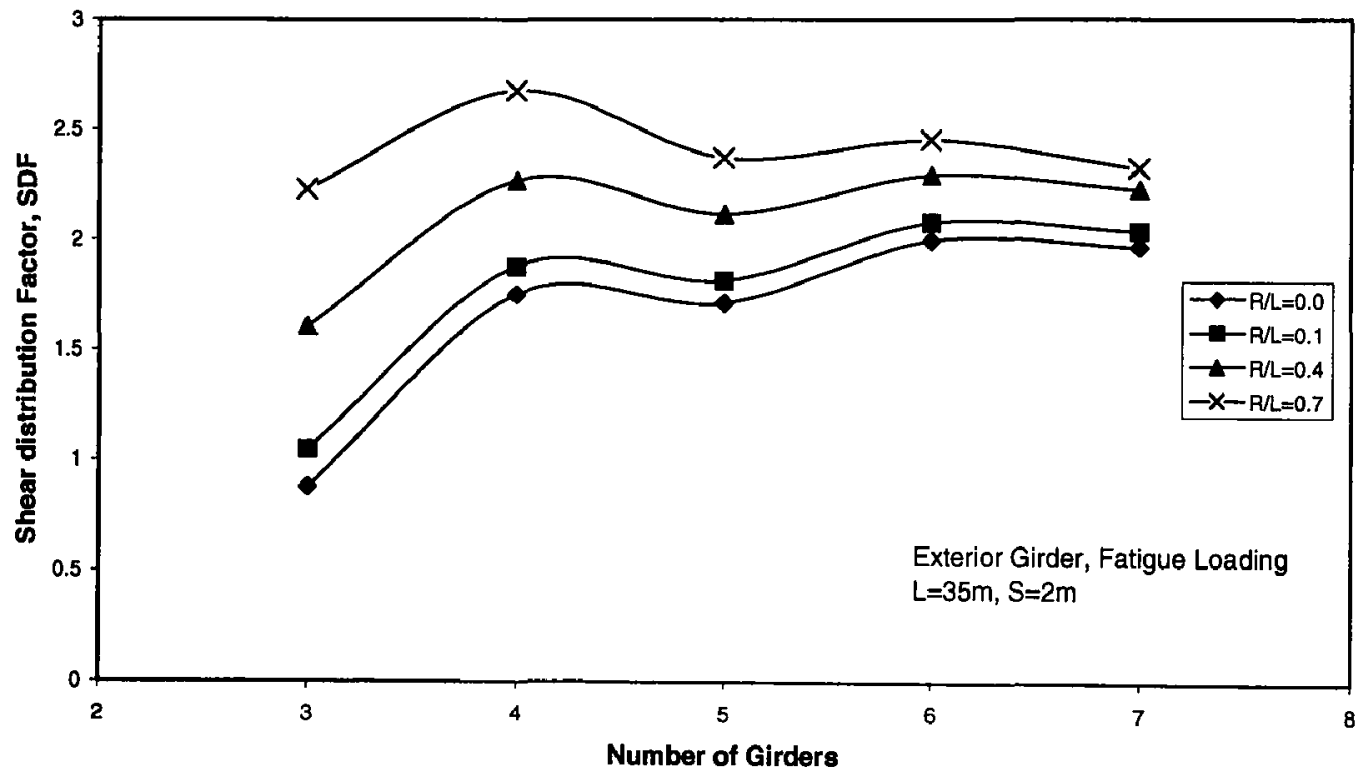

Figure 4. 20 Effect of Number of Girders on the Shear Distribution Factor for the Exterior Girder due to Fatigue Loading 


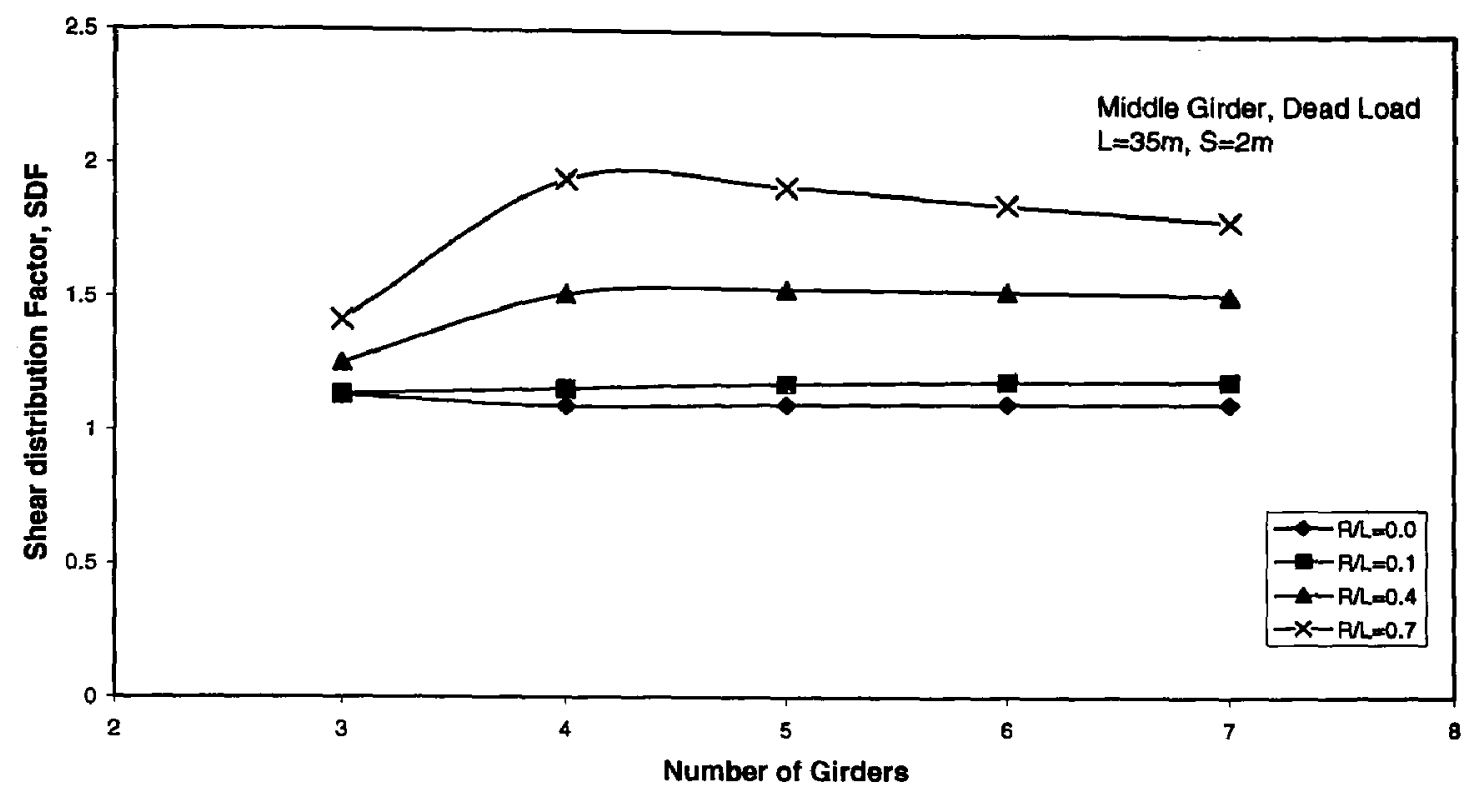

Figure 4. 21 Effect of Number of Girders on the Shear Distribution Factor for the Middle girder due to Dead Load

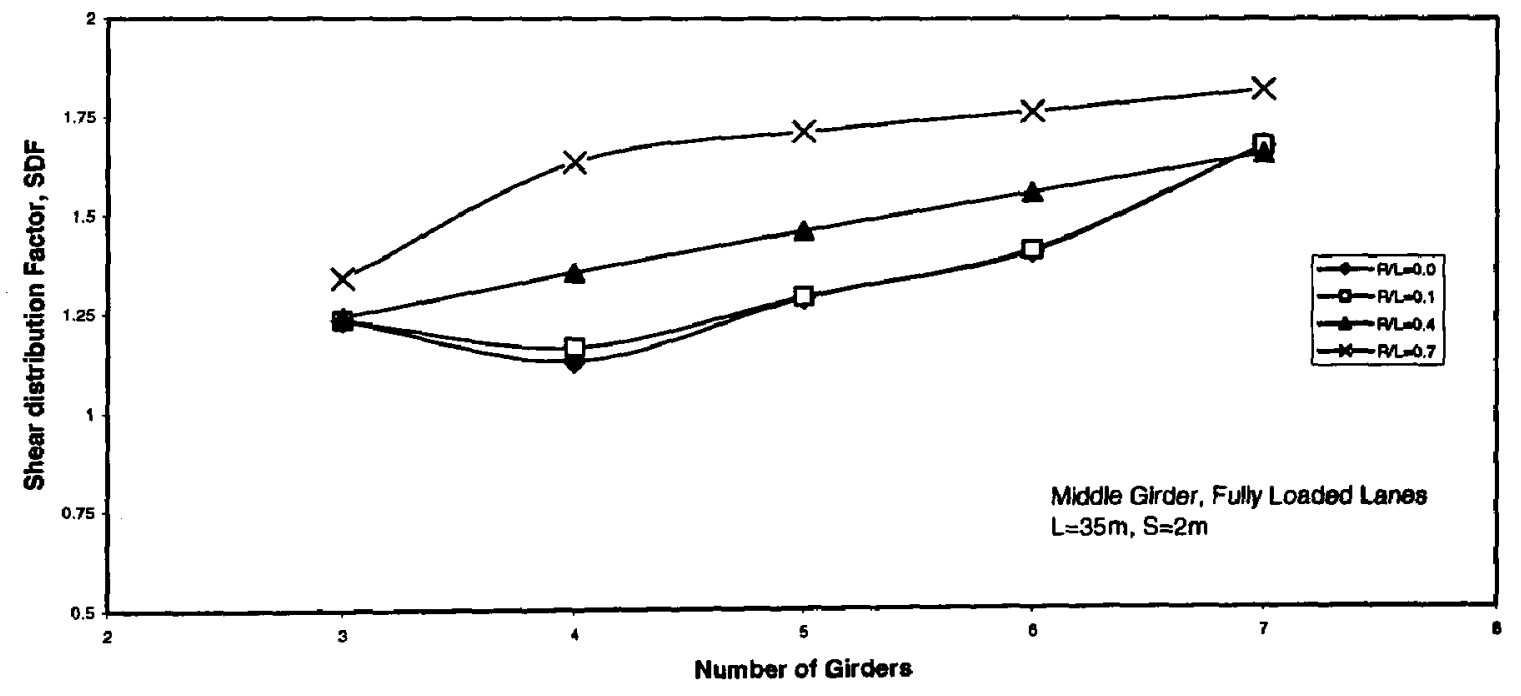

Figure 4. 22 Effect of Number of Girders on the Shear Distribution Factor for the Middle Girder due to Fully Loaded Lanes 


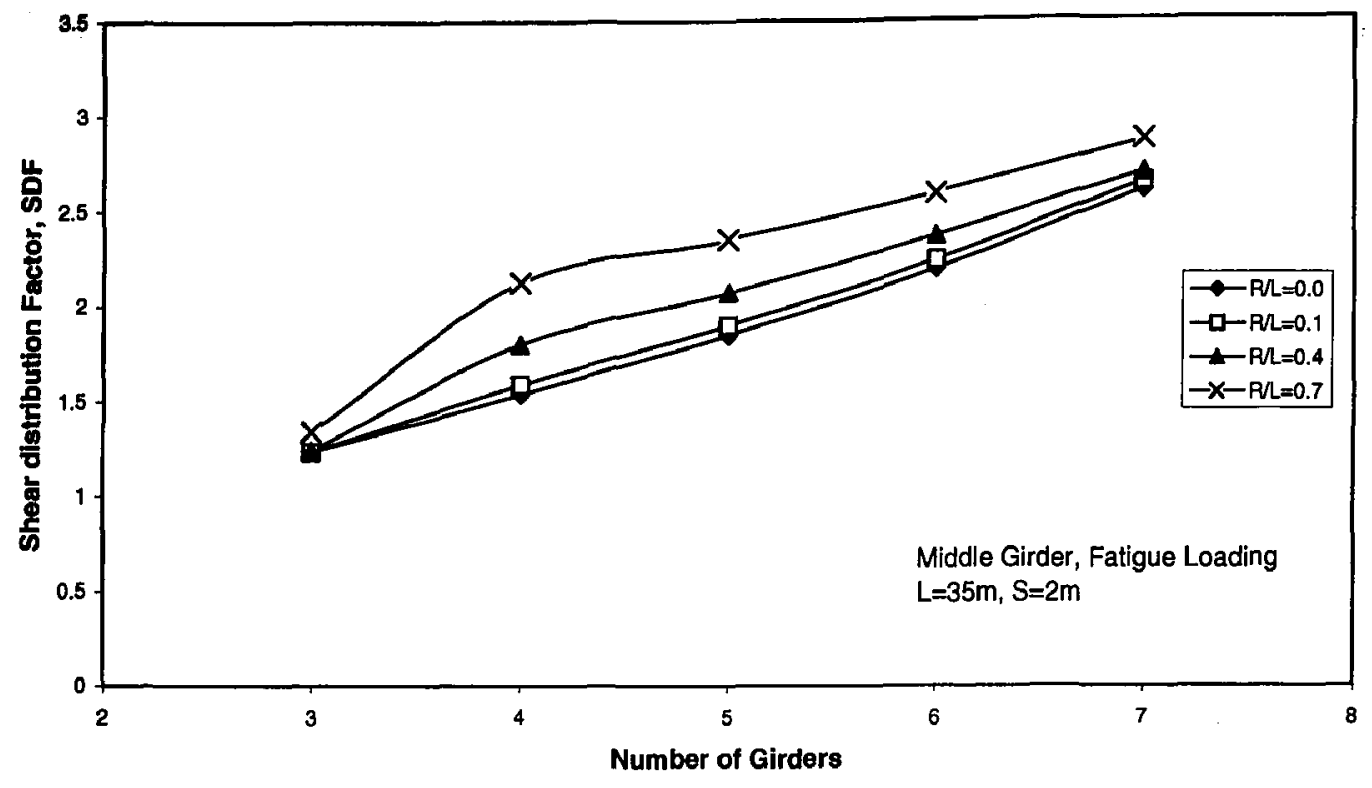

Figure 4.23 Effect of Number of Girders on the Shear Distribution Factor for the Middle girder due to Fatigue Loading

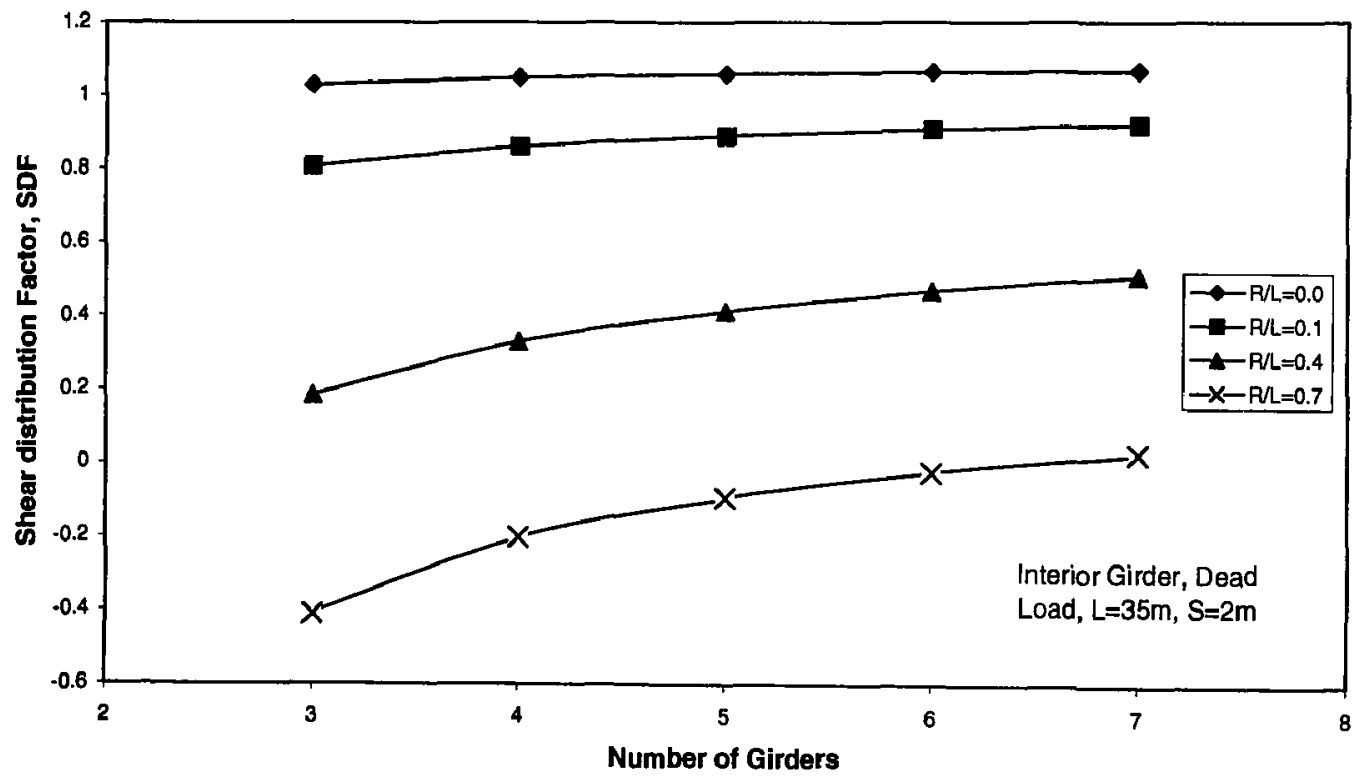

Figure 4.24 Effect of Number of Girders on the Shear Distribution Factor for the interior Girder due to Dead Load 


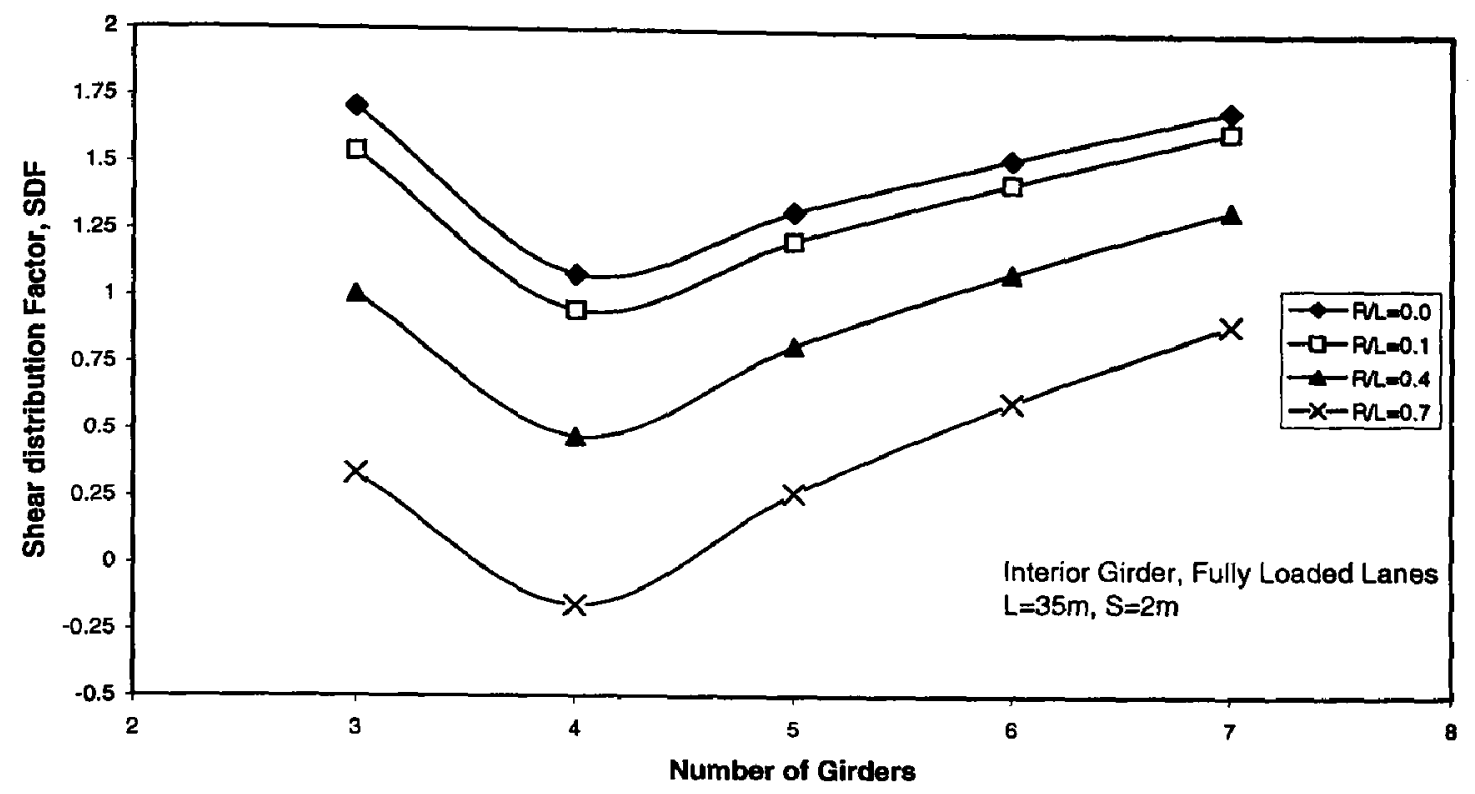

Figure 4. 25 Effect of Number of Girders on the Shear Distribution Factor for the Interior Girder due to Fully Loaded Lanes

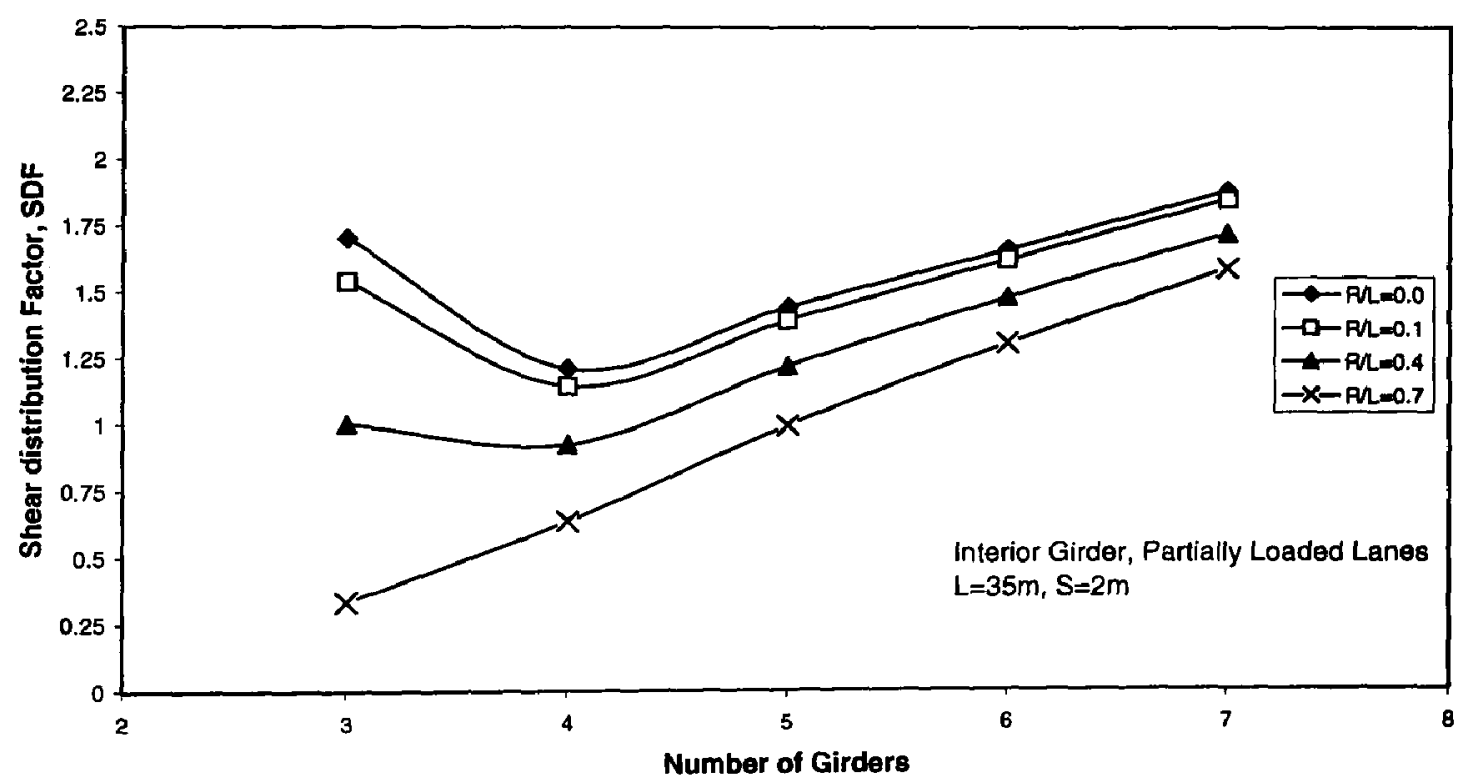

Figure 4. 26 Effect of Number of Girders on the Shear Distribution Factor for the Interior Girder due to Partially Loaded Lanes 


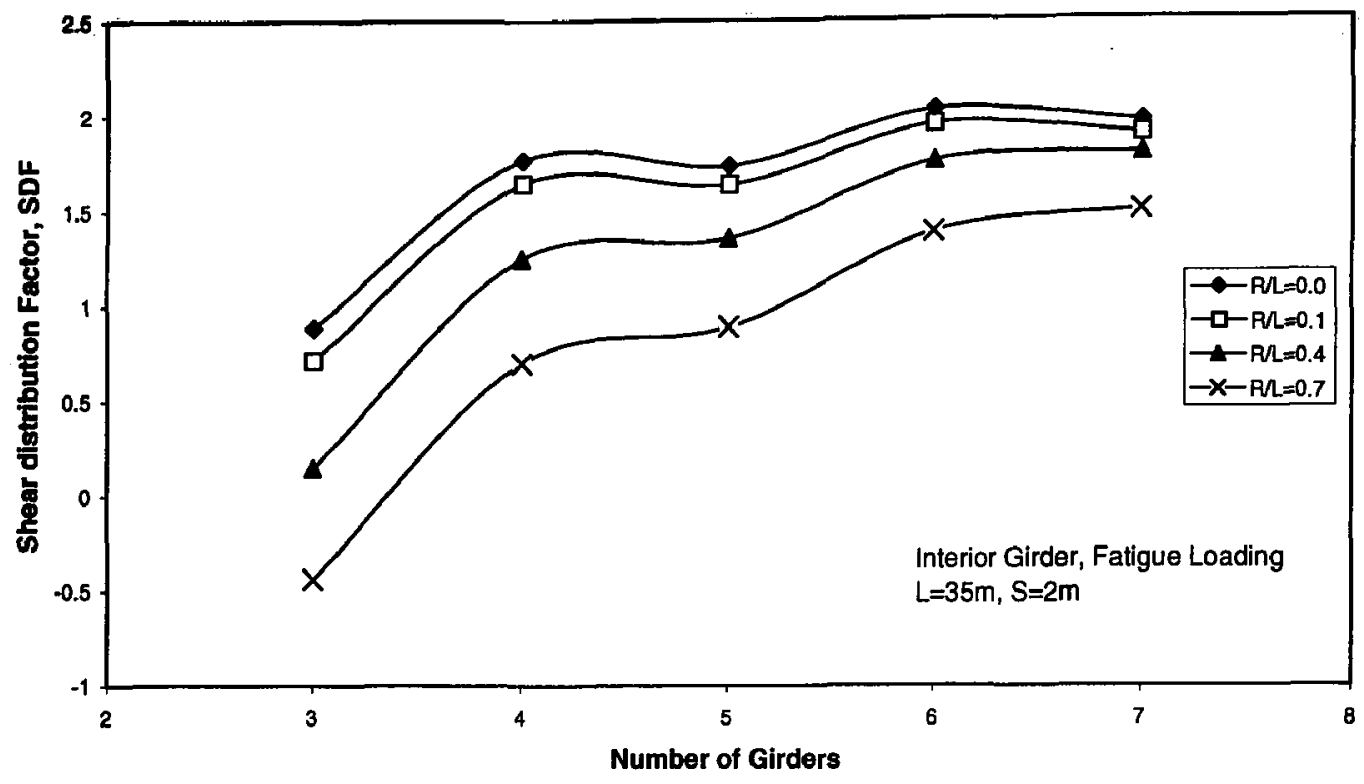

Figure 4. 27 Effect of Number of Girders on the Shear Distribution Factor for the Interior Girder due to Fatigue Loading

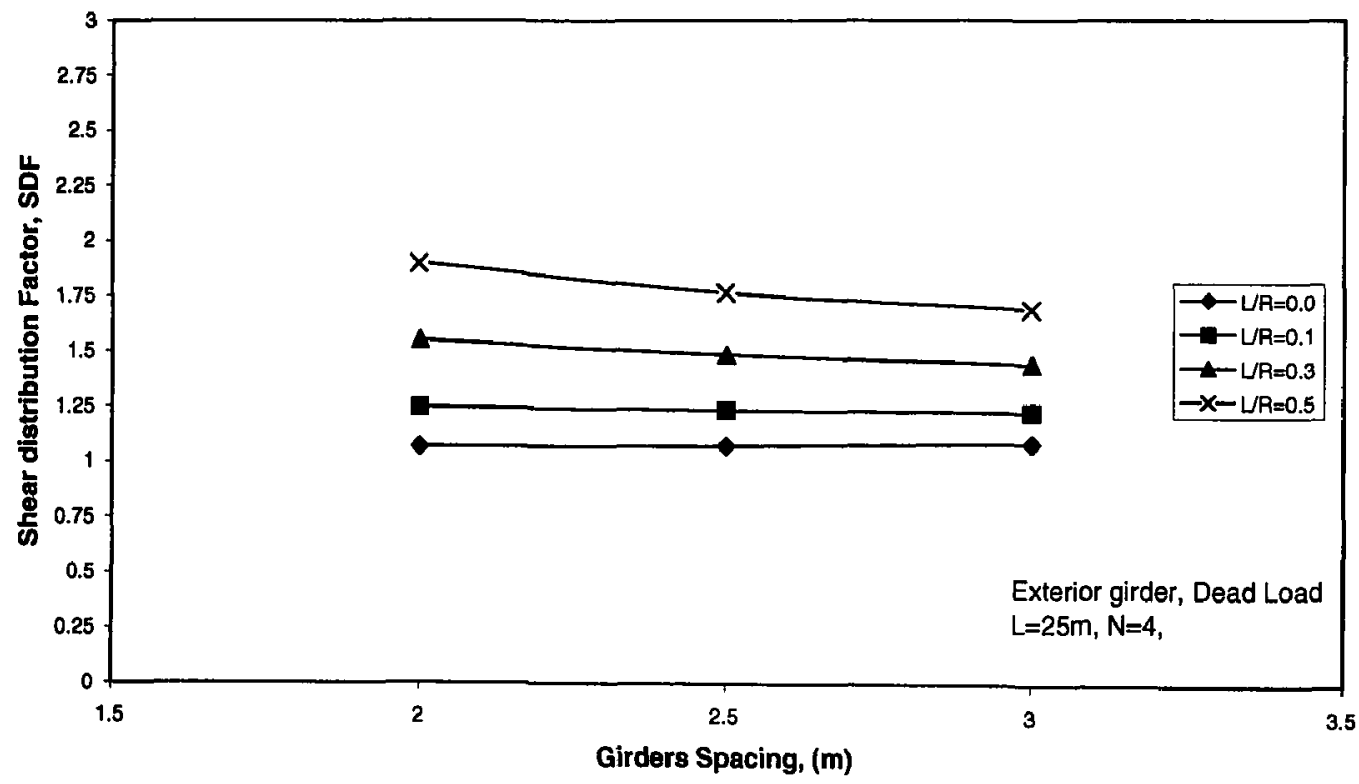

Figure 4. 28 Effect of Girder Spacing on the Shear Distribution Factor for the Exterior Girde1 due to Dead Load 


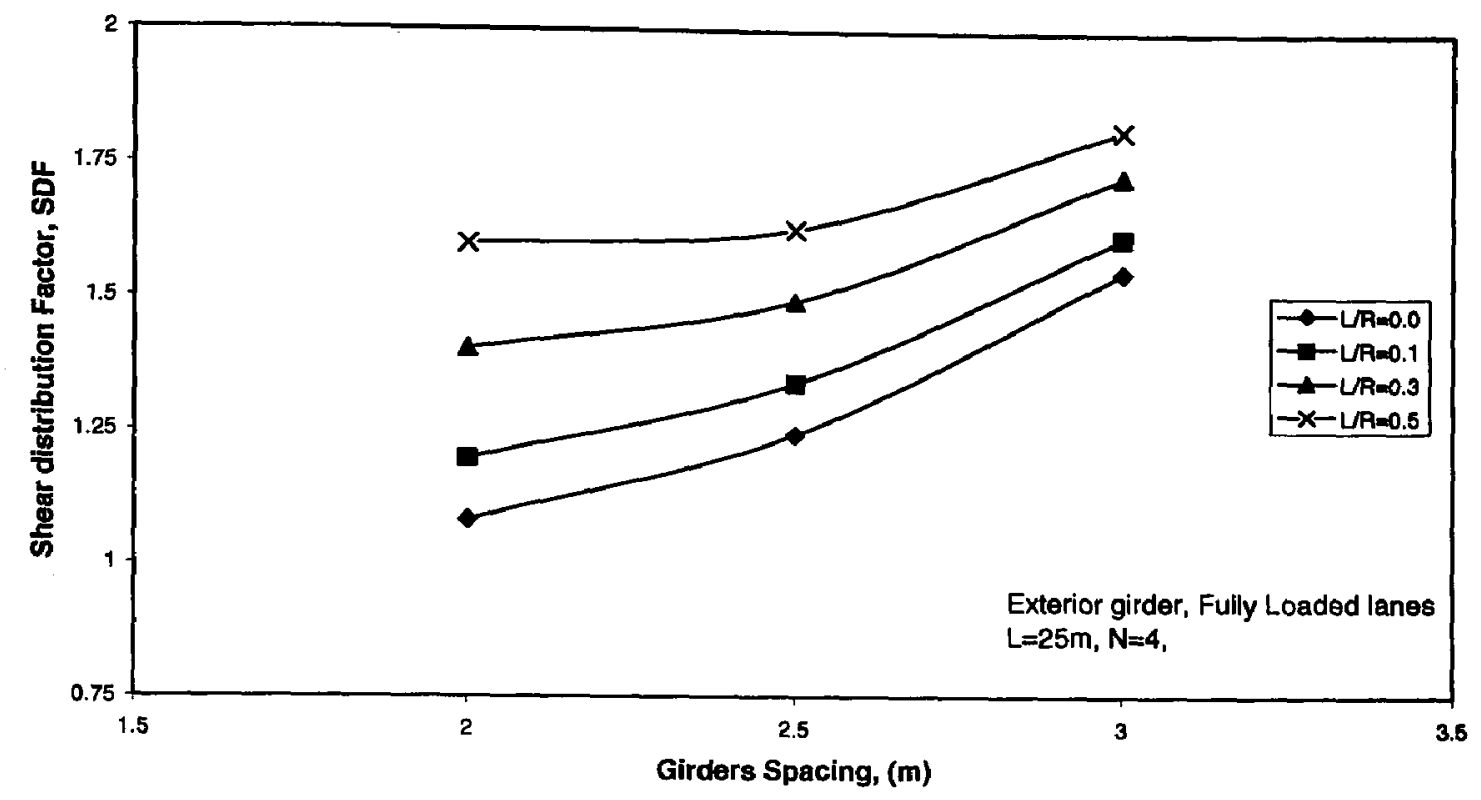

Figure 4. 29 Effect of Girder Spacing on the Shear Distribution Factor for the Exterior Girder due to Fully Loaded Lanes

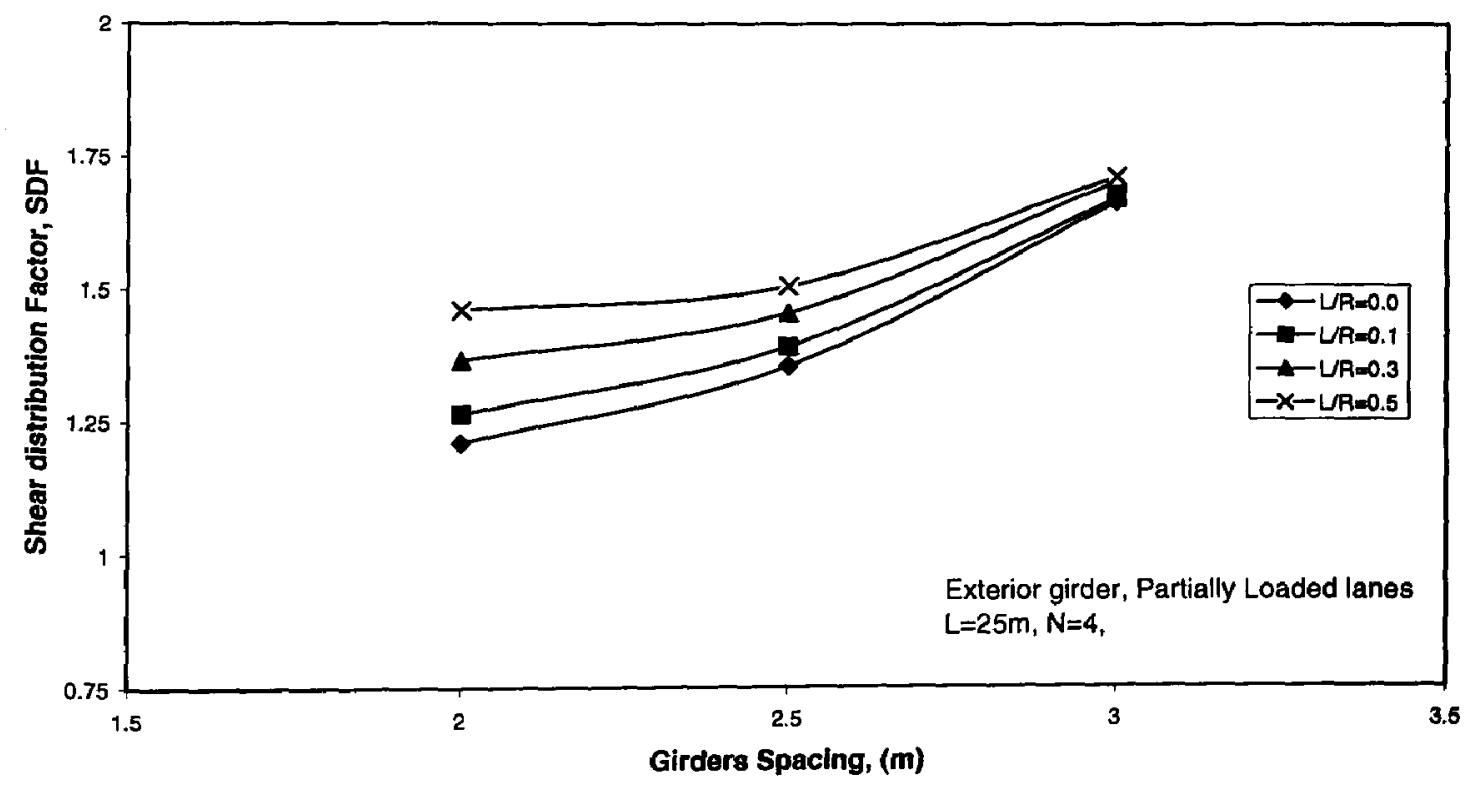

Figure 4. 30 Effect of Girder Spacing on the Shear Distribution Factor for the Exterior Girder due to Partially Loaded Lanes 


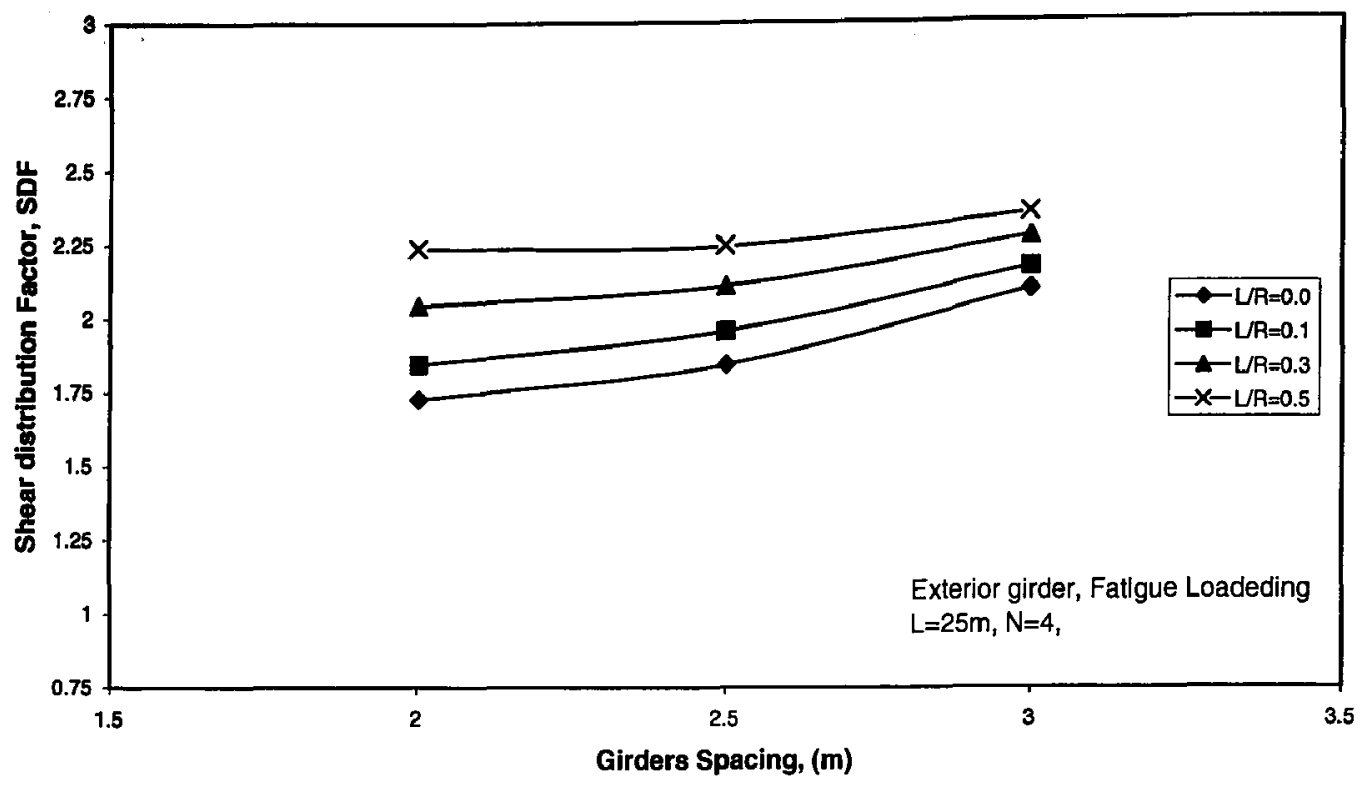

Figure 4. 31 Effect of Girder Spacing on the Shear Distribution Factor for the Exterior Girder due to Fatigue Loading

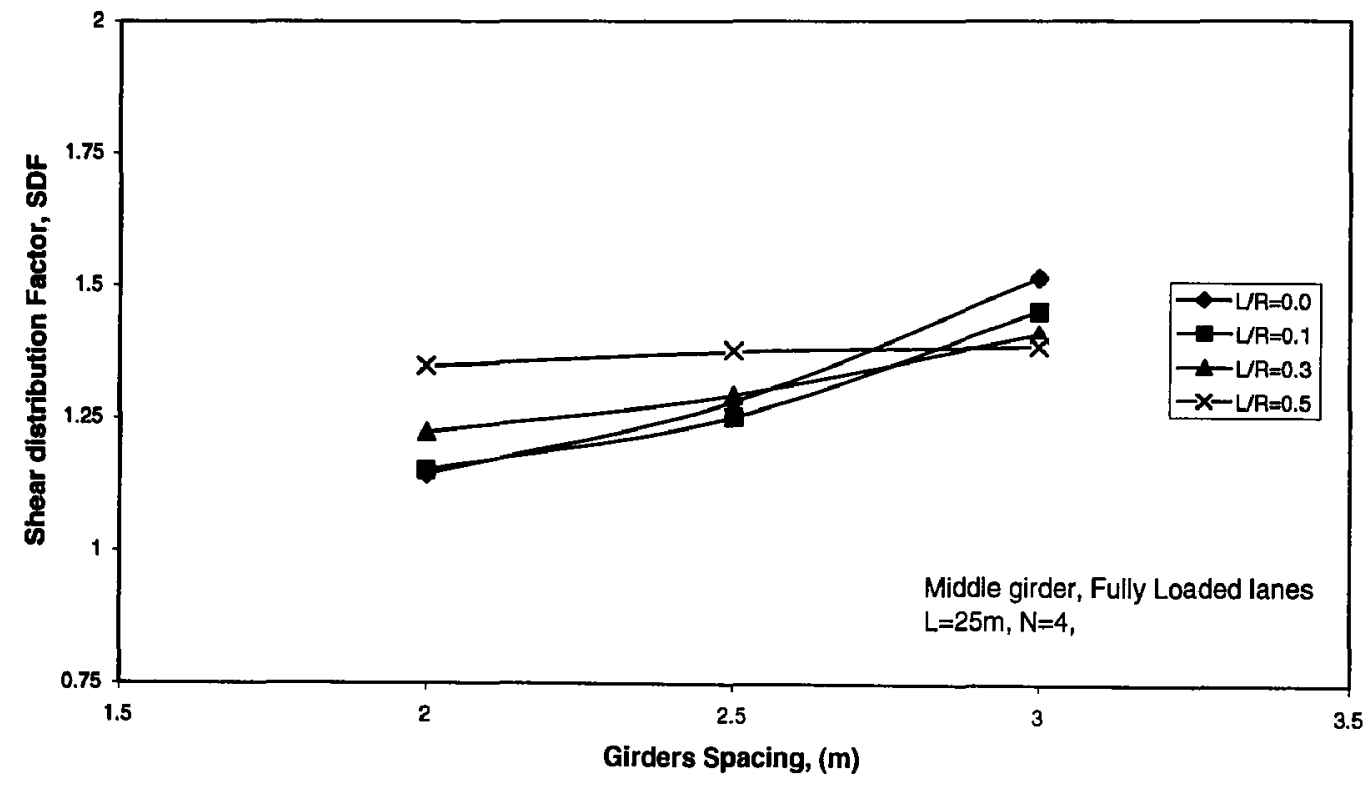

Figure 4. 32 Effect of Girder Spacing on the Shear Distribution Factor for the Middle Girder due to Fully Loaded Lanes 


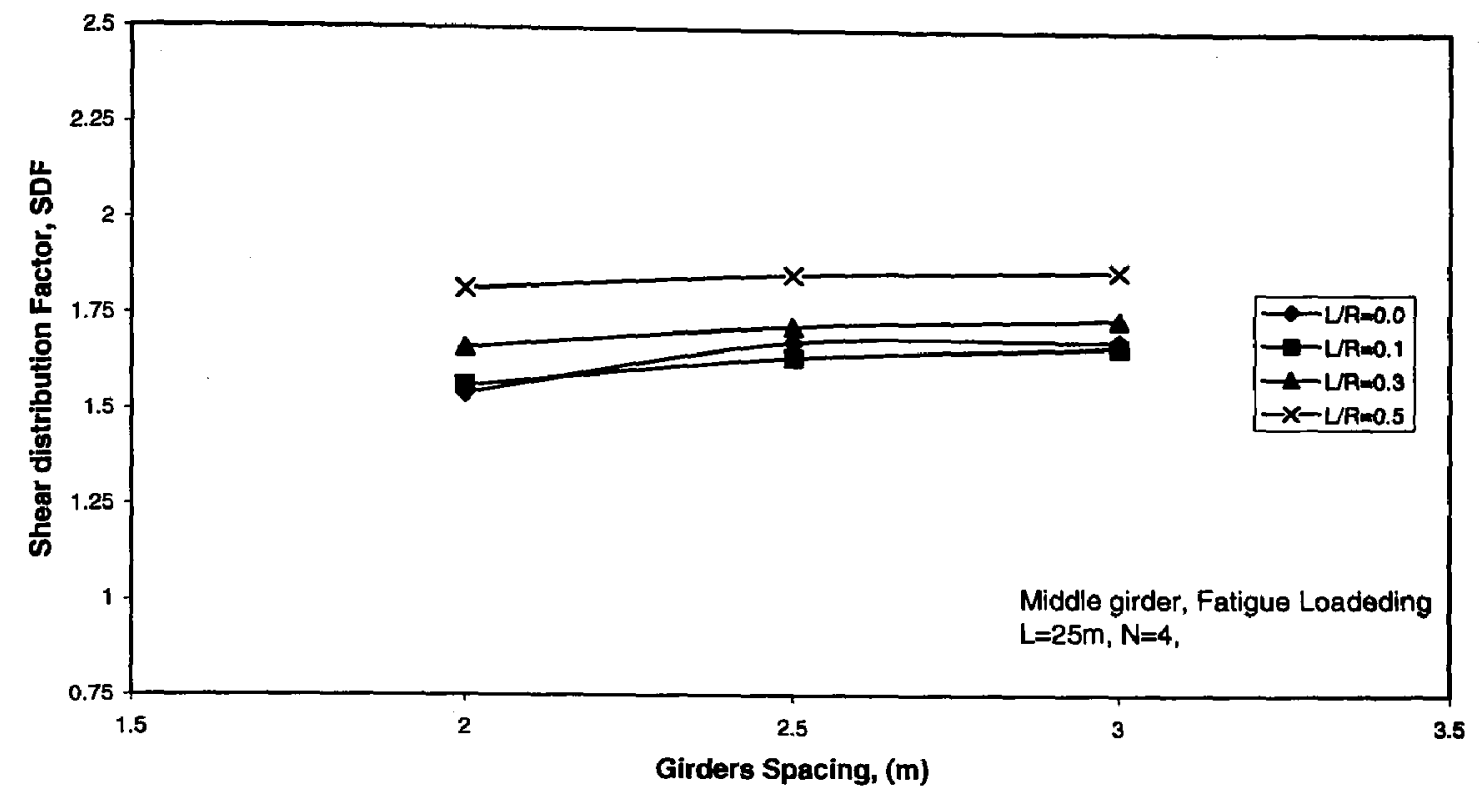

Figure 4. 33 Effect of Girder Spacing on the Shear Distribution Factor for the Middle Girder due to Fatigue Loading

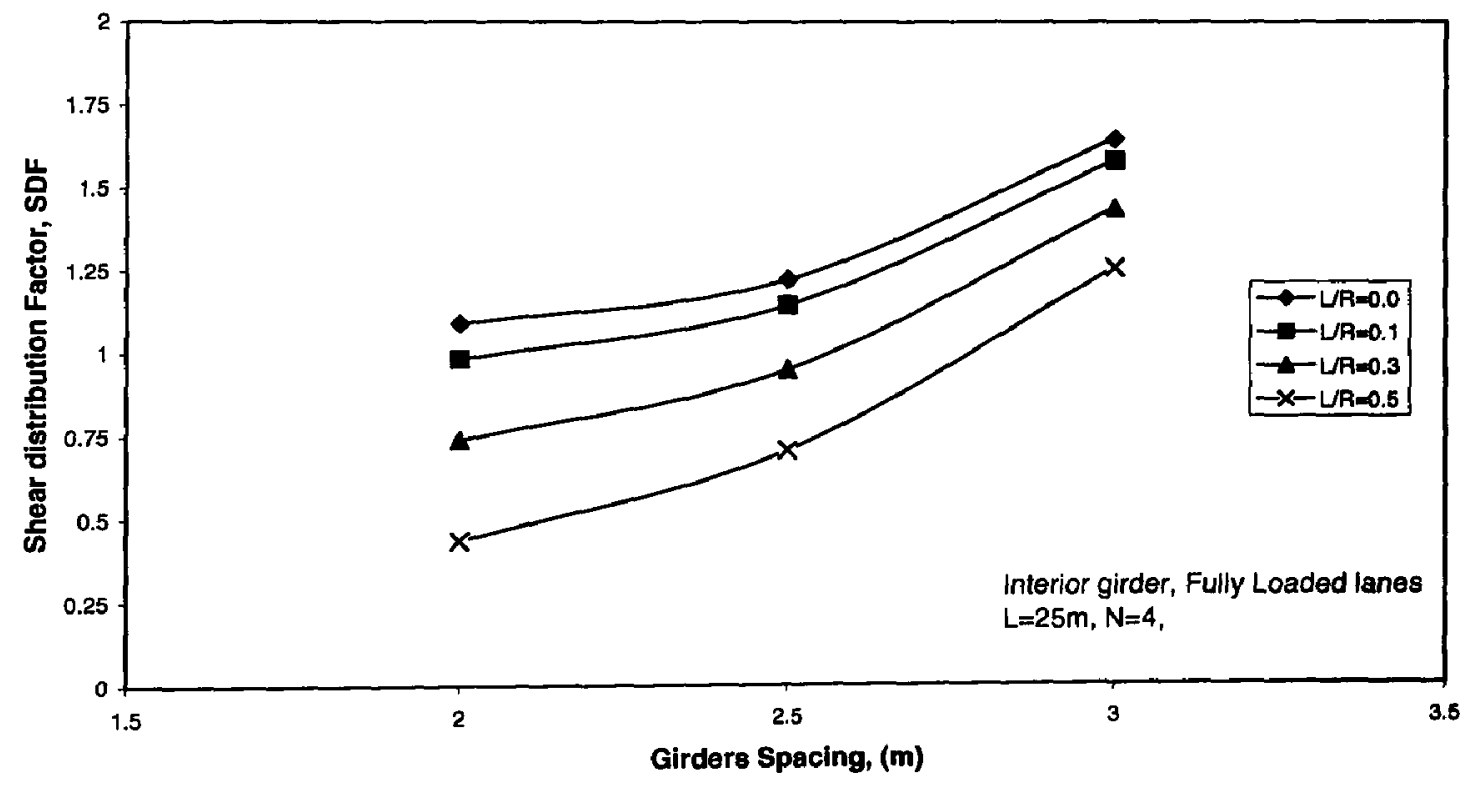

Figure 4. 34 Effect of Girder Spacing on the Shear Distribution Factor for the Interior Girder due to fully Loaded Lanes 


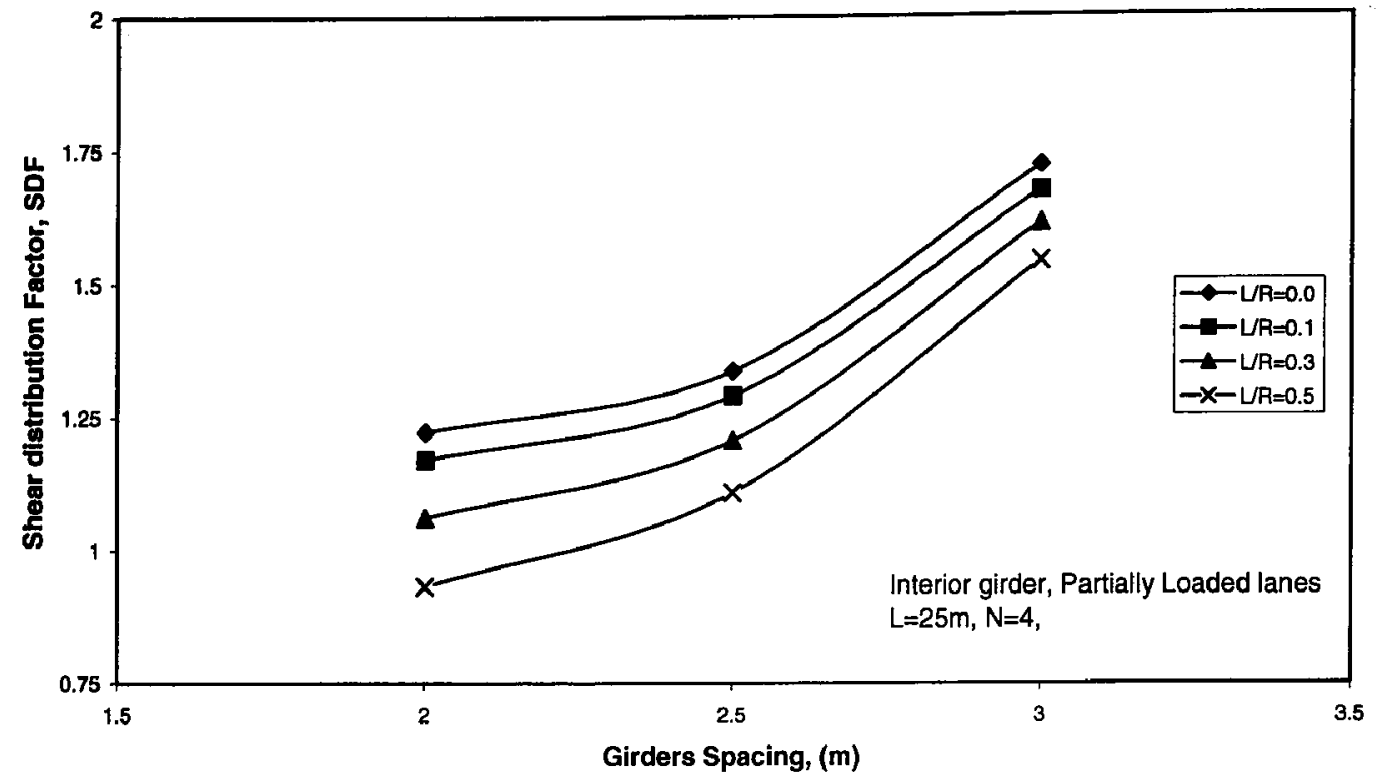

Figure 4. 35 Effect of Girder Spacing on the Shear Distribution Factor for the Interior Girdel due to Partially Loaded Lanes

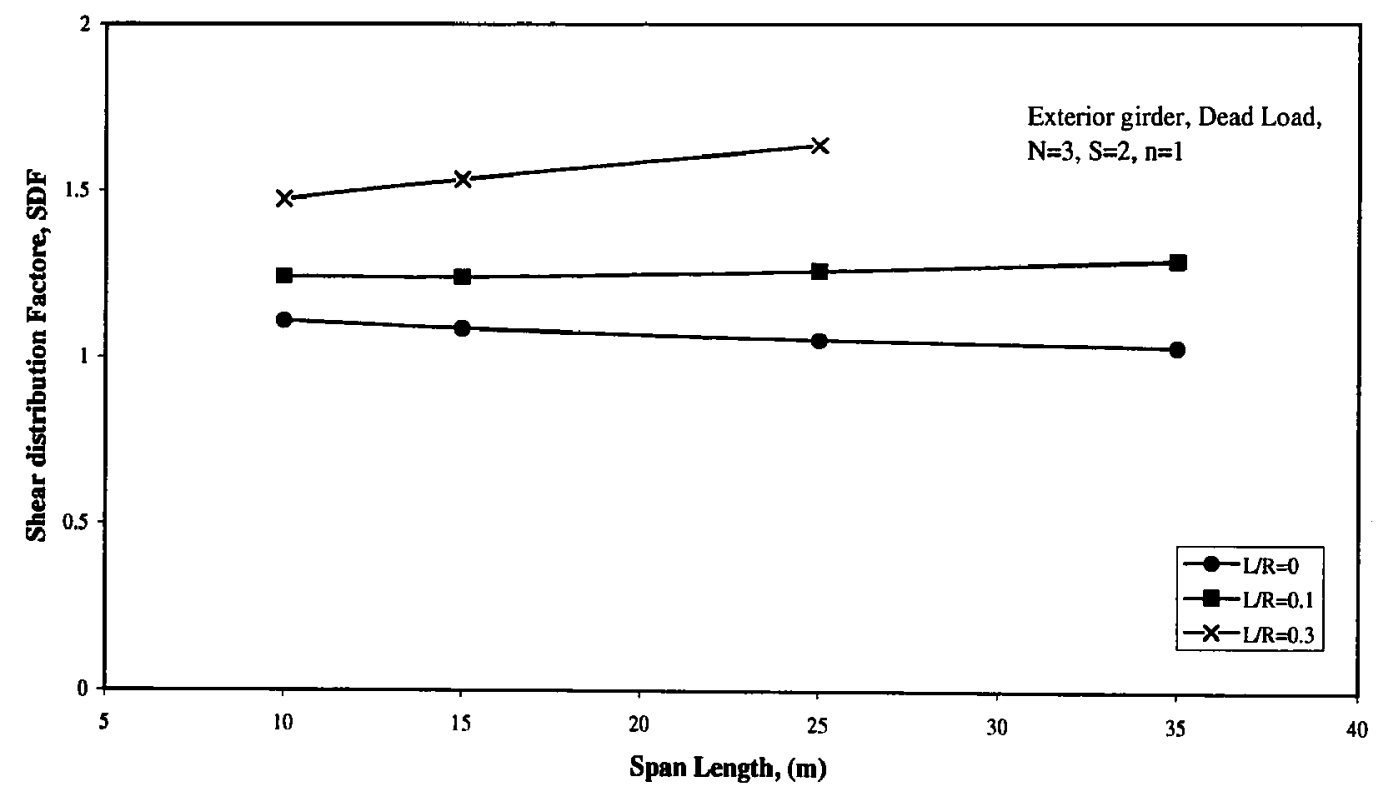

Figure 4. 36 Effect of Span Length on the Shear Distribution Factor for the Exterior Girder due to Dead Load 


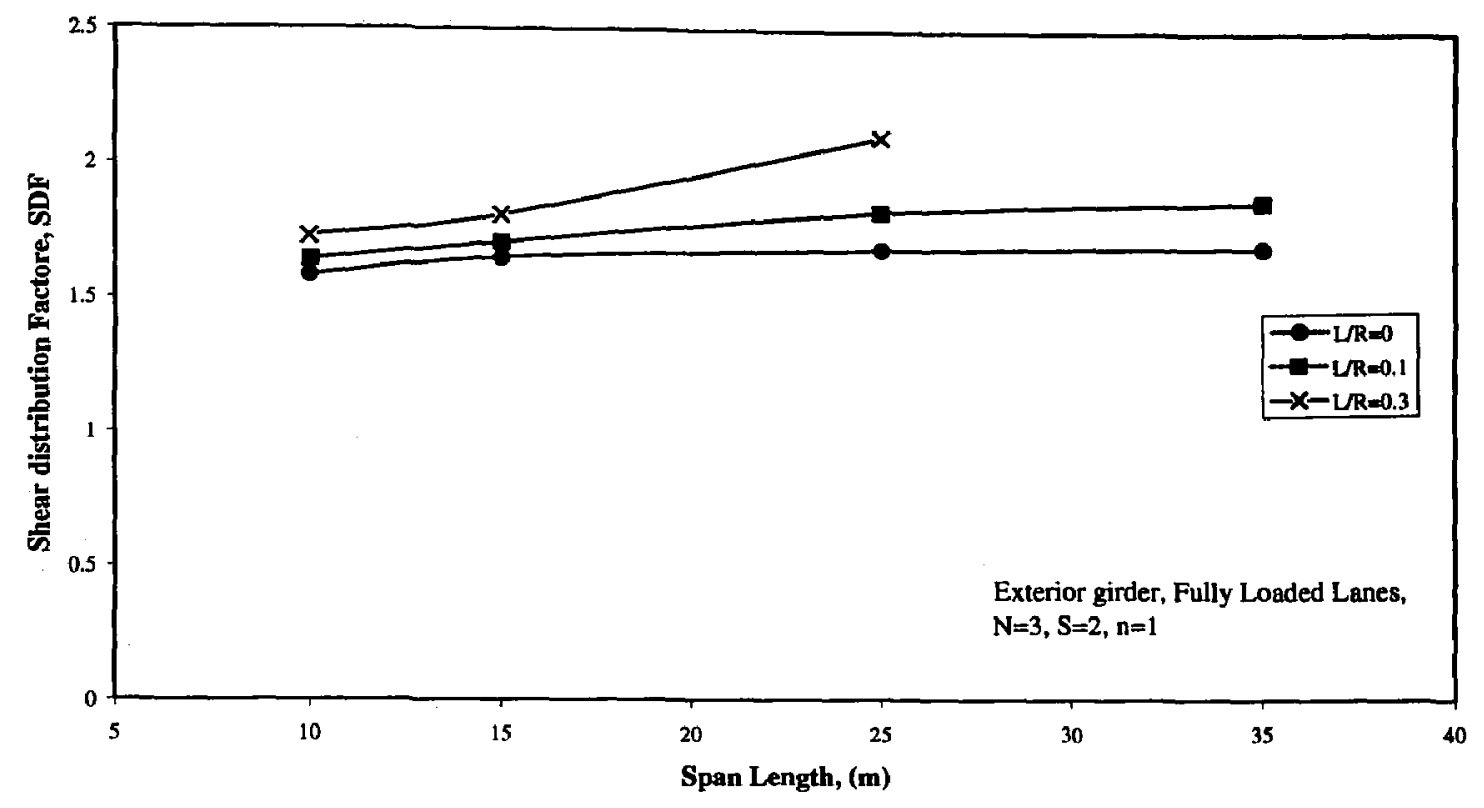

Figure 4. 37 Effect of Span Length on the Shear Distribution Factor for the Exterior Girder due to Fully Loaded Lanes

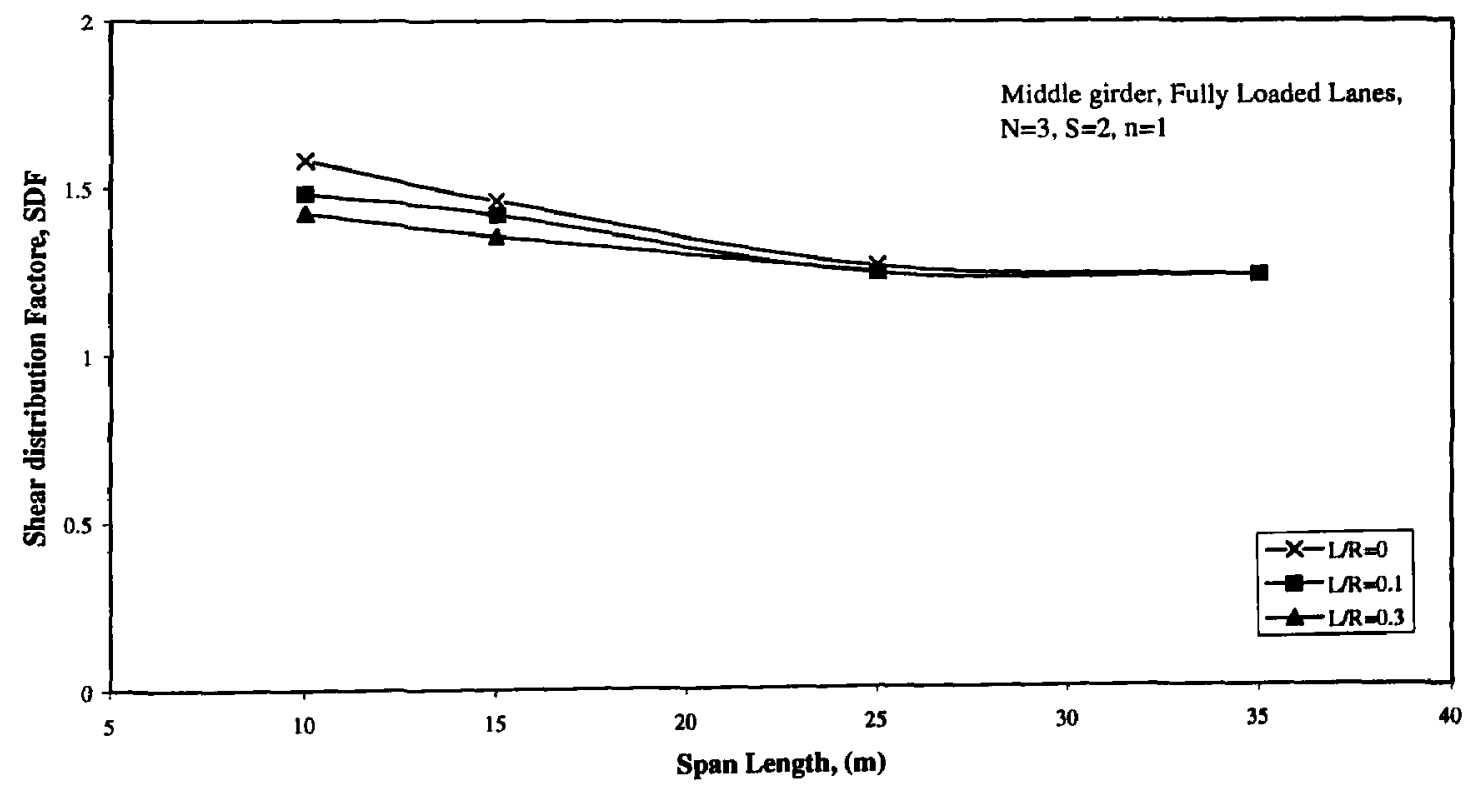

Figure 4. 38 Effect of Span Length on the Shear Distribution Factor for the Middle Girder due to Fully Loaded Lanes 


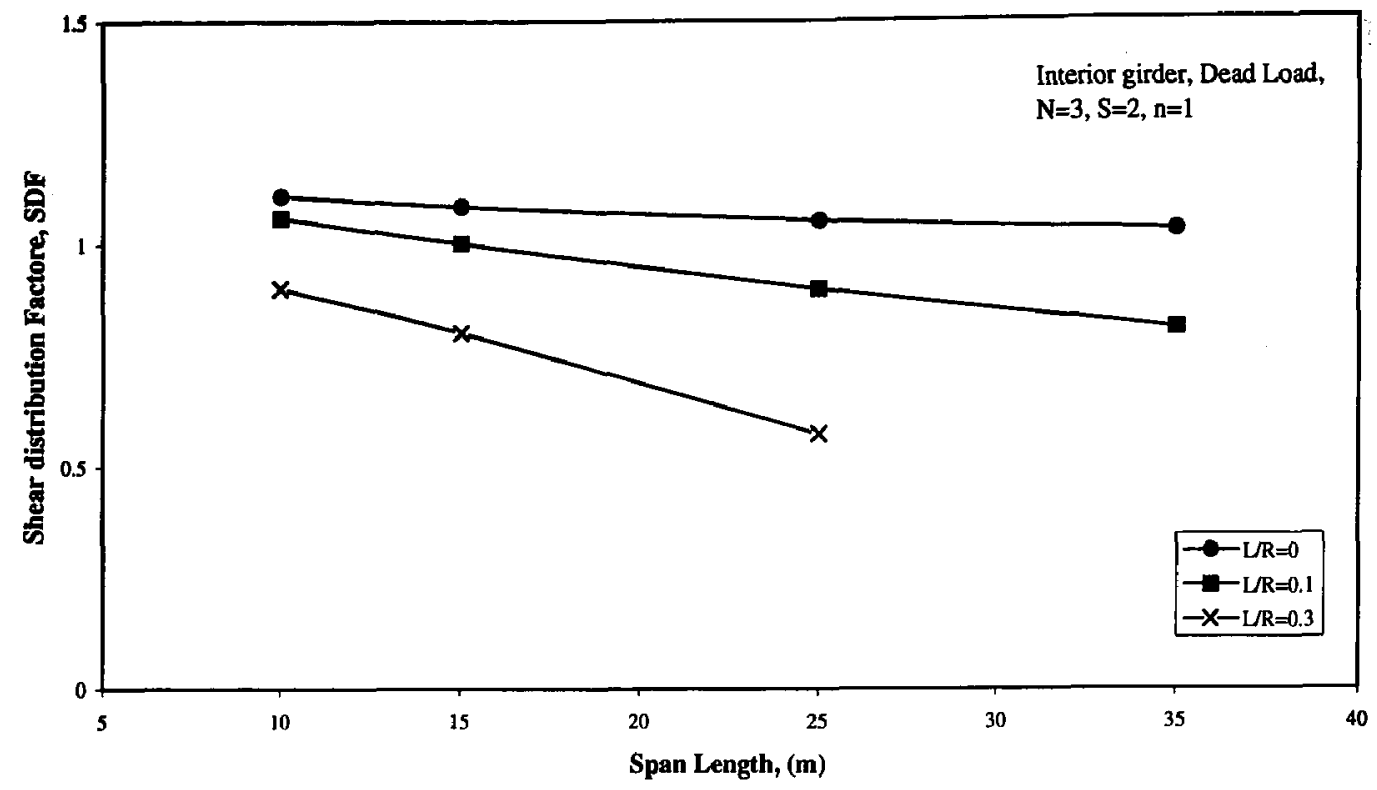

Figure 4. 39 Effect of Span Length on the Shear Distribution Factor for the Interior Girder due to Dead Load

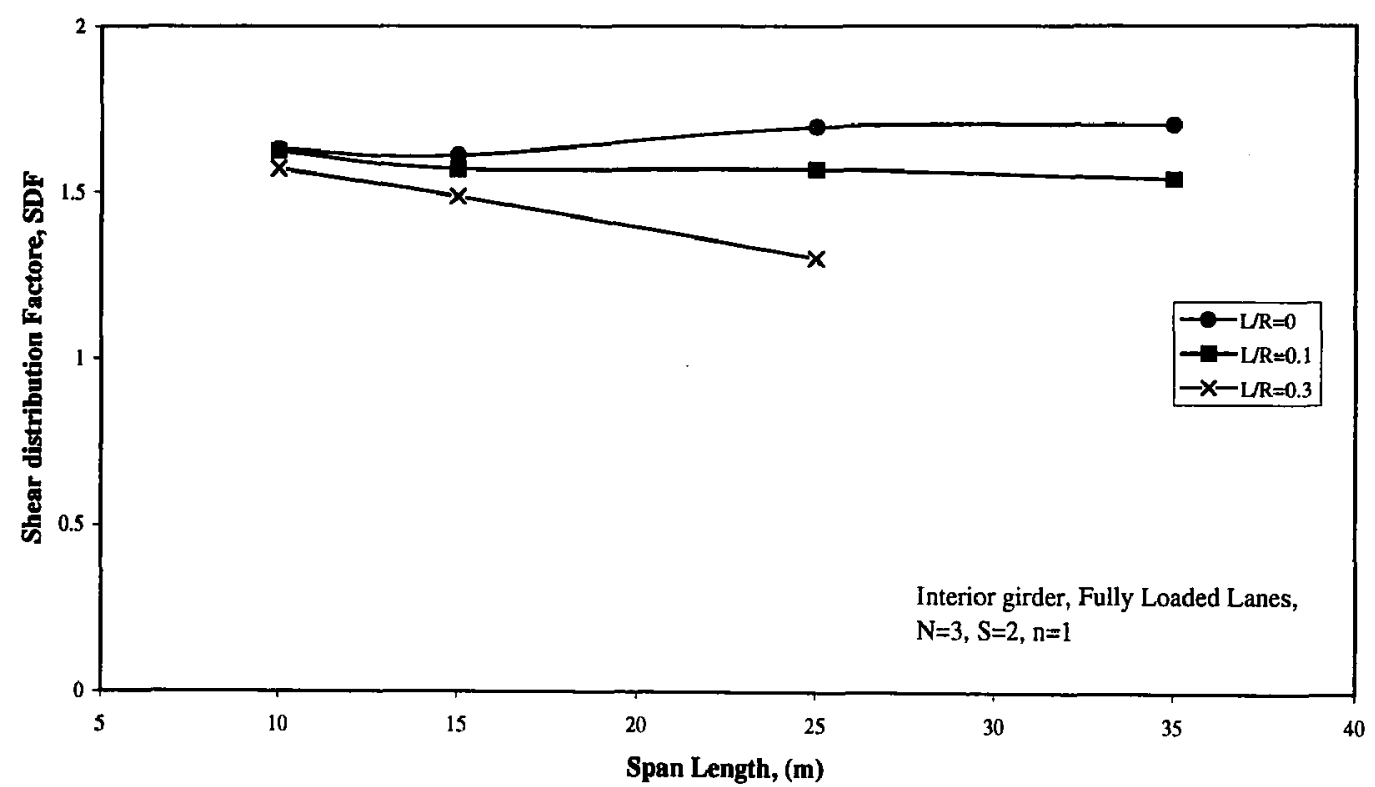

Figure 4. 40 Effect of Span Length on the Shear Distribution Factor for the Interior Girder due to Fully Loaded Lanes 


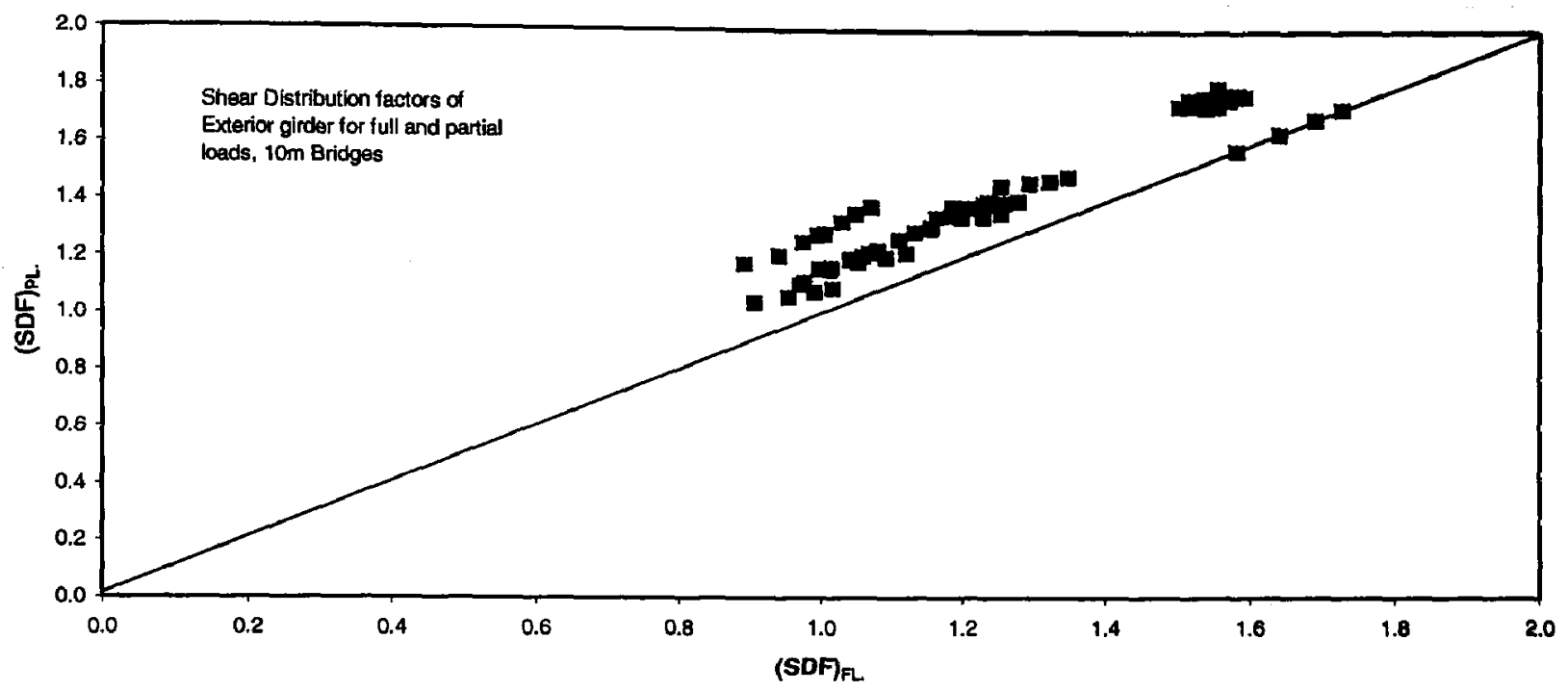

Figure 4. 41 Effect of Loading Conditions on the Shear Distribution Factor for the Exterior Girder of the 10-m-span Bridges

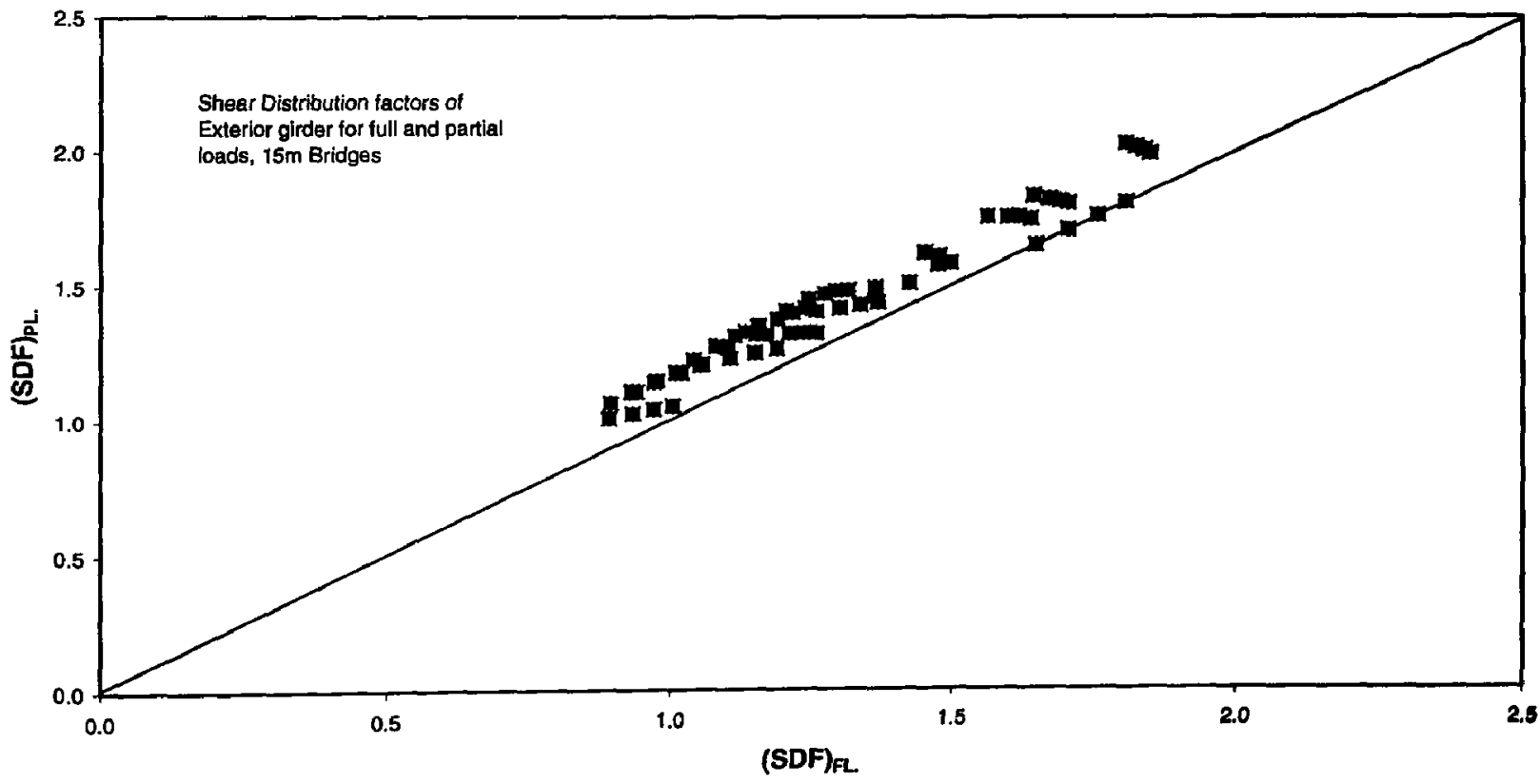

Figure 4. 42 Effect of Loading Conditions on the Shear Distribution Factor for the Exterior Girder of the 15-m-span Bridges 


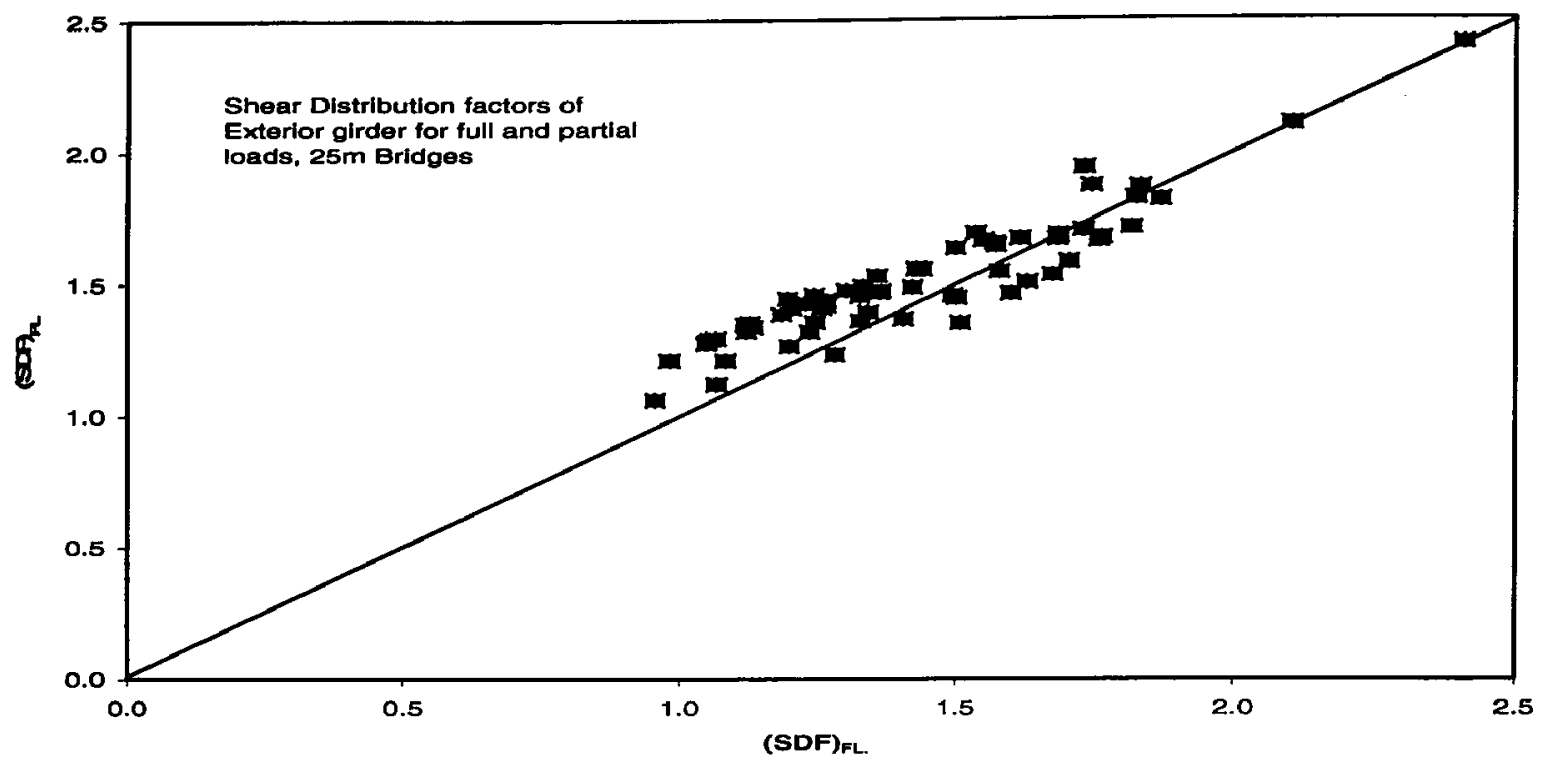

Figure 4. 43 Effect of Loading Conditions on the Shear Distribution Factor for the Exterior Girder of the 25-m-span Bridges

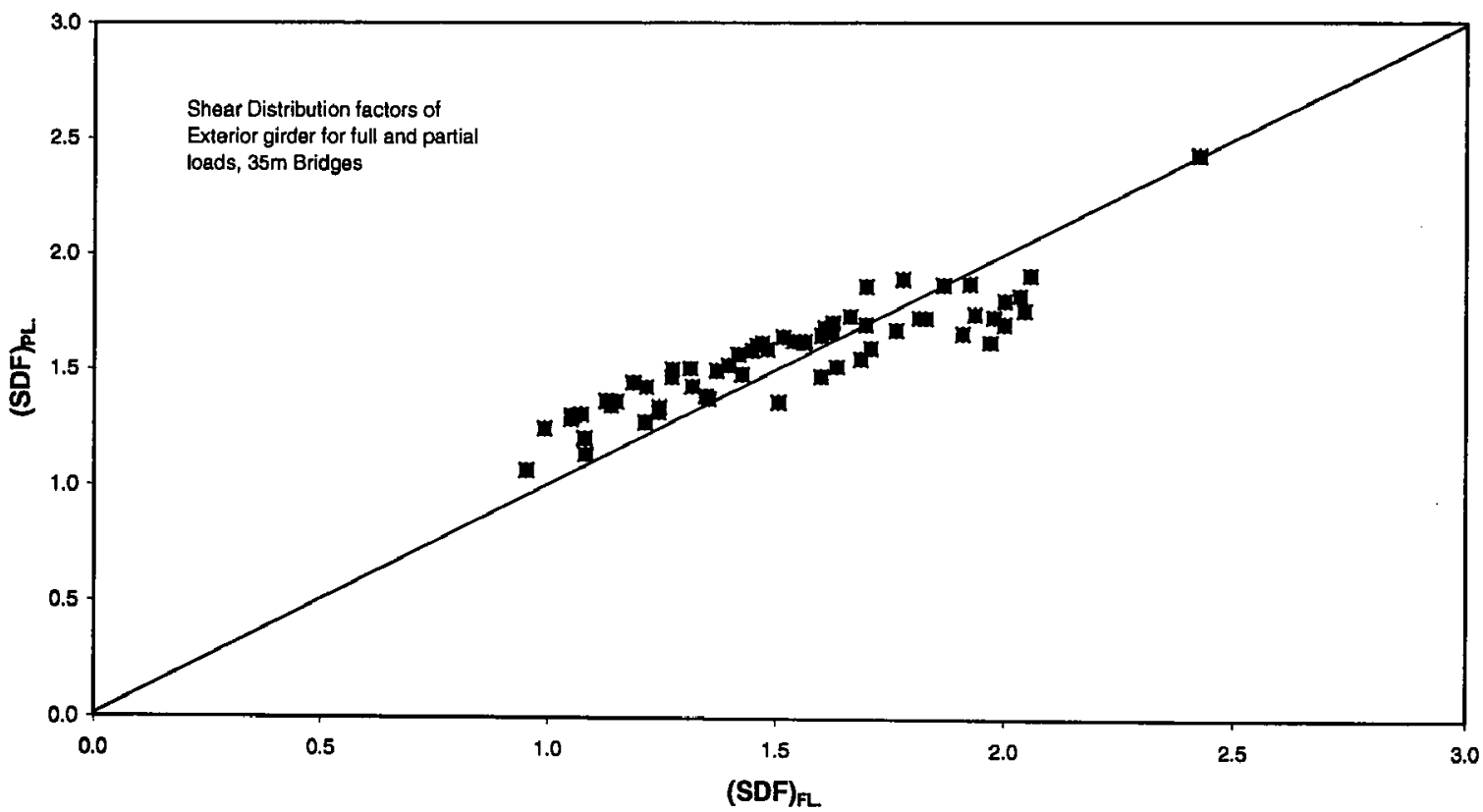

Figure 4. 44 Effect of Loading Conditions on the Shear Distribution Factor for the Exterior Girder of the 35-m-span Bridges 


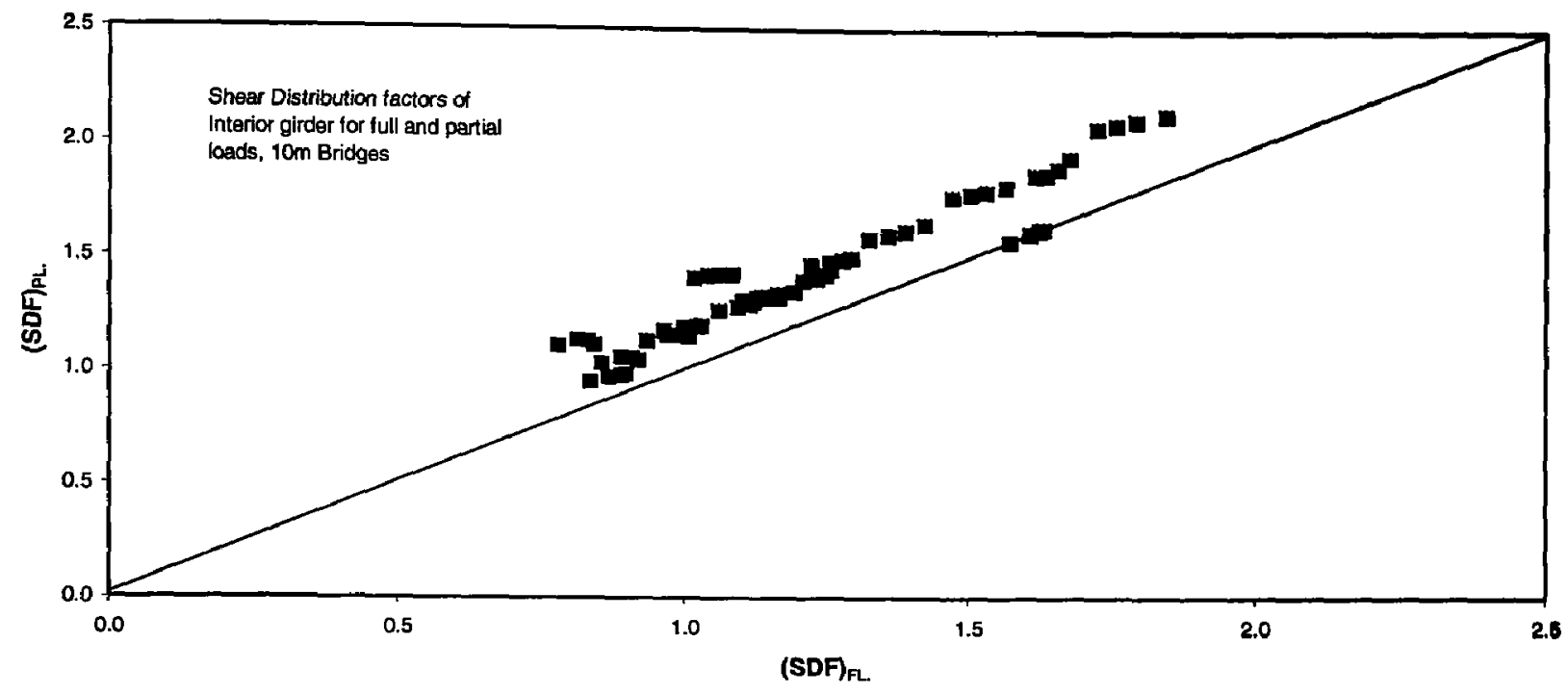

Figure 4. 45 Effect of Loading Conditions on the Shear Distribution Factor for the Interior Girder of the 10-m-span Bridges

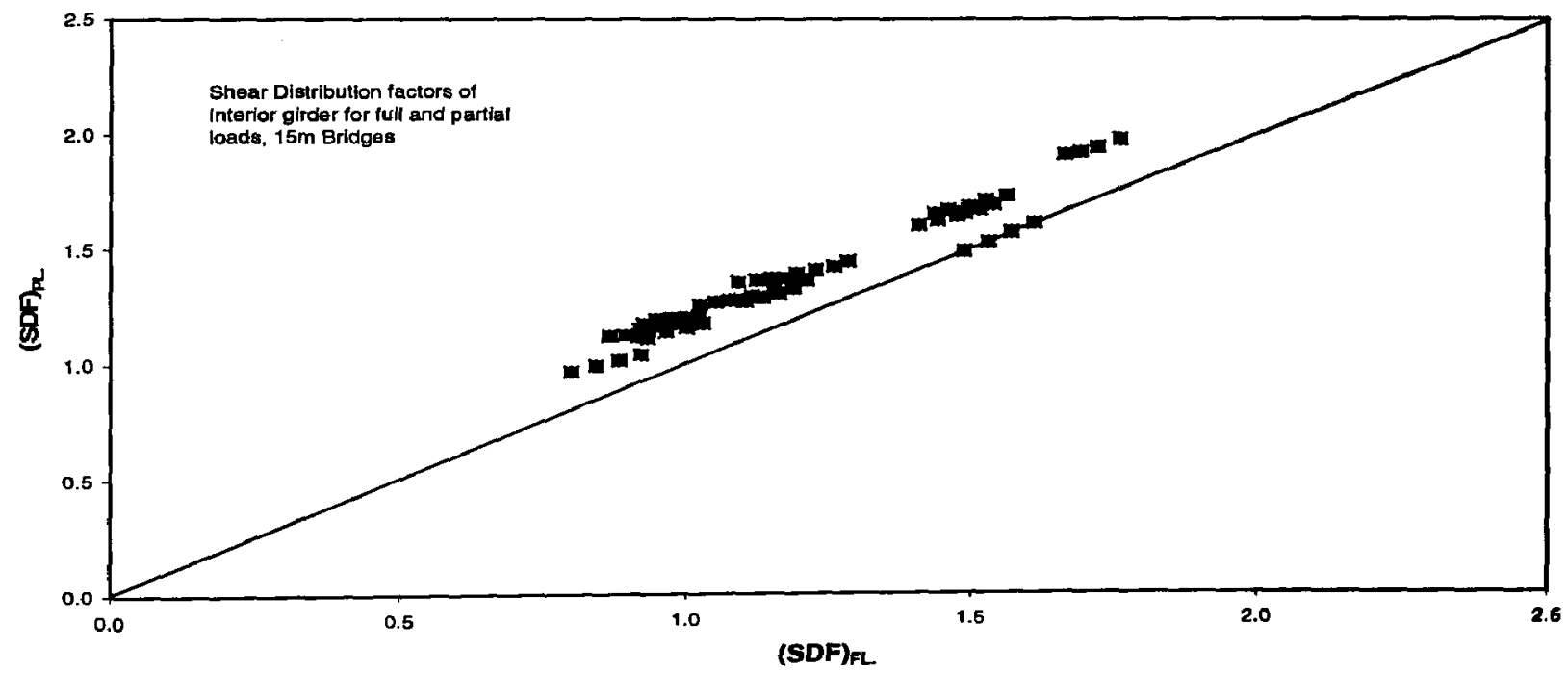

Figure 4. 46 Effect of Loading Conditions on the Shear Distribution Factor for the Interior Girder of the 15-m-span Bridges 


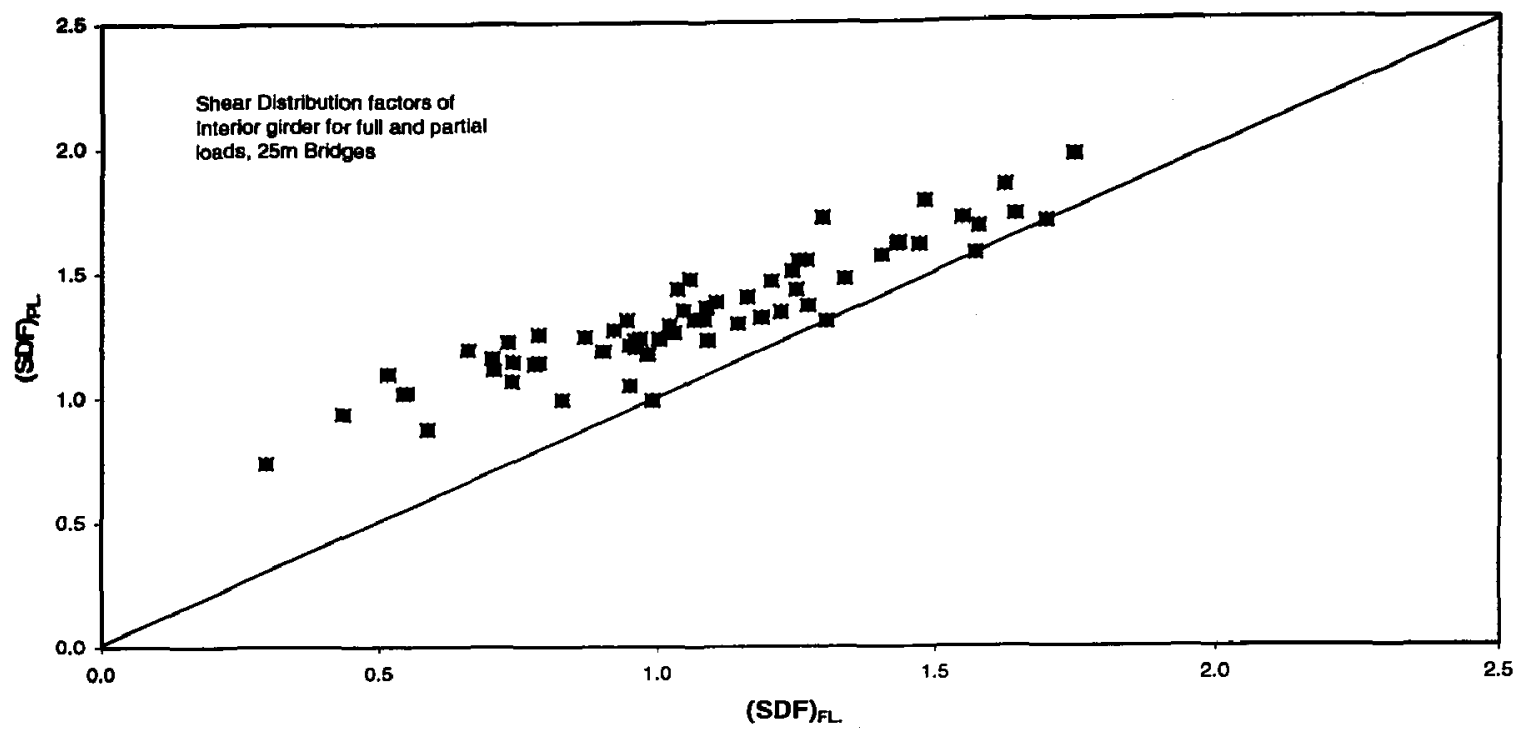

Figure 4. 47 Effect of Loading Conditions on the Shear Distribution Factor for the Interior Girder of the 25-m-span Bridges

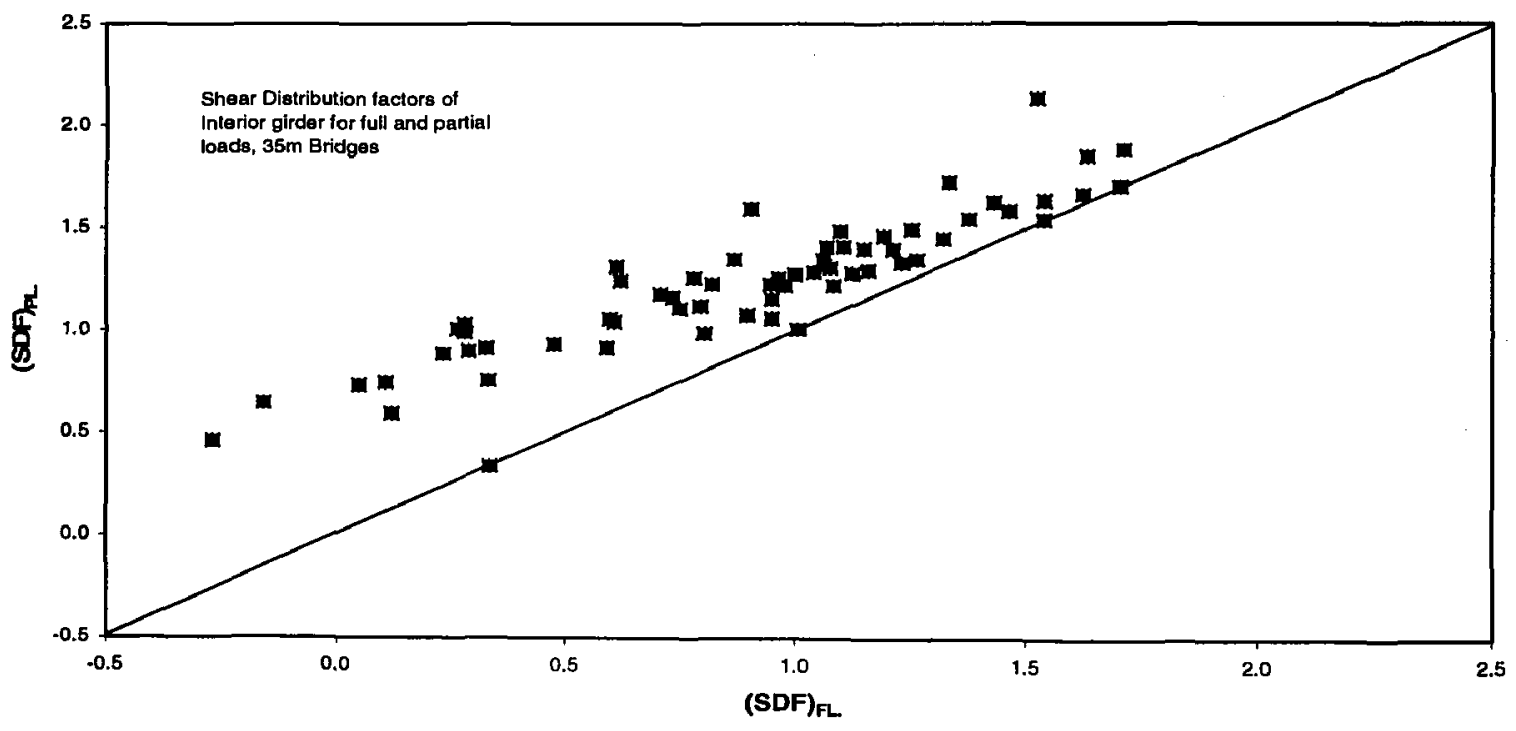

Figure 4. 48 Effect of Loading Conditions on the Shear Distribution Factor for the Interior Girder of the 35-m-span Bridges 


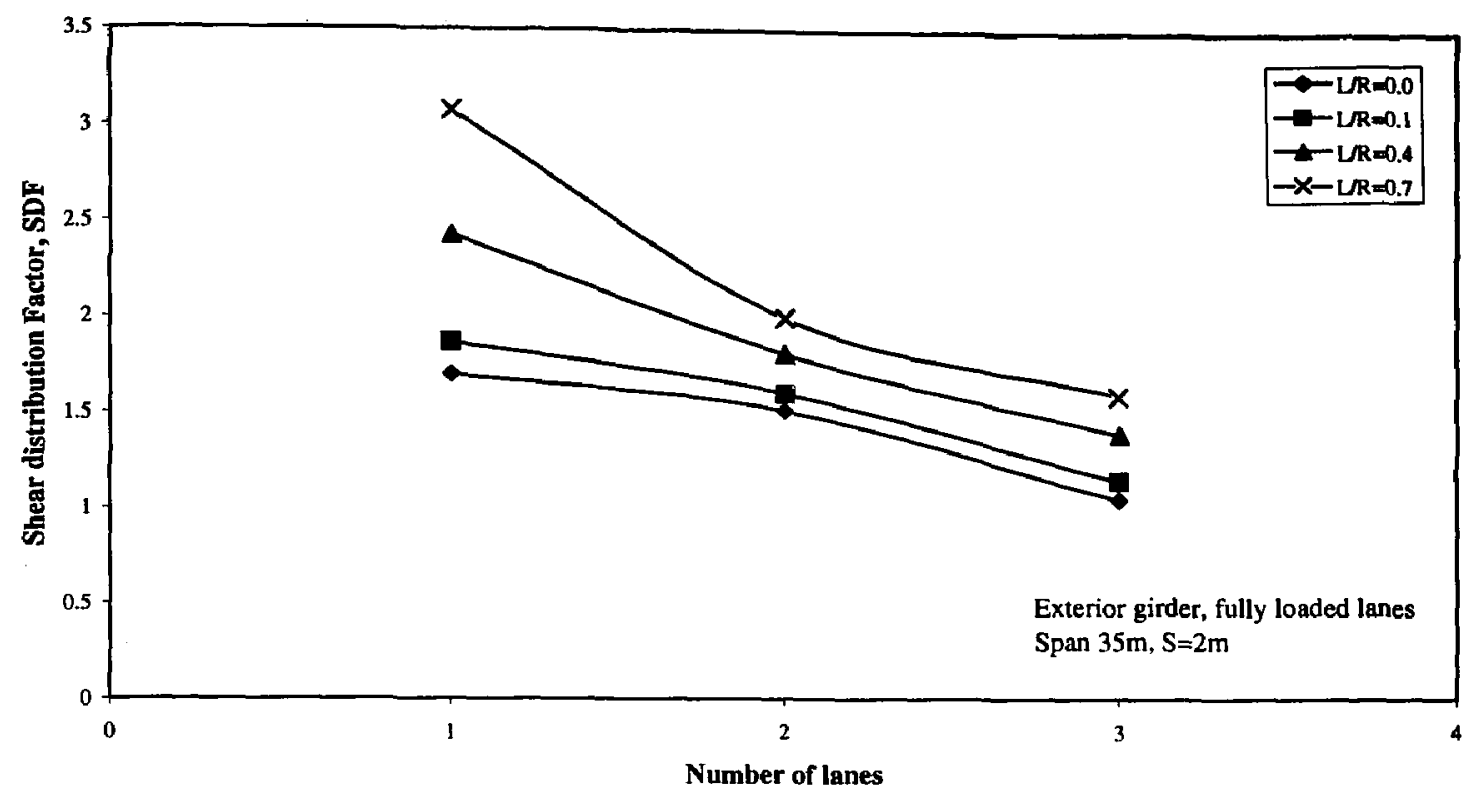

Figure 4. 49 Effect of Number of Lanes on the Shear Distribution Factor for the Exterior Girder due to Fully Loaded Lanes

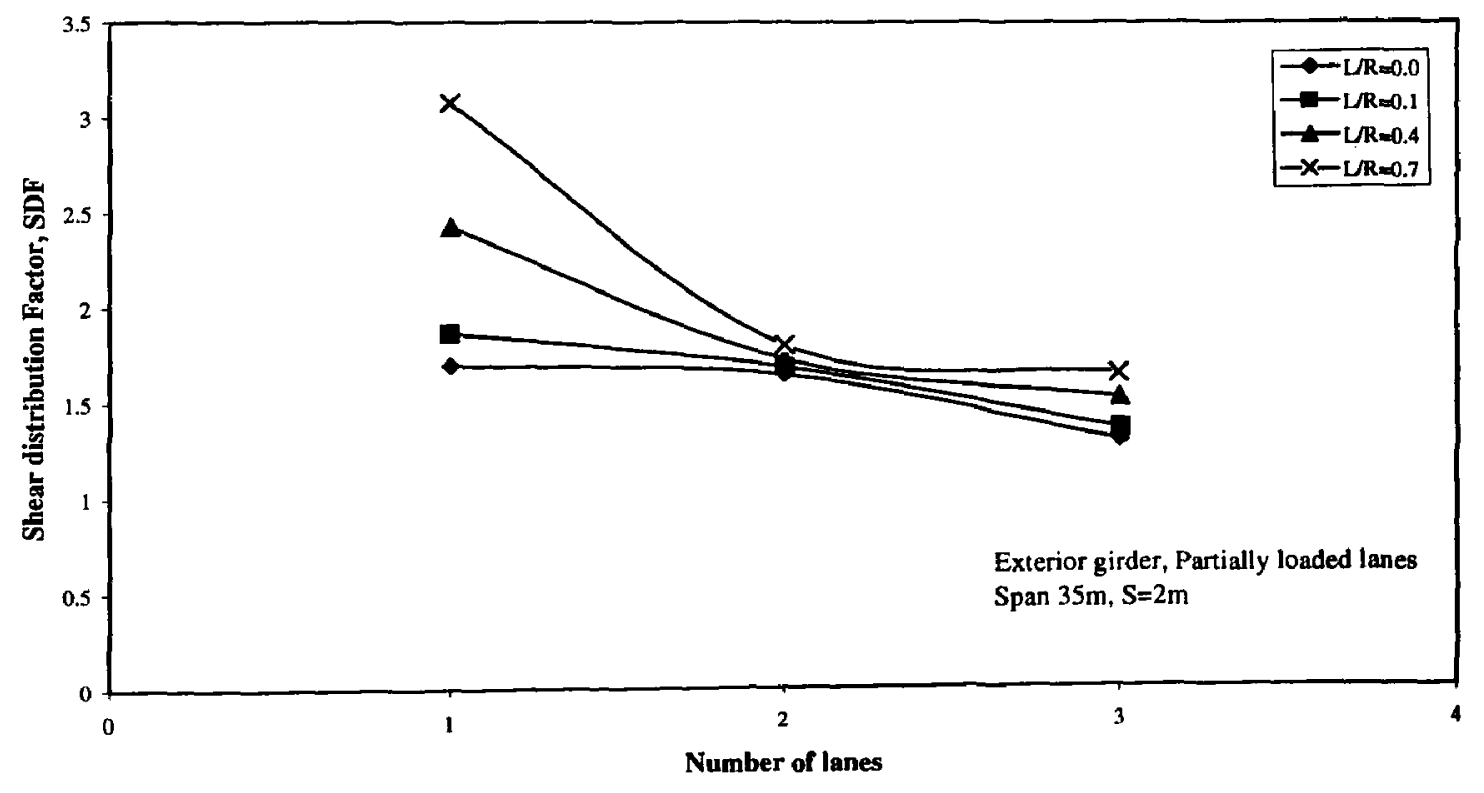

Figure 4. 50 Effect of Number of Lanes on the Shear Distribution Factor for the Exterior Girder due to Partially Loaded Lanes 


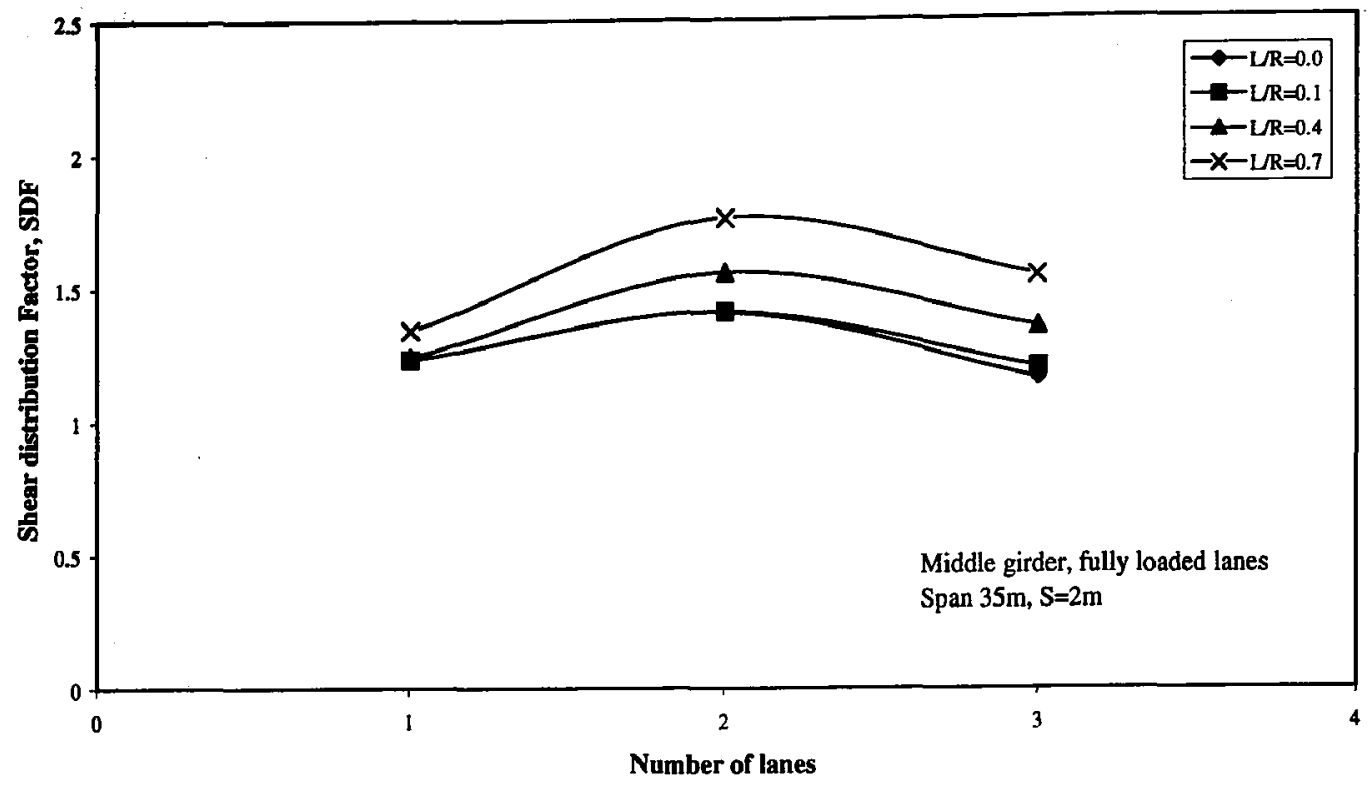

Figure 4.51 Effect of Number of Lanes on the Shear Distribution Factor for the Middle Girder due to Fully Loaded Lanes

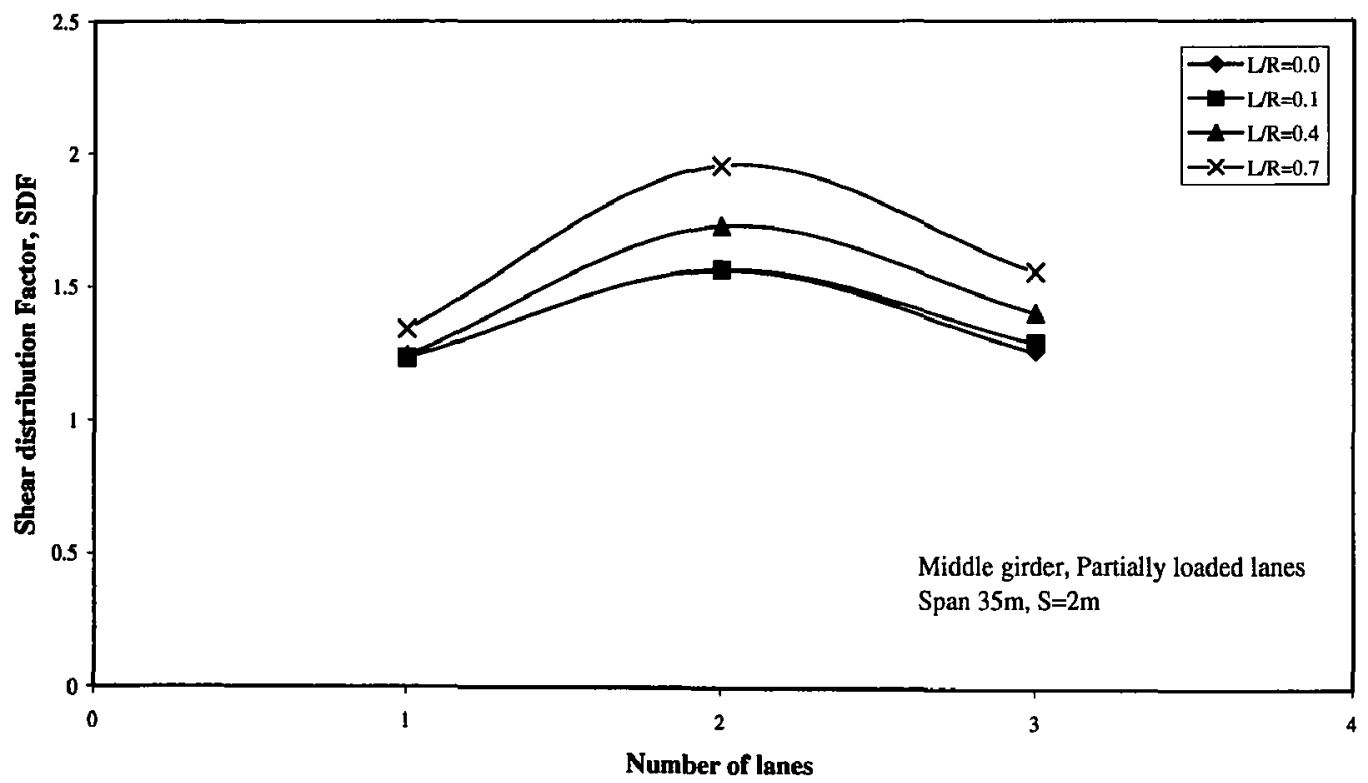

Figure 4.52 Effect of Number of Lanes on the Shear Distribution Factor for the Middle Girder due to Partially Loaded Lanes 


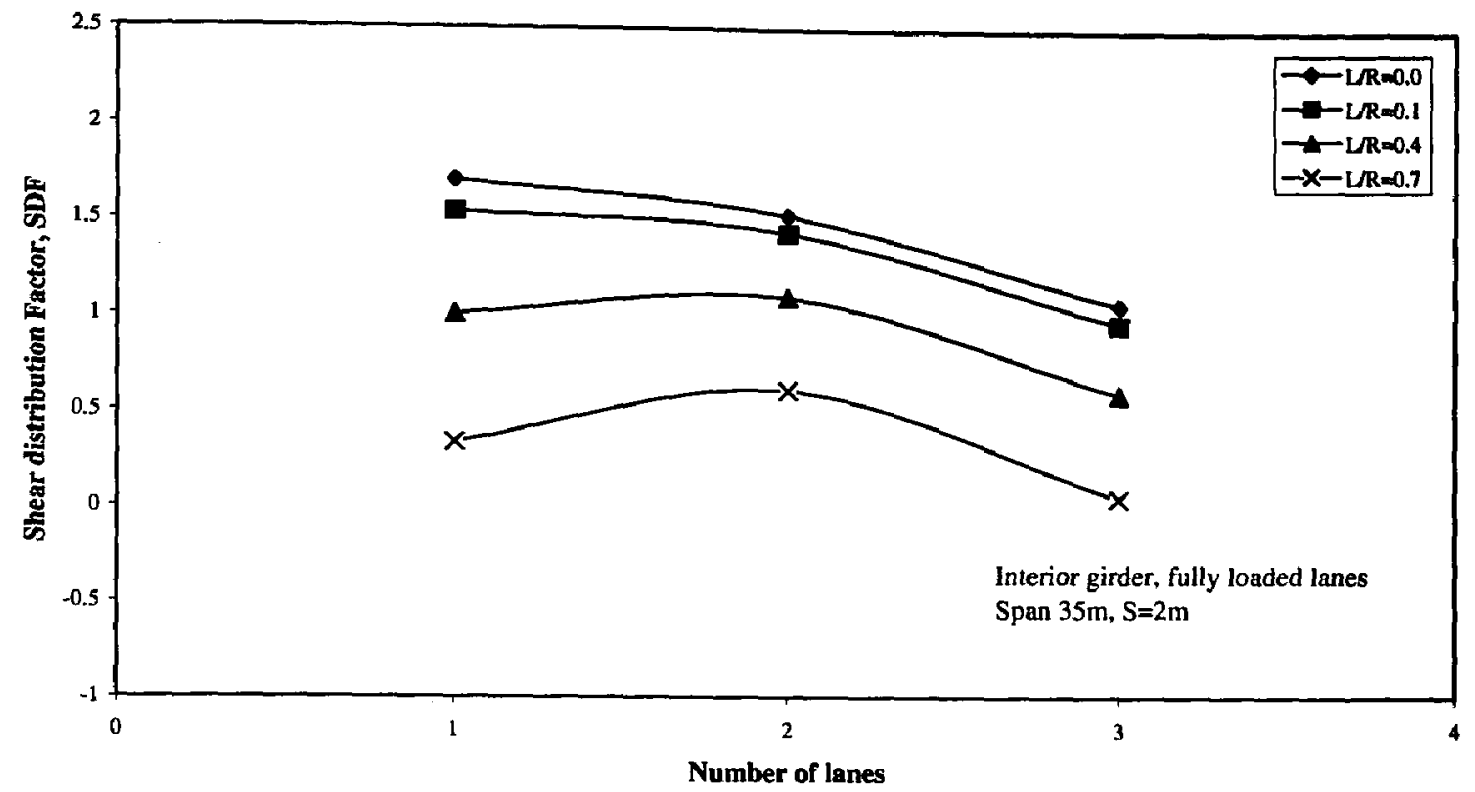

Figure 4. 53 Effect of Number of Lanes on the Shear Distribution Factor for the Interior Girder due to Fully Loaded Lanes

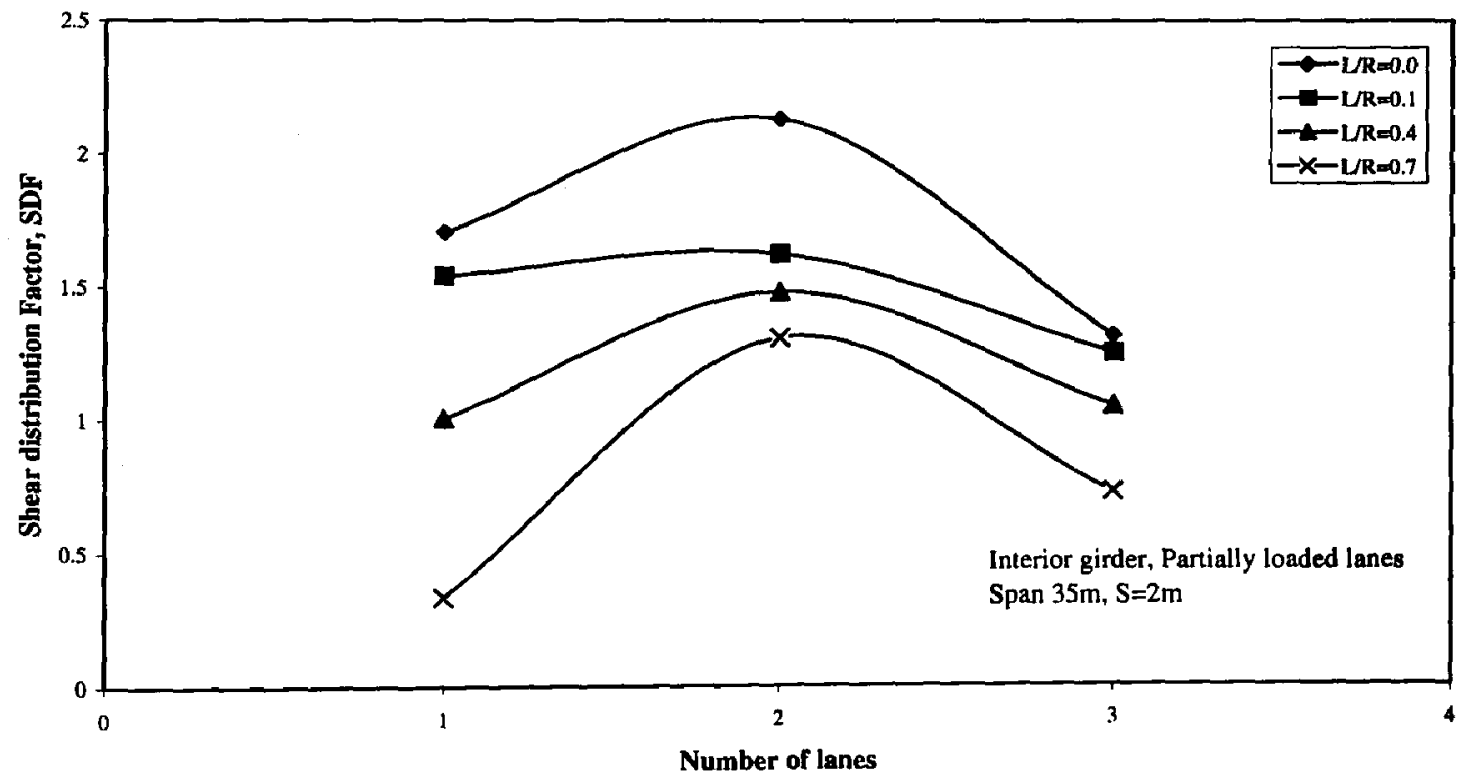

Figure 4. 54 Effect of Number of Lanes on the Shear Distribution Factor for the Interior Girder due to Partially Loaded Lanes 


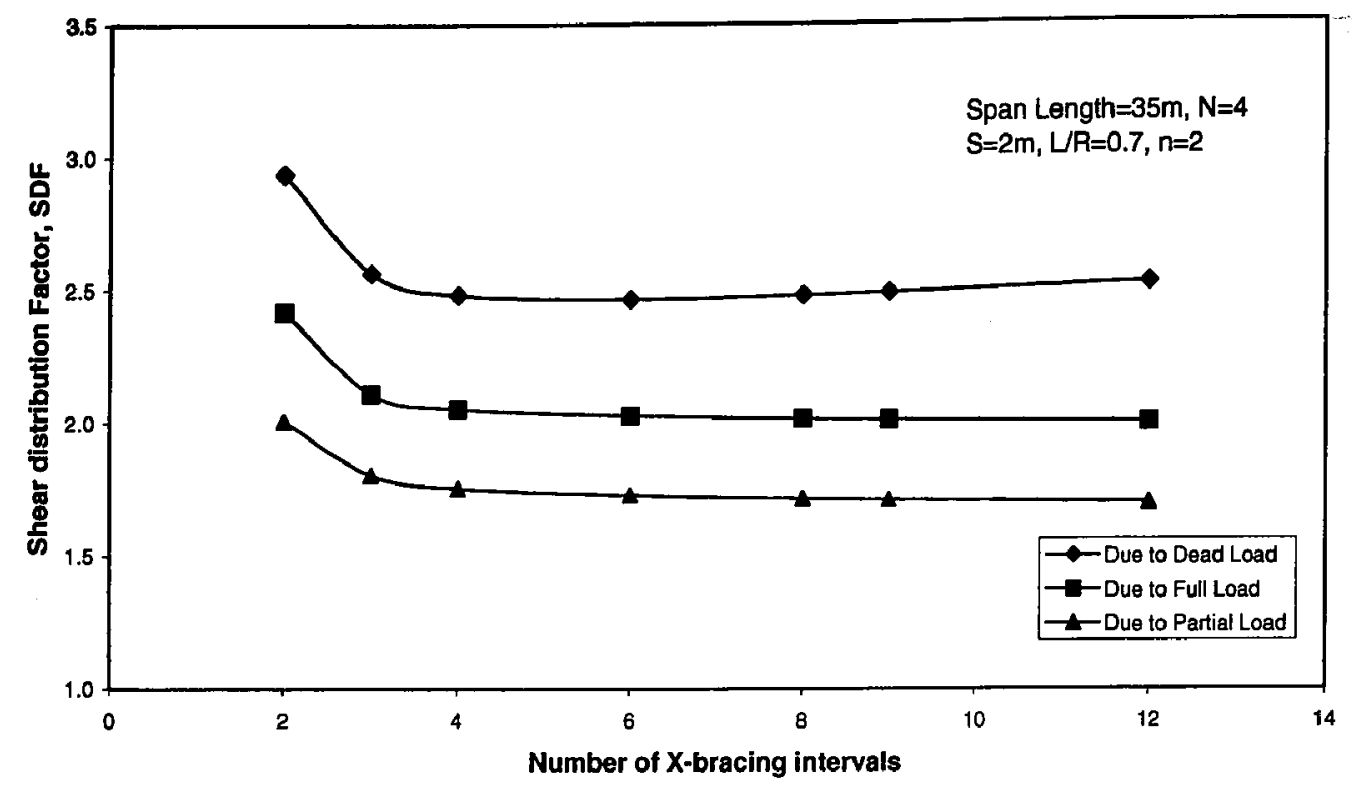

Figure 4.55 Effect of the Number of Cross-Bracing Intervals on the Shear Distribution Fact for the Exterior Girder

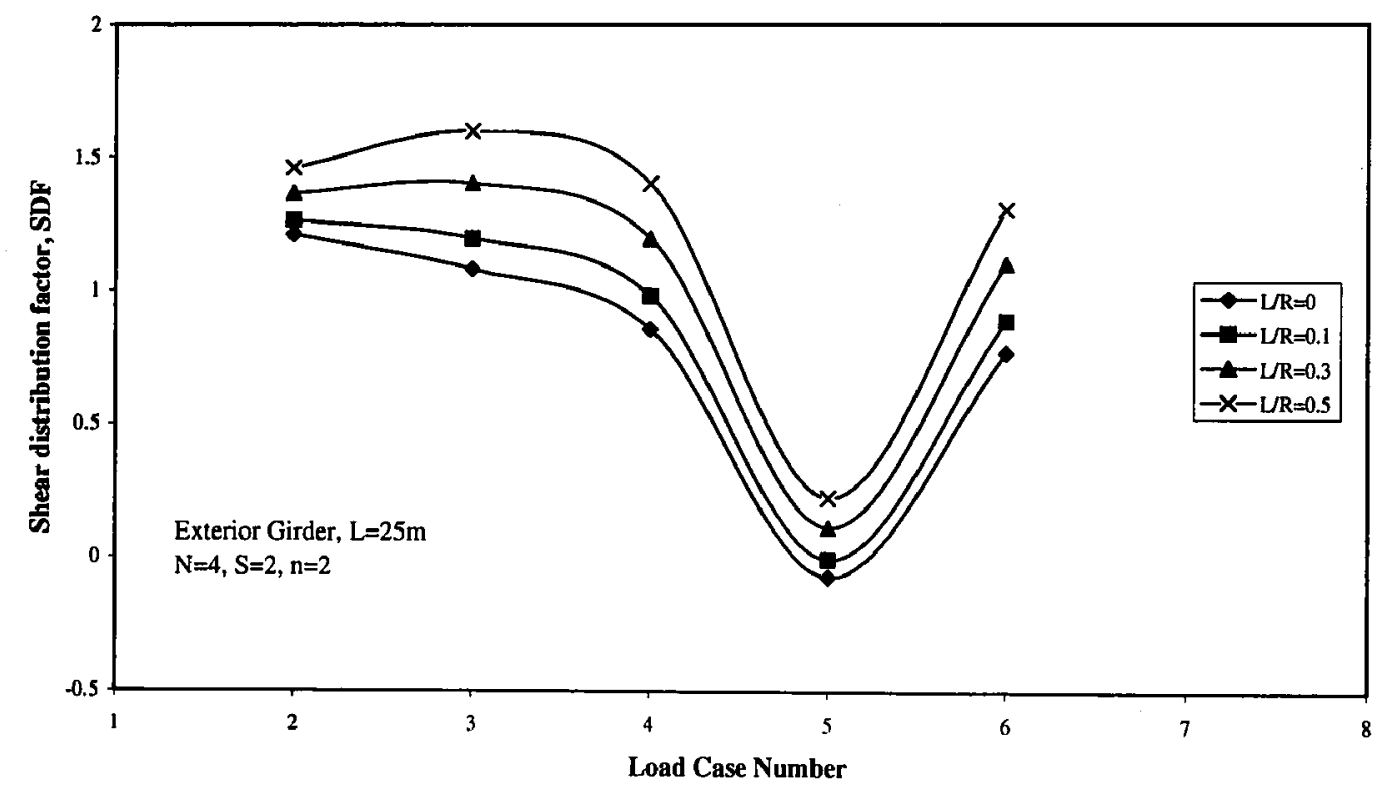

Figure 4.56 Effect of the Load Cases Number on the Shear Distribution Factor for the Exterior Girder of a two-lane Bridge 


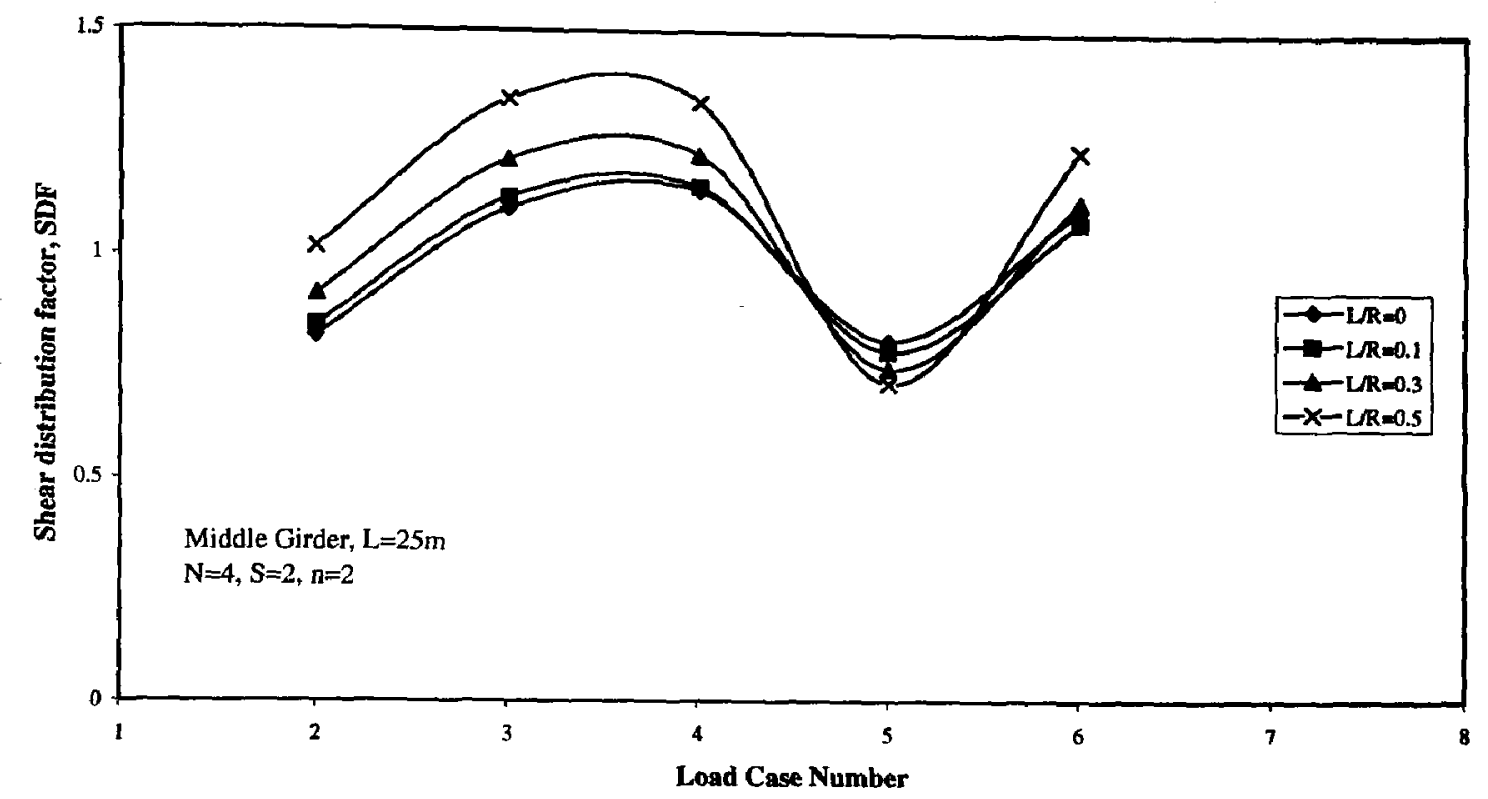

Figure 4. 57 Effect of the Load Cases Number on the Shear Distribution Factor for the Middle Girder of a two-lane Bridge

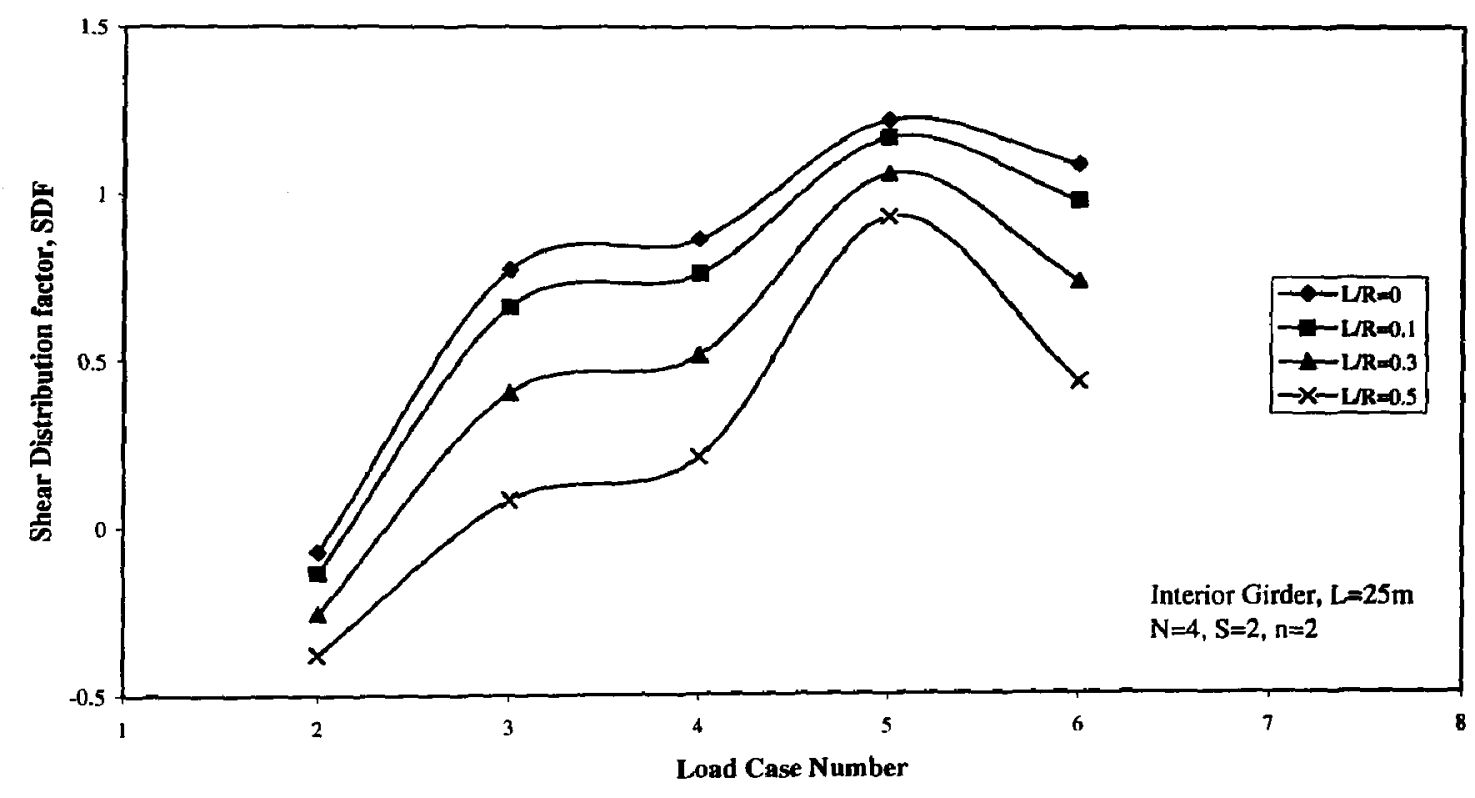

Figure 4. 58 Effect of the Load Cases Number on the Shear Distribution Factor for the Interior Girder of a two-lane Bridge 


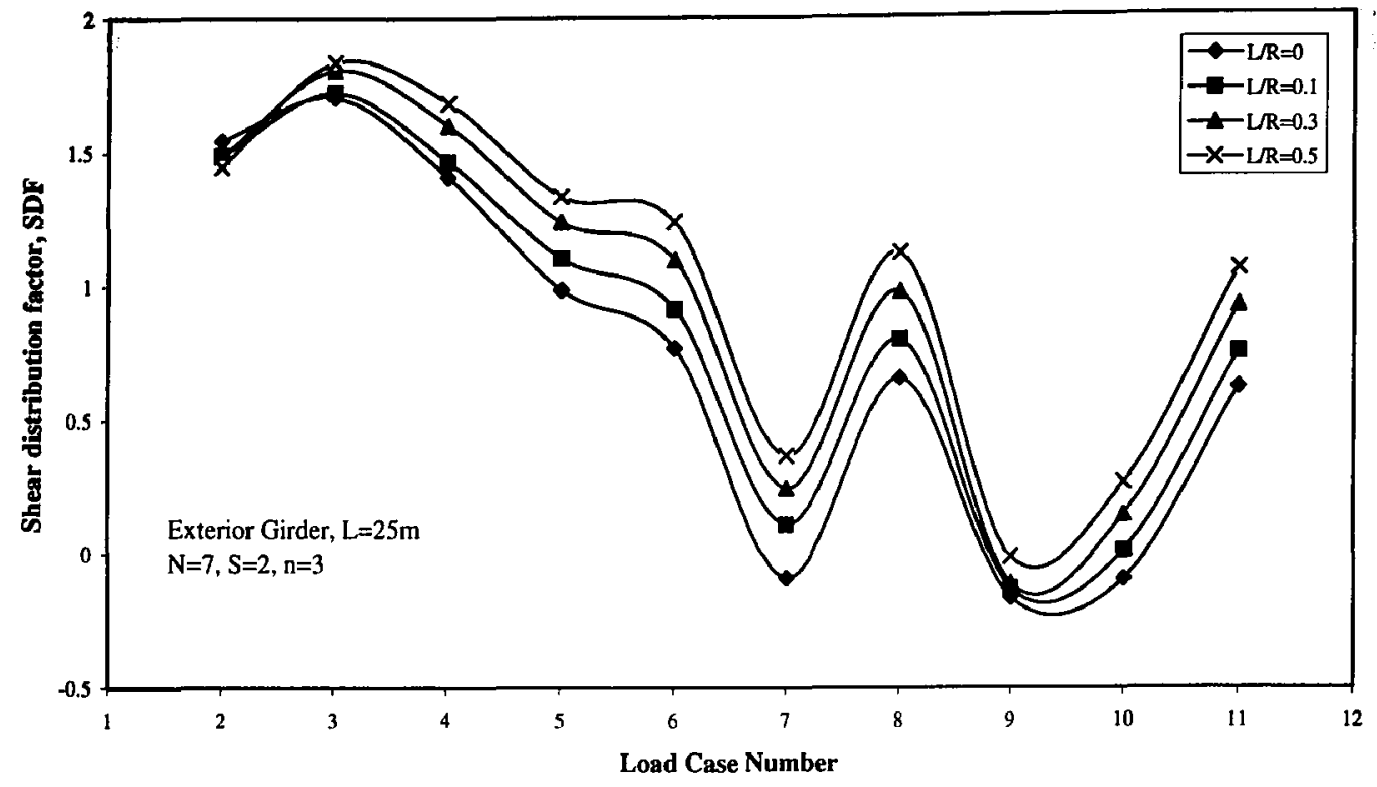

Figure 4.59 Effect of the Load Cases Number on the Shear Distribution Factor for the Exterior Girder of a 3-lane Bridge

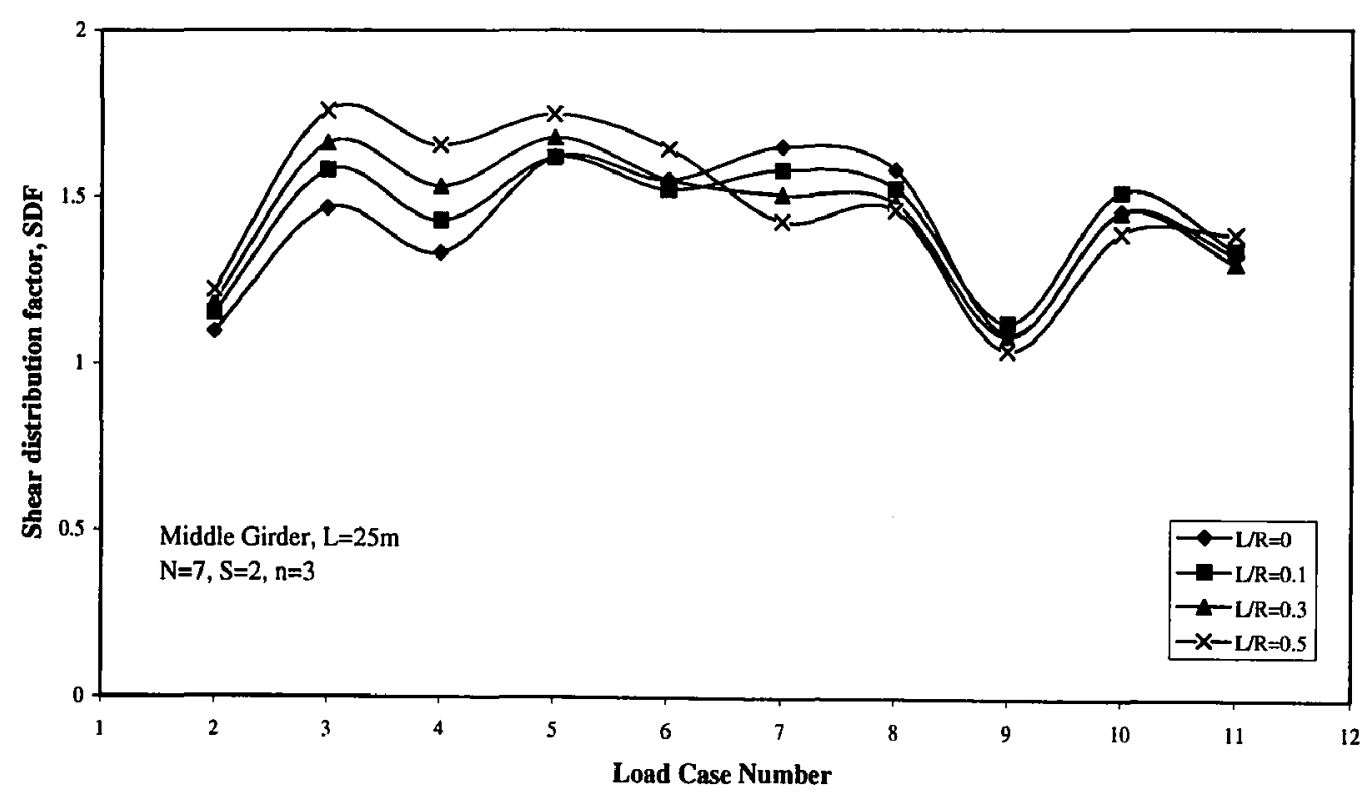

Figure 4. 60 Effect of the Load Cases Number on the Shear Distribution Factor for the Middle Girder of a 3-lane Bridge 


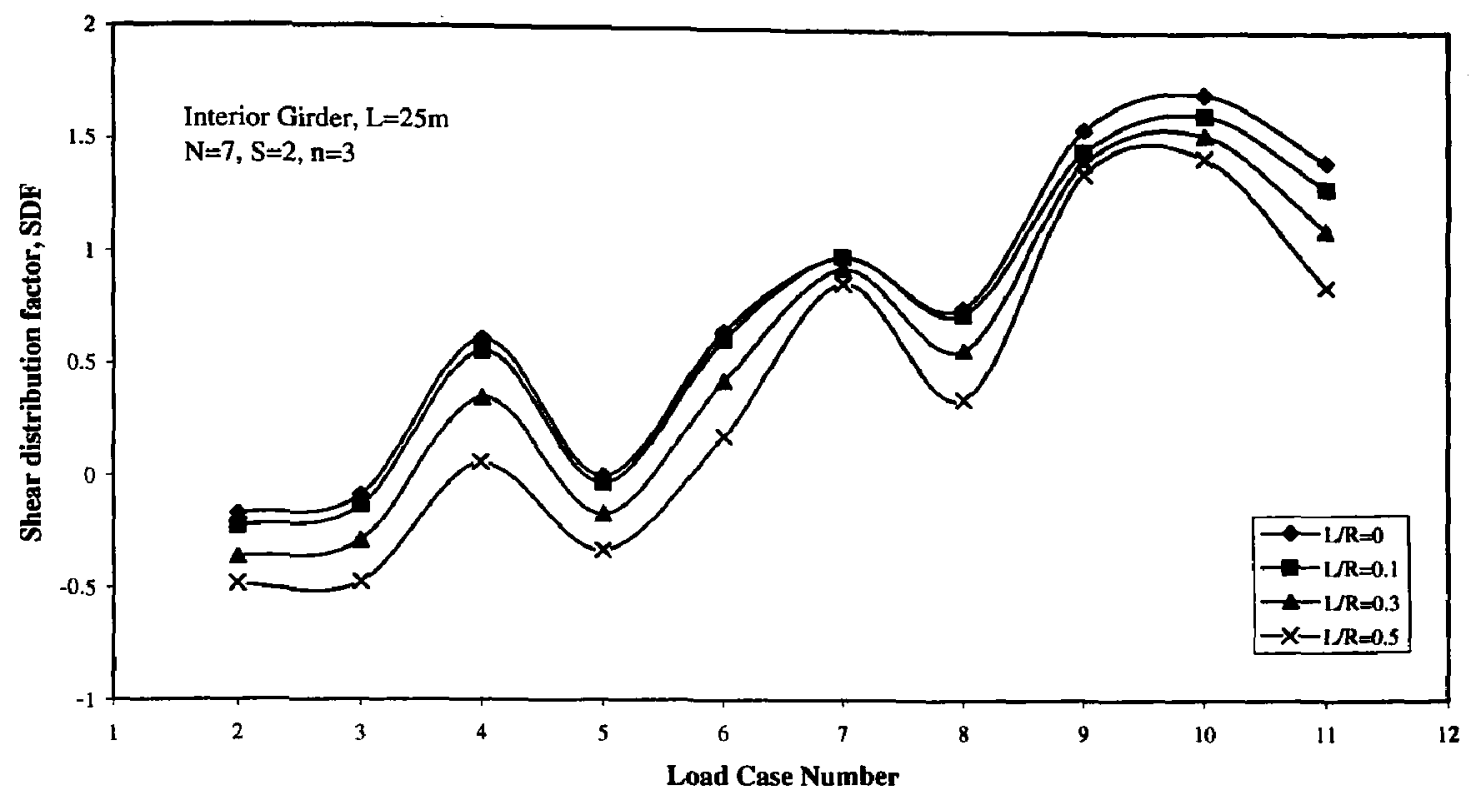

Figure 4. 61 Effect of the Load Cases Number on the Shear Distribution Factor for the Interior Girder of a 3-lane Bridge

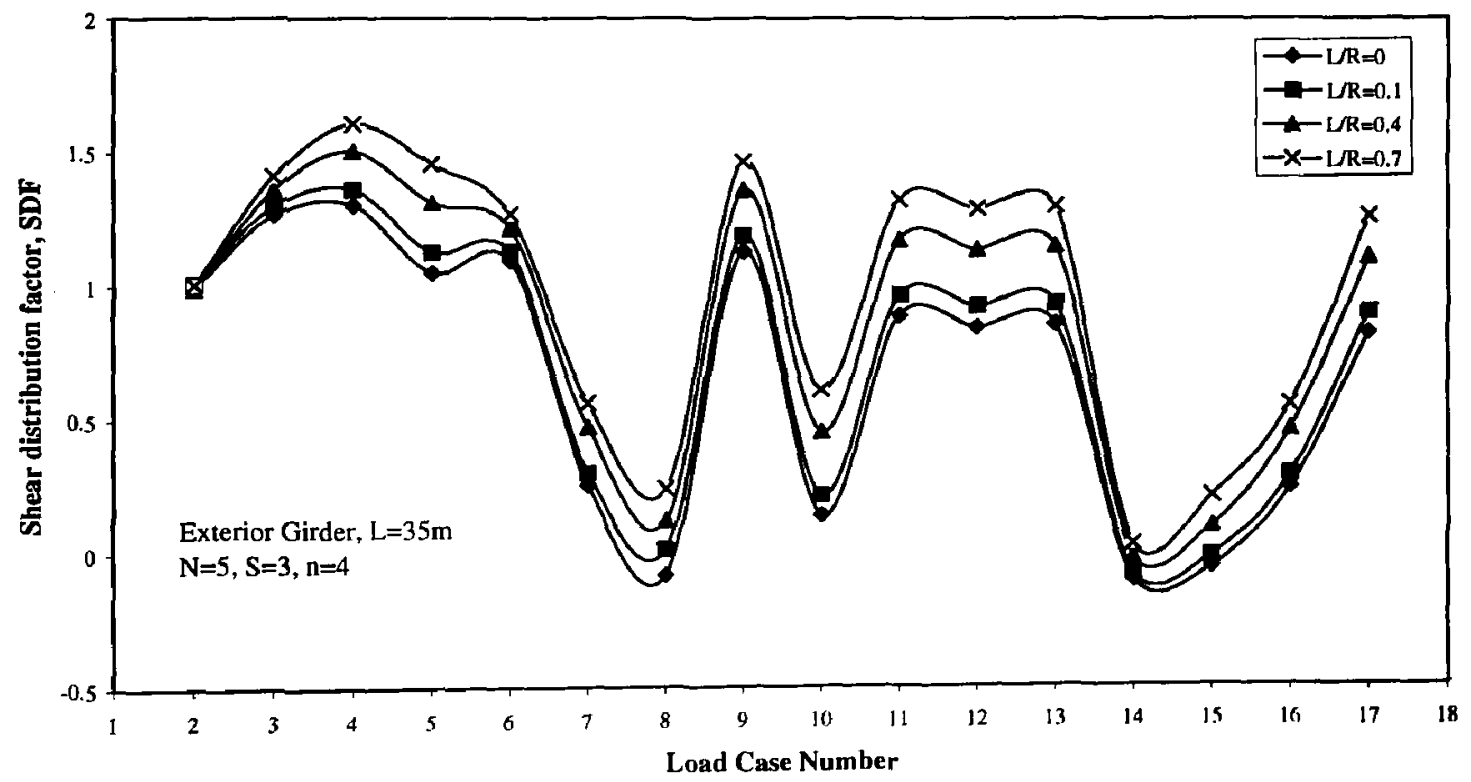

Figure 4. 62 Effect of the Load Cases Number on the Shear Distribution Factor for the Exterior girder of a 4-lane Bridge 


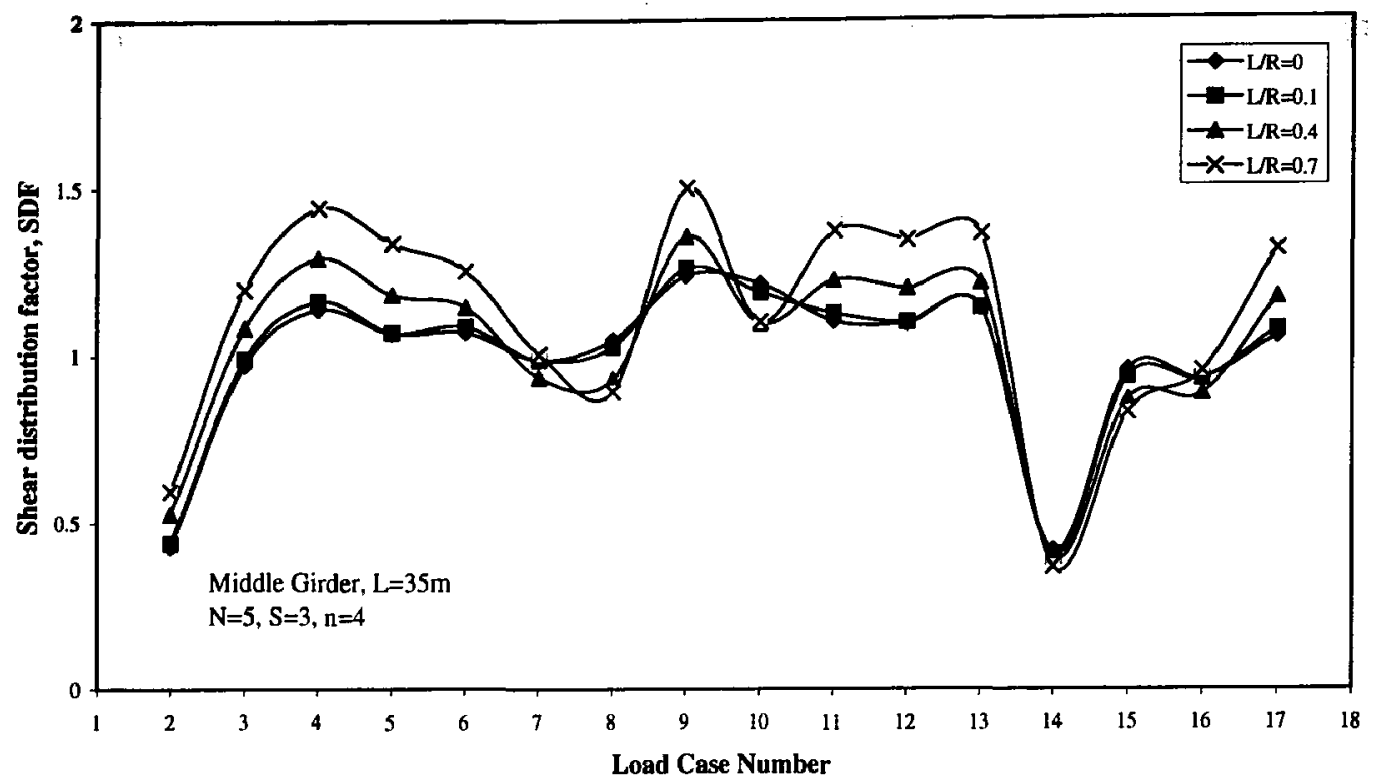

Figure 4. 63 Effect of the Load Cases Number on the Shear Distribution Factor for the Middl Girder of a 4-lane Bridge

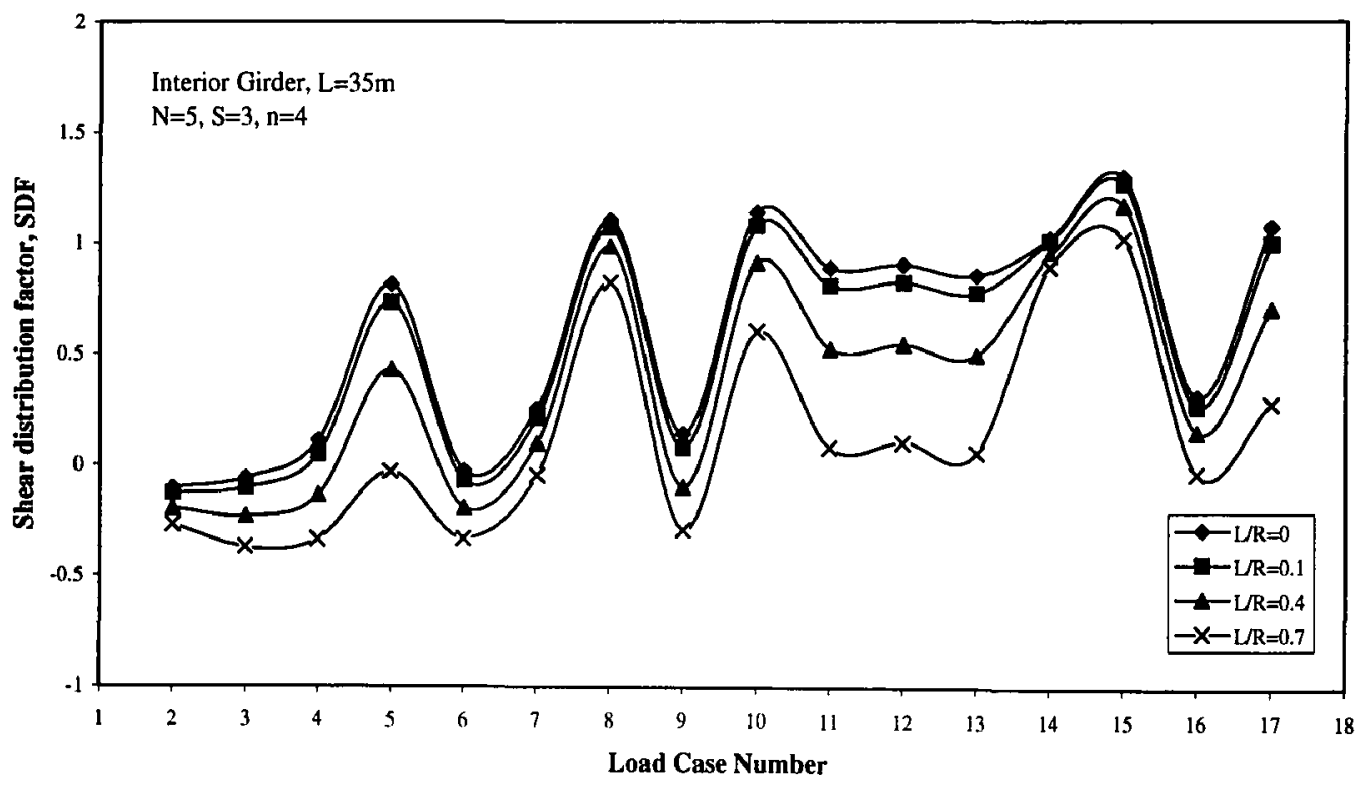

Figure 4. 64 Effect of the Load Cases Number on the Shear Distribution Factor for the Interior girder of a 4-lane Bridge 


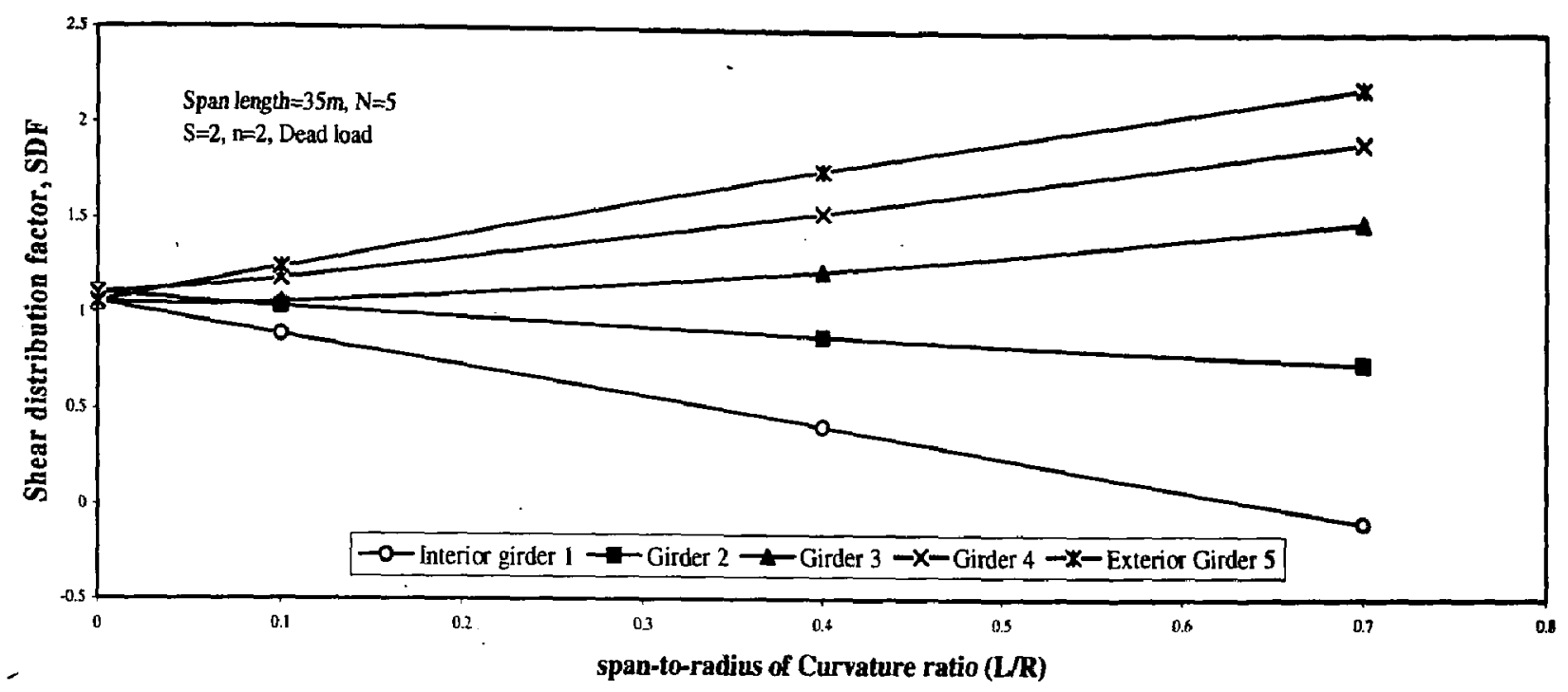

Figure 4. 65 Effect of Girder Location on the Shear Distribution Factor due to Dead Loading

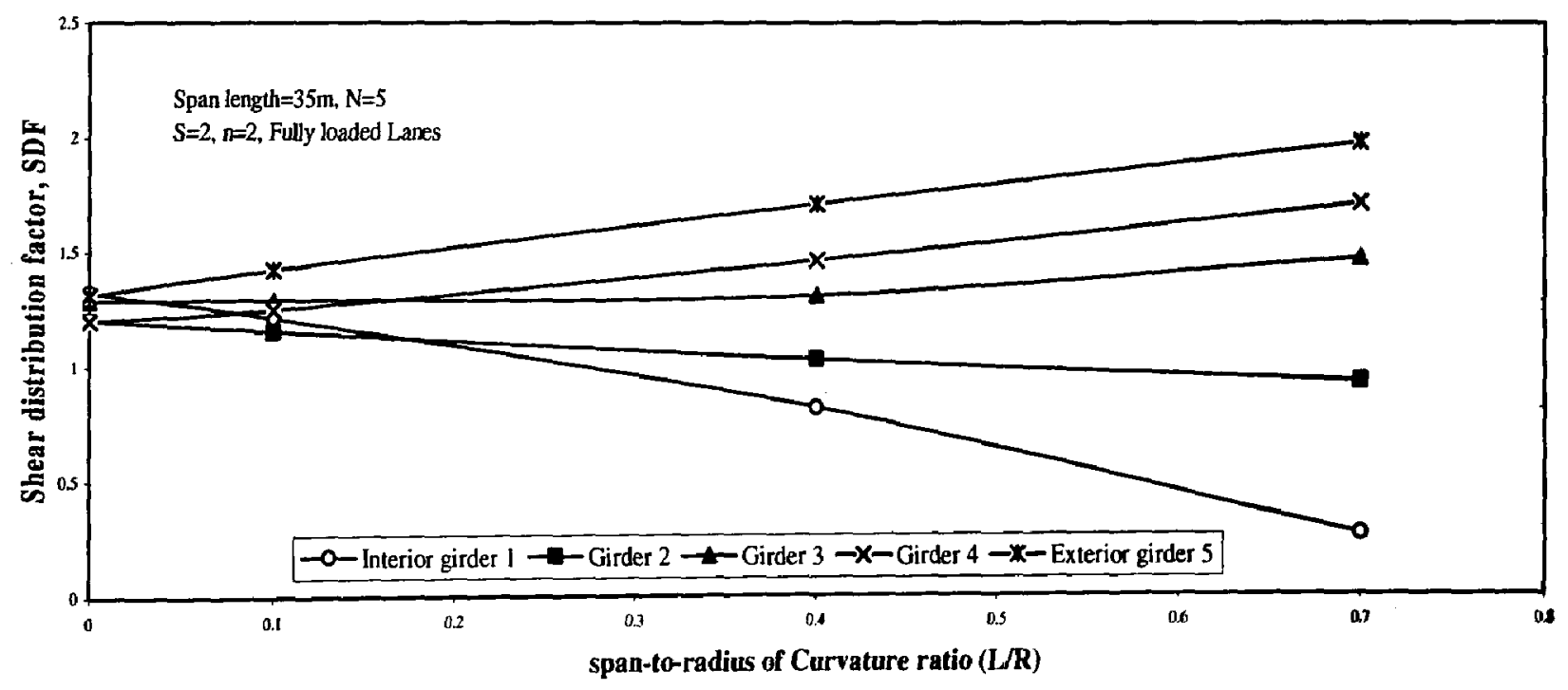

Figure 4. 66 Effect of Girder Location on the Shear Distribution Factor due to Fully Loaded Lanes 


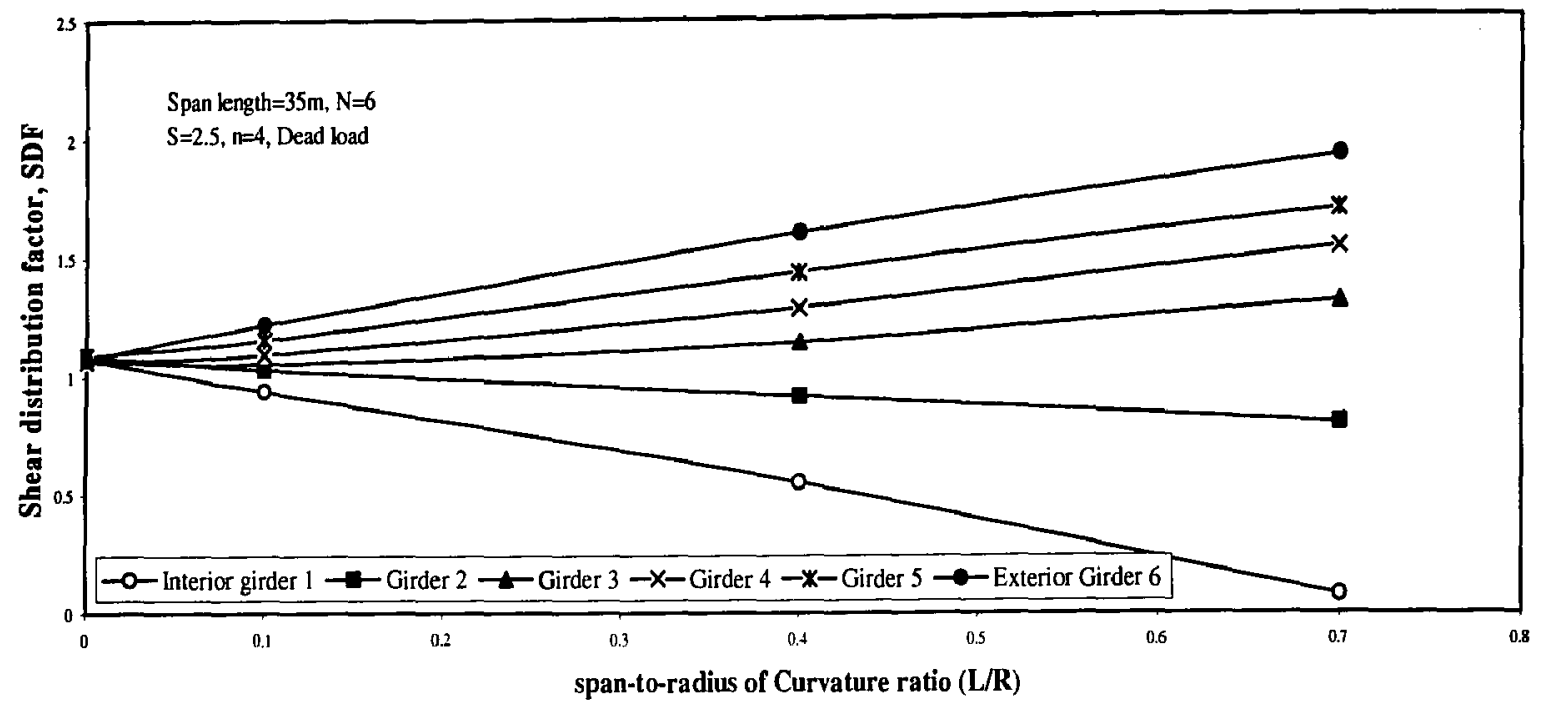

Figure 4. 67 Effect of Girder Location on the Shear Distribution Factor due to Dead Loadin

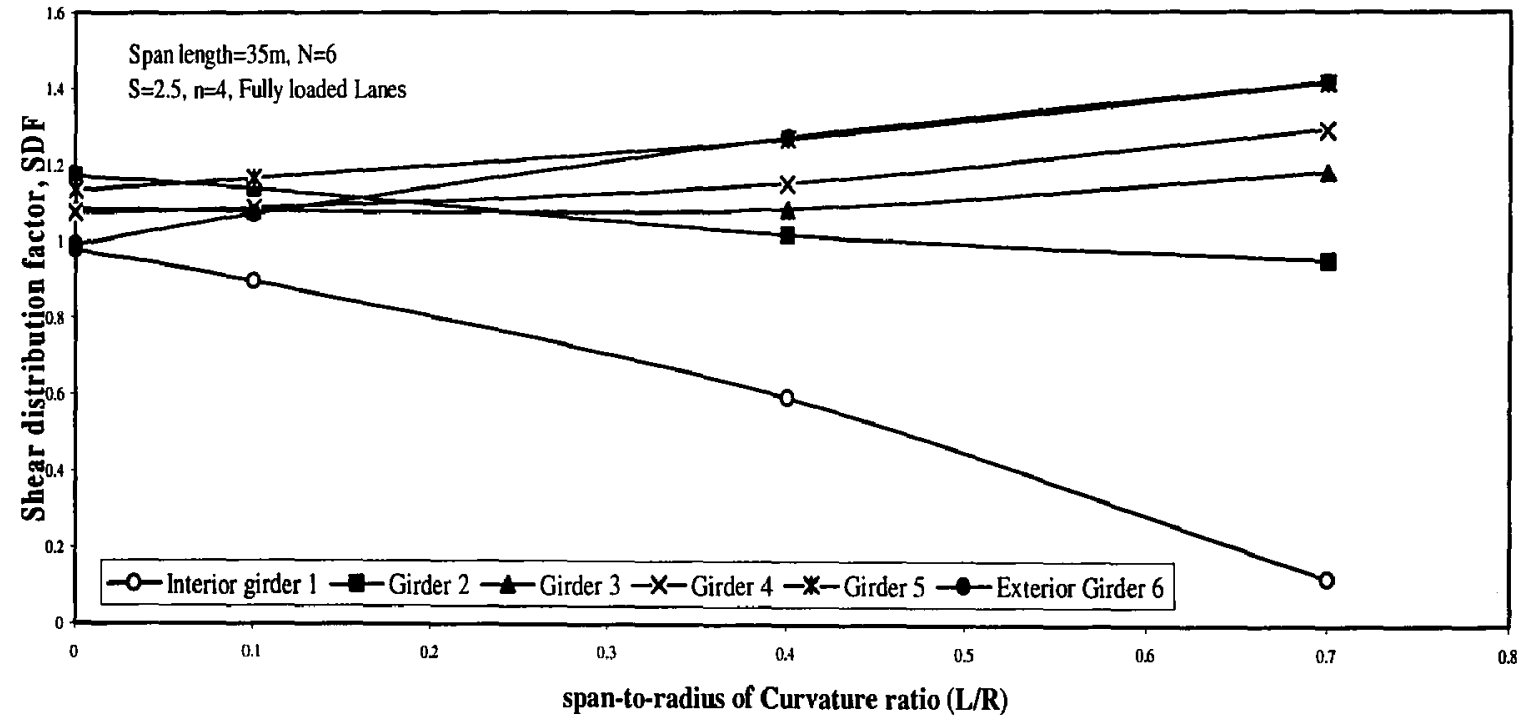

Figure 4. 68 Effect of Girder Location on the Shear Distribution Factor due to Fully Loade Lanes 


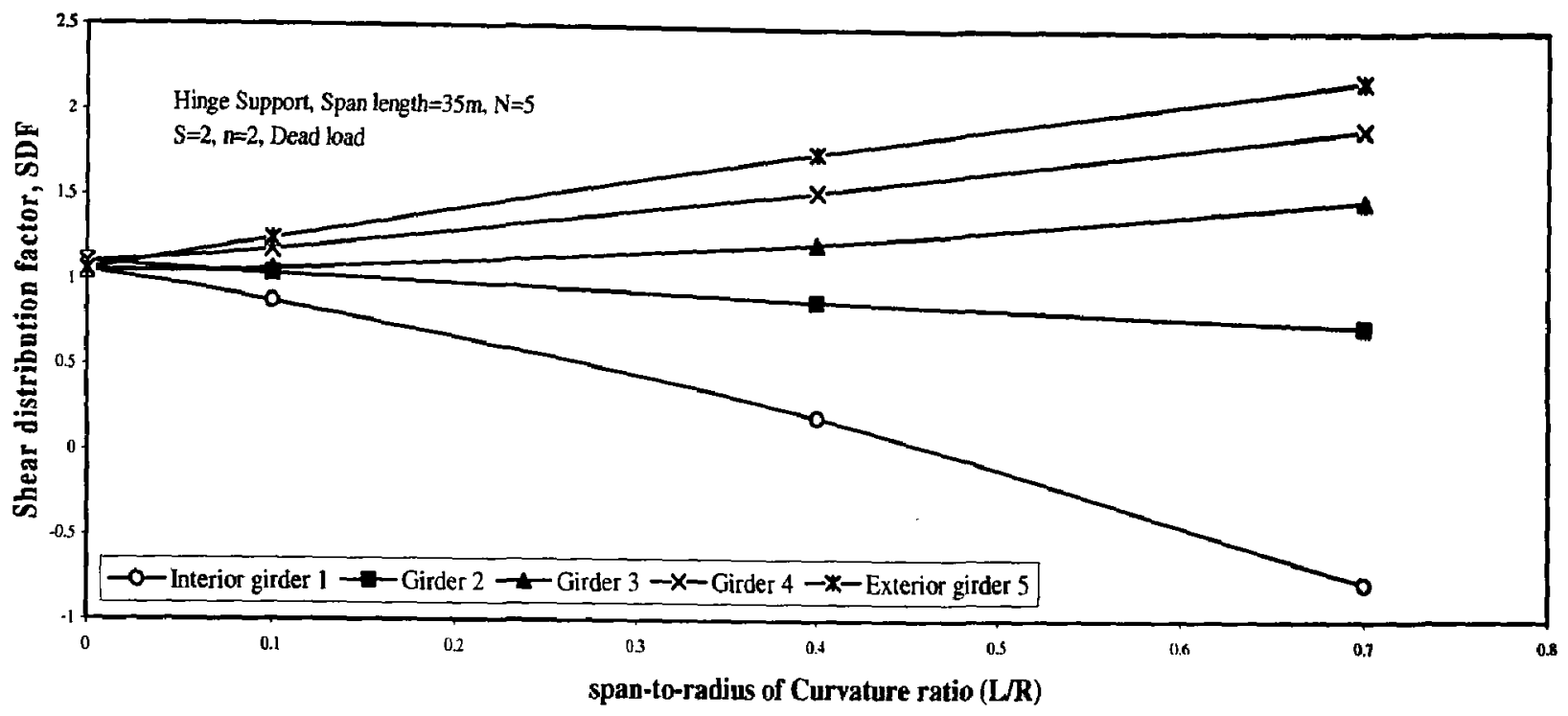

Figure 4. 69 Effect of the Type of Support on the Shear Distribution Factor due to Dead Loading (Hinge Support Line)

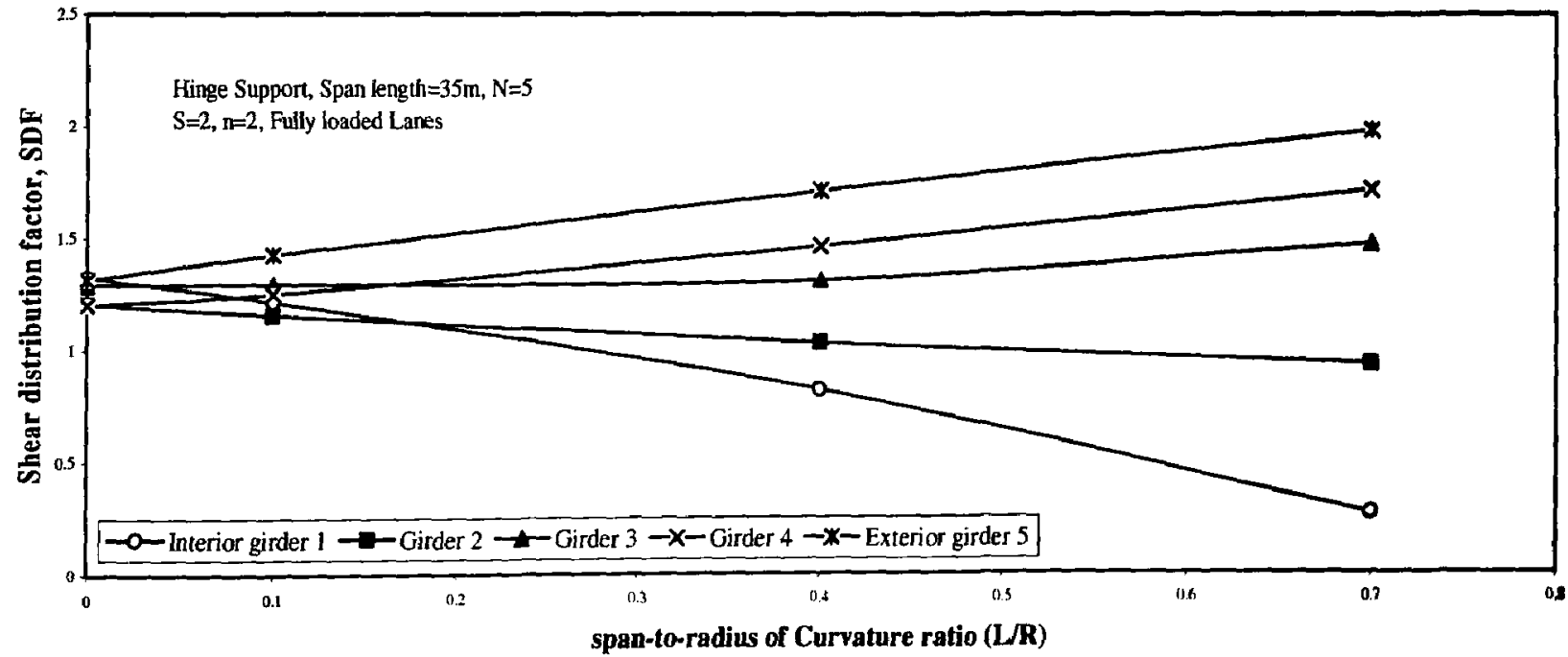

Figure 4. 70 Effect of the Type of Support on the Shear Distribution Factor due to Fully Loaded Lanes (Hinge Support Line) 


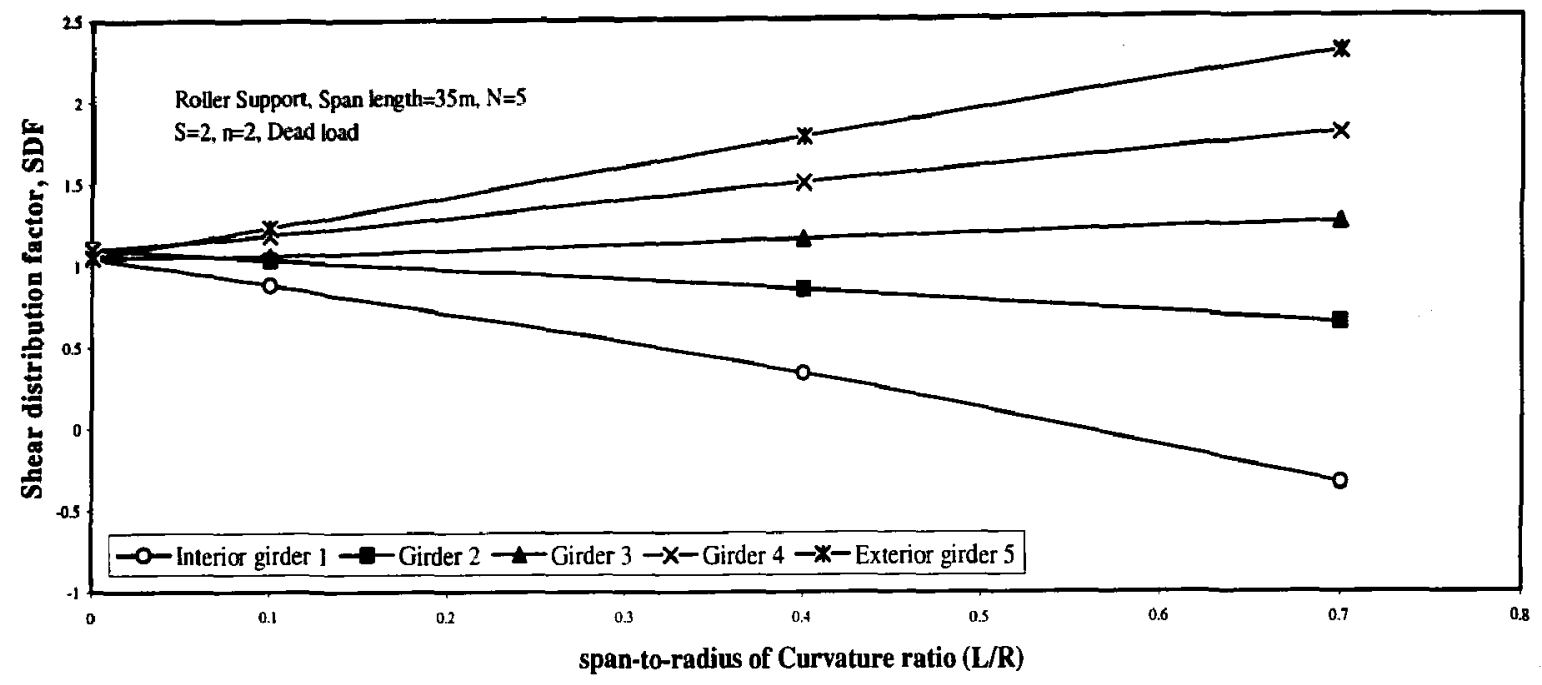

Figure 4. 71 Effect of the Type of Support on the Shear Distribution Factor due to Dead Loading (Roller Support Line)

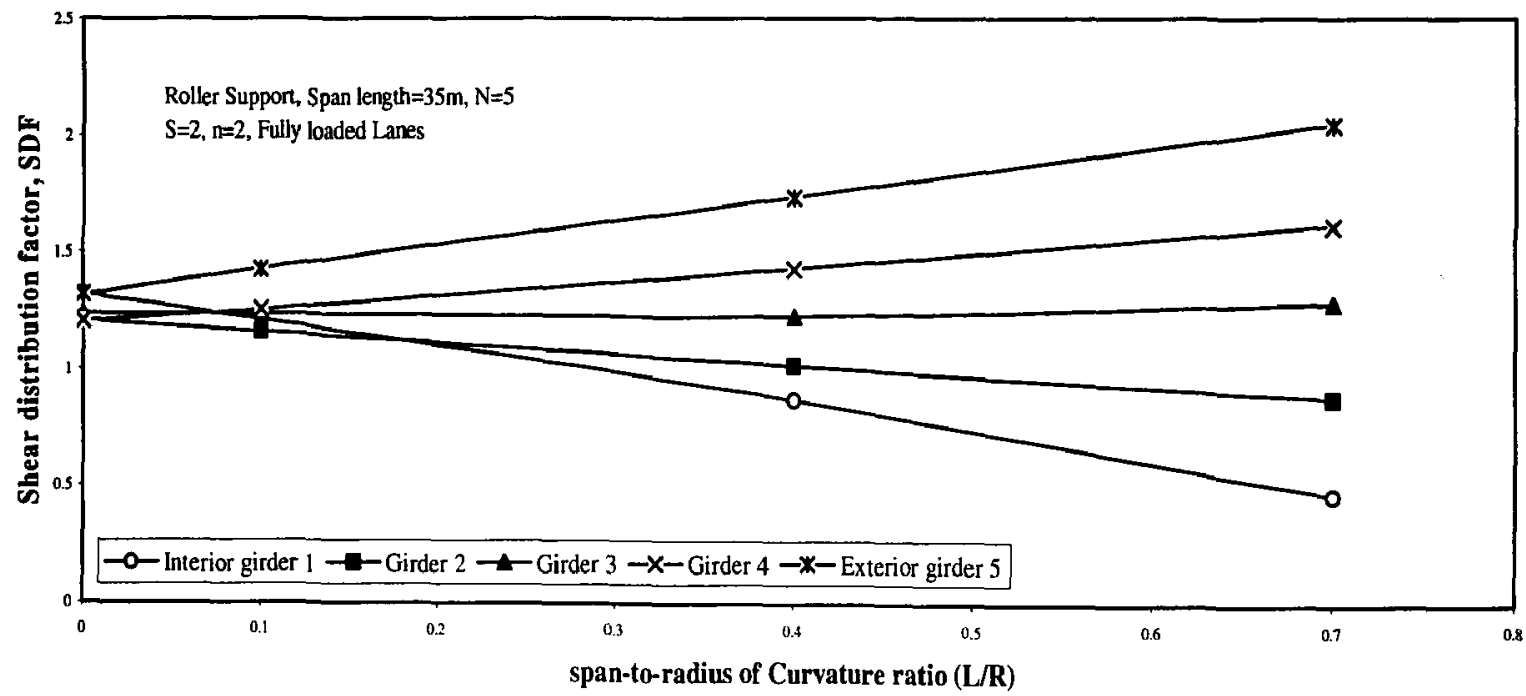

Figure 4. 72 Effect of the Type of Support on the Shear Distribution Factor due to Fully Loaded Lanes (Roller Support Line) 


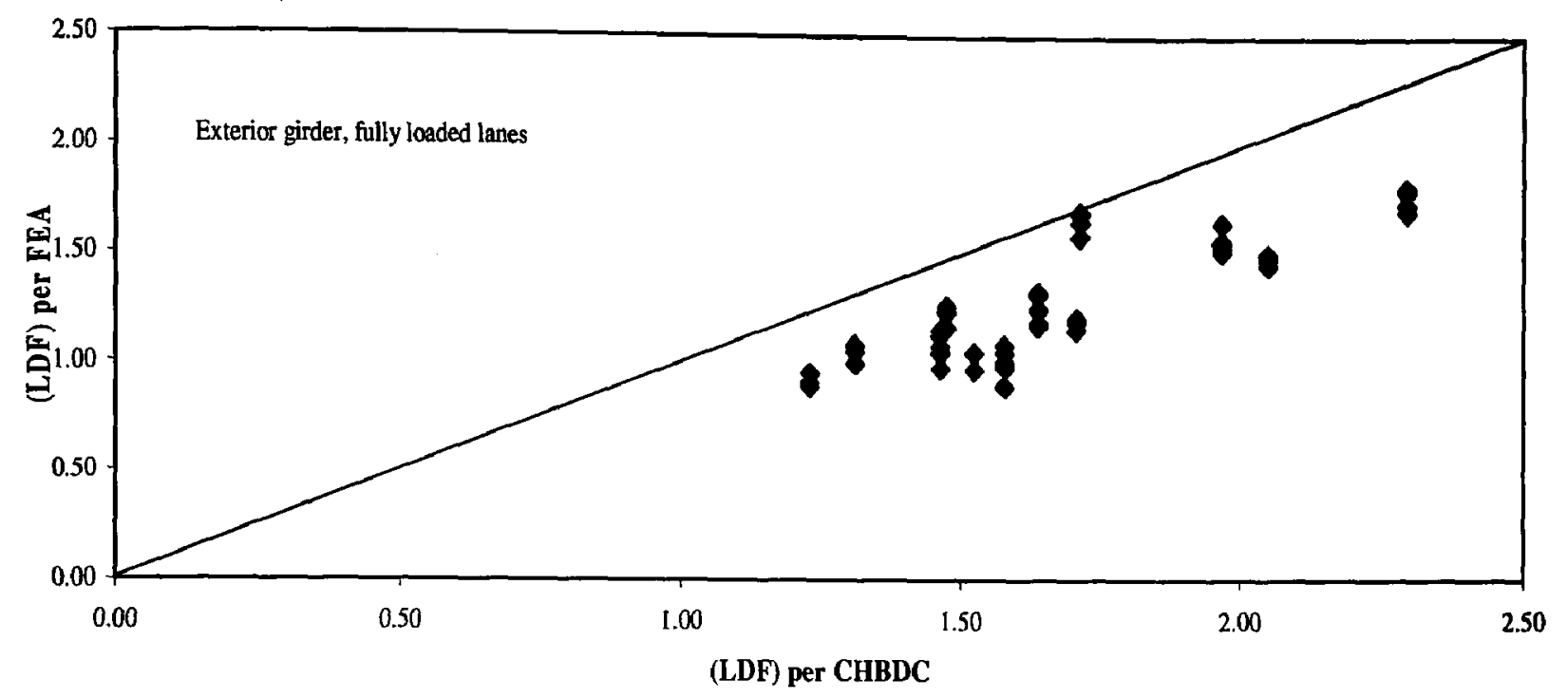

Figure 4. 73 Comparison between the Shear Distribution Factors of the Exterior Girder due to Truck Loading as Specified in the CHBDC and from the Current Study

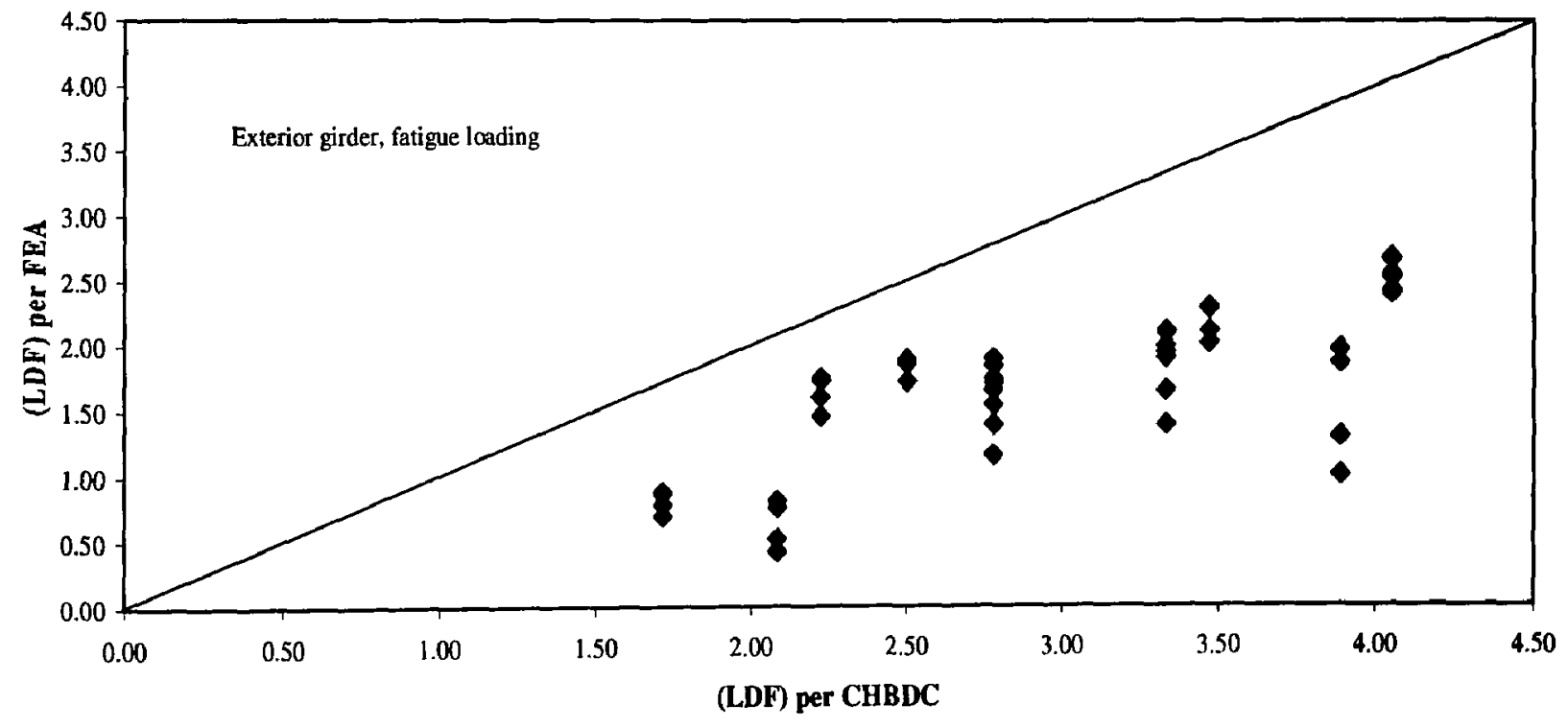

Figure 4. 74 Comparison between the Shear Distribution Factors of the Exterior Girder due to Fatigue Loading as Specified in the CHBDC and from the Current Study 


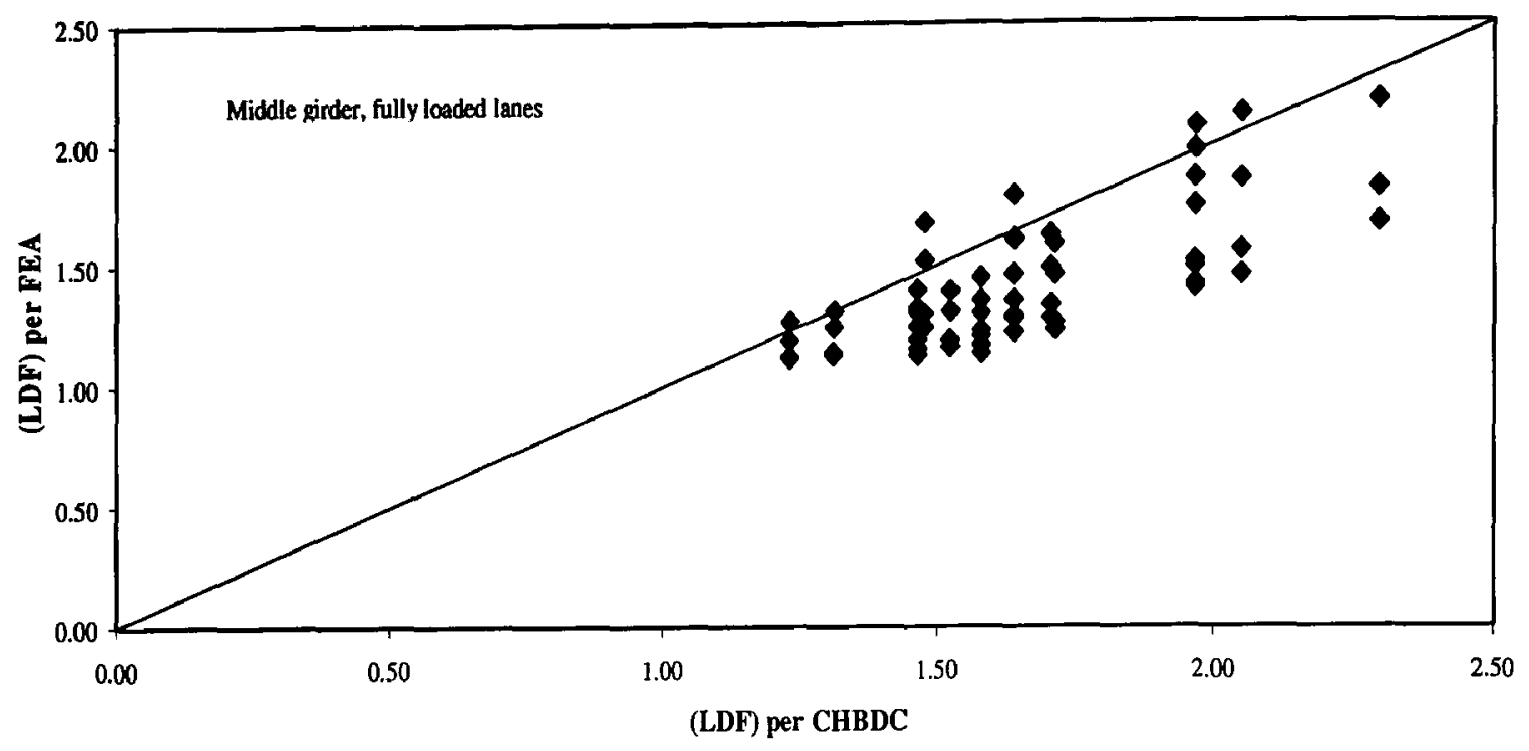

Figure 4.75 Comparison between the Shear Distribution Factors of the Middle Girder due tc Truck Loading as Specified in the CHBDC and from the Current Study

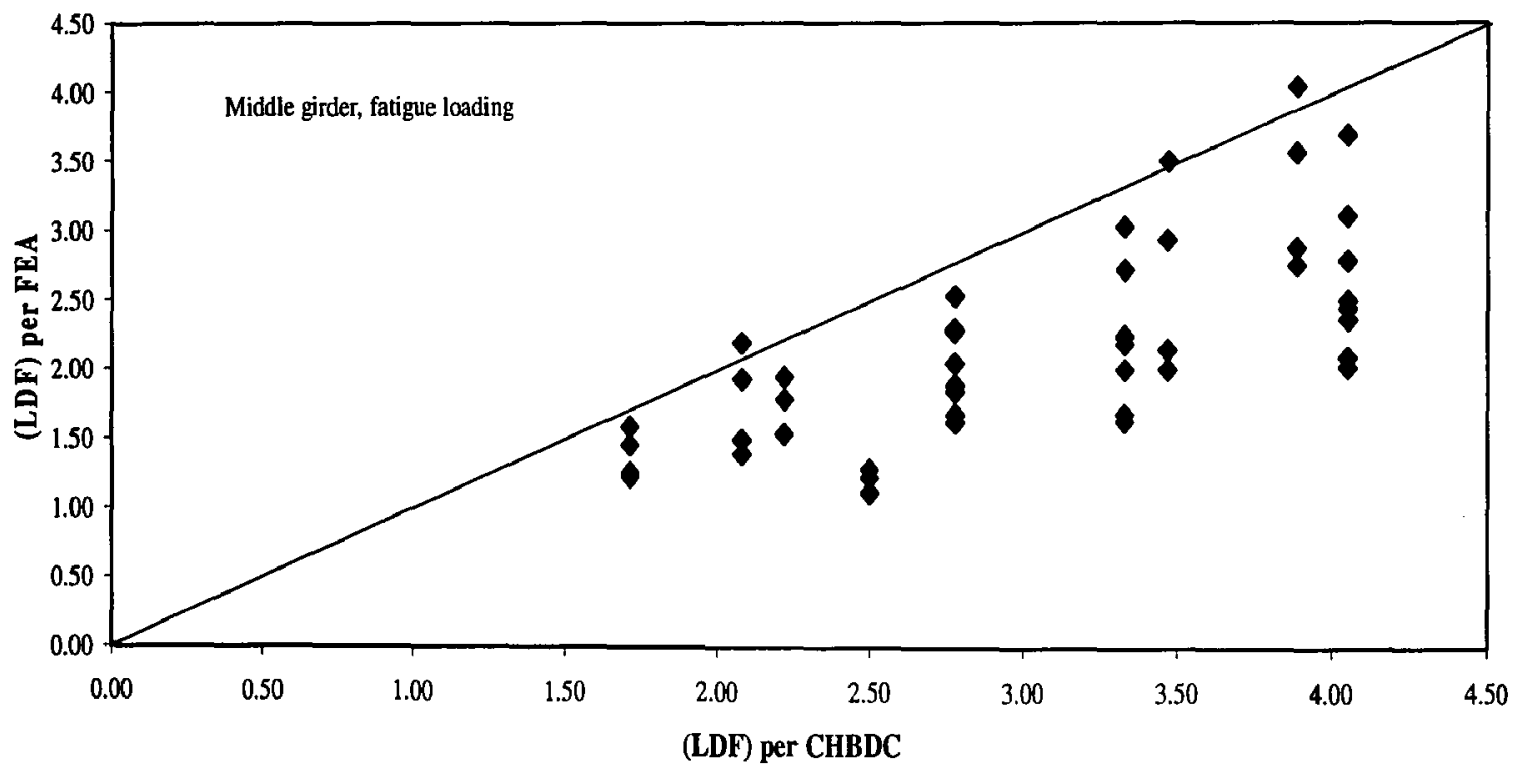

Figure 4.76 Comparison between the Shear Distribution Factors of the Middle Girder due $t$ Fatigue due to Truck Loading as Specified in the CHBDC and from the Current Study 


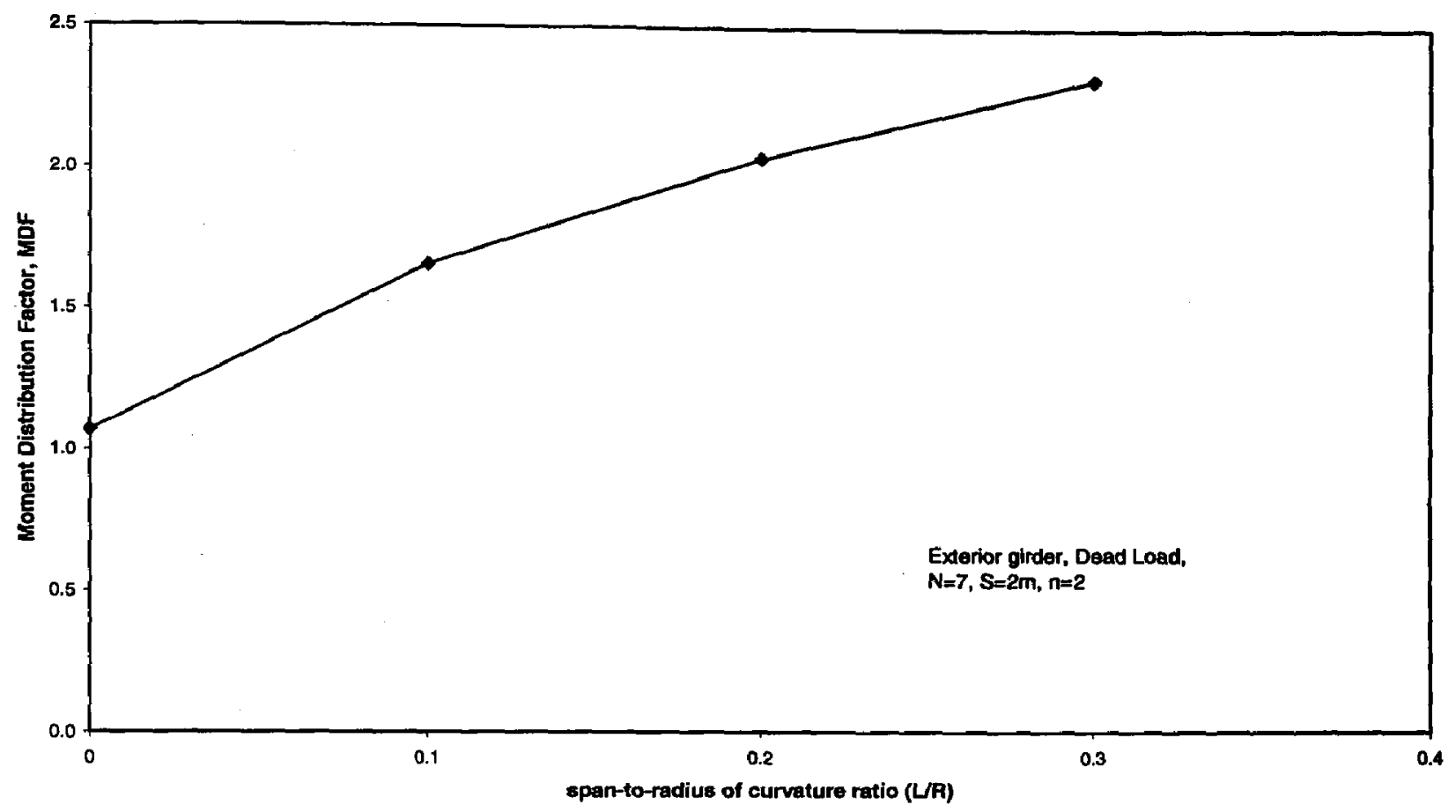

Figure 4.77 Effect of Curvature on the Moment Distribution Factor for the Exterior Girder due to Dead Load

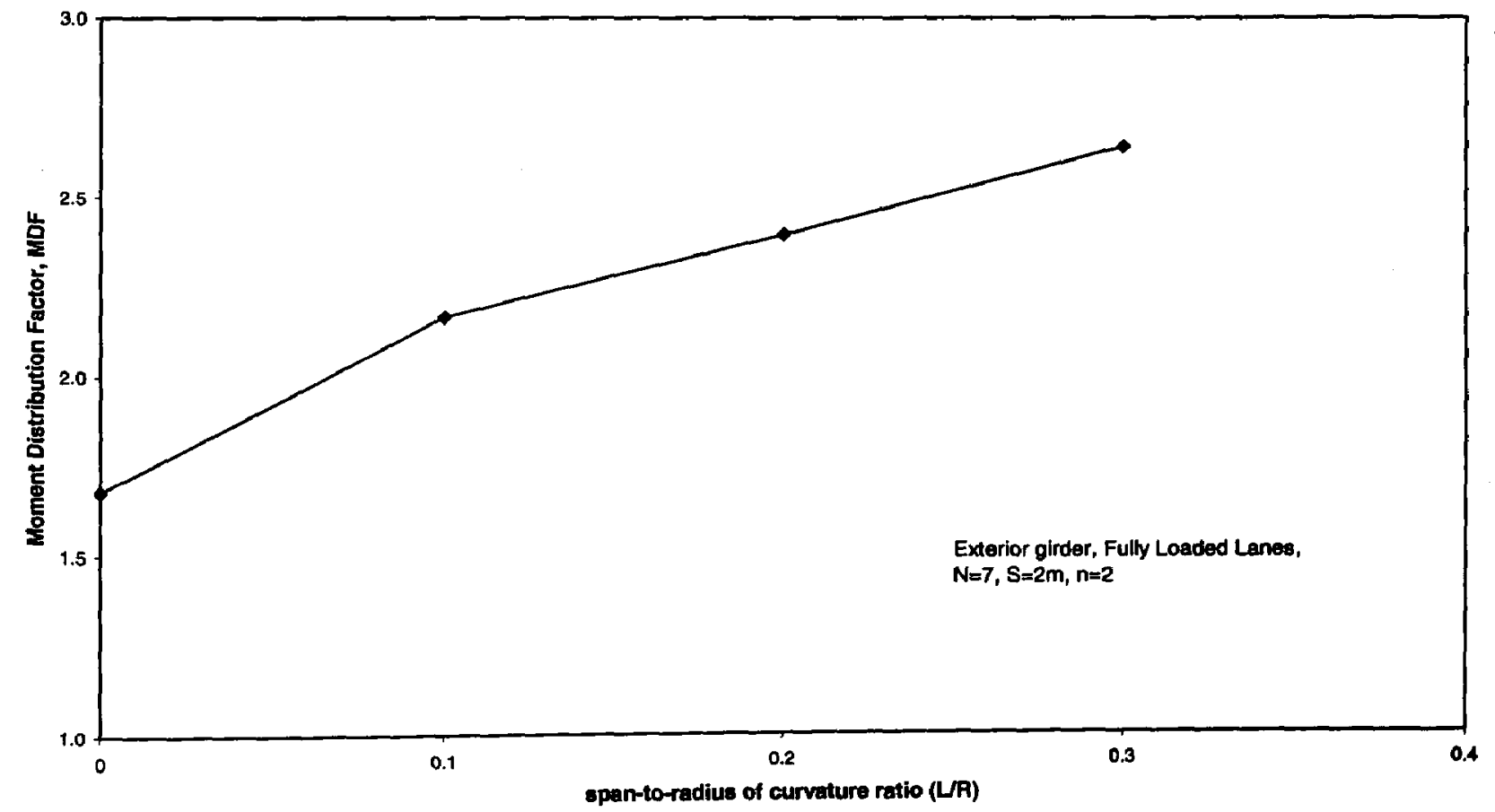

Figure 4. 78 Effect of Curvature on the Moment Distribution Factor for the Exterior Girder due to Fully Loaded Lanes 


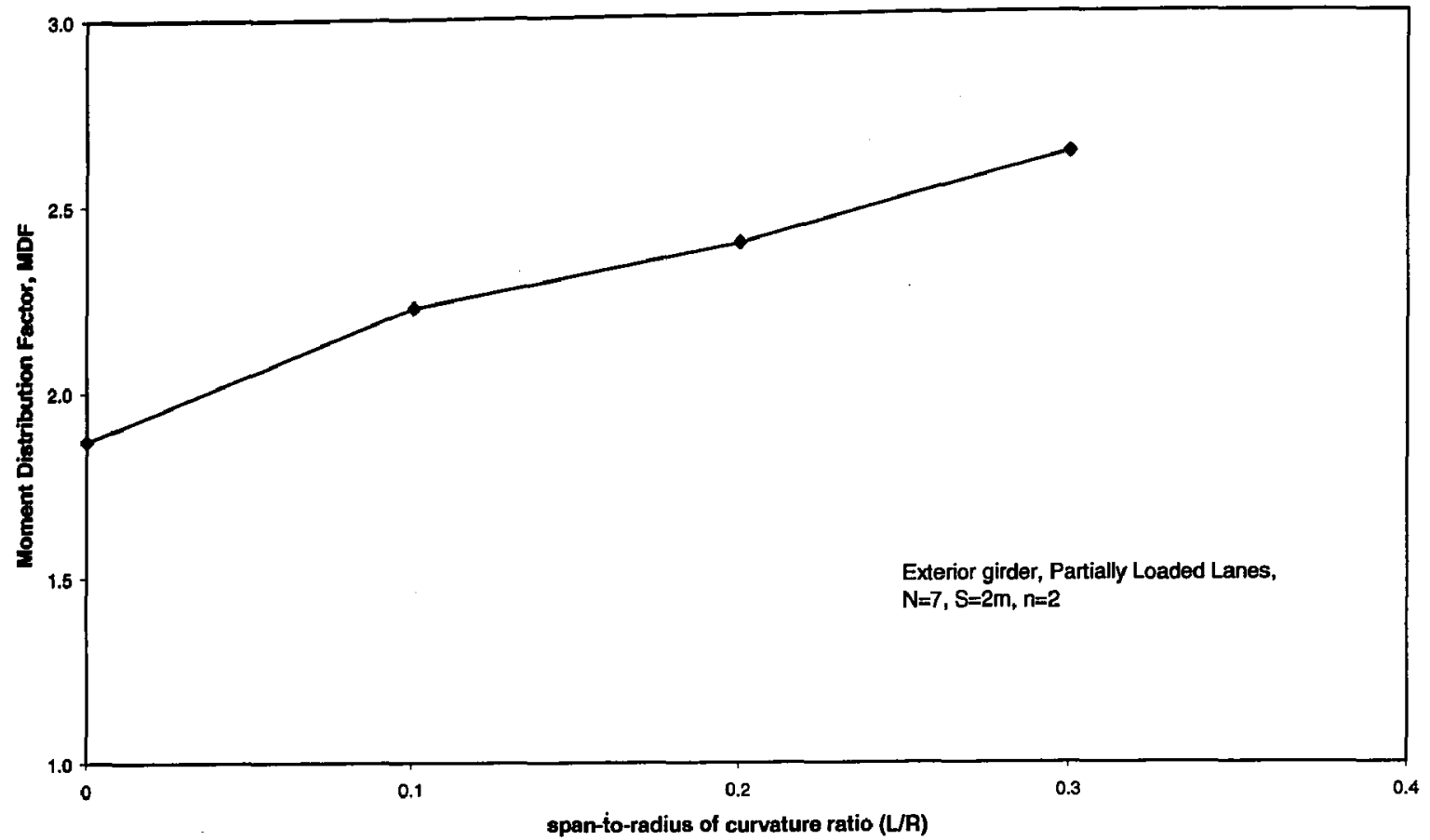

Figure 4. 79 Effect of Curvature on the Moment Distribution Factor for the Exterior Girder due to Partially Loaded Lanes

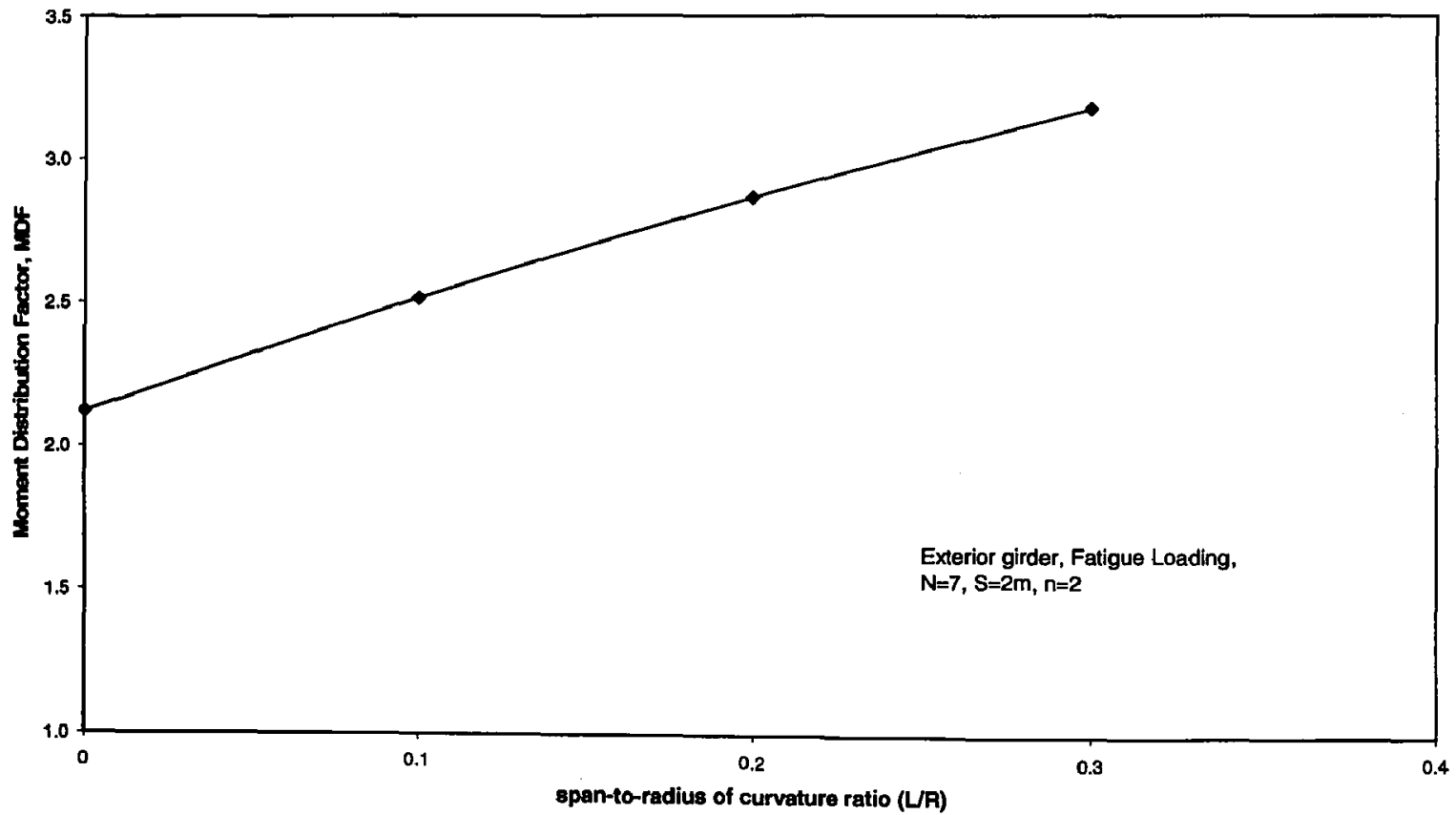

Figure 4. 80 Effect of Curvature on the Moment Distribution Factor for the Exterior Girder due to Fatigue Loading 


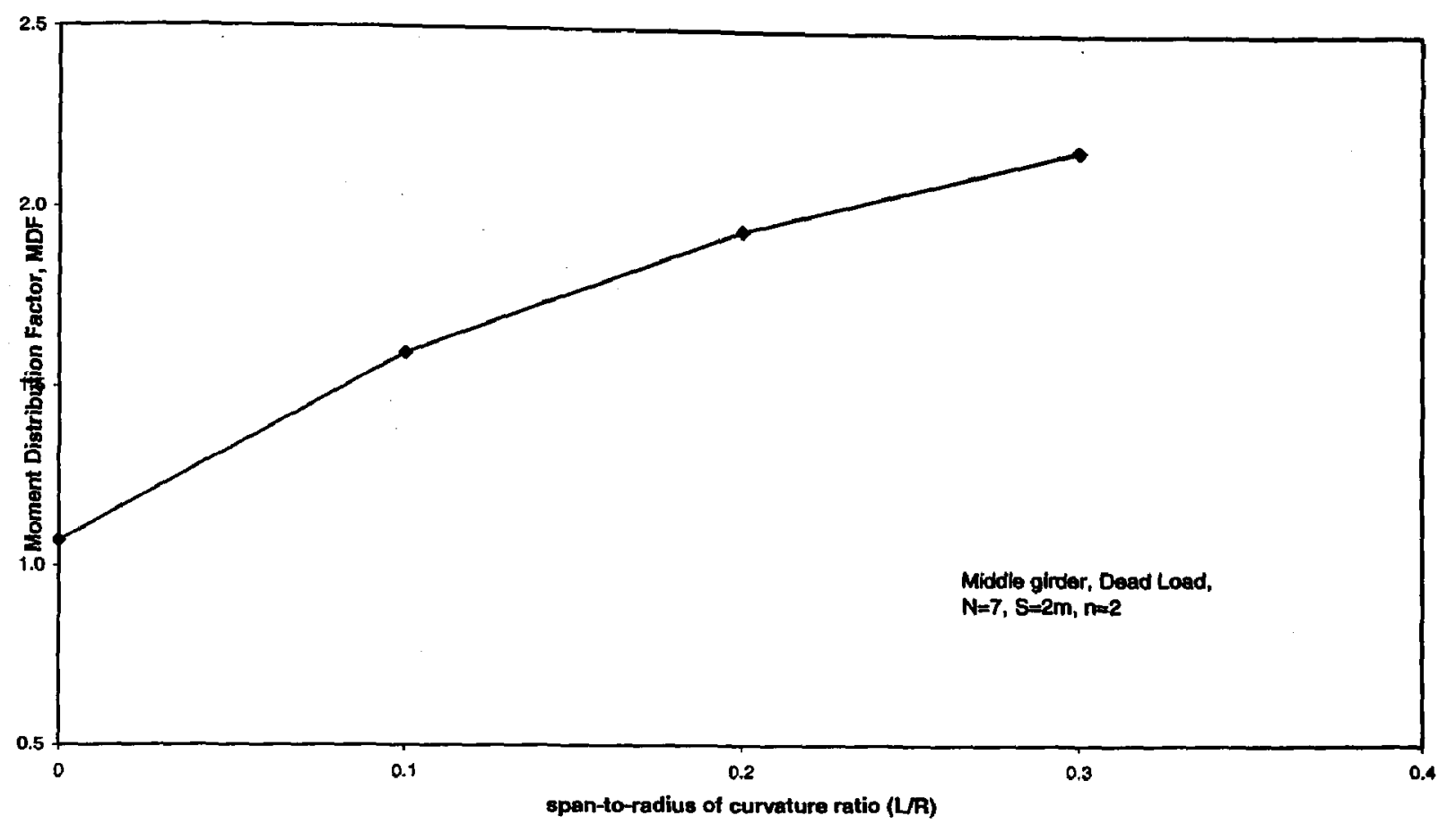

Figure 4. 81 Effect of Curvature on the Moment Distribution Factor for the Middle Girder due to Dead Load

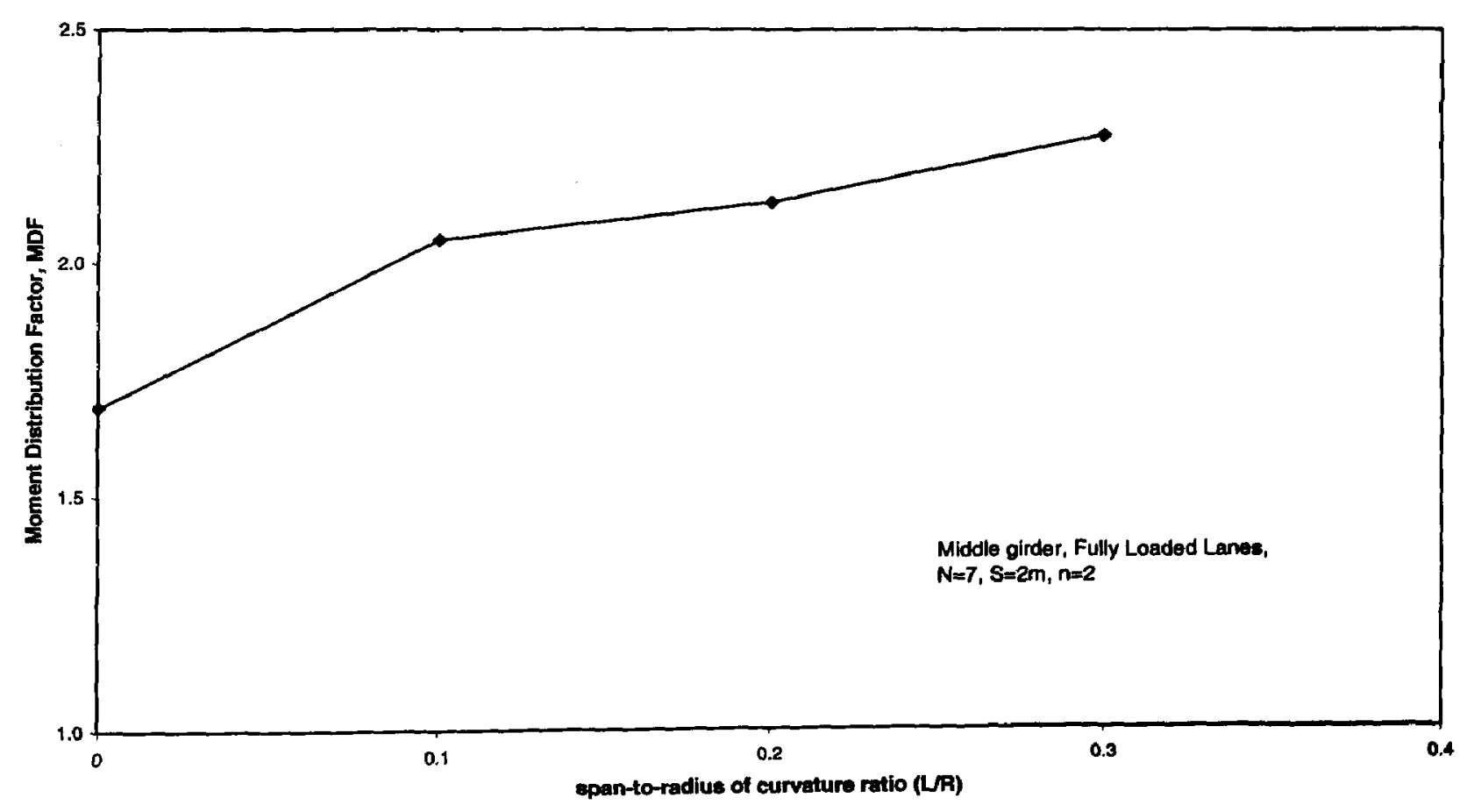

Figure 4. 82 Effect of Curvature on the Moment Distribution Factor for the Middle Girder due to Fully Loaded Lanes 


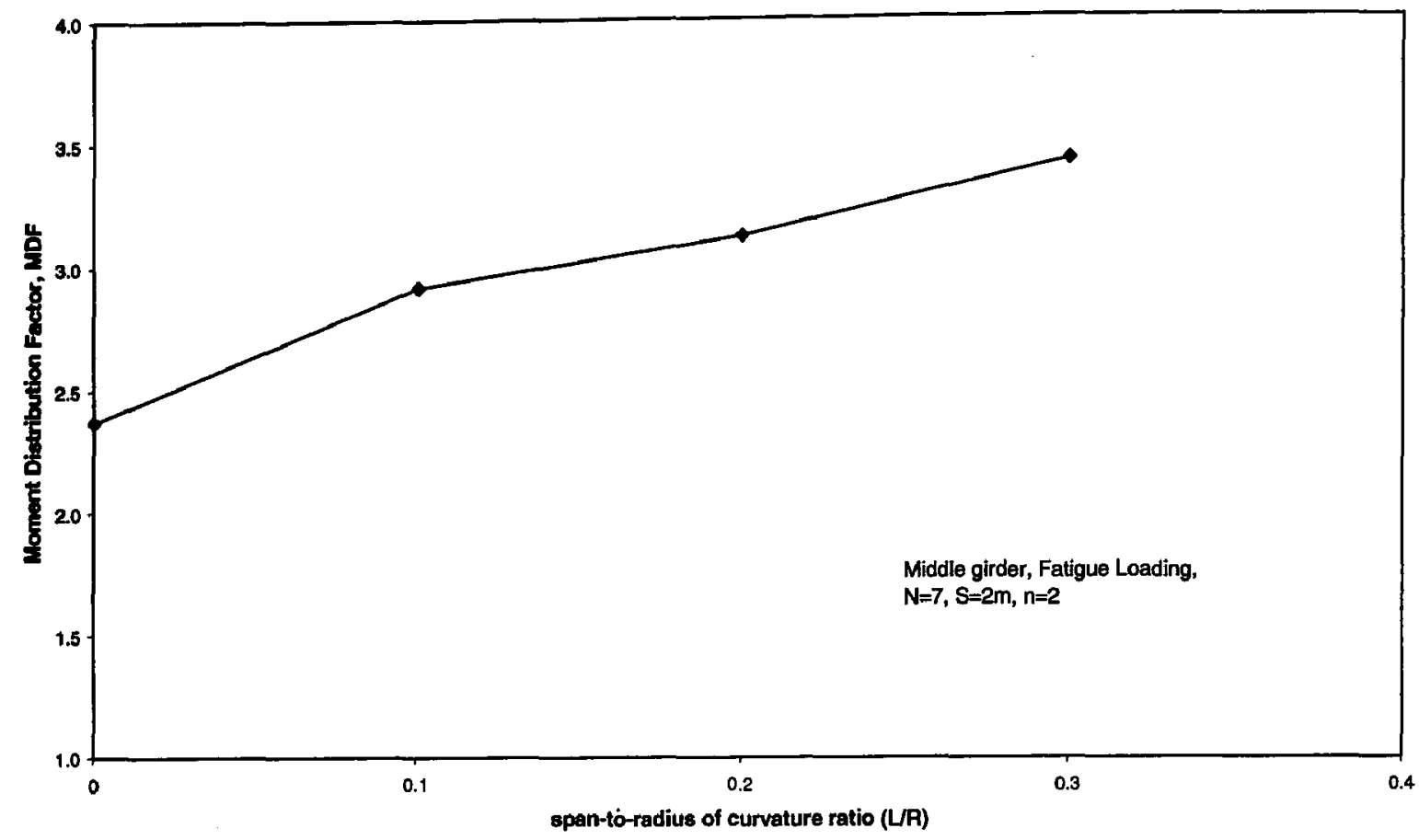

Figure 4. 83 Effect of Curvature on the Moment Distribution Factor for the Middle Girder due to Fatigue Loading

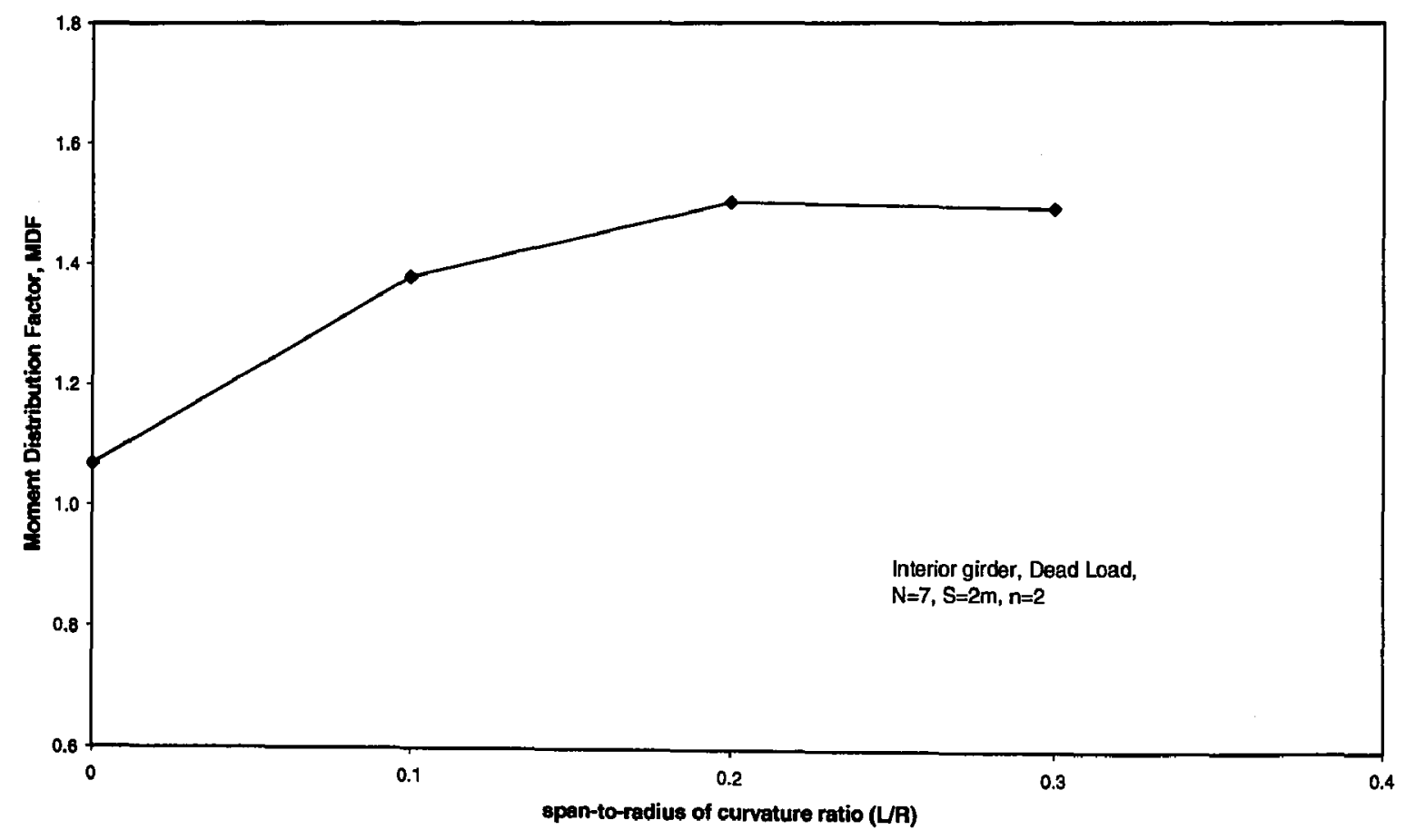

Figure 4. 84 Effect of Curvature on the Moment Distribution Factor for the Interior Girder due to Dead Load 


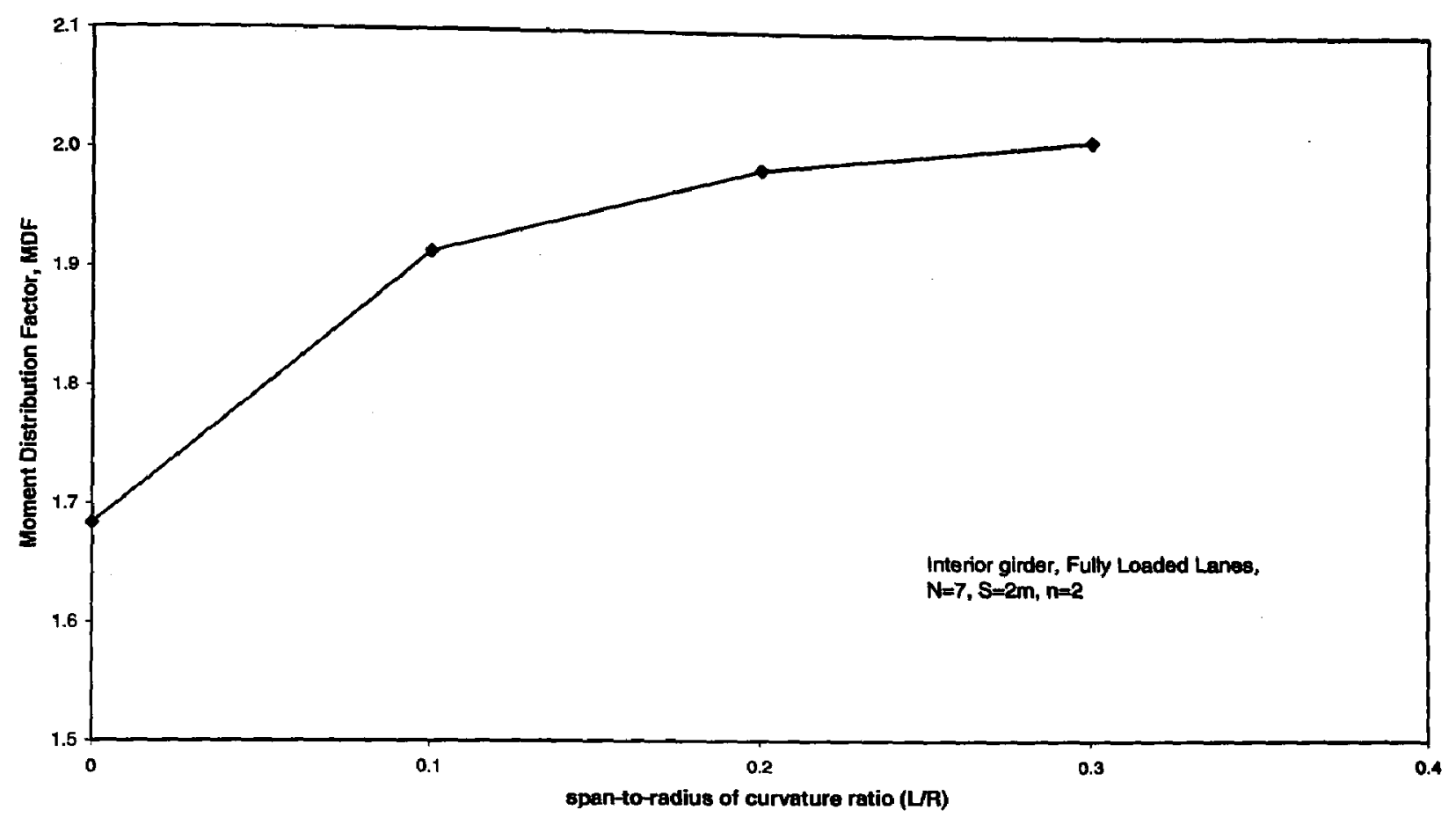

Figure 4. 85 Effect of Curvature on the Moment Distribution Factor for the Interior Girder due to Fully Loaded Lanes

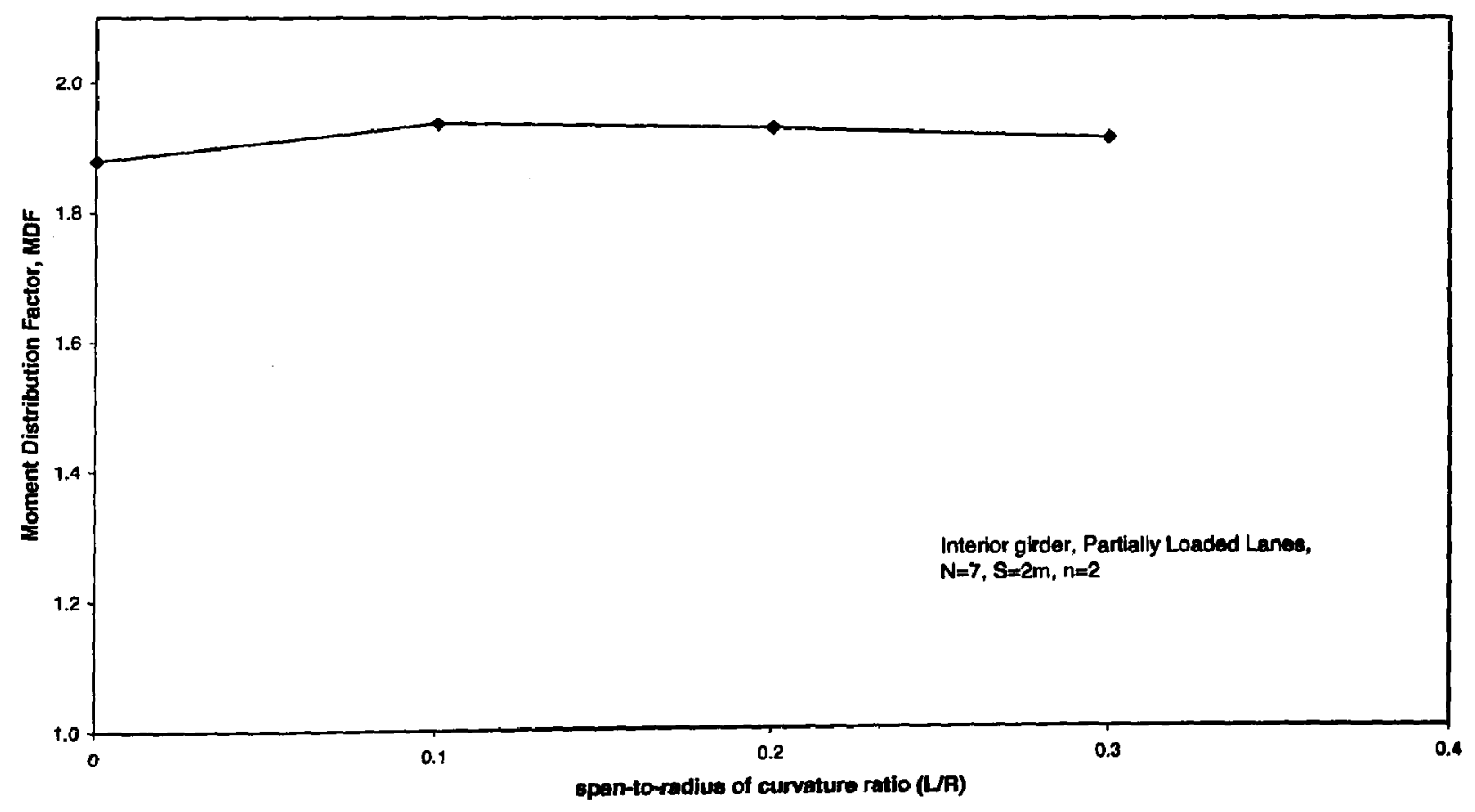

Figure 4. 86 Effect of Curvature on the Moment Distribution Factor for the Interior Girder due to Partially Loaded Lanes 


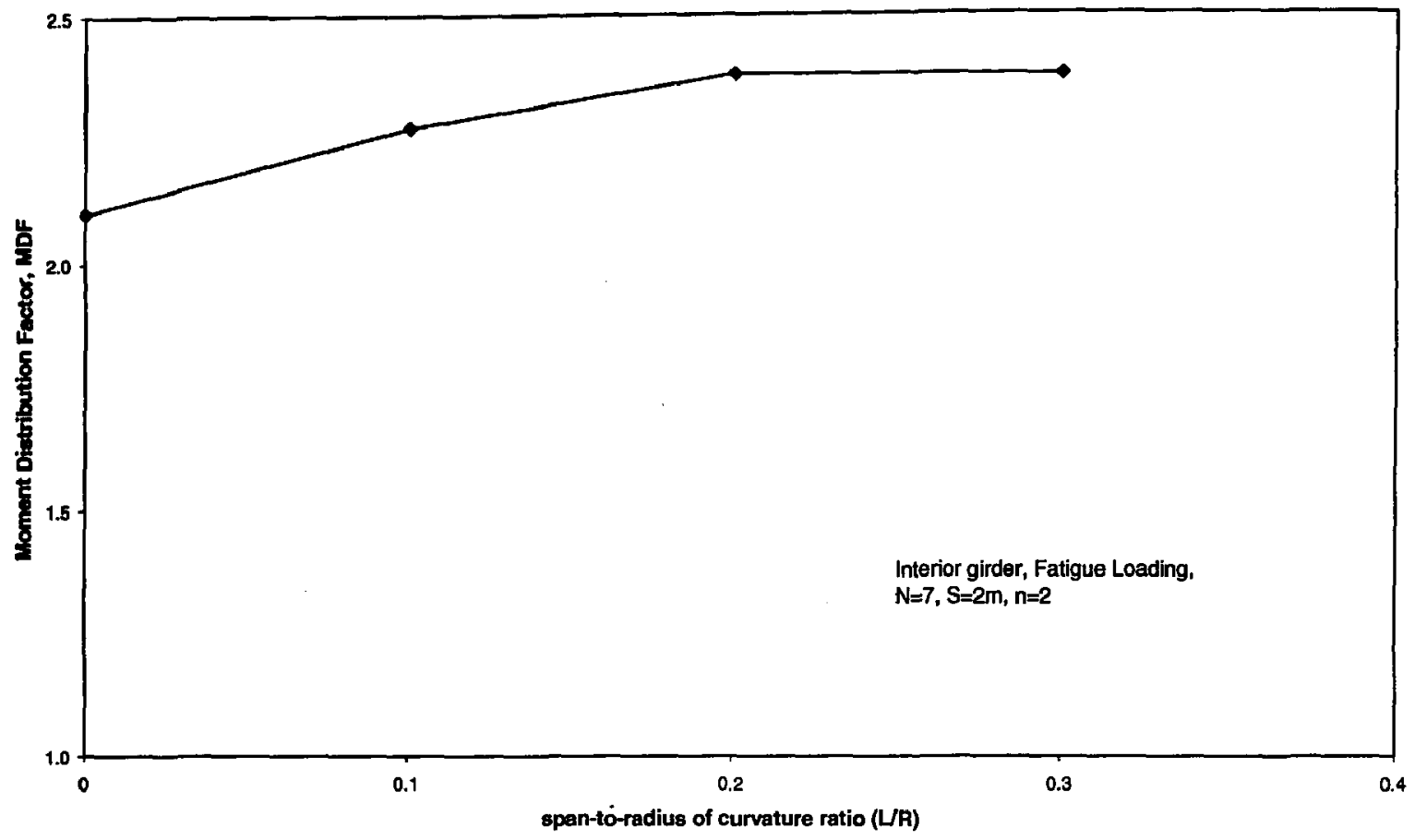

Figure 4.87 Effect of Curvature on the Moment Distribution Factor for the Interior Girder due to Fatigue Loading

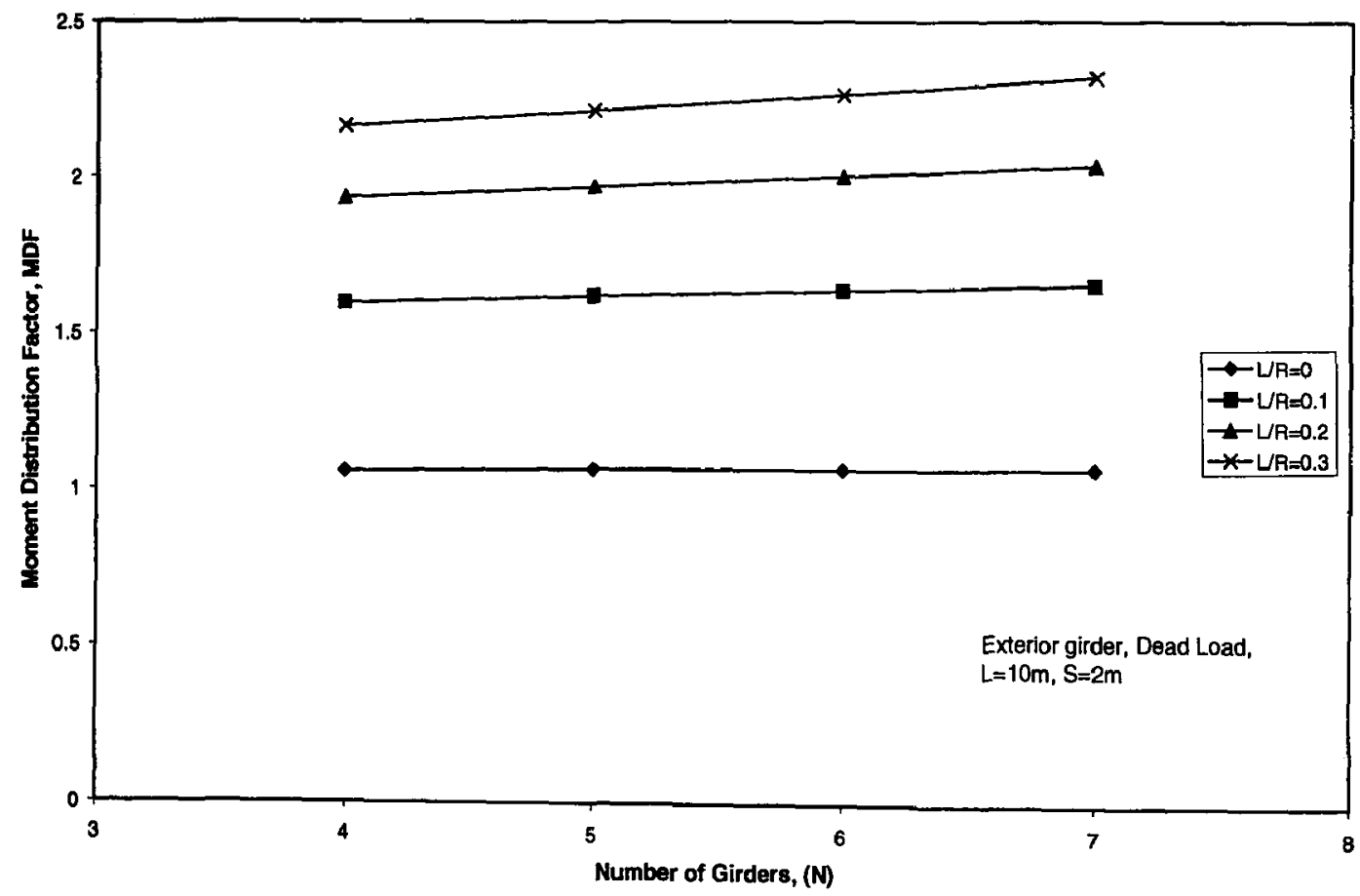

Figure 4. 88 Effect of Number of Girders on the Moment Distribution Factor for the Exterior Girder due to Dead Load 


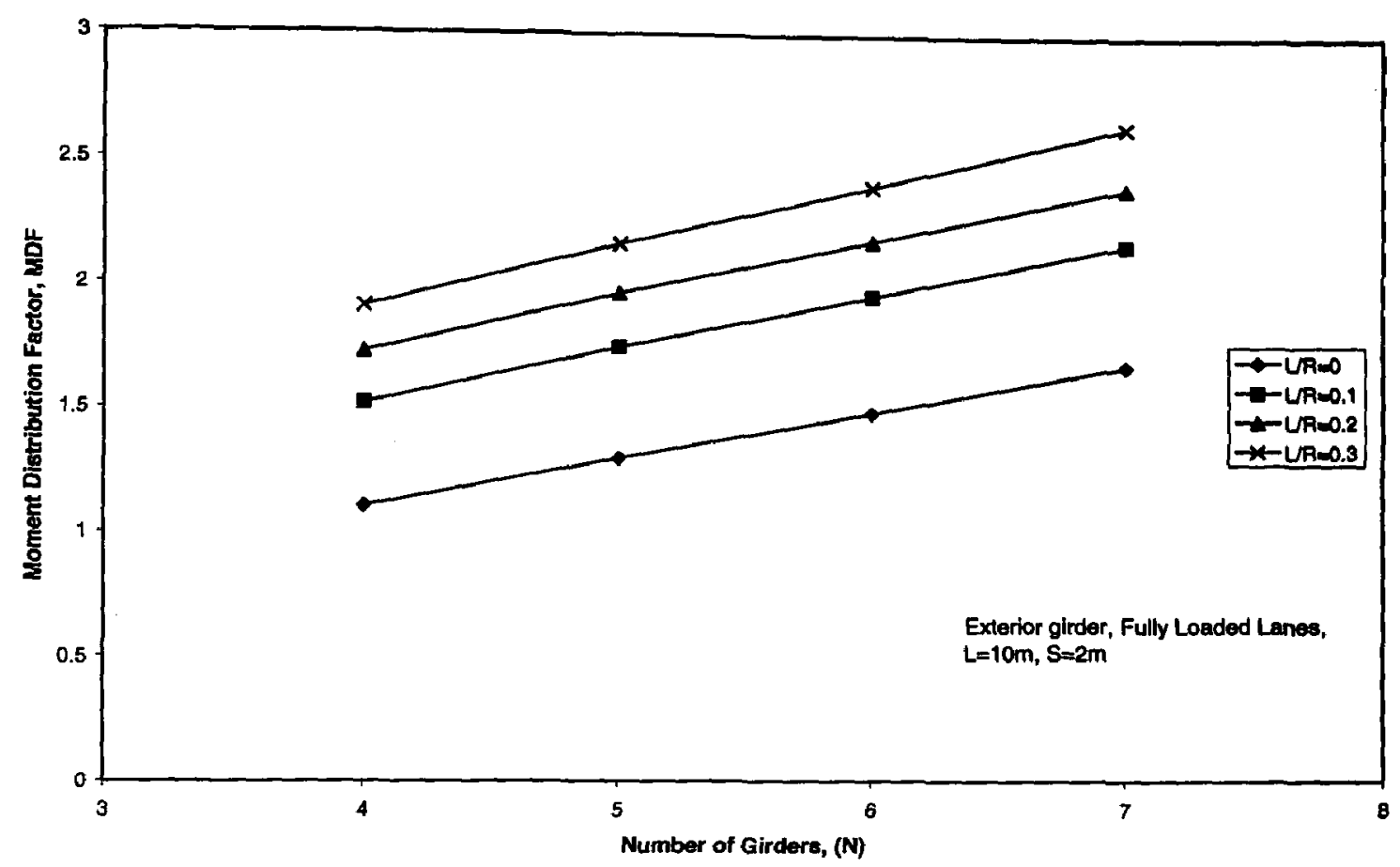

Figure 4. 89 Effect of Number of Girders on the Moment Distribution Factor for the Exterior Girder due to Fully Loaded Lanes

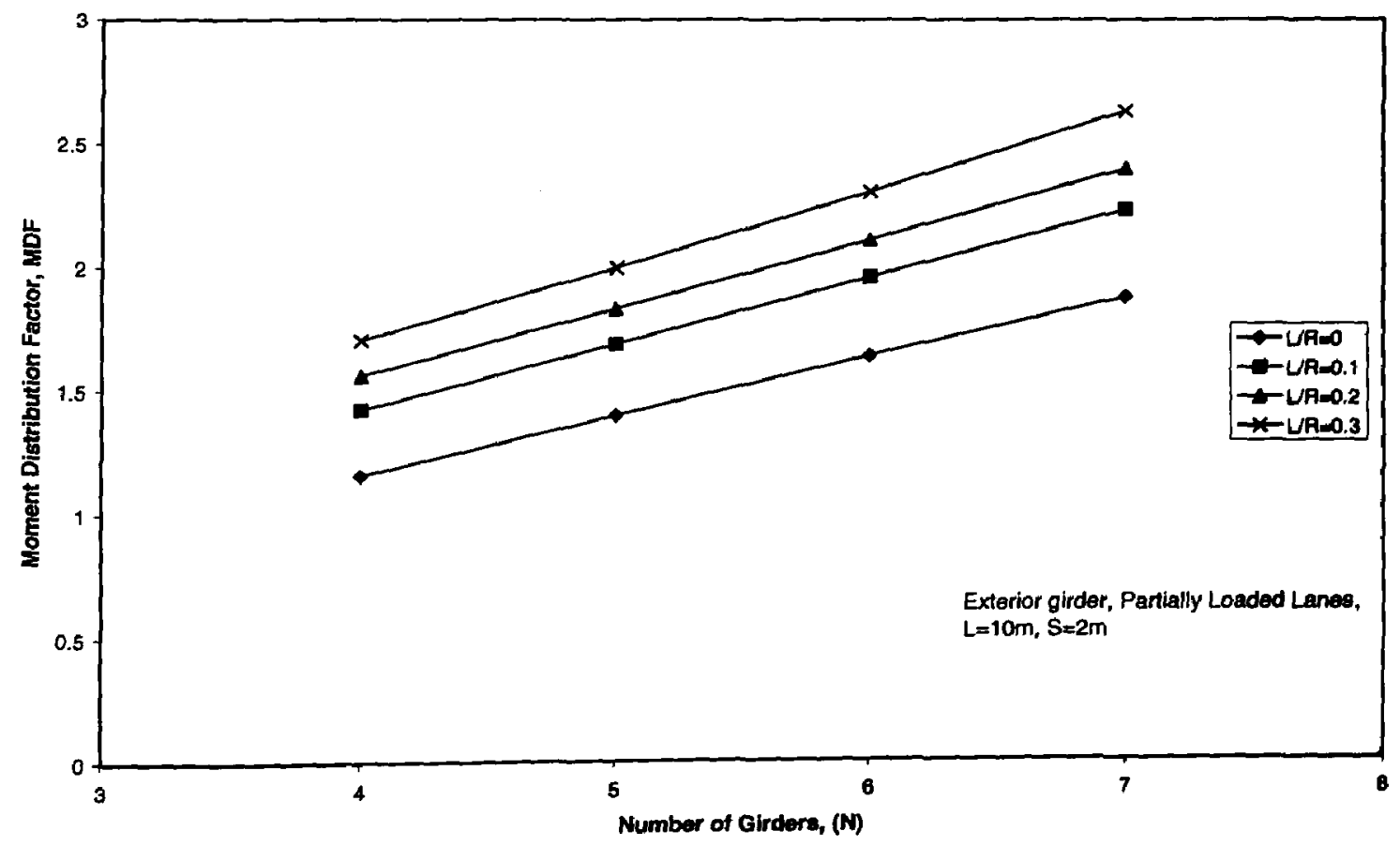

Figure 4.90 Effect of Number of Girders on the Moment Distribution Factor for the Exterior Girder due to Partially Loaded Lanes 


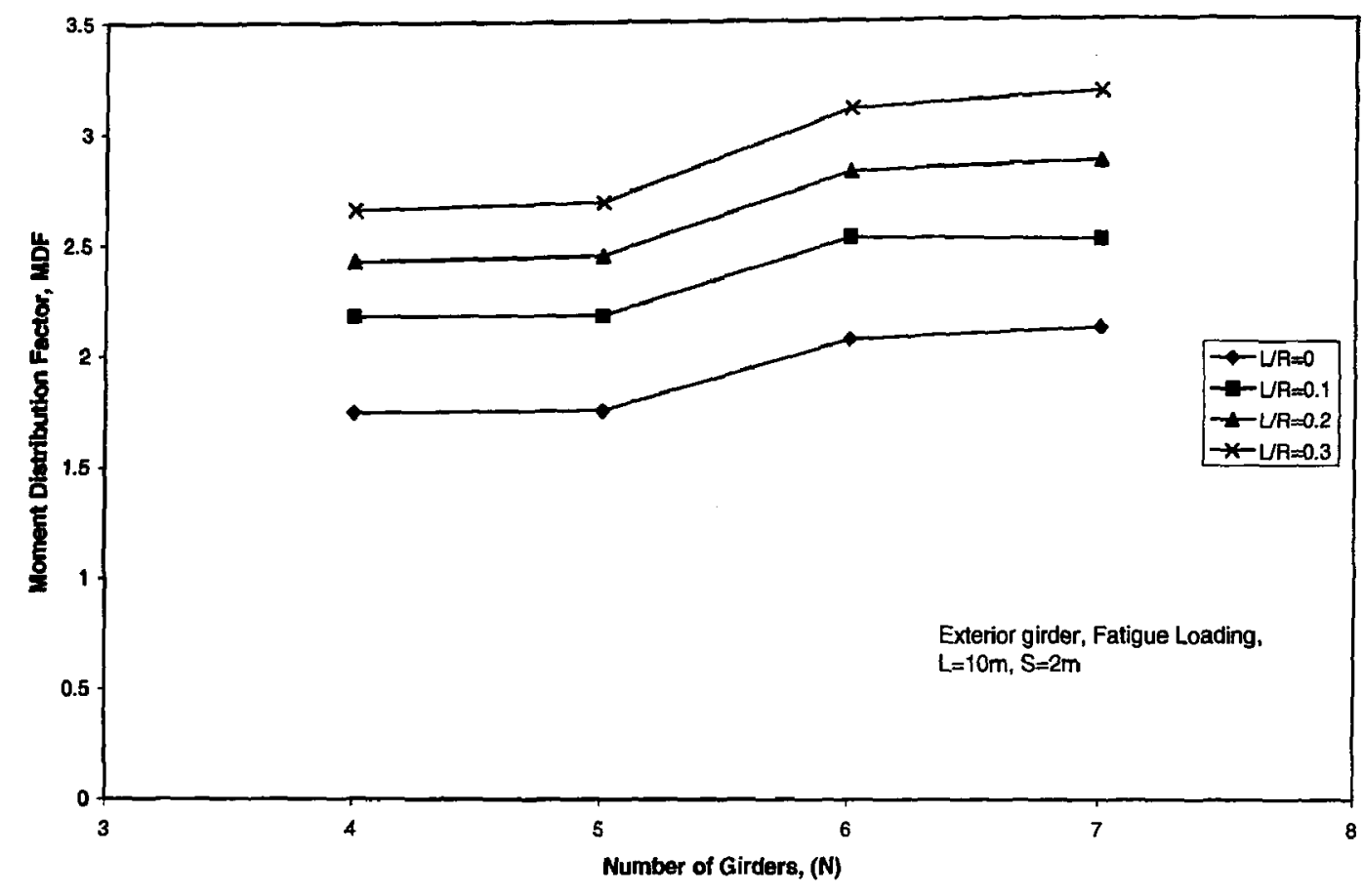

Figure 4.91 Effect of Number of Girders on the Moment Distribution Factor for the Exterior Girder due to Fatigue Loading

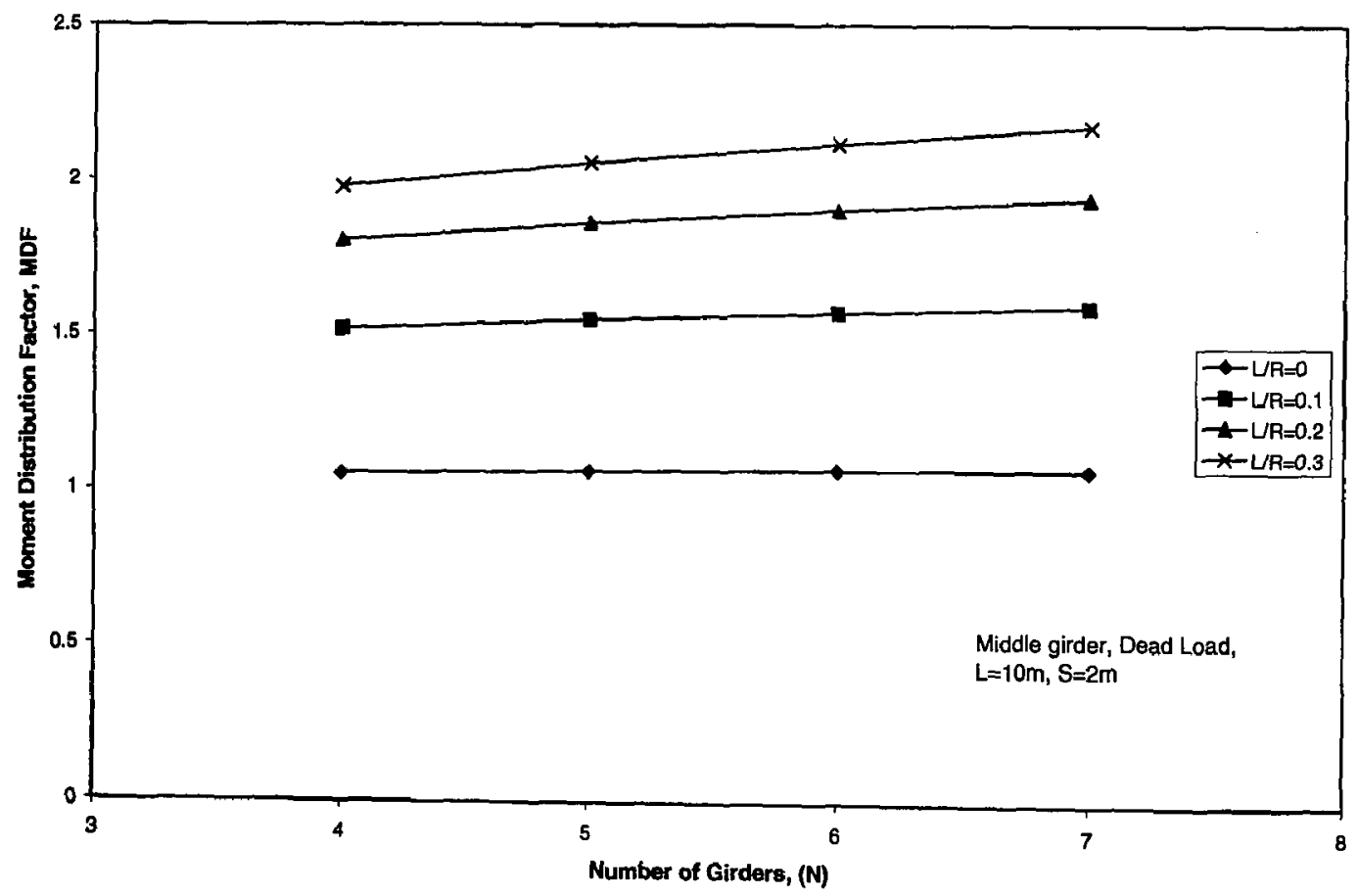

Figure 4.92 Effect of Number of Girders on the Moment Distribution Factor for the Middle Girder due to Dead Load 


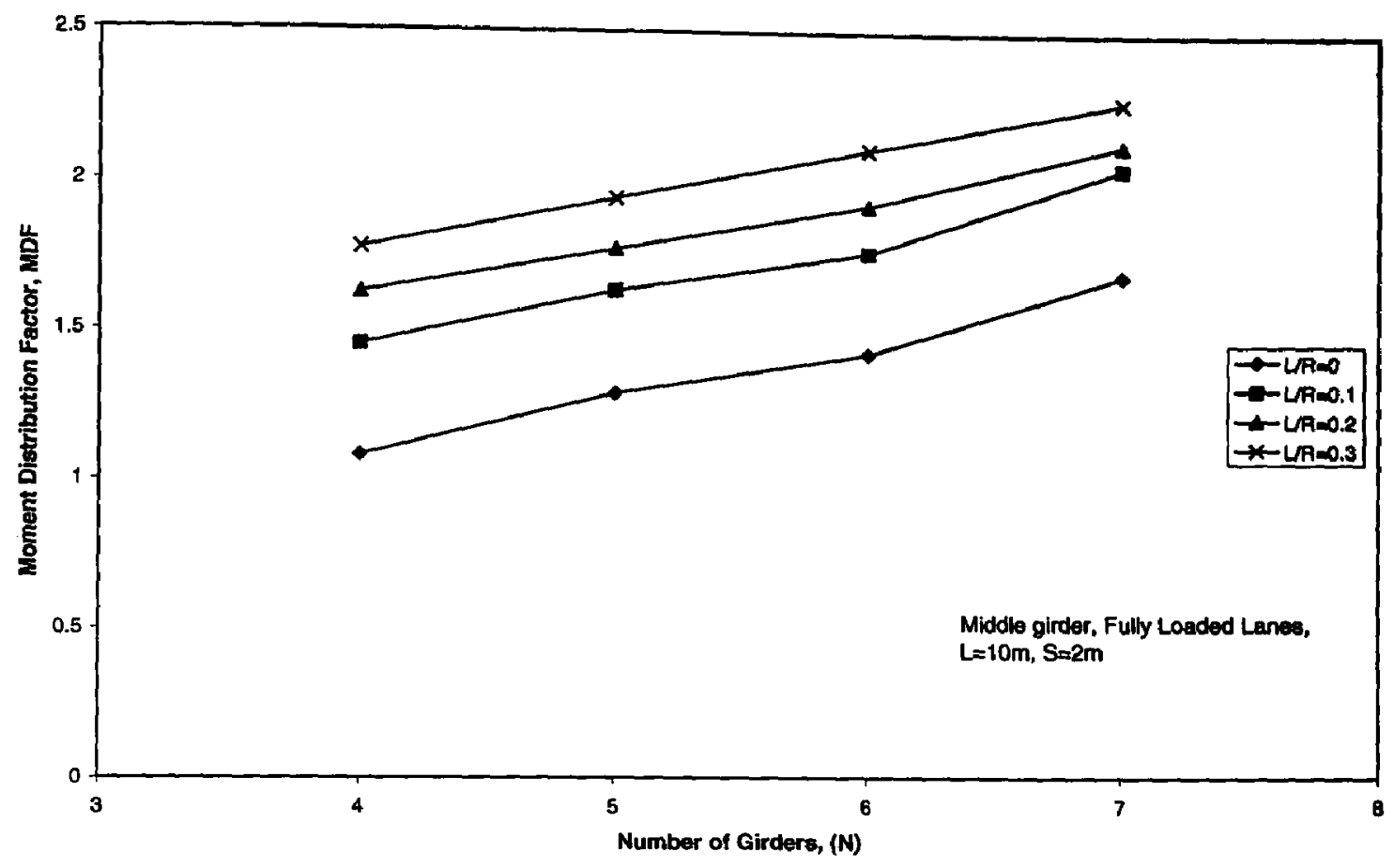

Figure 4.93 Effect of Number of Girders on the Moment Distribution Factor for the Middle Girder due to Fully Loaded Lanes

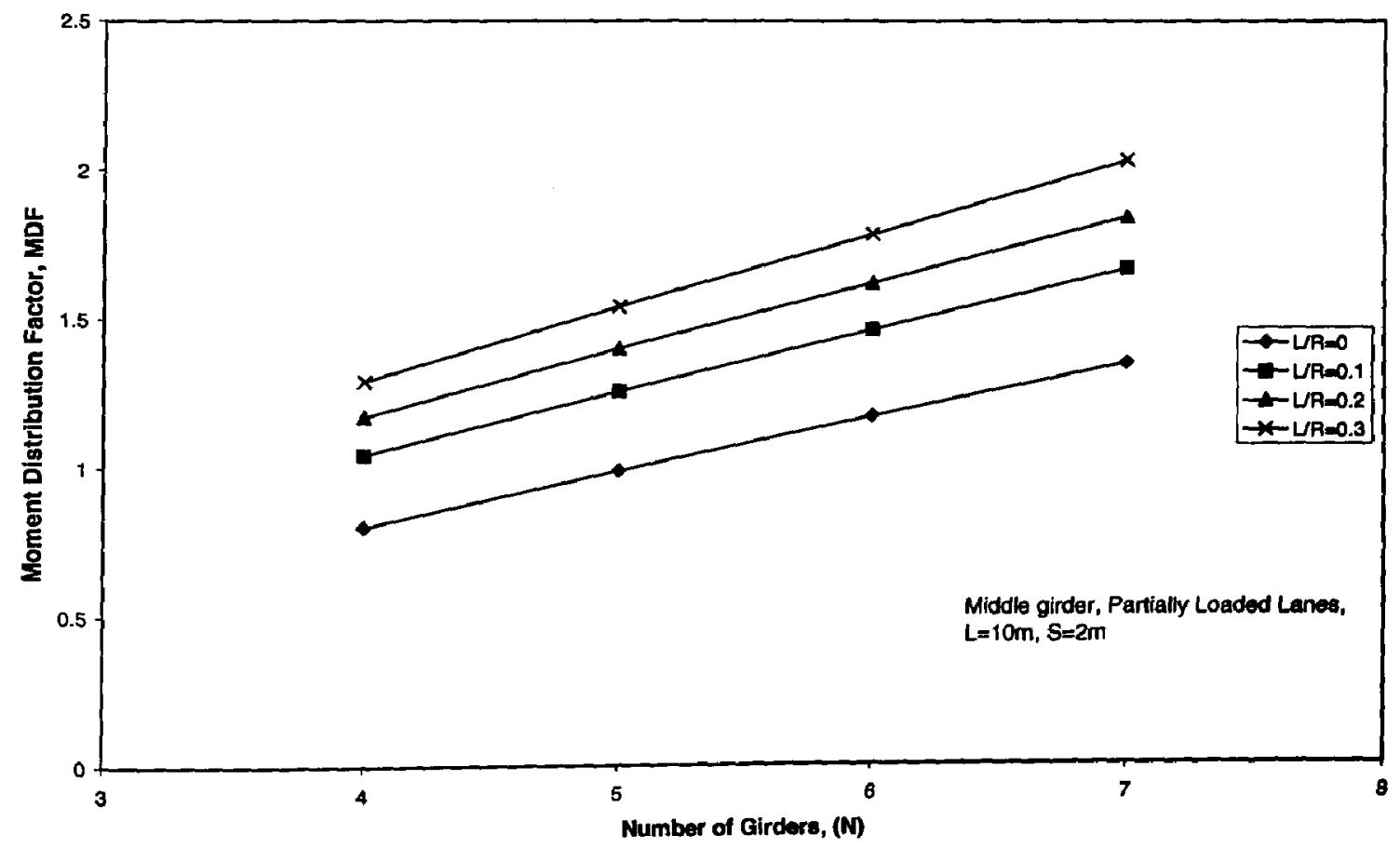

Figure 4.94 Effect of Number of Girders on the Moment Distribution Factor for the Middle Girder due to Partially Loaded Lanes 


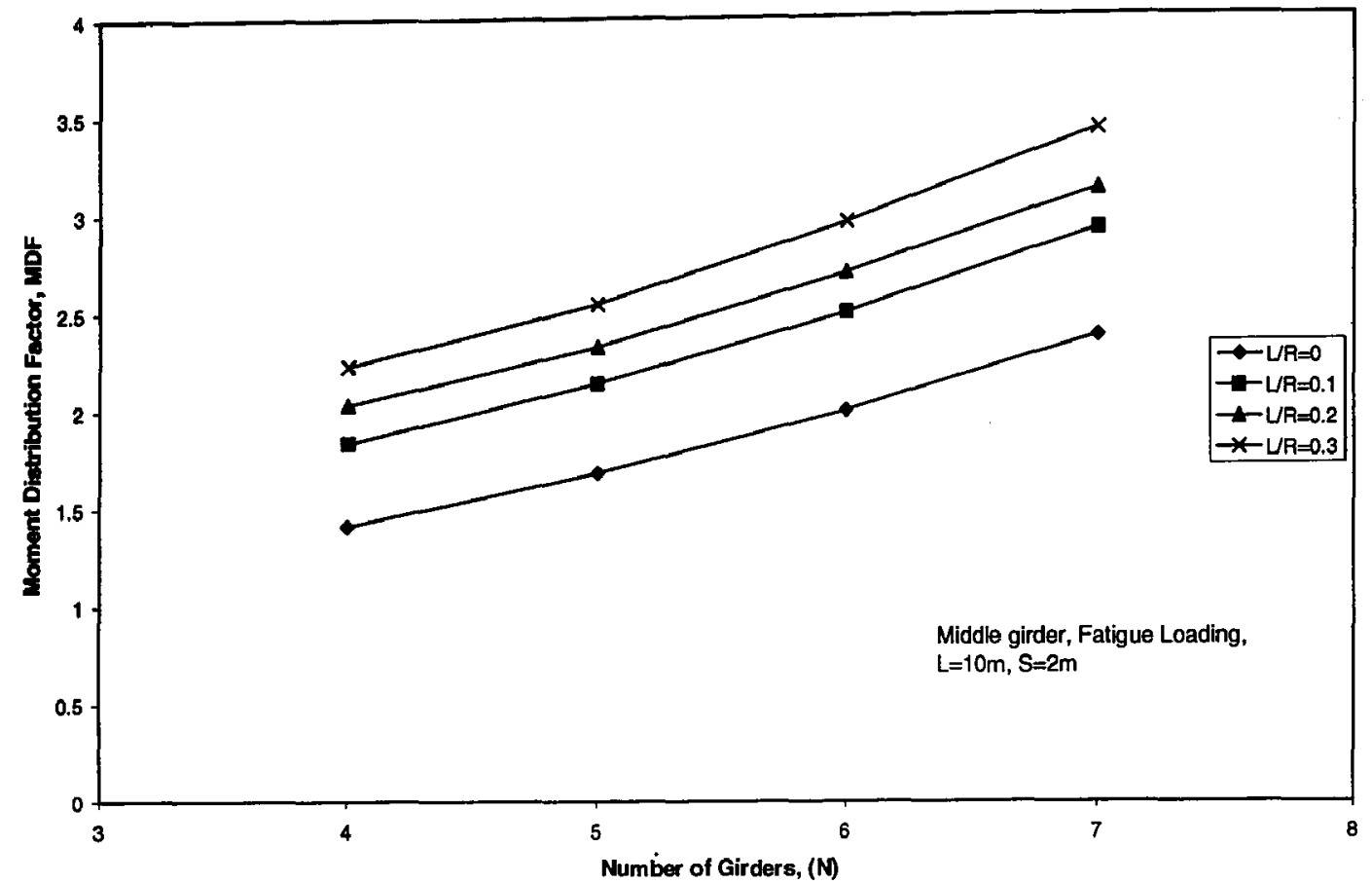

Figure 4.95 Effect of Number of Girders on the Moment Distribution Factor for the Middle Girder due to Fatigue Loading

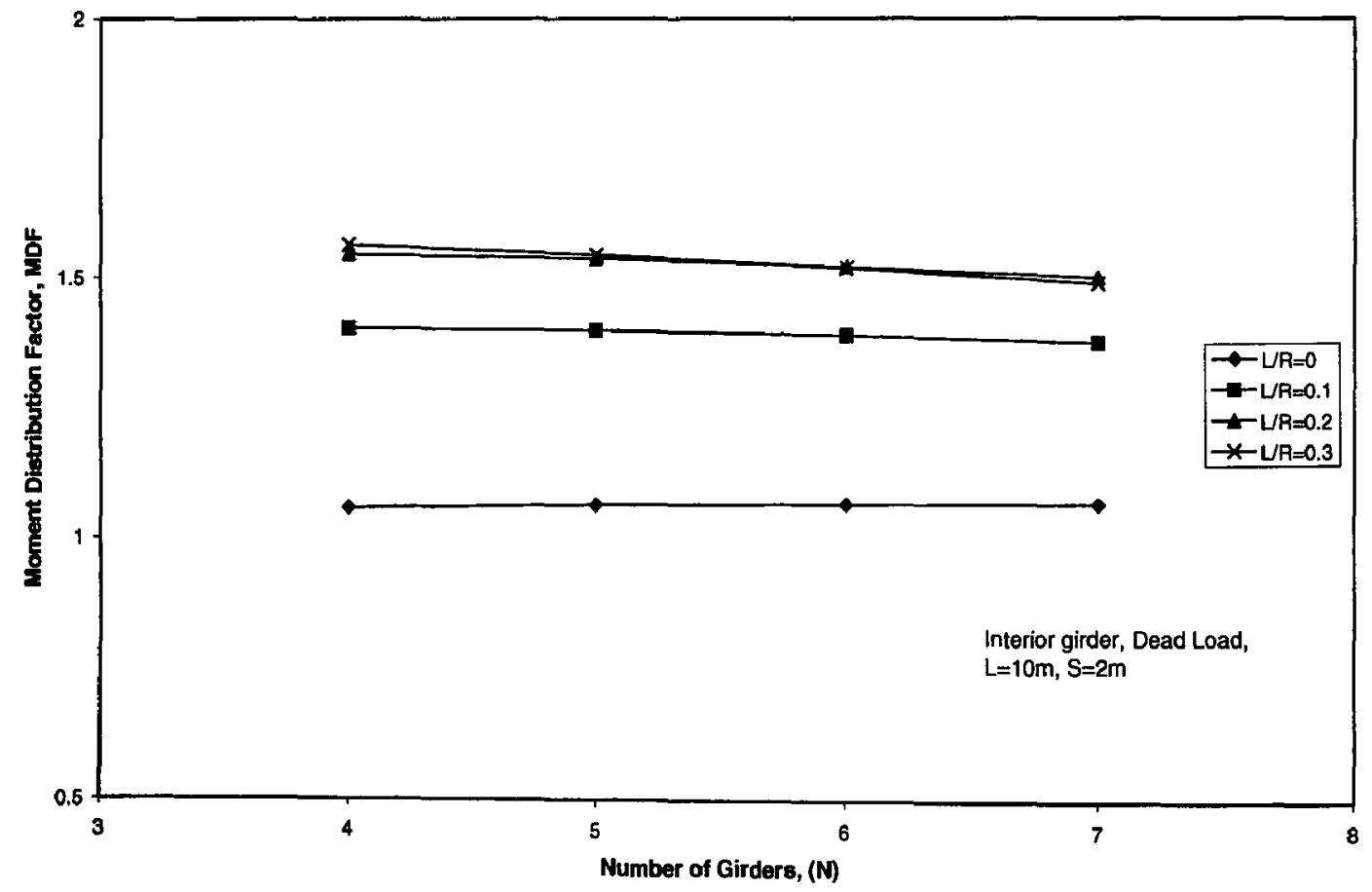

Figure 4.96 Effect of Number of Girders on the Moment Distribution Factor for the Interior Girder due to Dead Load 


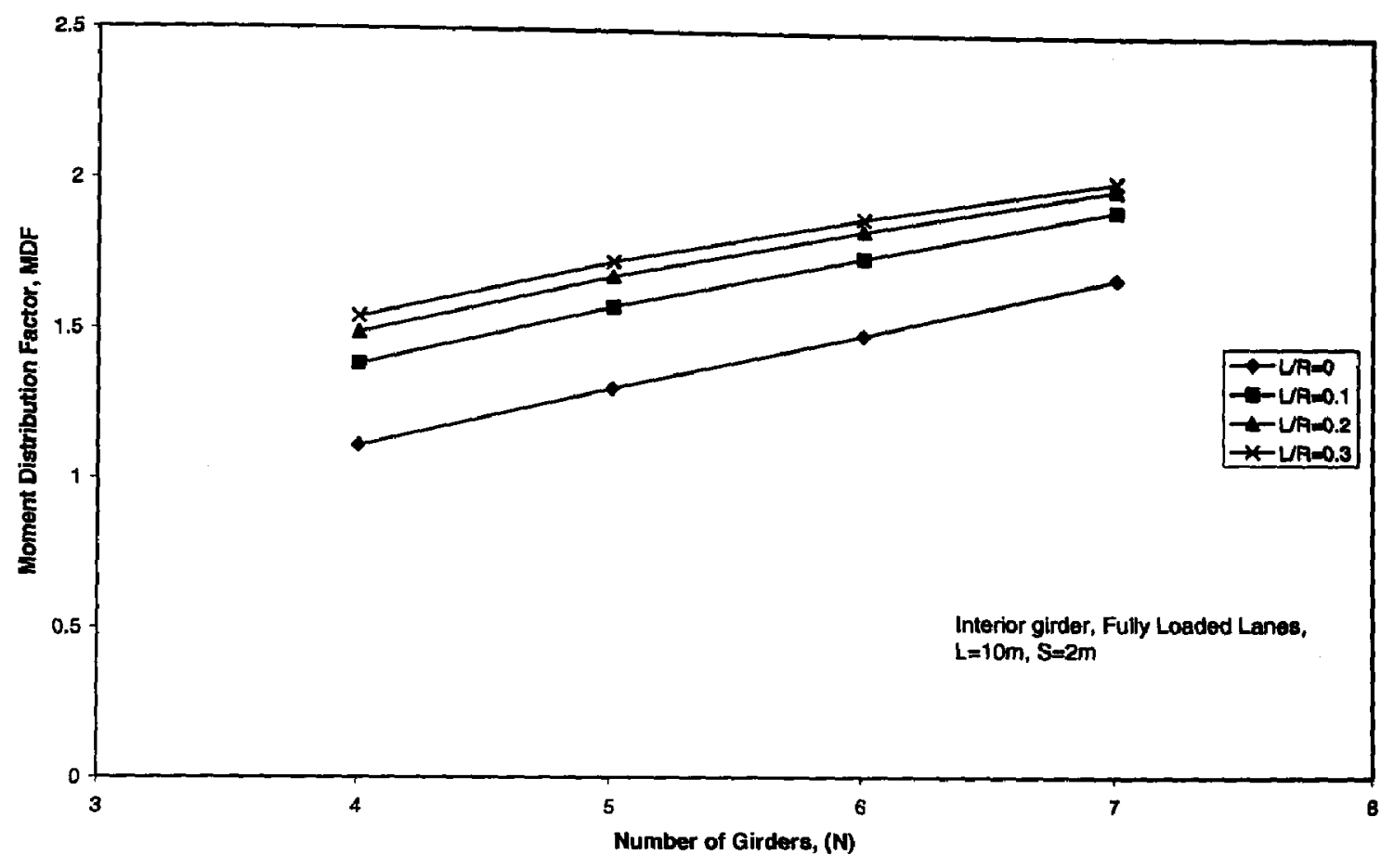

Figure 4.97 Effect of Number of Girders on the Moment Distribution Factor for the Interior Girder due to Fully Loaded Lanes

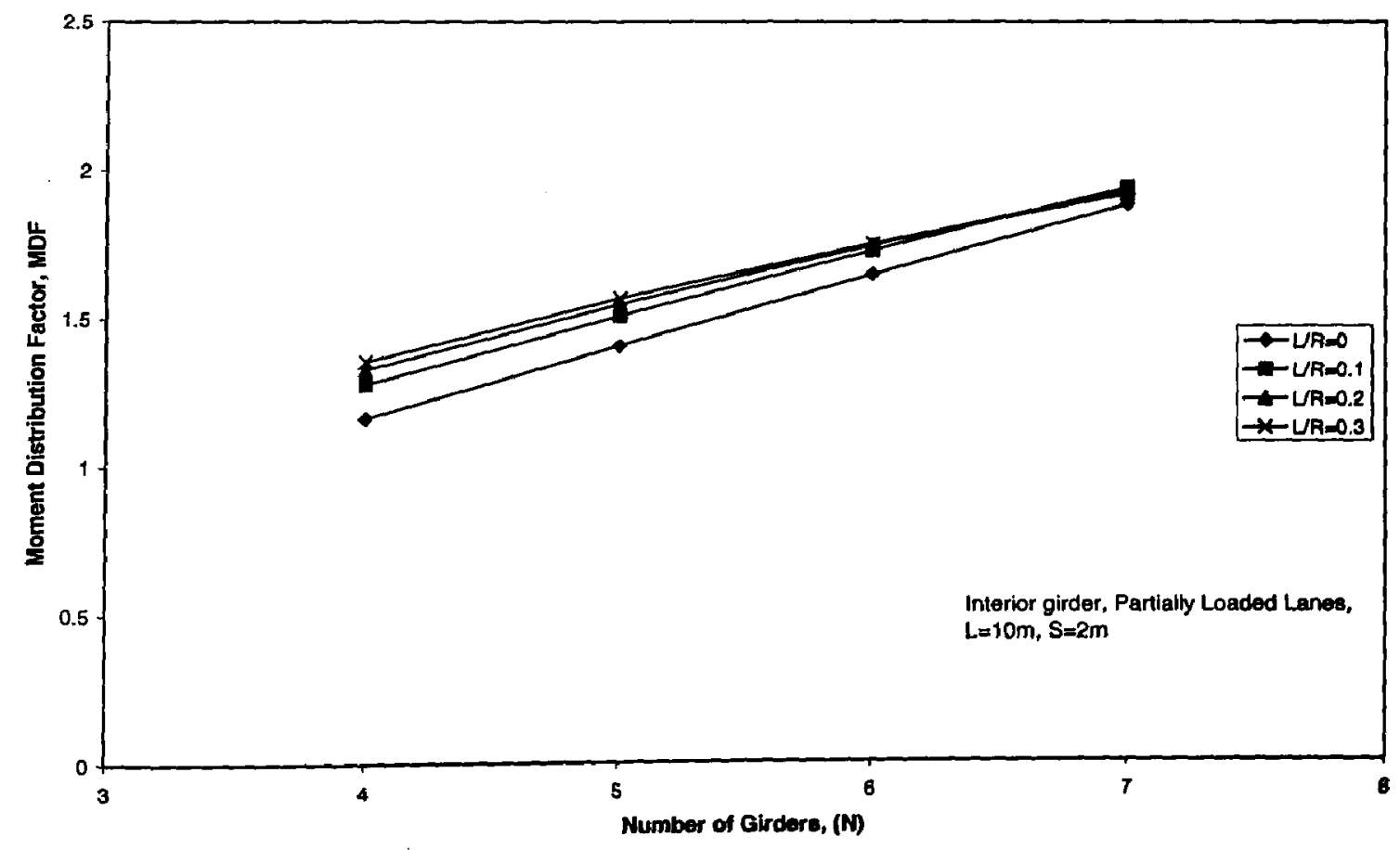

Figure 4.98 Effect of Number of Girders on the Moment Distribution Factor for the Interior Girder due to Partially Loaded Lanes 


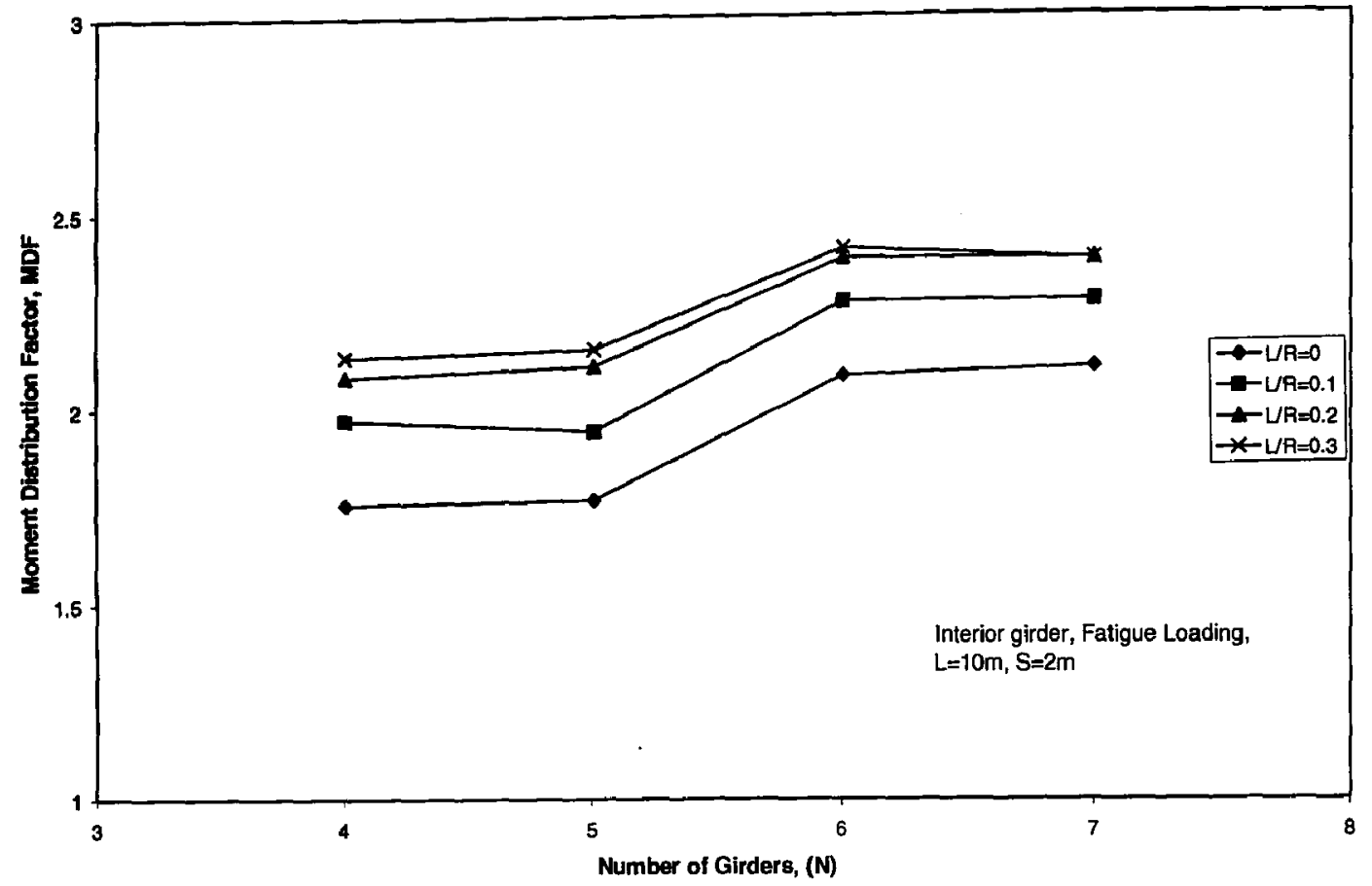

Figure 4.99 Effect of Number of Girders on the Moment Distribution Factor for the Interio Girder due to Fatigue Loading

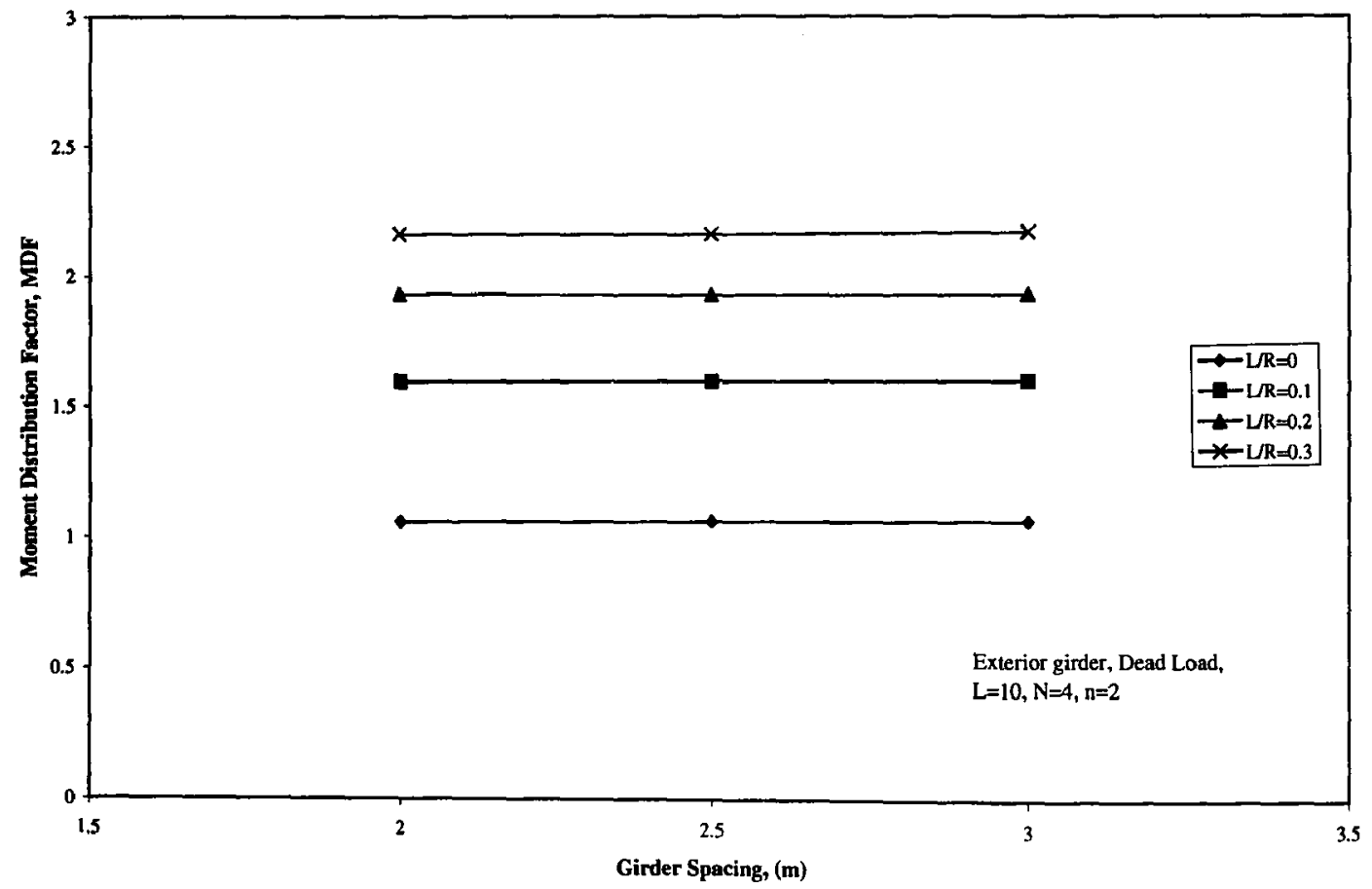

Figure 4. 100 Effect of Girder Spacing on the Moment Distribution Factor for the Exterio Girder due to Dead Load 


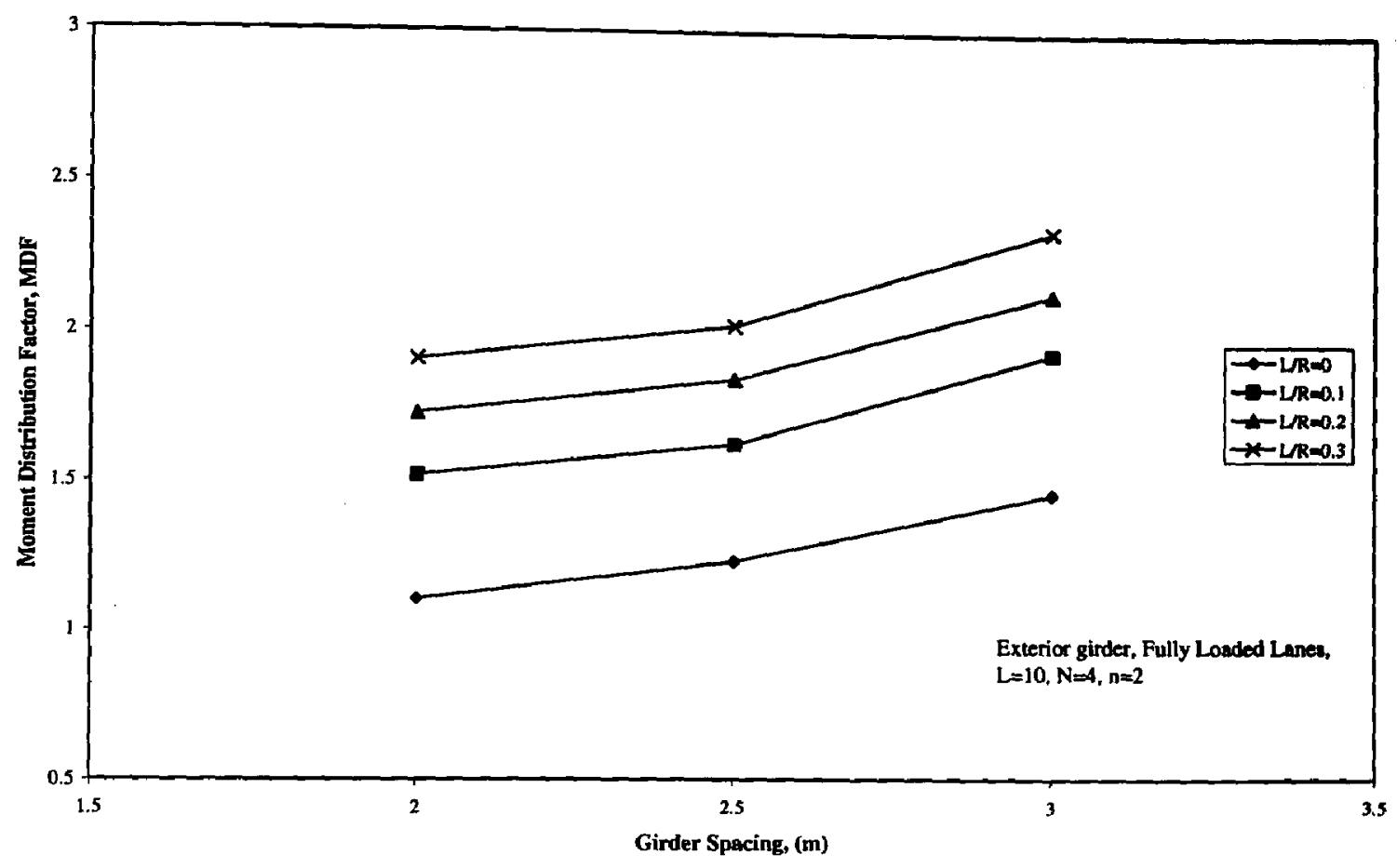

Figure 4. 101 Effect of Girder Spacing on the Moment Distribution Factor for the Exterior Girder due to Fully loaded Lanes

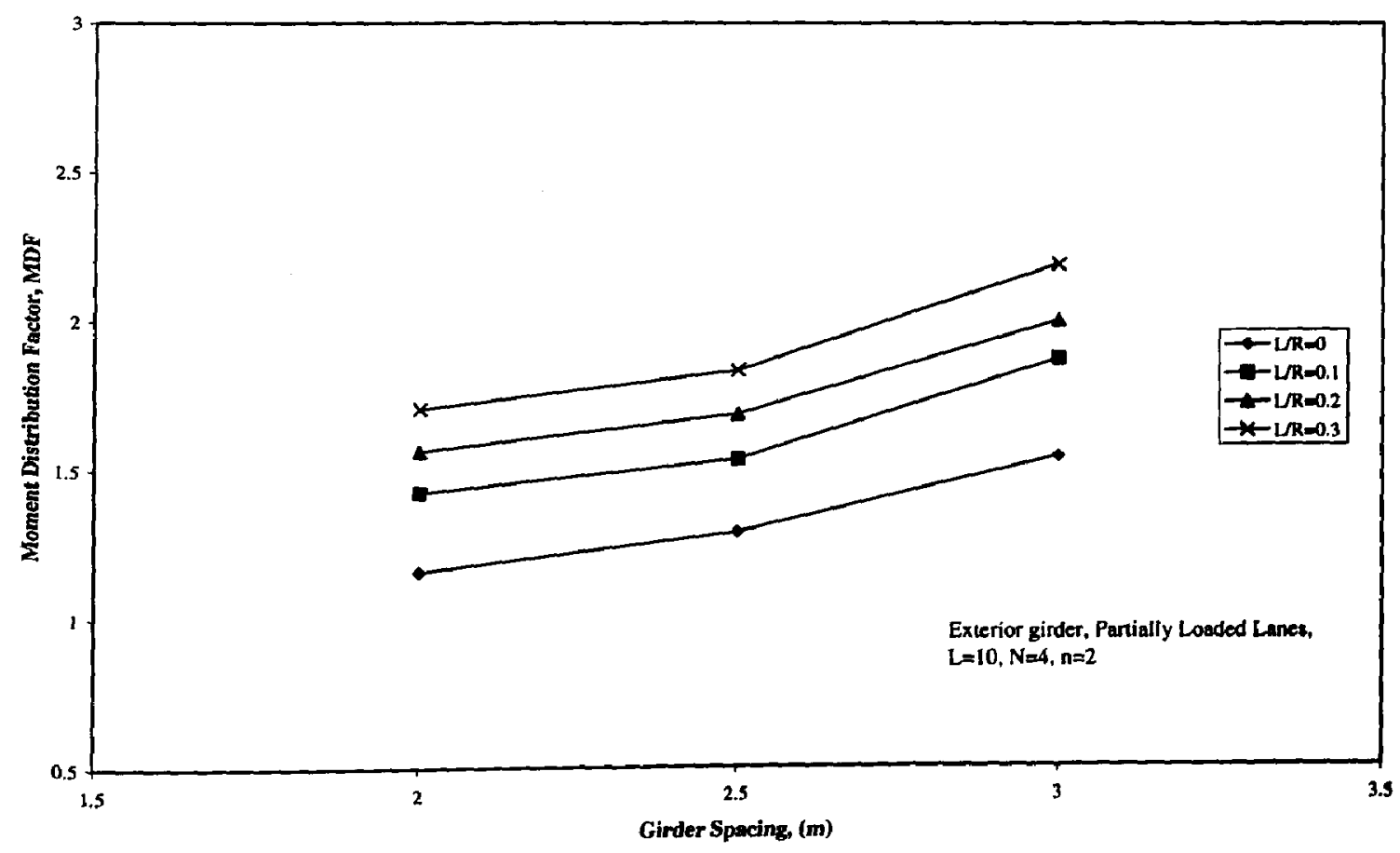

Figure 4. 102 Effect of Girder Spacing on the Moment Distribution Factor for the Exterior Girder due to Partially Loaded Lanes 


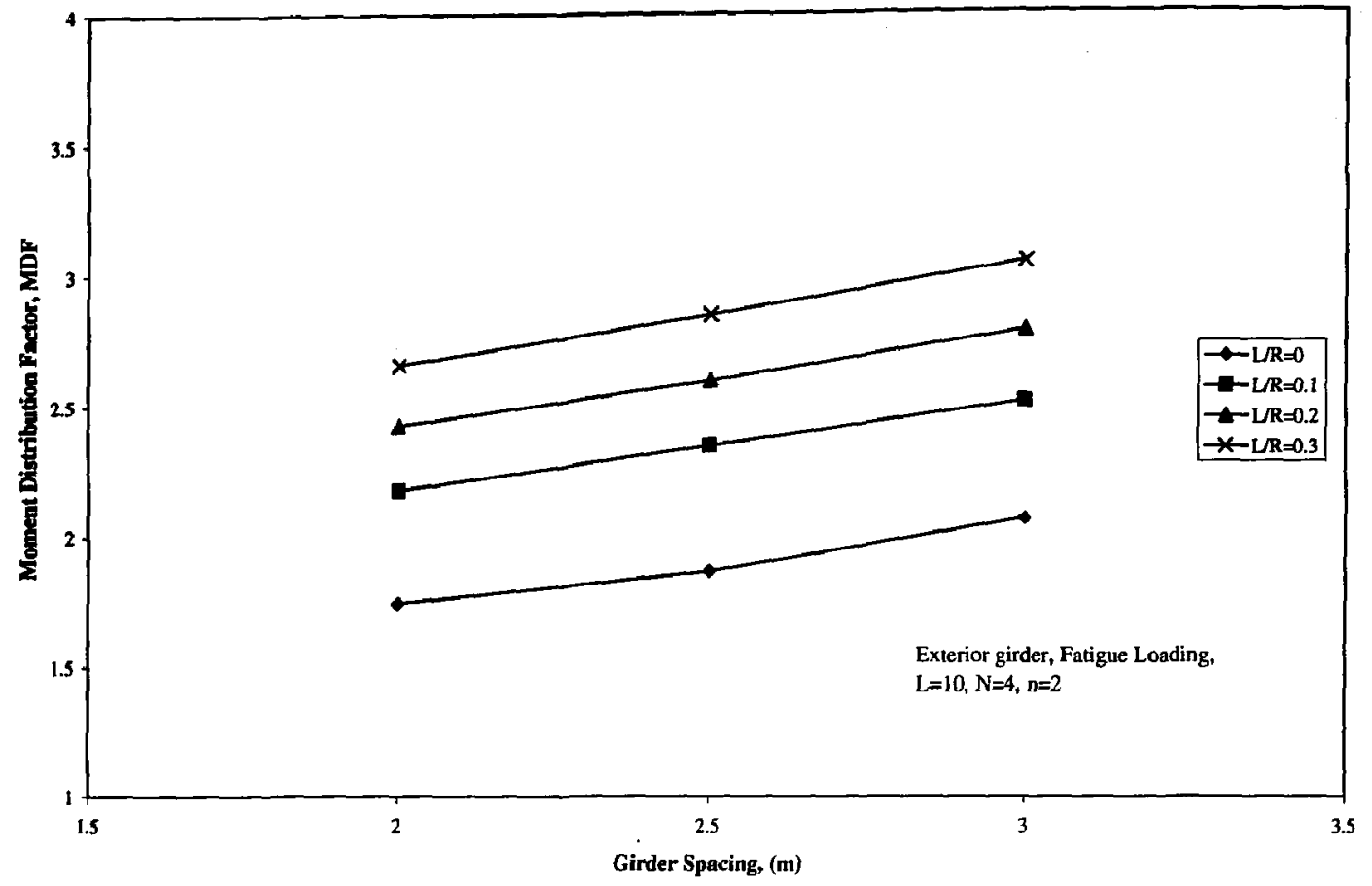

Figure 4. 103 Effect of Girder Spacing on the Moment Distribution Factor for the Exterior Girder due to Fatigue Loading

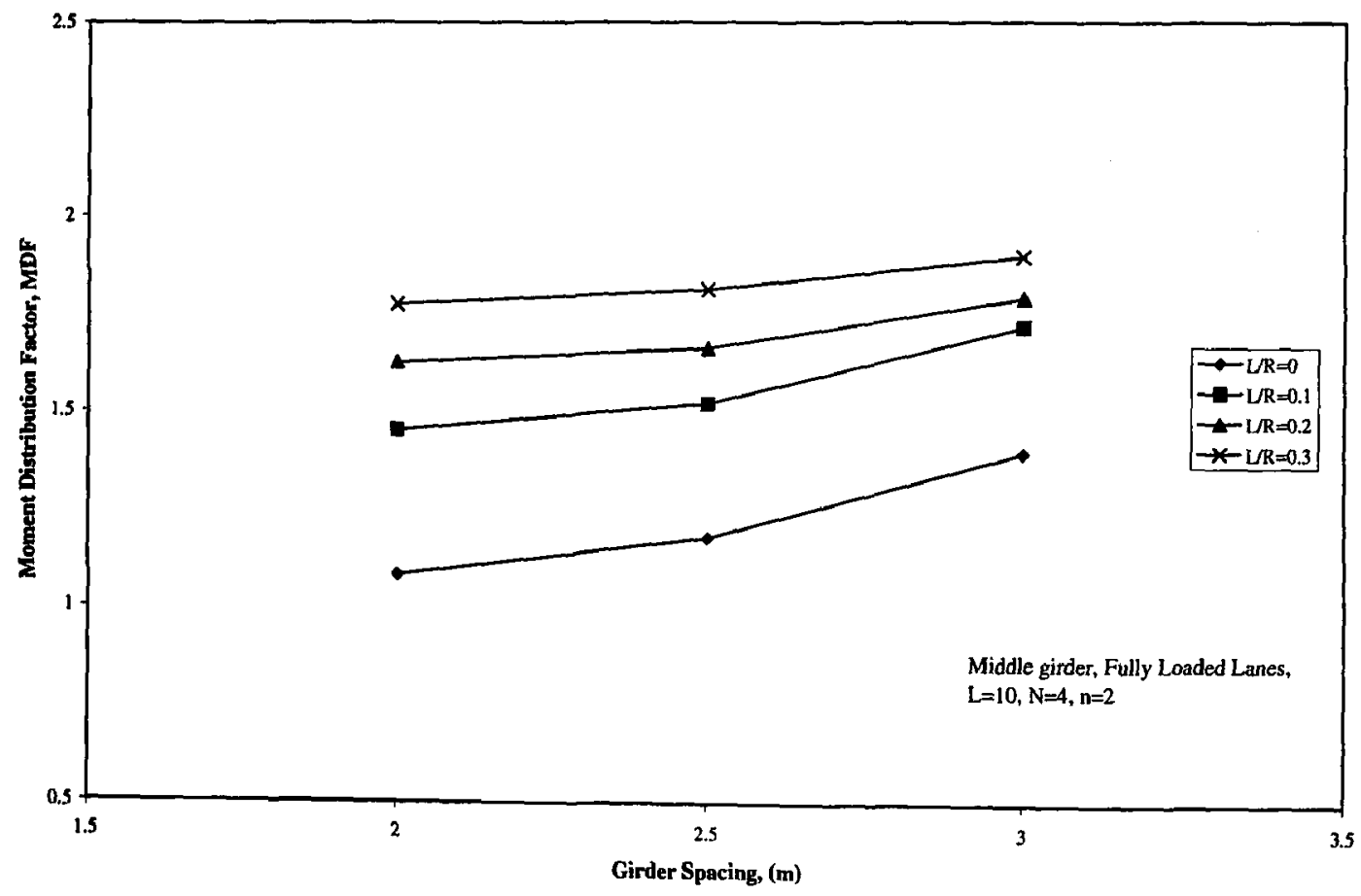

Figure 4. 104 Effect of Girder Spacing on the Moment Distribution Factor for the Middle Girder due to Fully Loaded Lanes 


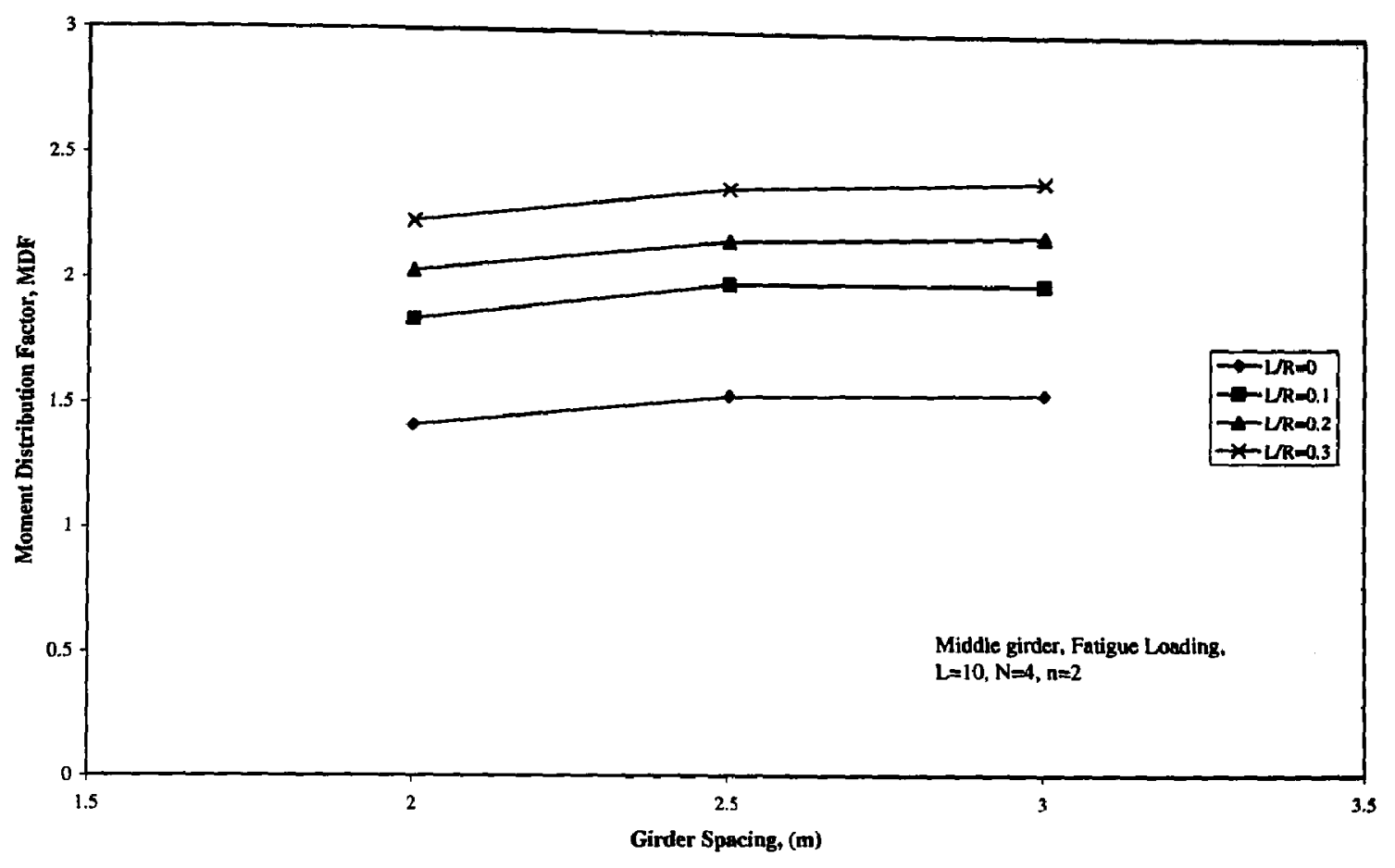

Figure 4. 105 Effect of Girder Spacing on the Moment Distribution Factor for the Middle Girder due to Fatigue Loading

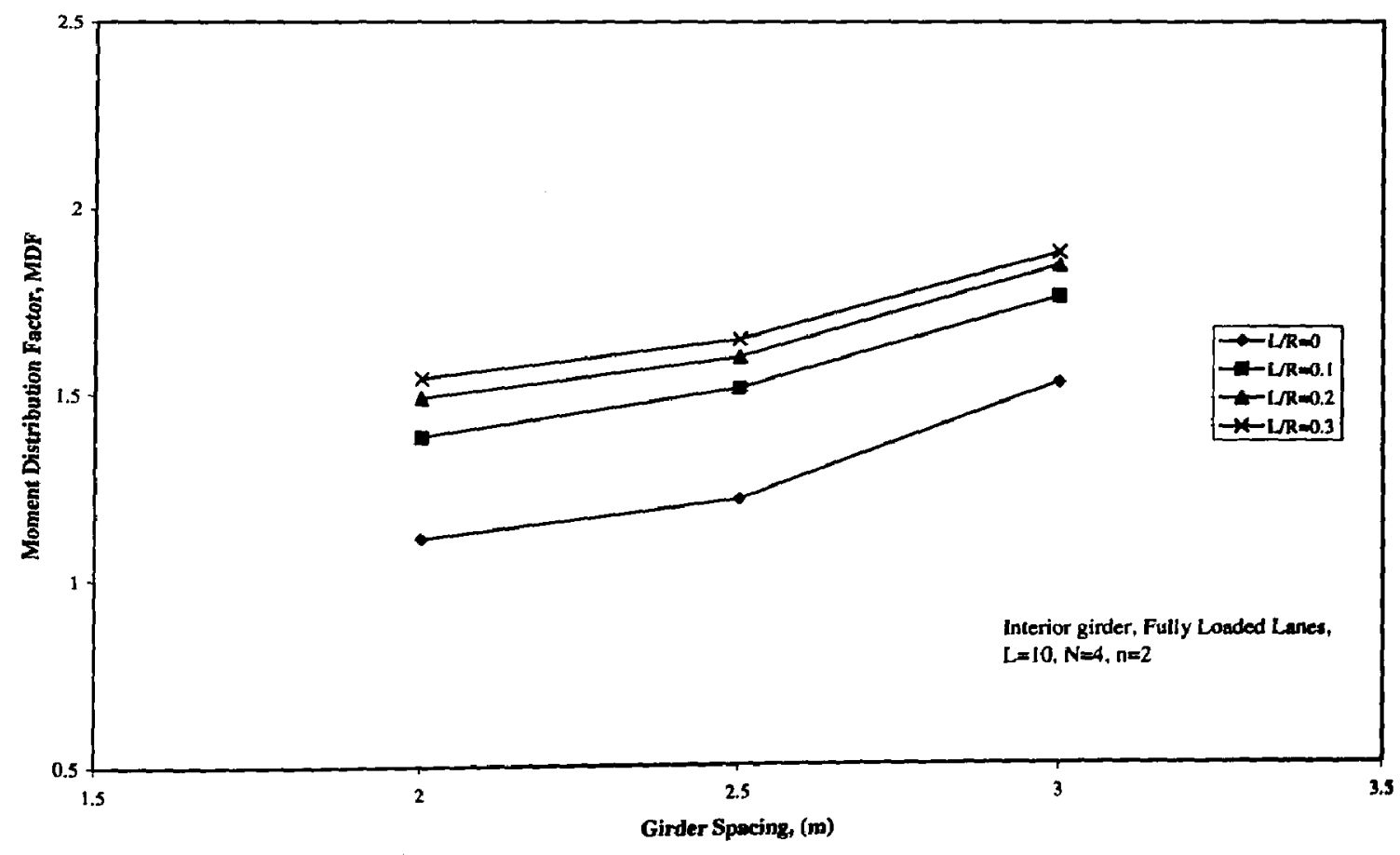

Figure 4. 106 Effect of Girder Spacing on the Moment Distribution Factor for the Interior Girder due to Fully Loaded Lanes 


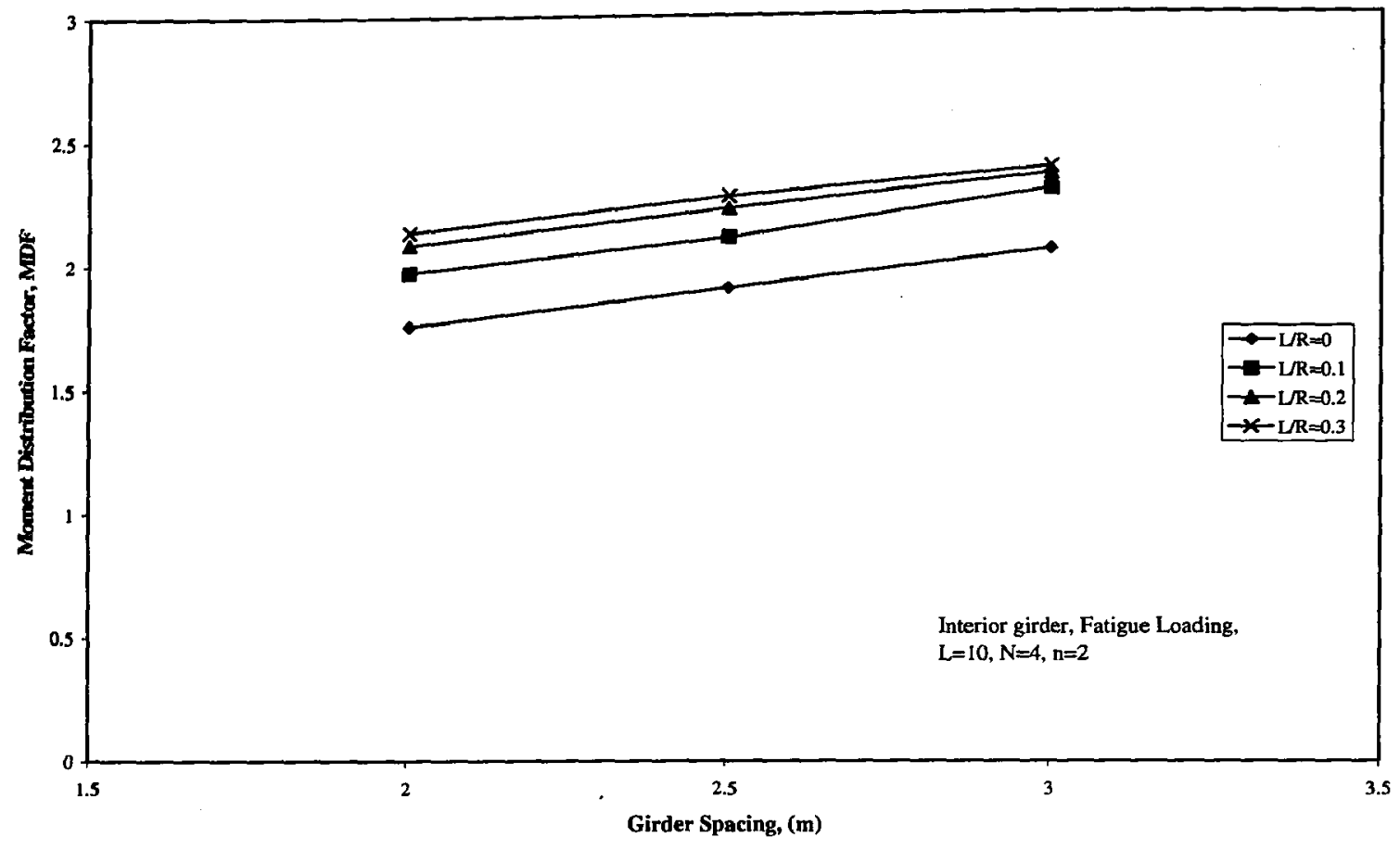

Figure 4. 107 Effect of Girder Spacing on the Moment Distribution Factor for the Interior Girde due to Fatigue Loading

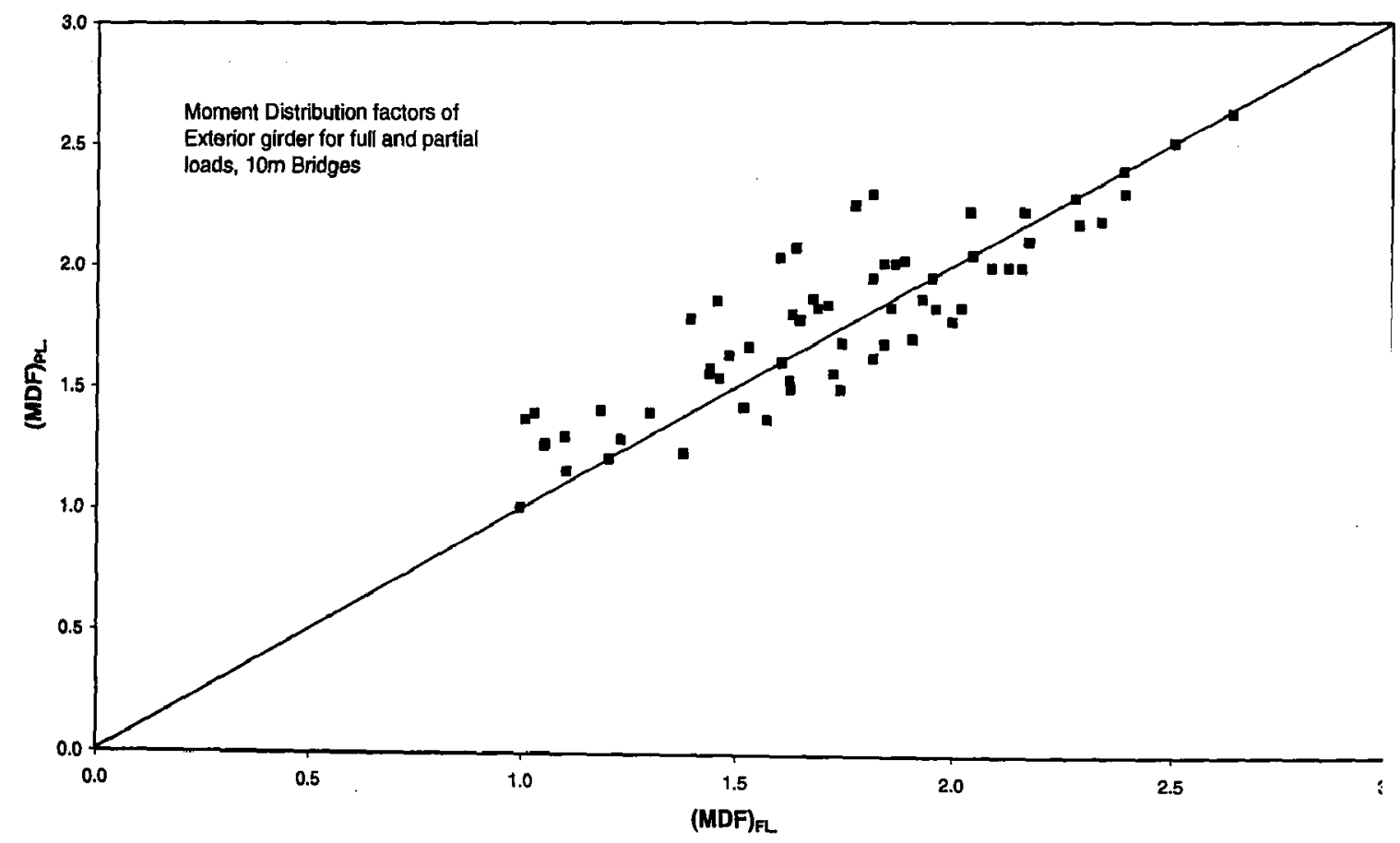

Figure 4. 108 Effect of Loading Conditions on the Moment Distribution Factor for the Exterior Girder of the 10-m-span Bridges 


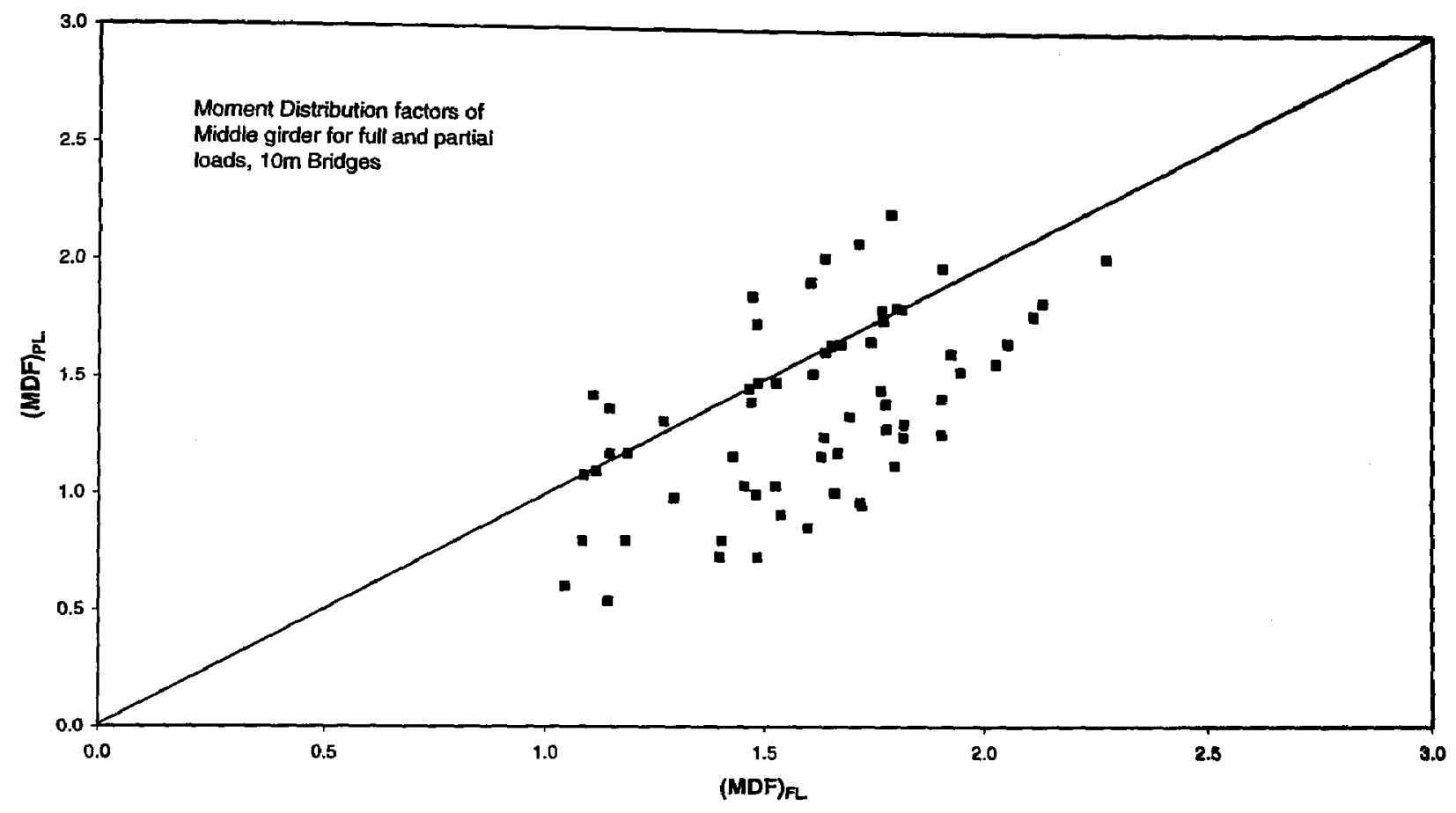

Figure 4. 109 Effect of Loading Conditions on the Moment Distribution Factor for the Middle Girder of the 10-m-span Bridges

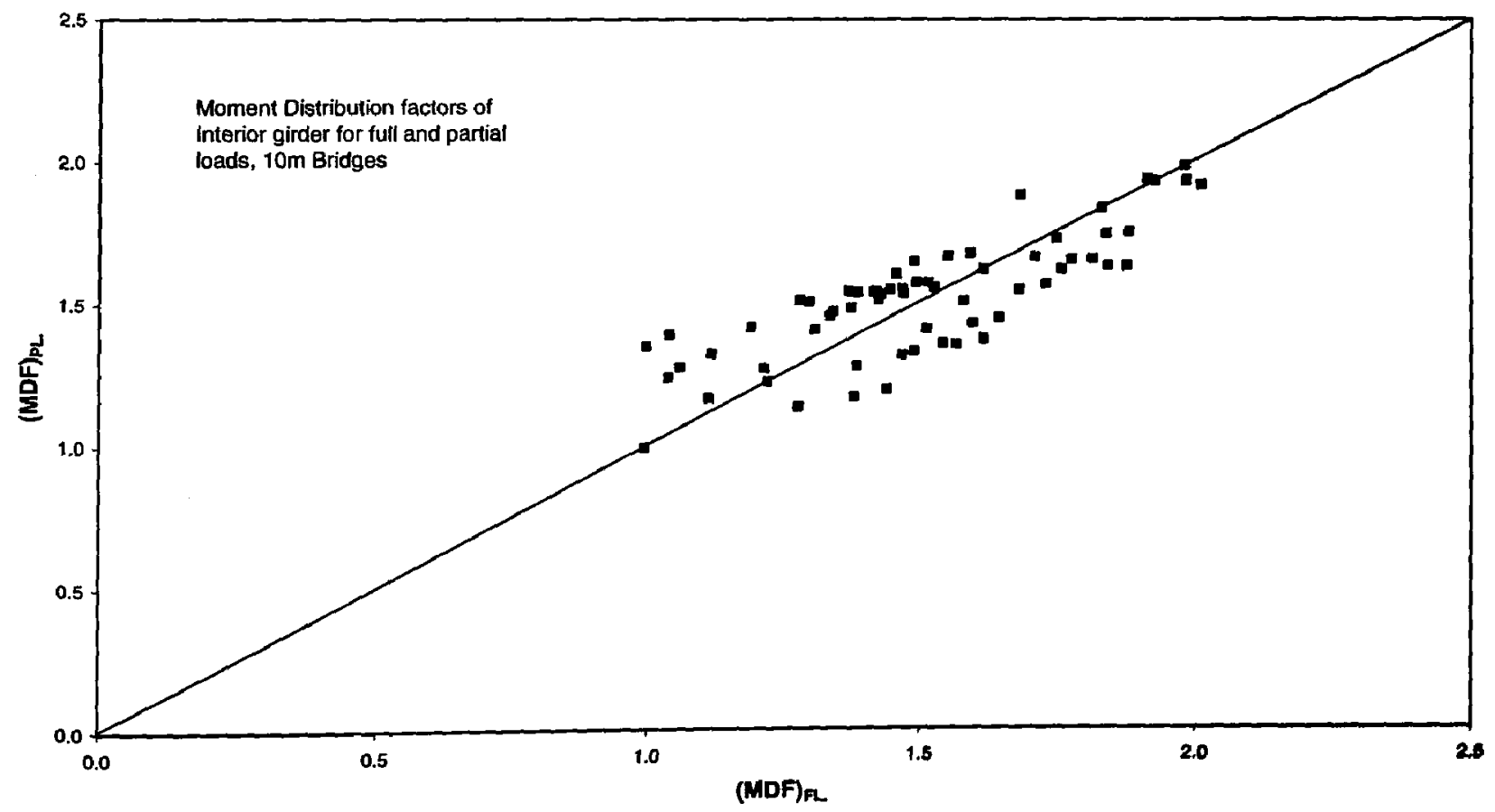

Figure 4. 110 Effect of Loading Conditions on the Moment Distribution Factor for the Interior Girder of the 10-m-span Bridges 


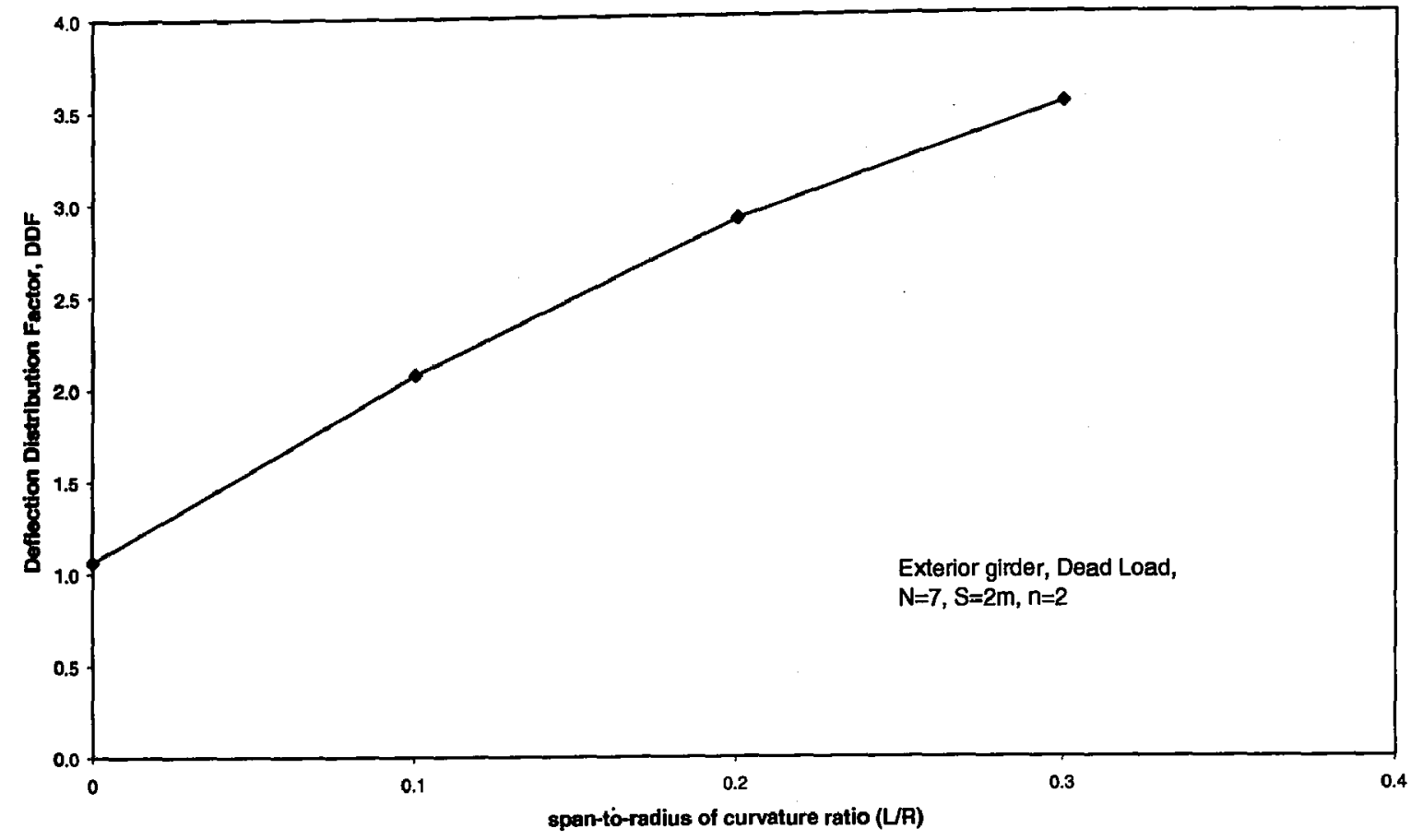

Figure 4. 111 Effect of Curvature on the Deflection Distribution Factor for the Exterior Girder due to Dead Load

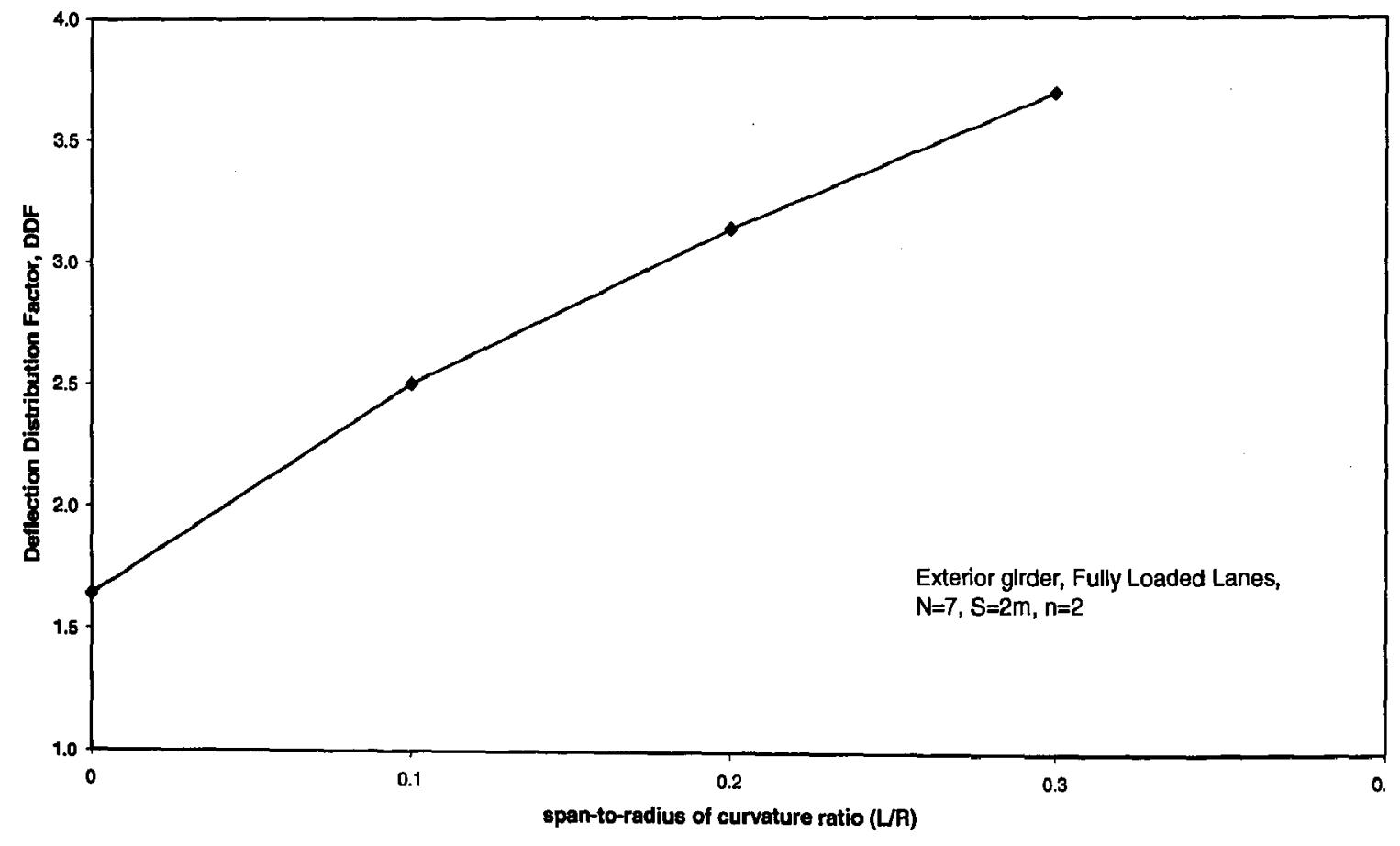

Figure 4. 112 Effect of Curvature on the Deflection Distribution Factor for the Exterior Girder due to Fully Loaded Lanes 


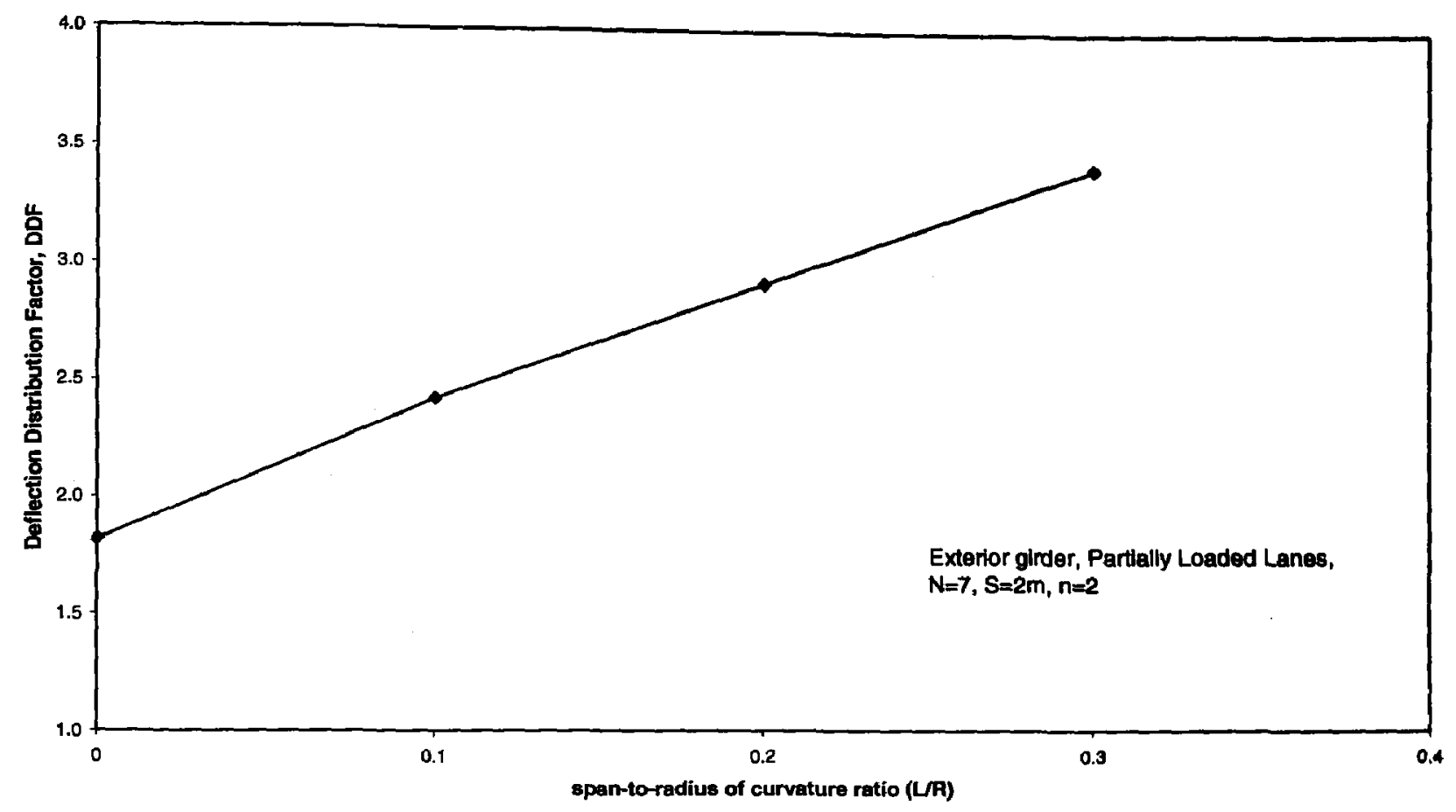

Figure 4. 113 Effect of Curvature on the Deflection Distribution Factor for the Exterior Girder due to Partially Loaded Lanes

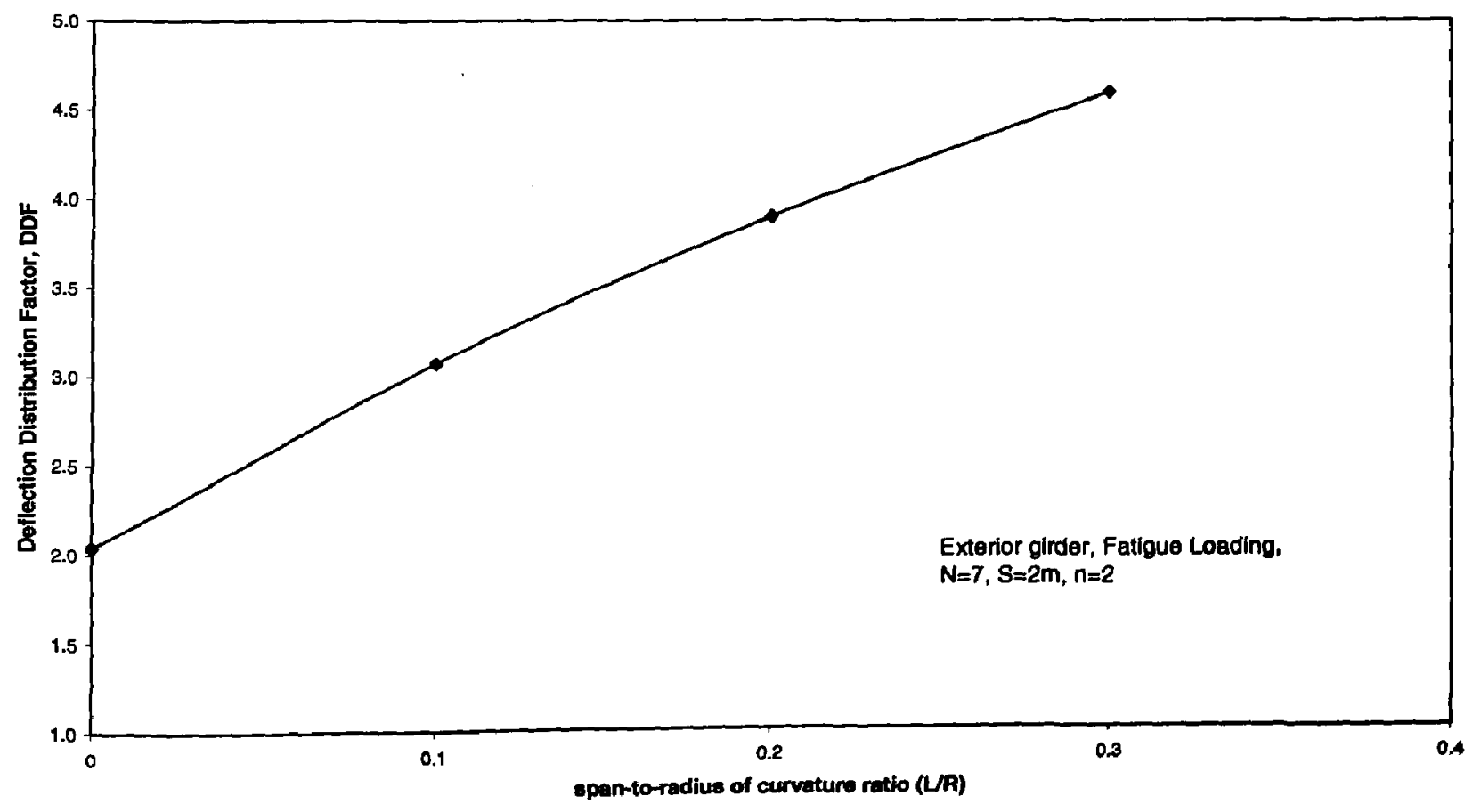

Figure 4. 114 Effect of Curvature on the Deflection Distribution Factor for the Exterior Girder due to Fatigue Loading 


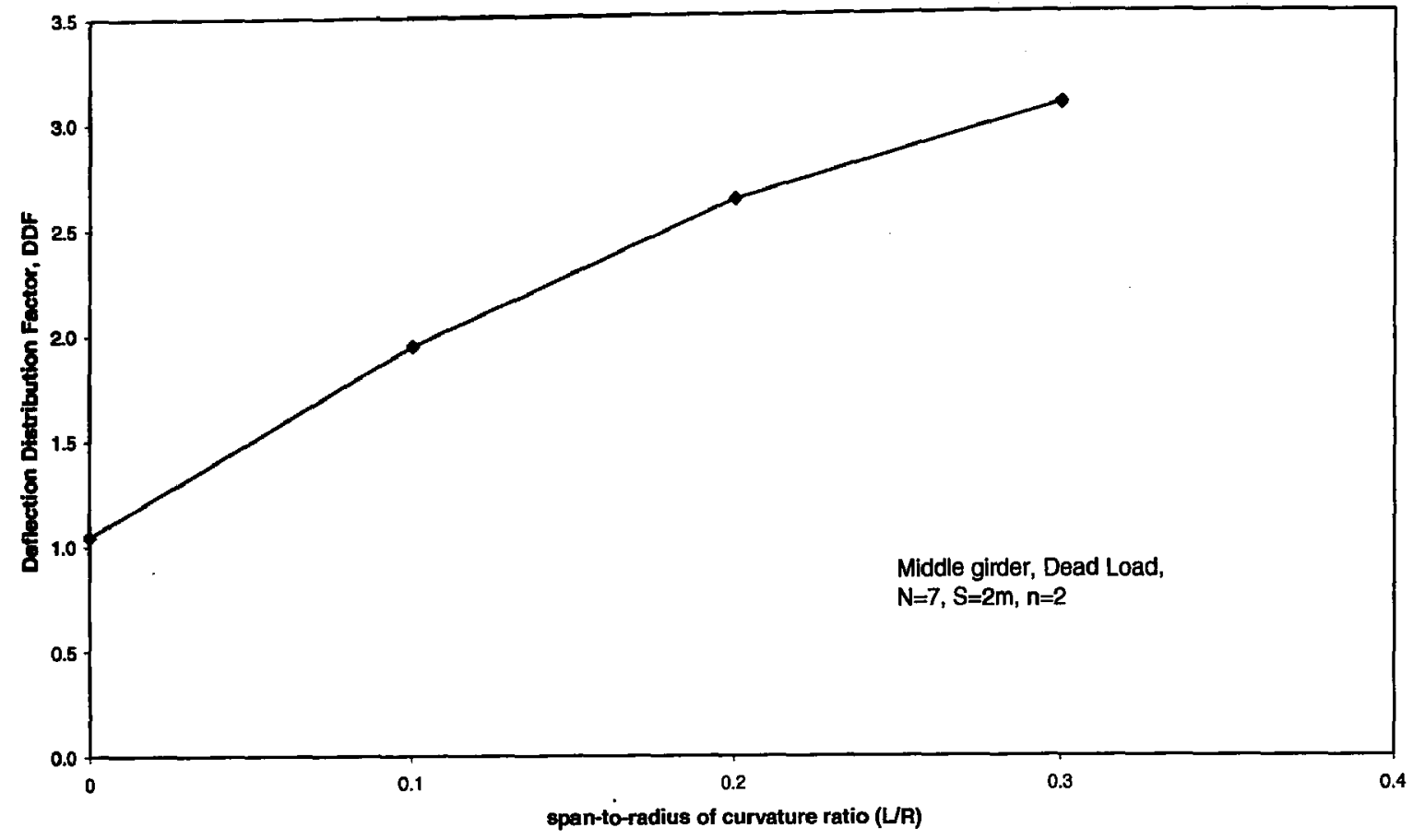

Figure 4. 115 Effect of Curvature on the Deflection Distribution Factor for the Middle Girde due to Dead Load

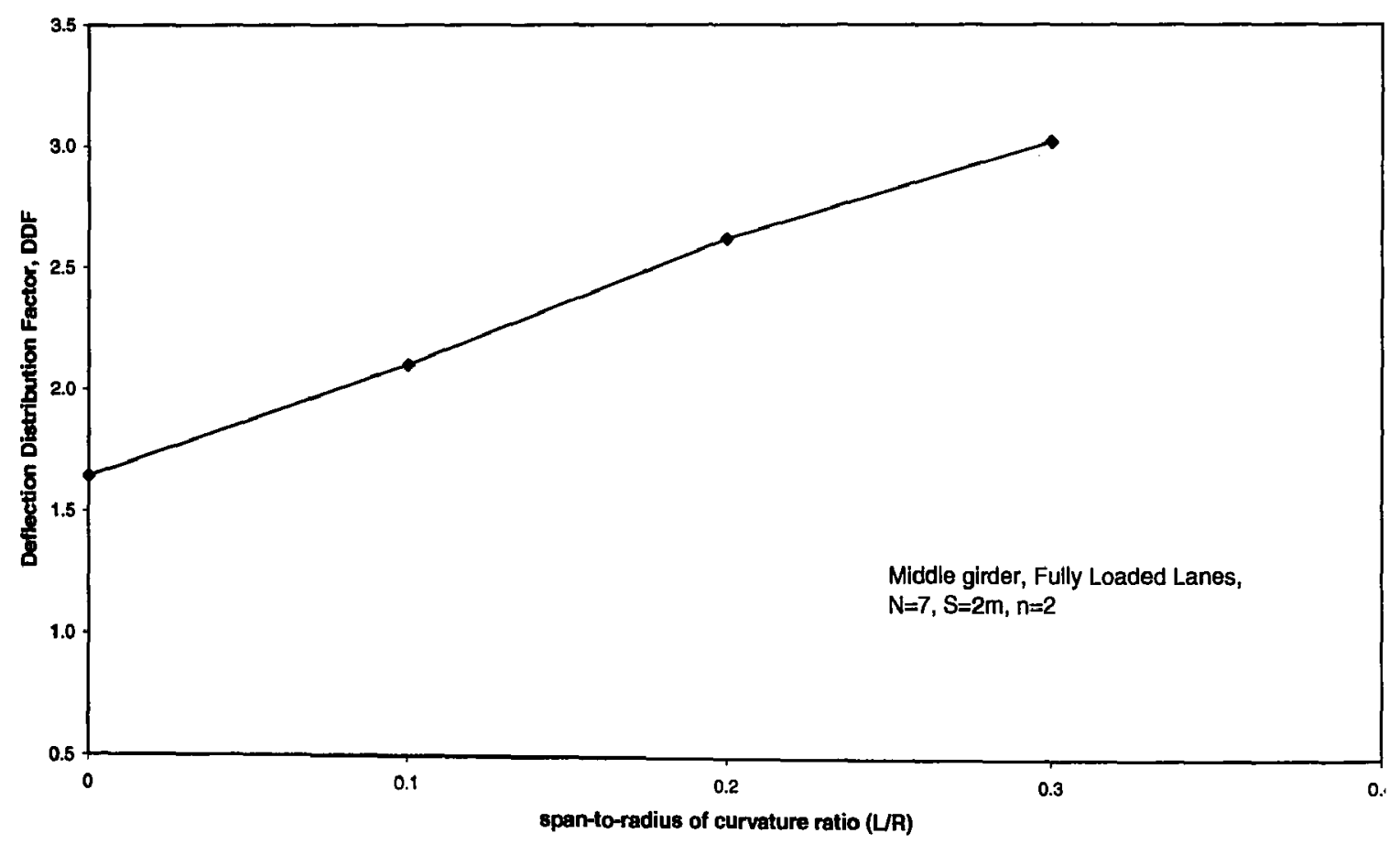

Figure 4. 116Effect of Curvature on the Deflection Distribution Factor for the Middle Girde due to Fully Loaded Lanes 


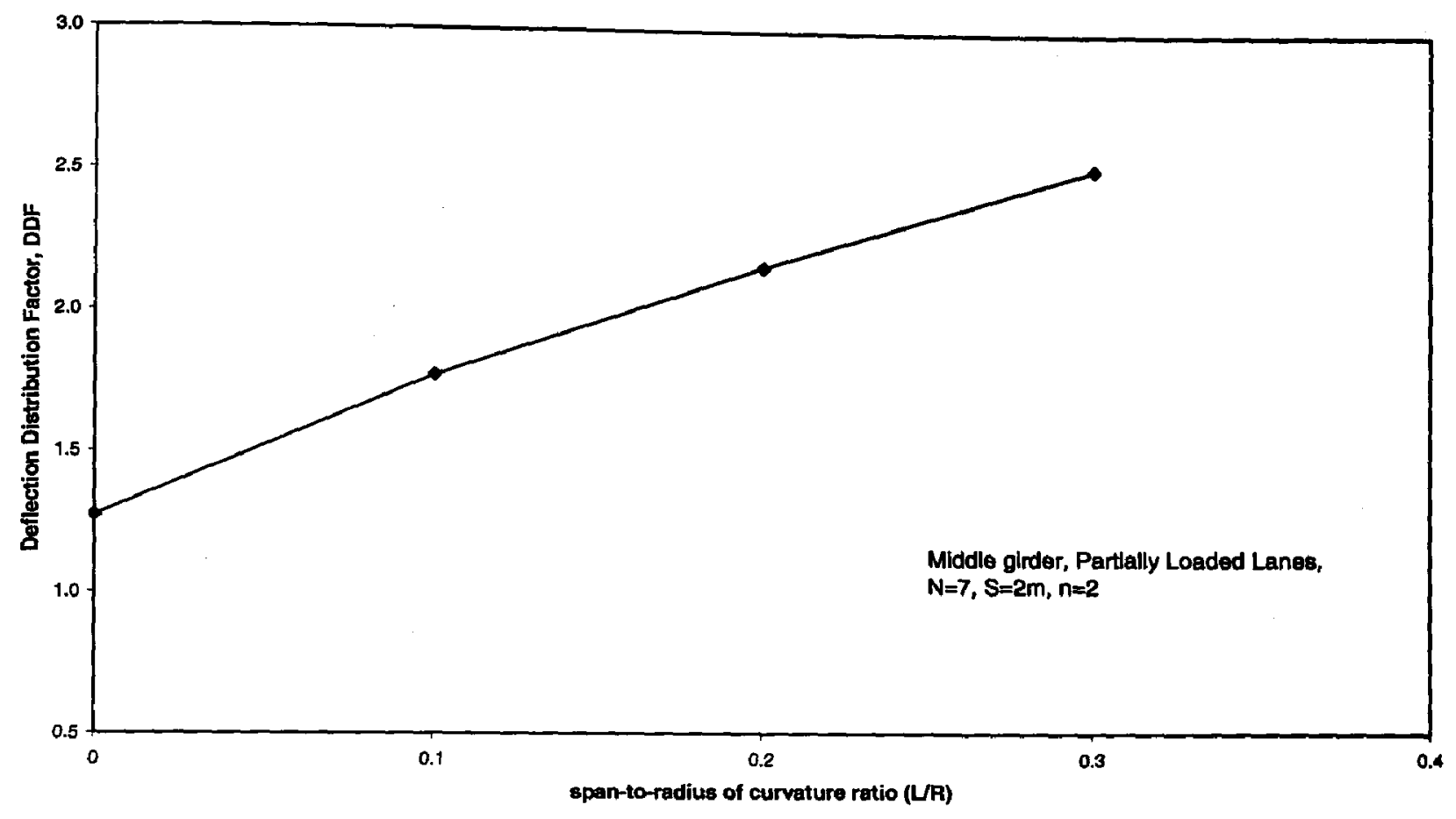

Figure 4. 117 Effect of Curvature on the Deflection Distribution Factor for the Middle Girder due to Partially Loaded Lanes

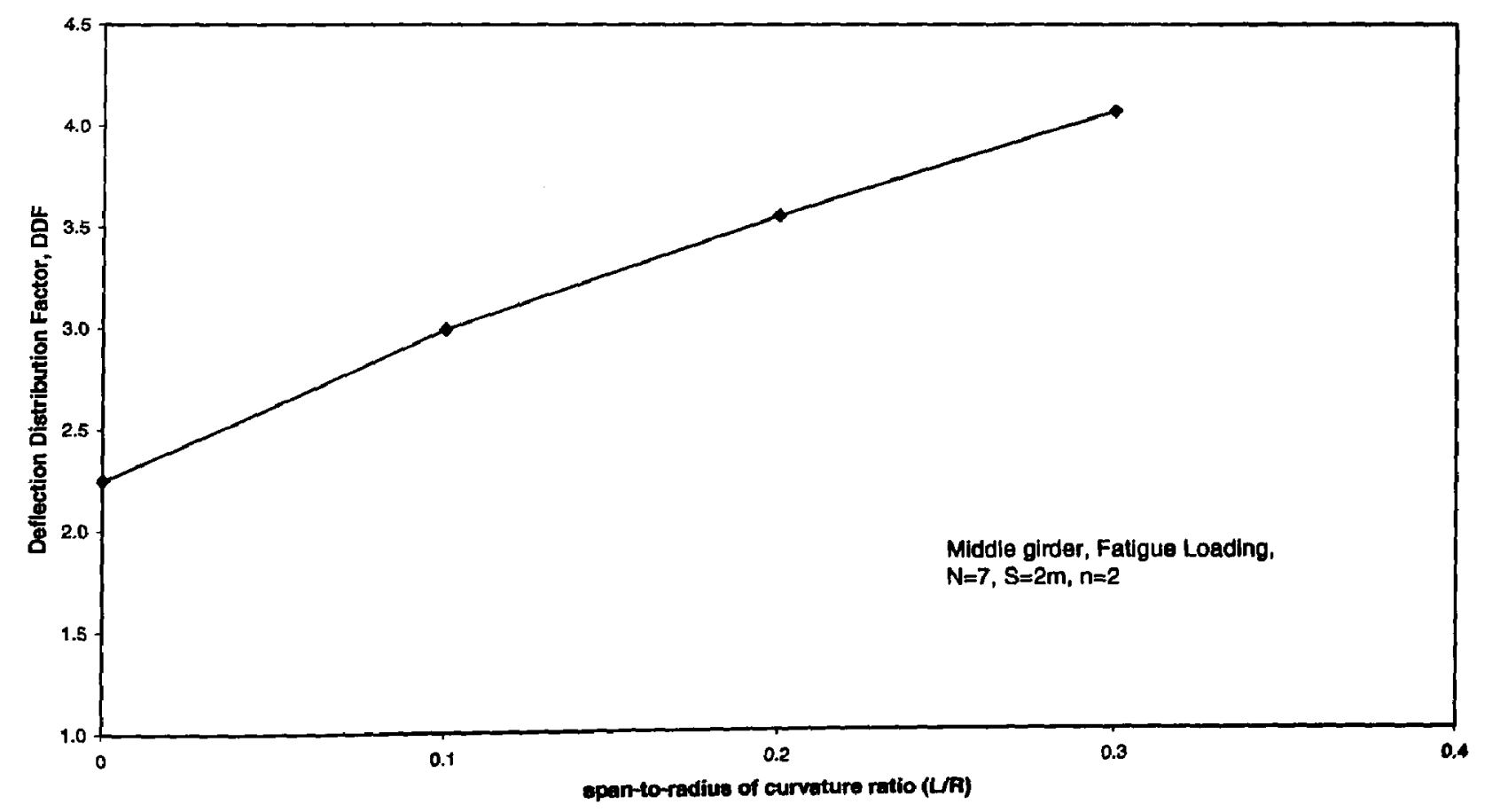

Figure 4. 118 Effect of Curvature on the Deflection Distribution Factor for the Middle Girder due to Fatigue Loading 


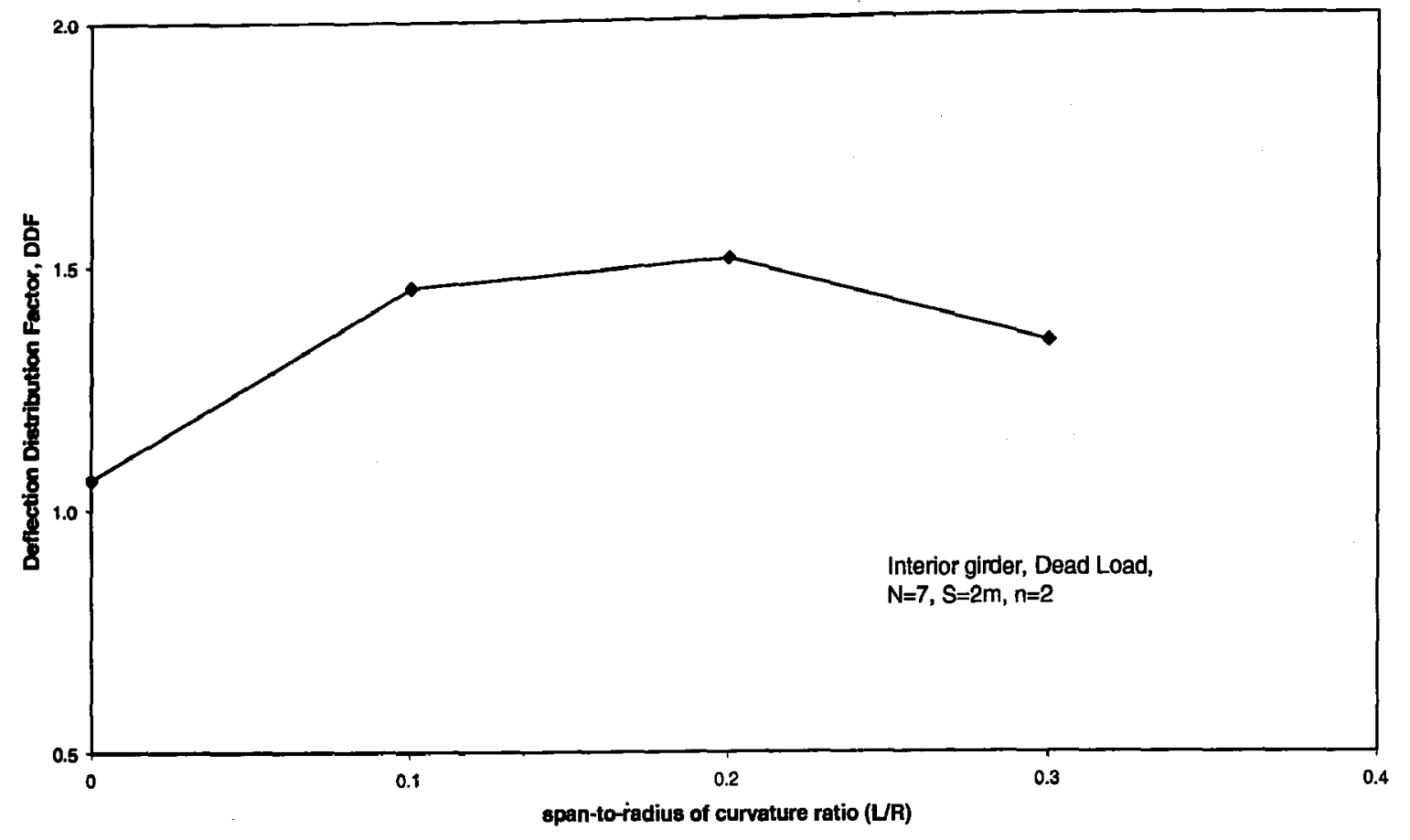

Figure 4. 119 Effect of Curvature on the Deflection Distribution Factor for the Interior Girder due to Dead Load

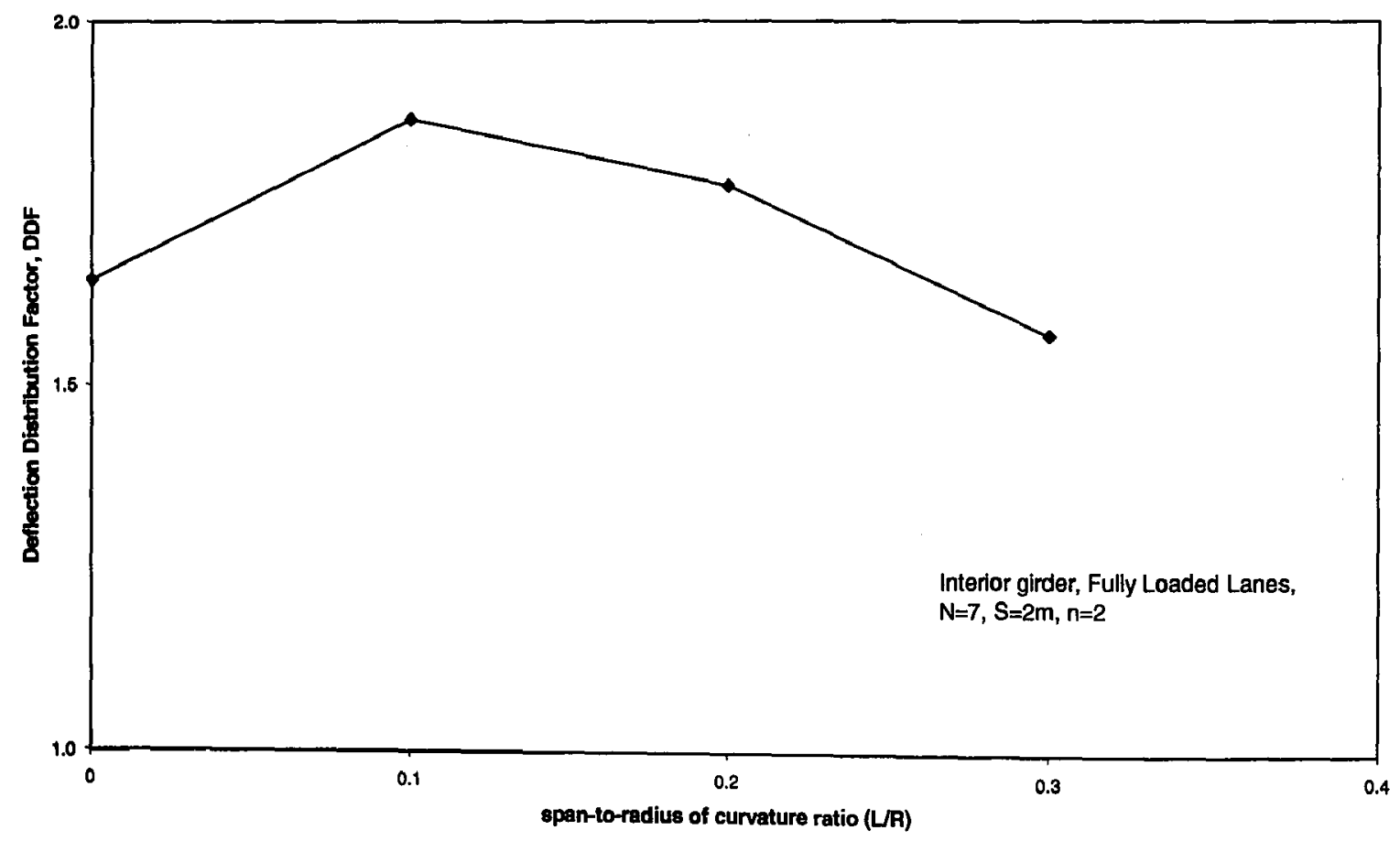

Figure 4. 120 Effect of Curvature on the Deflection Distribution Factor for the Interior Girde] due to Fully Loaded Lanes 


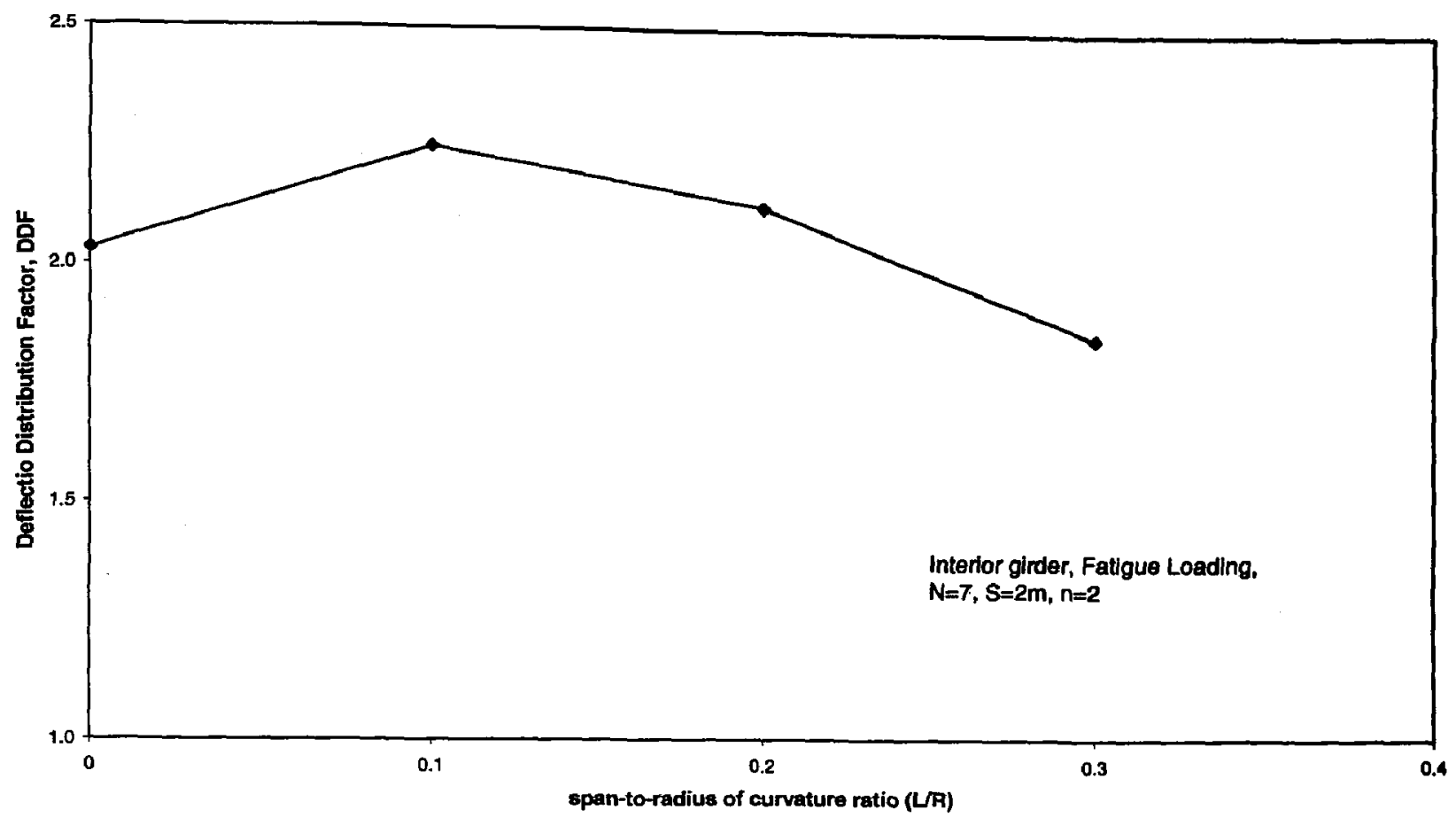

Figure 4. 121 Effect of Curvature on the Deflection Distribution Factor for the Interior Girder due to Fatigue Loading

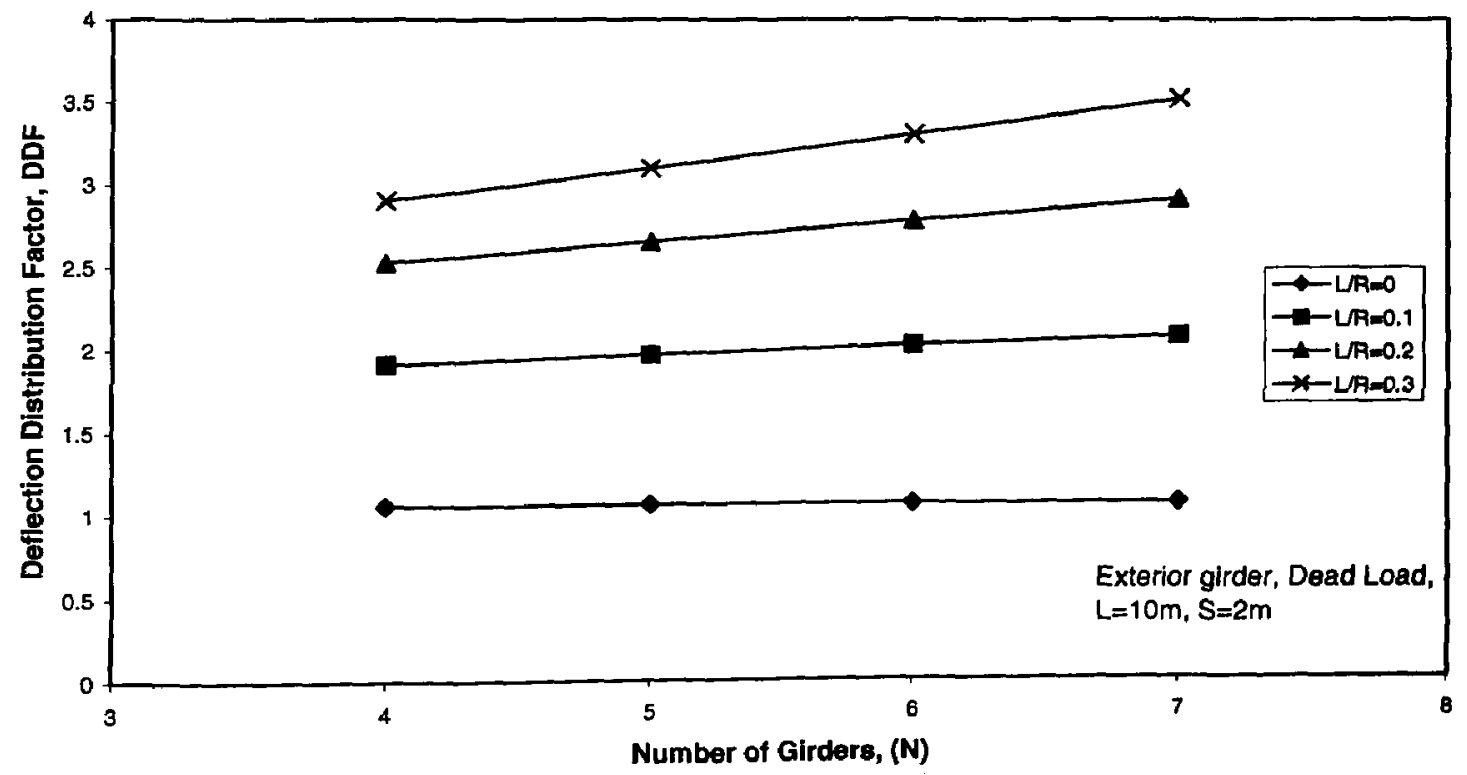

Figure 4. 122 Effect of Number of Girders on the Deflection Distribution Factor for the Exterior Girder due to Dead Load 


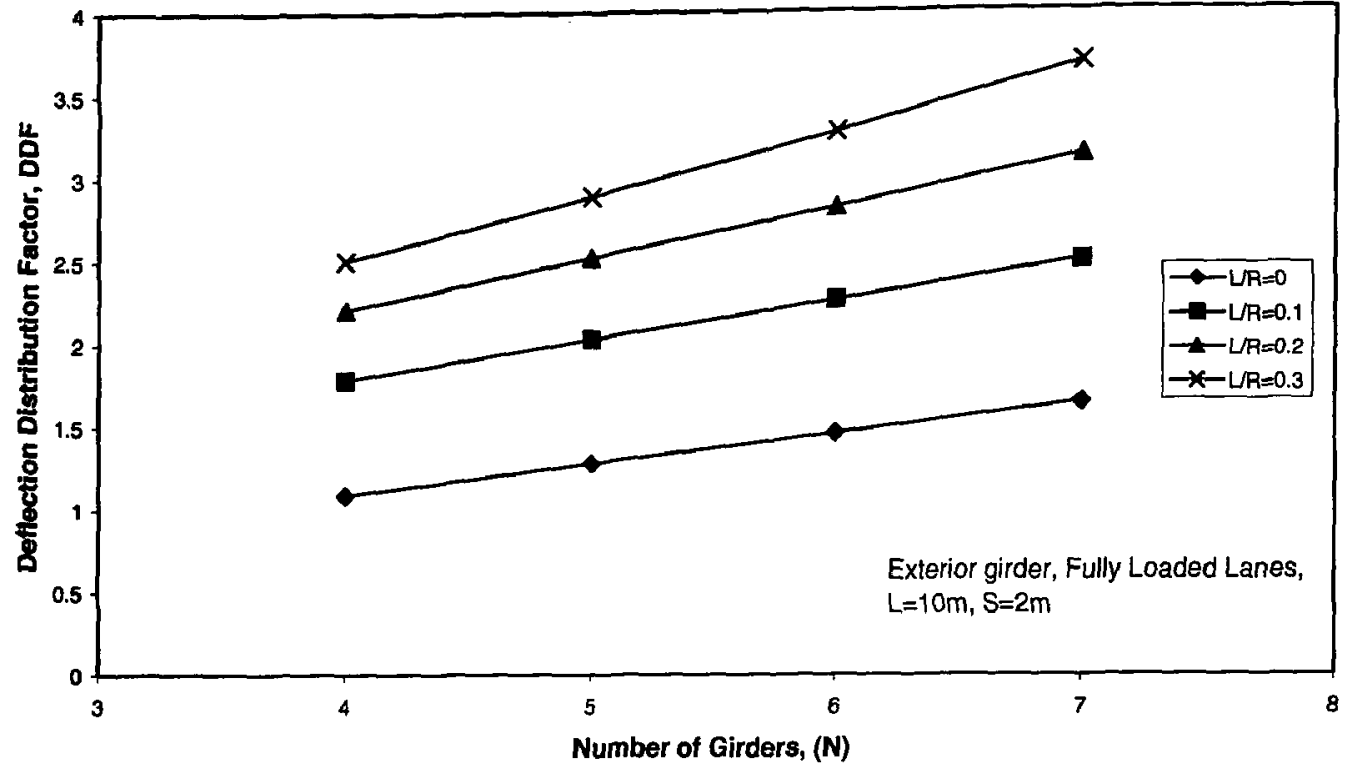

Figure 4. 123 Effect of Number of Girders on the Deflection Distribution Factor for the Exterior Girder due to Fully Loaded Lanes

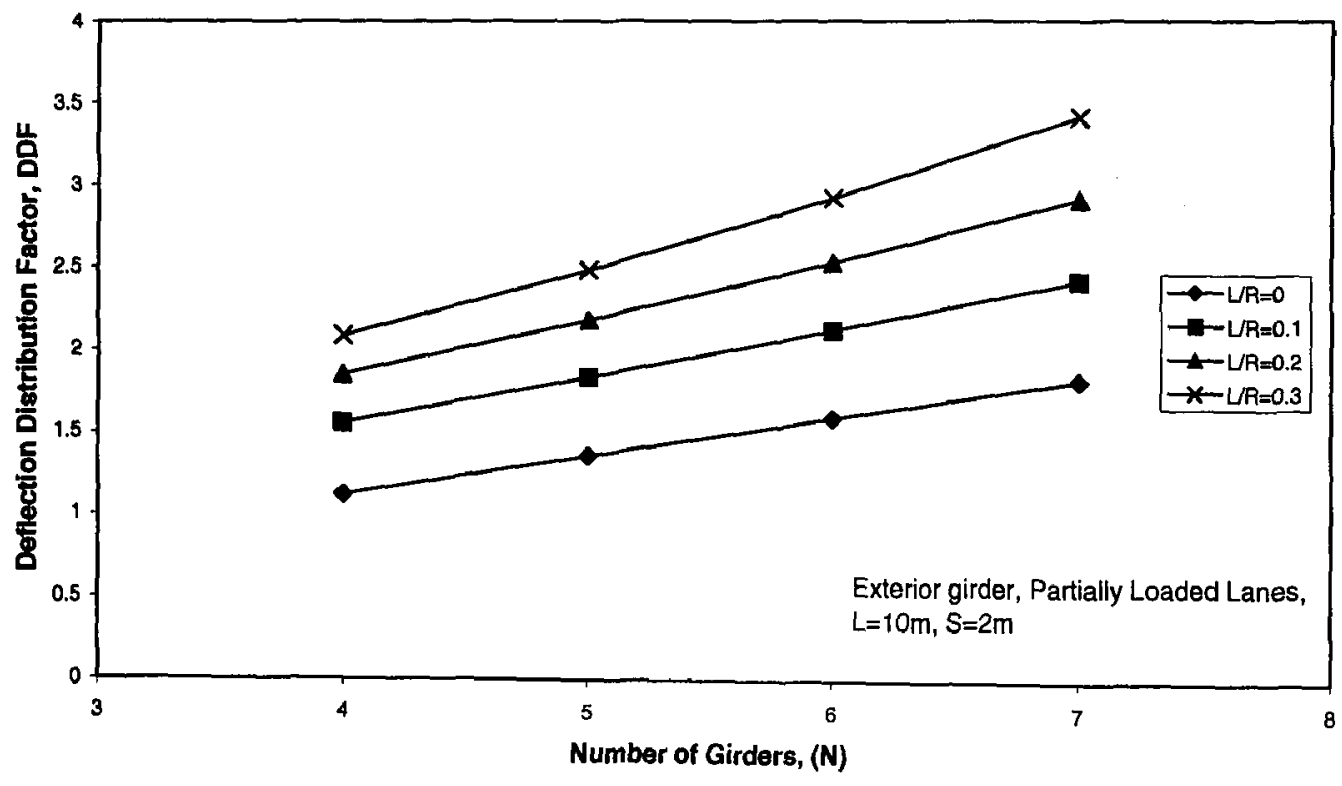

Figure 4. 124 Effect of Number of Girders on the Deflection Distribution Factor for the Exterior Girder due to Partially Loaded Lanes 


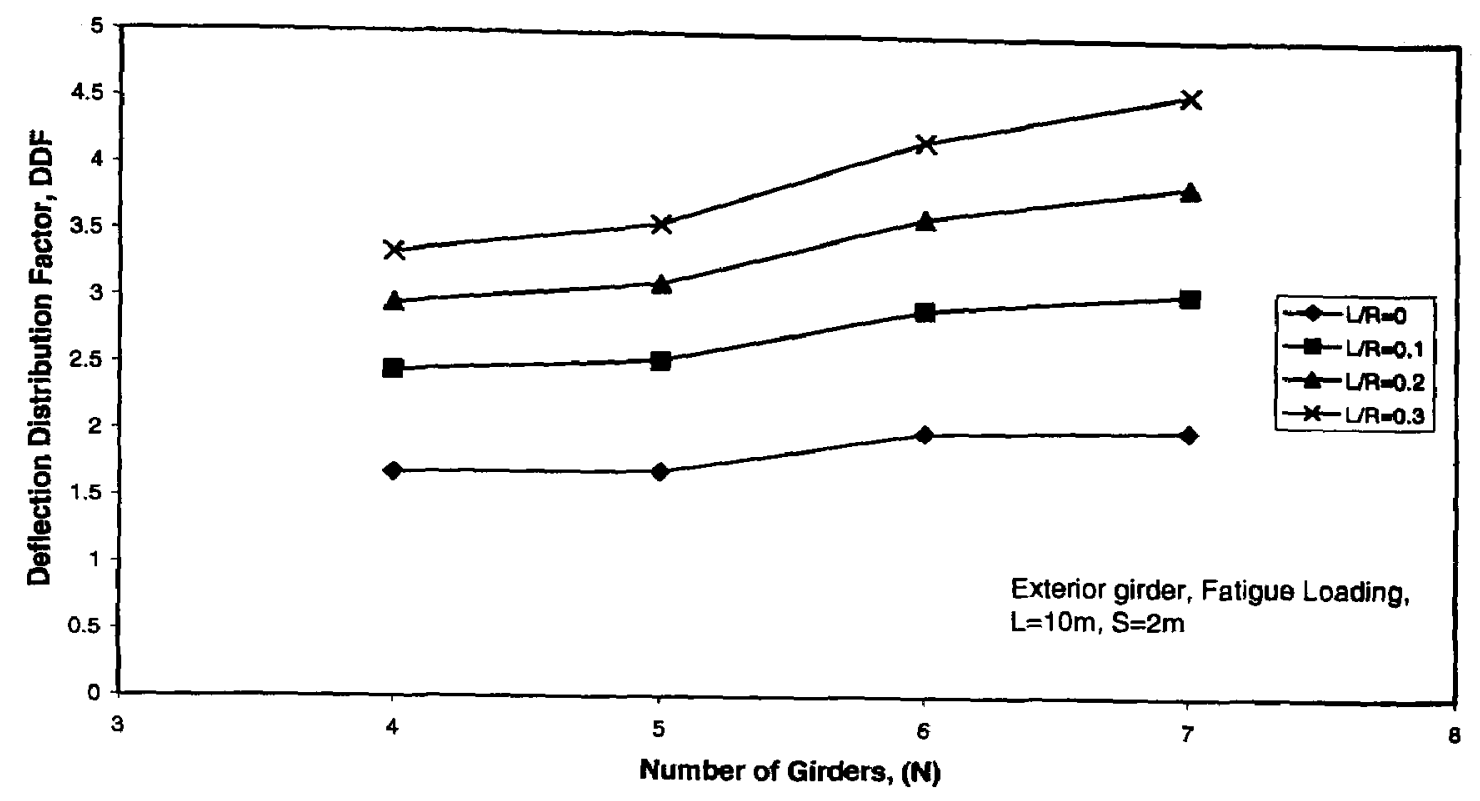

Figure 4. 125 Effect of Number of Girders on the Deflection Distribution Factor for the Exterior Girder due to Fatigue Loading

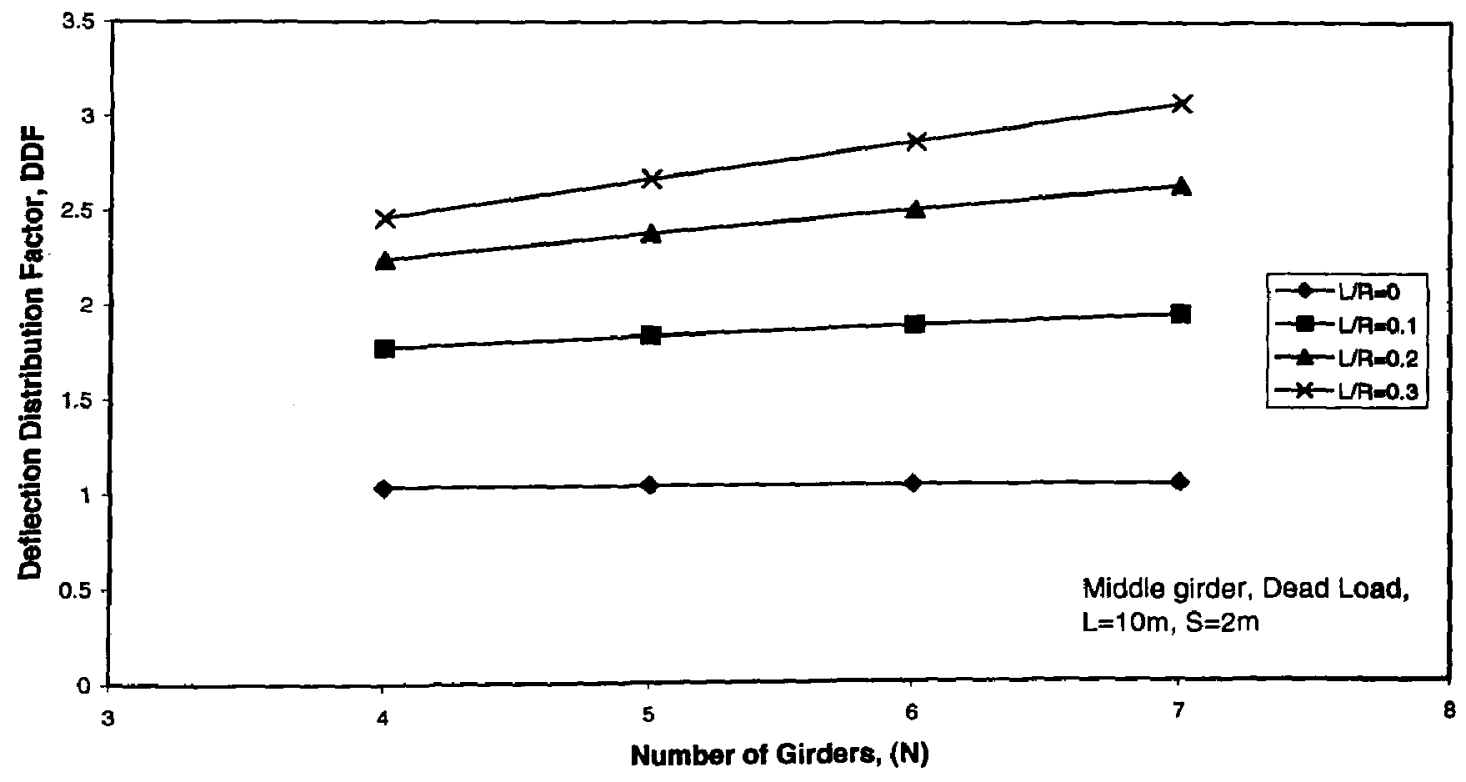

Figure 4. 126 Effect of Number of Girders on the Deflection Distribution Factor for the Middle Girder due to Dead Load 


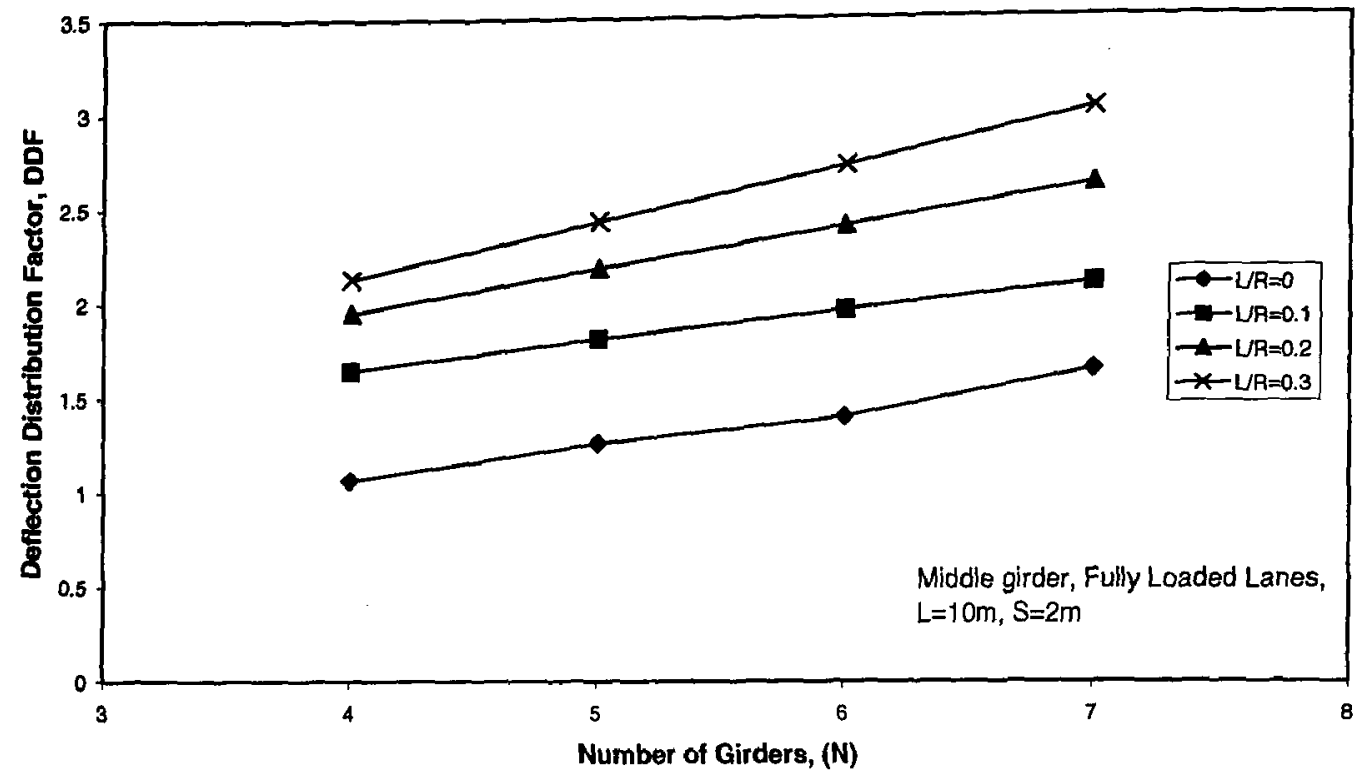

Figure 4.127 Effect of Number of Girders on the Deflection Distribution Factor for the Middle Girder due to Fully Loaded Lanes

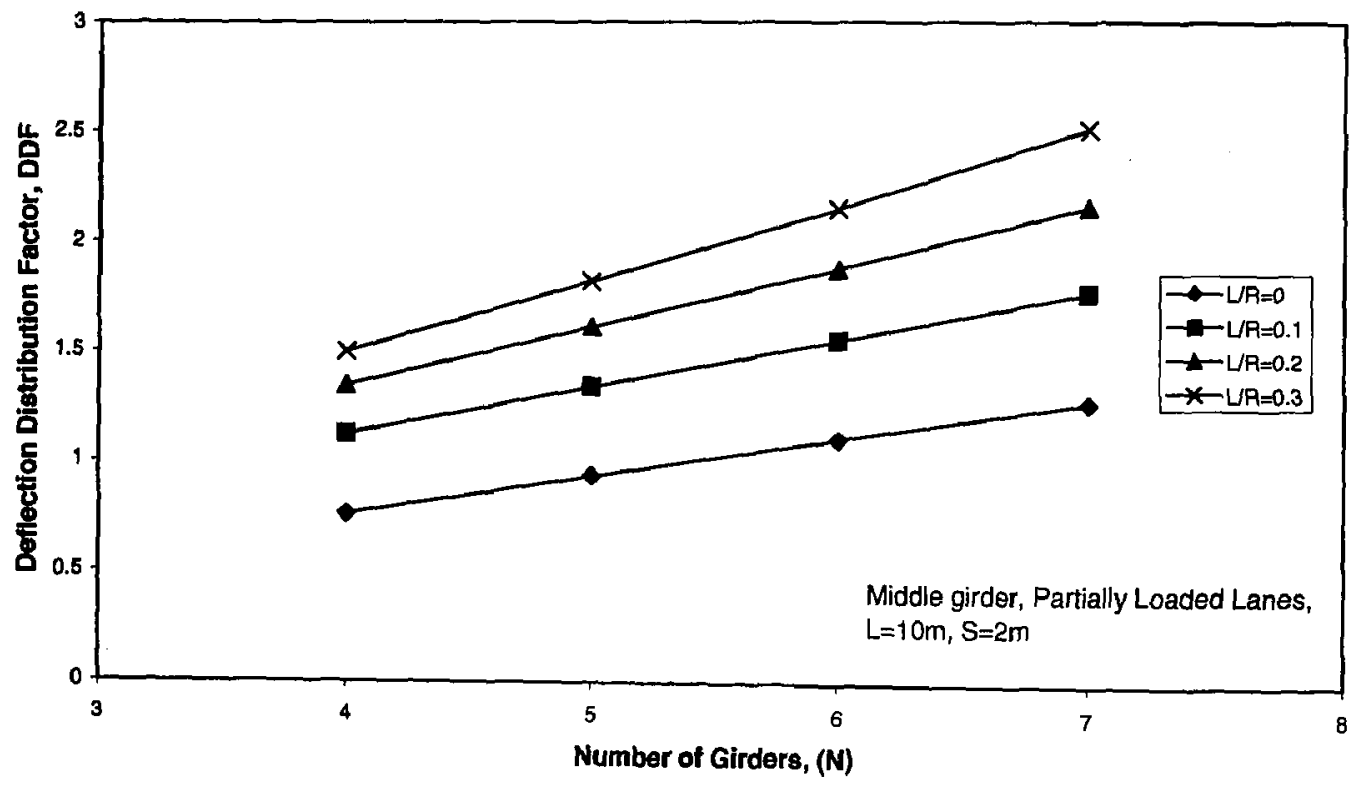

Figure 4. 128 Effect of Number of Girders on the Deflection Distribution Factor for the Middle Girder due to Partially Loaded Lanes 


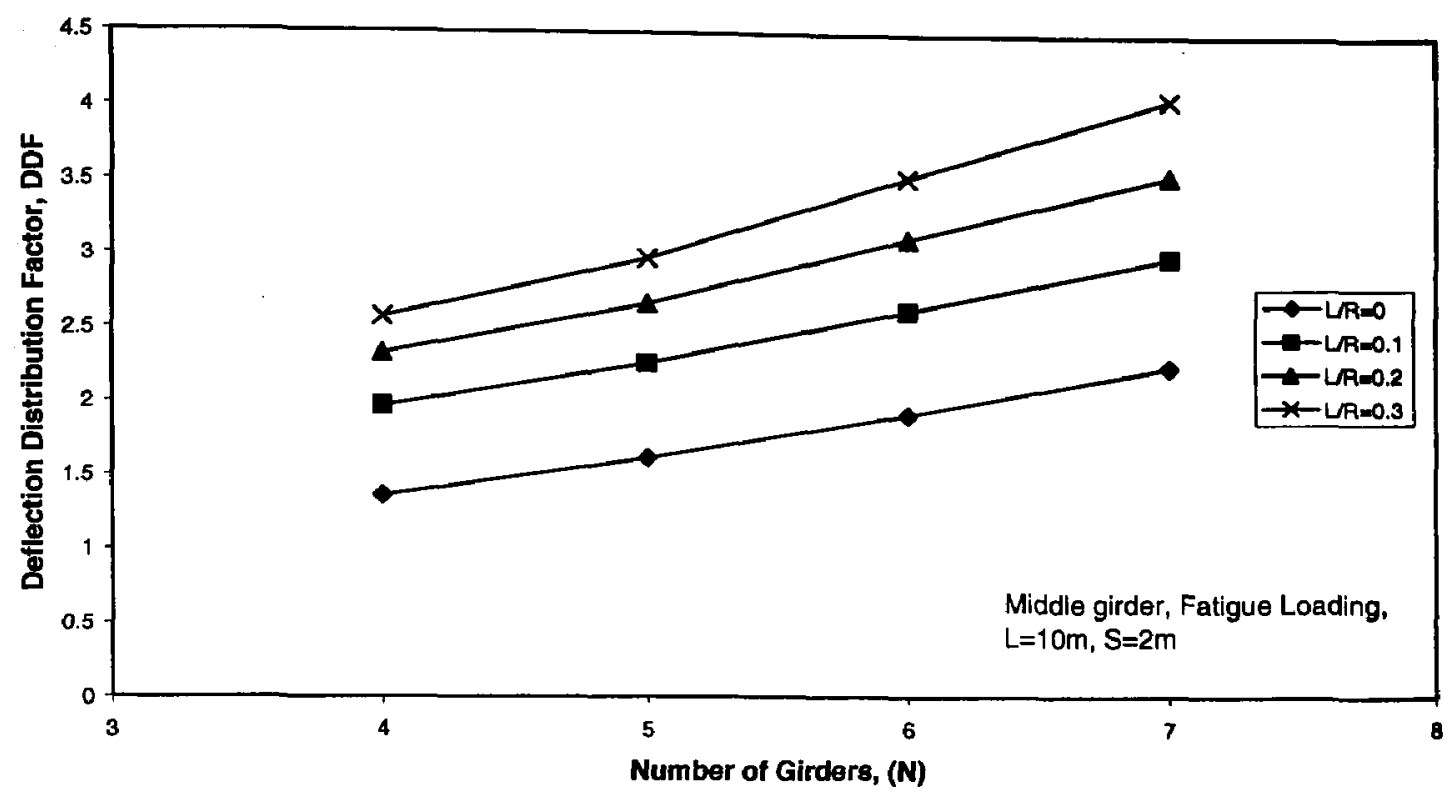

Figure 4. 129 Effect of Number of Girders on the Deflection Distribution Factor for the Middle Girder due to Fatigue Loading

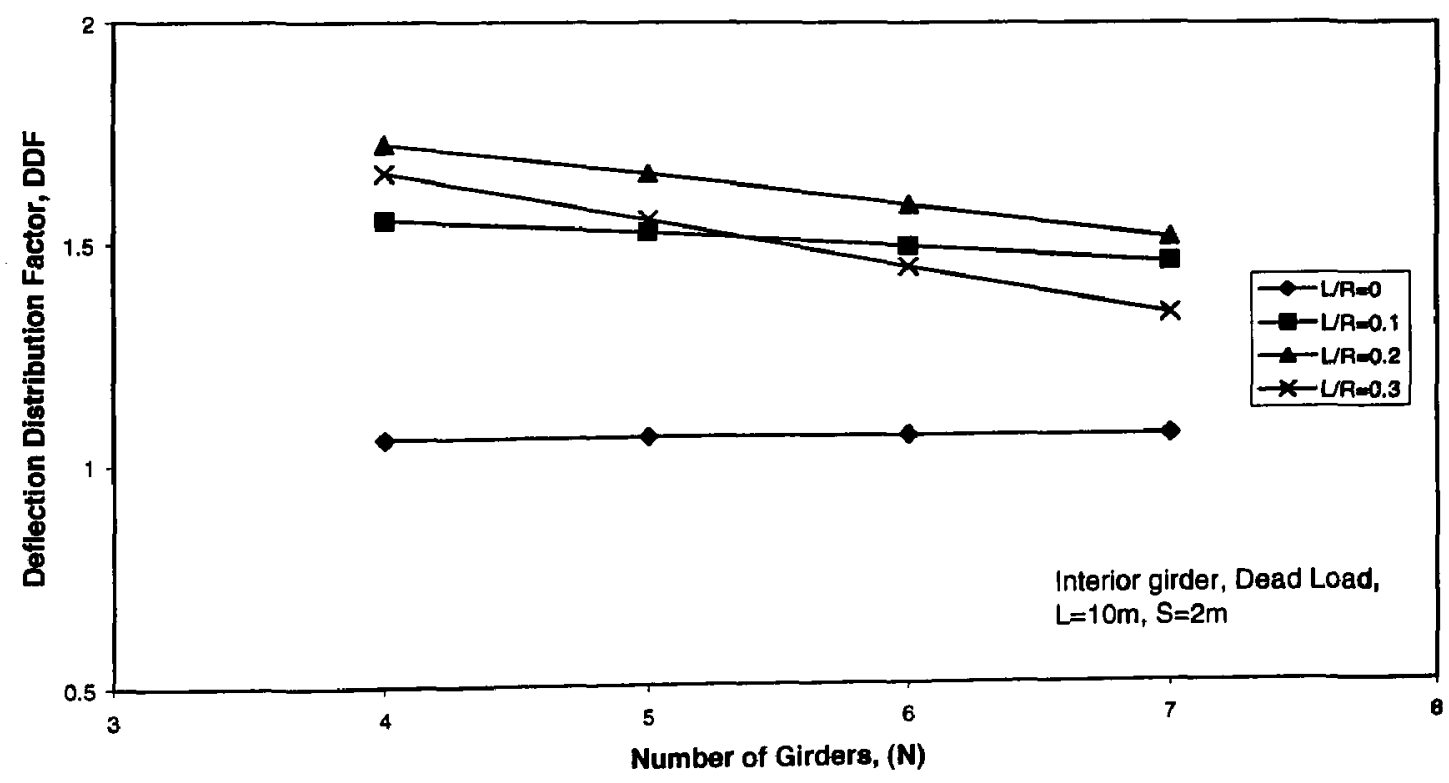

Figure 4. 130 Effect of Number of Girders on the Deflection Distribution Factor for the Interior Girder due to Dead Load 


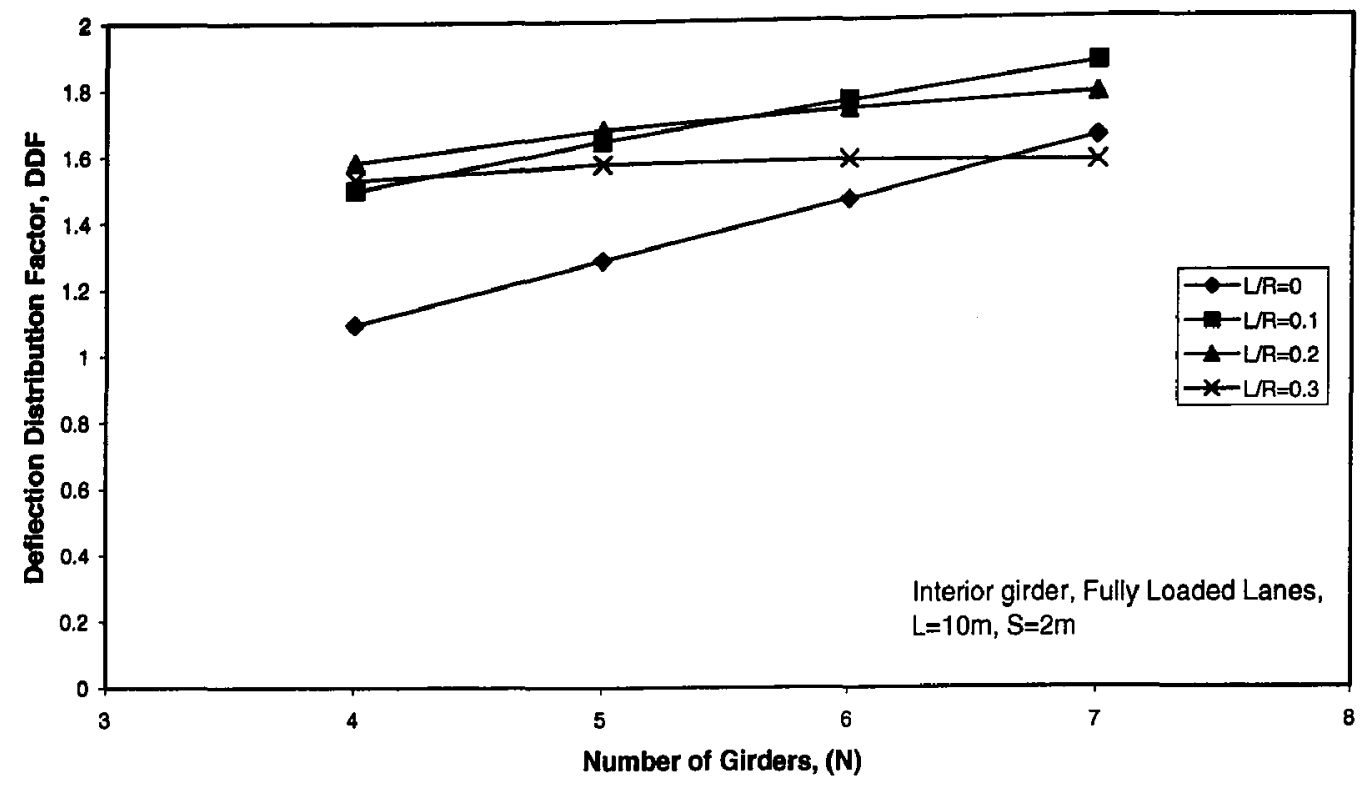

Figure 4. 131 Effect of Number of Girders on the Deflection Distribution Factor for the Interior Girder due to Fully Loaded Lanes

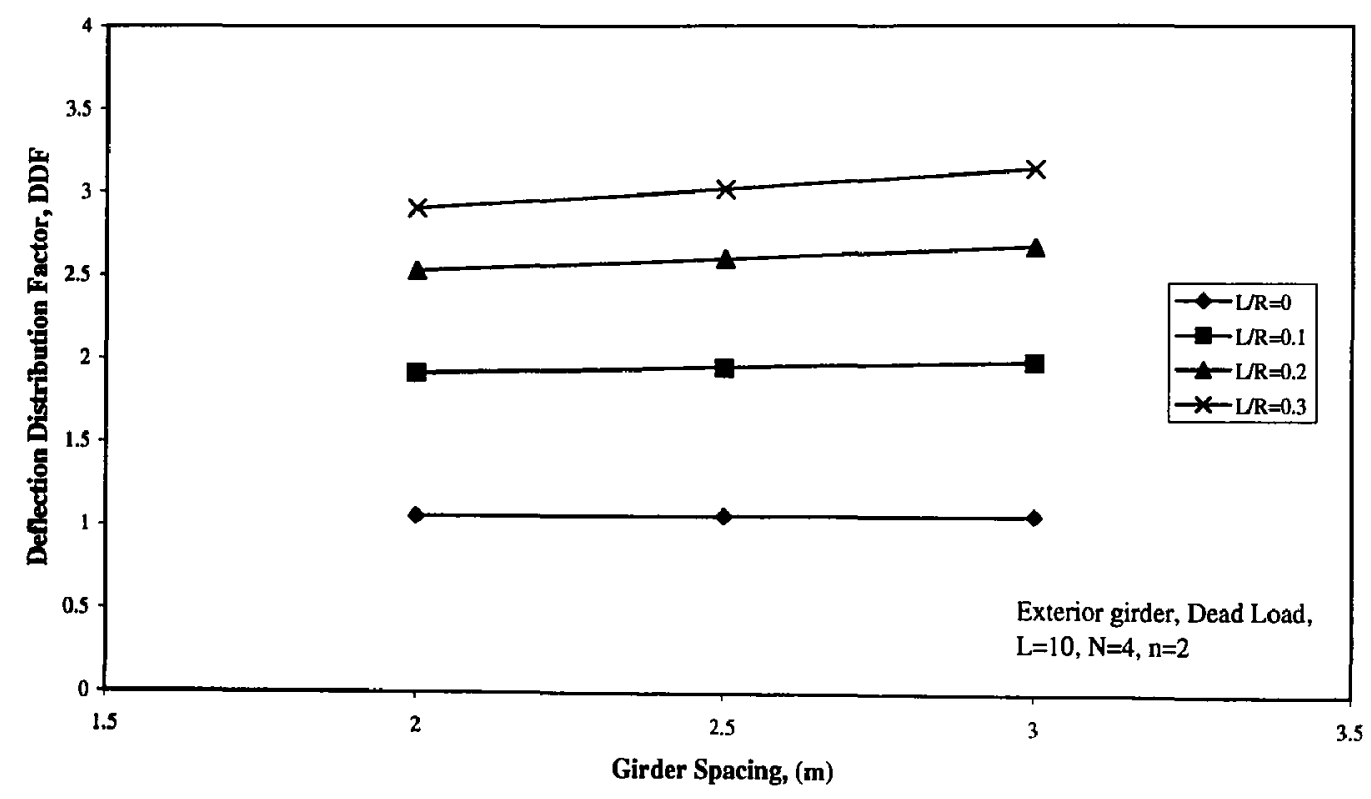

Figure 4. 132 Effect of Girder Spacing on the Deflection Distribution Factor for the Exterior Girder due to Dead Load 


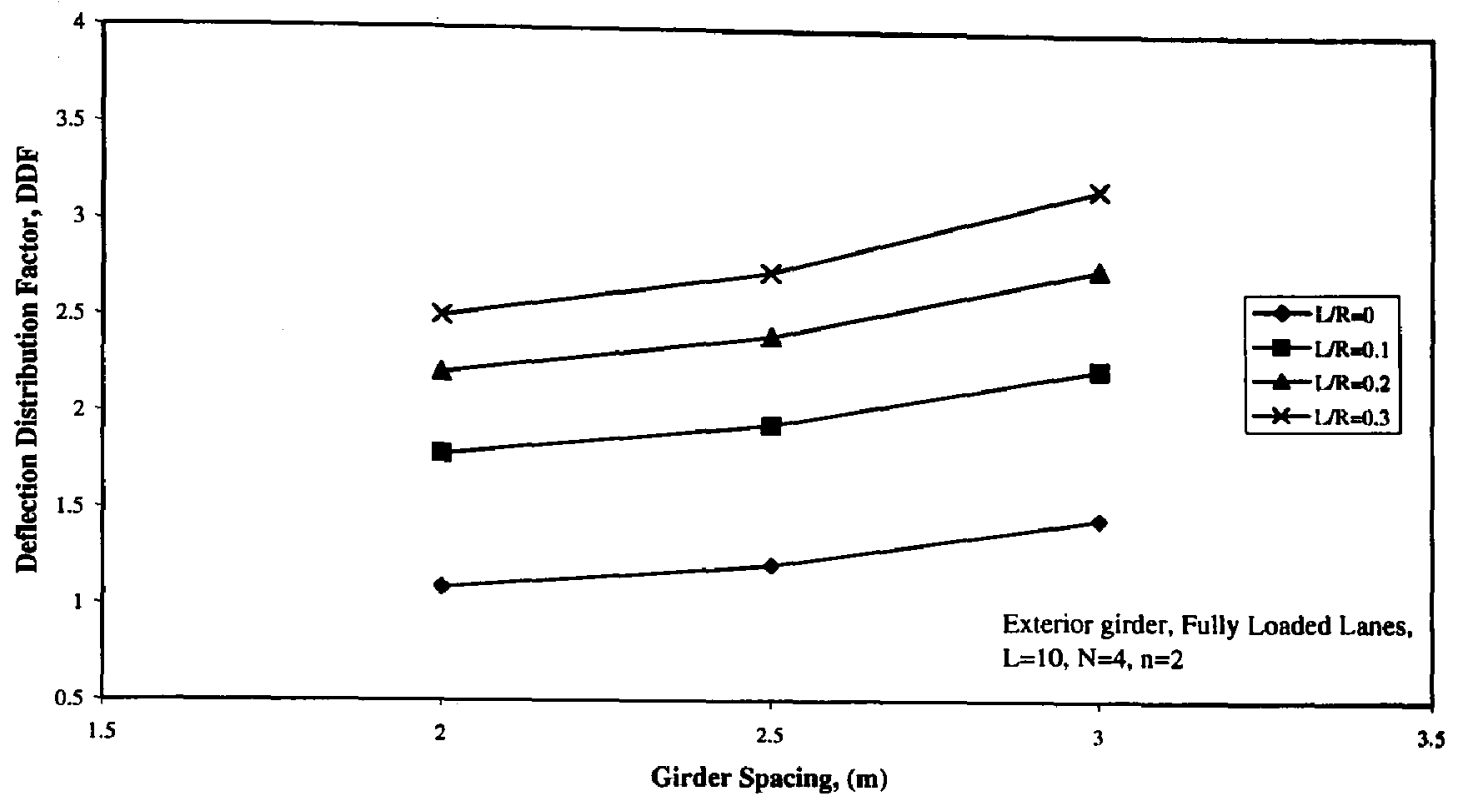

Figure 4. 133 Effect of Girder Spacing on the Deflection Distribution Factor for the Exterior Girder due to Fully Loaded Lanes

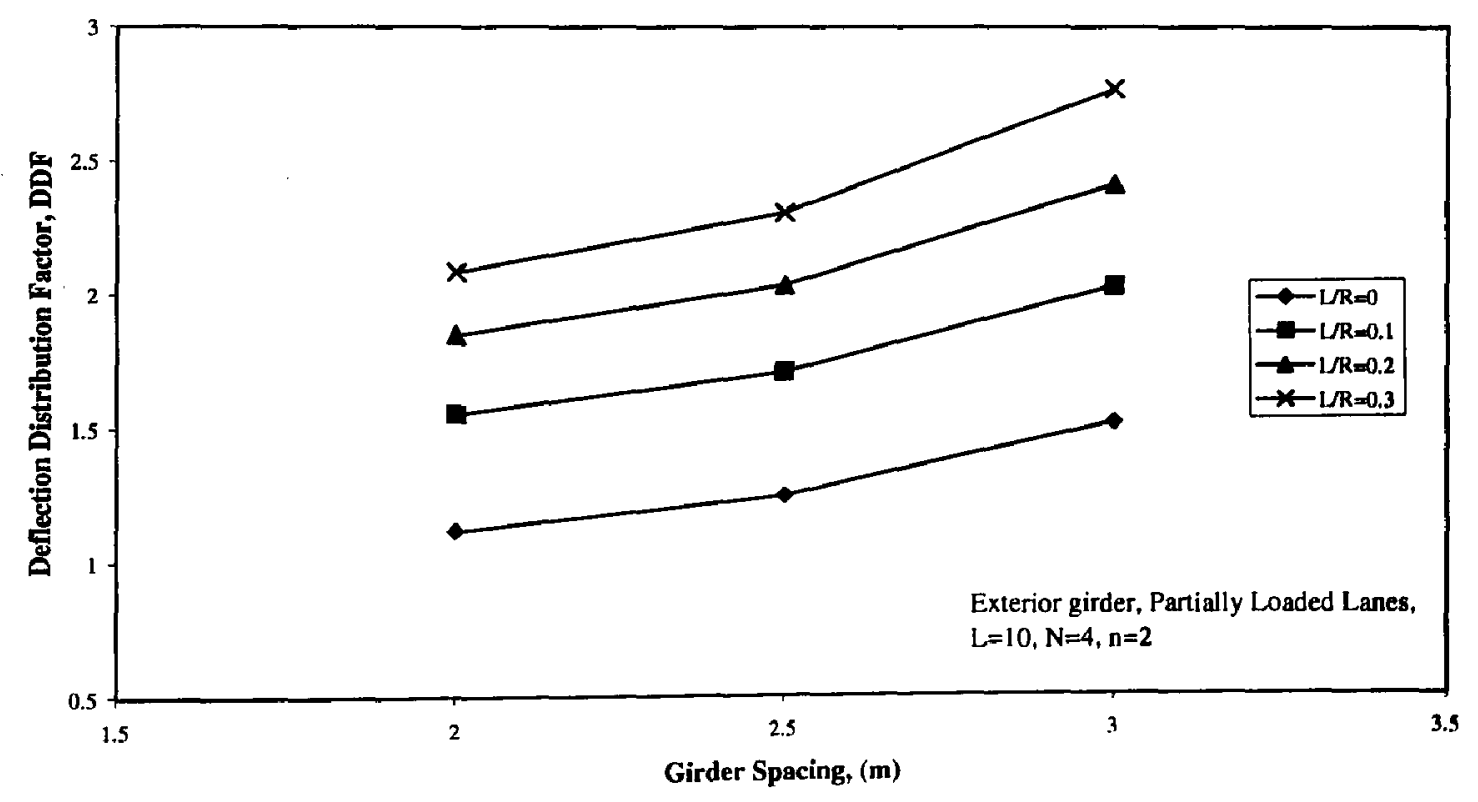

Figure 4. 134 Effect of Girder Spacing on the Deflection Distribution Factor for the Exterior Girder due to Partially Loaded Lanes 


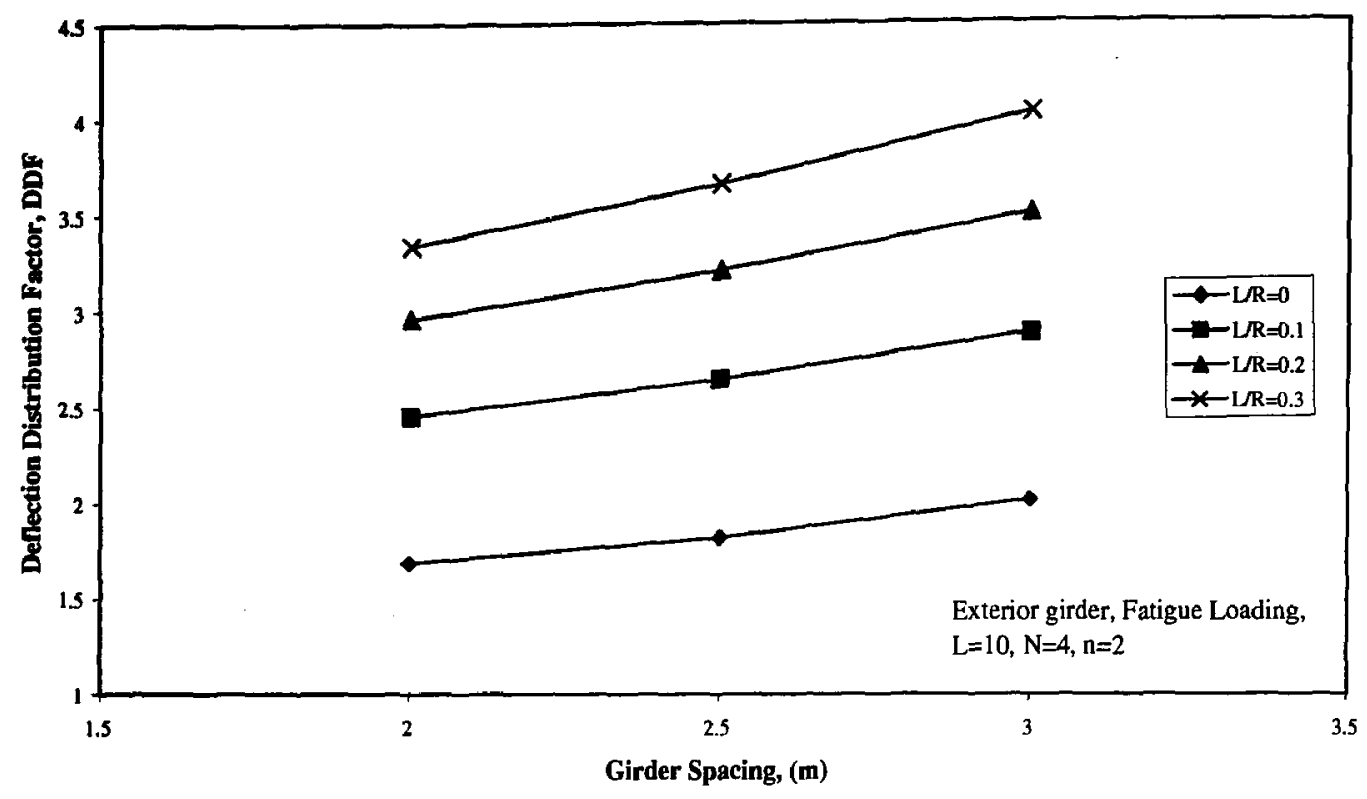

Figure 4. 135 Effect of Girder Spacing on the Deflection Distribution Factor for the Exterior Girder due to Fatigue Loading

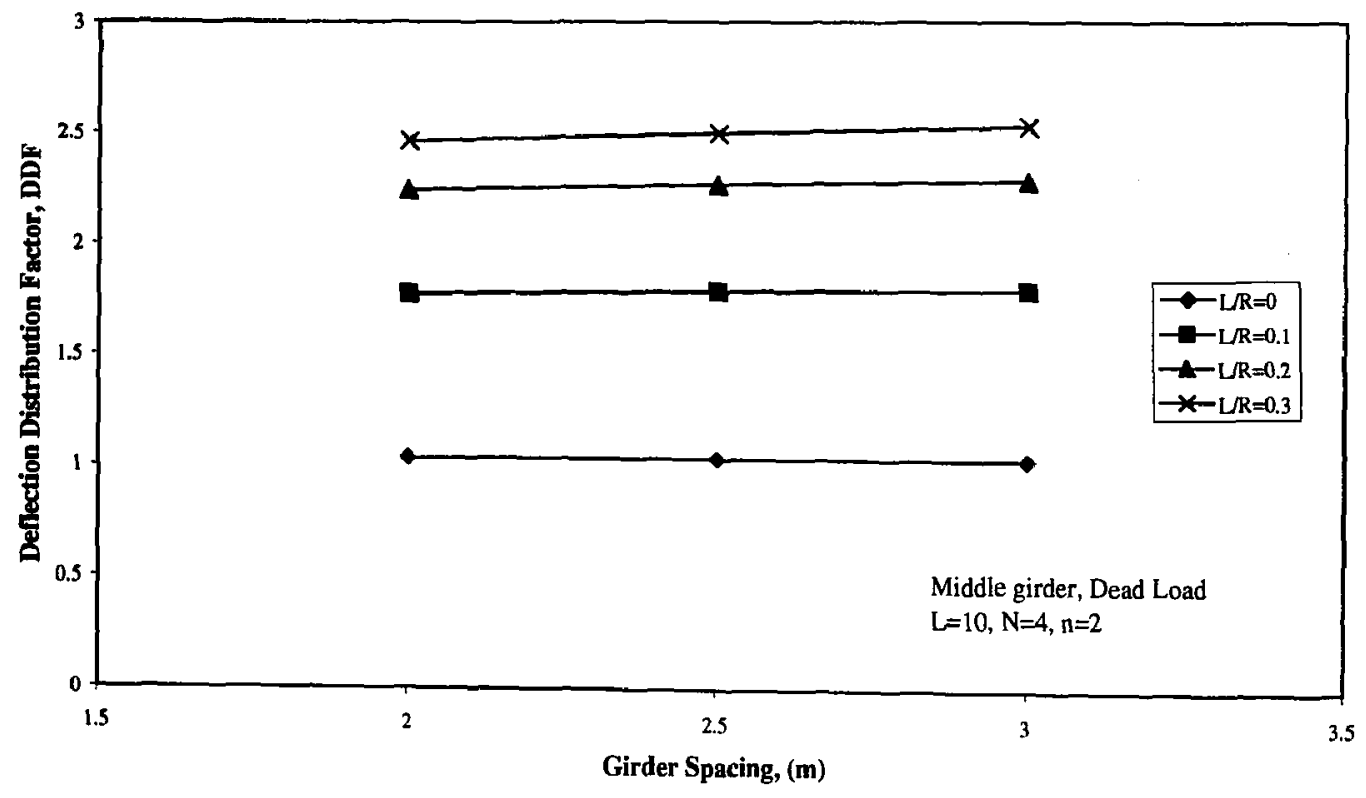

Figure 4. 136 Effect of Girder Spacing on the Deflection Distribution Factor for the Middle Girder due to Dead Load 


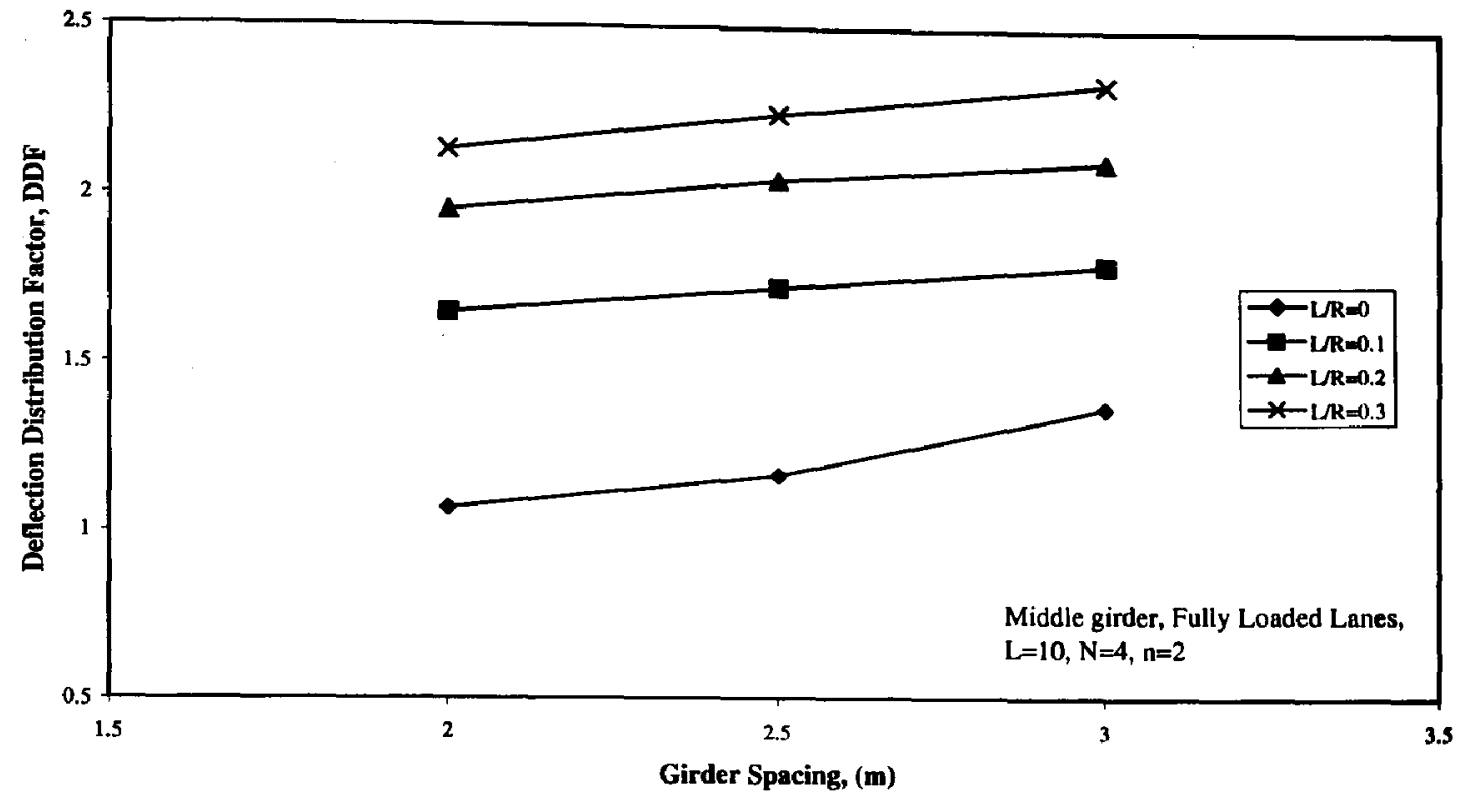

Figure 4. 137 Effect of Girder Spacing on the Deflection Distribution Factor for the Middle Girder due to Fully Loaded Lanes

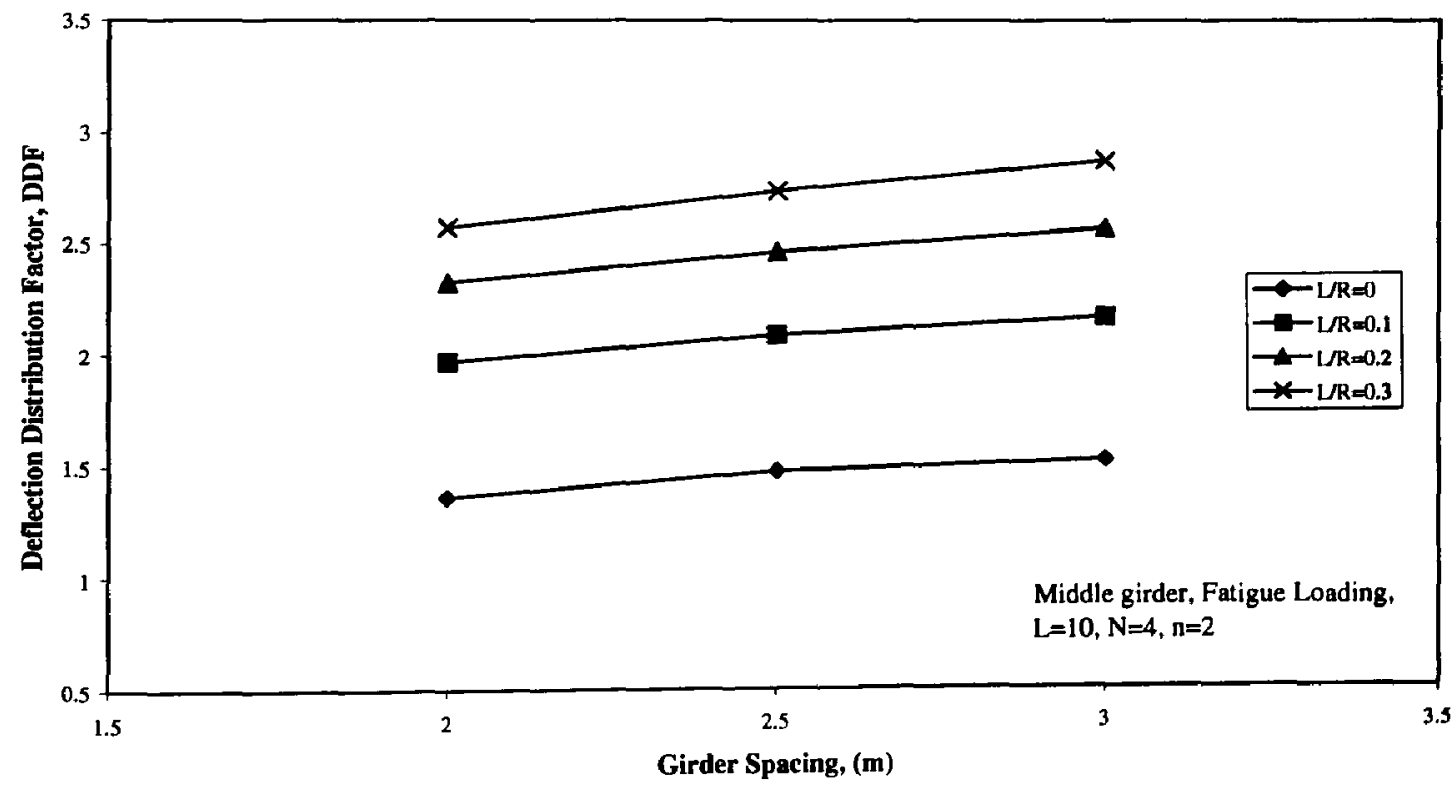

Figure 4. 138 Effect of Girder Spacing on the Deflection Distribution Factor for the Middle Girder due to Fatigue Loading 


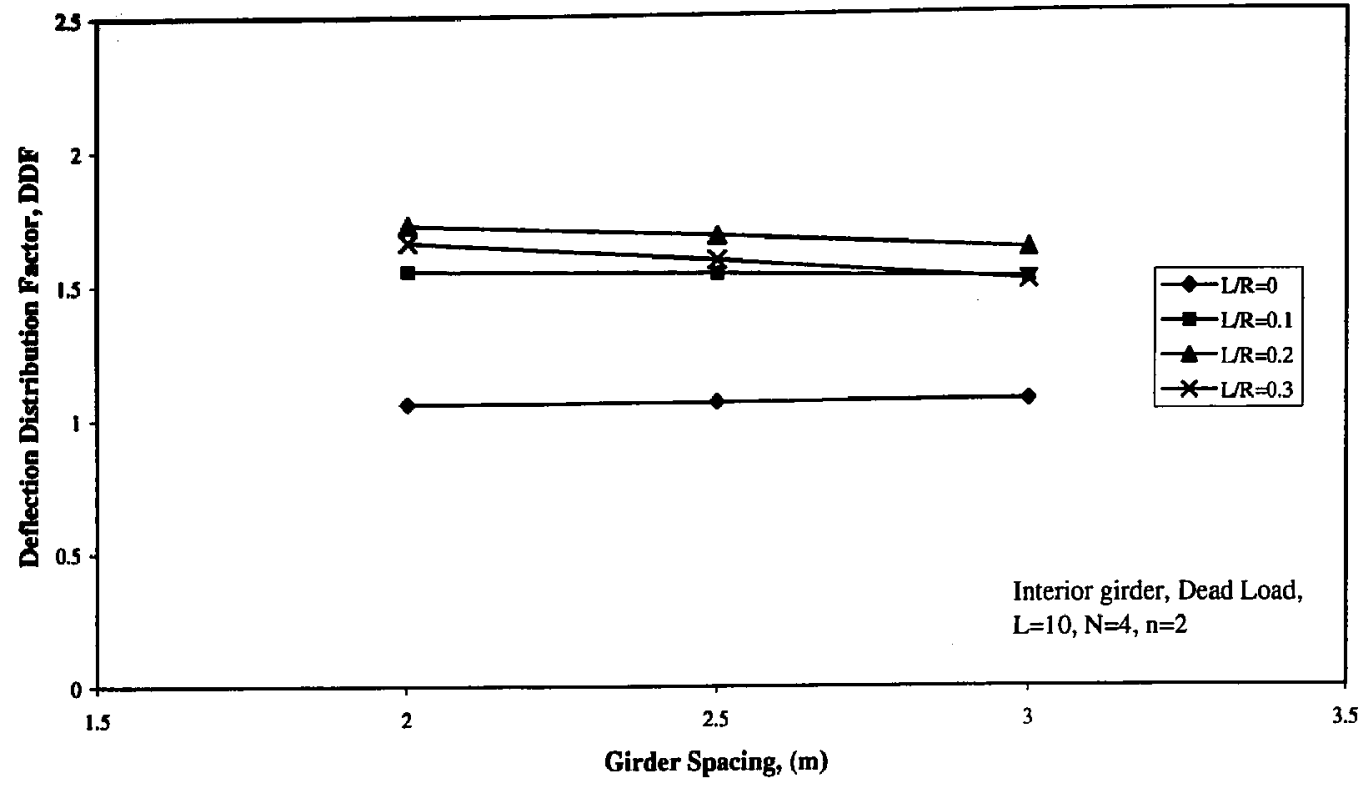

Figure 4. 139 Effect of Girder Spacing on the Deflection Distribution Factor for the Interior Girder due to Dead Load

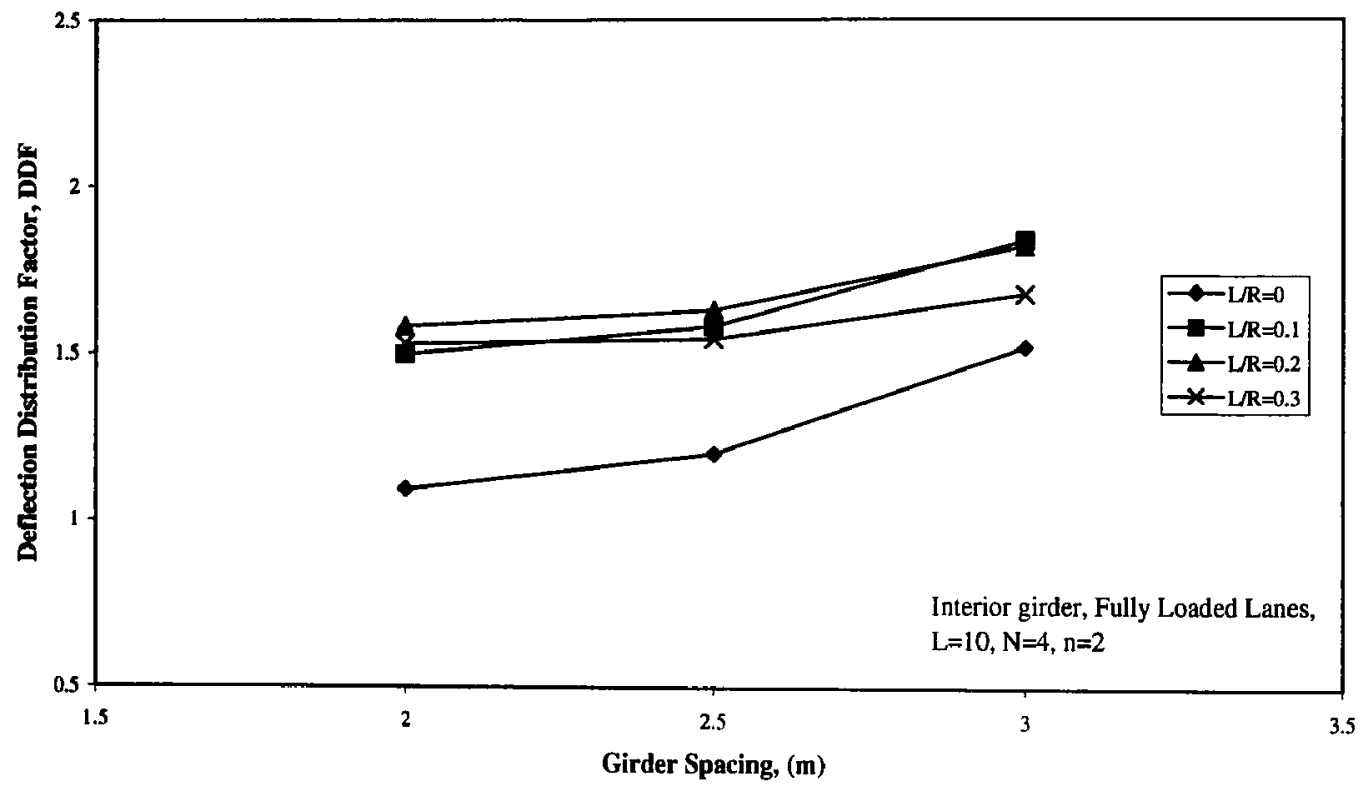

Figure 4.140 Effect of Girder Spacing on the Deflection Distribution Factor for the Interior Girder due to Fully Loaded Lanes 


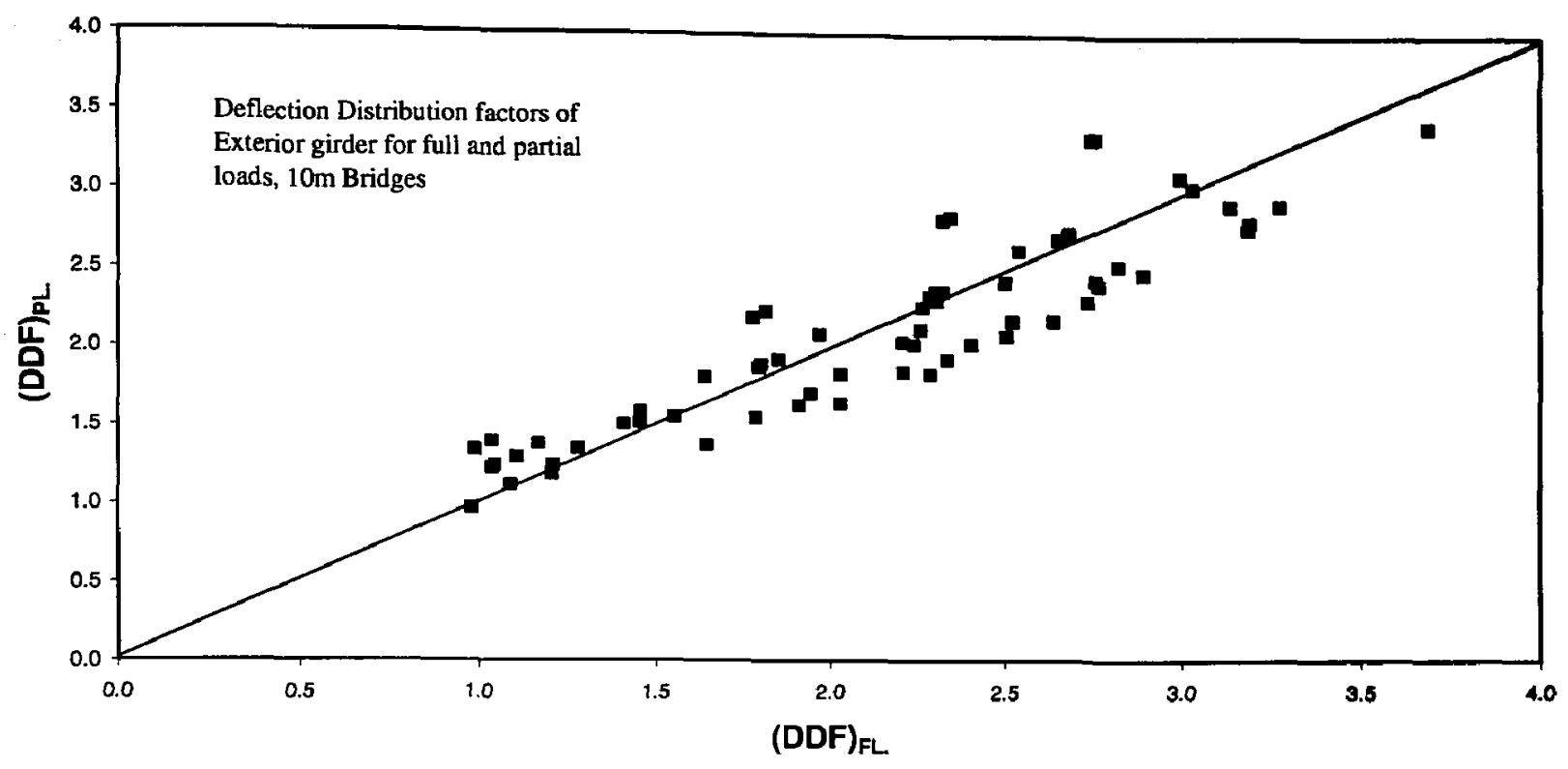

Figure 4. 141 Effect of Loading Conditions on the Deflection Distribution Factor for the Exterior Girder of 10-m-span Bridges

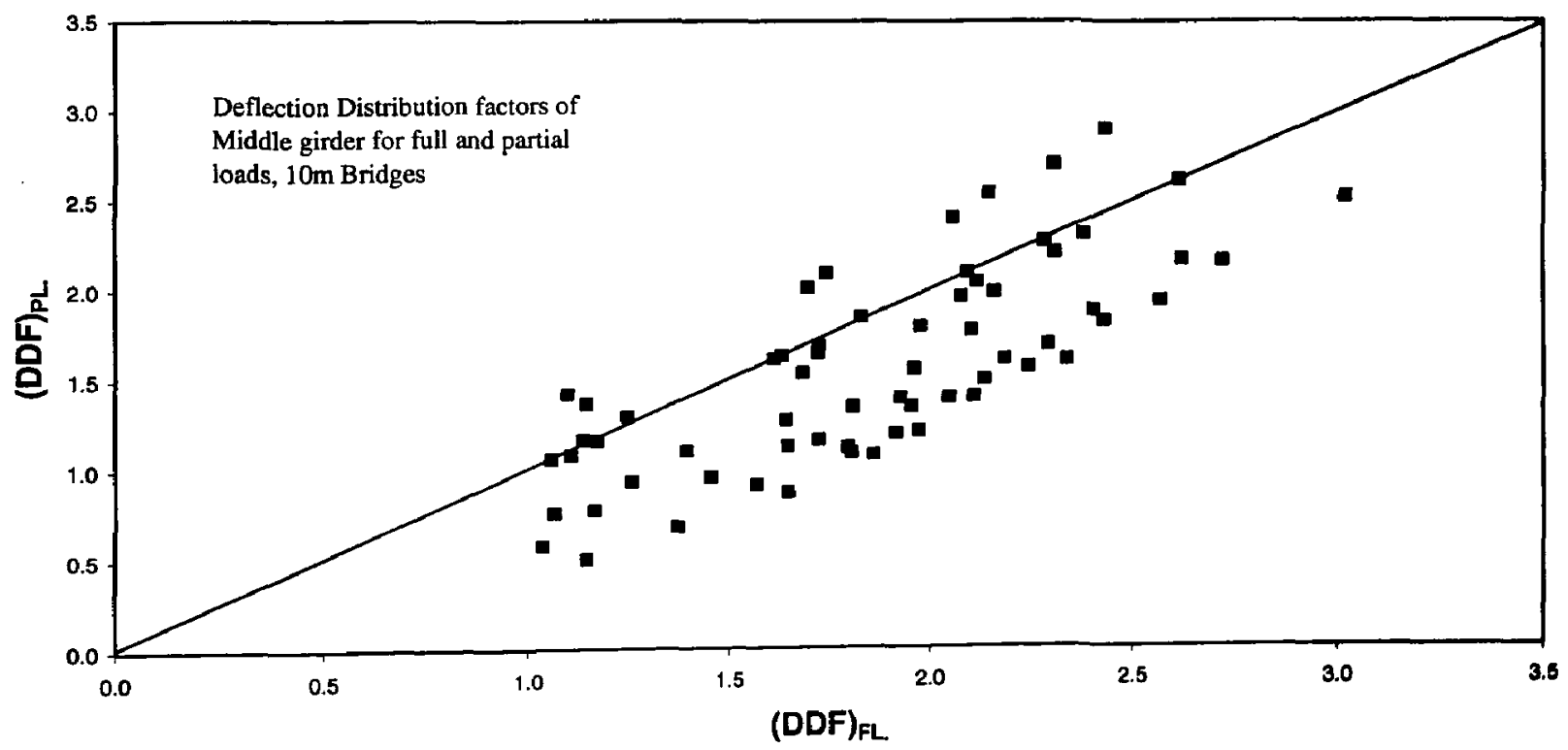

Figure 4. 142 Effect of Loading Conditions on the Deflection Distribution Factor for the Middle Girder of 10-m-span Bridges 


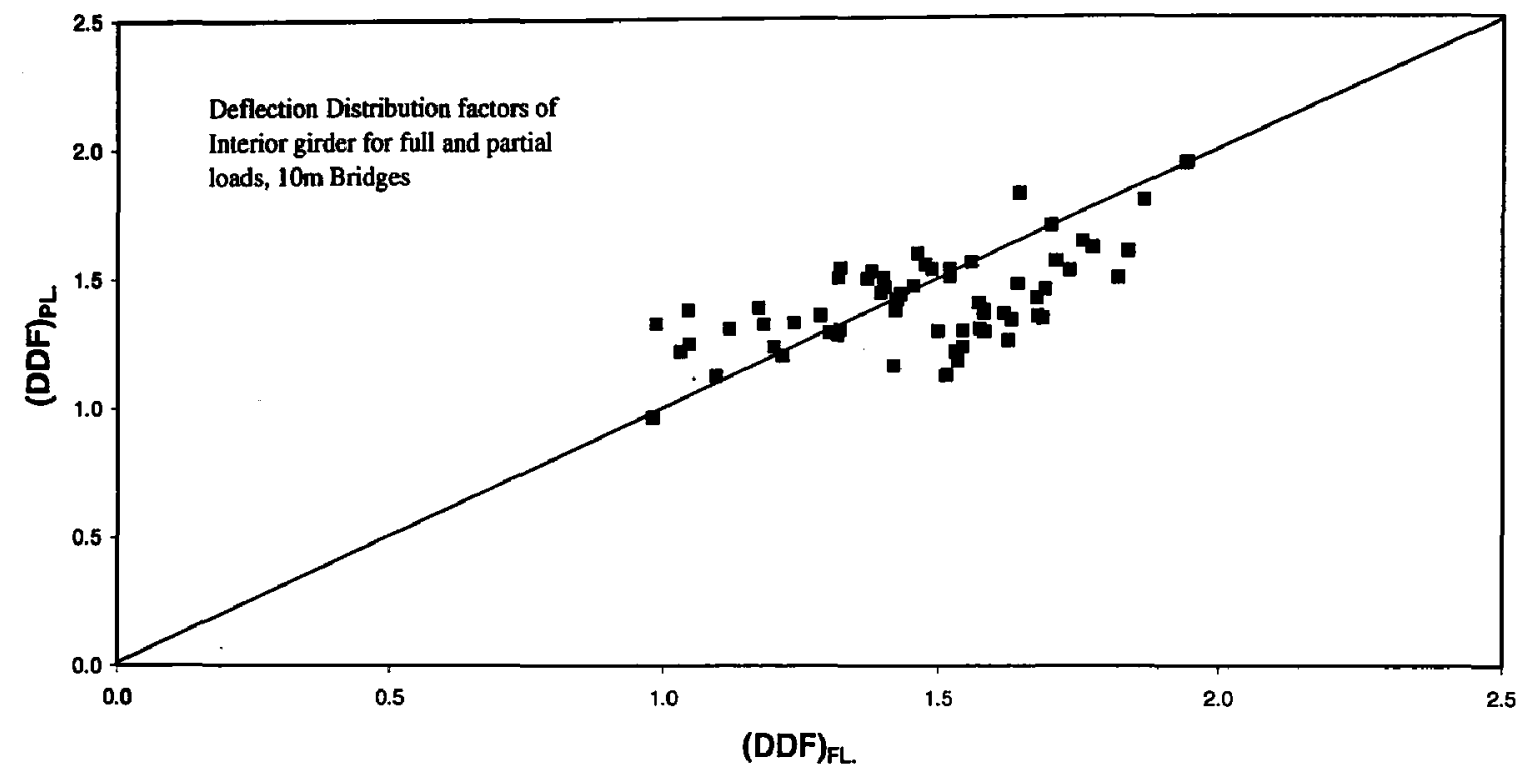

Figure 4. 143 Effect of Loading Conditions on the Deflection Distribution Factor for the Interior Girder of 10-m-span Bridges 


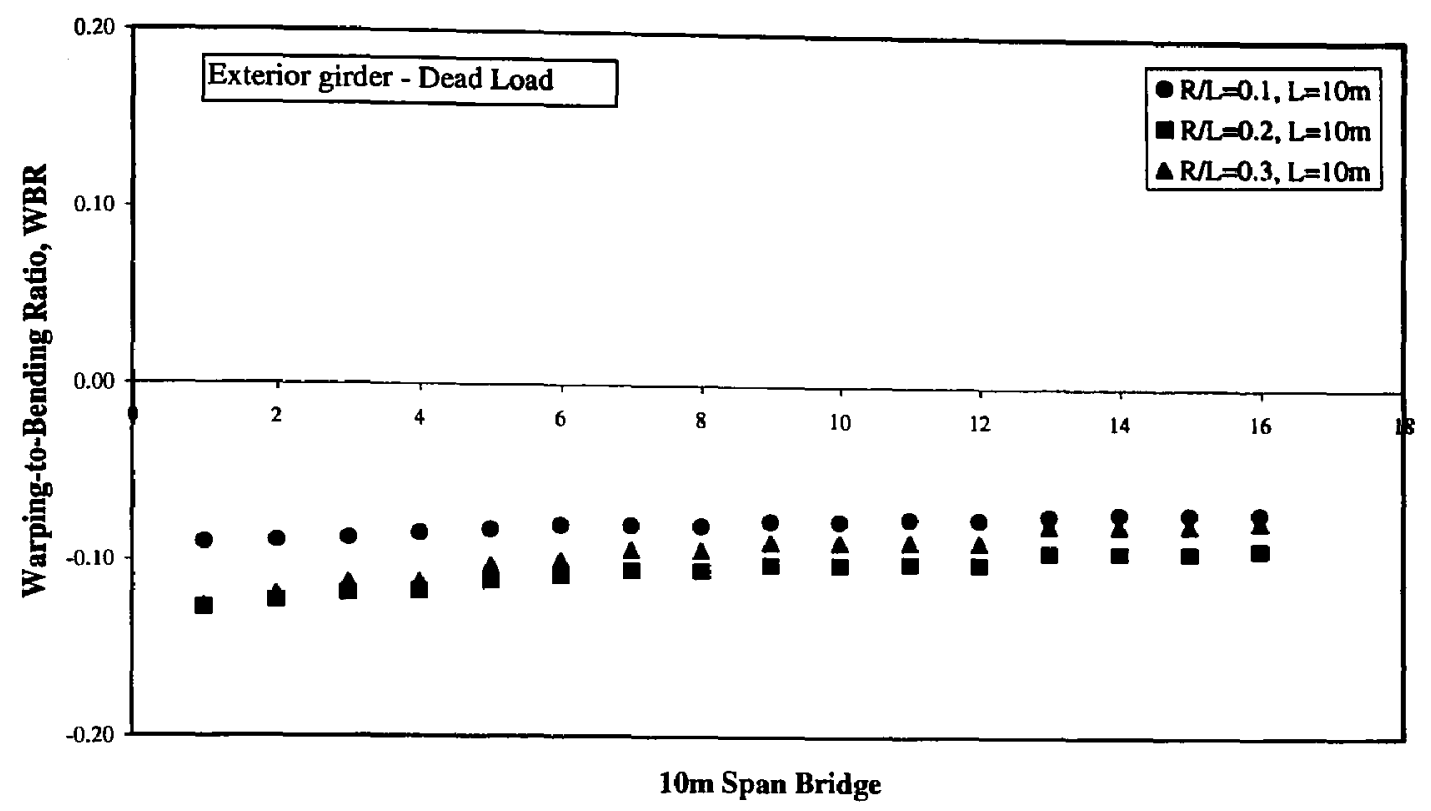

Figure 4. 144 Effect of Curvature on the Warping-to-Bending ratio for the Exterior Girder due to Dead Load

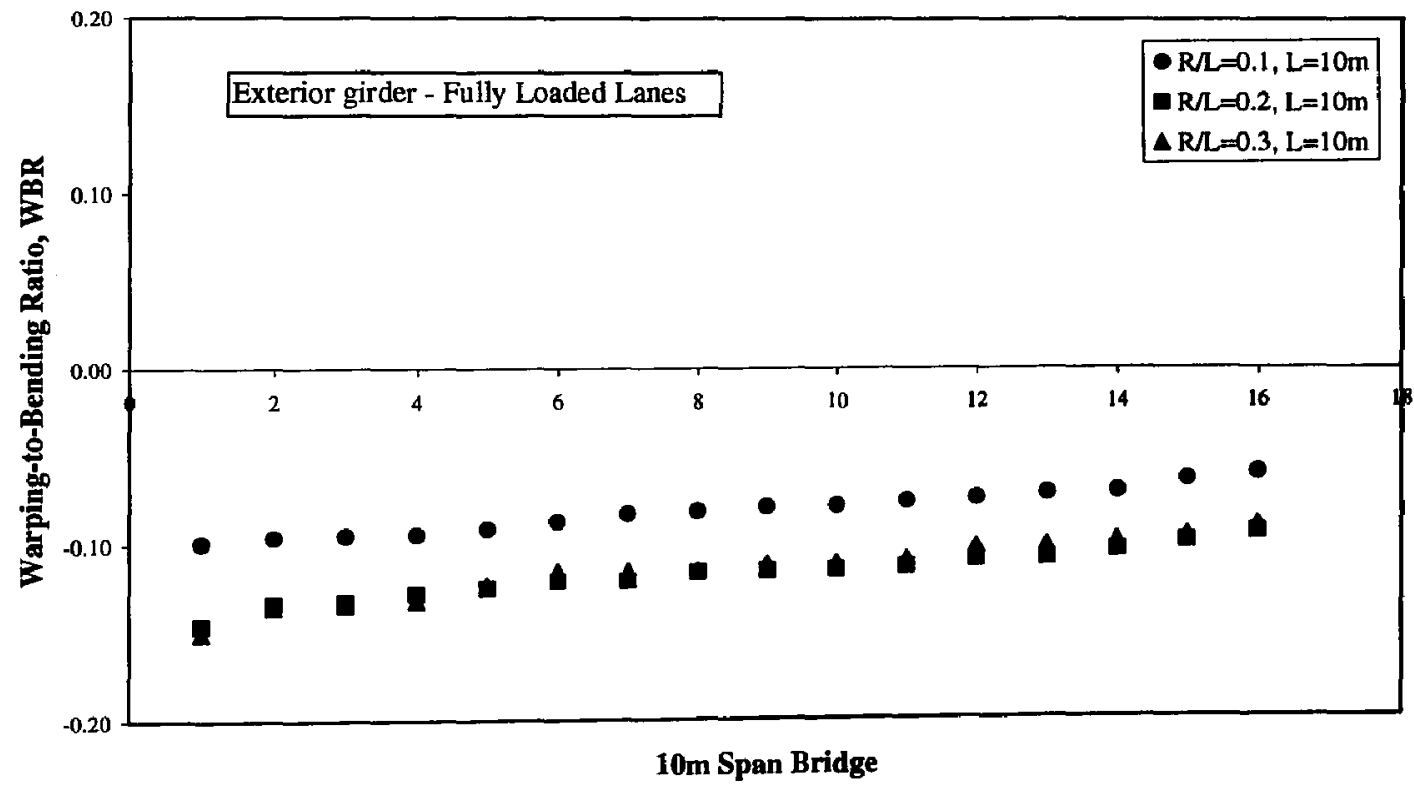

Figure 4. 145 Effect of Curvature on the Warping-to-Bending ratio for the Exterior Girder due to Fully Loaded Lanes 


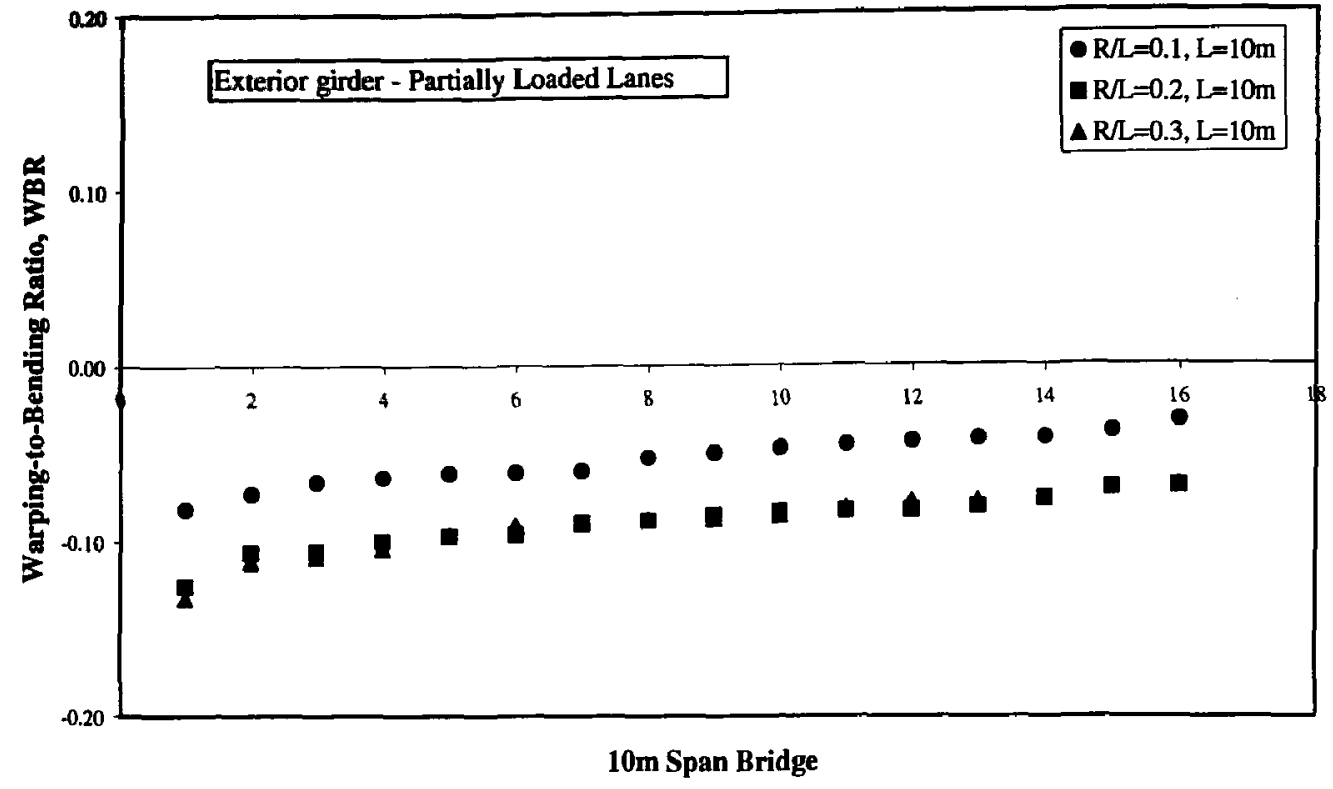

Figure 4. 146 Effect of Curvature on the Warping-to-Bending ratio for the Exterior Girder due to Partially Loaded Lanes

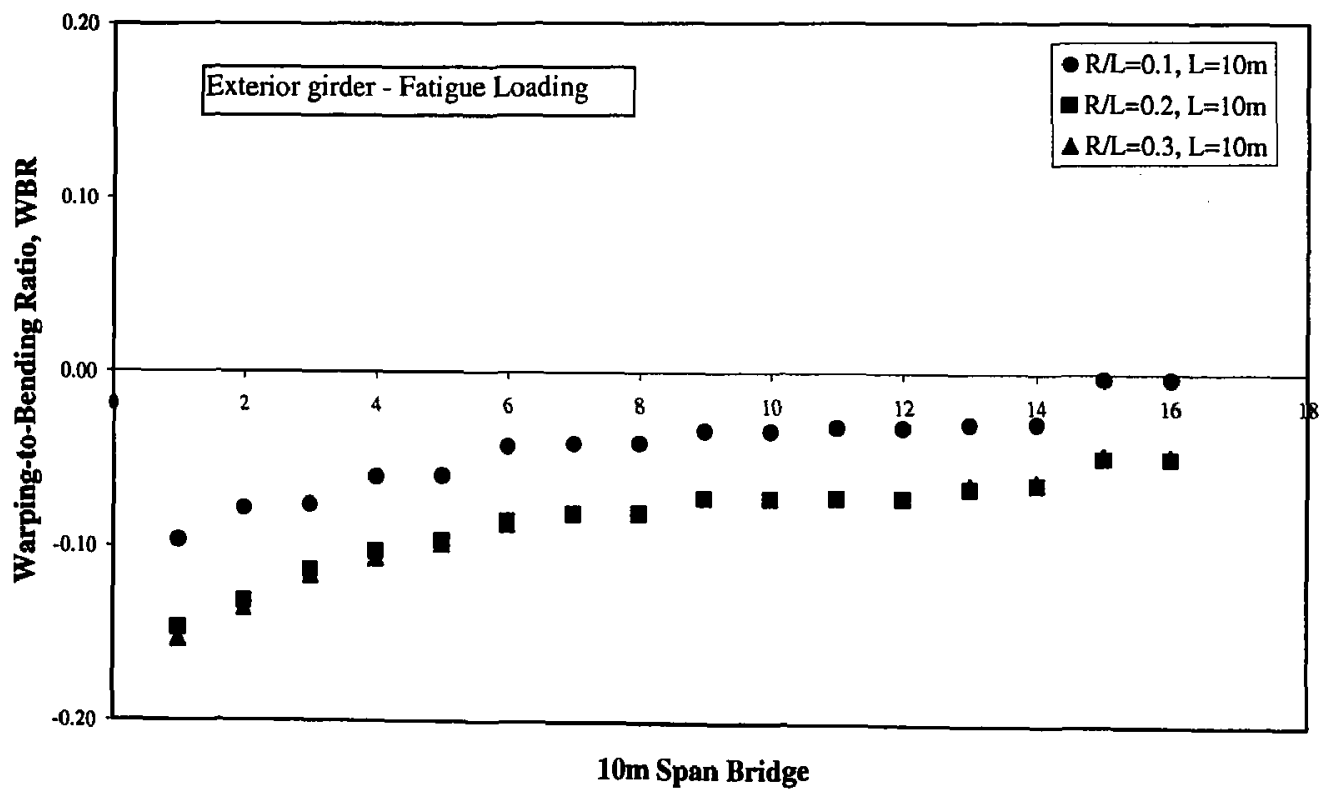

Figure 4.147 Effect of Curvature on the Warping-to-Bending ratio for the Exterior Girder due to Fatigue Loading 


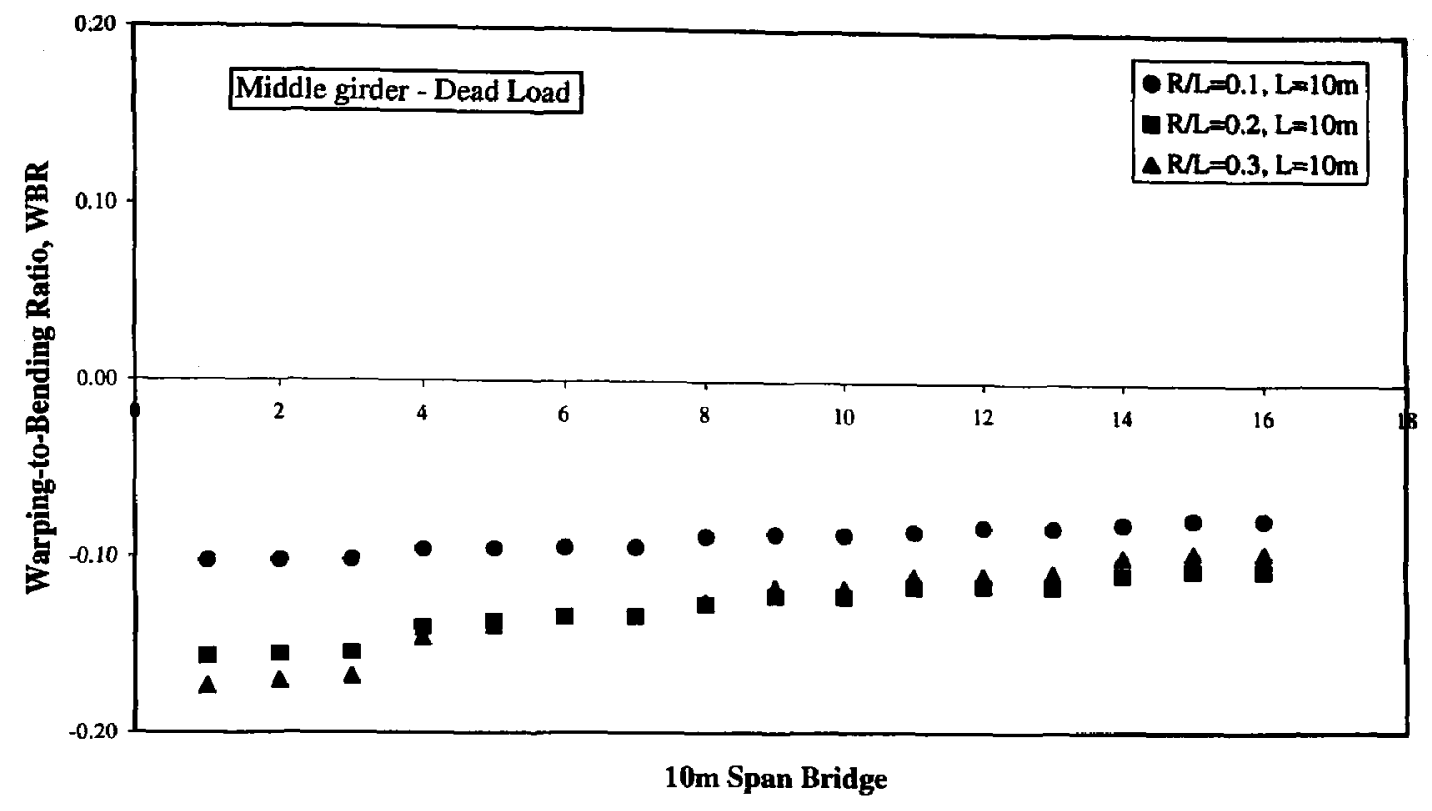

Figure 4. 148 Effect of Curvature on the Warping-to-Bending ratio for the Middle Girder due to Dead Load

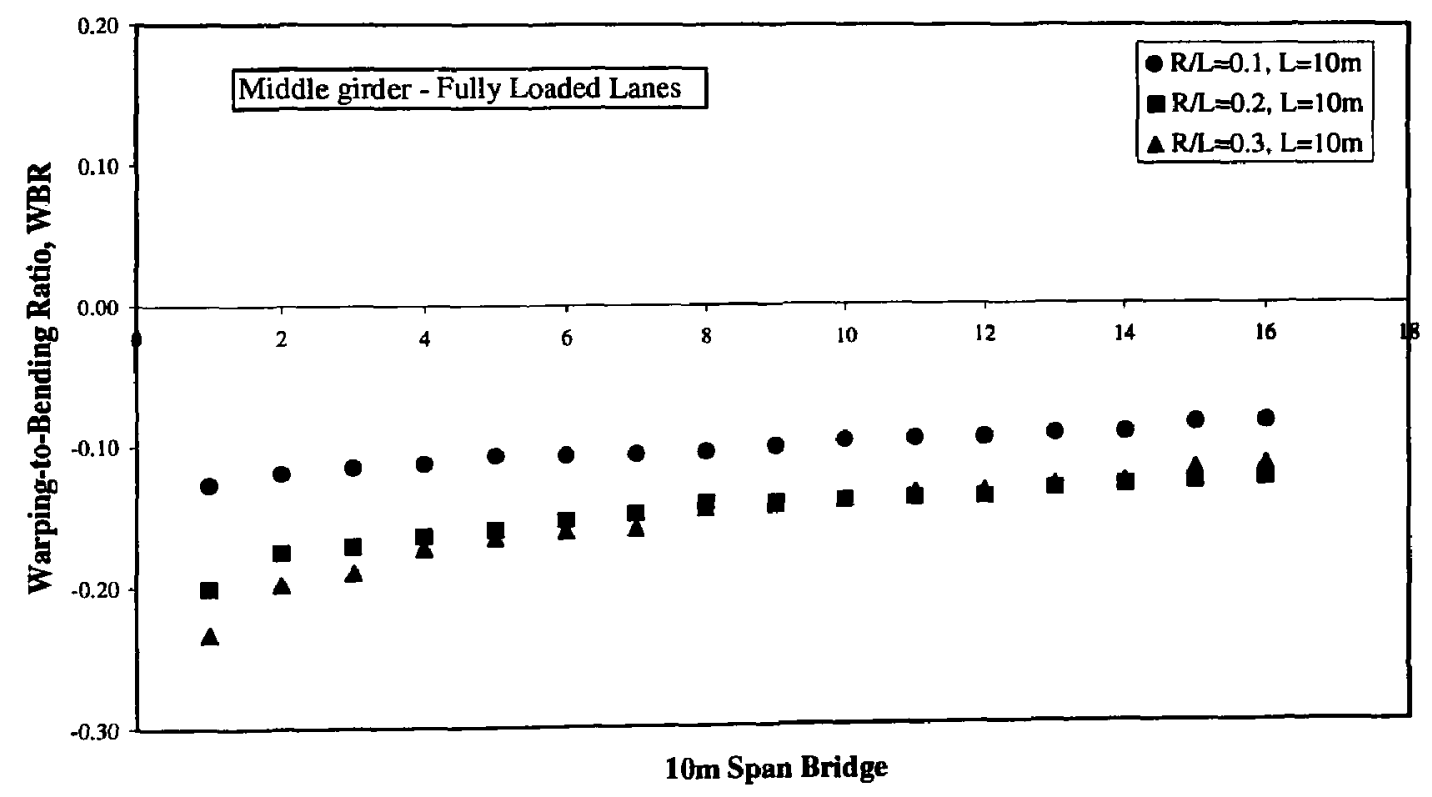

Figure 4. 149 Effect of Curvature on the Warping-to-Bending ratio for the Middle Girder due to Fully Loaded Lanes 


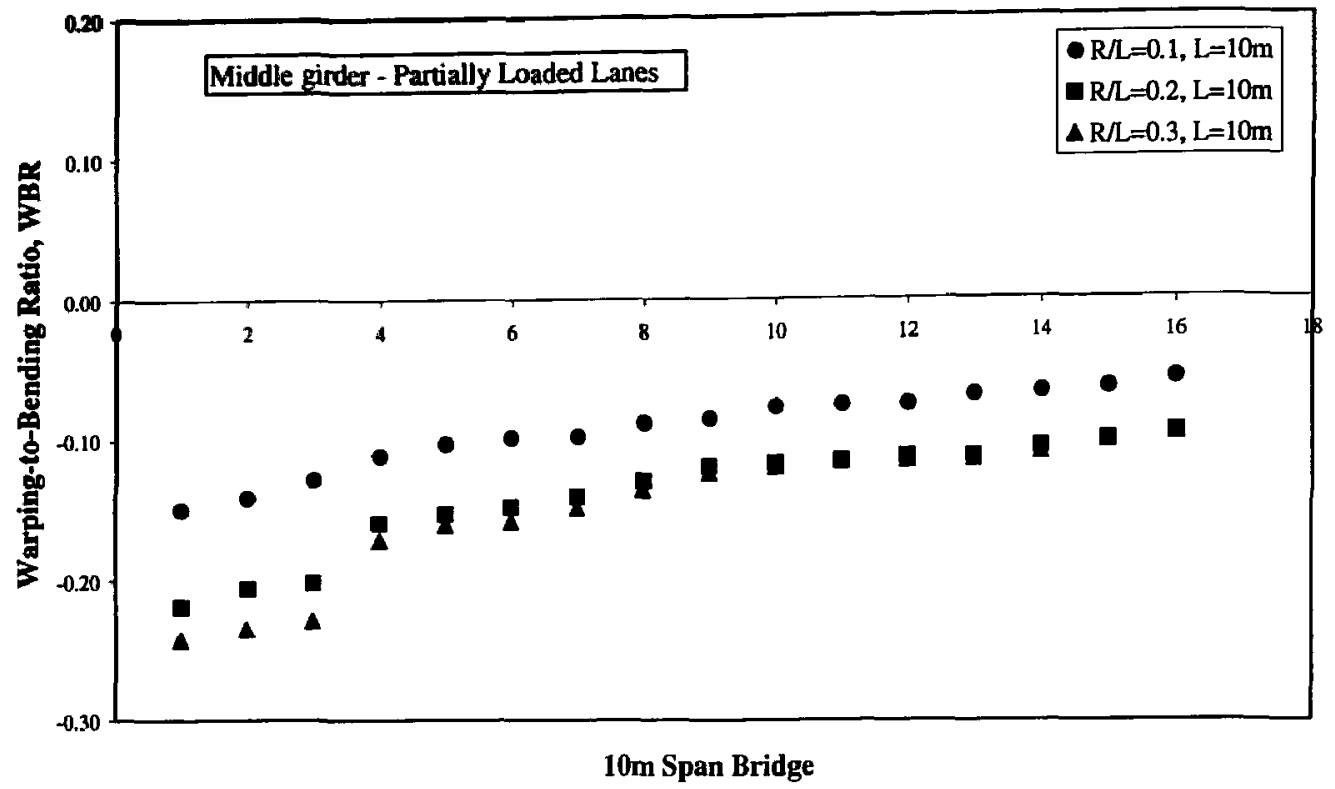

Figure 4. 150 Effect of Curvature on the Warping-to-Bending ratio for the Middle Girder due to Partially Loaded Lanes

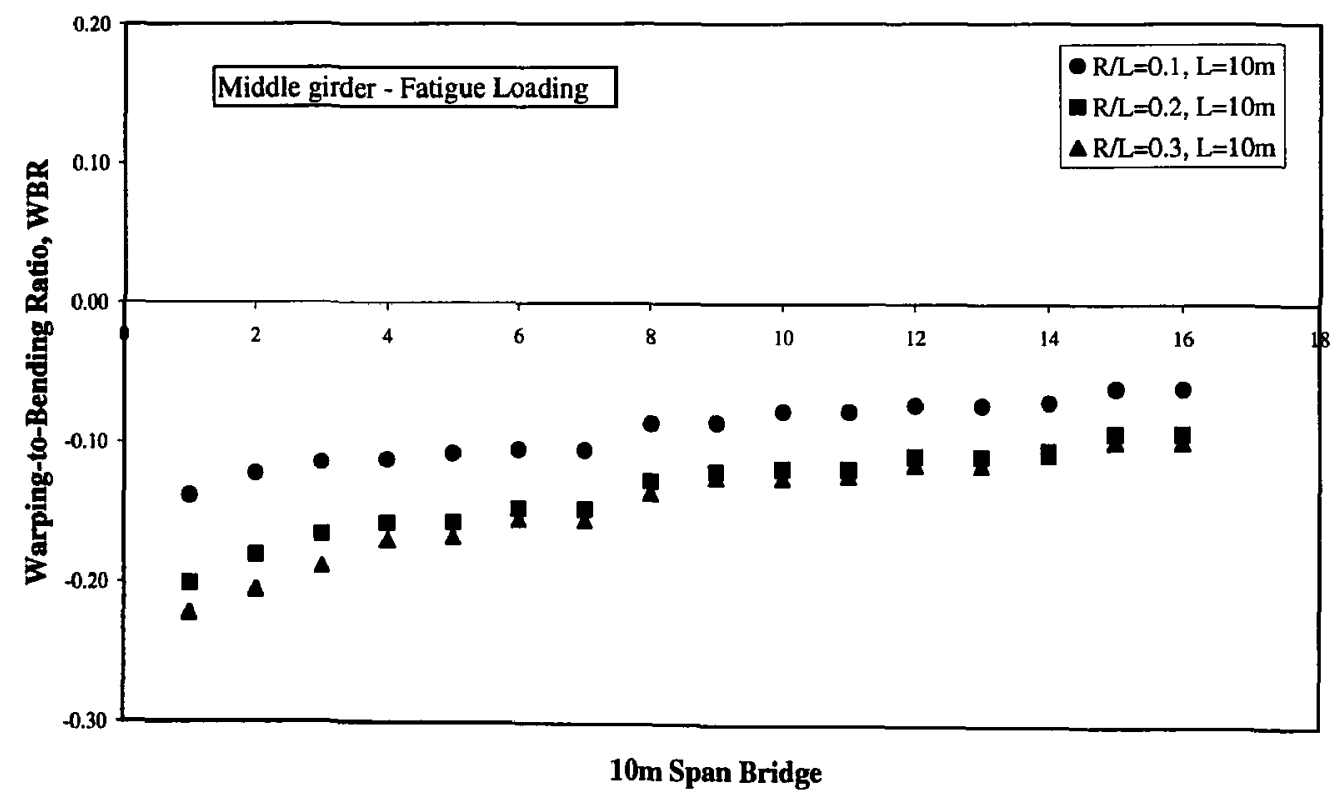

Figure 4. 151 Effect of Curvature on the Warping-to-Bending ratio for the Middle Girder due to Fatigue Loading 


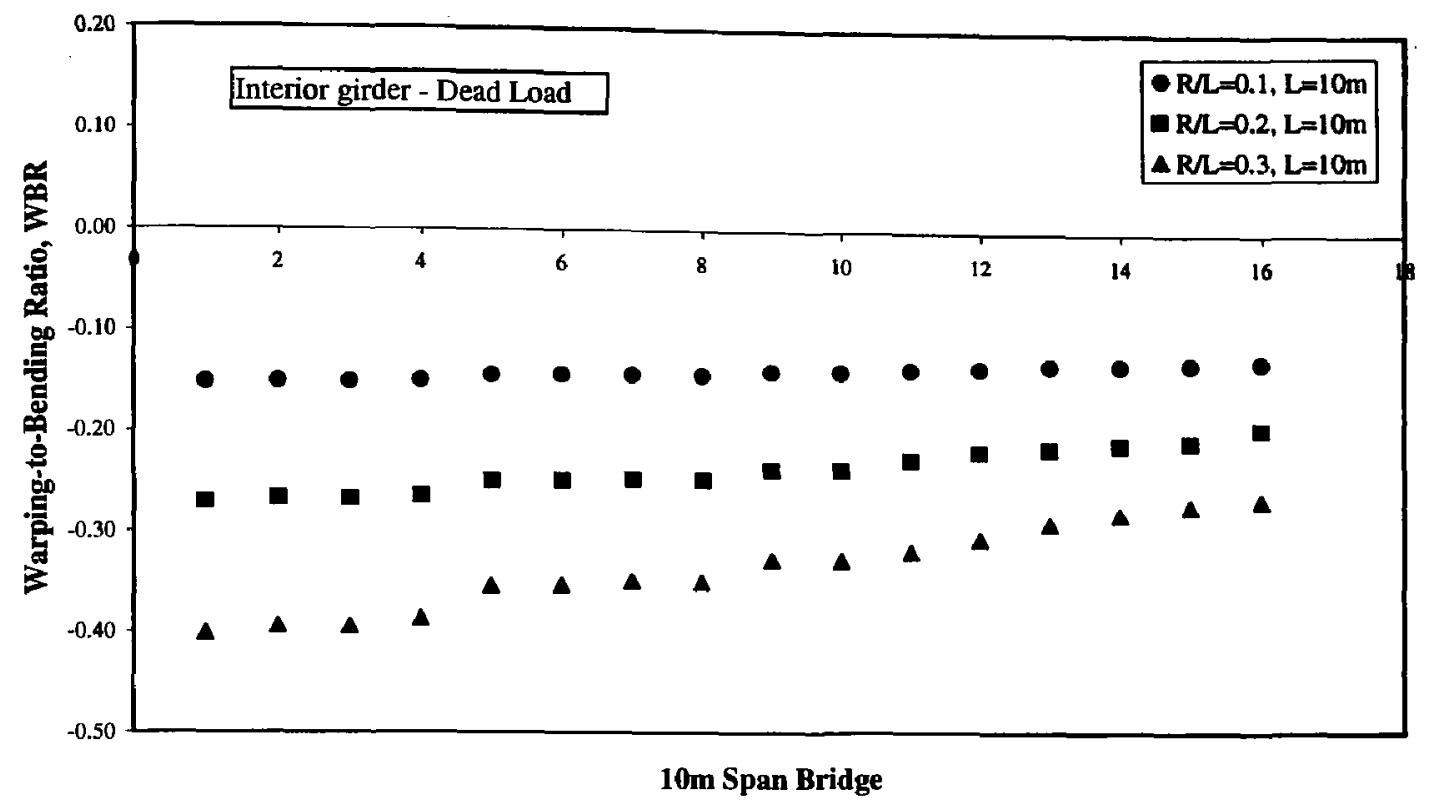

Figure 4. 152 Effect of Curvature on the Warping-to-Bending ratio for the Interior Girder due to Dead Load

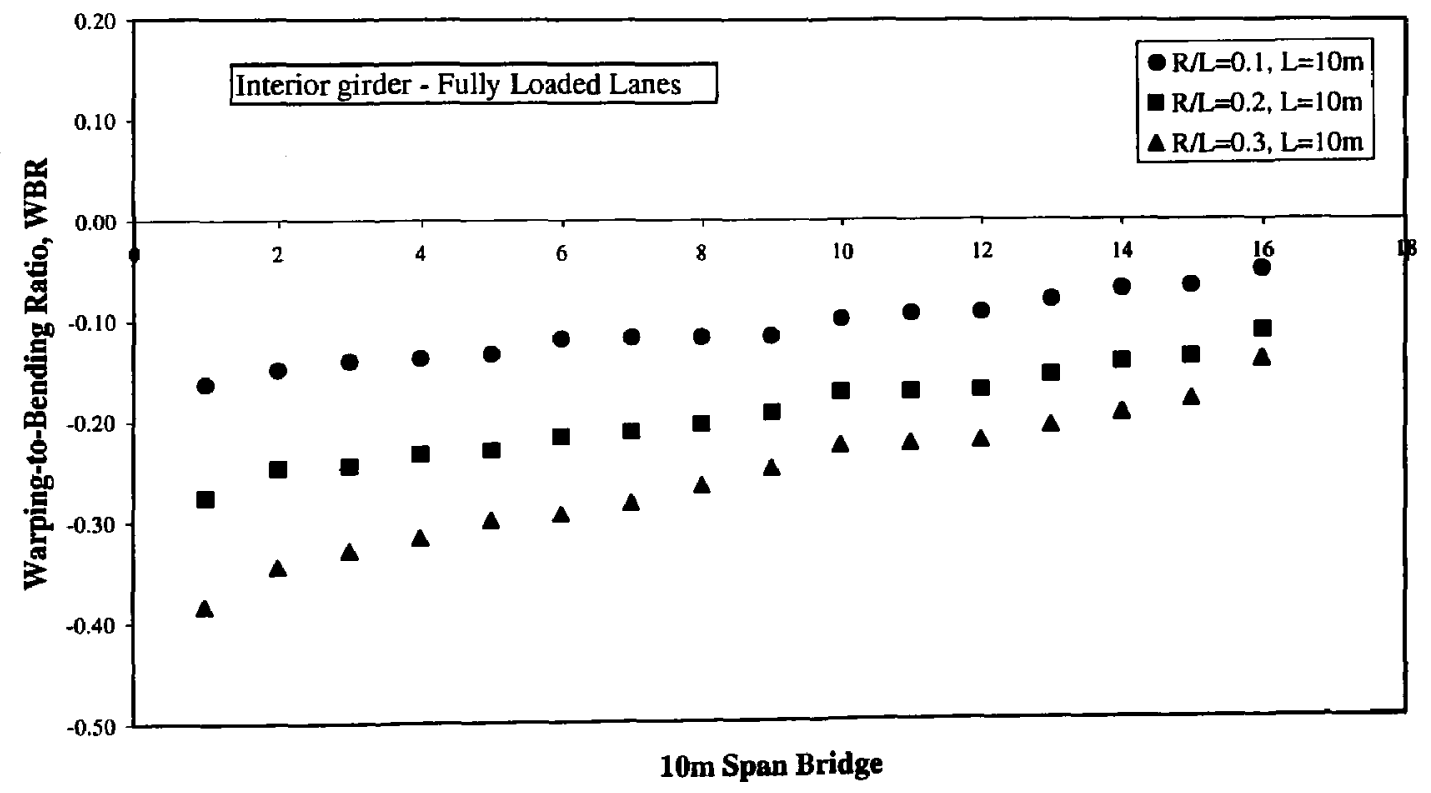

Figure 4. 153 Effect of Curvature on the Warping-to-Bending ratio for the Interior Girder due to Fully Loaded Lanes 


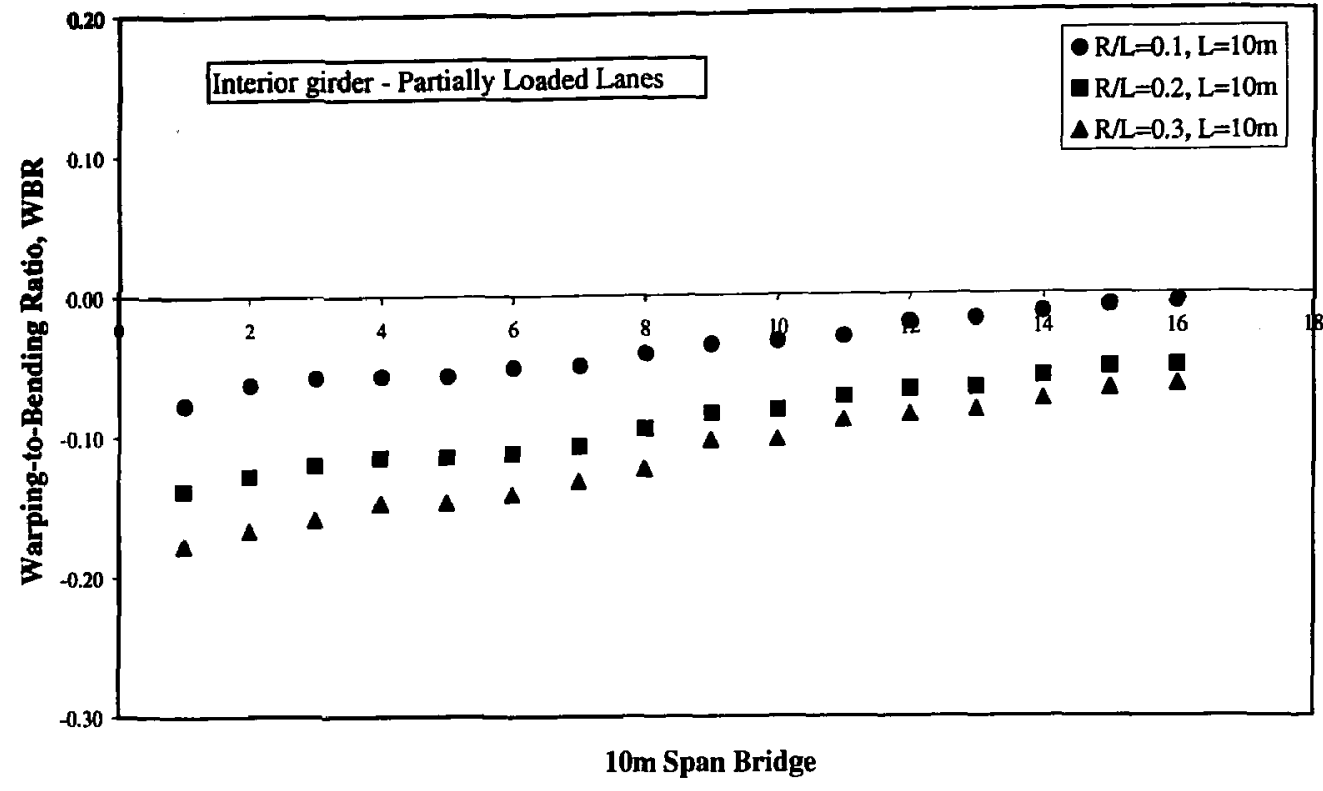

Figure 4. 154 Effect of Curvature on the Warping-to-Bending ratio for the Interior Girder due to Partially Loaded Lanes

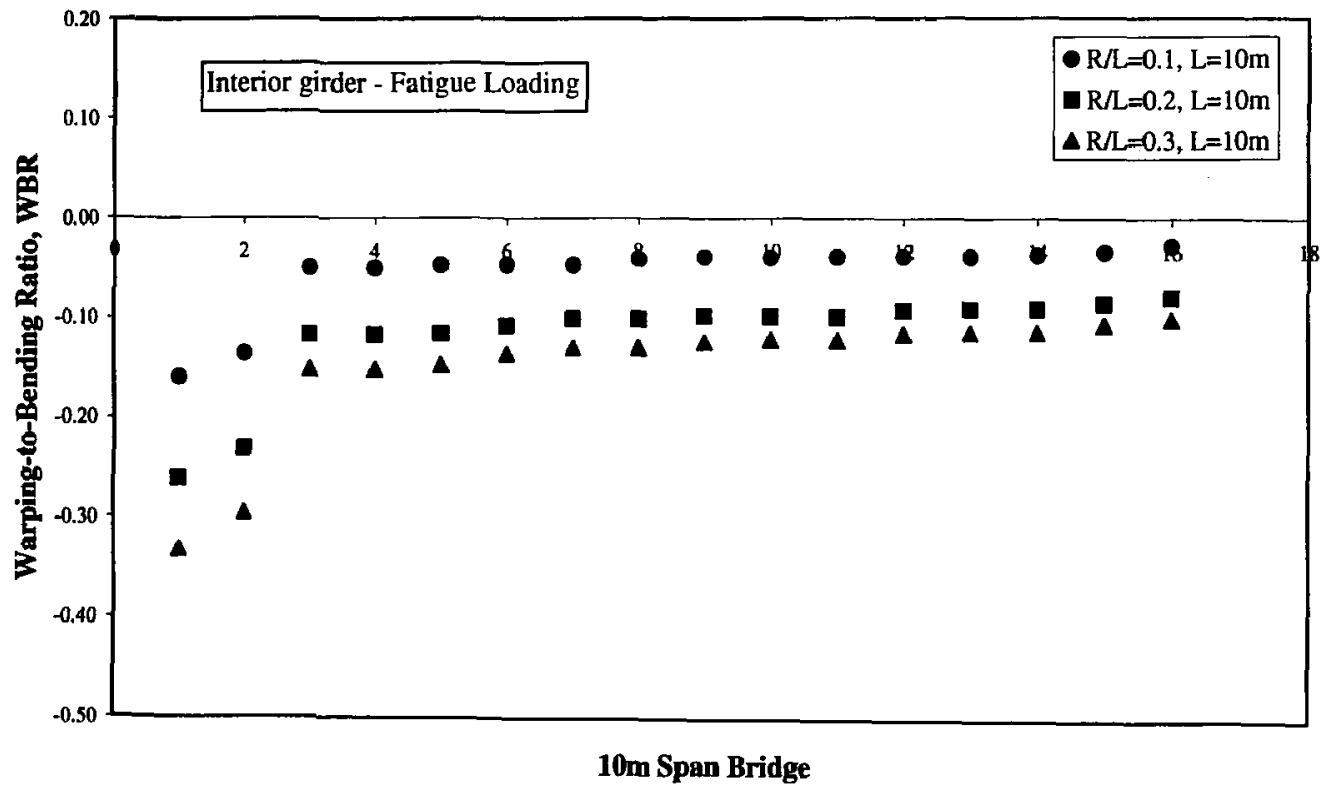

Figure 4.155 Effect of Curvature on the Warping-to-Bending ratio for the Interior Girder due to Fatigue Loading 


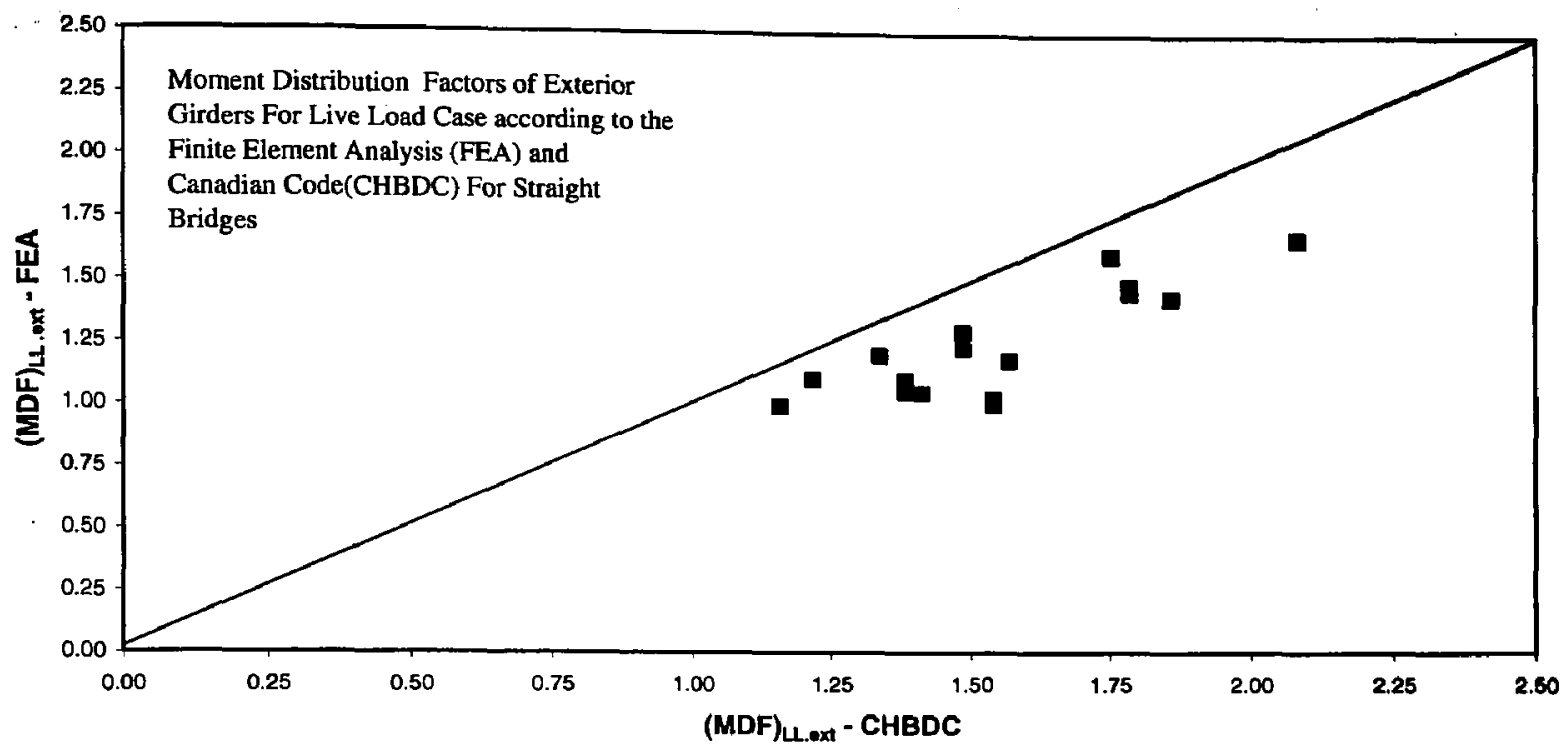

Figure 4. 156 Comparison between the Moment Distribution Factors of the Exterior Girder due to Truck Loading as Specified in the CHBDC and from the Current Study

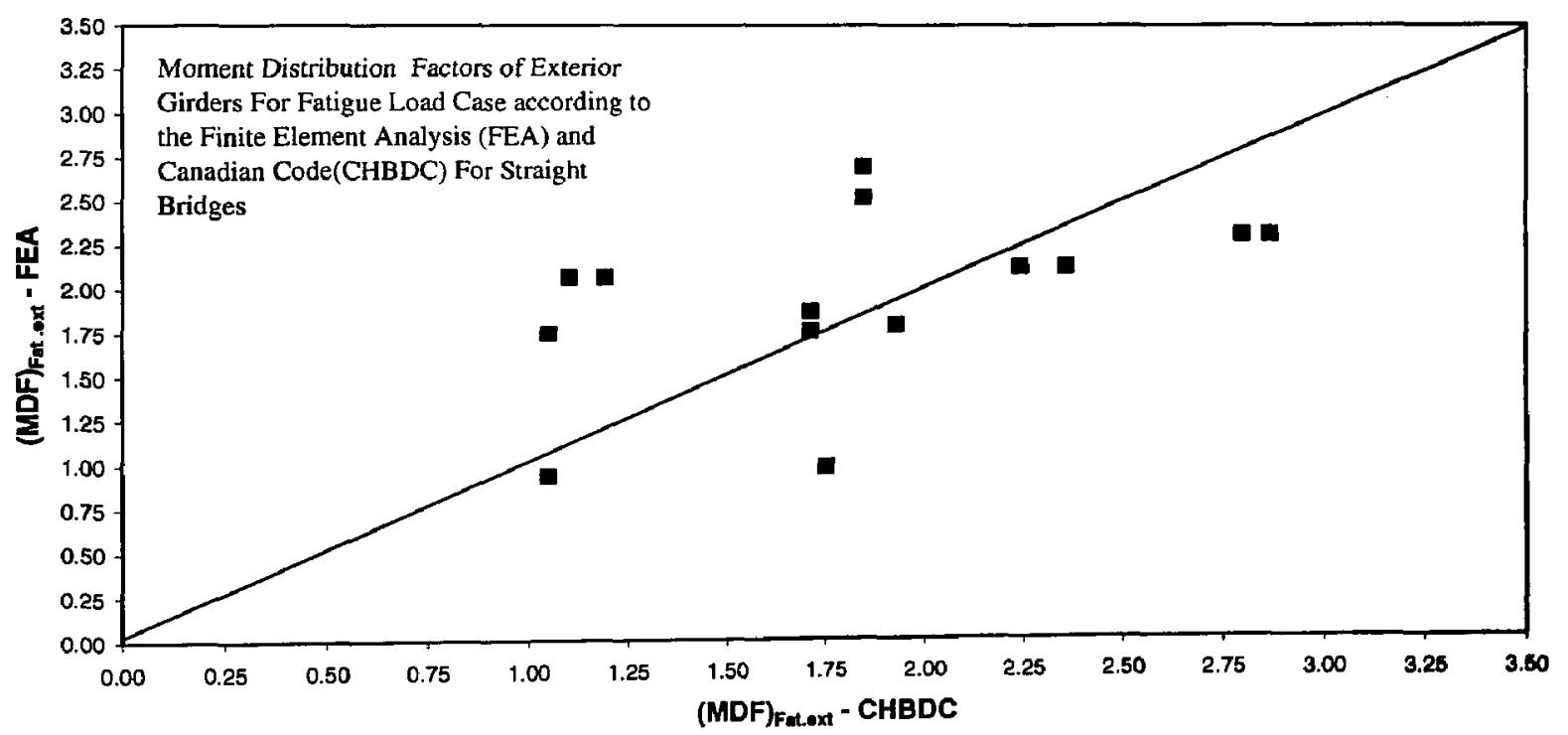

Figure 4. 157 Comparison between the Moment Distribution Factors of the Exterior Girder due to Fatigue Loading as Specified in the CHBDC and from the Current Study 


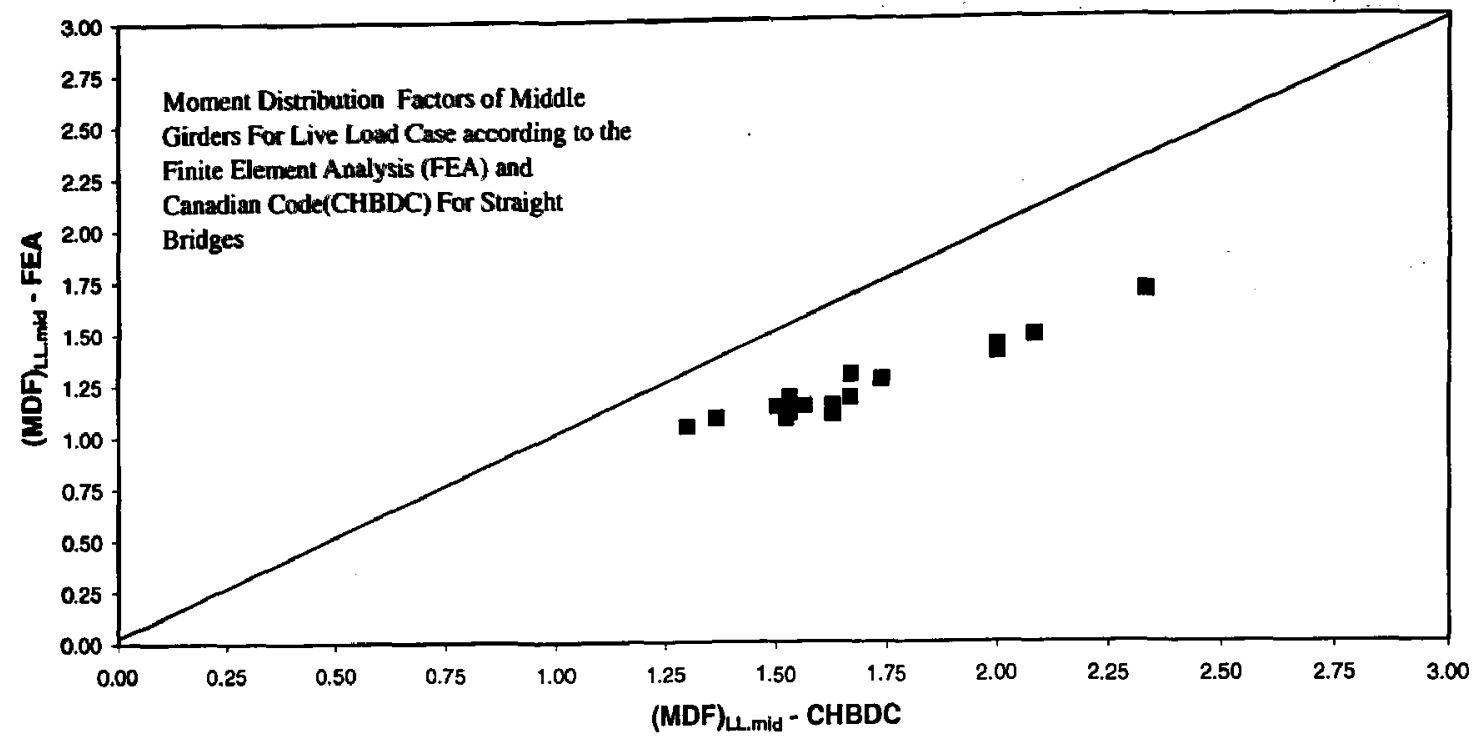

Figure 4. 158 Comparison between the Moment Distribution Factors of the Middle Girder due to Truck Loading as Specified in the CHBDC and from the Current Study

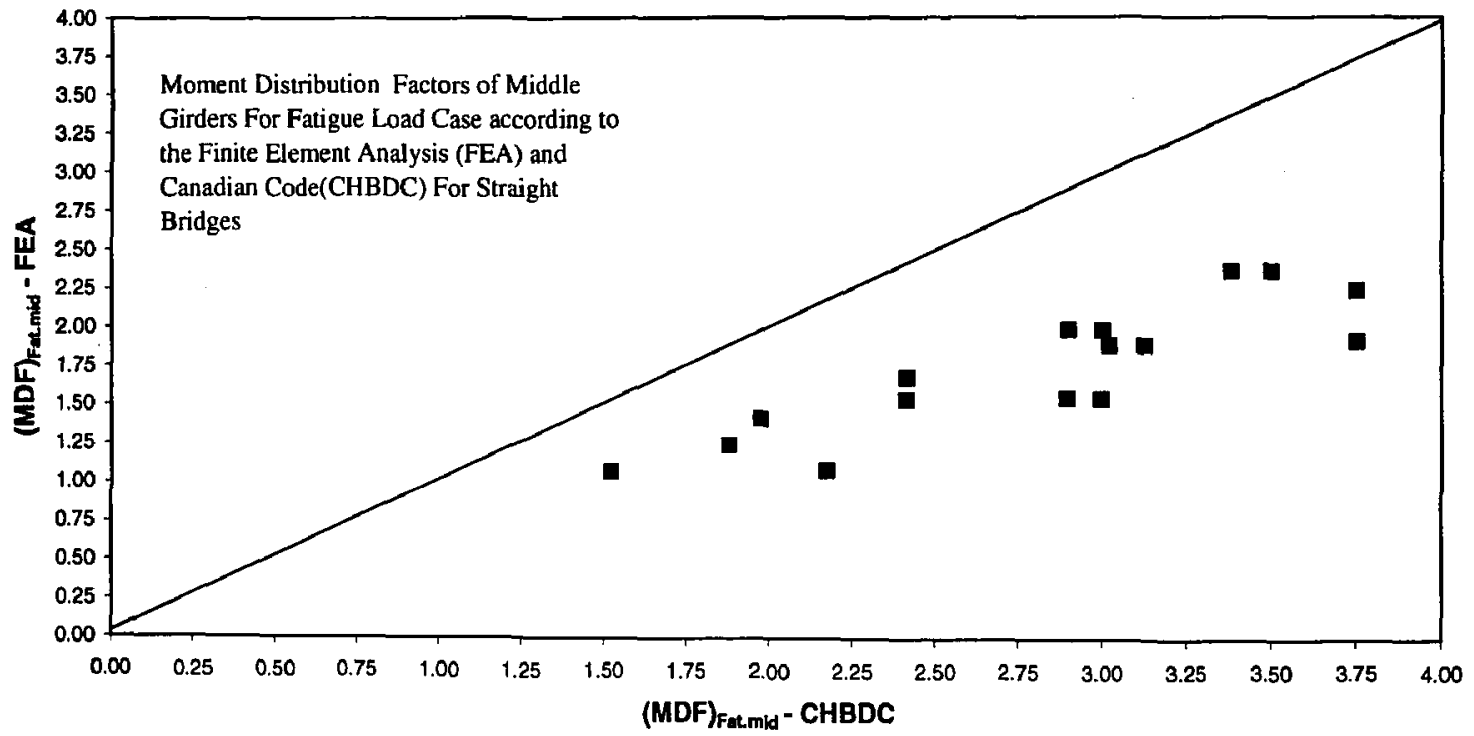

Figure 4. 159 Comparison between the Moment Distribution Factors of the Middle Girder due to Fatigue Loading as Specified in the CHBDC and from the Current Study 


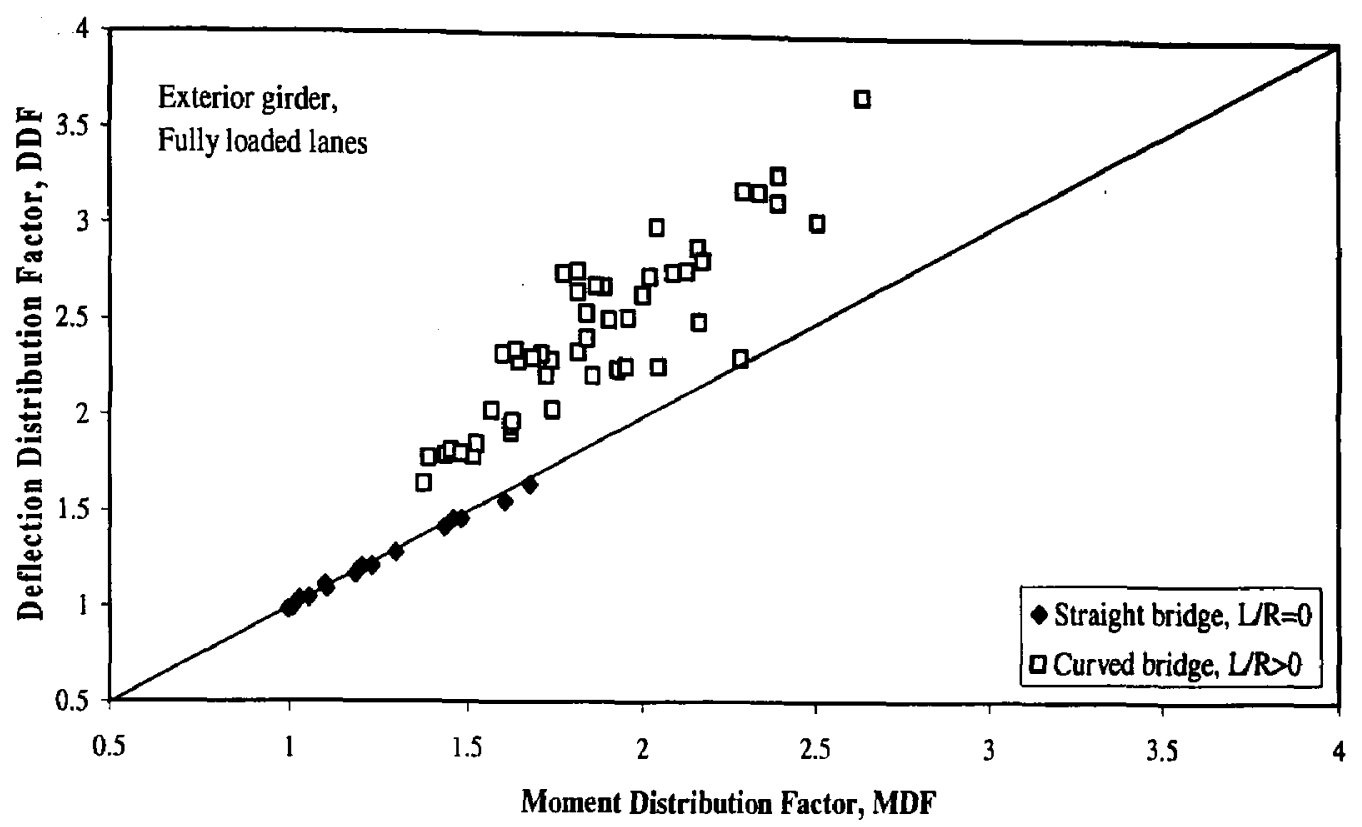

Figure 4. 160 Correlation between Moment and Deflection Distribution Factors for the Exterior Girder of the Studied bridges due to Truck Loading

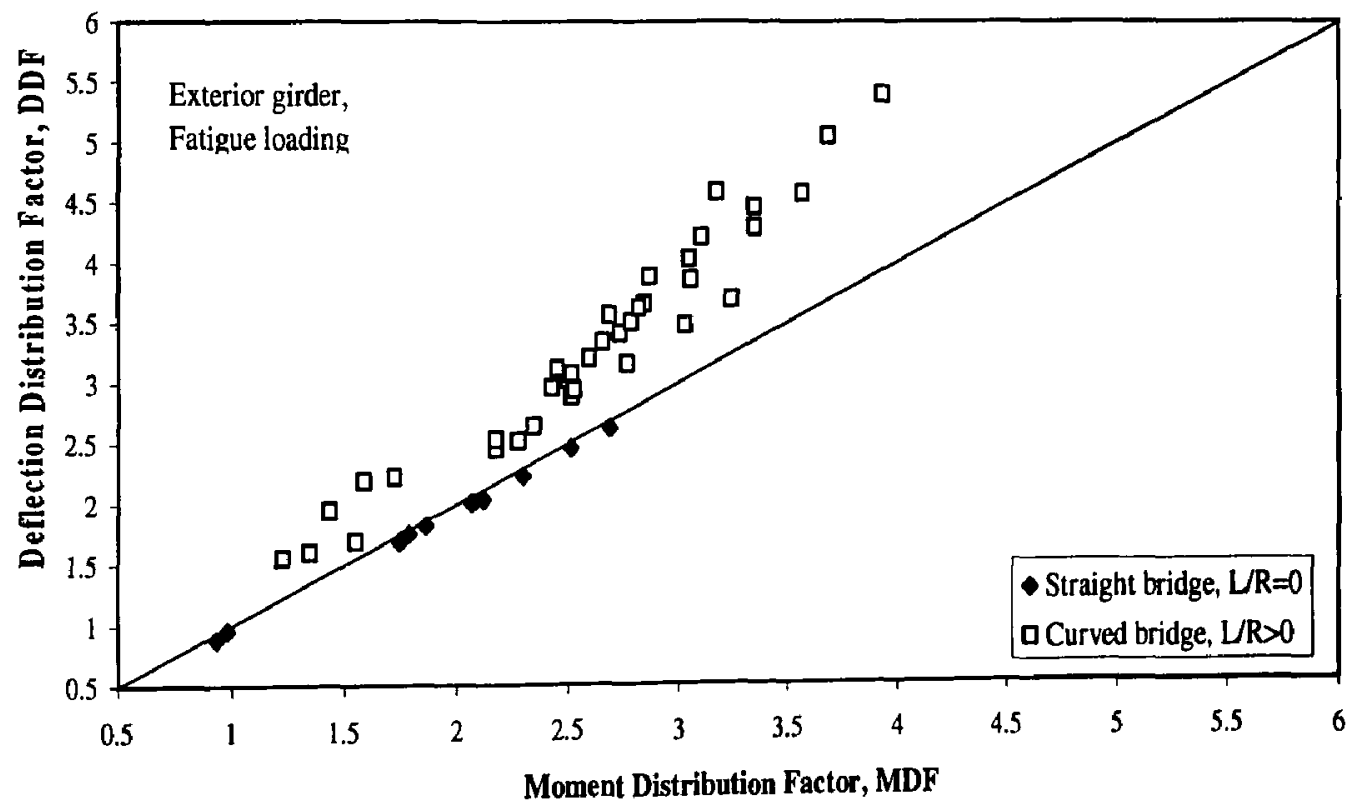

Figure 4. 161 Correlation between Moment and Deflection Distribution Factors for the Exterior Girder of the Studied bridges due to Fatigue Loading 


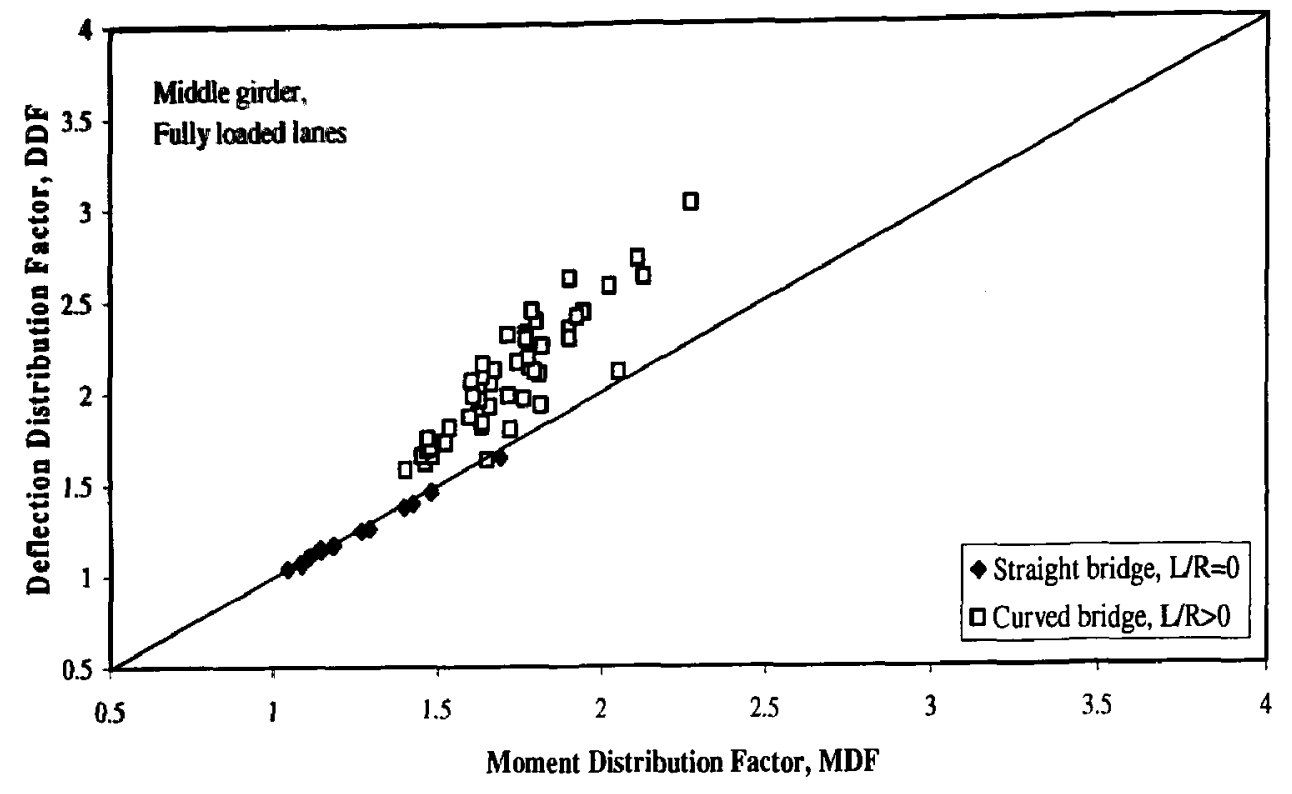

Figure 4. 162 Correlation between Moment and Deflection Distribution Factors for the Middle Girder of the Studied bridges due to Truck Loading

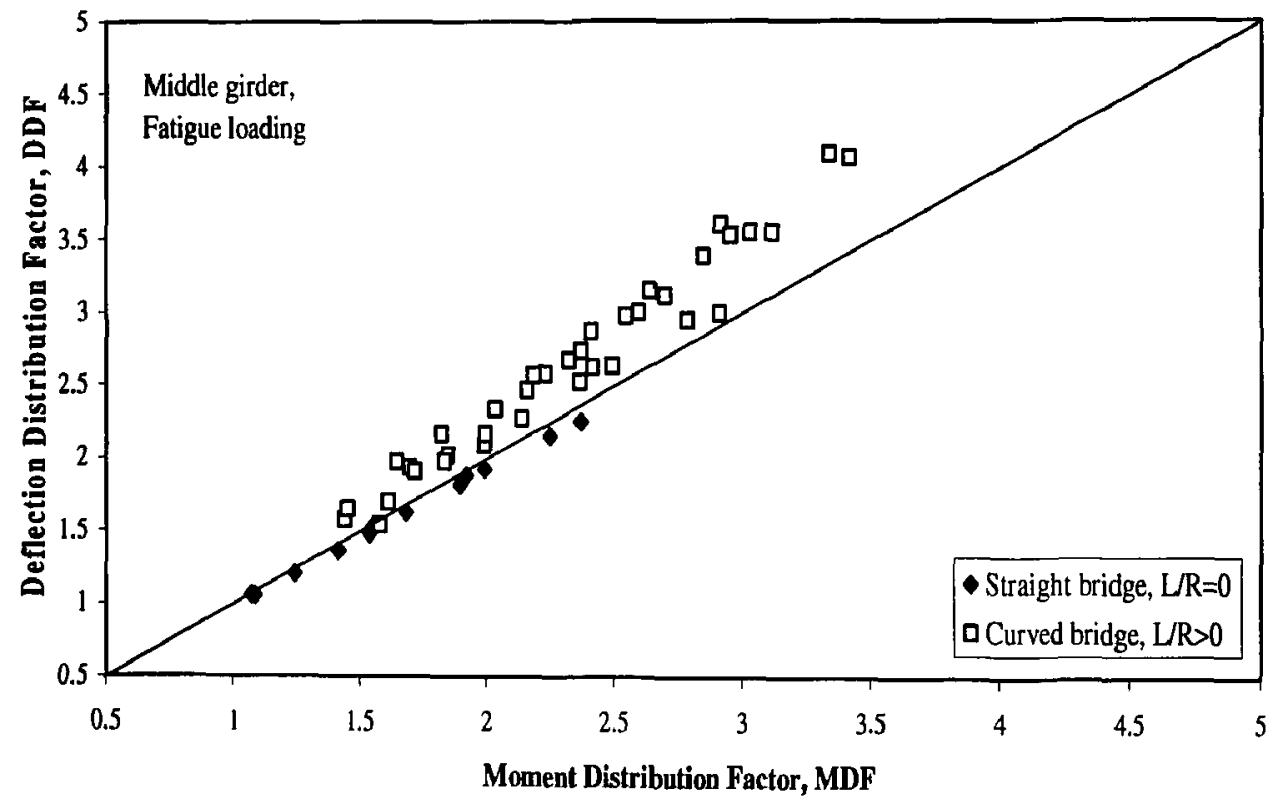

Figure 4. 163 Correlation between Moment and Deflection Distribution Factors for the Middle Girder of the Studied bridges due to Fatigue Loading 


\section{APPENDEX (A): SAP 2000 input file for a straight bridge (SDF)}




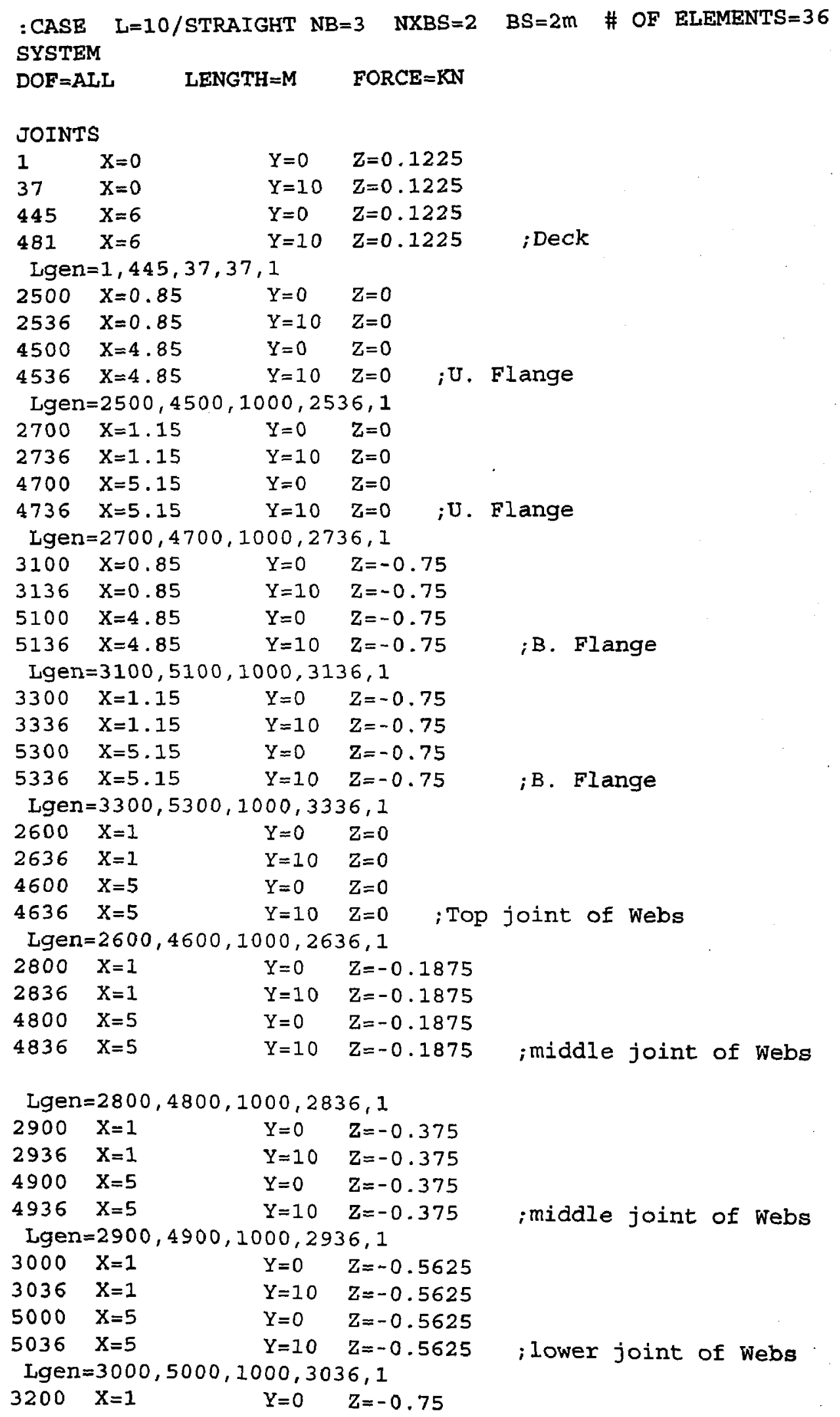




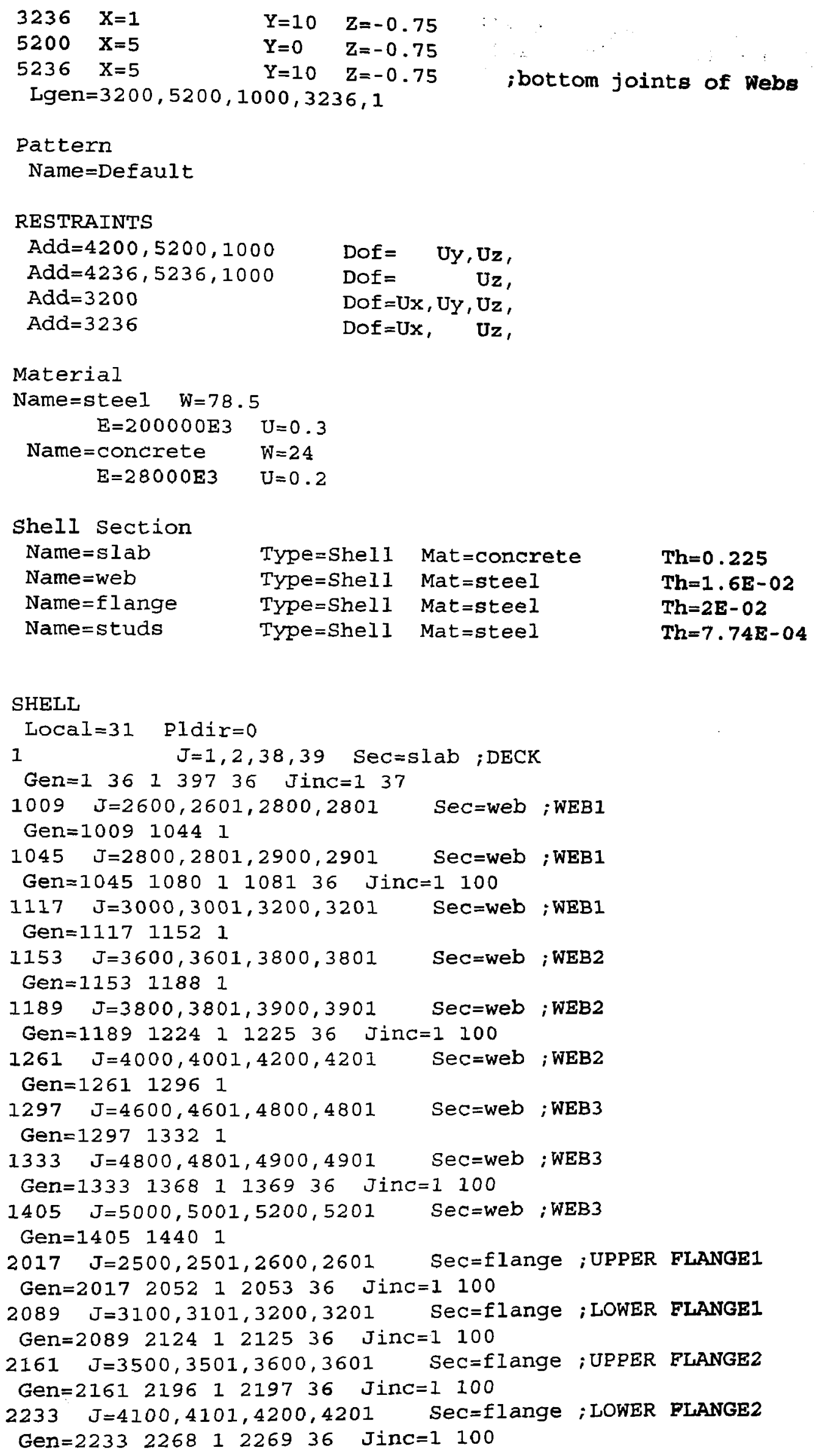


$2305 \mathrm{~J}=4500,4501,4600,4601 \quad \mathrm{SeC}=f$ lange ;UPPER FLANGE3

Gen $=2305 \quad 2340 \quad 12341 \quad 36$ Jinc $=1 \quad 100$

$2377 \mathrm{~J}=5100,5101,5200,5201 \quad \mathrm{Sec}=\mathrm{fl}$ ange ;LOWER FLANGE3

Gen $=23772412 \quad 12413 \quad 36 \quad$ Jinc $=1 \quad 100$

$3100 \mathrm{~J}=75,76,2600,2601$ Sec=studs ; studs 1

Gen $=3100 \quad 31351$

$3200 \mathrm{~J}=223,224,3600,3601$

Sec=studs ; studs 2

Gen $=320032351$

$3300 \mathrm{~J}=371,372,4600,4601 \quad$ Sec $=$ studs $;$ studs 3

Gen $=3300 \quad 3335 \quad 1$

Frame Section

Name=studs

Mat $=$ stee 1

$I=11922.9 \mathrm{E}-12 \quad \mathrm{~A}=387 \mathrm{E}-6 \quad \mathrm{AS}=387 \mathrm{E}-6$

Name $=$ dummy

Mat $=$ steel

$I=11922.9 \mathrm{E}-12 \quad \mathrm{~A}=387 \mathrm{E}-6 \quad \mathrm{AS}=387 \mathrm{E}-6$

Name=bracing

Mat $=$ steel

$I=0$

$A=7500 \mathrm{E}-6$

FRAME

Local $=13$ Pldir $=+Z+Y ;$ SAP90 default values

$1 \mathrm{~J}=2600,3600 \quad$ Sec=bracing Irel=R3,R2 Jrel=R3,R2,R1 Nseg=4 ; Xbracingl Gen $=1,9,4$ I inc $=18$ Jinc $=18$

$2 \mathrm{~J}=2600,4200 \quad$ Sec=bracing Irel=R3, R2 Jrel=R3, R2, R1, ; Xbracing1 Gen $=2,10,4 \quad$ I inc $=18 \quad \mathrm{Jinc}=18$

$3 \mathrm{~J}=3200,3600 \quad$ Sec=bracing Irel=R3, R2 Jrel=R3, R2, R1, ; Xbracing1

Gen $=3,11,4 \quad$ I inc $=18 \quad$ Jinc $=18$

$4 \mathrm{~J}=3200,4200 \quad \mathrm{Sec}=\mathrm{bracing}$ Irel=R3, R2 Jrel=R3, R2, R1, ; Xbracing1

Gen $=4,12,4$ Iinc $=18$ Jinc $=18$

$101 \mathrm{~J}=3600,4600$ Sec=bracing Irel=R3, R2 Jrel=R3, R2, R1, ; Xbracing2

Gen $=101,109,4 \quad$ Iinc $=18 \quad$ Jinc $=18$

$102 \mathrm{~J}=3600,5200 \mathrm{Sec}=\mathrm{bracing}$ Irel=R3, R2 Jrel=R3, R2, R1, ; Xbracing2

Gen $=102,110,4 \quad$ Iinc $=18 \quad \mathrm{JinC}=18$

$103 \mathrm{~J}=4200,4600$ Sec=bracing Irel=R3, R2 Jrel=R3, R2, R1, ; Xbracing2

Gen $=103,111,4 \quad$ Iinc $=18 \quad$ Jinc $=18$

$104 \mathrm{~J}=4200,5200$ Sec=bracing Irel=R3, R2 Jrel=R3, R2, R1, ; Xbracing2

Gen $=104,112,4 \quad$ Iinc $=18 \quad$ Jinc $=18$

$1300 \mathrm{~J}=75,76 \mathrm{Sec}=$ dummy ; dummy

Gen $=1300,1335,1 \quad$ Iinc=1 Jinc $=1$

$1400 \mathrm{~J}=112,113 \mathrm{Sec}=$ dummy ; dummy

Gen $=1400,1435,1 \quad$ Iinc $=1$ Jinc $=1$

$1500 \mathrm{~J}=149,150$ Sec=dummy ; dummy

Gen $=1500,1535,1$ Iinc $=1$ Jinc $=1$

$1600 \mathrm{~J}=186,187$ Sec=dummy ; dummy

Gen $=1600,1635,1$ Iinc $=1$ Jinc $=1$

$1700 \mathrm{~J}=223,224 \mathrm{Sec}=$ dummy ; dummy

Gen $=1700,1735,1$ I inc $=1$ Jinc $=1$

$1800 \mathrm{~J}=260,261$ Sec=dummy ; dummy

Gen $=1800,1835,1$ Iinc=1 Jinc $=1$

$1900 \mathrm{~J}=297,298$ Sec=dummy ; dummy

Gen $=1900,1935,1 \quad$ Iinc $=1$ Jinc $=1$

$2000 \mathrm{~J}=334,335$ Sec=dummy ; dummy

Gen $=2000,2035,1 \quad$ Iinc $=1$ Jinc $=1$

$2100 \mathrm{~J}=371,372$ Sec=dummy ; dummy

Gen $=2100,2135,1$ I inc $=1$ Jinc $=1$

Load

Name $=$ ow

Type $=$ Gravity $\quad$ Elem $=$ Frame 
Add $=$ * $U z=-1$,

Type=Gravity Elem=Shell

Add $=$ * $U z=-1$

; EXTERIOR GIRDER

; 1 lanes, 1truck

NAME $=E X T 1 L 1 T$

$\mathrm{ADD}=1702$

$\mathrm{ADD}=1706$

$\mathrm{ADD}=1730$

TYPE $=$ CONCENTRATED CSYS $=0$

$\begin{array}{ll}\mathrm{D}=0.044 & \mathrm{UZ}=-125.0 / 2 \\ \mathrm{D}=0.133 & \mathrm{UZ}=-125.0 / 2 \\ \mathrm{D}=0.066 & \mathrm{UZ}=-175.0 / 2\end{array}$

$R X=-125.0 / 2 *-0.10$

$R X=-125.0 / 2 *-0.10$

$\mathrm{RX}=-175.0 / 2 *-0.10$

$\mathrm{ADD}=2102$

$A D D=2106$

$\mathrm{D}=0.044$

$\mathrm{UZ}=-125.0 / 2$

$\mathrm{D}=0.133$

$\mathrm{UZ}=-125.0 / 2$

$\mathrm{ADD}=2130$

$\mathrm{D}=0.066$

$\mathrm{UZ}=-175.0 / 2$

$\mathrm{RX}=-125.0 / 2 * 0.10$

$\mathrm{RX}=-125.0 / 2 * 0.10$

$\mathrm{RX}=-175.0 / 2 * 0.10$

\section{; MIDDLE GIRDER}

; 1lanes

NAME $=M I D+f a t$

$\mathrm{ADD}=1502$

$\mathrm{ADD}=1506$

TYPE $=$ CONCENTRATED CSYS $=0$

$\mathrm{D}=0.044 \quad \mathrm{UZ}=-125.0 / 2$

$\mathrm{D}=0.133 \quad \mathrm{UZ}=-125.0 / 2$

$\mathrm{ADD}=1530$

$\mathrm{D}=0.066$

$\mathrm{UZ}=-175.0 / 2$

$A D D=1902$

$\mathrm{D}=0.044$

$\mathrm{D}=0.133$

$\mathrm{UZ}=-125 \cdot 0 / 2$

$A D D=1906$

$\mathrm{D}=0.066$

$\mathrm{UZ}=-125.0 / 2$

$\mathrm{UZ}=-175.0 / 2$

$\mathrm{RX}=-125.0 / 2 *-0.10$

$R X=-125.0 / 2 *-0.10$

$R X=-175.0 / 2 *-0.10$

$\mathrm{RX}=-125.0 / 2 * 0.10$

$\mathrm{RX}=-125.0 / 2 * 0.10$

$R X=-175.0 / 2 * 0.10$

INTERIOR GIRDER

; 1 lanes

NAME $=$ INT 1 I $1 \mathrm{~T}$

TYPE=CONCENTRATED CSYS $=0$

$A D D=1302$

$\mathrm{D}=0.044$

$\mathrm{UZ}=-125.0 / 2$

$\mathrm{D}=0.133$

$\mathrm{UZ}=-125.0 / 2$

$A D D=1306$

$\mathrm{D}=0.066$

$\mathrm{UZ}=-175.0 / 2$

$R X=-125.0 / 2 *-0.10$

$\mathrm{RX}=-125.0 / 2 *-0.10$

$R X=-175.0 / 2 *-0.10$

$\mathrm{ADD}=1702$

$\mathrm{D}=0.044$

$\mathrm{UZ}=-125 \cdot 0 / 2$

$\mathrm{UZ}=-125.0 / 2$

$\mathrm{RX}=-125 \cdot 0 / 2 * 0.10$

$\mathrm{D}=0.133$

$\mathrm{UZ}=-175.0 / 2$

$R X=-125.0 / 2 * 0.10$

$\mathrm{RX}=-175.0 / 2 * 0.10$

Output

ELEM=JOINT TYPE=DISP, REAC LOAD $=$ *

ELEM=SHELL TYPE=FORCE LOAD = *

ELEM=SHELL TYPE=STRESS LOAD $=$ *

ELEM=FRAME TYPE=JOINTF LOAD $=$ *

END 


\section{APPENDEX (B): SAP 2000 input file for a curved bridge (SDF)}




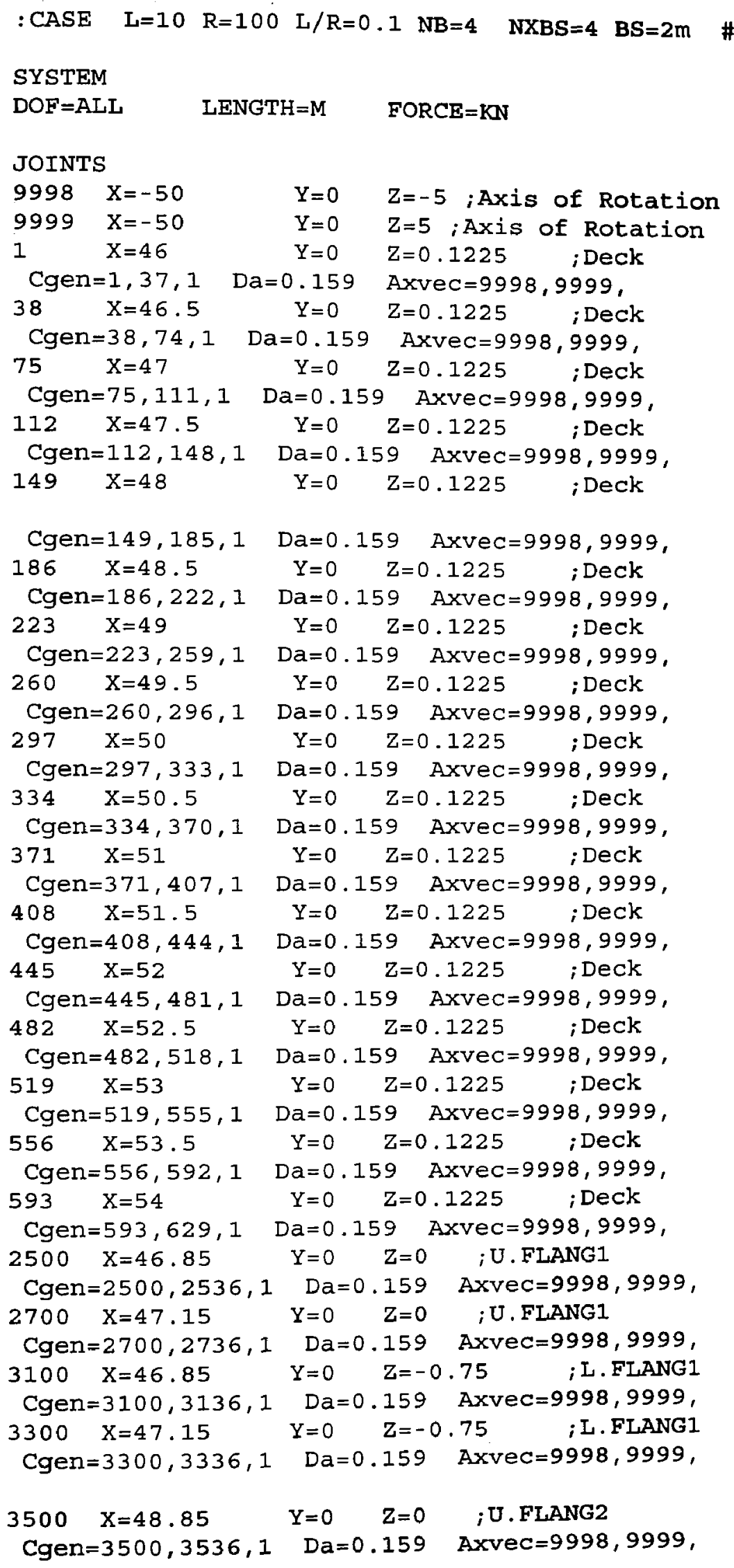




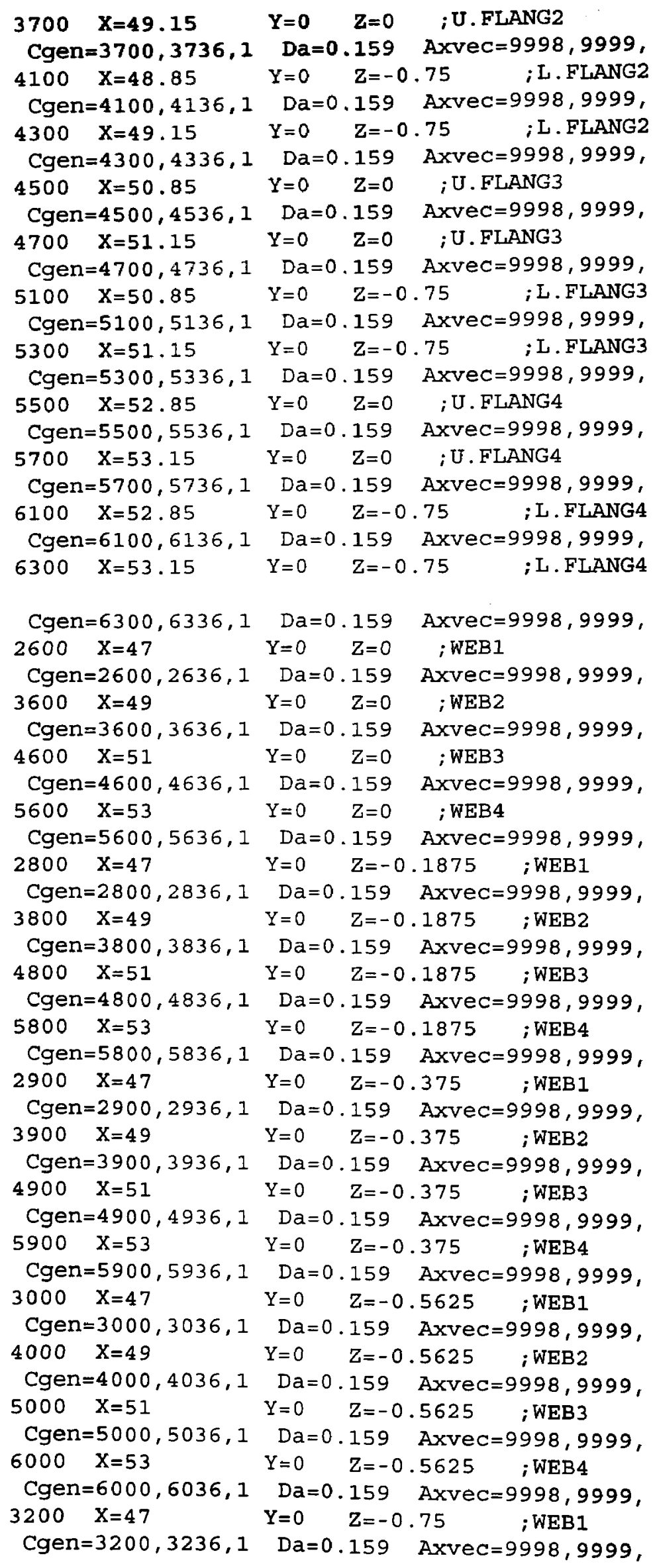




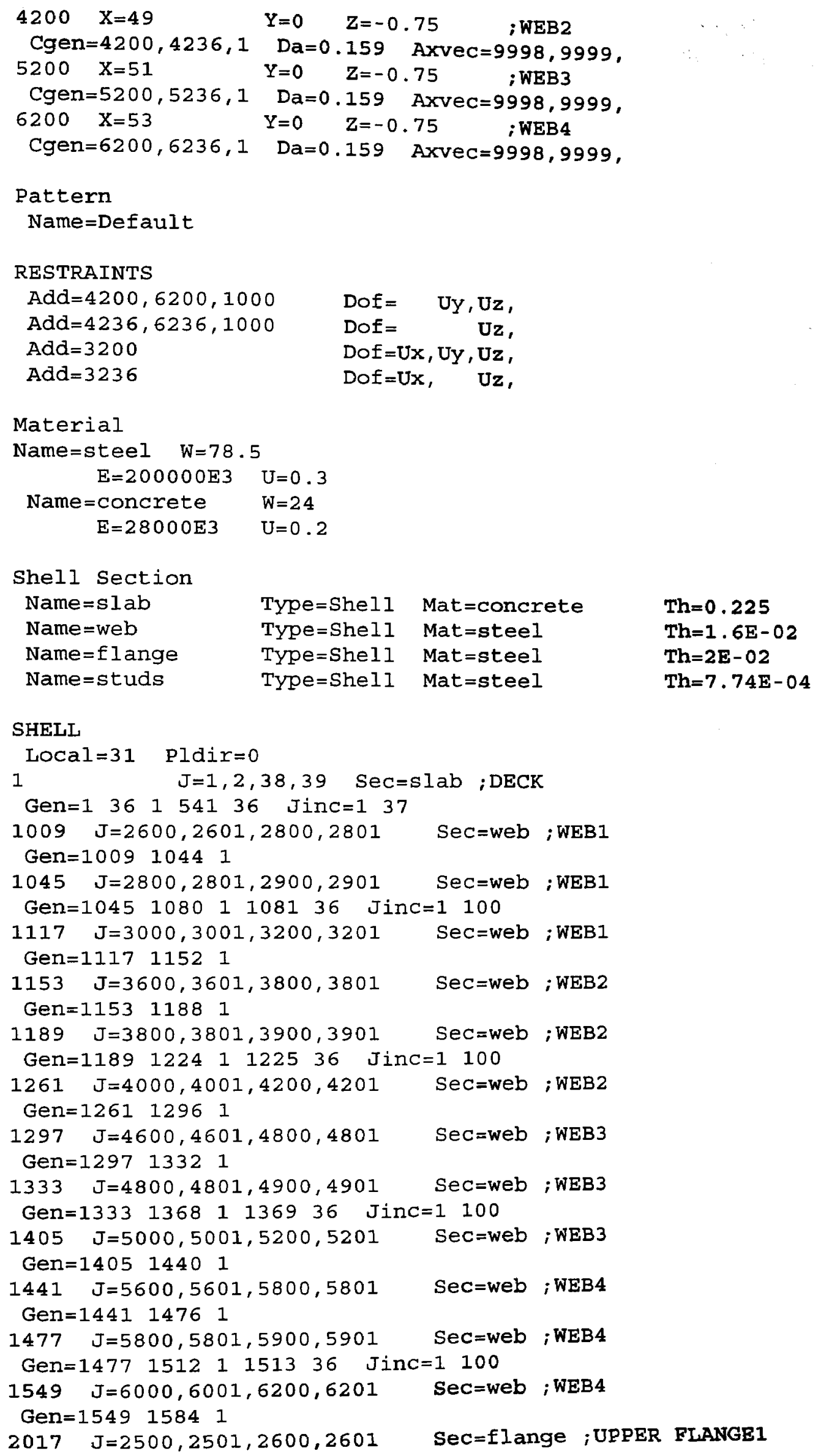




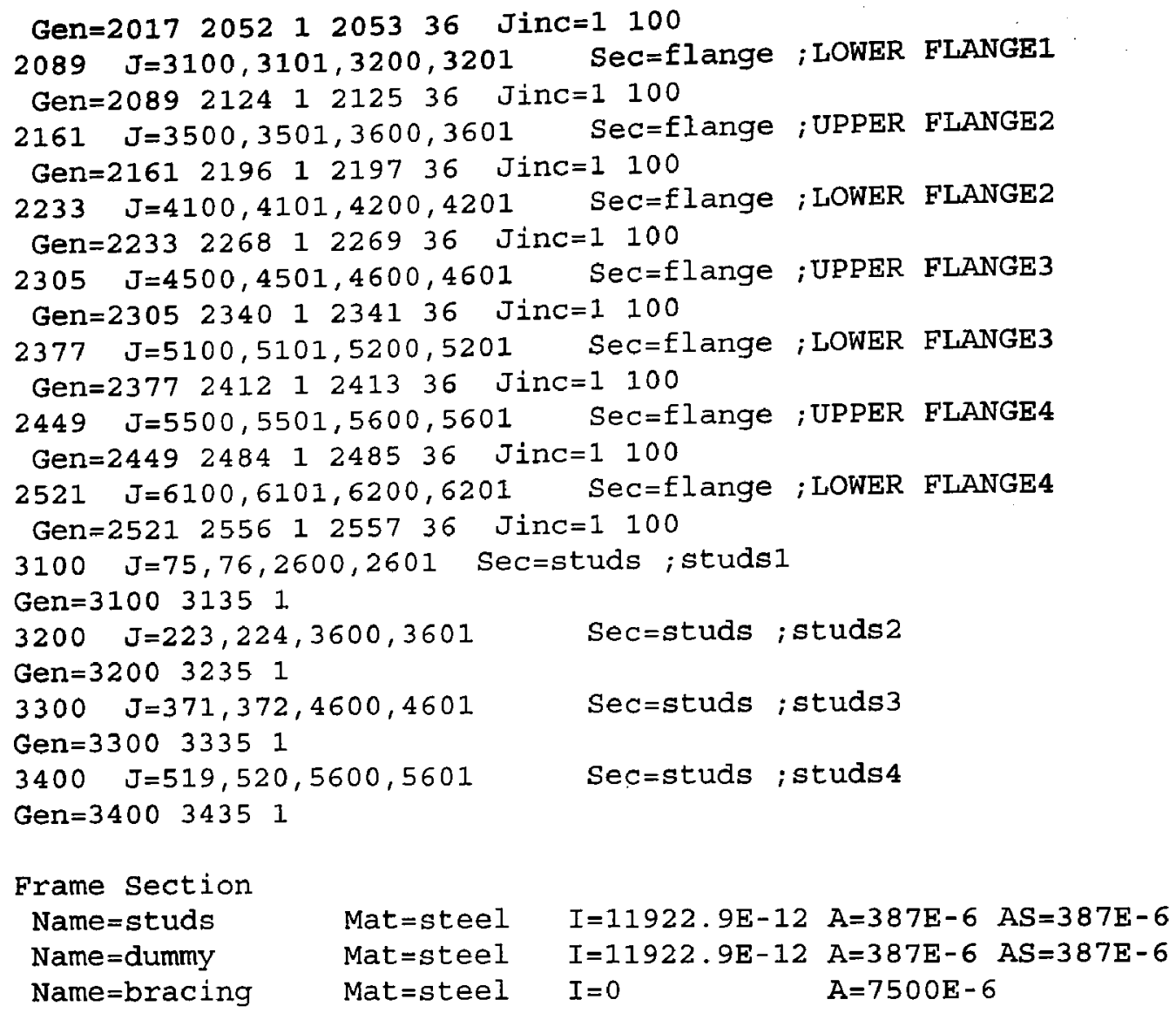

FRAME

Local $=13$ Pldir $=+Z+Y ;$ SAp90 default values

$1 \mathrm{~J}=2600,3600 \quad \mathrm{Sec}=\mathrm{bracing}$ Irel=R3, R2 Jrel=R3,R2,R1 Nseg=4 ;Xbracing1 Gen $=1,17,4$ I inc $=9$ Jinc $=9$

$2 \mathrm{~J}=2600,4200 \quad$ Sec=bracing Irel=R3, R2 Jrel=R3, R2, R1, ; Xbracing1 Gen $=2,18,4 \quad$ I inc $=9 \quad$ Jinc $=9$

$3 \mathrm{~J}=3200,3600 \quad$ Sec=bracing Irel=R3, R2 Jrel=R3, R2, R1, ; Xbracing1 Gen $=3,19,4 \quad$ I inc $=9$ Jinc $=9$

$4 \mathrm{~J}=3200,4200 \quad$ Sec=bracing Irel=R3, R2 Jrel=R3, R2, R1, ; Xbracing1 Gen $=4,20,4 \quad$ Iinc $=9 \quad$ Jinc $=9$

$101 \mathrm{~J}=3600,4600$ Sec=bracing Irel=R3, R2 Jrel=R3, R2, R1, ; Xbracing2 Gen $=101,117,4 \quad$ Iinc $=9 \quad$ Jinc $=9$

$102 \mathrm{~J}=3600,5200$ Sec=bracing Irel=R3, R2 Jrel=R3, R2, R1, ; Xbracing2 Gen $=102,118,4$ Iinc $=9$ Jinc $=9$

$103 \mathrm{~J}=4200,4600$ Sec=bracing Irel=R3, R2 Jrel=R3, R2, R1, ; Xbracing2 Gen $=103,119,4$ Iinc $=9$ Jinc $=9$

$104 \mathrm{~J}=4200,5200$ Sec=bracing Irel=R3, R2 Jrel=R3, R2, R1, ; Xbracing2 Gen $=104,120,4$ Iinc $=9$ Jinc $=9$

$201 \mathrm{~J}=4600,5600$ Sec=bracing Irel=R3, R2 Jrel=R3, R2, R1, ; Xbracing3 Gen $=201,217,4$ Iinc $=9$ Jinc $=9$

$202 \mathrm{~J}=4600,6200 \mathrm{Sec}=\mathrm{bracing}$ Irel=R3, R2 Jrel=R3, R2, R1, ; Xbracing3

Gen $=202,218,4 \quad$ Iinc $=9 \quad$ Jinc $=9$

$203 \mathrm{~J}=5200,5600$ Sec=bracing Irel=R3, R2 Jrel=R3, R2, R1, ; Xbracing3 Gen $=203,219,4$ Iinc=9 Jinc $=9$

$204 \mathrm{~J}=5200,6200$ Sec=bracing Irel=R3, R2 Jrel=R3, R2, R1, ; Xbracing3 


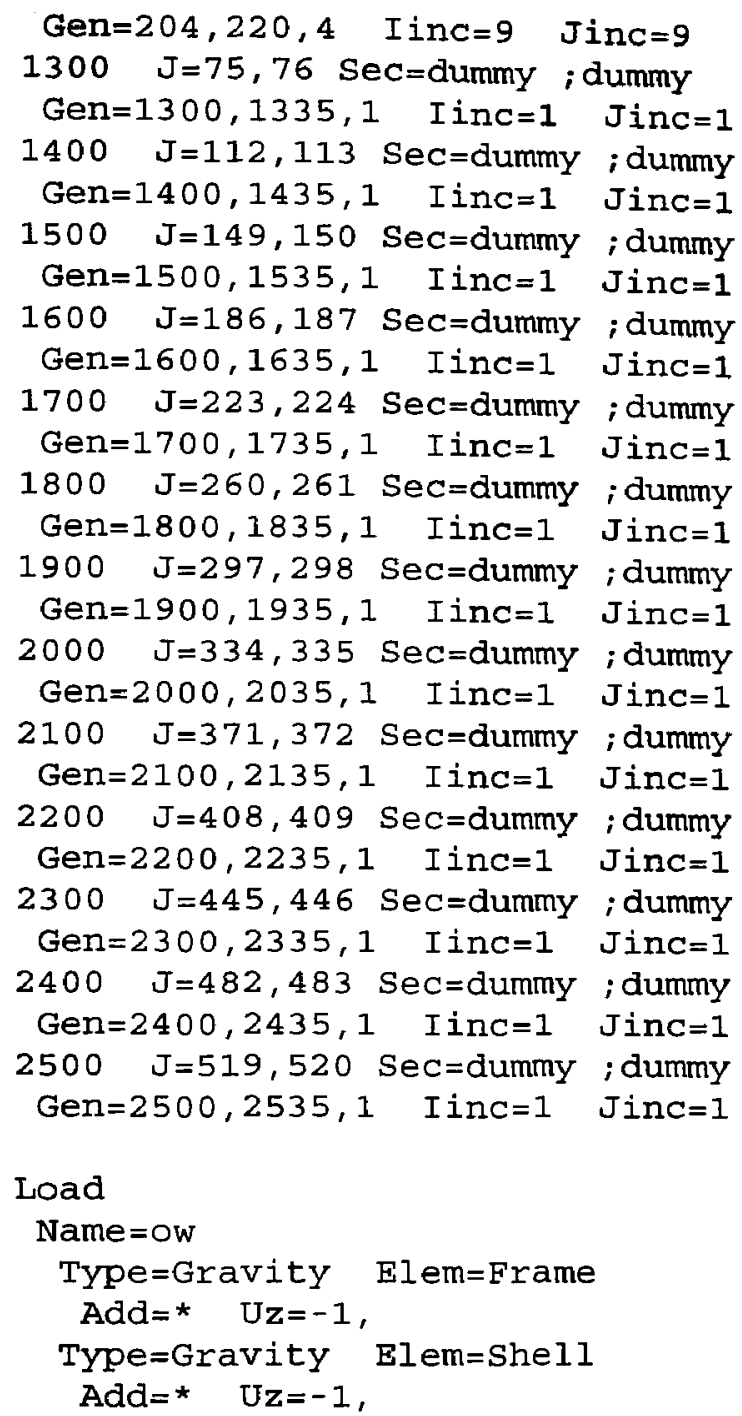

\section{; 2 Ianes, 1 truck
NAME=EXT2L1T \\ ; 2 lanes, 1 truck
NAME=EXT2L1T}

$\begin{array}{lll}\mathrm{TYPE}=\mathrm{CONCENTRATED} & \text { CSYS }=0 & \\ \mathrm{D}=0.044 & \mathrm{UZ}=-125.0 / 2 & \mathrm{RX}=-125.0 / 2 *-0.10 \\ \mathrm{D}=0.133 & \mathrm{UZ}=-125.0 / 2 & \mathrm{RX}=-125.0 / 2 *-0.10 \\ \mathrm{D}=0.066 & \mathrm{UZ}=-175.0 / 2 & \mathrm{RX}=-175.0 / 2 *-0.10 \\ \mathrm{D}=0.044 & \mathrm{UZ}=-125.0 / 2 & \mathrm{RX}=-125.0 / 2 * 0.10 \\ \mathrm{D}=0.133 & \mathrm{UZ}=-125.0 / 2 & \mathrm{RX}=-125.0 / 2 * 0.10 \\ \mathrm{D}=0.066 & \mathrm{UZ}=-175.0 / 2 & \mathrm{RX}=-175.0 / 2 * 0.10 \\ \mathrm{D}=0.044 & \mathrm{UZ}=-125.0 / 2 & \mathrm{RX}=-125.0 / 2 *-0.10 \\ \mathrm{D}=0.133 & \mathrm{UZ}=-125.0 / 2 & \mathrm{RX}=-125.0 / 2 *-0.10 \\ \mathrm{D}=0.066 & \mathrm{UZ}=-175.0 / 2 & \mathrm{RX}=-175.0 / 2 *-0.10 \\ & & \\ D=0.044 & \mathrm{UZ}=-125.0 / 2 & \mathrm{RX}=-125.0 / 2 * 0.10 \\ D=0.133 & \mathrm{UZ}=-125.0 / 2 & \mathrm{RX}=-125.0 / 2 * 0.10 \\ D=0.066 & \mathrm{UZ}=-175.0 / 2 & \mathrm{RX}=-175.0 / 2 * 0.10\end{array}$

\section{.}




\section{$\mathrm{ADD}=2102$ \\ $\mathrm{ADD}=2106$ \\ $\mathrm{ADD}=2130$ \\ $A D D=2502$ \\ $\mathrm{ADD}=2506$ \\ $A D D=2530$ \\ ; MIDDIE GIRDER \\ ; 2lanes \\ NAME $=M I D 2 L$ \\ $A D D=1402$ \\ $A D D=1406$ \\ $A D D=1430$ \\ $\mathrm{ADD}=1802$ \\ $\mathrm{ADD}=1806$ \\ $\mathrm{ADD}=1830$ \\ $\mathrm{ADD}=\mathbf{2 0 0 2}$ \\ $\mathrm{ADD}=\mathbf{2 0 0 6}$ \\ $A D D=2030$ \\ $\mathrm{ADD}=2402$ \\ $A D D=2406$ \\ $\mathrm{ADD}=2430$}

; INTERIOR GIRDER

; 2 lanes, 2 trucks NAME $=I N T 2 L 2 T$

$\mathrm{ADD}=1302$

$\mathrm{ADD}=1306$

$\mathrm{ADD}=1330$

$\mathrm{ADD}=1702$

$\mathrm{ADD}=1706$

$\mathrm{ADD}=1730$

$\mathrm{ADD}=2002$

$A D D=2006$

$A D D=2030$

$\mathrm{ADD}=2402$

$A D D=2406$

$\mathrm{ADD}=2430$

; INTERIOR GIRDER

; 2 lanes, 1truck

NAME=INT2L $1 \mathrm{~T}$

$\mathrm{ADD}=1302$

$\mathrm{ADD}=1306$

$\mathrm{ADD}=1330$

$A D D=1702$

$\mathrm{ADD}=1706$

$\begin{array}{ll}D=0.044 & \mathrm{UZ}=-125.0 / 2 \\ D=0.133 & \mathrm{UZ}=-125.0 / 2 \\ \mathrm{D}=0.066 & \mathrm{UZ}=-175.0 / 2 \\ \mathrm{D}=0.044 & \mathrm{UZ}=-125.0 / 2 \\ \mathrm{D}=0.133 & \mathrm{UZ}=-125.0 / 2 \\ D=0.066 & \mathrm{UZ}=-175.0 / 2\end{array}$

$D=0.066$

TYPE $=$ CONCENTRATED CSYS $=0$

$\begin{array}{lll}D=0.044 & \mathrm{UZ}=-125.0 / 2 & \mathrm{RX}=-125.0 / 2 *-0.10 \\ \mathrm{D}=0.133 & \mathrm{UZ}=-125.0 / 2 & \mathrm{RX}=-125.0 / 2 *-0.10 \\ \mathrm{D}=0.066 & \mathrm{UZ}=-175.0 / 2 & \mathrm{RX}=-175.0 / 2 *-0.10 \\ \mathrm{D}=0.044 & \mathrm{UZ}=-125.0 / 2 & \mathrm{RX}=-125.0 / 2 * 0.10 \\ \mathrm{D}=0.133 & \mathrm{UZ}=-125.0 / 2 & \mathrm{RX}=-125.0 / 2 * 0.10 \\ \mathrm{D}=0.066 & \mathrm{UZ}=-175.0 / 2 & \mathrm{RX}=-175.0 / 2 * 0.10 \\ & & \\ D=0.044 & \mathrm{UZ}=-125.0 / 2 & \mathrm{RX}=-125.0 / 2 *-0.10 \\ D=0.133 & \mathrm{UZ}=-125.0 / 2 & \mathrm{RX}=-125.0 / 2 *-0.10 \\ D=0.066 & \mathrm{UZ}=-175.0 / 2 & \mathrm{RX}=-175.0 / 2 *-0.10 \\ & & \\ D=0.044 & \mathrm{UZ}=-125.0 / 2 & \mathrm{RX}=-125.0 / 2 * 0.10 \\ D=0.133 & \mathrm{UZ}=-125.0 / 2 & \mathrm{RX}=-125.0 / 2 * 0.10 \\ D=0.066 & \mathrm{UZ}=-175.0 / 2 & \mathrm{RX}=-175.0 / 2 * 0.10\end{array}$

TYPE $=$ CONCENTRATED CSYS $=0$

$\begin{array}{lll}\mathrm{D}=0.044 & \mathrm{UZ}=-125.0 / 2 & \mathrm{RX}=-125.0 / 2 *-0.10 \\ \mathrm{D}=0.133 & \mathrm{UZ}=-125.0 / 2 & \mathrm{RX}=-125.0 / 2 *-0.10 \\ \mathrm{D}=0.066 & \mathrm{UZ}=-175.0 / 2 & \mathrm{RX}=-175.0 / 2 *-0.10 \\ \mathrm{D}=0.044 & \mathrm{UZ}=-125.0 / 2 & \mathrm{RX}=-125.0 / 2 * 0.10 \\ \mathrm{D}=0.133 & \mathrm{UZ}=-125.0 / 2 & \mathrm{RX}=-125.0 / 2 * 0.10 \\ \mathrm{D}=0.066 & \mathrm{UZ}=-175.0 / 2 & \mathrm{RX}=-175.0 / 2 * 0.10 \\ \mathrm{D}=0.044 & \mathrm{UZ}=-125.0 / 2 & \mathrm{RX}=-125.0 / 2 *-0.10 \\ \mathrm{D}=0.133 & \mathrm{UZ}=-125.0 / 2 & \mathrm{RX}=-125.0 / 2 *-0.10 \\ \mathrm{D}=0.066 & \mathrm{UZ}=-175.0 / 2 & \mathrm{RX}=-175.0 / 2 *-0.10 \\ & & \\ D=0.044 & \mathrm{UZ}=-125.0 / 2 & \mathrm{RX}=-125.0 / 2 * 0.10 \\ D=0.133 & \mathrm{UZ}=-125.0 / 2 & \mathrm{RX}=-125.0 / 2 * 0.10 \\ D=0.066 & \mathrm{UZ}=-175.0 / 2 & \mathrm{RX}=-175.0 / 2 * 0.10\end{array}$

TYPE $=$ CONCENTRATED CSYS $=0$

$\mathrm{D}=0.044 \quad \mathrm{UZ}=-125.0 / 2$

$\mathrm{D}=0.133 \quad \mathrm{UZ}=-125.0 / 2$

$\mathrm{D}=0.066 \quad \mathrm{UZ}=-175.0 / 2$

$\mathrm{D}=0.044 \quad \mathrm{UZ}=-125.0 / 2$

$\mathrm{D}=0.133 \quad \mathrm{UZ}=-125.0 / 2$
$\mathrm{RX}=-125.0 / 2 *-0.10$

$\mathrm{RX}=-125.0 / 2 *-0.10$

$R X=-175.0 / 2 *-0.10$

$\mathrm{RX}=-125.0 / 2 * 0.10$

$\mathrm{RX}=-125.0 / 2 * 0.10$

$\mathrm{RX}=-175.0 / 2 * 0.10$
$\mathrm{RX}=-125.0 / 2 *-0.10$
$\mathrm{RX}=-125.0 / 2 *-0.10$
$\mathrm{RX}=-175.0 / 2 *-0.10$
$\mathrm{RX}=-125.0 / 2 * 0.10$
$\mathrm{RX}=-125.0 / 2 * 0.10$
$\mathrm{RX}=-175.0 / 2 * 0.10$
$\mathrm{RX}=-125.0 / 2 *-0.10$
$\mathrm{RX}=-125.0 / 2 *-0.10$
$\mathrm{RX}=-175.0 / 2 *-0.10$
$\mathrm{RX}=-125.0 / 2 * 0.10$
$\mathrm{RX}=-125.0 / 2 * 0.10$
$\mathrm{RX}=-175.0 / 2 * 0.10$

0
0
0
0
0


$\mathrm{ADD}=1730$

$\mathrm{D}=0.066$

$\mathrm{UZ}=-175.0 / 2$

$R X=-175.0 / 2 * 0.10$

; FATIGUE EXTERIOR

; 2 lanes, 1truck

NAME $=$ FTEXT $2 \mathrm{~L}$

$A D D=2002$

$\mathrm{ADD}=\mathbf{2 0 0 6}$

$\mathrm{ADD}=\mathbf{2 0 3 0}$

$\mathrm{ADD}=2402$

$A D D=2406$

$\mathrm{ADD}=2430$

FATIGUE INTERIOR

; 2 lanes, 1truck

NAME $=F T I N T 2 L$

$\mathrm{ADD}=1402$

$\mathrm{ADD}=1406$

$\mathrm{ADD}=1430$

$\mathrm{ADD}=1802$

$\mathrm{ADD}=1806$

$\mathrm{ADD}=1830$
TYPE $=$ CONCENTRATED CSYS $=0$

$\mathrm{D}=0.044 \quad \mathrm{UZ}=-125.0 / 2$

$\mathrm{D}=0.133 \quad \mathrm{UZ}=-125.0 / 2$

$\mathrm{D}=0.066 \quad \mathrm{UZ}=-175.0 / 2$

$\mathrm{D}=0.044 \quad \mathrm{UZ}=-125.0 / 2$

$D=0.133 \quad U Z=-125.0 / 2$

$\mathrm{D}=0.066 \quad \mathrm{UZ}=-175.0 / 2$

TYPE $=$ CONCENTRATED CSYS $=0$

$\mathrm{D}=0.044 \quad \mathrm{UZ}=-125.0 / 2$

$\mathrm{D}=0.133 \quad \mathrm{UZ}=-125.0 / 2$

$\mathrm{D}=0.066 \quad \mathrm{UZ}=-175.0 / 2$

$\mathrm{D}=0.044 \quad \mathrm{UZ}=-125.0 / 2$

$\mathrm{D}=0.133$

$\mathrm{D}=0.066$

$\mathrm{UZ}=-125.0 / 2$

$\mathrm{UZ}=-175.0 / 2$
$\mathrm{RX}=-125.0 / 2 *-0.10$

$R X=-125.0 / 2 *-0.10$

$R X=-175.0 / 2 *-0.10$

$\mathrm{RX}=-125.0 / 2 * 0.10$

$\mathrm{RX}=-125.0 / 2 * 0.10$

$R X=-175.0 / 2 * 0.10$

Output

ELEM=JOINT TYPE=DISP, REAC LOAD= *

ELEM=SHELL TYPE=FORCE LOAD $=$ *

ELEM=SHELL TYPE=STRESS LOAD=*

ELEM=FRAME TYPE=JOINTF LOAD=*

END 


\section{APPENDEX (C): Excel data sheet for section and girder properties}




\section{The reactions of single girder for D.L,L.L}

idge $35 \mathrm{~m}$

spacing $2 \mathrm{~m}$

$\begin{array}{rr} & \text { ts } \\ 2 & 0.225 \\ 0.3 & 0.02 \\ .016 & 1.73 \\ 0.3 & 0.02\end{array}$

\begin{tabular}{rll}
\multicolumn{1}{r}{$\begin{array}{l}\text { A(t)X } \\
Y i\end{array}$} & $Y i$ & $Y^{\star}(t)$ \\
1.8825 & 0.11864 & 1.49712 \\
1.76 & 0.01056 & 1.49712 \\
0.885 & 0.0245 & 1.49712 \\
0.01 & 0.00006 & 1.49712 \\
\cline { 2 - 3 } & 0.15376 & 1.49712
\end{tabular}

\begin{tabular}{rlr} 
Ys & $l(t)$ & \multicolumn{1}{l}{ ls } \\
0.885 & 0.00963 & \\
0.885 & 0.00041 & 0.00459 \\
0.885 & 0.01727 & 0.0069 \\
0.885 & 0.01327 & 0.00459 \\
\cline { 2 - 2 } & 0.04059 & 0.01609
\end{tabular}

le

\begin{tabular}{lrr} 
le & $w(\mathrm{kN} / \mathrm{m} 3)$ & $W i(\mathrm{kN} / \mathrm{m})$ \\
& 24 & 10.8 \\
& 78.5 & 0.471 \\
& 78.5 & 2.17288 \\
& 78.5 & 0.471 \\
\hline 0.03691 & & 13.9149
\end{tabular}

35

$244.6119 \quad 244.6119$

spacing $2.5 \mathrm{~m}$

$\begin{array}{rrr} & \text { ts } & \text { n } \\ 2.5 & 0.225 \\ 0.3 & 0.02 \\ 1.016 & 1.73 \\ 0.3 & 0.02\end{array}$

\section{$A(t) X$}

0.14831

$0.01056-1.54838$

$0.0245 \quad 1.54838$

$0.00006 \quad 1.54838$

$\begin{array}{ll}0.18342 & 1.54838\end{array}$

\begin{tabular}{rlr} 
Ys & $l(t)$ & \multicolumn{1}{l}{ Is } \\
0.885 & 0.00913 & \\
0.885 & 0.00027 & 0.00459 \\
0.885 & 0.01908 & 0.0069 \\
0.885 & $\frac{0.0142}{0}$ & 0.00459 \\
& 0.04268 & 0.01609
\end{tabular}

le

le

0.038

i) spacing $3.0 \mathrm{~m}$

\begin{tabular}{|c|c|c|c|c|c|c|}
\hline \multicolumn{2}{|c|}{ ts } & $n$ & Area(t) & $Y i$ & \multicolumn{2}{|l|}{$A(t) X$} \\
\hline 3 & 0.225 & 7.14 & 0.09454 & 1.8825 & 0.17797 & 1.5876 \\
\hline 0.3 & 0.02 & 1 & 0.006 & 1.76 & 0.01056 & 1.5876 \\
\hline 0.016 & 1.73 & 1 & 0.02768 & 0.885 & 0.0245 & 1.5876 \\
\hline 0.3 & 0.02 & 1 & 0.006 & 0.01 & 0.00006 & 1.5876 \\
\hline & & & 0.13422 & & 0.21308 & 1.5876 \\
\hline
\end{tabular}

\begin{tabular}{rlr} 
Ys & $l(t)$ & \multicolumn{1}{l}{ Is } \\
0.885 & 0.00862 & \\
0.885 & 0.00018 & 0.00459 \\
0.885 & 0.02057 & 0.0069 \\
0.885 & 0.01493 & 0.00459 \\
& 0.0443 & 0.01609
\end{tabular}

le

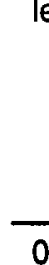

$w(k N / m 3) \quad W i(k N / m) \quad$ span

$24 \quad 16.2$

$78.5 \quad 0.471$

$78.5 \quad 2.17288$

$78.5 \quad 0.471$

$0.04007 \quad 19.3149$




\begin{tabular}{|c|c|c|c|c|c|c|c|c|c|c|c|c|c|c|c|c|}
\hline \multicolumn{17}{|c|}{ idge 25m } \\
\hline \multicolumn{17}{|c|}{ spacing $2 \mathrm{~m}$} \\
\hline \multicolumn{2}{|c|}{ ts } & \multirow[t]{2}{*}{$n$} & \multirow[b]{2}{*}{7.14} & \multirow{2}{*}{$\begin{array}{l}\text { Area }(t) \\
0.06303\end{array}$} & \multirow{2}{*}{$\begin{array}{l}\text { Yi } \\
\quad 1.3825\end{array}$} & \multirow{2}{*}{$\begin{array}{l}A(t) X \\
Y i \\
0.08713\end{array}$} & \multirow{2}{*}{$\begin{array}{l}Y^{*}(t) \\
1.13245\end{array}$} & \multirow{2}{*}{$\begin{array}{l}\text { Ys } \\
0.635\end{array}$} & \multirow{2}{*}{$\begin{array}{l}I(t) \\
0.00421\end{array}$} & \multirow[t]{2}{*}{ Is } & \multirow[t]{2}{*}{ le } & \multirow{2}{*}{$\begin{array}{r}w(k N / m 3) \\
24\end{array}$} & \multirow{2}{*}{$\begin{array}{r}W i(k N / m) \\
10.8\end{array}$} & \multirow[t]{2}{*}{ span } & \multirow[t]{2}{*}{$\left(R_{\mathrm{A}}\right)_{\mathrm{DL}}$} & \multirow[t]{2}{*}{$\left(\mathrm{R}_{\mathrm{L}}\right)_{\mathrm{DL}}$} \\
\hline 2 & 0.225 & & & & & & & & & & & & & & & \\
\hline 0.3 & 0.02 & & 1 & 0.006 & 1.26 & 0.00756 & 1.13245 & 0.635 & $9.8 \mathrm{E}-05$ & 0.00234 & & 78.5 & 0.471 & & & \\
\hline .016 & 1.23 & & 1 & 0.01968 & 0.635 & 0.0125 & 1.13245 & 0.635 & 0.00735 & 0.00248 & & 78.5 & 1.54488 & & & \\
\hline \multirow[t]{3}{*}{0.3} & 0.02 & & 1. & 0.006 & 0.01 & 0.00006 & 1.13245 & 0.635 & 0.00756 & 0.00234 & & 78.5 & 0.471 & & & \\
\hline & & & & 0.09471 & & 0.10725 & 1.13245 & & 0.01922 & 0.00717 & 0.01741 & & 13.2869 & 25 & & \\
\hline & & & & & & & & & & & & & & & 166.873 & 166.873 \\
\hline \multicolumn{17}{|c|}{ spacing $2.5 \mathrm{~m}$} \\
\hline \multicolumn{2}{|r|}{ ts } & $\mathrm{n}$ & & Area $(t)$ & $\mathrm{Yi}$ & $\begin{array}{l}A(t) X \\
Y i\end{array}$ & $Y^{*}(t)$ & Ys & $I(t)$ & Is & le & $\mathrm{w}(\mathrm{kN} / \mathrm{m} 3)$ & $\mathrm{Wi}(\mathrm{kN} / \mathrm{m})$ & span & $\left(\mathrm{R}_{\mathrm{R}}\right)_{\mathrm{DL}}$ & $\left(\mathrm{R}_{\mathrm{L}}\right)_{\mathrm{DL}}$ \\
\hline 2.5 & 0.225 & & 7.14 & 0.07878 & 1.3825 & 0.10892 & 1.16812 & 0.635 & 0.00395 & & & 24 & 13.5 & & & \\
\hline 0.3 & 0.02 & & 1 & 0.006 & 1.26 & 0.00756 & 1.16812 & 0.635 & 5.1E-05 & 0.00234 & & 78.5 & 0.471 & & & \\
\hline 016 & 1.23 & & 1 & 0.01968 & 0.635 & 0.0125 & 1.16812 & 0.635 & 0.00807 & 0.00248 & & 78.5 & 1.54488 & & & \\
\hline \multirow[t]{3}{*}{0.3} & 0.02 & & 1. & 0.006 & 0.01 & 0.00006 & 1.16812 & 0.635 & 0.00805 & 0.00234 & & 78.5 & 0.471 & & & \\
\hline & & & & 0.11046 & & 0.12903 & 1.16812 & & 0.02013 & 0.00717 & 0.01818 & & 15.9869 & 25 & & \\
\hline & & & & & & & & & & & & & & & 200.622803 & 200.62282 \\
\hline \multicolumn{17}{|c|}{ spacing $3.0 \mathrm{~m}$} \\
\hline \multicolumn{2}{|c|}{ ts } & $\mathrm{n}$ & & Area $(t)$ & Yi & $\begin{array}{l}A(t) X \\
Y_{i}\end{array}$ & $Y^{*}(t)$ & Ys & $I(t)$ & is & le & $\mathrm{w}(\mathrm{kN} / \mathrm{m} 3)$ & $\mathrm{Wi}(\mathrm{kN} / \mathrm{m})$ & span & $\left(\mathrm{R}_{\mathrm{R}}\right)_{\mathrm{DL}}$ & $\left(\mathrm{R}_{\mathrm{L}}\right)_{\mathrm{DL}}$ \\
\hline 3 & 0.225 & & 7.14 & 0.09454 & 1.3825 & 0.1307 & 1.19488 & 0.635 & 0.00373 & & & 24 & 16.2 & & & \\
\hline 0.3 & 0.02 & & 1 & 0.006 & 1.26 & 0.00756 & 1.19488 & 0.635 & 2.6E-05 & 0.00234 & & 78.5 & 0.471 & & & \\
\hline 016 & 1.23 & & 1 & 0.01968 & 0.635 & 0.0125 & 1.19488 & 0.635 & 0.00865 & 0.00248 & & 78.5 & 1.54488 & & & \\
\hline \multirow[t]{3}{*}{0.3} & 0.02 & & 1. & 0.006 & 0.01 & 0.00006 & 1.19488 & 0.635 & 0.00842 & 0.00234 & & 78.5 & 0.471 & & & \\
\hline & & & & 0.12622 & & 0.15082 & 1.19488 & & 0.02083 & 0.00717 & 0.01878 & & 18.6869 & 2 & & \\
\hline & & & & & & & & & & & & & & & 234.372809 & 234.37282 \\
\hline
\end{tabular}




\begin{tabular}{|c|c|c|c|c|c|c|c|c|c|c|c|c|c|c|c|}
\hline \multicolumn{16}{|c|}{ idge $15 \mathrm{~m}$} \\
\hline \multicolumn{16}{|c|}{ spacing $2 m$} \\
\hline \multicolumn{2}{|c|}{ ts } & \multirow[b]{2}{*}{7.14} & \multirow{2}{*}{$\begin{array}{l}\text { Area(t) } \\
0.06303\end{array}$} & \multirow{2}{*}{$\begin{array}{l}Y i \\
0.8825\end{array}$} & \multirow{2}{*}{$\begin{array}{l}A(t) X \\
Y i \\
0.05562\end{array}$} & \multirow{2}{*}{$\begin{array}{l}Y^{*}(t) \\
0.74663\end{array}$} & \multirow{2}{*}{$\begin{array}{l}\text { Ys } \\
0.385\end{array}$} & \multirow{2}{*}{$\begin{array}{l}I(t) \\
0.00143\end{array}$} & \multirow[t]{2}{*}{ Is } & \multirow[t]{2}{*}{ le } & \multirow{2}{*}{$\begin{array}{r}w(k N / m 3) \\
24\end{array}$} & \multirow{2}{*}{$\begin{array}{r}W i(k N / m) \\
10.8\end{array}$} & \multirow[t]{2}{*}{ span } & \multirow[t]{2}{*}{$\left(R_{R}\right)_{D L}$} & \multirow[t]{2}{*}{$\left(\mathrm{R}_{\mathrm{L}}\right)_{\mathrm{DL}}$} \\
\hline 2 & 0.225 & & & & & & & & & & & & & & \\
\hline 0.3 & 0.02 & 1 & 0.006 & 0.76 & 0.00456 & 0.74663 & 0.385 & 1.3E-06 & 0.00084 & & 78.5 & 0.471 & & & \\
\hline .016 & 0.73 & 1 & 0.01168 & 0.385 & 0.0045 & 0.74663 & 0.385 & 0.00205 & 0.00052 & & 78.5 & 0.91688 & & & \\
\hline \multirow[t]{3}{*}{0.3} & 0.02 & 1 & 0.006 & 0.01 & 0.00006 & 0.74663 & 0.385 & 0.00326 & 0.00084 & & 78.5 & 0.471 & & & \\
\hline & & & 0.08671 & & 0.06474 & 0.74663 & & 0.00673 & 0.00221 & 0.00605 & & 12.6589 & 15 & & \\
\hline & & & & & & & & & & & & & & 95.413667 & 95.413663 \\
\hline \multicolumn{16}{|c|}{ spacing $2.5 \mathrm{~m}$} \\
\hline \multicolumn{2}{|c|}{ ts } & $\mathrm{n}$ & Area(t) & $Y i$ & $\begin{array}{l}A(t) X \\
Y i\end{array}$ & $Y^{*}(t)$ & Ys & $I(t)$ & Is & le & $\mathrm{w}(\mathrm{kN} / \mathrm{m} 3)$ & $W i(k N / m)$ & span & $\left(\mathrm{R}_{\mathrm{A}}\right\rangle_{\mathrm{DL}}$ & $\left(\mathrm{R}_{\mathrm{L}}\right)_{\mathrm{DL}}$ \\
\hline 2.5 & 0.225 & 7.14 & 0.07878 & 0.8825 & 0.06952 & 0.76752 & 0.385 & 0.00137 & & & 24 & 13.5 & & & \\
\hline 0.3 & 0.02 & 1 & 0.006 & 0.76 & 0.00456 & 0.76752 & 0.385 & $5.4 \mathrm{E}-07$ & 0.00084 & & 78.5 & 0.471 & & & \\
\hline 1.016 & 0.73 & 1 & 0.01168 & 0.385 & 0.0045 & 0.76752 & 0.385 & 0.00223 & 0.00052 & & 78.5 & 0.91688 & & & \\
\hline \multirow[t]{3}{*}{0.3} & 0.02 & 1 & 0.006 & 0.01 & 0.00006 & 0.76752 & 0.385 & 0.00344 & 0.00084 & & 78.5 & 0.471 & & & \\
\hline & & & 0.10246 & & 0.07864 & 0.76752 & & 0.00705 & 0.00221 & 0.00632 & & 15.3589 & 15 & & \\
\hline & & & & & & & & & & & & & & 115.663678 & 115.66365 \\
\hline \multicolumn{16}{|c|}{ ) spacing $3.0 \mathrm{~m}$} \\
\hline \multicolumn{2}{|r|}{ ts } & $n$ & Area(t) & Yi & $\begin{array}{l}A(t) X \\
Y i\end{array}$ & $Y^{*}(t)$ & Ys & $I(t)$ & Is & le & $\mathrm{w}(\mathrm{kN} / \mathrm{m} 3)$ & Wi $(k N / m)$ & span & $\left(R_{\mathrm{B}}\right)_{\mathrm{DL}}$ & $\left(\mathrm{R}_{\mathrm{L}}\right)_{\mathrm{DL}}$ \\
\hline 3 & 0.225 & 7.14 & 0.09454 & 0.8825 & 0.08343 & 0.78285 & 0.385 & 0.00134 & & & 24 & 16.2 & & & \\
\hline 0.3 & 0.02 & 1 & 0.006 & 0.76 & 0.00456 & 0.78285 & 0.385 & 3.3E-06 & 0.00084 & & 78.5 & 0.471 & & & \\
\hline 0.016 & 0.73 & 1 & 0.01168 & 0.385 & 0.0045 & 0.78285 & 0.385 & 0.00237 & 0.00052 & & 78.5 & 0.91688 & & & \\
\hline \multirow[t]{3}{*}{0.3} & 0.02 & 1 & 0.006 & 0.01 & 0.00006 & 0.78285 & 0.385 & 0.00358 & 0.00084 & & 78.5 & 0.471 & & & \\
\hline & & & 0.11822 & & 0.09255 & 0.78285 & & 0.00729 & 0.00221 & 0.00653 & & 18.0589 & 15 & & \\
\hline & & & & & & & & & & & & & & 135.913683 & 135.91366 \\
\hline
\end{tabular}




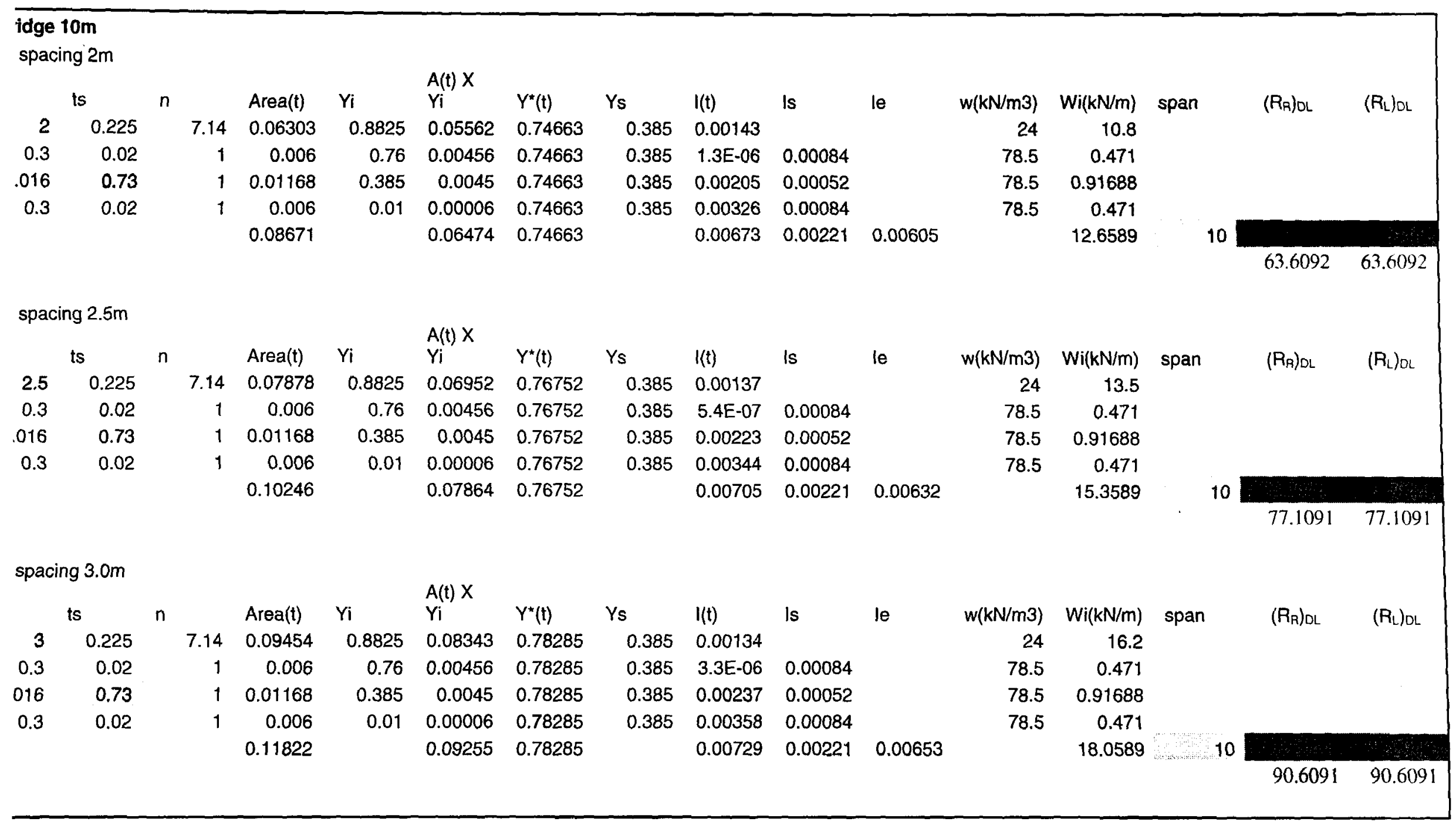


. 